\title{
Economie Statistique
}

\section{Economics AND

Logement et marchés du logement

Housing and housing markets

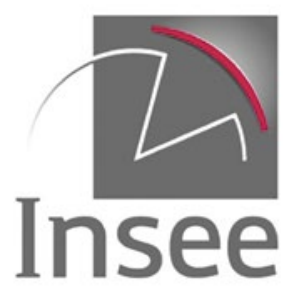




\section{Economie Statistique}

\section{Economics AND Statistics}

\section{OÙ SE PROCURER}

\section{Economie et Statistique / Economics and Statistics}

Les numéros sont en accès libre sur le site www.insee.fr. Il est possible de s'abonner aux avis de parution sur le site.

La revue peut être achetée sur le site www.insee.fr via la rubrique "Acheter nos publications".

La revue est également en vente dans 200 librairies à Paris et en province.

\section{HOW TO GET}

\section{Economie et Statistique / Economics and Statistics}

The issues and articles are available in open access on the Insee website: www.insee.fr. Publication alerts can be subscribed on-line.

The printed version of the journal (in French) can be purchased on the Insee website www.insee.fr and in 200 bookshops in Paris and province.
Directeur de la publication / Director of Publication: Jean-Luc TAVERNIER

Rédactrice en chef / Editor in Chief: Laurence BLOCH Rédactrice en chef adjointe / Deputy Editor in Chief: Sophie PONTHIEUX

Rédacteur associé / Associate Editor: Clément CARBONNIER Assistant éditorial / Editorial Assistant: Étienne de LATUDE Traductions / Translations: UBIQUS

Tour PB5, 1 avenue du Général-de-Gaulle, 92074 Paris La Défense Cedex Maquette PAO et impression / CAP and printing: JOUVE

1, rue du Docteur-Sauvé, BP3, 53101 Mayenne

\section{Conseil scientifique / Scientific Committee}

Jacques LE CACHEUX, président (Université de Pau et des pays de l'Adour) Laurence BLOCH (Insee)

Jérôme BOURDIEU (École d'économie de Paris)

Pierre CAHUC (Sciences Po)

Gilbert CETTE (Banque de France et École d'économie d'Aix-Marseille) Yannick L'HORTY (Université de Paris-Est - Marne la Vallée)

Daniel OESCH (Life Course and Inequality Research (LINES) et Institut des sciences sociales - Université de Lausanne)

Katheline SCHUBERT (École d'économie de Paris, Université Paris I)

Claudia SENIK (Université Paris-Sorbonne

et École d'économie de Paris)

Louis-André VALLET (Observatoire sociologique du changement-Sciences Po/CNRS)

François-Charles WOLFF (Université de Nantes)

\section{Comité éditorial / Editorial Advisory Board}

Luc ARRONDEL (École d'économie de Paris)

Lucio BACCARO (Max Planck Institute for the Study of Societies-Cologne et Département de Sociologie-Université de Genève)

Antoine BOZIO (Institut des politiques publiques/École d'économie de Paris)

Clément CARBONNIER (Théma/Université de Cergy-Pontoise et LIEPP-

Sciences Po)

Erwan GAUTIER (Banque de France et Université de Nantes)

Pauline GIVORD (Ocde et Crest)

Florence JUSOT (Université Paris-Dauphine, Leda-Legos et Irdes)

François LEGENDRE (Erudite/Université Paris-Est)

Claire LELARGE (Université de Paris-Sud (Paris-Saclay) et Crest)

Claire LOUPIAS (Direction générale du Trésor)

Sophie PONTHIEUX (Insee et Crest)

Ariell RESHEF (École d'économie de Paris, Centre d'économie de la Sorbonne et CEPII)

Thepthida SOPRASEUTH (Théma/Université de Cergy-Pontoise) 


\section{Economie Statistique}

Economics ${ }^{\text {ANO }}$ Statistics 
The views or opinions expressed by the authors engage only themselves, and neither the institutions they work with, nor Insee. 


\section{Economie et Statistique / Economics and Statistics}

Issue 500-501-502-2018

HOUSING AND HOUSING MARKETS

5 Introduction - Housing: A space-time good

Alain Trannoy

HOUSING SYSTEMS IN THE OCDE

13 Building a typology of housing systems to inform policies in OECD and EU member States

This article establishes a typology of housing systems in OECD and EU countries, based mainly on data from the new OECD Affordable Housing Database. Four groups are identified among a sample of 32 countries, reflecting primarily housing conditions, tenure structures and household indebtedness.

Christophe André and Thomas Chalaux

37 Comment - On building typologies of housing systems in the OECD

Christine M. E. Whitehead

SUPPLY, DEMAND AND PRICES ON HOUSING MARKETS

45 Does issuing building permits reduce the cost of land?

An estimation based on the demand for building land in France

Building land is a major limiting factor in the production of new housing, which has suffered high inflation over the recent period. Issuance of building permits increases the supply of building land but has only a small effect on land prices.

Jean-Sauveur Ay, Jean Cavailhès, Mohamed Hilal and Julie Le Gallo

69 New or old, why would housing price indices differ?

An analysis for France

In France, the price indices for new and second-hand housing followed different trends over the period 2006-2015. Beyond differences in methodology, the lower volatility of the prices of new homes during the 2009 crisis seems to be explained by the functioning of the new and second-hand housing markets.

Thomas Balcone and Anne Laferrère

97 Accessibility, local pollution and housing prices. Evidence from Nantes Métropole, France

It is commonly admitted that location and environmental amenities are capitalized in real-estate values. A spatial hedonic price model applied to 5,590 transactions highlights the only weak influence of environmental quality variables (air quality, traffic noise) on apartment prices in Nantes Métropole.

Dorothée Brécard, Rémy Le Boennec and Frédéric Salladarré 
117 Rising inequalities in access to home ownership among young households in France, 1973-2013

While the rate of homeownership among households aged 25 to 44 is stable over the period 1973-2013, disparities according to standard of living have increased considerably. Changes in family configurations, and family transfers (donations and inheritances) have contributed to these changes.

Carole Bonnet, Bertrand Garbinti and Sébastien Grobon

\section{The dynamisation and subsequent vulnerability of the Dutch} owner-occupied sector. An analysis of 1986-2012

Since the 1980s, Dutch owner-occupiers of all ages and household types have become more mobile. The transition from dominance by "immobile" traditional family households to more dynamic household types has contributed to this increase, while ageing had a somewhat dampening effect.

Kees Dol and Harry van der Heijden

\section{Consumption, household portfolios and the housing market}

\section{in France}

Evidence from a 6-equation model for consumption and components of household portfolios suggests financial wealth effects in France comparable to those in the US or the UK, but housing wealth effects far weaker: aggregate consumption falls with higher house prices, other things equal. Valérie Chauvin and John Muellbauer

EVALUATIONS OF IMPACT AND METHODS

179 The impact of the 2014 increase in the real estate transfer taxes on the French housing market

The 0.7 percentage point increase in RETT on real estate transactions in 2014 in many departments has been anticipated the month before in the form of a very strong increase in transactions, offset by a sharp reduction in sales in the next three months.

Guillaume Bérard and Alain Trannoy

201 Does information to buyers affect the sales price of a property? Mandatory disclosure and the hedonic price model - A test on French data

The hedonic price model is based on the assumption of perfect and complete information of buyers. But the introduction of the obligation to inform buyers and tenants in June 2006 was, in certain cases, accompanied by a decrease in sales prices, calling this assumption into question. Amélie Mauroux

\section{An evaluation of the methods used by European countries} to compute their official house price indices

National statistical institutes in Europe differ in the methods, mostly hedonic ones, they use to compute their official house price indices. The article examines the theoretical properties of these methods, and how they compare empirically, using micro-level datasets for Sydney and Tokyo.

Robert J. Hill, Michael Scholz, Chihiro Shimizu and Miriam Steurer 


\title{
Introduction Housing: A space-time good
}

\author{
Alain Trannoy*
}

\begin{abstract}
Housing is a crucial good for households, both as a consumer good via the flow of services it fosters, and as an essential component of a homeowner's wealth. It is also crucial because it accounts for more than a quarter of household's expenses, and an increase in rent or property prices instantly has a major impact on their living standards, choice of location, mobility, and savings options. Finally, housing is unique as an element of space-time, space and time that cannot be separated in this instance. These themes are examined in this special issue, with a variety of approaches and different perspectives, providing valuable information on a number of outstanding issues.
\end{abstract}

JEL Classification: R31, R38

Keywords: housing, space-time, inequality, mobility, localization, public policy, local markets

\section{Reminder:}

The opinions and analyses in this article

are those of the author(s) and

do not

necessarily reflect

their institution's

or Insee's views.
*École des Hautes Études en Sciences Sociales (EHESS), et École d'Économie d'Aix-Marseille (AMSE) (alain.trannoy@univ-amu.fr)

Received on 12 September 2018

Translated from the original version : « Le logement : un bien espace-temps »

To cite this article: Trannoy, A. (2018). Introduction: Housing: A space-time good. Economie et Statistique / Economics and Statistics, 500-501-502, 5-11.

https://doi.org/10.24187/ecostat.2018.500t.1942 
$\mathbf{W}$ hy housing? Economists can propose a thousand reasons, among which the fact that it makes up the largest share of household budgets, the largest share of their wealth, a basic good that has an impact on poverty and inequality, a marker of segregation, a crucial catalyst in the 2008 financial crisis, and lastly because its price has been on the rise since the mid-1990s. Housing economics is becoming a field of study in its own right in France and this is a good thing. This is illustrated by the publication of this special issue of Economie et Statistique/Economics and Statistics as well as the recent issue of Annals of Economics and Statistics. These editorial initiatives are to be commended as they demonstrate a desire to bring scientific knowledge up to par with that of other developed countries, particularly the United States. It is significant, moreover, that Economie et Statistique/Economics and Statistics welcomes a number of contributions from European economists for the occasion. Naturally, the ten studies compiled could not adopt the same point of view. Before looking at the issue covered in each article, a crucial original conceptual feature of housing should be highlighted. Housing is an element of space-time, which cannot be separated in this instance.

Housing is the only good that can be defined purely by a location and a land-use, land which is a scarce factor. It necessarily requires land consumption. Housing is also a sustainable good that is defined by a consumption flow and a capital stock. Hence the dynamic dimension. Housing is an element of space-time, and these two elements cannot be disentangled. Microeconomic theory gives pride of place to dynamic analysis, and less to spatial theory despite its recognition in Von Thünen's remarkable analysis of 1826, which can be considered the first microeconomic analysis, coming even before that of Augustin Cournot. But to produce a comprehensive housing analysis there needs to be a link between a spatial analysis and a dynamic analysis, and that is what makes the analysis both difficult and exciting. These spatio-temporal back and forth are of importance.

Firstly, events, and therefore time, are stored in the price of land. One example is the crisis of 2007 which affected different territories in different ways. Deindustrialisation accelerated, devastating many territories and bringing down land and real estate prices where people, in addition to losing their jobs, saw some of the value of their wealth go down the drain. Yet, at the same time, people living in large metropolitan areas saw the price of their housing soar in favour of a post-industrial society where many Western countries (the United States, Great Britain and France) specialise in the design, marketing and commercialisation of products, leaving the production phase to developing economies and emerging countries. These design operations are mostly concentrated in cities so as to benefit from the agglomeration externalities in the form of the exchange of ideas inspired by dense and varied individual contacts.

Conversely, a scarcity or an abundance of land can have a long-term impact on the economic future of an urban region. For example in France, the Côte d'Azur, sandwiched between the sea and the Alps, lacks available land, which hinders its expansion, whereas a city like Nantes, one of the most vibrant in France, is fortunate to have a major land stock right near the city centre. This partly explains the results, somewhat surprising at first glance, obtained by Dorothée Brécard, Rémy Le Boennec and Frédéric Salladarré who find for this city, using a hedonic model, a relatively low valorization of environmental goods (proximity of public transport, air quality, etc.), even though the city is considered an example of environmental leadership. The fortune of having a stock of fairly affordable housing thanks to an ambitious social housing policy close to the centre with the 
Île de Nantes, and the relative uniformity of the city, prevent a mechanism of differentiation in valorization.

This spatio-temporal perspective is central to the approach of the article by Jean-Sauveur Ay, Mohamed Hilal, Julie Le Gallo and Jean Cavailhès which offers a remarkable insight into the understanding of the process behind changes in development land prices. Land represents on average $30 \%$ of the total cost of the construction of a detached house and the floor area represents on average $15 \%$ of the plot. In line with the findings of another study in this issue, by Thomas Balcone and Anne Laferrère, which will be discussed later, it seems that in recent past, the price of developed land has risen faster than that of structures for new constructions. The fact is also documented in a recent paper by Knoll, Schularick and Steger (2017) that real estate inflation is governed by the rise in land value in most developed countries. This could suggest that a more generous building permit policy would likely curb the rise in development land prices and that some of the real estate increase is simply maintained by a Malthusian policy when it comes to issuing building permits. But this is not exactly the avenue of thought taken by J.-S. Ay and his co-authors. The four authors estimate a structural model in which the price of developed land depends on construction measured at the same time in terms of the number of residences allowed, the floor area allowed and the plot sizes allowed. The construction variable is instrumented by variables related to the type of land, its topography, the agricultural opportunity cost and the presence of industrial wasteland. The choice of the first variable and in particular the proportion of clay land is rightly of interest. Indeed, clay land is more unstable and pushes up construction costs, with no possibility of reverse causality: an increase in developed land prices cannot increase the share of clay land. These four variables are supply variables and it is known that to identify the slope of a demand curve, an attempt must be made to detect the exogenous supply variations in order to be able to "slide along a demand curve". The authors then obtain a household housing demand that is very elastic to land prices. The elasticity of inverse demand for land is 0.3 (in absolute terms), and therefore demand elasticity is greater than 3 . This confirms the fact that the total deregulation of development land supply, certainly a solution to be avoided for environmental reasons, would help ensure that the rise in residential demand flattens out without a rise in prices. On the contrary, the article by Thomas Balcone and Anne Laferrère documents a housing demand that does not "settle" easily, and also adopts a spatio-temporal analysis.

France has a policy of significant government intervention in the housing sector as regards regulation, financing and taxation, and these various types of intervention are full of mechanisms whose efficacy would be worth assessing. The constant changes in public policy in France are in this respect an opportunity for carrying out impact studies, taking advantage of spatial differentiation or the specific features of local housing markets. The article by Guillaume Bérard and Alain Trannoy uses a new database made available to researchers by the CGEDD, the MEDOC database along with the Fidji database, to measure the impact of the 2014 increase in real estate transfer taxes (RETT) paid by the buyer of a real estate asset. As of the first of January 2014, the départements have been able to increase the departmental share of these rates by more than $0.7 \%$ of the transaction amount (from 3.8 to $4.5 \%$ ). As they have not all done so and especially not all at the same time, this sets the stage for a natural experiment. The authors obtain a significant sales anticipation effect the month prior to the tax hike, more than compensated for by a drop in the number of transactions in the three subsequent months. However, the net effect is fairly low, 
estimated at around 15,000 transactions "lost" due to the tax rise at national level, in other words, $1.5 \%$ of the total annual transactions. This confirms that housing demand is fairly resilient, estimated this time on the second-hand housing market. Overall, this low elasticity to price is rather normal for a basic good, one that is considered essential, but more importantly one that influences well-being in a crucial way. Households are without doubt more prepared to sacrifice food or clothing in the event of financial difficulties rather than cut back on their real estate aspirations.

Housing, along with heating and lighting, is by far the biggest share of household budgets at more than $26 \%$, twice that of food ${ }^{1}$. As such, an increase in housing prices or rent has a major impact on living standards. In addition, there is a qualitative factor. Housing is a primary good, a basic good recognised as such in the Universal Declaration of Human Rights, and the Charter of Fundamental Rights of the European Union. In its decision of 19 January 1995, the French Constitutional Council considered "the possibility of having decent housing a state obligation". This compulsory right to housing (known as the Droit au logement opposable, DALO) is enshrined in Besson's law (loi Besson). The issue of inequality and poverty is therefore correlatively associated with a person's occupation of a residence or lack of residence, for example, for homeless people. The work presented here by Carole Bonnet, Bertrand Garbinti and Sébastien Grobon goes into this theme of inequality from the perspective of unequal access to home ownership. The rate of property owners among young, low-income households aged 25 to 44 years old dropped by 50\% between 1973 and 2013 (16\% compared with 32\%). The contribution of the analysis is to demonstrate that many factors contributed to this decline, and especially a certain number of structural changes such as the fact that these low-income households now live increasingly in large cities where the price of land is a barrier, whereas 40 years earlier, many of them lived in the country and owned their home. This decline in small rural home ownership is a major factor that is often glossed over. While the desire to become a property owner is almost unanimously widespread and perfectly legitimate, property hampers mobility compounded by high transaction costs. In a changing economy, encouraging low-income households to become homeowners might be a poisoned chalice. However, ensuring that the housing budget is not too onerous for the lowest budgets is a policy that does not hinder their mobility. The mobility of young households is also examined in the study by Kees Dol and Harry van der Heijden on the Netherlands, where they document increasing mobility, particularly among young homeowners prior to the 2008 crisis. This increased mobility was stopped short by the crisis, and particularly affected highly indebted households.

There is a sense that different societies react differently to this quandary of how to intervene in the housing market, perhaps in line with their politico-philosophical systems. Esping-Andersen's famous distinction (1990) between liberal systems (English-speaking countries), social democratic systems (Nordic countries and the Netherlands) and corporatist systems (Germany, France) is well known. In the first, social welfare cover is just a safety net and, beyond that, individual responsibility mostly prevails. The second type of system uses universal transfers, and the third focuses more on solidarity within certain circles, such as the family, employees, the agricultural community, etc. Clearly, it is an interesting perspective, but within a country, several sources of inspiration may coexist. For example, the rationale behind the social housing movement in France is undeniably universalist, whereas

1. 2015 data, source Eurostat. 
the rationale behind the " $1 \%$ logement" employee home-loan scheme is inspired by a corporatist model. It is therefore possible that the perspective is different or simply more complex for housing. Kemeny (1995) offered a more simple perspective in which he compares dualist rental markets - in which the poor are relegated to social housing reserved for them - and unitary rental markets - in which the private and social housing stock compete and comply with the same regulations. In fact, the traditional contrast between society's liberal or social democratic approaches comes back into play. As regards housing, France historically belongs among the second group of countries, and the social housing movement is closely linked with this approach. The study by Christophe André and Thomas Chalaux seeks to establish a new typology across all OECD countries, which are still fairly disparate in terms of living standards, based on a new database created by the OECD for this purpose. The Affordable Housing Database (AHD) will in any case be extremely useful to social science researchers. One lesson learnt from this database is that the social democratic countries of Northern Europe, the Netherlands, Denmark, Sweden, Iceland and Norway, are countries where property owners (including homeowners) are now the majority at between $50 \%$ and $70 \%$. Moreover, homeowner households are, in terms of tenure, the dominant category and account for about $40 \%$ of the population. Socio-political repercussions or correlations can be expected, as property owner status engenders more conservative values which lay behind for example the abolished inheritance tax in Sweden in 2005, the abolished wealth tax in Denmark in 1997, and a rise in inequalities in both countries.

Housing is also the primary form of saving for French people, as two-thirds of the value of their wealth is made up of housing, and housing loans account for $85 \%$ of consumer credit. As such, a drop in the value of property assets, in a downturn in the real estate market, has immediate macro-economic repercussions, as shown by the subprime crisis in the United States, and the Irish and Spanish real estate crises. One of the major channels in the contemporary link between finance and macroeconomics is housing, and it's fortunate that one of the articles in this special edition, by Valérie Chauvin and John Muellbauer, contributes to its better understanding in the case of France, showing that the financial accelerator was weaker in our country than in the United States and the United Kingdom during the real estate price boom (1996-2008). The effects of financial wealth on consumption are comparable to those seen in the United States and the United Kingdom. However, the effects of real estate wealth are weaker in France than in these two countries, taking into account the absence of loans on the value of real estate assets (home equity withdrawals). One of the specifics of real estate is in fact that it is an asset that can be acquired with money that one does not have. In the new-build market, there is nothing wrong with borrowing to invest, because building individual wealth boosts gross fixed capital formation. In the second-hand housing market, it is more questionable as it is simply an exchange of assets between two households. Stock market margin calls, requesting additional payment in the event of depreciation, financially ruined and wiped out small investors during the 1929 crash and have, since, been stringently regulated. They were based at that time on a system of borrowing to buy stock (with low cover) similar to a real estate loan in the second-hand housing market. The hybrid status of housing as both a consumer good and a basic good, and the many frictions in this market, make the monetary authorities less strict when it comes to real estate loans, when clearly debt leverage can bring about a boom cycle and leave many households vulnerable in the event of an economic downturn, not to mention certain financial institutions. Debt in the second-hand housing market introduces a long-ignored macroeconomic risk factor and one that only a stringent macroprudential policy 
can mitigate. It is fortunate in this respect that the article by Thomas Balcone and Anne Laferrère compares trends in real estate prices in both the resale and the new homes market sectors. In line with the understanding of the role of credit, the old housing market is more volatile than the new homes market. It passes on fluctuations in credit policy more drastically, and in this case the credit crunch of 2009. This article also fosters reflection on price indexes which are the thermometers of the housing market. Progress in the precision and accuracy of the thermometer is essential so as not to misinterpret changes in the housing market. This is all the more true for France due to the significant gap between rents and prices in the country since the end of the 1990s, a specific puzzle, perfect to arouse the curiosity of economists.

Before going any further to understand it, it is crucial to ensure that it is not the result of an artefact. In this respect, valuable information can be found in the study by Robert J. Hill, Michael Scholz, Chihiro Shimizu, and Miriam Steurer, who compare the theoretical properties of several hedonic methods and other methods used in various European Union countries, and test them on price data from two large non-European cities, Sydney and Tokyo. In addition to recommending the use of hedonic methods, over that of appraisals, the method developed by Insee and used as a calculation in the Notaires-Insee index is recommended because it is simple to use and gives more stable results for smaller samples. Beyond the legitimate pride of having a method created by the Insee teams validated, this result is important for two reasons. Firstly, for showing that the gap between prices and rents is not a statistical illusion in our country. Secondly, because this index can be used to assess changes in prices in local markets. Yet, real estate markets are local markets, and small-town France is composed of many distinct markets with few annual transactions.

The hedonic method is also the theme chosen by Amélie Mauroux. Rosen's theoretical model (1974) assumes perfect information concerning the various characteristics that are important for the existence of an equilibrium price for each of the differentiated properties that makes up each residence. The author tests this theory for an environmental risk, in this instance, the risk of flooding. The implementation of a regulatory provision, known as the "information des acquéreurs et locataires" (IAL), or obligation to inform buyers and tenants, introduced in France in 2006, offers the opportunity to conduct a natural quasi-experiment. Only properties on ground floor are affected by this informational shock, but they are affected considerably. The properties in question are subject to a $9 \%$ drop in value. This type of study, could be extended by a cost-benefit analysis of the advantages of public investments to limit the risk of flooding (see for example a cost-benefit analysis based on hedonic estimations in Gravel et al., 2006).

This special issue provides great insight from a number of perspectives and no doubt will help inform policy deciders and stimulate the interest of researchers and students in this field, which is at the crossroads of so many different economic approaches. 


\section{BIBLIOGRAPHY}

Esping-Andersen, G. (1990). The Three Worlds of Welfare Capitalism. Princeton: Princeton University Press.

Gravel, N., Michelangeli, A. \& Trannoy, A. (2006). Measuring the social value of local public goods: an Empirical Analysis within Paris Metropolitan Area. Applied Economics, 38(16), 1945-1961.

https://doi.org/10.1080/00036840500427213

Kemeny, J. (1995). From Public Housing to the Social Market. Rental Policy, Strategies in comparative perspective. London: Routledge.

Knoll, K., Schularick, M. \& Steger, T. (2017). No Price Like Home: Global House Prices, 1870-2012. American Economic Review, 107(2), 331-353.

https://doi.org/10.1257/aer.20150501

Rosen, S. (1974). Hedonic prices and implicit markets: product differentiation in pure competition. Journal of Political Economy, 82(1), 34-55.

https://www.jstor.org/stable/1830899 



\title{
Building a typology of housing systems to inform policies in OECD and EU member States
}

\author{
Christophe André* and Thomas Chalaux*
}

\begin{abstract}
This article establishes a typology of housing systems in OECD and EU countries, using principal component and cluster analysis on housing market context and housing conditions variables from the new OECD Affordable Housing Database (AHD), as well as data on household indebtedness. We identify four groups among a sample of 25 countries, subsequently extended to 32, as countries for which a more limited set of information is available are added to the baseline analysis. A group named "Northern", as it covers mainly Northern Europe, including Germany, features extended private rental and generally high household debt. A "Western" group, which includes France and the United Kingdom, has higher homeownership rates and more social housing. "Southern-Central" and "Eastern" groups gather European countries, where outright homeownership is prevalent, but housing conditions are poorer. Both the country coverage and the set of variables considered in this article are wider than in most previous studies and findings are broadly consistent with the comparative housing literature for the countries with overlapping coverage.
\end{abstract}

JEL Classification: C38, I38, R28, R38

Keywords: housing, cluster analysis, principal components, government policy

Reminder:

The opinions and analyses in this article

are those of the author(s)

and do not

necessarily reflect

their institution's

or Insee's views.
*Organisation for Economic Co-operation and Development (OECD), Economics Department (christophe.andre@oecd.org; thomas.chalaux@oecd.org).

The views expressed in this article are those of the authors and do not necessarily reflect the official views of the OECD or its member countries. The authors would like to thank Alice Pittini, Anne-Laure Samson and two anonymous referees for useful comments and suggestions.

Received on 24 June 2017, accepted after revisions on 26 February 2018 
$\mathbf{H}$ ousing is a basic need and is recognised as a human right in many national constitutions and international declarations, including the Universal Declaration of Human Rights and the Charter of Fundamental Rights of the European Union. Access to good-quality affordable housing is essential for achieving broader social policy objectives, such as reducing poverty and enhancing equality of opportunity, social inclusion and mobility, as well as health and well-being. Nevertheless, a significant number of households in OECD and EU countries still face a housing cost overburden, live in overcrowded dwellings or are even homeless. Global trends in urbanisation, rising housing prices and higher income inequality tend to exacerbate housing difficulties. Weak income growth, high unemployment and public spending cuts have further worsened the situation of the most vulnerable over recent years in many countries, where restoring access to good-quality affordable housing for all is a major challenge for policymakers.

Against this background, the OECD has developed the Affordable Housing Database (AHD), which brings together cross-national information from OECD and EU member states on housing market context, housing conditions, and public policies, to help governments monitor access to good-quality affordable housing and strengthen the knowledge base for policy evaluation. The effectiveness and efficiency of housing policy measures depends on the context in which they are implemented and on interactions with broader social and economic structures and policies. Hence, assessing the outcomes and potential impact of housing policies requires a system-level approach. Housing systems vary widely across OECD and EU countries, making international comparisons and benchmarking challenging. Identifying groups of countries with broadly similar housing systems allows both assessing the relative performance of different systems in terms of housing outcomes and comparing countries with their most relevant peers. In this article, we derive from the information included in the $A H D$ a typology of housing systems based on housing market features and conditions indicators, using principal component analysis (PCA) and cluster analysis. This approach allows us to get a comprehensive picture of housing outcomes across countries and to understand how different housing indicators relate to each other.

Our baseline analysis covers 25 countries and 34 variables. Seven countries, for which fewer variables are available, are subsequently added to the analysis. Four groups of countries are identified: two groups include the most advanced OECD economies, where inhabitants benefit from relatively good housing conditions in general, even if some population segments are facing difficulties in accessing decent and affordable housing. The two groups are mainly differentiated by tenure structure and level of household indebtedness. The first, which includes most of Northern Europe (in particular Germany), as well as the United States and Switzerland, is characterised by a large share of owners with mortgages, high household debt levels and a relatively high proportion of private sector tenants. The second, which includes much of the western part of continental Europe (especially France), along with Ireland and the United Kingdom, is characterised by larger shares of outright owners and social sector tenants. The two remaining groups enjoy less favourable housing conditions. One, with intermediate housing conditions includes part of Southern and Central and Eastern Europe (CEE), while the group with the most unfavourable housing conditions is exclusively made up of CEE countries.

While quantitative information on housing market context, housing conditions and household indebtedness is available for most countries in the database, variable definitions often differ across countries and information on policies is often qualitative and patchy, which restrains the scope for systematic data analysis. Nevertheless, examining the information on policies within and across the country groups previously determined allows us to identify some similarities and differences in housing policies.

The rest of the article is organised as follows: the next section briefly reviews the literature on housing systems; the third section describes the new OECD Affordable Housing Database; the fourth section derives the typology of housing systems through PCA and cluster analysis and describes the main characteristics of the groups of countries obtained in terms of housing outcomes and policies; the fifth section discusses the results and concludes.

\section{Housing systems: a brief review of the literature}

This article is essentially an empirical study aimed at establishing a typology of OECD and 
EU housing systems to inform policy decisions. Nevertheless, theories can shed light on the forces which have shaped housing systems and provide insights into the way they might evolve in the future. A major divide in the field of comparative housing research is between convergence and divergence theories. Convergence theories assume that countries tend to go through a similar development process and that differences in housing systems mostly reflect different stages of economic development (Donnison, 1967; Donnison \& Ungerson, 1982). While industrialisation, urbanisation and the development of the welfare state enhanced the role of the government in housing and led to the emergence of a large social rental sector in many industrialised countries, post-industrial societies are generally expected to converge towards a model of dominant homeownership, with a residual social rental sector (Harloe, 1995). Nevertheless, and despite the impact of global factors (e.g. urbanisation, downward trend in interest rates, deregulation of mortgage markets and pressure on public finances) on housing markets, country specificities remain marked (Steinmetz, 2015). Divergence theories point to the role of social structures and ideological choices in shaping housing systems (Kemeny \& Lowe, 1998; Van der Hejden, 2013 and references therein) and, since the 1990 s, have fostered research on typologies of housing systems (Hoekstra, 2010).

Two divergence theories have been particularly influential: the welfare state regime theory of Esping-Andersen (1990) and the theory of rental systems of Kemeny (1992, 1995). Esping-Andersen distinguishes three ideal typical welfare state regimes: the liberal regime, with strong reliance on markets and limited state intervention (mainly confined to a social safety net), the social-democratic regime characterised by universal highquality public services, and the corporatist regime, with relatively high government involvement in welfare provision (but not on an universal basis) and an important role played by the family and non-profit organisations. Examples of liberal regimes include the United States and the United Kingdom, sociodemocratic regimes include the Nordic countries and corporatist regimes include France and Germany. Importantly, Esping-Andersen's typology is based on social security and pensions, health and education, but not housing, which is often considered as the "wobbly pillar" of the welfare state (Torgensen, 1987), as for the majority of households it is provided through the market. Nevertheless, Esping-Andersen's typology has become a common reference in comparative housing research (Hoekstra, 2010; Van der Heijden, 2013). Kemeny distinguishes between integrated rental systems, where market and social rental housing compete with each other and are subject to similar regulations, and dual rental systems, where market and social segments are strictly separated, with the latter essentially catering to low-income households. Dual systems characterise Anglo-Saxon countries, but are also found in Belgium, Finland, Italy and Norway. Integrated systems include Austria, Denmark, France, Germany, the Netherlands, Sweden and Switzerland (Kemeny, 2006). Kemeny assumes that where policies encourage homeownership, the cost of buying houses will restrain possibilities of raising taxes to finance welfare. He therefore posits a negative relationship between homeownership and public welfare (Kemeny, 2005) ${ }^{1}$. It is often assumed that the ideological and power structures shaping welfare systems would lead to similar distributional outcomes in housing and other areas of welfare. However, the housing system may either reinforce or counteract the influence of the welfare system (Stephens \& Fitzpatrick, 2007) and there are serious difficulties in applying Esping-Andersen's and Kemeny's frameworks in comparative housing research, not least because systems have evolved since these typologies were established and their geographical coverage is limited (Stephens, 2016).

The typologies of Esping-Andersen and Kemeny have only seldom been confronted to housing data. Hoekstra (2003) translates the welfare state typology into housing market features and finds that Esping-Andersen's typology applies well to the Netherlands in the 1980 s, but less so in the 1990 s, as changes in housing policies have not matched the evolution of the welfare system between the two periods. Hoekstra (2005) extends the analysis to $12 \mathrm{EU}$ countries, adding a Mediterranean group to Esping-Andersen's typology. He performs a cluster analysis, based on six variables related to tenure and housing type and quality. He finds only two clusters, of which one contains the Mediterranean countries

\footnotetext{
1. Asset-based welfare, which assumes that households could take responsibility for their welfare (especially during retirement) by building up assets, rather than relying on state transfers, has also been widely discussed in the literature and policy circles (Doling \& Ronald, 2010).
} 
and the second all the others, pointing to limited differences between the three original welfare regimes on the housing variables included in the analysis. Castles (1998) tested Kemeny's hypothesis of a negative relationship between homeownership and public welfare on 20 OECD countries. He found a negative correlation between the homeownership rate and various measures of public welfare, albeit somewhat weaker in 1990 than in 1960 (Kemeny, 2005). Hoekstra (2009) assesses Kemeny's typology against data on tenure distribution, housing quality, income distribution of tenants and rent levels from the European Community Household Panel (ECHP) for Belgium, Ireland and the United Kingdom (assumed to be representative of dual rental systems) and Austria, Denmark and the Netherlands (assumed to be representative of integrated rental systems) ${ }^{2}$. He finds reasonable support for Kemeny's typology, even though there are signs of convergence between the two rental systems.

Dewilde (2017) investigates whether housing regimes across 15 Western-European countries can be characterised by their outcomes for low-income young and elderly people. Using ECHP data, she performs two cluster analyses, respectively for 1995 and 2012. Even though the 2012 analysis contains three more countries than the 1995 one, there are only relatively small differences between the two. In 2012, four groups of countries are identified: unitary rental market countries with high mortgage debt and a large affordable rental stock (Denmark, Netherlands, Norway, Sweden); countries with a dual rental market, but a fairly large affordable housing stock and moderate mortgage debt (Austria, Finland, Germany, United Kingdom); traditional mortgage-based homeownership countries with state support for ownership (Belgium, France, Ireland, Portugal, Spain); Mediterranean countries with high outright homeownership (Greece, Italy). Dewilde and De Decker (2016) extend the analysis to the evolution of housing outcome inequalities. They find that in countries with highly "commodified" housing regimes low income households experience more affordability problems but better housing conditions and that over time affordability has declined for low-income households and tenants in the private rental sector relative to middle-income households in Western Europe, a trend which can be explained by increased "financialisation" of housing and declining supply of private rental housing ${ }^{3}$.

\section{The new OECD Affordable Housing Database}

Across the OECD, low-income households are increasingly struggling with high housing costs and poor housing quality, in terms of living space available, adequacy of sanitary conditions and neighbourhood quality (Salvi del Pero et al., 2016). Therefore, the OECD was mandated by its member countries to develop new tools to assess the effectiveness and efficiency of different approaches to affordable housing. The first phase of the project identified the main challenges households are facing to access good-quality affordable housing, the main housing policy instruments put in place by OECD countries and the degree to which they overlap with social policies. In a second phase, the OECD developed, with support from the European Commission, a new on-line database, the OECD Affordable Housing Database (AHD), which was released in early $2017^{4}$. This new tool aims at helping countries measure access to good quality affordable housing and at strengthening the knowledge base needed for policy evaluation, by providing cross-country comparable indicators on housing outcomes and housing policy practices. The $A H D$ includes 39 OECD and EU countries, but in many cases the information is incomplete. Limited data coverage is a particular issue for non-European countries, which restricts the possibilities for comparative analysis across continents. While the use of broad policy instruments is documented for most countries, details of policies, which are essential to ensure comparability, are often only available for a limited set of countries. Hence, different country samples are used in this paper, according to data availability (see Box).

Information in the $A H D$ was drawn from different OECD sources, other readily available international and national databases, and, for some topics, a specific questionnaire.

\footnotetext{
2. Hoekstra (2009) does not include France in the analysis. France would belong to the dual rental system, with a clear distinction between social housing and the private rental market.

3. There is no obvious single definition of commodification in housing (Doling, 1999: Dewilde \& De Decker, 2016). A possible characterisation of "commodified" housing is a regime where housing is mainly allocated through the market and access is related to ability to pay. "Financialisation" refers to the increased dependence of housing markets on globalised financial markets through mortgage finance (Aalbers, 2008).

4. http://www.oecd.org/social/affordable-housing-database.htm. This webpage contains information about data sources, cross-country comparability, and, where relevant, raw data or descriptive information. This is particularly important as data collected at the national level may rely on definitions that are not harmonised across countries.
} 


\section{Box - Coverage of the OECD Affordable Housing Database and samples in the analyses}

The OECD Affordable Housing Database includes 39 countries. However, for some the information is sparse. Hence, various samples are used across this paper, reflecting data availability and trade-offs between the number of countries included in the analyses and the richness of the set of variables taken into account. Table A summarises the samples used in figures, tables and statistical analyses.

\section{Table A}

\begin{tabular}{|c|c|c|c|c|c|c|c|c|c|}
\hline Country & $\begin{array}{l}\text { ISO } \\
\text { code }\end{array}$ & $\begin{array}{l}\text { Housing } \\
\text { tenure } \\
\text { (Fig. I) }\end{array}$ & $\begin{array}{l}\text { Tenant } \\
\text { housing } \\
\text { cost } \\
\text { burden } \\
\text { (Fig. II-A) }\end{array}$ & $\begin{array}{l}\text { Over- } \\
\text { crowding } \\
\text { rate } \\
\text { (Fig. II-B) }\end{array}$ & $\begin{array}{c}\text { Policy } \\
\text { indicators } \\
\text { (Fig. III, IV) }\end{array}$ & $\begin{array}{c}\text { Baseline } \\
\text { sample (Fig } \\
\text { V, VI, VII; } \\
\text { Tab. 1-A, 2) }\end{array}$ & $\begin{array}{c}\text { Extended } \\
\text { sample } \\
\text { (Fig. VIII; } \\
\text { Tab. 1 B) }\end{array}$ & $\begin{array}{c}\text { Sample with } \\
\text { good housing } \\
\text { conditions and } \\
\text { policy coverage } \\
\text { (Tab. 3) }\end{array}$ & $\begin{array}{l}\text { Housing } \\
\text { allowances } \\
\text { (Tab. 4) }\end{array}$ \\
\hline Australia & AUS & $\mathrm{x}$ & $x$ & & $\mathrm{x}$ & & & & $x$ \\
\hline Austria & AUT & $x$ & $x$ & $x$ & $x$ & $x$ & $x$ & $x$ & $x$ \\
\hline Belgium & BEL & $x$ & $x$ & $x$ & & $x$ & $x$ & & $x$ \\
\hline Bulgaria & BUL & $x$ & $x$ & $x$ & $\mathrm{x}$ & & & & $x$ \\
\hline Canada & CAN & $x$ & $x$ & & $x$ & & & & \\
\hline Chile & $\mathrm{CHL}$ & $x$ & $x$ & $\mathrm{X}$ & $x$ & & $\mathrm{X}$ & & $\mathrm{x}$ \\
\hline Croatia & CRO & $x$ & $x$ & $x$ & $x$ & & $x$ & & $x$ \\
\hline Cyprus (a) & CYP & $x$ & $x$ & $x$ & $x$ & & $x$ & & $x$ \\
\hline Czech Republic & CZE & $\mathrm{x}$ & $x$ & $\mathrm{x}$ & $\mathrm{x}$ & $\mathrm{x}$ & $x$ & $\mathrm{x}$ & $x$ \\
\hline Denmark & DNK & $x$ & $x$ & $x$ & & $x$ & $x$ & & $x$ \\
\hline Estonia & EST & $x$ & $x$ & $x$ & $x$ & $x$ & $x$ & $\mathrm{x}$ & $x$ \\
\hline Finland & FIN & $x$ & $x$ & $x$ & $x$ & $x$ & $x$ & $x$ & $x$ \\
\hline France & FRA & $x$ & $x$ & $x$ & $x$ & $x$ & $x$ & $x$ & $x$ \\
\hline Germany & DEU & $x$ & $x$ & $x$ & $x$ & $x$ & $x$ & $x$ & $x$ \\
\hline Greece & GRC & $x$ & $x$ & $x$ & $x$ & $x$ & $x$ & $x$ & $x$ \\
\hline Hungary & HUN & $\mathrm{X}$ & $x$ & $x$ & $x$ & $x$ & $x$ & $x$ & $x$ \\
\hline Iceland & ISL & $x$ & $x$ & $x$ & & $x$ & $x$ & & $x$ \\
\hline Ireland & IRL & $x$ & $x$ & $x$ & & $x$ & $x$ & $x$ & $x$ \\
\hline Italy & ITA & $x$ & $x$ & $x$ & $x$ & $x$ & $x$ & & $x$ \\
\hline Japan & JPN & & $x$ & $x$ & $x$ & & & & $x$ \\
\hline Korea & KOR & $\mathrm{x}$ & & $x$ & $x$ & & & & $x$ \\
\hline Latvia & LVA & $\mathrm{x}$ & $\mathrm{x}$ & $x$ & $x$ & $\mathrm{X}$ & $x$ & $\mathrm{x}$ & $x$ \\
\hline Lithuania & LTU & $x$ & $x$ & $x$ & $x$ & & $x$ & & $x$ \\
\hline Luxembourg & LUX & $x$ & $x$ & $x$ & $x$ & & $x$ & & $x$ \\
\hline Malta & MLT & $x$ & $x$ & $x$ & $x$ & & $x$ & & $x$ \\
\hline Mexico & MEX & $x$ & $x$ & $x$ & $x$ & & $x$ & & \\
\hline Netherlands & NLD & $x$ & $x$ & $x$ & $x$ & $\mathrm{x}$ & $x$ & $\mathrm{x}$ & $\mathrm{x}$ \\
\hline New Zealand & NZL & & & & $x$ & & & & $x$ \\
\hline Norway & NOR & $x$ & $x$ & $x$ & $x$ & $x$ & $x$ & $x$ & $x$ \\
\hline Poland & $\mathrm{POL}$ & $x$ & $x$ & $x$ & $x$ & $x$ & $x$ & $x$ & $x$ \\
\hline Portugal & PRT & $x$ & $x$ & $x$ & $x$ & $x$ & $x$ & $x$ & $x$ \\
\hline Romania & ROM & $x$ & & & $x$ & & & & $x$ \\
\hline Slovak Republic & SVK & $x$ & $x$ & $x$ & $x$ & $x$ & $x$ & $x$ & $x$ \\
\hline Slovenia & SVN & $x$ & $x$ & $x$ & $x$ & $x$ & $x$ & $x$ & $x$ \\
\hline Spain & ESP & $\mathrm{x}$ & $x$ & $x$ & $x$ & $\mathrm{x}$ & $x$ & $\mathrm{x}$ & $x$ \\
\hline Sweden & SWE & $x$ & $x$ & $X$ & $x$ & $x$ & $x$ & $x$ & $x$ \\
\hline Switzerland & CHE & $x$ & $x$ & $x$ & $x$ & $\mathrm{x}$ & $x$ & $\mathrm{x}$ & $x$ \\
\hline United Kingdom & GBR & $x$ & $x$ & $x$ & $x$ & $x$ & $x$ & $x$ & $x$ \\
\hline United States & USA & $x$ & $x$ & $x$ & $x$ & $x$ & $x$ & $x$ & $x$ \\
\hline Number of countries & & 37 & 36 & 35 & 35 & 25 & 32 & 21 & 37 \\
\hline
\end{tabular}


More precisely, data were extracted from the OECD National Accounts Database, the Housing Prices Database, the Social Expenditure Database (SOCX) and Tax-Benefit models. In addition, indicators on housing tenure, affordability and quality were derived from micro-data available from the European Union Statistics on Income and Living Conditions survey (EU-SILC) and national-level household surveys. Finally, indicators on housing policy instruments and related levels of public support, as well as on homelessness, were developed using both quantitative and qualitative information collected through a questionnaire submitted to ministry officials and experts in all OECD member countries, as well as Bulgaria, Croatia, Cyprus 5 , Lithuania, Malta and Romania $^{6}$. Thirty-five countries answered the questionnaire, at least partially.

The $A H D$ includes indicators covering three main dimensions: housing market context; housing conditions; and public policies towards affordable housing. The first part includes data on the total housing stock, the number of dwellings per thousand inhabitants, the distribution of housing in urban versus rural areas, the share of vacant homes and residential construction, for selected years (2000, 2010, 2013 and 2015 or latest year available). Housing prices, rents and price-to-income ratios are available, but only in the form of indices, not actual levels. The distribution of households across tenures is also available (Figure I), even though differences in definitions limit the data comparability across countries, notably with respect to rental. In particular, there are great differences in the extent private rental dwellings are allocated through market forces (Crook \& Kemp, 2014). In countries with integrated rental systems and a large housing stock owned by housing associations, like Denmark and the Netherlands, all tenants are classified as renting in the private sector, because the data from $E U-S I L C$ do not allow a distinction by type of tenant. Similarly, the large Swedish stock of municipal rental housing is not classified as social housing, as it is generally allocated on the basis of waiting lists rather than according to needs-related criteria, even though it plays an important role in housing low-income households (Pittini \& Laino, 2012). Regulations and the dominance of non-profit landlords in these integrated rental systems tend to lower rent levels and increase security of tenure compared to markets dominated by private providers. Data by income quintiles are also included in the database. Finally, household structure and living arrangements across different age groups are described. Given the scope of this article, in particular its cross-sectional approach, and data availability and comparability, we only use, from this part of the $A H D$, data on tenure and the percentage of 15-29 year-olds living with their parents.

Data from the second part of the $A H D$ look at living conditions in terms of affordability, quality of dwellings and housing exclusion. Affordability is measured by the housing cost burden (relative to income) and housing overburden rates (share of households spending more than $40 \%$ of their income on housing) for different types of households. Figure II shows a high housing cost burden for tenants in the bottom quintile of the income distribution, as well as high overcrowding rates for the same category of households in many countries. Household debt-to-income ratios derived from the OECD National Accounts Database complement housing cost measures, which for homeowners are affected by differences in mortgage repayment structures ${ }^{7}$. Indicators of housing quality in the $A H D$ include dwellings physical characteristics, amenities (e.g. flushing toilet), living space available (e.g. number of rooms) and housing deprivation $^{8}$. These measures help identify the incidence of the poorest housing conditions, but more indicators would be needed to compare housing quality more widely in advanced economies, for example along the dimensions of building quality and maintenance, energy efficiency, noise insulation, neighbourhood quality and distance to public amenities. Housing affordability and quality indicators require not only detailed information regarding the dwelling but also household income and composition (such as the age and number of household members). These indicators were found in household surveys: $E U-S I L C$ for European countries, except Germany, where a national survey is used, as for non-European

5. In this article, Cyprus refers to the area under the effective control of the Government of the Republic of Cyprus, i.e. the southern part of the island.

6. The European Commission Social Policy Committee sub-group on indicators (ISG) also helped to collect information for non-OECD members of the European Union.

7. The data refer to total household debt rather than mortgage debt. However, the latter accounts on average for about two-thirds of household liabilities in OECD countries.

8. Housing deprivation occurs if the dwelling: has a leaking roof, damp walls, floors or foundation, or rot in window frames or floor; has neither a bath nor a shower; has no flushing toilet for exclusive use of the household; is considered too dark. 
Figure I

\section{Housing tenure distribution, 2014 or latest year available}

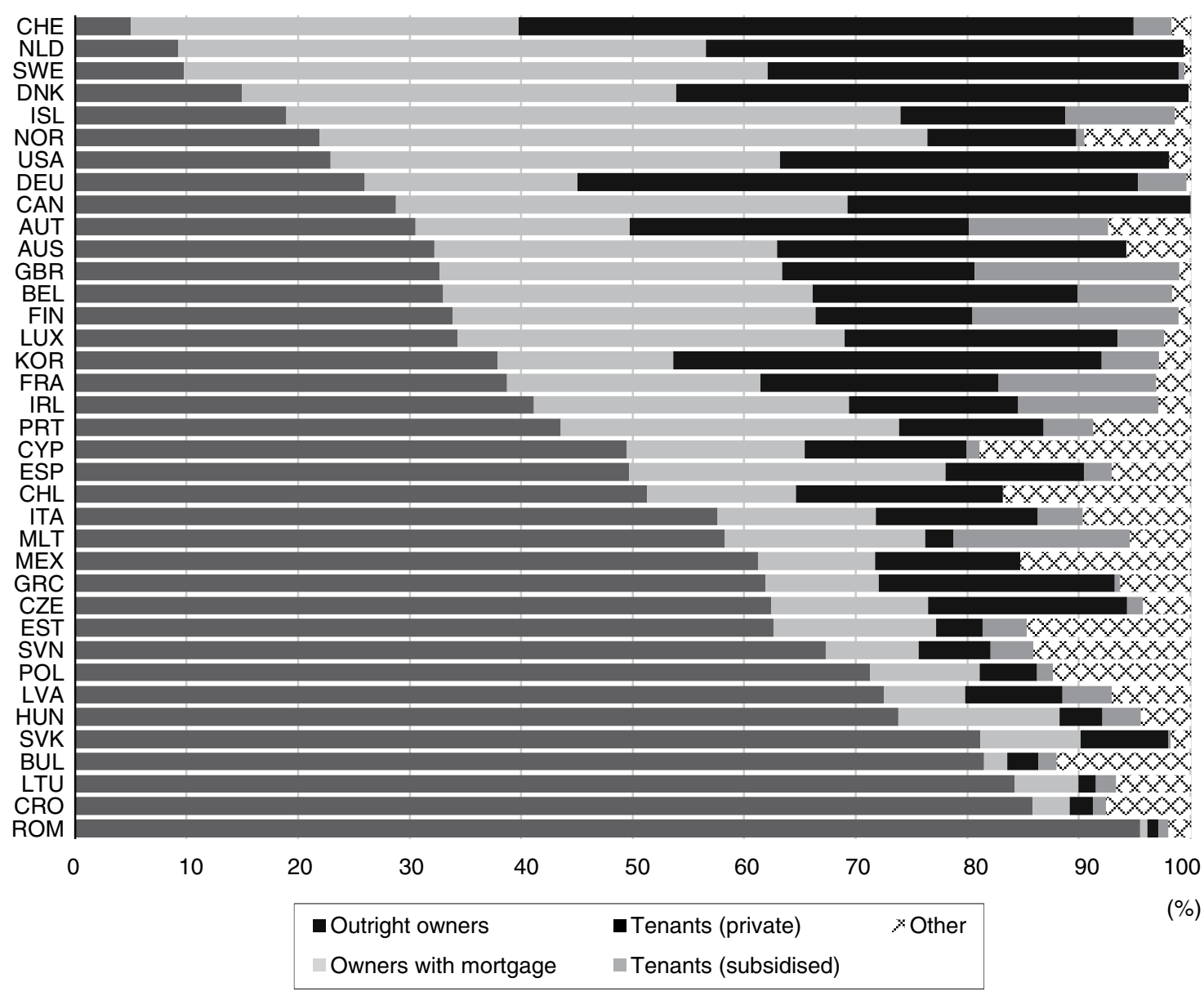

Note: OECD calculations based on European Survey on Income and Living Conditions (EU-SILC) and national surveys. In countries with integrated rental systems and a large housing stock owned by housing associations, like Denmark and the Netherlands, all tenants are classified as renting in the private sector, because the data from EU-SILC do not allow a distinction by type of tenant. Similarly, the large Swedish stock of municipal rental housing is not classified as social housing. For details, see http://www.oecd.org/social/affordable-housing-database.htm.

Reading note: In Switzerland, the housing tenure distribution is $5 \%$ of outright owners, $35 \%$ of owners with mortgage, $55 \%$ of private tenants, $3 \%$ of subsidised tenants and $2 \%$ of other categories.

Coverage: 37 countries (cf. Box)

Sources: OECD, Affordable Housing Database $(A H D)$.

Figure II Housing costs and overcrowding rate of low-income households

A- Tenant housing cost burden

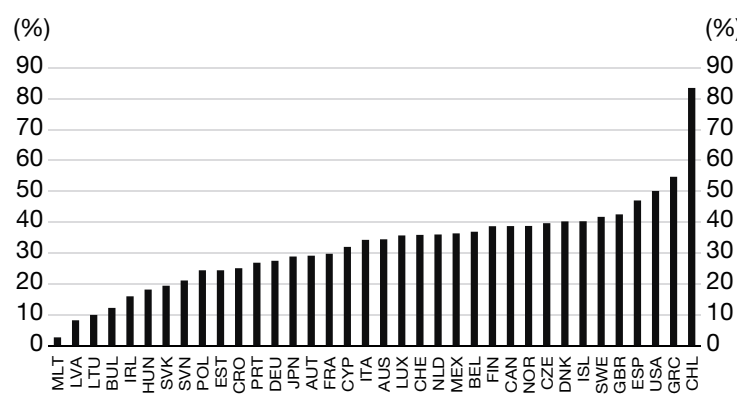

B - Overcrowding rate

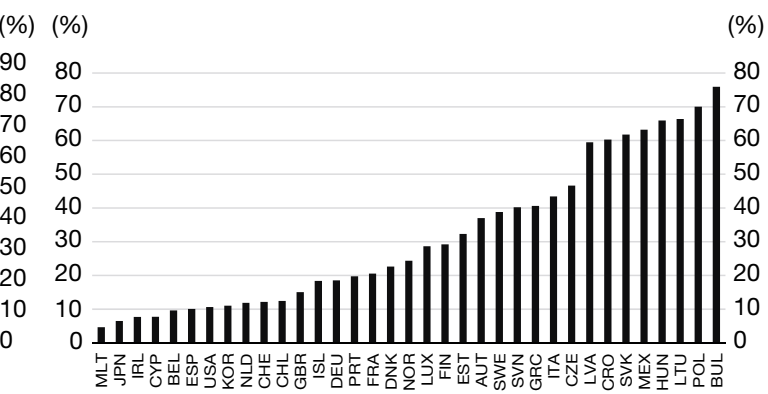

Note: The housing cost burden refers to the median rent burden as a share of disposable income in the bottom quintile of the income distribution. The overcrowding rate refers to the share of overcrowded tenant households in the bottom quintile of the income distribution. OECD calculations based on European Survey on Income and Living Conditions (EU-SILC) and national surveys. For details, see http://www.oecd. org/social/affordable-housing-database.htm.

Coverage: 36 and 35 countries for panel $A$ and $B$ respectively (cf. Box).

Sources: OECD, Affordable Housing Database (AHD). 
countries $^{9}$. The percentage of homeless people is available for some countries, but definitions of homelessness vary widely across countries, making international comparisons difficult.

The third part of the $A H D$ gives an overview of policy measures that directly support access to affordable housing. The policy indicators are based on the country expert responses to the 2016 OECD Questionnaire on Social and Affordable Housing (QuASH). They contain a wide range of information on policy measures and details of national schemes, different types of support for homeowners, housing allowances eligibility criteria and payment rates, social housing stock and new construction, and agencies and governance of the social housing sector. Figure III provides an overview of the use of housing policy instruments across countries. Most countries have housing allowances, as well as social rental housing. In addition, many support homeownership, in particular through tax advantages.

Policy instruments may either be complements or substitutes. For example, housing allowances to tenants in the private rental sector and social housing can, to some extent, be seen as substitutes. Since the 1980s, governments in many OECD countries have favoured housing allowances over social housing, in particular to lower capital costs, enhance equality in access to housing and reduce disincentives to housing mobility. Mortgage relief schemes and instruments encouraging borrowing for homeownership, like mortgage interest deductibility or subsidised mortgages, can be complements, as higher indebtedness generates vulnerability of households to economic shocks, increasing the relevance of relief schemes. To investigate associations between housing policy instruments, we perform a multiple correspondence analysis (MCA) on the eight binary indicators showing the presence or absence of specific policies in each country (Figure IV). The correlations between the factors obtained and the principal components derived from housing market features and housing condition indicators will be subsequently examined to assess relationships between housing policies and outcomes. The first factor, which explains nearly $30 \%$ of the variance of the dataset, is associated with the variety of policy instruments used. Countries using the most policy instruments feature on the left side of the axis, while those using few instruments stand on the right side. The second factor, which explains about $18 \%$ of the variance, is more difficult to interpret. The top part is associated with the presence of mortgage relief for over-indebted homeowners and the absence of subsidies for the development of affordable homeownership and of subsidised mortgages and guarantees to homebuyers. The bottom part is associated with the absence of social housing, tax relief for access to homeownership and mortgage relief for over-indebted homeowners, as well as with the presence of subsidies for the development of affordable homeownership. Hence, the countries at the upper end of the chart tend to provide tax relief and a safety net to homeowners, but no subsidies. Those at the bottom

9. For details, see $h$ ttp://www.oecd.org/social/affordable-housing-database.htm Dewilde (2015) provides a useful assessment of strengths and weaknesses of EU-SILC data for housing research.

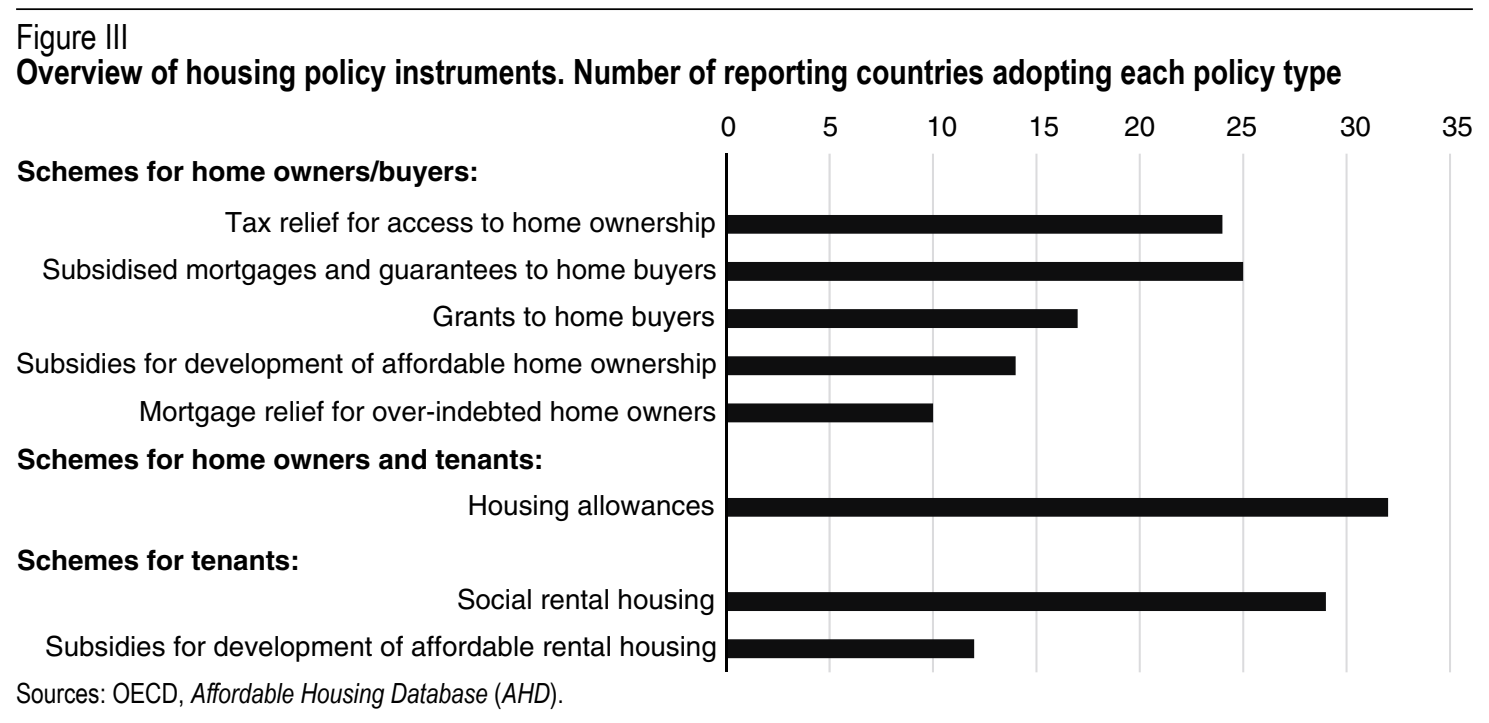


end tend to be characterised by the absence of social housing, but use subsidies to promote affordable homeownership. Altogether, associations between housing policy instruments do not show clear patterns.

A limitation of this analysis is that it only uses binary variables, which account for the availability of instruments, but not for the intensity of their use and differences in design across countries. Unfortunately, the country coverage of quantitative indicators is too narrow to allow a systematic analysis of correlations. In many countries, the data currently available do not allow a reliable evaluation of the share of public spending directed towards different policies. While information on some instruments, like housing allowances, covers a large sample of countries, other data, like spending on social housing, are patchy. Another reason for the lack of clear pattern in the policy mix may be the presence of overlapping policy instruments, notably linked to path dependency and the persistence of old instruments when new ones are introduced.

\section{A typology of housing systems}

To reveal the main features of housing systems, a PCA is performed on variables representing housing market context, housing conditions and household indebtedness. To avoid scalerelated distortions, the variables are standardised to zero mean and unit variance. Next, cluster analysis is used to group countries with similar profiles. Finally, in order to shed light

\section{Figure IV}

Multiple correspondence analysis on policy instruments

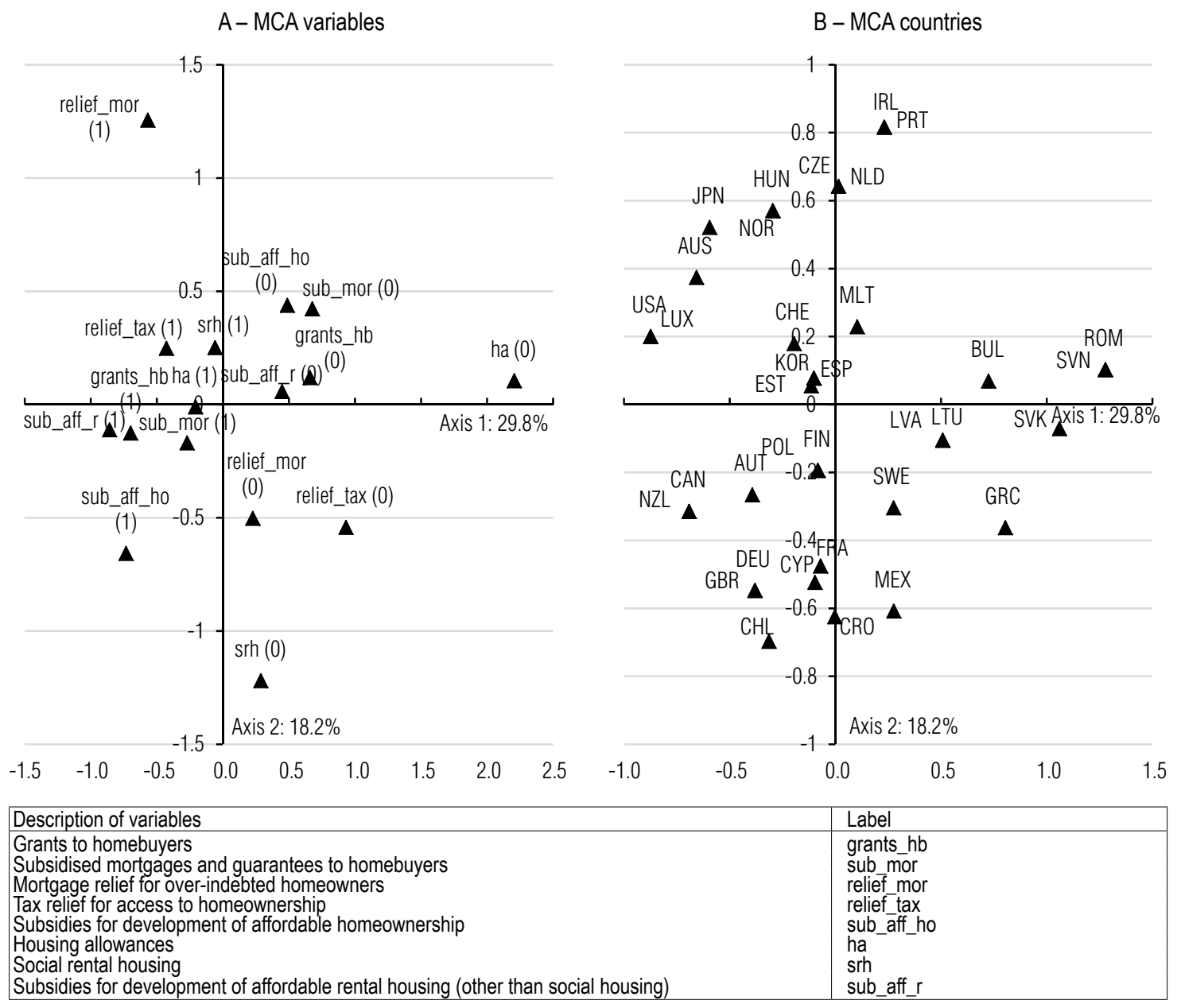

Reading note: $(0)$ and (1) refer to the absence/existence of the policy in the country. For example, ha( 0$)$ means that housing allowances are absent. The percentage indicated on each axis refers to the percentage of variance explained by the axis.

Coverage: 35 countries (cf. Box)

Sources: OECD, Affordable Housing Database $(A H D)$; authors' calculations. 
on the main characteristics of housing systems, we test for differences in the means of the indicators included in the analysis across country groups. We also look at the values of policy indicators across country groups, albeit in a less systematic way, as the information is less comprehensive than for the variables included in the PCA. Our baseline analysis includes 25 countries, for which 34 variables, covering the most important characteristics of a housing system, are available. Further analysis, based on a narrower set of variables, allows us to assign, albeit more tentatively, seven countries to the groups identified in our baseline analysis. Seven of the 39 countries included in the $A H D$ are discarded, as data are too patchy to allow meaningful analysis (cf. Box).

The PCA reveals a very strong first principal component (horizontal axis), which explains nearly $60 \%$ of the variance of the dataset and opposes high outright homeownership, but with relatively poor housing conditions, to more indebtedness and private rental, but with overall better housing conditions. The correlation circle (Figure V) shows that most variables are strongly correlated with the axis.

On the right side of the axis, we find high overcrowding and deprivation rates, a high proportion of youth living with their parents, as well as a high share of outright owners, even in the bottom part of the income distribution. On the left side of the axis, dwellings have more rooms, a large share of households are owners with mortgages - often with large debt - or tenants in the private rental sector - often with a high housing cost burden. The second principal component (vertical axis) explains slightly less than $10 \%$ of the overall variance. It essentially differentiates countries where low income households are mainly housed in the private rental sector from those where a substantial share of low income households is housed in social rental housing. Unsurprisingly, a high share of low-income households lodged in the private rental sector tends to be associated with higher overcrowding rates. Other principal components explain too small a share of the variance to yield significant insights into the analysis.

Plotting the countries on the map defined by the first two principal components reveals clear patterns (Figure VI). Four Eastern Europe countries feature on the right end of the first axis, which is associated with relatively poor housing conditions and a high share of outright owners. This is consistent with relatively low income by OECD and EU standards and with the fact that policies following the transition from socialist to market economies have allowed most households to access homeownership. However, a large part of the housing stock was of poor quality and few households had the means to invest in renovation. Moving left on the horizontal axis, we find other Eastern Europe countries, as well as some Mediterranean countries, with intermediate housing conditions and high homeownership rates, except for the Czech Republic, whose transition path has diverged from that of other Eastern Europe countries, resulting in a higher share of tenants compared to other countries in the region (Hegedüs et al., 2011). The wealthiest OECD countries are located to the left of the vertical axis, which is associated with larger homes and a more diversified tenure structure, with more owners with mortgages and tenants in the private rental sector. The upper left quadrant groups the Nordic countries - except Finland - and the Netherlands, as well as Germany, Switzerland and the United States. The Nordics and the Netherlands, beyond their socio-economic similarities, share some common housing and mortgage market characteristics, in particular high mortgage debt and a fairly large rental stock. Germany and Switzerland have the largest proportion of private sector tenants in Europe. Despite its fairly high homeownership rate, the United States houses a significant portion of its population in the private rental market and has a high average income level, which explains its position on the chart ${ }^{10}$. Countries in the bottom left quadrant - and Austria, which is near the border - look a bit more heterogeneous. Consistent with the interpretation of the second principal component (vertical axis) as mainly opposing social to private renting, most of these countries have a significant social housing stock, although this is not the case in Portugal and Spain.

Going one step further, we use cluster analysis to sort countries into homogeneous groups. The same standardised variables as in the PCA are included and the Ward method, which maximises the between-group of countries

10. Australia, Canada and New Zealand's housing systems share some similarities with that of the United States, particularly in terms of tenure structure. Unfortunately, it was not possible to include these countries in the analysis, because too many variables are unavailable in the AHD. The other Anglo-Saxon countries included in the analysis, Ireland and the United Kingdom, differ significantly from the United States, notably by their relatively large social rental housing stock. 
Figure V

\section{Principal component analysis on housing systems: Correlation circle}

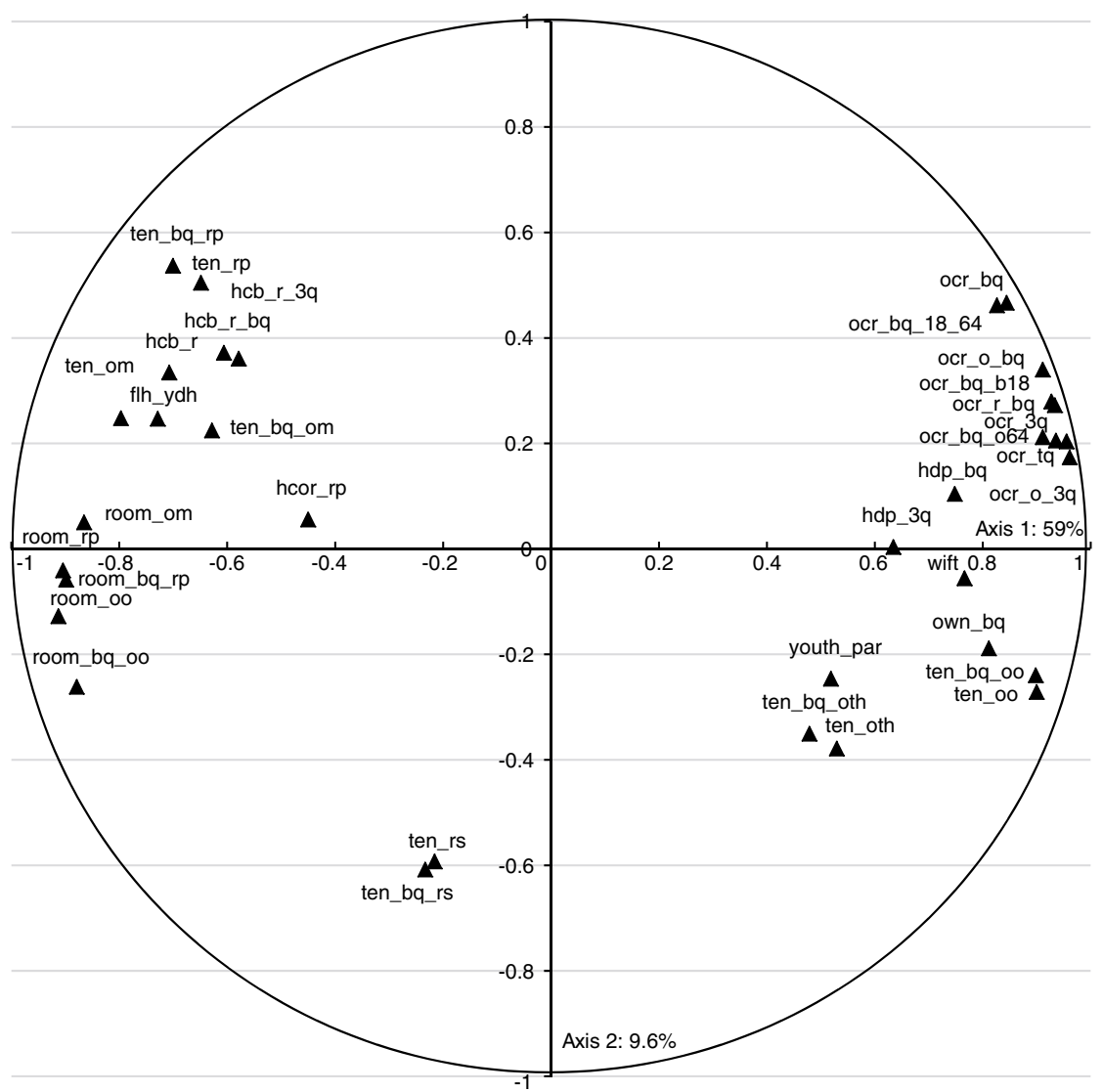

\begin{tabular}{|c|c|}
\hline Description of variables & Label \\
\hline $\begin{array}{l}\text { Households' housing cost burden as a share of disposable income, tenants } \\
\text { Overall } \\
\text { Bottom quintile } \\
\text { Third quintile }\end{array}$ & $\begin{array}{l}\text { hcb_r } \\
\text { hcb_r_bq } \\
\text { hcb_r_3a }\end{array}$ \\
\hline Housing cost overburden rate among low-income private sector tenants & hcor_rp \\
\hline $\begin{array}{l}\text { Average number of rooms per household member } \\
\text { Outright owners } \\
\text { Owners with mortgage } \\
\text { Tenants (private) } \\
\text { Outright owners, bottom quintile } \\
\text { Tenants (private), bottom quintile } \\
\end{array}$ & $\begin{array}{l}\text { room_00 } \\
\text { room_om } \\
\text { room_rp } \\
\text { room_bq_oo } \\
\text { room_bq_rp }\end{array}$ \\
\hline $\begin{array}{l}\text { Overcrowding rates } \\
\text { Bottom quintile } \\
\text { Third quintile } \\
\text { Top quintile } \\
\text { Low and middle-income households, owners, bottom quintile } \\
\text { Low and middle-income households, owners, third quintile } \\
\text { Low and middle-income households, tenants, bottom quintile } \\
\text { Bottom quintile, age below } 18 \\
\text { Bottom quintile, age 18-64 } \\
\text { Bottom quintile, age over } 64\end{array}$ & $\begin{array}{l}\text { ocr_bq } \\
\text { ocr_3q } \\
\text { ocr_tq } \\
\text { ocr_o_bq } \\
\text { ocr_o_3q } \\
\text { ocr_r_bq } \\
\text { ocr_bq_b18 } \\
\text { Ocr_bq_18_64 } \\
\text { Ocr_bq_064 }\end{array}$ \\
\hline Share of poor households without exclusive flushing toilet & wift \\
\hline $\begin{array}{l}\text { Housing deprived population } \\
\text { Bottom quintile } \\
\text { Third quintile }\end{array}$ & $\begin{array}{l}\text { hdp_bq } \\
\text { hdp_3q }\end{array}$ \\
\hline $\begin{array}{l}\text { Tenure structure } \\
\text { Outright owners } \\
\text { Owners with mortgage } \\
\text { Tenants (private) } \\
\text { Tenants (subsidised) } \\
\text { Others } \\
\text { Owners, bottom quintile } \\
\text { Outright owners, bottom quintile } \\
\text { Owners with mortgage, bottom quintile } \\
\text { Tenants (private), bottom quintile } \\
\text { Tenants (subsidised), bottom quintile } \\
\text { Others, bottom quintile }\end{array}$ & $\begin{array}{l}\text { ten_oo } \\
\text { ten_om } \\
\text { ten_rp } \\
\text { ten_rs } \\
\text { ten_oth } \\
\text { own_bq } \\
\text { ten_bq_oo } \\
\text { ten_bq_om } \\
\text { ten_bq_rp } \\
\text { ten_bq_rs } \\
\text { ten_bq_oth }\end{array}$ \\
\hline Share of $15-29$ living with their parents & youth_par \\
\hline Household liabilities as a share of disposable income & flh_ydh \\
\hline
\end{tabular}

Reading note: The variable hdp_3q (housing deprived population in the third quintile) presents a correlation of 0.64 with the first principal component and a null correlation with the second principal component. The percentage indicated on each axis refers to the percentage of variance explained by the axis.

Coverage: 25 countries (cf. Box).

Sources: OECD, Affordable Housing Database (AHD); authors' calculations. 
variance relative to the within-group of countries variance is used. The dendrogramme (Figure VII) suggests that the sample can be divided into four groups of countries. The first group includes a large part of the western side of continental Europe (Austria, Belgium, France, Portugal and Spain), Ireland and the United Kingdom, as well as Finland. The rest of Northern Europe is classified in the second group, which includes Denmark, Iceland, Norway and Sweden, as well as Germany and the Netherlands, together with Switzerland and the United States. The third group includes the Mediterranean countries which are not in the first group (Italy and Greece) and part of Central and Eastern Europe (Czech Republic, Estonia, Slovenia), the rest of which forms the fourth group (Hungary, Latvia, Poland and the Slovak Republic). To facilitate the presentation of the results, in what follows we will name the country groups, respectively, "Western", "Northern", "Southern-Central" and "Eastern". Overall, the classification is broadly in line with our priors, based on housing market and institutional information. Nevertheless, a few remarks on specific cases are in order before moving to more detailed analyses. Finland is classified in the first group rather than with the other Nordic countries because it has more outright owners, a lower household debt-to-income ratio and more social rental housing than these countries ${ }^{11}$. Mediterranean countries are split into two groups. This mainly reflects a lower average number of rooms and higher overcrowding rates in Greece and Italy than in Portugal and Spain, as well as somewhat higher proportions of owners with mortgages and levels of household debt in the latter two. CEE countries are mainly sorted into two different groups on the basis of the average number of rooms and overcrowding rates.

In order to gain further insight into the factors which differentiate country groups, we test for the significance of differences in the means of housing market context, housing conditions and indebtedness variables across groups, using standard Student tests. Table 1 displays variable means by country group and Table 2

11. As noted above, dwellings owned by Swedish municipalities and Danish and Dutch housing associations are not classified as social housing, even though they play an important role in housing low-income households.

\section{Figure VI}

\section{Principal component analysis on housing systems: Mapping of countries}

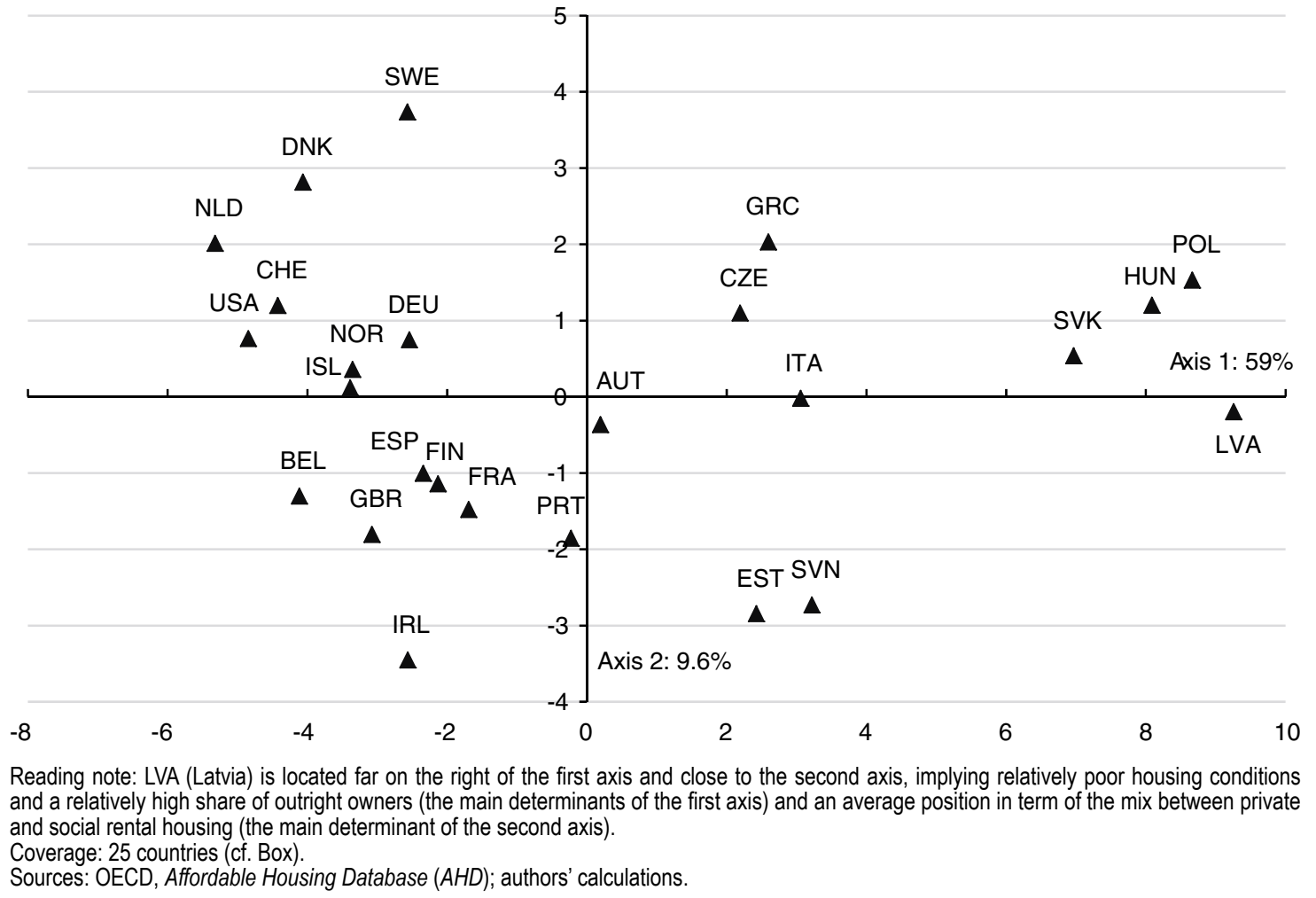


shows the test results for each variable and pair of country groups.

The "Western" and "Northern" groups, which include the most advanced OECD economies, are clearly differentiated by tenure structure and level of household indebtedness, but differences in housing conditions are generally insignificant. Only the number of rooms for owners with mortgages is significantly higher in the "Northern" than in the "Western" group, although only at the $10 \%$ confidence level. Conversely, differences in tenure variables are generally significant at least at the 5\% level and often at the $1 \%$ level. The "Northern" group has more owners with mortgages, higher household debt levels and more private sector tenants than the "Western" group, which has more outright owners and social sector tenants. The same differences in tenure patterns between the two groups of countries are observed in the whole population and in the bottom quintile of the income distribution. The share of youth living with their parents is lower in the "Northern" group (at the $10 \%$ level), which may, to some extent, reflect easier access to mortgages and wider rental options. Differences in the means of housing conditions variables across groups other than the "Western" and "Northern" are generally significant, most often at the $1 \%$ level. The number of rooms per dwelling is lower in all tenures in the "Southern-Central" group than in the "Western" and "Northern" groups and even lower in the "Eastern" group.

Overcrowding shows a consistent picture, with the highest rates in the "Southern-Central" group and particularly in the "Eastern" group. The situation is particularly acute for bottom

\section{Figure VII}

\section{Cluster analysis of housing systems on baseline sample: Dendrogramme}

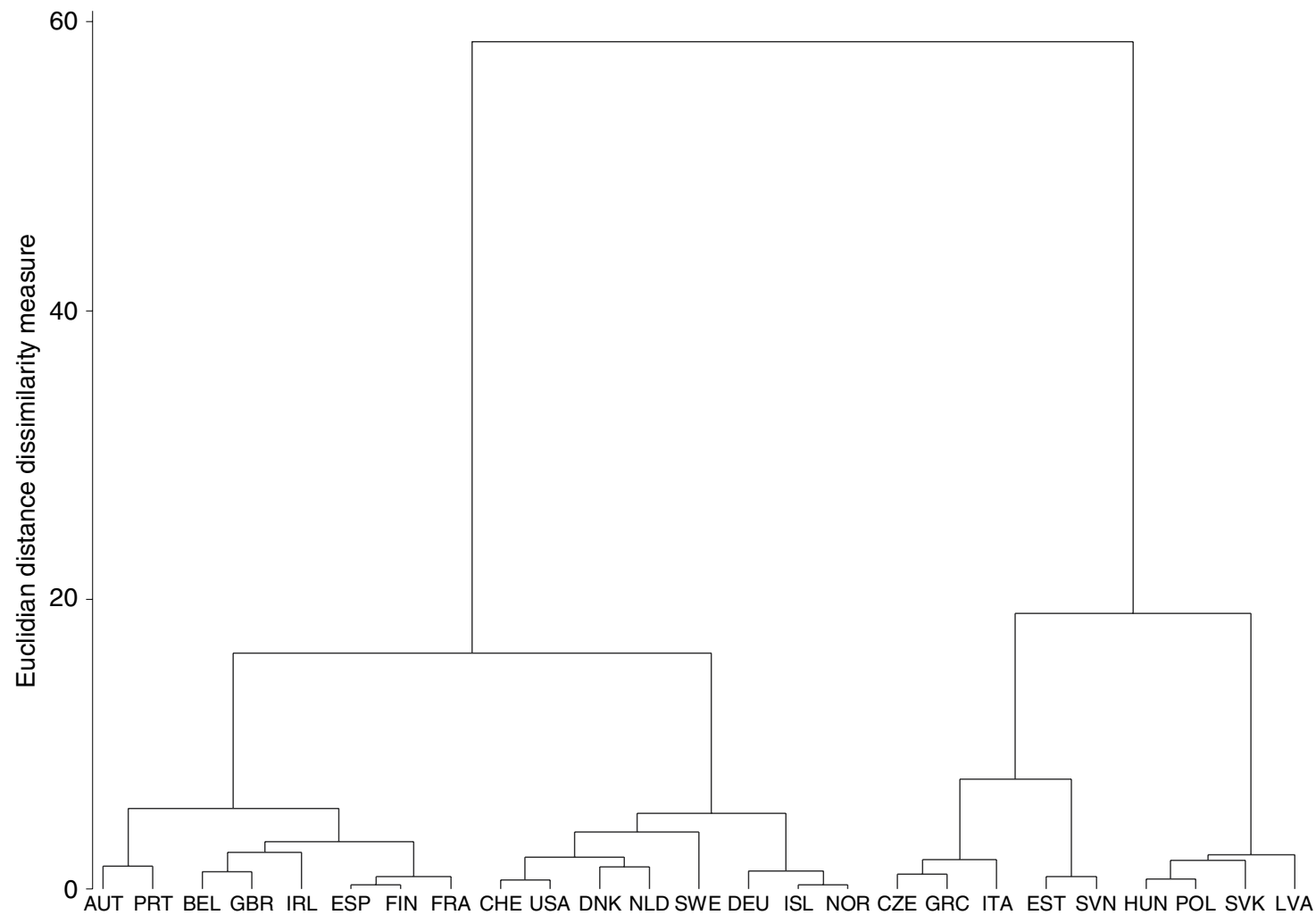

Note: In countries with integrated rental systems and a large housing stock owned by housing associations, like Denmark and the Netherlands, all tenants are classified as renting in the private sector, because the data from EU-SILC do not allow a distinction by type of tenant. Similarly, the large Swedish stock of municipal rental housing is not classified as social housing.

Reading note: The dendrogramme shows the hierarchical clustering of the countries, using Ward's method and Euclidian distances. Hungary, Poland, the Slovak Republic and Latvia share strong similarities and the most comparable other group is made of the Czech Republic, Greece, Italy, Estonia and Slovenia.

Coverage: 25 countries (cf. Box)

Sources: OECD, Affordable Housing Database (AHD); authors' calculations. 
Table 1

Variable means by country group

\begin{tabular}{|c|c|c|c|c|c|c|c|c|c|c|}
\hline \multirow[b]{2}{*}{ Variables } & \multicolumn{5}{|c|}{ A. Baseline sample } & \multicolumn{5}{|c|}{ B. Extended sample } \\
\hline & $\begin{array}{c}\text { Overall } \\
(25)\end{array}$ & $\begin{array}{l}\text { Western } \\
\text { (8) }\end{array}$ & $\begin{array}{l}\text { Northern } \\
(8)\end{array}$ & $\begin{array}{l}\text { Southern- } \\
\text { Central } \\
\text { (5) }\end{array}$ & $\begin{array}{l}\text { Eastern } \\
\text { (4) }\end{array}$ & $\begin{array}{l}\text { Overall } \\
(32)\end{array}$ & $\begin{array}{l}\text { Western } \\
\text { (9) }\end{array}$ & $\begin{array}{l}\text { Northern } \\
\text { (9) }\end{array}$ & $\begin{array}{l}\text { Southern- } \\
\text { Central } \\
(7)\end{array}$ & $\begin{array}{l}\text { Eastern } \\
\quad(7)\end{array}$ \\
\hline \multicolumn{11}{|c|}{ Households' housing cost burden as a share of disposable income, tenants } \\
\hline Overall & 0.23 & 0.24 & 0.27 & 0.22 & 0.13 & 0.22 & 0.22 & 0.27 & 0.22 & 0.14 \\
\hline Bottom quintile & 0.33 & 0.33 & 0.39 & 0.35 & 0.17 & 0.33 & 0.30 & 0.38 & 0.41 & 0.20 \\
\hline Third quintile & 0.19 & 0.20 & 0.21 & 0.20 & 0.12 & - & - & - & - & - \\
\hline $\begin{array}{l}\text { Housing cost overburden rate among } \\
\text { low-income private sector tenants }\end{array}$ & 0.37 & 0.44 & 0.38 & 0.40 & 0.18 & 0.38 & 0.42 & 0.38 & 0.42 & 0.27 \\
\hline \multicolumn{11}{|c|}{ Average number of rooms per household member } \\
\hline Outright owners & 2.41 & 2.72 & 2.89 & 1.90 & 1.50 & 2.34 & 2.71 & 2.92 & 1.94 & 1.53 \\
\hline Owners with mortgage & 1.82 & 1.95 & 2.25 & 1.43 & 1.19 & 1.78 & 1.99 & 2.23 & 1.53 & 1.19 \\
\hline Tenants (private) & 1.74 & 1.93 & 2.06 & 1.44 & 1.09 & 1.75 & 2.10 & 2.04 & 1.51 & 1.15 \\
\hline Outright owners, bottom quintile & 2.68 & 3.04 & 3.14 & 2.19 & 1.66 & 2.60 & 3.07 & 3.18 & 2.20 & 1.68 \\
\hline Tenants (private), bottom quintile & 1.69 & 1.85 & 2.05 & 1.36 & 1.09 & - & - & - & - & - \\
\hline \multicolumn{11}{|l|}{ Overcrowding rates } \\
\hline Bottom quintile & 0.19 & 0.11 & 0.14 & 0.21 & 0.40 & 0.19 & 0.08 & 0.15 & 0.20 & 0.36 \\
\hline Third quintile & 0.11 & 0.04 & 0.04 & 0.15 & 0.32 & 0.12 & 0.03 & 0.04 & 0.13 & 0.31 \\
\hline Top quintile & 0.07 & 0.02 & 0.01 & 0.09 & 0.25 & 0.07 & 0.02 & 0.01 & 0.08 & 0.23 \\
\hline $\begin{array}{l}\text { Low and middle-income households, } \\
\text { owners, bottom quintile }\end{array}$ & 0.11 & 0.03 & 0.05 & 0.14 & 0.33 & 0.12 & 0.03 & 0.05 & 0.12 & 0.31 \\
\hline $\begin{array}{l}\text { Low and middle-income households, } \\
\text { owners, third quintile }\end{array}$ & 0.08 & 0.02 & 0.02 & 0.12 & 0.28 & 0.09 & 0.02 & 0.02 & 0.10 & 0.28 \\
\hline $\begin{array}{l}\text { Low and middle-income households, } \\
\text { tenants, bottom quintile }\end{array}$ & 0.31 & 0.19 & 0.20 & 0.41 & 0.64 & 0.32 & 0.14 & 0.21 & 0.36 & 0.64 \\
\hline Bottom quintile, age below 18 & 0.29 & 0.17 & 0.17 & 0.39 & 0.67 & 0.30 & 0.12 & 0.17 & 0.36 & 0.65 \\
\hline Bottom quintile, age 18-64 & 0.26 & 0.16 & 0.19 & 0.31 & 0.52 & 0.26 & 0.11 & 0.19 & 0.29 & 0.49 \\
\hline Bottom quintile, age over 64 & 0.09 & 0.04 & 0.03 & 0.12 & 0.27 & 0.09 & 0.03 & 0.03 & 0.11 & 0.23 \\
\hline $\begin{array}{l}\text { Share of poor households } \\
\text { without exclusive flushing toilet }\end{array}$ & 0.05 & 0.02 & 0.01 & 0.05 & 0.19 & 0.07 & 0.02 & 0.01 & 0.05 & 0.25 \\
\hline \multicolumn{11}{|l|}{ Housing deprived population } \\
\hline Bottom quintile & 0.02 & 0.01 & 0.00 & 0.01 & 0.11 & 0.03 & 0.00 & 0.00 & 0.01 & 0.14 \\
\hline Third quintile & 0.00 & 0.00 & 0.00 & 0.00 & 0.02 & 0.01 & 0.00 & 0.00 & 0.00 & 0.05 \\
\hline \multicolumn{11}{|l|}{ Tenure structure } \\
\hline Outright owners & 0.42 & 0.38 & 0.16 & 0.62 & 0.75 & 0.46 & 0.42 & 0.18 & 0.56 & 0.76 \\
\hline Owners with mortgage & 0.27 & 0.28 & 0.43 & 0.12 & 0.10 & 0.24 & 0.27 & 0.42 & 0.13 & 0.09 \\
\hline Tenants (private) & 0.21 & 0.18 & 0.37 & 0.13 & 0.06 & 0.19 & 0.15 & 0.35 & 0.16 & 0.06 \\
\hline Tenants (subsidised) & 0.05 & 0.11 & 0.02 & 0.03 & 0.02 & 0.05 & 0.11 & 0.03 & 0.04 & 0.02 \\
\hline Others & 0.05 & 0.04 & 0.02 & 0.10 & 0.06 & 0.06 & 0.06 & 0.02 & 0.10 & 0.08 \\
\hline Owners, bottom quintile & 0.51 & 0.46 & 0.36 & 0.63 & 0.78 & 0.54 & 0.49 & 0.36 & 0.57 & 0.79 \\
\hline Outright owners, bottom quintile & 0.39 & 0.34 & 0.15 & 0.57 & 0.73 & 0.43 & 0.38 & 0.16 & 0.51 & 0.76 \\
\hline Owners with mortgage, bottom quintile & 0.12 & 0.12 & 0.20 & 0.05 & 0.05 & 0.11 & 0.12 & 0.20 & 0.06 & 0.04 \\
\hline Tenants (private), bottom quintile & 0.31 & 0.27 & 0.56 & 0.17 & 0.08 & 0.28 & 0.22 & 0.56 & 0.21 & 0.06 \\
\hline Tenants (subsidised), bottom quintile & 0.09 & 0.20 & 0.04 & 0.04 & 0.04 & 0.08 & 0.19 & 0.04 & 0.05 & 0.03 \\
\hline Others, bottom quintile & 0.08 & 0.07 & 0.04 & 0.16 & 0.10 & 0.10 & 0.09 & 0.04 & 0.16 & 0.12 \\
\hline Share of $15-29$ living with their parents & 0.61 & 0.60 & 0.50 & 0.71 & 0.70 & - & - & - & - & - \\
\hline $\begin{array}{l}\text { Household liabilities as a share } \\
\text { of disposable income }\end{array}$ & 1.32 & 1.34 & 1.97 & 0.83 & 0.57 & - & - & - & - & - \\
\hline
\end{tabular}

Reading note: The numbers indicated in the table are the averages of each indicator for the identified group of countries.

Coverage: 25 countries for the left part, 32 countries for the right part (cf. Box).

Sources: OECD, Affordable Housing Database (AHD); authors' calculations. 
Table 2

\section{Test of differences in variable means across clusters}

\begin{tabular}{|c|c|c|c|c|c|c|}
\hline & $\begin{array}{l}\text { Western } \\
\text { vs } \\
\text { Northern }\end{array}$ & $\begin{array}{l}\text { Western vs } \\
\text { Southern- } \\
\text { Central }\end{array}$ & $\begin{array}{l}\text { Western } \\
\text { vs } \\
\text { Eastern }\end{array}$ & $\begin{array}{l}\text { Northern vs } \\
\text { Southern- } \\
\text { Central }\end{array}$ & $\begin{array}{l}\text { North- } \\
\text { ern vs } \\
\text { Eastern }\end{array}$ & $\begin{array}{c}\text { Southern- } \\
\text { Central vs } \\
\text { Eastern }\end{array}$ \\
\hline \multicolumn{7}{|c|}{ Households' housing cost burden as a share of disposable income, tenants } \\
\hline Overall & & & *** & & *** & ** \\
\hline Bottom quintile & & & ** & & *** & ** \\
\hline Third quintile & & & ** & & *** & ** \\
\hline $\begin{array}{l}\text { Housing cost overburden rate among low-income private } \\
\text { sector tenants }\end{array}$ & & & ** & & ** & ** \\
\hline \multicolumn{7}{|l|}{ Average number of rooms per household member } \\
\hline Outright owners & & *** & *** & *** & *** & * \\
\hline Owners with mortgage & * & *** & *** & *** & *** & \\
\hline Tenants (private) & & *** & $* * *$ & *** & *** & ** \\
\hline Outright owners, bottom quintile & & *** & $* * *$ & $* * *$ & *** & * \\
\hline Tenants (private), bottom quintile & & *** & *** & *** & *** & \\
\hline \multicolumn{7}{|l|}{ Overcrowding rates } \\
\hline Bottom quintile & & ** & *** & & *** & *** \\
\hline Third quintile & & $* * *$ & *** & *** & *** & *** \\
\hline Top quintile & & $* * *$ & $* * *$ & *** & *** & $* * *$ \\
\hline Low and middle-income households, owners, bottom quintile & & $* * *$ & *** & *** & *** & *** \\
\hline Low and middle-income households, owners, third quintile & & $* * *$ & *** & *** & *** & $* * *$ \\
\hline Low and middle-income households, tenants, bottom quintile & & $* * *$ & *** & *** & $* * *$ & *** \\
\hline Bottom quintile, age below 18 & & *** & *** & *** & *** & $* * *$ \\
\hline Bottom quintile, age 18-64 & & *** & *** & ** & *** & *** \\
\hline Bottom quintile, age over 64 & & *** & $* * *$ & $* * *$ & *** & $* * *$ \\
\hline Share of poor households without exclusive flushing toilet & & & *** & & *** & *** \\
\hline \multicolumn{7}{|l|}{ Housing deprived population } \\
\hline Bottom quintile & & & *** & & *** & $* * *$ \\
\hline Third quintile & & & *** & & *** & *** \\
\hline \multicolumn{7}{|l|}{ Tenure structure } \\
\hline Outright owners & $* \star *$ & $* \star *$ & $\star * \star *$ & *** & *** & $* * *$ \\
\hline Owners with mortgage & $* * *$ & *** & *** & *** & *** & \\
\hline Tenants (private) & $* * *$ & & * & *** & *** & \\
\hline Tenants (subsidised) & $* * *$ & *** & *** & & & \\
\hline Others & & ** & & $* * *$ & * & \\
\hline Owners, bottom quintile & ** & $* * *$ & *** & *** & $* * *$ & ** \\
\hline Outright owners, bottom quintile & *** & $* * *$ & *** & *** & $* * *$ & *** \\
\hline Owners with mortgage, bottom quintile & ** & * & * & *** & *** & \\
\hline Tenants (private), bottom quintile & $* * *$ & & ** & *** & $* * *$ & \\
\hline Tenants (subsidised), bottom quintile & *** & *** & *** & & & \\
\hline Others, bottom quintile & & ** & & *** & & \\
\hline Share of $15-29$ living with their parents & * & * & & *** & *** & \\
\hline Household liabilities as a share of disposable income & ** & * & ** & *** & $* * *$ & \\
\hline
\end{tabular}

Note: ${ }^{*},{ }^{* *},{ }^{* * *}$ respectively denotes a $10 \%, 5 \%$ and $1 \%$ probability of means equality.

Reading note: The table displays the significance of the mean equality tests between groups of countries; for example, the average overall households' housing cost burden of the Western countries is not significantly different from the one of the Northern countries, but significantly different at the $1 \%$ threshold from the one of the Eastern countries.

Coverage: 25 countries (cf. Box).

Sources: OECD, Affordable Housing Database (AHD); authors' calculations. 
quintile income earners. In the "Eastern" group, close to one in five dwellings has no flushing toilet, while this proportion is negligible in countries of other groups, except Estonia. The housing deprivation rate is also relatively high in the "Eastern" group, where it exceeds $10 \%$ in the bottom income quintile, whereas it is below $1 \%$ in other country groups ${ }^{12}$. The housing cost burden for private sector tenants is similar across country groups, except in the "Eastern" group, where it is lower, although this may be of limited relevance given the low share of private rentals in the countries of this group. Indeed, about $85 \%$ of households are homeowners in these countries and most of them own outright. The tenancy structure is relatively similar in the "Southern-Central" group, although the share of outright owners is somewhat lower.

A number of countries were not incorporated in our baseline typology, as this would have restrained the set of indicators which could have been included in the analysis. Nevertheless, for seven of these countries, the variables available allow a meaningful classification of their housing system. Hence, we now perform our PCA and cluster analysis on a restricted set of variables, dropping the household debt-to-income ratio, the household housing cost burden for tenants in the third income quintile, the average number of rooms per household member for private sector tenants in the bottom income quintile and the proportion of youth living with their parents, but including seven additional countries, namely Chile, Croatia, Cyprus, Lithuania, Luxembourg, Malta and Mexico. The omission of variables has only a minor impact on the results for the initial set of countries, with only Austria changing clusters, moving from "Western" to "Southern-Central", mainly because of the removal of the share of youth living with their parents. The assignment of the additional countries to the groups identified in the baseline analysis looks plausible: Croatia, Lithuania and Mexico join the "Eastern" group, Chile joins the "Southern-Central" group, Luxembourg joins the "Northern" group, and Cyprus and Malta join the "Western" group (Figure VIII).

We now turn to the links between housing market structures and housing conditions on the one hand and housing policies on the other. The correlation between the first principal component of the PCA, which can be interpreted as measuring housing conditions (with negative values indicating better standards), and the first two factors of the multiple correspondence analysis (MCA) on policy indicators shown on Figure IV are only about 0.3 and 0.2 respectively and are not statistically significant, which suggests that relations between policy settings and housing outcomes are weak (Table 3). As the first factor of the MCA can be interpreted as an indicator of the variety of policy instruments used by a country (with negative numbers implying a greater variety), the positive correlation with the first principal component would suggest a relation between the scope of housing policies and housing conditions, but it is not statistically significant. Interestingly, the correlation between housing conditions and GDP per capita is close to 0.8 and highly significant, highlighting the influence of general living standards on housing conditions. This summary analysis of relations between housing conditions and policy settings based on factor analysis reveals a somewhat fuzzy picture and the need for more qualitative analysis.

The binary nature of availability indicators for the eight types of housing policy instruments included in the MCA is a strong limitation, as the extent and amount spent on similar policy measures can vary greatly across countries. Unfortunately, most quantitative indicators included in the OECD Affordable Housing Database are only available for a relatively small set of countries, the only exception being variables related to housing allowances. This precludes a systematic quantitative analysis. Therefore, we proceed in a more qualitative manner, trying to analyse policy features across the country groups identified above, even if the small sample size makes statistical comparisons of proportions of countries implementing each housing policy measure irrelevant ${ }^{13}$.

On the four housing policy instruments used in the vast majority of the countries in the sample, we note some differences across groups. Only the Slovak Republic and Slovenia have no housing allowances. The countries of the "Eastern" and "Southern-Central" group spend a very small fraction of their GDP on housing allowances, with the exception of the

12. Homelessness rates were not included in the analysis because the data are patchy and definitions are not homogenous across countries. The data available show no clear pattern across our country groups. However, relatively high homelessness rates tend to prevail in Anglo-Saxon countries.

13. Indeed, Fisher tests are unable to detect statistically significant between-group differences in the proportion of countries using any particular policy instrument. 
Czech Republic (Table 4) ${ }^{14}$. While all countries of the "Western" and "Northern" group have housing allowances, the amounts spent differ widely. Despite recent cuts in housing benefits, the United Kingdom spends 1.4\% of GDP on housing allowances, by far the largest amount in the OECD. Factors behind this high number include high rents, a relatively high share of private sector tenants, wide income inequality, rent-setting mechanisms for affordable housing (more than $70 \%$ of housing allowance recipients are tenants in the subsidised sector) and the design of government support for low-income households.

14. Relatively high spending on housing allowances in Croatia largely reflects significant allowances for utility costs.

Figure VIII

Cluster analysis of housing systems on extended sample: Dendrogramme

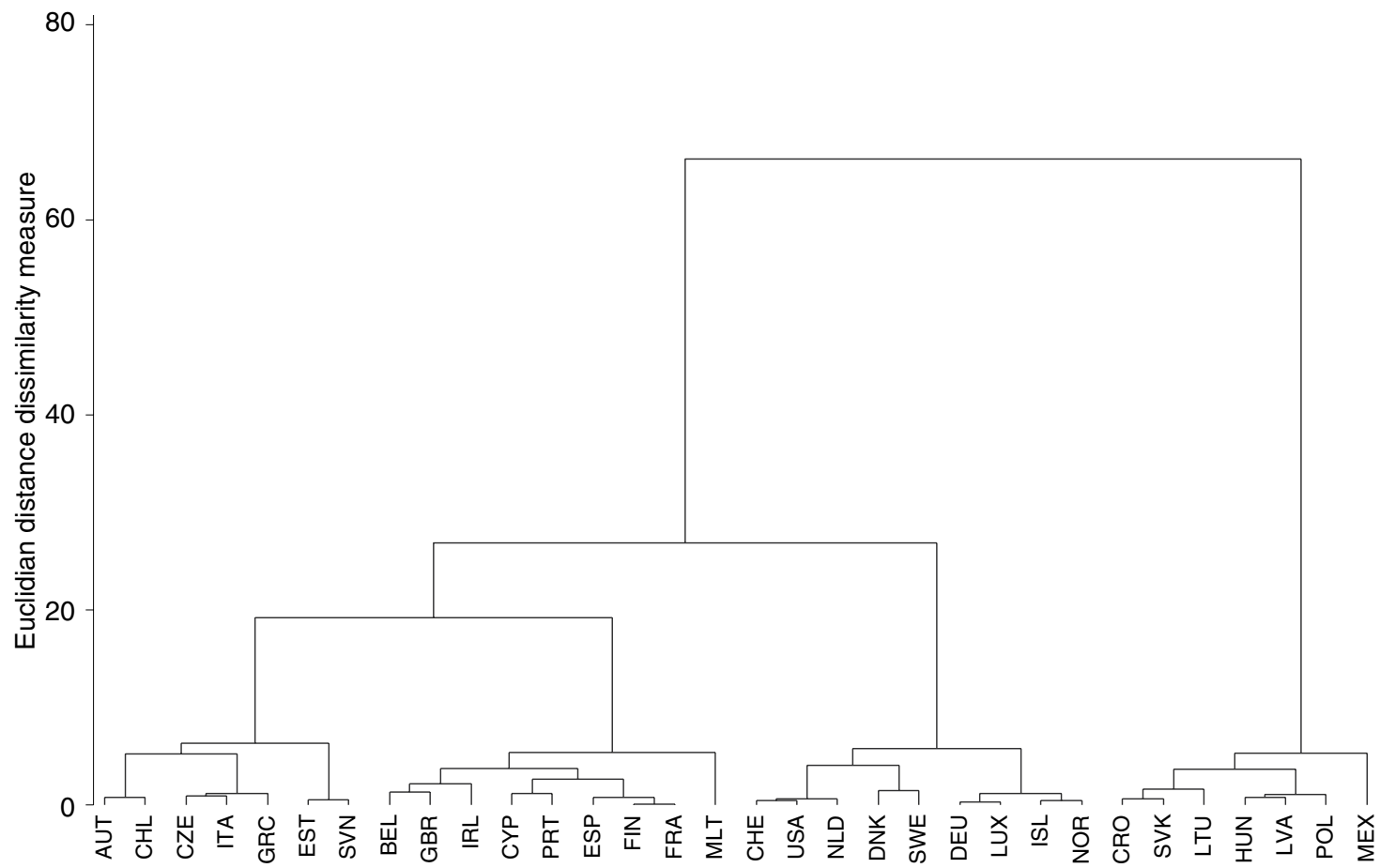

Note: In countries with integrated rental systems and a large housing stock owned by housing associations, like Denmark and the Netherlands, all tenants are classified as renting in the private sector, because the data from EU-SILC do not allow a distinction by type of tenant. Similarly, the large Swedish stock of municipal rental housing is not classified as social housing.

Reading note: The dendrogramme shows the hierarchical clustering of countries, using Ward's method and Euclidian distances.

Coverage: 32 countries (cf. Box)

Sources: OECD, Affordable Housing Database $(A H D)$; authors' calculations.

Table 3

Correlations between housing conditions, policies and GDP

\begin{tabular}{|l|c|c|c|c|}
\hline & $\begin{array}{c}\text { Housing conditions } \\
\text { axis 1 }\end{array}$ & $\begin{array}{c}\text { Housing conditions } \\
\text { axis 2 }\end{array}$ & $\begin{array}{c}\text { Policy instruments } \\
\text { axis 1 }\end{array}$ & $\begin{array}{c}\text { Policy instruments } \\
\text { axis 2 }\end{array}$ \\
\hline Policy instruments axis 1 & 0.326 & 0.039 & & \\
Policy instruments axis 2 & 0.210 & -0.104 & & \\
\hline GDP per capita, PPP (current international \$) & $-0.784^{* \star *}$ & 0.025 & -0.279 & -0.318 \\
GDP per capita (current US \$) & $-0.800^{* \star *}$ & 0.107 & -0.308 & -0.245 \\
\hline
\end{tabular}

Note: ${ }^{* *}$ denotes non-zero correlation at the $99 \%$ confidence level. The correlations have been computed on the set of countries for which both housing conditions and policy indicators are available. The Housing conditions axes are the first two axes from the PCA on variables representing housing market context, housing conditions and household indebtedness. The policy instruments axes are the first two axes of the MCA on the eight binary indicators showing the presence or absence of specific policies in each country.

Coverage: 21 countries (cf. Box)

Sources: OECD, Affordable Housing Database (AHD); authors' calculations. 
Finland and France spend around $0.8 \%$ of GDP on housing allowances, partly on support for social sector tenants. The Mediterranean countries of the "Western" group, which have high homeownership rates, spend a negligible amount on housing allowances. Austria and Ireland are in an intermediate position ${ }^{15}$ Half of the countries of the "Northern" group, namely Denmark, Germany, the Netherlands

15. Data for Belgium are not available.

Table 4

Features of housing allowances across countries

\begin{tabular}{|c|c|c|c|c|c|c|c|c|}
\hline \multirow[t]{2}{*}{ Country } & \multirow{2}{*}{$\begin{array}{l}\text { Total govern- } \\
\text { ment spending } \\
\text { (2015 or latest, } \\
\text { in } \% \text { of GDP) }\end{array}$} & \multicolumn{2}{|c|}{$\begin{array}{l}\text { Share of households } \\
\text { receiving housing allowance } \\
(2014 \text {, in \%) }\end{array}$} & \multicolumn{5}{|c|}{$\begin{array}{l}\text { Tenure shares of low-income households receiving housing allowances } \\
\qquad(2014 \text {, in \%) }\end{array}$} \\
\hline & & $\begin{array}{l}\text { Bottom } \\
\text { quintile }\end{array}$ & $3^{\text {rd }}$ quintile & $\begin{array}{l}\text { Outright } \\
\text { owners }\end{array}$ & $\begin{array}{l}\text { Owners with } \\
\text { mortgage }\end{array}$ & $\begin{array}{l}\text { Tenants } \\
\text { (private) }\end{array}$ & $\begin{array}{c}\text { Tenants } \\
\text { (subsidised) }\end{array}$ & Others \\
\hline Australia & 0.27 & & & & & & & \\
\hline Austria & 0.16 & 16.40 & 1.15 & 0.00 & 0.00 & 70.52 & 23.44 & 6.04 \\
\hline Belgium & & 0.82 & 0.06 & & & & & \\
\hline Bulgaria & 0.10 & 0.00 & 0.00 & & & & & \\
\hline Chile & 0.01 & & & & & & & \\
\hline Croatia & 0.24 & 5.43 & 0.21 & 54.10 & 0.63 & 10.12 & 6.51 & 28.64 \\
\hline Cyprus & 0.02 & 3.93 & 3.34 & & & & & \\
\hline Czech Republic & 0.27 & 13.76 & 1.24 & 28.42 & 2.17 & 60.44 & 6.93 & 2.05 \\
\hline Denmark & 0.48 & 35.43 & 9.35 & 6.42 & 0.00 & 93.58 & 0.00 & 0.00 \\
\hline Estonia & 0.04 & 5.57 & 1.35 & 56.74 & 0.00 & 9.19 & 5.30 & 28.77 \\
\hline Finland & 0.82 & 53.18 & 8.66 & 7.10 & 2.72 & 34.35 & 55.01 & 0.82 \\
\hline France & 0.83 & 49.43 & 17.77 & 1.24 & 6.88 & 57.29 & 33.92 & 0.67 \\
\hline Germany & 0.48 & & & & & & & \\
\hline Greece & & 0.00 & 0.07 & & & & & \\
\hline Hungary & 0.00 & 28.05 & 5.55 & 67.16 & 15.43 & 1.67 & 8.14 & 7.60 \\
\hline Iceland & & 37.02 & 31.29 & 0.47 & 43.27 & 28.02 & 28.25 & 0.00 \\
\hline Ireland & 0.21 & 49.50 & 24.96 & 47.51 & 6.44 & 14.10 & 29.88 & 2.07 \\
\hline Italy & & 2.94 & 1.14 & 7.62 & 7.38 & 42.02 & 35.20 & 7.77 \\
\hline Japan & 0.12 & & & & & & & \\
\hline Korea & 0.06 & & & & & & & \\
\hline Latvia & 0.08 & 23.02 & 4.63 & 62.26 & 0.40 & 12.28 & 14.49 & 10.58 \\
\hline Lithuania & 0.06 & 6.83 & 1.45 & 78.45 & 4.35 & 0.00 & 8.40 & 8.80 \\
\hline Luxembourg & & 9.69 & 12.38 & 2.96 & 64.57 & 0.00 & 32.47 & 0.00 \\
\hline Malta & 0.01 & 34.89 & 11.48 & 40.41 & 8.19 & 3.26 & 39.95 & 8.20 \\
\hline Netherlands & 0.47 & 44.65 & 1.80 & 0.18 & 0.00 & 99.69 & 0.00 & 0.13 \\
\hline New Zealand & 0.48 & & & & & & & \\
\hline Norway & 0.09 & 11.16 & 0.35 & 8.36 & 19.09 & 53.43 & 2.34 & 16.78 \\
\hline Poland & 0.05 & 7.13 & 0.84 & 35.83 & 2.47 & 12.69 & 2.28 & 46.73 \\
\hline Portugal & 0.01 & 3.63 & 10.32 & & & & & \\
\hline Romania & & 0.00 & 0.00 & & & & & \\
\hline Slovak Republic & & 0.66 & 0.00 & & & & & \\
\hline Slovenia & & 3.89 & 0.33 & & & & & \\
\hline Spain & 0.01 & 1.79 & 0.90 & & & & & \\
\hline Sweden & 0.45 & 32.75 & 1.47 & 6.87 & 9.73 & 80.16 & 0.77 & 2.47 \\
\hline Switzerland & & 1.87 & 0.55 & & & & & \\
\hline United Kingdom & 1.41 & 29.06 & 13.23 & 0.00 & 0.27 & 28.50 & 71.23 & 0.00 \\
\hline United States & 0.10 & & & & & & & \\
\hline
\end{tabular}

Coverage: 37 countries (cf. Box)

Sources: OECD, Affordable Housing Database (AHD); authors' calculations. 
and Sweden have relatively high spending on housing allowances, close to $0.5 \%$ of GDP. This is consistent with extensive welfare states and integrated rental markets catering to a large share of the population. Spending on housing allowances is low in Norway and the United States, to some extent because of high homeownership rates ${ }^{16}$.

After housing allowances, the most widely used policy instruments are social housing, tax relief for access to homeownership, and subsidised mortgages and guarantees to homebuyers. Mortgage interest can be deducted from taxable income in all countries of the "Northern" group, except Germany. The associated forgone tax revenue can be substantial, amounting to $0.5 \%$ of GDP in the United States and more than $2 \%$ of GDP in the Netherlands ${ }^{17}$. Mortgage interest deductibility is also available in countries of the "Western" group, except France and the United Kingdom ${ }^{18}$. In other groups, mortgage interests are tax deductible in only about half of the countries. Subsidised mortgages and guarantees do not show a clear pattern across groups, although they are usual in CEE countries and often absent in Mediterranean countries. Most countries have social rental housing, even though this tenure has declined over recent decades. As construction has been relatively limited in most countries, the size of the social housing stock mainly reflects historical developments. Within our sample, only Austria and France spend significantly more than $0.1 \%$ of GDP on public support to social rental housing (respectively $0.4 \%$ and $0.3 \%)^{19}$.

The four remaining policy instruments are used by less than half of the countries. Grants to homebuyers are the largest in Chile $(0.45 \%$ of GDP) and to a much lesser extent in Austria, Cyprus and Malta (around $0.1 \%$ of GDP). Subsidies for the development of affordable homeownership and rental housing are largely absent from the "Southern-Central" and "Eastern" groups. No clear pattern is discernible in other groups, although these subsidies are found in most Anglo-Saxon countries (including Australia, Canada and New Zealand). Half of the countries in the "Northern" group have mortgage relief schemes for over-indebted homeowners, while the proportion is close to one fourth in other groups. Although relief schemes are most prevalent in the "Northern" group, spending on such schemes is highest in Hungary, which has suffered an acute mortgage crisis following the depreciation of its currency in 2008, as a large share of loans were denominated in euros or Swiss francs.

\section{Discussion and scope for future research}

The classification of housing systems based on indicators from the $A H D$ identifies clearly four groups of countries. The sorting of countries largely occurs along the two dimensions of housing conditions and tenure structure. Housing conditions are strongly correlated with GDP per capita and tend to be relatively poor in Central and Eastern Europe, even though there are significant differences within the region, which are reflected in different groupings in our analysis ${ }^{20}$. Our classification of some CEE countries with Southern European countries is consistent with similarities in housing and welfare structures across these countries identified by Mandič and Mrzel (2017), albeit with the exception of the Czech Republic. The case of CEE countries also seems to be another illustration of the inverse relationship between housing conditions and affordability for low-income households found by Dewilde and De Decker (2016) across Western Europe. On average, relatively poor housing conditions are matched by relatively good affordability in CEE countries, partly because many households are outright own$\mathrm{ers}^{21}$. Due to policies implemented during the transition from socialist to market economies, homeownership largely prevails in these countries, but the housing stock is generally of poor quality and households tend to have limited resources to invest in renovation. Hence, raising housing standards remains a major challenge in this region (Rosenfeld, 2015) 22 .

\footnotetext{
16. In addition, the amount spent on housing vouchers in the United States is limited by the fact that they are not entitlements. Spending data are not available for Iceland and Switzerland, but shares of recipients suggest relatively high spending in the former and low spending in the latter. 17. Since 2013, interest deductibility on new loans in the Netherlands is restricted to mortgages with regular repayment of the principal over a maximum period of 30 years. In addition, the rate of tax relief is being gradually reduced on both existing and new loans (Kierzenkowski et al., 2014).

18. Since 2013, Spain removed interest deductibility for new mortgages (IMF, 2015).

19. Australia, Korea and New Zealand, which are not in our data analysis because of insufficient data availability, also spend significant amounts on social housing (respectively $0.3 \%, 0.5 \%$ and $0.3 \%$ of GDP).

20. Our clustering of CEE countries is slightly different from the groups identified by Soaita \& Dewilde (2017), who find that the Baltic states form a separate cluster and all the other CEE countries included in our study form another single cluster.

21. Affordability is, however, an issue for tenants in many of CEE largest cities.

22. An important dimension which is not included in our analysis, but reinforces the diagnosis is energy efficiency, which is particularly low in CEE countries and can result in high energy costs for households.
} 
Our clustering of other countries is broadly consistent with findings of the literature, even though both our country sample and our number of variables are wider than in most other studies. Our "Northern" cluster includes Esping-Andersen's social-democratic group, but also a number of more disparate countries with relatively large private rental markets. A common characteristic of these countries is that their rental markets are largely integrated in the sense of Kemeny. In these systems, rents tend to be moderate and security of tenure high, generally leading to better housing conditions for tenants than in dual markets. At first glance, it is somewhat surprising to find the United States in this group. A reason may be the limitations of the tenure variable already mentioned, which hide differences between tenants in the private and subsidised sectors in some countries ${ }^{23}$. Another reason may be that because of data limitations, we were not able to include other countries that share some common housing characteristics with the United States, like Australia, Canada and New Zealand. The inclusion of data on the quality of dwellings and neighbourhoods in which they are located would presumably also help differentiate the United States from the other countries of the "Northern" cluster. Further work will be needed in that respect. Nevertheless, one should also note that beyond similarities in welfare regimes, the United States and the United Kingdom have different housing systems (e.g. large social housing stock and high spending on housing allowances in the United Kingdom; generous tax relief on mortgage interest in the United States). Hence, it is not surprising that these countries belong to different clusters.

While the split between the "Northern" and the "Western" group is largely consistent with Kemeny's typology, there are some differences. In Kemeny's typology, Austria and France have integrated rental markets, while Norway has a dual rental market. However, the case for classifying the French rental market as unified is weak at the current juncture. The shares of households in private and subsidised rental housing are respectively around $24 \%$ and $14 \%$, and the private market is not very tightly regulated. Austria is difficult to classify, in particular given the strong specificities of the municipality of Vienna's housing policy, compared to the rest of the country (Reinprecht, 2007). On the 15 Western-European countries common to the two studies, we find similarities between our clusters and those of Dewilde
(2017) based on 2012 data, including the identification of a Scandinavian group, which also includes the Netherlands and a split in Mediterranean countries, with Portugal and Spain grouped with Belgium, France and Ireland, while Greece and Italy form a separate cluster. Interestingly, the cluster analysis performed by Dewilde on 1995 data groups all Mediterranean countries together, as does the classification of Hoekstra (2005), which uses data from 2000 and 2001. This suggests that Mediterranean countries have diverged since the early 2000s. Dewilde's classification differs from ours in several ways. Germany is grouped with Austria, Finland and the United Kingdom, rather than with Scandinavian countries. This cluster is distinguished from another group containing countries from our "Western" cluster (Belgium, France, Ireland, Portugal and Spain). The split within our "Western" group in Dewilde's analysis is driven by better housing conditions and a lower housing cost burden for young and elderly households in Dewilde's second group (which includes Germany). Dewilde's focus on young and elderly households seems to explain a slightly different clustering from ours, with one more cluster for comparable country coverage. Conversely, Hoekstra (2005), using six more general variables related to tenure and housing type and quality, only distinguishes two groups among 12 European countries, one grouping the Mediterranean countries and the other including countries pertaining to both our "Northern" and "Western" groups.

The analysis of policies is constrained by more data gaps than for housing market context, housing conditions and household indebtedness, as well as by the qualitative nature of a large part of the information available. This limits the scope for systematic statistical analysis. Nevertheless, the data from the $A H D$ provide a useful, albeit partial, picture of housing policy settings across OECD and EU countries. First, the groups of countries we have identified on the basis of housing market context, housing conditions and household indebtedness do not show clear specificities in their policy mix. Most countries use a large variety of policy instruments. This may be due to path dependency, as some instruments are difficult to remove when new ones are introduced, to the diversity of issues to address, which may require multiple instruments or to

23. Particularly Denmark, the Netherlands and Sweden. 
inconsistencies in housing systems, with overlapping policies. Further data collection and research will be needed in that area. Second, the most widely used policy instruments are demand-side instruments, in particular housing allowances and support for homebuyers through tax relief and other types of mortgage subsidies. Most countries have social housing, but the stock has recently been expanding only in few OECD countries (Salvi del Pero et al., 2016) ${ }^{24}$. Demand-side instruments have advantages over supply-side subsidies, in particular in terms of impact on residential and labour mobility, equity of access and ease of administration. However, if the increase in demand for rental housing induced by the housing allowance is not matched by an increase in housing supply, rents will increase. This may particularly occur in areas where physical or regulatory constraints to homebuilding are tight. Indeed, international evidence suggests that demand-side subsidies have generally not prompted the supply response policymakers expected. The focus on housing allowances to support low-income households in Australia, Canada, New Zealand and the United Kingdom since the 1980s or 1990s has been accompanied by growing difficulties for low-income households to access adequate housing, as policies may have paid too little attention to supply-side issues (Maclennan, 2005). Policies favouring demand-side support have generally been unable to stimulate supply, exacerbating affordability problems and social segregation in many advanced economies (Lawson \& Milligan, $2007)^{25}$. Studies find that housing allowances increase rents in Finland (Kangasharju, 2010; Viren, 2013), France (Laferrère \& Le Blanc 2004; Fack 2005), the United Kingdom (Gibbons \& Manning 2006), and the United States (Susin, 2002). Notwithstanding, housing vouchers in the United States seem to have provided equally good housing at a much lower cost than project-based housing assistance (Olsen \& Zabel, 2014). Evidence of capitalisation of tax relief on mortgage interests into housing prices is found in a panel of 17 OECD countries ${ }^{26}$ (Andrews, 2010), a sample of European countries ${ }^{27}$ and the United States (Damen et al., 2016) and countryspecific studies on the Netherlands (Brounen \& Neuteboom, 2008), Sweden (Berger et al., 2000) and the United States (Capozza et al. 1996). Tax relief on mortgage interests tends to be regressive, as homeownership rates generally increase with income (Andrews et al., 2011), and to push up household debt, which has risen markedly over the past two decades, creating vulnerabilities for households, the financial system and the wider economy (André, 2016). Finally, the US subprime crisis has shown the limitations of policies trying to promote homeownership among low-income households by relaxing credit standards. More generally, the widely assumed superiority of owning over renting in monetary terms in the United States has been challenged (Beracha $\&$ Johnson, 2012). The $A H D$ provides a knowledge base for further research to improve the design and evaluation of housing policies. In particular, it can be used to examine how policy measures affect various housing outcomes (e.g. housing conditions, affordability, housing price volatility, mortgage debt and housing wealth) in different housing systems. Widening its indicator and country coverage would allow more systematic statistical analysis. Given the long-lasting impact of policies on housing affordability and quality, the snapshot of housing policies at a point in time provided in the $A H D$ would need to be expanded in the time dimension to allow a full evaluation of housing policies. Other avenues for further research include studying links between the dimensions included in the $A H D$ and mortgage market structures, as well as factors affecting housing supply, especially land-use planning.

24. Between 2000 and 2015, the number of social rental housing dwellings increased in Austria, the Czech Republic, Estonia, France, Japan (2000-2013), the Netherlands, New Zealand (2000-2013) and Norway. In half of these countries, the share of social rental housing still declined as a share of the total housing stock. Increases were strong in the Czech Republic and Estonia, but from very low starting levels (OECD Affordable Housing Database).

25. The study covers Belgium, Canada, Denmark, France, Germany, Ireland, Netherlands, New Zealand, Switzerland, United Kingdom and United States.

26. Australia, Canada, Denmark, Finland, France, Germany, Italy, Ireland, Japan, Netherlands, New Zealand, Norway, Spain, Sweden, Switzerland, United Kingdom and United States.

27. Belgium, Denmark, Finland, Netherlands, Norway, Sweden and United Kingdom. 


\section{BIBLIOGRAPHY}

Aalbers, M.B. (2008). The Financialization of Home and the Mortgage Market Crisis. Competition \& Change, 12(2), 148-166. https://doi.org/10.1179\%2F102452908X289802

André, C. (2016). Household debt in OECD countries: Stylised facts and policy issues. $O E C D$ Economics Department Working Papers № 1277. https://doi.org/10.1787/5jm3xgtkk1f2-en

Andrews, D. (2010). Real House Prices in OECD Countries: The Role of Demand Shocks and Structural and Policy Factors. OECD Economics Department Working Papers № 831.

http://dx.doi.org/10.1787/5km33bqzhbzr-en

Andrews, D., Caldera Sánchez, A. \& Johansson, А̊ (2011). Housing Markets and Structural Policies in OECD Countries. OECD Economics Department Working Papers $\mathrm{N}^{\circ} 836$.

https://doi.org/10.1787/5kgk8t2k9vf3-en

Beracha, E. \& Johnson, K.H. (2012). Lessons from Over 30 Years of Buy versus Rent Decisions: Is the American Dream Always Wise? Real Estate Economics, 40(2), 217-247.

https://dx.doi.org/10.1111/j.1540-6229.2011.00321.x

Berger, T., Englund, P., Hendershott, P. H. \& Turner, B. (2000). The Capitalization of Interest Subsidies: Evidence from Sweden. Journal of Money, Credit and Banking, 32(2), 199-217. https://doi.org/10.2307/2601239

Brounen, D. \& Neuteboom, P. (2008). De Effectiviteit van Hypotheekrenteaftrek (Effectivity of mortgage interest deductibility). EconomischStatistische Berichten, 93(4529), 120-121.

https://www.historischnieuwsblad.nl/nl/artikel/10741/ geschiedenis-van-de-hypotheekrenteaftrek.html

Capozza, D.R., Green, R.K. \& Hendershott, P.H. (1996). Taxes, Mortgage Borrowing, and Residential Land Prices. In: Aaron H.A. \& Gale W.G. (Eds.). Economic Effects of Fundamental Tax Reform, 171-210. Washington, D.C.: Brookings Institution Press.

Castles, F. G. (1998). The Really Big Trade-Off: Home Ownership and the Welfare State in the New World and the Old. Acta Politica, 33(1), 5-19. https://doi.org/10.1080/14036090510032727

Crook, T. \& Kemp, P.A. (Ed.) (2014). Private Rental Housing, Comparative Perspectives. Cheltenham: Edward Elgar publishing.
Damen, S., Vastmans, F. \& Buyst E. (2016). The Effect of Mortgage Interest Deduction and Mortgage Characteristics on House Prices. Journal of Housing Economics, 34, 15-29.

https://doi.org/10.1016/j.jhe.2016.06.002

Dewilde, C. (2015). What Have ECHP and EU-SILC to Contribute to the Comparative Study of Housing? Critical Housing Analysis, 2(2), 19-26. https://doi.org/10.13060/23362839.2015.3.3.238

Dewilde, C. (2017). Do housing regimes matter? Assessing the concept of housing regimes through configurations of housing outcomes. International Journal of Social Welfare, 26(4), 384-404. https://doi.org/10.1111/ijsw.12261

Dewilde, C. \& De Decker, P. (2016). Changing Inequalities in Housing Outcomes across Western Europe. Housing, Theory and Society, 33(2), 121-161. https://doi.org/10.1080/14036096.2015.1109545

Doling, J. (1999). De-commodification and Welfare: Evaluating Housing Systems. Housing, Theory and Society, 16(4), 156-164.

https://doi.org/10.1080/14036099950149884

Doling, J. \& Ronald, R. (2010). Home ownership and asset-based welfare. Journal of Housing and the Built Environment, 25(2), 165-173.

https://doi.org/10.1007/s10901-009-9177-6

Donnison, D. (1967). The Government of Housing. London: Penguin Books.

Donnison, D. \& Ungerson, C. (1982). Housing Policy. London: Penguin Books.

Fack, G. (2005). Pourquoi les ménages à bas revenus paient-ils des loyers de plus en plus élevés ? Économie et Statistique, 381-382, 17-40.

https://www.insee.fr/fr/statistiques/fichier/1376573/ es381-382b.pdf

Esping-Andersen, G. (1990). The Three Worlds of Welfare Capitalism. Princeton: Princeton University Press.

Gibbons, S. \& Manning, M. (2006). The incidence of U.K. housing benefit: Evidence from the 1990s reforms. Journal of Public Economics, 90(4-5), 799-822. http://doi.org/10.1016/j.jpubeco.2005.01.002

Harloe, M. (1995). The People's Home? Social Rented Housing in Europe and America. Oxford: Basil Blackwell. 
Hegedüs, J., Lux, M. \& Sunega, P. (2011). Decline and Depression: The Impact of the Global Economic Crisis on Housing Markets in Two Post-Socialist States. Journal of Housing and the Built Environment, 26(3), 315-333.

https://doi.org/10.1007/s10901-011-9228-7

Hoekstra, J. (2003). Housing and the welfare state in the Netherlands, An application of EspingAndersen's typology. Housing, Theory and Society, 20(2), 58-71.

https://doi.org/10.1080/14036090310000634

Hoekstra, J. (2005). Is there a connection between welfare state regime and dwelling type? An exploratory statistical analysis. Housing Studies, 20(3), 475-495. https://doi.org/10.1080/02673030500062509

Hoekstra, J. (2009). Two types of rental system? An exploratory empirical test of Kemeny's rental system typology. Urban Studies, 46(1), 45-62. https://doi.org/10.1177\%2F0042098008098636

Hoekstra, J. (2010). Divergence in European welfare and housing systems. Sustainable Urban Areas № 38. Amsterdam: Delft University Press, IOS Press BV.

IMF (2015). IMF Multi-Country Report Housing Recoveries: Cluster Report on Denmark, Ireland, Kingdom of The Netherlands - The Netherlands, and Spain. IMF Country Report No $15 / 1$.

https://www.imf.org/ /media/Websites/IMF/importedfull-text-pdf/external/pubs/ft/scr/2015/_cr1501.ashx

Kangasharju, A. (2010). Housing Allowance and the Rent of Low-income Households. The Scandinavian Journal of Economics, 112(3), 595-617.

https://dx.doi.org/10.1111/j.1467-9442.2010.01615.x

Kemeny, J. (1992). Housing and Social Theory. London: Routledge.

Kemeny, J. (1995). From Public Housing to the Social Market. Rental Policy, Strategies in comparative perspective. London: Routledge.

Kemeny, J. \& Lowe, S. (1998). Schools of Comparative Housing Research: From Convergence to Divergence. Housing Studies, 13(2), 161-176. https://doi.org/10.1080/02673039883380

Kemeny, J. (2005). "The Really Big Trade-Off" between Home Ownership and Welfare: Castles' Evaluation of the 1980 Thesis, and a Reformulation 25 Years on. Housing, Theory and Society, 22(2), 59-75. https://doi.org/10.1080/14036090510032727

Kemeny, J. (2006). Corporatism and Housing Regimes. Housing, Theory and Society, 23(1), 1-18. https://doi.org/10.1080/14036090500375423
Kierzenkowski, R., Havrylchyk, O. \& Beynet, P. (2014). Making the Banking Sector More Resilient and Reducing Household Debt in the Netherlands. OECD Economics Department Working Papers No 1156.

https://doi.org/10.1787/5jxz9z0fhcwj-en

Laferrère, A. \& Le Blanc, D. (2004). How do housing allowances affect rents? An empirical analysis of the French case. Journal of Housing Economics, 13(1), 36-67.

https://doi.org/10.1016/j.jhe.2004.02.001

Lawson, J. \& Milligan, V. (2007). International trends in housing and policy responses. AHURI Final Report $\mathrm{N}^{\circ} 110$.

https://www.ahuri.edu.au/_data/assets/pdf_file/ 0012/2136/AHURI_Final_Report_No110_International_ trends_in_housing_and_policy_responses.pdf

Maclennan, D. (2005). Housing policies: New times, new foundations. York: Joseph Rowntree Foundation.

https://www.jrf.org.uk/report/housing-policiesnew-times-new-foundations

Mandič, S. \& Mrzel, M. (2017). Home ownership in post-socialist countries: the negative impact of the transition period on old-age welfare. In: Dewilde, C. \& Ronald, R. (Eds.), Housing wealth and welfare, chap. 8, pp. 189-213. Cheltenham: Edward Elgar publishing.

https://doi.org/10.4337/9781785360961.00018

Olsen, E. O. \& Zabel, J. E. (2015). US Housing Policy. In: Duranton, G., Henderson, J. V. \& Strange, W. C. (Eds.), Handbook of Regional and Urban Economics, vol. 5, chap. 14, pp. 887-986. Amsterdam: North Holland.

https://doi.org/10.1016/B978-0-444-59531-7. 00014-4

Pittini, A. \& Laino, E. (2012). Housing Europe Review 2012. Bruxelles: CECODHAS Housing Europe.

Reinprecht, C. (2007). Social Housing in Austria. In: Whitehead C. \& Scanlon K. (Eds.), Social Housing in Europe, chap. 5, pp. 35-43 London: London School of Economics and Political Science.

Rosenfeld, O. (2015). Social Housing in the UNECE Region: Models, Trends and Challenges. Geneva: United Nations, Economic Commission for Europe. https://www.unece.org/fileadmin/DAM/hlm/ documents/Publications/Social_Housing_in_UNECE_ region.pdf

Salvi del Pero, A., Adema, W., Ferraro, V. \& Frey, V. (2016). Policies to Promote Access to Good-Quality 
Affordable Housing in OECD Countries. OECD Social, Employment and Migration Working Papers No 176.

https://doi.org/10.1787/5jm3p5gl4djd-en

Soaita, A. M. \& Dewilde, C. (2017). A Critical-Realist View of Housing Quality within the Post-Communist EU States: Progressing towards a Middle-Range Explanation. Housing, Theory and Society, 1-32. https://doi.org/10.1080/14036096.2017.1383934

Steinmetz, H. (2015). Les politiques du logement en Europe: comparaisons. Cahiers français, 388, 8-14. http://www.ladocumentationfrancaise.fr/var/storage/ libris/3303330403884/3303330403884_EX.pdf

Stephens, M. (2016). Using Esping-Andersen and Kemeny's Welfare and Housing Regimes in Comparative Housing Research. Critical Housing Analysis, 3(1), 19-29.

https://doi.org/10.13060/23362839.2016.3.1.250

Stephens, M. \& Fitzpatrick, S. (2007). Welfare Regimes, Housing Systems and Homelessness: How are they linked? European Journal of Homelessness, $1,201-211$.

https://www.feantsaresearch.org/download/ejh_ vol1_thinkpiece15730722341054309703.pdf

Susin, S. (2002). Rent Vouchers and the Price of Low-Income Housing. Journal of Public Economics, 83(1), 109-152.

https://doi.org/10.1016/S0047-2727(01)00081-0

Torgersen, U. (1987). Housing: The Wobbly Pillar under the Welfare State. In: Turner, B., Kemeny, J. \& Lundqvist, L. J. (Eds.), Between State and Market: Housing in the Post-Industrial Era, pp. 116-126. Göteborg: Almqvist \& Wiksell.

Van der Heijden, H. (2013). West European Housing Systems in a Comparative Perspective. Sustainable Urban Areas № 46. Amsterdam: Delft University Press, IOS Press BV.

Viren, M. (2013). Is the housing allowance shifted to rental prices? Empirical Economics, 44(3), 1497-1518. https://doi.org/10.1007/s00181-012-0589-x 


\title{
Comment \\ On building typologies of housing systems in the OECD
}

\author{
Comment on the article "Building a typology of housing systems to informe policies \\ in OECD and EU member states” by Christophe André and Thomas Chalaux
}

\section{Christine M. E. Whitehead*}

\begin{abstract}
This paper discusses the first major piece of work based on the new OECD Affordable Housing Database (AHD). That work uses statistical techniques to develop a typology of OECD countries based mainly on housing market and policy variables which both helps to describe how attributes vary across countries and can form a basis for further comparative analyses. The paper starts by commenting on the strengths of the data, methodology and outputs arising from their analysis and goes on to discuss the attributes of the resultant typology and what they mean for how the typology might be used. The paper then goes on to discuss two pieces of research that generated topic specific typologies, the first where the $A H D$ provided a valuable starting point for a more detailed qualitative comparative analysis of a particular housing policy - safety nets for mortgagors -, and another where broader based OECD data helped to define the problem of whether increased regulation was limiting access to homeownership among younger households.
\end{abstract}

JEL Classification: G15, I38, R28, R38

Keywords: housing, government policy, mortgages, regulation, comparative analysis

Reminder:

The opinions and analyses in this article

are those of the author(s)

and do not

necessarily reflec

their institution's

or Insee's views.
* London School of Economics (c.m.e.whitehead@lse.ac.uk)

Received on 17 September 2018

To cite this article: Whitehead, C. M. E. (2018). Comment - On building typologies of housing systems in the OECD. Economie et Statistique/Economics and Statistics, 500-501-502, 37-43. https://doi.org/10.24187/ecostat.2018.500t.1944 


\section{The research}

The starting point for "Building a typology of housing systems to inform policies in OECD and EU member states" is the publication in 2017 of the OECD's Affordable Housing Database $(A H D)^{1}$ which has been developed to help countries monitor access to good-quality affordable housing and strengthen the knowledge base for policy evaluation. The database includes indicators from OECD countries and EU member states grouped along three main dimensions: housing market context, housing conditions, and public policies towards affordable housing.

The article provides a second stage in making this database operational: the construction of a typology of housing systems using principal component analysis and cluster analysis based on housing market features and housing condition indicators included in the database supplemented by other OECD data, notably on household indebtedness. The objective of such a typology is to provide a tool which researchers can use first to describe and group the major attributes of housing systems across countries and potentially to assess the relative importance of economic and other conditions in determining the success of particular housing policies.

The article follows a fairly well-trodden path particularly in the European context, where a range of different approaches to classification (in particular Epsing-Andersen (1990), Kemeny $(1992,1995)$, Kemeny \& Lowe (1998)) already exist. These have been used to evidence debates on the convergence or divergence of housing policies and outcomes as well as the relevance of social structures and ideological choices in determining outcomes notably in the context of welfare and rental systems. The researchers here however step back from these debates and look only to identify patterns and the attributes of the groupings that emerge. As such it is very much a tool to be used by others rather than at this stage drawing implications for instance about such issues as path dependency or the relative success of different types of policy between the identified categories.

The methodology used for developing the typology is straightforward and well understood but it is used in a particularly careful and comprehensive fashion. The data used come mainly from the new database which concentrates on three main topic areas: the housing market context (an interesting use of the term market?); housing conditions including affordability, quality and to a limited degree accessibility but concentrating on homelessness; and public policies notably government financial support by tenure, social housing provision and rent and security legislation. There are clearly gaps, and indeed some inaccuracies, particularly where the questions are rather general and use terminology which may be unclear to the country expert filling in the form or where the country in question uses country-specific definitions and variables. Some particularly difficult definitions - such as the position of social housing in Sweden - are identified. Overall the database provides a rich source of information but at a level which would only act as a starting point for anyone wishing to research any individual country or indeed particular issues across countries. At this stage however, André and Chalaux are only asking whether the data can identify groups of countries which can be clearly distinguished from one another based on statistical techniques.

Such groupings are indeed identified, based on twenty-five OECD member countries. The resulting typology is generally consistent with earlier classifications - which in the main use fewer variables and a smaller number of, mainly European, countries. Four groups emerge from the analysis: "Northern", covering most of Northern Europe, including Germany and Switzerland but also the USA, which feature high levels of private rental accommodation and generally high household debt; "Western", including France, the United Kingdom, Ireland and south western European countries as well as Finland and Austria, which have relatively high homeownership rates and more social housing; "South Central" including Mediterranean countries such as Italy and Greece as well as Eastern Europe countries such as the Czech Republic, Estonia and Slovenia - where high levels of outright ownership dominate - although arising from different causes; and "Eastern" made up of Hungary, Latvia, Poland and the Slovak Republic - which are also distinguished by high outright ownership but also by poorer housing conditions. The final two groups are clearly differentiated by the statistical analysis but have many attributes in common. Adding a further seven countries where data are more limited but does not change the basic picture.

1. OECD (2017) Affordable Housing Database. Available at: http://www. oecd.org/social/affordable-housing-database.htm 
It is interesting to note the emphasis on tenure in distinguishing the groups. This leads to some questions of interpretation, notably with respect to the inclusion of both Germany and the USA in the Northern category. This may be in part because other Anglo-Saxon countries such as Australia, Canada and New Zealand are not included in the analysis because of lack of $A H D$ data. However, the substantive problem is that while both countries have relatively high proportions of private renting the attributes of their rental systems are completely different (with rent stabilisation and indefinite security of tenure in Germany - as is the case for most countries in the group, while the USA experience is of short term tenancies and generally market determined rents) (Whitehead et al., 2012; Scanlon \& Whitehead, 2014). The findings raise at least three issues in relation to their robustness - and therefore the use to which such categorisations should be put. First, while, as already noted, the typology is generally consistent with earlier research based on similar methodologies, the results differ somewhat from other classifications based more on governance, regulatory frameworks and economic approach than housing specific variables. In this context for instance, "Milestone in European Housing Finance" (Lunde \& Whitehead, 2016) identifies five categories - Anglo-Saxon; Scandinavian widely defined to include the Netherlands and sometimes France; Corporatist systems notably Germany and Austria; ex-Communist countries; and Southern Europe. This type of approach would almost certainly put the USA in a different category - the Anglo-Saxon one rather than with Germany. Equally France would be in the Northern Europe category.

Second, is the appropriate level of analysis for categorisation purposes at housing system level (as implied here) or, given housing is so affected by macro-economic and other factors, should housing specific variables be supplemented or indeed replaced by more variables that reflect the context in which housing decisions are made? In this context it is worth noting that the correlation analysis shows a much stronger relationship between GDP per head and housing conditions than between housing policies and these conditions - but equally that GDP per head is not strongly related to the use of policy instruments. Third, is the typology likely to remain stable over time? Again housing finance provides an example. In Lunde and Whitehead $(2014 ; 2016)$ groups are identified at the beginning and end of the period, based not only on how finance systems have developed but also on outcomes since the Global Financial Crisis. Not surprisingly the groups, now, while to some extent reflecting the original categorisation, show that the reasons for successful and unsuccessful outcomes varied greatly both within and between the identified groups. Research concentrating on the position of a single or a smaller number of countries within an overall categorisation also shows that outcomes are often unpredictable in terms of initial categorisations (Tutin \& Vorms, 2014; Priemus \& Whitehead, 2014; Scanlon et al., 2011).

It is important to stress that the authors do not claim anything more for the typology than that a clear statistically based categorisation emerges from these data. It is for other researchers to put these materials to use in the context of particular housing questions.

This comment now goes on to discuss two pieces of research where the data and typology could form useful inputs - one where some of the $A H D$ data have already been used and one where there might be considerable potential as the database is expanded.

\section{Mortgage Safety Nets}

As part of a study of how UK mortgage safety nets have been changing (Williams et al., 2017) we looked at how they worked in a range of countries across the OECD. Our starting point was the data in the Affordable Housing Database which has within it material which could provide relevant information on housing allowances across all tenures and on public spending in support of home ownership.

\section{Using the Affordable Housing Database}

The Affordable Housing Database showed that some 33 OECD countries, of which 25 are in Europe, had some forms of housing allowances in place for low income households in the rented sector. However, only half of these countries had in place housing allowances for low income owner-occupiers ${ }^{2}$ (including 12 of the 25 European countries). One additional country (Denmark) had them only for the elderly; another, Switzerland, had allowances only in some cantons.

\footnotetext{
2. These were widely spread across the OECD groups including: Austria, Cyprus, Czech Republic, Finland, France, Germany, Greece, Latvia, Norway, Poland, Sweden and UK.
} 
The database $\mathrm{e}^{3}$ splits public spending on financial support for homebuyers into three categories: (i) grants - which are mainly about increasing access for first time buyers of different types; (ii) mortgage subsidies and guarantees which are there to reduce interest rate costs by providing potential support and (iii) mortgage tax relief for over-indebted home owners, subsidies and measures to avoid foreclosure on residential dwellings, owned by households in financial distress. The data show that some 8 European countries ${ }^{4}$ as well as Canada, New Zealand and the USA use forms of mortgage guarantee but these are mainly supporting access to home-ownership by reducing risks to lenders. Only 8 countries - Australia, Hungary, Ireland, Japan, the Netherlands, Norway, Portugal and the United States - actually responded to the final question on helping borrowers in financial distress ${ }^{5}$. They identified particular schemes including subsidies to mortgage interest payments; contributions to paying off arrears; postponement of payments; refinancing; and mortgage to rent initiatives. What the commentary also shows is that types of support are not easily categorised; many countries have large numbers of interventions (not all of which were reported); and it was not possible to obtain information on the scale of assistance given.

\section{More detailed examples}

We also asked a range of country experts about the experience in their countries with respect to three groups of policies: traditional approaches put in place by government or industry to provide income support or address changes in individual circumstances; short term measures put in place by government and/or industry when there were major problems in the mortgage market; and longer term regulatory changes, aimed at ensuring those who buy can maintain their mortgages when circumstances change.

The responses showed that housing allowances are not usually available to owneroccupiers. Rather households must depend on more general income protection policies - but also industry initiatives. However, in many Western European countries, levels of out-of-work benefits, especially those that are linked to previous earnings levels, are relatively high and so are seen to remove the need for measures specifically related to mortgage costs (Ditch et al., 2001).
Responses to crises appear to fall into three main categories:

- those countries (such as Germany, the Czech Republic, Canada and to lesser degree France, Slovenia and Sweden) where there have been few mortgage specific problems in the past and the Global Financial Crisis had little effect on the market. In these countries, little or nothing has changed in terms of how the individual is treated in the face of unexpected problems;

- those where there had been earlier crises - notably Australia, Portugal and Sweden, but also the UK, where policies put in place in response to these crises appeared relatively adequate after the Global Financial Crisis;

- countries (ranging from the extremes of Spain and Ireland but including more stable countries such as the Netherlands and also the USA) that suffered severe housing market problems associated with more fundamental economic and financial difficulties following on from the Global Financial Crisis. In these countries governments usually put in place an, often hurried, range of measures to limit foreclosure, restructure mortgage payments and sometimes to transfer the household or the dwelling into the rental sector.

Finally, macro-stabilisation regulatory changes since 2008 have been relatively consistent across countries. Most of the emphasis has been on limiting lender capacity to make higher risk loans or increasing their costs to the institutions. These constraints in turn affect who can obtain a mortgage and so impact on future risks. This may reduce the need for safety nets to be put in place - at least with respect to the mortgage market.

Overall, the cross-country evidence suggests that, where mortgage payments are not being kept up to date, the most usual approach is to ensure appropriate negotiations take place between mortgage lender and borrower to restructure payments, e.g., to extend the mortgage and to backload payments to a time when the borrower can pay. Subsidies to individuals are rare and where they exist may have to be financed by the industry.

\footnotetext{
3. Table PH2-1 Public spending on grants and financial support to home buyers.

4. Table PH2-1.2 Croatia, Estonia, Finland, Latvia, Luxembourg, the Netherlands, Sweden and the UK.

5. Table PH2-1.3 Mortgage relief for over-indebted home owners: overview of existing measures.
} 


\section{Relevance to the typology}

There are probably three main messages in relation to the André-Chalaux typology:

- The example reinforces the relative importance of economic pressures and macroeconomic policy as compared to housing policies in determining housing outcomes;

- The example also suggests that if the typology is based mainly on housing market and housing policy variables it is likely to be fairly unstable in the face of macro-economic change. So for instance, in the housing finance context examined here the USA and Germany would be extremely unlikely to be in the same group; while France and Austria look like the odd ones out in the "Western" group;

- Third, the database itself cannot - and is not meant to - provide the level of detail that can enable analysis of specific housing issues, but it can be a useful starting point as it was in this piece of research.

\section{Access to homeownership among younger households}

It might have been expected that another project undertaken for the OECD in 2017, on whether changes in mortgage regulation has impacted on young people's capacity to access owneroccupation (Whitehead \& Williams, 2017), would have benefitted from the Affordable Housing Database. In practice, however, the most relevant OECD data came from Society at a Glance (OECD, 2016 and earlier years) which includes information on the proportion of younger people under 30 living with parents and on the employment rates of this group.

The evidence showed that in twenty-three countries the proportion of younger people under thirty was above the OECD average of just under $60 \%$ living with parents in 2014 . It also showed that seven of the top nine countries lay within groups "South Central" and "Eastern" of the André-Chalaux typology, the other two being Spain and Portugal. Importantly, the proportion of younger people living with parents across the OECD had risen since 2007 with Italy, Hungary, Greece and France among those with the biggest increases. Evidence on employment rates among younger people suggests a similar picture - with the number of jobs taken by this age group falling by $8 \%$ on average since 2007 ; but by a quarter or more in seven countries all but one of which (Ireland) correspond to the countries with the highest increases in those living with parents and are included in groups "South Central" and "Eastern" of the André-Chalaux typology. These data were undoubtedly part of the reason for commissioning the research.

In practice however the Affordable Housing Database included little of relevance to this particular project except for the data on home ownership policies which identified some policies supporting access to homeownership. In particular, the material on regulation is limited to the rented sector. As a result, the research depended significantly on regulatory data from other sources and on country experts and the statistical and other data they could provide.

Again a typology was developed specific to the project, distinguishing countries by the scale of impact of the Global Financial Crisis, what had happened to lending and the extent to which mortgage regulation had changed - ranging from countries such as Germany and Slovenia where regulation was basically unchanged and lending had increased since the Global Financial Crisis to countries such as Greece and Hungary where there was still almost no lending taking place and regulatory change was more general: countries in between had concentrated more on mortgage specific regulation which had impacted on levels of lending and eligibility.

A core issue was the scale of deposit required. In this context there are four distinct reasons why it has become more difficult in addition to regulatory change: private rent increases make it more difficult for potential owners to save for a deposit; real incomes, notably for younger people, have often decreased making it harder to save; interest rates on savings have declined - making it more difficult to achieve a given deposit; and house prices have often risen, so deposit requirements are higher. The importance of parental assistance had clearly increased - but in a number of countries with high unemployment and falling incomes family capacity has also declined.

Even if people can save the deposit (itself increased by the regulation) in most countries it has always been necessary to have a permanent job in order to obtain a mortgage. But the proportion of younger people with job security has been falling. This growing group of potential 
owner-occupiers would therefore generally not be able to enter the sector.

Other problems relate to the capacity to make repayments: unemployment and job insecurity have risen rapidly especially among younger people while real incomes have often fallen. In this context renting a home becomes a logical choice because of its flexibility. Equally, individual attitudes to risk appear to have become more conservative. So it appears to be that demand has declined rather than that regulation has been the constraining factor.

Overall, therefore, while regulation is having a direct impact on access to mortgages in most countries included in the analysis, there are many other reasons why younger households are finding it more difficult to buy

\section{Conclusions}

"Building a typology of housing systems to inform policies in OECD and EU member states" has many valuable attributes. One of the most immediately relevant is that it helps to introduce a wider audience to the new OECD Affordable Housing Database - an important addition to the OECD's growing databank. Even though there are clearly gaps, its publication will of itself almost certainly provide an incentive to member countries to improve their own data.

The analysis presented - based on principle components and cluster analysis techniques identifies four groups of OECD countries. However perhaps the most immediately important result is a simple correlation analysis which suggests that market factors are far more closely correlated with outcomes than housing policies. This may in part be a result of data deficiencies - in particular there is no evidence on the scale of the interventions and the data available suggest that by no means all interventions were captured. But it also reflects the strongly held view held by many commentators that housing is more affected by the wider economic environment than by housing specific interventions.

However, it is important to stress that the techniques used are not hypothesis based and say nothing about causality. The biggest issue in this context is therefore whether the variables included in the analysis provide a good starting point for further analysis that looks more closely at individual relationships and behaviour. The two pieces of more policy specific research discussed in this paper use OECD data sources in this way as a starting point but then go on to more qualitative analysis which generates problem specific typologies rather than the more data driven one presented by André and Chalaux.

It is less clear that the specific typology generated can be used as more than a starting point for discussion. While it is relatively consistent with earlier more ideologically based classifications (e.g. Epsing-Andersen, 1990; Kemeny, 1992, 1995; Kemeny \& Lowe, 1998) this may of itself be a matter of concern as the housing world has changed rapidly since these studies were undertaken. Classifications can be expected to change over time as well as because different variables are included.

The argument that it is wider economic and indeed social variables that are more important in terms of housing outcomes than housing specific variables, suggests a somewhat different approach to the selection of variables. Equally when the topic to be discussed is more specific, such as is the case with the two examples discussed here, one would expect to see different data used and a different classification arise.

Most importantly this paper should be seen for what it is - a very careful statistical analysis of new and interesting data that will support the development of high quality comparative research into housing markets and policy. 


\section{BIBLIOGRAPHY}

Ditch, J., Lewis, A. \& Wilcox, S. (2001). Social housing, tenure and housing allowances: an international review. London: Department for Work and Pensions.

Esping-Andersen, G. (1990). The Three Worlds of Welfare Capitalism. Princeton: Princeton University Press.

Kemeny, J. (1992). Housing and Social Theory. London: Routledge.

Kemeny, J. (1995). From Public Housing to the Social Market. Rental Policy, Strategies in comparative perspective. London: Routledge.

Kemeny, J. \& Lowe, S. (1998). Schools of Comparative Housing Research: From Convergence to Divergence. Housing Studies, 13(2), 161-176.

https://doi.org/10.1080/02673039883380

Lunde, J. \& Whitehead, C. (2014). Milestones in Housing Finance across Europe. Mortgage Info ENHR Special Edition. Brussels: EMF and ECBC.

Lunde, J. \& Whitehead, C. (2016). Milestone in European Housing Finance. Oxford: Wiley Blackwell.

OECD (2016). Society at a Glance, 2016. Paris: OECD.

Priemus H. \& Whitehead, C. (2014). Interactions between the financial crisis and national housing markets. Journal of Housing and the Built Environment, 29(2), 193-200.

https://doi.org/10.1007/s10901-013-9382-1
Scanlon, K., Lunde, J. \& Whitehead, C. (2011). Responding to the Housing and Financial Crises: Mortgage Lending, Mortgage Products and Government Policies. International Journal of Housing Policy, 11(1), 23-49.

https://doi.org/10.1080/14616718.2011.548585

Scanlon, K. \& Whitehead, C. (2014). Rent stabilisation: principles and international experience. A report for London Borough of Camden, London: London Borough of Camden.

Tutin, C. \& Vorms, B. (2014). French housing markets after the subprime crisis: from exuberance to resilience. Journal of Housing and the Built Environment, 29(2), 277-298.

https://www.jstor.org/stable/43907271

Whitehead, C., Markkanen, S., Monk, S., Scanlon, K. \& Tang, C. (2012). The private rented sector in the new century-a comparative approach. Copenhagen: Realdania, December 2012.

Whitehead, C. \& Williams P. (2017). Changes in the regulation and control of mortgage markets and access to owner-occupation among younger households. OECD Social, Employment and Migration Working Papers, $\mathrm{N}^{\circ}$ 196. Paris: OECD. https://doi.org/10.1787/e16ab00e-en

Williams, P., Wilcox, S. \& Whitehead, C. (2017). Challenges for our Home Ownership Safety Net: UK and International Perspectives. London, UK Finance. 



\title{
Does issuing building permits reduce the cost of land? An estimation based on the demand for building land in France
}

\author{
Jean-Sauveur Ay*, Jean Cavailhès*, Mohamed Hilal* and Julie Le Gallo*
}

\begin{abstract}
While the aggregate value of constructed land rose from $45 \%$ to nearly $260 \%$ of gross domestic product in France between 1998 and 2006, stabilising after the crisis, regulatory constraints on construction are used to explain the rise in land prices, which are weighing on production costs for new housing units. Here we analyse to what extent the issuance of building permits reduces the price of land. We first propose a theoretical assignment model of heterogeneous households (in terms of preferences) to heterogeneous building plots (in terms of location) to study the effects of construction on the price of land. We then estimate the inverse demand for building land by instrumenting construction (quantity) by instrumental variables relating to the nature of the land, to its topography, to the agricultural opportunity cost and to the presence of industrial brownfields. A $1 \%$ increase in the number of permits issued resulted in a moderate decrease in land prices of $0.3 \%$, on average. The effect, which differs according to the type of construction, increases with proximity to dense zones.
\end{abstract}

JEL Classification: R14, R31, R52

Keywords: land policy, land development, assignment model, instrumental variables

Reminder:

The opinions and analyses in this article

are those of the author(s)

and do not

necessarily reflect

their institution's

or Insee's views.
*CESAER, AgroSup Dijon, INRA, Univ. Bourgogne Franche-Comté (jean-sauveur.ay@inra.fr; mohamed.hilal@inra.fr; julie.le-gallo@agrosupdijon.fr;
j.cavailhes@orange.fr) We would like to thank the Department of Statistical Data and Studies (SDES) of the Ministry of Ecological and Social Transition for providing data; Sylvain Moreau, Frédéric Minodier and Laurent Wilms for Sit@del2 and Claire de Kermadec for the EPTB.

Received on 31 May 2017, accepted after revisions on 4 May 2018

Translated from the original version in French: « Délivrer des permis de construire pour diminuer le coût du foncier ? Une estimation par la demande de terre constructible en France »

To cite this article: Ay, J.S., Cavailhès, J., Hilal, M. \& Le Gallo, J. (2018). Does issuing building permits reduce the cost of land? An estimation based on the demand for building land. Economie et Statistique / Economics and Statistics, 500-501-502, 45-67. https://doi.org/10.24187/ecostat.2018.500t.1945 
B etween 1998 and 2006, the aggregate value of built land rose from $45 \%$ to $257 \%$ of GDP and has stabilized at slightly lower levels since the crisis $(222 \% \text { in } 2016)^{1}$. Developed land inflation therefore affects all advanced economies and has contributed to about $80 \%$ of real estate inflation at the macro-economic level since the Second World War (Knoll et al., 2017). This inflation is a major economic and political issue, directly responsible for the increase in the weight of housing in household budgets and with strong implications for non-housing purchasing power and the distribution of wealth (Bonnet et al., 2015).

The solutions proposed to mitigate this inflation mainly revolve around the growth of construction to increase the quantity of housing units and to bring down prices. Given the increasing weight of developed land, land appears to be the most severe limiting factor, and suffering the highest inflation, it is therefore the natural lever to increase housing supply. However, this lever is the subject of much controversy between its supporters (Repentin \& Braye, 2005; Atelier parisien d'urbanisme, 2007; Trannoy \& Wasmer, 2013; Fondation Abbé Pierre, 2016) and its opponents (Bisault, 2009; Société d'aménagement foncier et d'établissement rural, 2018; Courtoux \& Claveirole, 2015; Fondation pour la nature et l'homme, 2016). This lack of consensus stems both from questioning the diagnosis of a supply deficit (Cornuel, 2017) and the need to take into account the induced effects of land development on agriculture, the environment and living conditions (Béchet et al., 2017). We propose to address this controversy through the location of building plots and their suitability with regard to household preferences. The heterogeneity of land and its immobility being determining factors of its relative scarcity (Ay, 2011; Cavailhès et al., 2011b), it is a question of studying to what extent construction must be adapted to demand for it to actually translate into a fall in the price of building land.

According to the literature, the relationship between construction and the price of building land is often approached from the point of view of supply (Gyourko \& Molloy, 2015). Studies differ in the way supply is defined, either in terms of the number of housing units produced by the construction sector, or in terms of the areas authorised for construction by land-use policies. Early publications refer, more or less explicitly, to the concept of housing production function where land is an input in order to estimate the extent to which construction responds to the price of land (Epple et al., 2010; Combes et al., 2016b). Saiz (2010) provides an estimate of the price elasticity of housing supply in the United States based on exogenous changes in demand measured in demographic terms. It also appears that these elasticities depend on the distribution of land slopes within the cities. Caldera and Johansson (2013) set out to categorise OECD countries according to the responsiveness of construction to building land prices. North American countries appear the most sensitive (elasticity greater than 1), continental European countries the most rigid (elasticity less than 0.5 ), while the countries of Northern Europe are somewhere in the middle. For France, the estimated value is 0.36 , a result recently confirmed by Chapelle (2017), who obtains the same order of magnitude. The other publications on land-use policies (for surveys of the literature, see Duranton \& Puga, 2015; Glaeser \& Gyourko, 2018) generally show that regulation of land use by restricting the supply of building land increases the price of land and reduces the volume of construction. The results of these studies, which focus on land use regulations, differ according to the policy studied (Grieson \& White, 1981), the empirical strategy used (Quigley \& Rosenthal, 2005) and the effects measured (Turner et al., 2014). These publications are echoed in France and feed the academic literature (Lecat, 2006; Levasseur, 2013; Geniaux et $a l ., 2015)$ and professional literature (Benard, 2007; Charmes, 2007; Comby, 2015).

Here we analyse the effect of construction on the price of building land in terms of demand emanating from households looking for land on which to build a dwelling. The relevance of this angle of attack rests on two main points. On the one hand, in the French context, application for a building permit is a legally required prerequisite for construction, often done at the same time as purchasing the land. Building land transactions make it possible to observe the price of land, which corresponds to the cost of land for construction. On the other hand, the decision to look at land markets from a demand perspective allows for the implementation of an identification method based on exogenous variations in actual construction. While the usual

1. Insee, 2016 financial statements base 2010, https://www.insee.fr/fr/ statistiques/2832716? sommaire $=2832834$. 
approaches for estimating the demand for building land are based on hedonic methods, which marginally value land features and neglect construction (Kuminoff et al., 2013), here we use the theoretical framework of an assignment model derived from an analysis of the labour market (Sattinger, 1993). This type of model has recently been applied to the housing market by Landvoigt et al. (2014); we apply it to the building land market, where the price of land arises from the balance between household demand for land and supply that we consider to be exogenous. Using a similar methodology, Hilber and Vermeulen (2016) use regional differences and a land regulation reform in England to estimate the impacts of local supply constraints on the relationship between local average incomes and the price of land.

Our empirical approach focuses on the market for land intended for the construction of individual houses. We use the Sit@del2 databases (1974-2015) for building permits issued, and the EPTB survey (2006-2014) on land prices, together with data on soils, topography and agricultural opportunity costs (the value of agricultural production that is lost by assigning land to housing), as well as the presence of former industrial sites. We econometrically estimate an inverse demand equation for land, where constructed quantities are instrumented by exogenous supply variations. Permits and prices result both from supply effects and demand effects, that we aim to distinguish here. Economic theory considers the price elasticity of demand to be negative as, for a given demand function, increasing the quantity of land offered should lead to a decrease in its price. These are the expected effects of a supply shock in partial equilibrium. Conversely, for a given supply, a demand shock caused by increasing the demand for land should lead to price increases if the price elasticity of supply is positive. This simultaneity, due to the market equilibrium, manifests itself in a large number of constructions in desired and expensive locations, regardless of supply (Geniaux et al., 2015). This correlation complicates the estimation of the causal effects associated with changes in supply. Furthermore, we propose an approach using instrumental variables in which constructed quantities are projected on exogenous variations in land availability, with exogeneity of supply being understood as independence from prices. For this purpose, we use variables present in the empirical literature (soil type, topography) and other more original variables (the opportunity cost of agriculture and industrial brownfields).

The theoretical model shows that the price of land decreases with the number of building permits issued and, that this elasticity of demand is even more negative when the location of the land corresponds to household preferences. The empirical analysis confirms the results of the theoretical model, with a negative elasticity of the order of -0.3 . This estimation (taken as an absolute value) is significantly higher in municipalities in the ninth density decile (above 387.1 inhab. $/ \mathrm{km}^{2}$ ) compared to those in the first decile (less than 26.5 inhab. $/ \mathrm{km}^{2}$ ).

\section{Data}

The population of interest, i.e. the land plots for which the price is observed, corresponds to the population of the EPTB survey, namely plots of land belonging to individuals who have been granted building permits for individual houses in the detached housing sector (excluding sub-divisions, see Box 1). For the period 2006-2014, pooling of EPTB observations provided a sample of 873,823 observations. For 315,825 of them (36.1\%), the applicant did not buy the land on which the deposit was placed or did not answer the question about the price of the land. Georeferencing nevertheless enables them to be mapped (Figure I-A). Research (not reported here) based on the Insee Housing survey of 2013 show that, for about $10 \%$ of the houses built, the owners obtained the land by inheritance or donation. This reason does not seem sufficient to explain the loss of more than $30 \%$ of the observations. An additional selection source is the inability to georeference the plot, resulting in a loss of 172,817 observations $(19.8 \%)$. Observations were also lost due to the atypical values of some variables, mainly regarding prices and surface areas. For each of the variables reported in Table 1, we eliminate 105,966 observations $(12.1 \%)$ whose values are extreme in terms of the interquartile ratio, meaning that the value is higher (lower) than the upper (lower) quartile plus (minus) 1.5 times interquartile range. We obtain a final sample of 279,215 observations $(31.9 \%$ of the initial population), which size is comparable to that of various empirical studies using the EPTB without cadastral georeferencing (Vermont, 2016; Combes et al., 2016b). The spatial distributions of 
the EPTB observations used in the analyses are presented in Figure I-B. Although limited to the diffuse housing sector, these land price observations are concentrated in urban areas with a spatial distribution very close to that of the issued building permits, as in the Sit@del2 database.

Each observation in the final sample is matched to municipal construction measures from building permits filed between 1974 and 2015, derived from the raw data in Sit@del2 (Box 1). This measure of construction includes all residential construction, not only pure individual houses resulting from single-unit construction projects, but also grouped individual houses resulting from multi-unit construction projects for individual houses or a single individual house with outbuildings, and collective housing defined by excluding the first two. Figure II shows the number of housing units, floor areas and land areas permitted for construction at the national level. It compares the evolution of construction in the detached housing sector relative to other sectors. The total number of units authorised annually between 1974 and 2016 varies by more than double between years, from 250,000 in the mid-1990s to almost 550,000 at the peak of 2006. Individual housing and collective housing intersect to form the largest source of new housing, while grouped individual housing represents about three times less units built than for each of the previous modalities. In terms of floor area, individual houses (single and grouped) represent almost half of total construction, due to significantly larger surfaces than collective housing. This gap has narrowed sharply in the recent years, due to the decreasing size of houses and the relative increase in the construction of collective buildings. In terms of land area, the gap is even wider between pure individual houses and collective housing, while the latter shows levels close to grouped individual houses: individual houses account for approximately $90 \%$ of the total surface area intended for construction.

Table 1 presents the statistics describing the variables in the database for econometric analysis. The average price of building land is 88 Euros per $\mathrm{m}^{2}$ for an average surface area of just over $1,000 \mathrm{~m}^{2}$. The average cost of building an individual house is 1,097 Euros per $\mathrm{m}^{2}$ for an average floor area of $127 \mathrm{~m}^{2}$. The characteristics of the houses in the sample are less variable than the characteristics of the land plots. Land represents, on average, $30 \%$ of the total building cost of an individual house, and the floor area covers on average $15 \%$ of the land area. We use five qualitative variables

Figure I

Distribution and selection of the EPTB observation sample for econometric analysis

A - Initial sample (EPTB)

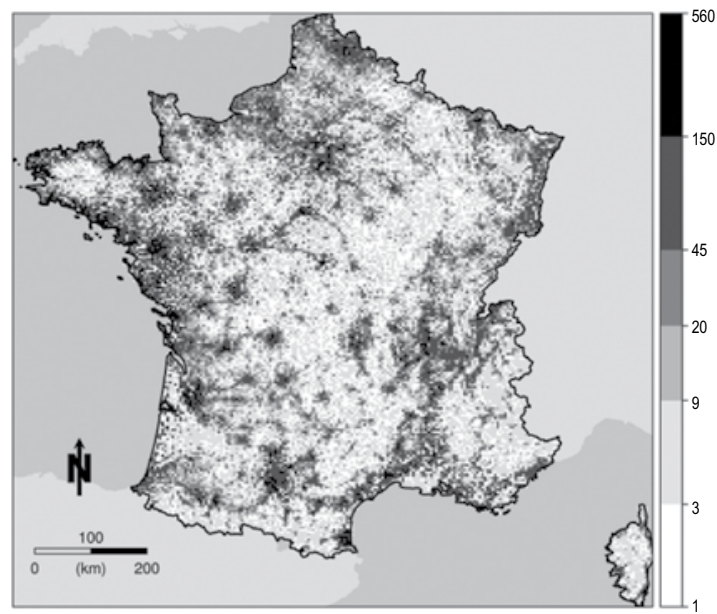

$B$ - Final sample selected for the estimation

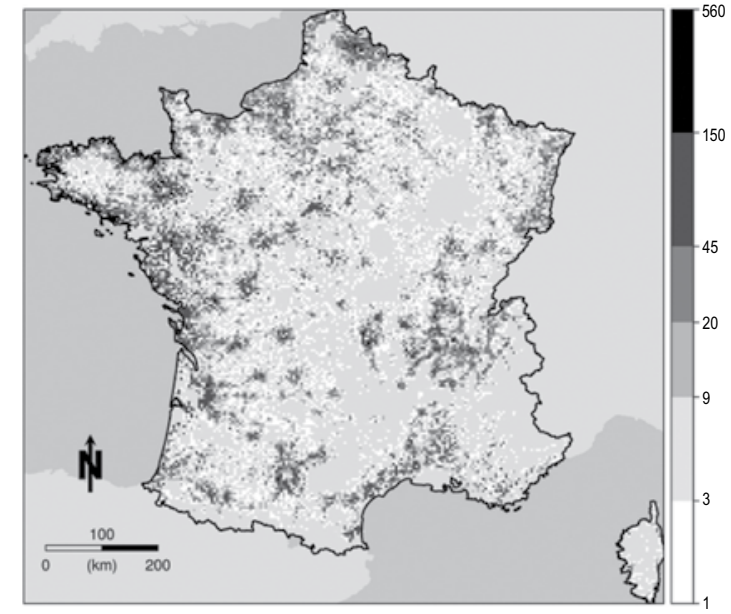

Note: The resolution of the raster for mapping the EPTB observations is $4 \mathrm{~km}$. For each raster cell, map A shows the 701,006 georeferenced observations present in the initial sample $(\mathrm{N}=873,823)$. Map B shows the observations used in the econometric analysis $(N=279,215)$. The reduction in the size of the sample is due to a variety of factors: land was not purchased by the applicant, or missing or atypical values for important variables. Coverage: Metropolitan France.

Sources: EPTB (SDES), Sit@del2 (SDES), Insee; authors' treatment. 
Figure II

Evolution of construction from 1974 to 2016 according to building permits

A - Annual number of units authorised by type, from 1974 to 2016

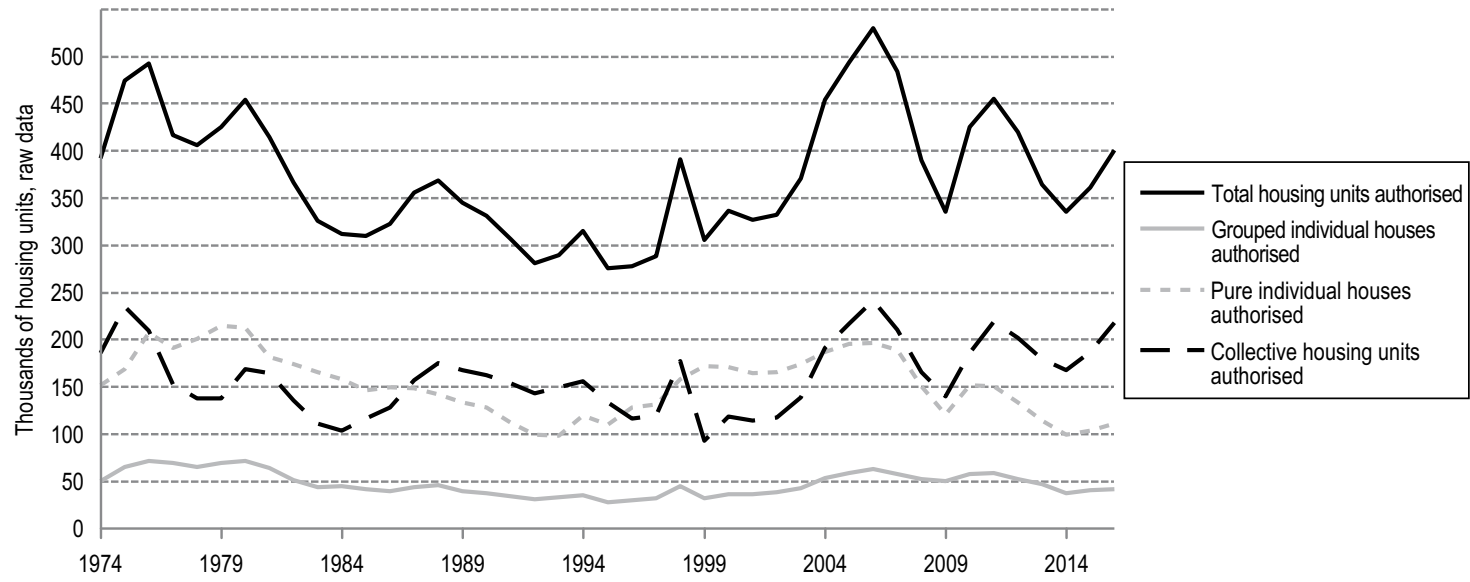

B - Annual surface area of units authorised by type, from 1974 to 2016

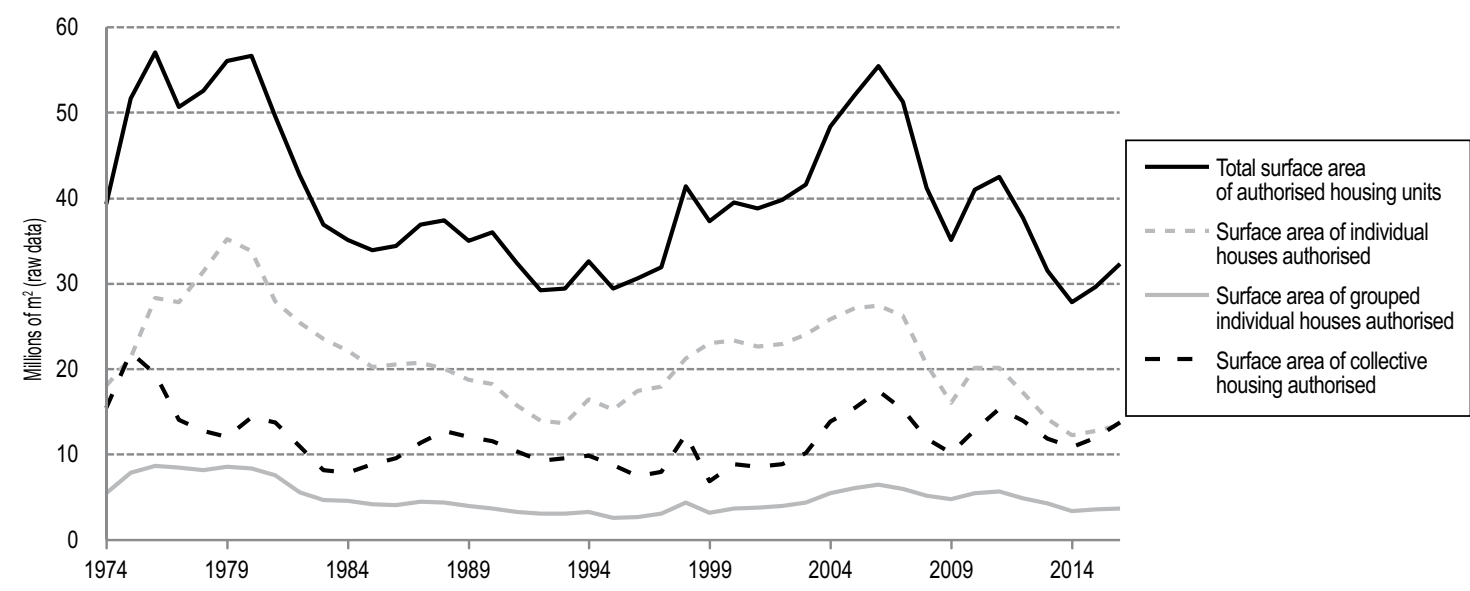

C - Annual surface areas of authorised plots for housing units by type from 1974 to 2016

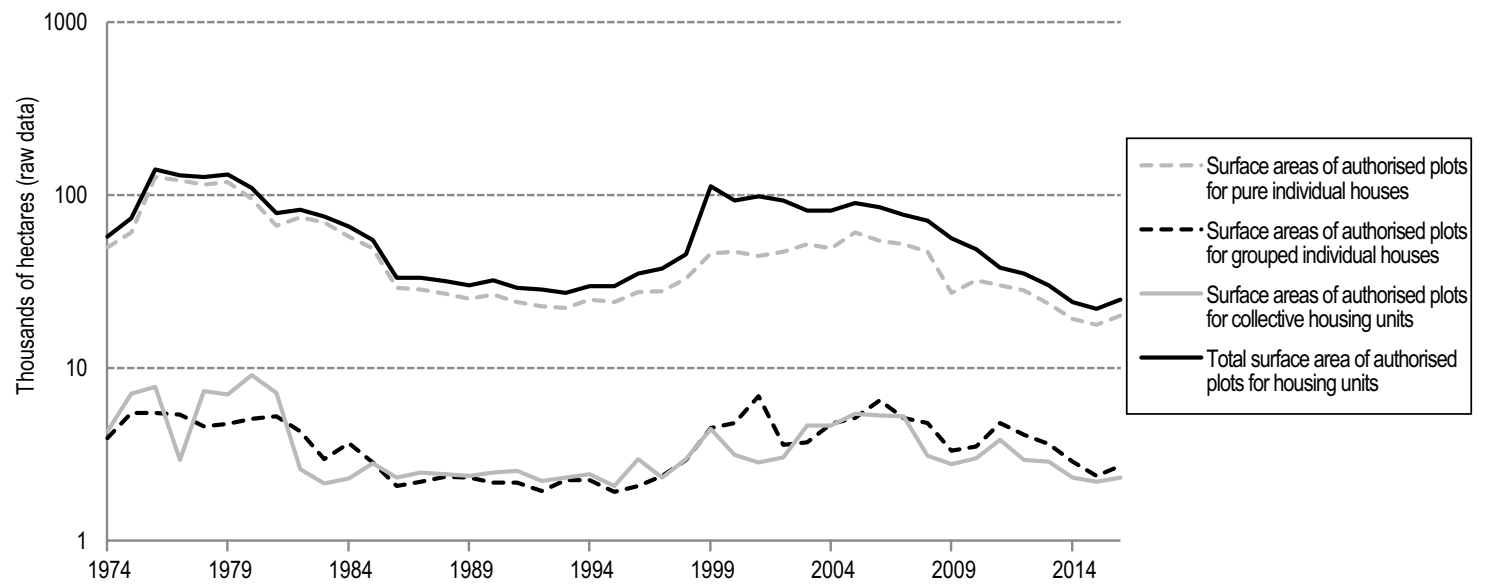

Note: Total permissible housing includes the three categories presented, as well as residential housing, which are units built by a developer for occupation by a highly targeted public depending on the type of residence, along with the provision of specific services. The annual values are calculated from all the authorized building permits, referenced at the date of authorisation. The values for the number of housing units and the floor area have been disseminated by the SDES at the municipal level since 2005 (http://www.statistiques.developpement-durable.gouv.fr/donnees-ligne/r/sitdel2-donnees-detaillees-logements.html). Data on plot surface areas are not publicly available, so come from the same raw data for building permits. To an unknown extent, the latter overestimate the surface areas actually artificialised due to abandoned building permits and initially large cadastral plots which are not fully constructed. By way of comparison, Cerema's data from the DGFiP show annualised artificialised surface areas of around 32.2 thousand hectares per year between 2006 and 2015, which is not far from the values presented here. Conversely, Cerema data have less historical depth than the Sit@del2 data and do not distinguish between residential and non-residential uses.

Coverage: Metropolitan France.

Sources: Sit@del2 (SDES). 
Table 1

Descriptive statistics for the variables in the database used in the regressions

\begin{tabular}{|c|c|c|c|c|c|}
\hline & N. observations & Mean & Standard error & Min & $\operatorname{Max}$ \\
\hline Price of land (current Euros $/ \mathrm{m}^{2}$ of land) & 279,231 & 87.8 & 72.8 & 5.0 & 429.9 \\
\hline Cost of the house (current Euros $/ \mathrm{m}^{2}$ floor area) & 279,231 & 1096.8 & 315.5 & 6.2 & $7,254.9$ \\
\hline Surface area of the plot $\left(\mathrm{m}^{2}\right)$ & 279,231 & 1027.2 & 673.0 & 100.0 & 4653.0 \\
\hline Floor area $\left(m^{2}\right)$ & 279,231 & 126.9 & 34.1 & 50.0 & 289.0 \\
\hline Ratio of land price to total price (\%) & 279,231 & 30.9 & 12.4 & 0.5 & 99.4 \\
\hline Ratio of floor area to total area (\%) & 278,577 & 16.3 & 8.7 & 2.0 & 99.4 \\
\hline Altitude of the plot (m) & 279,231 & 149.3 & 141.8 & 0.0 & 823.5 \\
\hline Slope of the plot (\%) & 279,231 & 3.9 & 3.6 & 0.0 & 21.3 \\
\hline Population density in 1990 (inhab. $\left./ \mathrm{km}^{2}\right)^{*}$ & 279,231 & 171.3 & 260.8 & 1.6 & 3766.3 \\
\hline Housing units authorised 1974-2014 (log (num)) $)^{*}$ & 279,231 & 6.1 & 1.2 & 1.1 & 9.0 \\
\hline Floor area authorised 1974-2014 $\left(\log \left(m^{2}\right)\right)^{*}$ & 279,231 & 10.9 & 1.2 & 5.6 & 13.5 \\
\hline Land area authorised 1974-2014 $\left(\log \left(\mathrm{m}^{2}\right)^{*}\right.$ & 279,231 & 13.5 & 1.0 & 7.5 & 15.9 \\
\hline Land area artificialised 2006--2015 $\left(\log \left(\mathrm{m}^{2}\right)\right)^{*}$ & 279,215 & 11.8 & 1.2 & 3.0 & 14.2 \\
\hline $\begin{array}{l}\text { Portion of surface area subject to shrinkage } \\
\text { or swelling of clays }(\%)^{*}\end{array}$ & 279,231 & 22.9 & 29.4 & 0.0 & 100.0 \\
\hline Standard gross agricultural income 2014 (Euros/ha)* & 279,231 & 9553.1 & 11477.0 & 6.0 & 142343.0 \\
\hline Share of inhabitants on slopes between 10 and $15 \%(\%)^{*}$ & 279,231 & 5.2 & 9.3 & 0.0 & 100.0 \\
\hline Share of inhabitants on slopes above $15 \%(\%)^{*}$ & 279,231 & 3.0 & 8.7 & 0.0 & 100.0 \\
\hline Number of old industrial sites (num)* & 279,231 & 0.2 & 0.6 & 0.0 & 9.0 \\
\hline
\end{tabular}

Notes: The first six variables were taken from the EPTB survey (SDES). Topographic variables are obtained by georeferencing and merging with BD ALTI (IGN). The population density in 1990 (Insee) is a municipal variable merged through the code of the municipality. The first three variables for building permits come from Sit@del2 (SDES), the fourth variable on artificialised surface areas comes from Cerema (from the DGFiP), they are also merged with the code of the municipality. The last five variables are used as instrumental variables, also merged at the municipal level (see Box 3). They come respectively from the BRGM (re-swell of clay soils), from the SSP (agricultural census for 1988 and agricultural accounting information network 1989-2014), from cross-referencing of the grid population data (Insee) and BD ALTI from the IGN, and finally from Basias (BRGM). * Variables measured at the municipal level.

Coverage: Metropolitan France.

Sources: EPTB (SDES), Sit@del2 (SDES), Insee, BD ALTI (IGN), Cerema, Basias (BRGM), SSP; authors' treatments.

present in the EPTB: the date of purchase of the land, servicing of the land, the presence of an intermediary at the time of purchase, the socio-professional category of the buyer and their age at the time of applying for the building permit. The statistics for these variables are presented in Table A-1 in the Appendix.

Georeferencing of the EPTB observations allows the merging with a digital elevation model at a resolution of 75 metres (BD ALTI) to estimate the altitude and slope of the plots. These land characteristics are used as control variables in the price equations. In our empirical strategy, they nevertheless prove to be decisive in distinguishing price variations due to plot characteristics from those due to construction in the municipality. We use municipal population densities of 1990 (Insee) as the main measure of both the position of the plot on the urban-rural gradient and the induced accessibility to jobs and services. Density is preferred to positioning criteria in terms of the centre of the urban area (and its size) because this variable has the advantage of not depending on division of the land, which is somewhat arbitrary. The 1990 density value is used to reduce random correlations with prices over the 2007-2015 period. Construction variables are summed for each municipality for the last 40 years. Construction is measured both in terms of the number of authorised housing units, authorised floor areas and authorised areas of land, and includes individual and grouped individual houses and collective housing, as households arbitrate between these different housing offers. The area artificialised over the 2006-2015 period is calculated from the changes in the purpose of land plots: natural, agricultural or forested areas and built-up areas in the cadastral sense. The last five variables in Table 1 


\section{Box 1 - Databases: EPTB and Sit@de/2}

The units surveyed in the Building Land Price Survey (Enquête sur le prix des terrains à bâtir, EPTB) are individuals who have been authorized to build individual houses. Collection was done by post. The first EPTB survey covering the entire French territory dates from 1985, it was stopped at national level in 1996. It was relaunched in 2006 and has been exhaustive since 2010. We use the raw unadjusted EPTB data for 2006-2014 referenced on the date the land was purchased. The data allows the price of land to be traced back to the 1990s, although in almost $75 \%$ of cases, the land is purchased in the year the permit is filed. Georeferencing data comes from Sit@del2, the information and automated processing system for basic data on housing and premises, provided by the Department of Statistical Data and Studies (SDES). The 2007-2015 permits are geocoded to the plot identifier using the cadastral information (Majic /l from the DGFiP).

The Sit@de/2 information system contains all building permits processed by the planning centres. We only use residential permits. Information on construction work and completion of works is provided at the initiative of the petitioners, it is less reliable and is therefore not used here. The data refer to the actual date: they record the authorisations at the actual date of the event and not at the time of forwarding to the SDES. These data are net of cancellations. This source is administrative with its own limitations, such as breaks in collection, mis-entered variables and permits which did not result in construction. Nevertheless, it appears to be the most reliable source for measuring construction at the municipal level over a long period. are instrumental variables used to control the endogeneity of construction in econometric models (presented later in the Empirical Strategy).

\section{Theoretical model}

We consider a set of households seeking to acquire land to build a housing unit within an urban area. Potentially buildable land plots differ by their location, which households value differently. We note $\theta \geq 0$ this location, which is a one-dimensional measure of what we describe as the quality of the land. Household preferences regarding this quality constitute a second dimension of heterogeneity. These two dimensions of the building land market are matched using a stylized assignment model, along the lines of Landvoigt et al. (2014). We also apply the principle of assignment to construction, which is new in this literature mainly focused on the existing housing stock.

Each household is looking for a single land plot of a given size and maximizes its utility under a budgetary constraint. Utility depends on the consumption of a quantity $c$ of a composite good at a price standardized to 1 , and of the synthetic measure $\theta$ of the quality of the land purchased. The utility function, $U(c, \theta)$, is increasing and concave in each of its arguments. By noting $p(\theta)$ the price of land of quality $\theta$ and $R$ being the disposable income of the household, we substitute the saturated budget constraint for the variable $c$ in the utility function to obtain program (1) and the optimality condition (2) (we note $U_{x}^{\prime}$ the partial derivative of $U$ with respect to $x$ ):

$$
\begin{aligned}
& \max _{\theta}\{U(R-p(\theta), \theta)\}, \\
& p^{\prime}(\theta)=U_{{ }^{\prime}}^{\prime} / U^{\prime}{ }_{c} \equiv \chi \geq 0 .
\end{aligned}
$$

A rational choice is therefore to equalize the marginal value of the quality of the plot $p^{\prime}(\theta)$ and the marginal rate of substitution (MRS) between quality and the composite good. This presentation of demand for quality is standard in hedonic approaches applied to housing and building land (Kuminoff et al., 2013). According to Landvoigt et al. (2014), we note $\chi$ the MRS corresponding to a given household at equilibrium. Unlike the usual analyses, which consider a representative household, this MRS is heterogeneous for the population of potential land buyers. It corresponds to the quality consumed at equilibrium and is distributed in the population according to a distribution function $f(\chi)$ of mass 1 .

Given this demand for building land and certain quality criteria, one necessary condition for construction is to obtain a permit. We assume that permits are obtained simultaneously with the purchase of the land for a proportion $\rho \in[0,1]$ of households. At equilibrium, the equalization of supply and demand gives the distribution of construction between 
the various locations through the $G(\theta)=\rho F(\chi)$ function, which corresponds to the quantity of land actually built on with a quality lower than $\theta$. The function $F$ is the cumulative function corresponding to the distribution of household preferences. This equilibrium condition describes the assignment of households to land plots such that each land quality value corresponds to a type of household. We also note that the function $g(\theta)$, derived from $G(\theta)$, does not integrate to the unit because not all plots are built on in equilibrium. Given the empirical strategy employed, this distribution is assumed to be exogenous.

The price structure is then directly derived from this assignment, consistent with the rationality of individual choice. Rather than expressing the quality of a building land plot as a function of the corresponding household type, it is customary to consider the type of household as a function of the type of land, which makes it possible to write the assignment function (3) as follows:

$$
\chi(\theta)=F^{-1}[G(\theta) / \rho] .
$$

This function assigns MRS $\chi(\theta)$ of the household occupying it at equilibrium, to each land quality $\theta$. It represents the relationship between the two distributions in the form of a Quantile-Quantile diagram ( $Q-Q$ plot $)$, which are frequently used in statistics to compare two distributions. A representation of the assignment function for specified distributions is shown in Box 2. Combining (3) with the optimality condition (2), we see that the assignment function gives the marginal willingness-to-pay for quality. We also note that, if the two distributions are identical, $F=G$ and all households receive a building permit, the marginal willingness-to-pay is proportional to quality $p^{\prime}(\theta)=\theta$. Conversely, still for $\rho=1$, if the cumulative distribution of supply is thicker than demand, $G(\theta)>F(\chi(\theta))$, marginal willingness-to-pay for quality is less than proportional to quality, and therefore smaller than in the case with identical distributions. This result is due to the fact that the relative abundance of land of quality inferior to $\theta$ leads households to accept lower quality levels. Box 2 presents, in more detail, the role of land distribution where the same total quantity is constructed, but with a different distribution along the land quality distribution. It therefore appears that, for a given quantity of construction, the effect on the price becomes stronger as the characteristics of these plots come into line with the preferences of households (Landvoigt et al., 2014).

By setting the price of the lowest quality land $p(0)=0$ to 0 , the price of land of quality $\theta$ is obtained by integrating the marginal willingness-to-pay:

$$
p(\theta)=\int_{0}^{\theta} F^{-1}[G(\tilde{\theta}) / \rho] d \tilde{\theta},
$$

which enables us to deduce some results at equilibrium. It therefore appears that the price of the land increases with quality, that increasing the proportion of permits issued decreases the price of the land, and that this reduction increases in absolute value with quality:

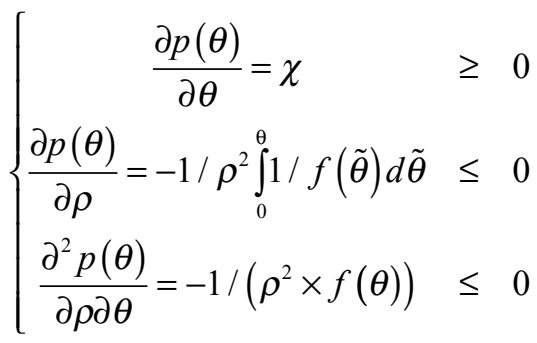

A direct consequence of this model is that construction produces heterogeneous effects along the land quality gradient. Depending on the distribution of marginal willingness-to-pay for quality at equilibrium, the same construction distribution may have differentiated effects on the price of land. Symmetrically, for the same distribution of preferences, the distribution of construction along the quality gradient may have differentiated effects on the price of land. Two major lessons for the empirical section of our work can be drawn from this modelling process. On the one hand, demand for building land does not have constant elasticity as in the case of demand from homogeneous households, indifferent at any point in space (Duranton \& Puga, 2015). The inverse demand equation therefore presents interactions between the quantity and the quality of construction. On the other, the theoretical model assumes construction to be exogenous (see also Box 2). However, this is not the case in reality and the inverse demand function cannot be directly estimated using contextual data (joint evolution of quantities and prices). The evolution of the quantity of available 
housing depends on supply-side strategies (municipal building policies, etc.), which are themselves influenced by local demand. In order to remedy the problem of simultaneity inherent in any analysis of market equilibrium based on contextual data, variables which influence construction levels without having a direct impact on the equilibrium price of land are used as instrumental variables. They are presented in more detail in the next section, and in Box 3 in particular.

\section{Empirical strategy}

In line with the previous theoretical insights, we estimate the effect of construction on the price of building land through the demand of households in terms of location. The prices are assumed to be determined according to a reverse demand function which makes the unit price of land plots dependant of construction supply in the following way:

$$
\begin{gathered}
p_{i t}=\beta_{1} \cdot \theta_{c(i)}+\beta_{2} \cdot \hat{q}_{c(i)}+\beta_{3} \cdot \theta_{c(i)} \times \hat{q}_{c(i)}+W_{i t} \lambda+ \\
\alpha_{u(i)}+\eta_{t}+\varepsilon_{i t} .
\end{gathered}
$$

Variables relating to the price per square meter $p_{i t}$ of plot $i$ on date $t$, as well as to location $\theta_{c(i)}$ and to construction $\hat{q}_{c(i)}$, are specified logarithmically so that the $\beta$ coefficients can be interpreted as elasticities. These elasticities are defined conditionally to a land characteristics vector called $W_{i t}$, by annual indicators that control the cyclical macroeconomic effects $\eta_{t}$ (GDP growth, interest rate or inflation rate) and spatial fixed effects $\alpha_{u(i)}$ that control for unobserved spatial heterogeneity not observed at the scale of urban areas or employment zones according to specifications ${ }^{2}$. Construction at equilibrium and the quality gradient are measured at the municipal level and merged with the location $c(i)$ of the price observations. The municipal scale is used as this is the scale at which building permits are issued. Despite the presence of spatial fixed effects, the locations chosen could be otherwise spatially segmented (neighbourhoods of municipalities, buffer zones, etc.). In the absence of a priori theoretical assumptions, construction is measured in terms of the number of housing units constructed, constructed floor areas and areas of developed land plots. These municipal values do not have a temporal dimension and are duplicated for all observations in the same municipality, which produces a correlation between them but, using the usual assumptions, does not bias the estimated coefficients, and the errors between observations for different municipalities remain non-correlated (Angrist \& Pischke, 2008). Standard errors are corrected by clustering the estimated residuals at scale $c(i)$ of the municipalities. The quality of a location is measured by the population density in 1990 (as a proxy for accessibility to jobs and services) ${ }^{3}$.

The interaction between land quality $\theta_{c(i)}$ and construction measures $\hat{q}_{c(i)}$ in the inverse demand equation allows one to test the properties of the theoretical model described by the equations (5) in a simple manner. As such, the decrease in the inverse elasticity of demand with land quality corresponds to the restriction $\beta_{3}<0$. The increase of prices with quality corresponds to the restriction $-\beta_{1} / \beta_{3}>\hat{q}_{c(i)}$. Negativity of the price elasticity of demand corresponds to the restriction $-\beta_{2} / \beta_{3}<\theta_{c(i)}$, still for $\beta_{3}<0$. Equation (6) uses the projected values for construction $\hat{q}_{c(i)}$ rather than the actual values observed due to the simultaneity of the latter. The equation is estimated using a two-stage least squares procedure with instrumental variables derived from the soil and topographic characteristics, an exogenous measure of the opportunity cost of agriculture and the presence of former industrial sites (these variables are presented in detail in Box 3). The validity of these instruments derives from the fact that they influence construction without being determined by the price of the land. The intuition behind this strategy is to bring the empirical model closer to the theoretical model in which construction is exogenous, whereas this is typically not the case in reality. Table 2 assesses the relevance of the instruments for projecting construction. Note that these regressions are estimated at the municipal level which is the same as for construction observations and that they include the control variables for which the results are not reported. Fisher's

\footnotetext{
2. An urban area is a group of municipalities, contiguous and with out division, constituted by an urban cluster (urban unit) and by rural communes or urban units of which at least $40 \%$ of the employed resident population works in the area or in the municipalities surrounding it (https://www.insee.fr/fr/metadonnees/definition/c2070). The term, urban unit is used to refer to a municipality or group of municipalities with a continuous constructed zone (no break of more than 200 metres between two buildings), and home to at least 2,000 inhabitants (https:// www.insee.fr/fr/metadonnees/definition/c1501). An employment zone is a geographical area within which most of the active population resides and works, and in which establishments may find most of the manpower necessary for the jobs on offer (https://www.insee.fr/fr/metadonnees/ definition/c1361).

3. Robustness tests have been carried out using distances/times as a measure of location without the results changing, these estimates are available on request.
} 


\section{Box 2 - Simulation of a parametrized assignment model}

In line with the Alonso-Mills-Muth seminal model in urban economics, we assume that the quality $\theta$ of land is the distance $d$ to the city centre in an urban area of radius $\bar{x}$. For analytical reasons (growth of the assignment function) we measure the location of land based on the distance to the boundary of the urban area. The city centre is therefore located at $x=\bar{x}$ and the periphery at $x=0$. To promote understanding, the graphs in Figure A allow the distance to the city centre $x-\bar{x}$ on the $x$-axis to show the usual negative price gradients in the urban economy.

The distribution of existing land is considered to be exogenous here because alternative construction scenarios are compared. Similarly, as we are reasoning at identical total construction, the share of building permits issued $\rho$ is fixed at 1 (its effect on prices is studied in the text). The purpose of this box is to specify the roles of various

\section{Figure A}

Distribution of built land, household assignment and land prices according to three location scenarios $A, B$ and $C$

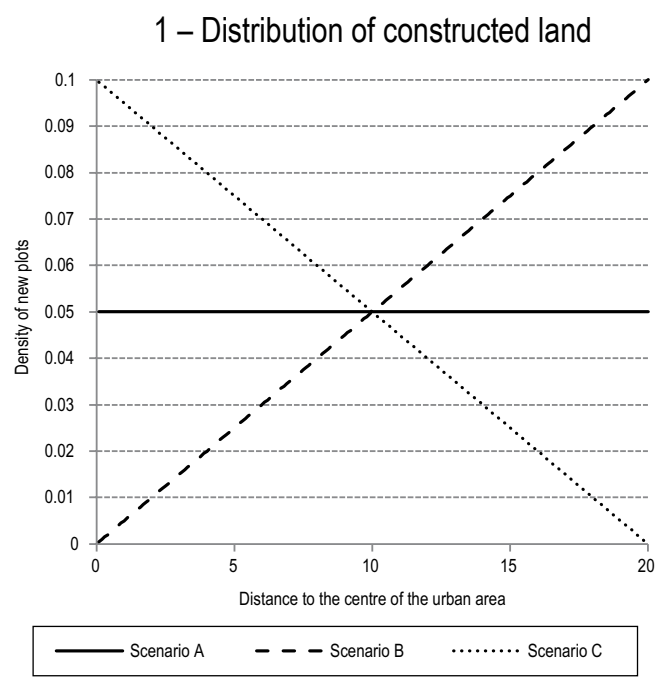

3 - Price of building land

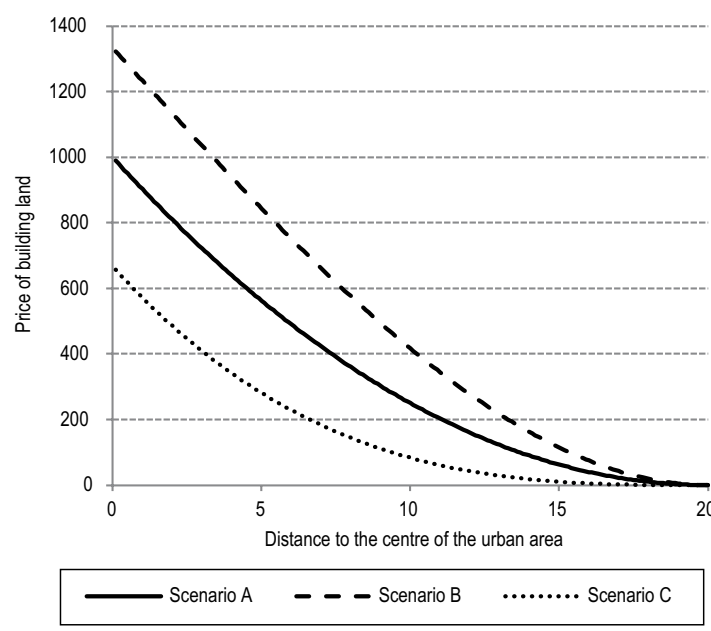

2 - Assignment of households to plots

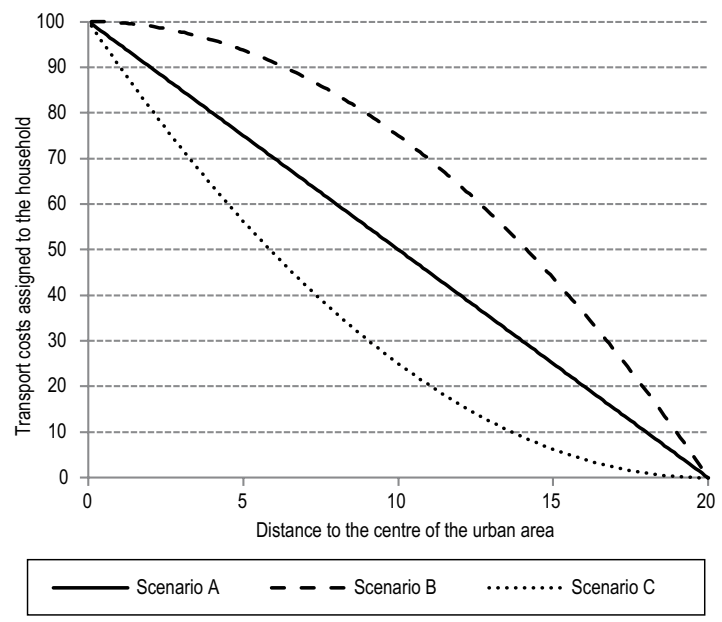

4 - Differences in land prices between scenarios

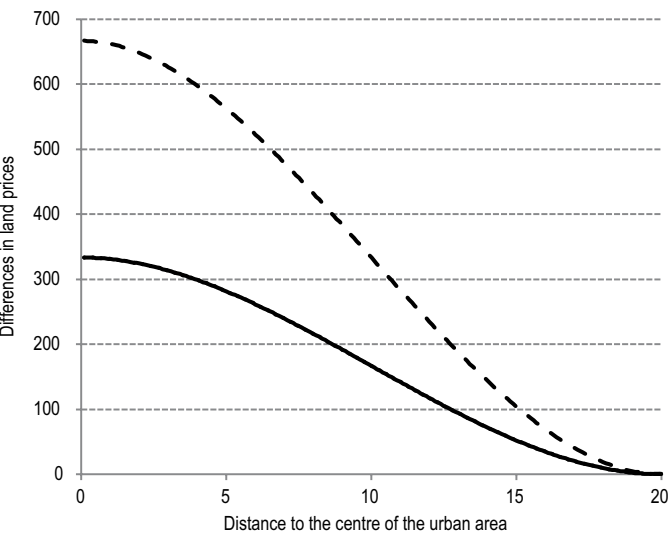

Distance to the centre of the urban area

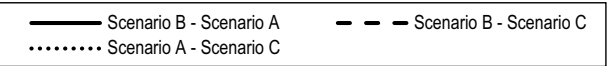

Note: The three construction scenarios A, B and C differ according to the location of building plots, while the distribution of households is identical (uniform law). The total amount of building land is normalized to 1 in all three scenarios. To simulate equilibriums, the radius of the urban area is calibrated to 20 , the maximum marginal cost of travel to 100 and the price of land is assumed to be zero at the boundary of the urban area. Note that, in part 4 of the Figure, the two upper curves overlap as the distributions are symmetrical.

Reading note: In scenario A, the spatial distribution of the plots is uniform, as are household preferences. The curves of scenario A serve as the reference. In scenario $B$, the distribution of constructed plots increases with distance (Figure A-1). This over-representation of construction around the periphery, compared to scenario $A$, leads households to be located further away: in Figure A-2, households with transport costs of 60 are further away $(12.6 \mathrm{~km})$. The relative scarcity of land near the centre (Figure A-1) leads to higher prices (Figure A-3). This price differential is more pronounced as one gets closer to the centre (Figure A-4). 
Box 2 - (contd.)

distributions of heterogeneity. We will consider three equilibrium distributions of construction $h_{M}$ corresponding to three scenarios $M=A, B$ and $C$. They all make the same amount of land constructible, but with different spatial distributions:

- Scenario A is a uniform distribution: $h_{A}(x)=1 / \bar{x}$

- Scenario B favours the periphery:

$$
h_{B}(x)=2(\bar{x}-x) / \bar{x}^{2}
$$

- Scenario $C$ favours the centre: $h_{C}(x)=2 x / \bar{x}^{2}$

Figure A-1 represents the distribution of construction in these three scenarios as a function of the distance to the centre of the urban area. Households are assumed to have logarithmic utility, exclusively drawn from the consumption of the composite good $c$ whose price is normalized to 1 . As in the more general model of the text, they consume a fixed amount of land. The heterogeneity of preferences is modelled using unit costs $\tau$ to travel to the city centre. The distribution of $\tau$ is assumed to be uniform of mass 1 in $[0, \bar{\tau}]$, and so $f(\tau)=1 / \bar{\tau}$. This heterogeneity in terms of travel costs results from different opportunity costs of the time spent in transport. Households will maximize the utility gained from non-land and non-travel consumption within the budget constraint $R \geq p(x)+\tau(\bar{x}-x)+c$, where $R$ is the earned income and $p(x)$ is the price of land. The constraint is saturated then substituted into utility to obtain the programme:

$$
\max _{x}\{U(x) \equiv \log (R-p(x)-\tau(\bar{x}-x))\} .
$$

Each household is assumed to choose the optimal location under the condition of optimality $p^{\prime}(x)=\tau$. This condition means that the marginal willingness-to-pay to build closer to the city centre is equal to the marginal cost of the trips avoided in this way. As explained in the text, the assignment function for a given scenario maps one type of household to each plot location based on the equilibrium conditions of the market. As such, noting $H_{M}(x)$ the cumulative functions associated with distributions of new building plots in scenarios $M=A, B, C$, we get:

$$
\begin{cases}\tau_{A}(x)= & (\bar{\tau} / \bar{x}) \times x \\ \tau_{B}(x)= & (\bar{\tau} / \bar{x}) \times\left(2 x-x^{2} / \bar{x}\right) \\ \tau_{c}(x)= & (\bar{\tau} / \bar{x}) \times\left(x^{2} / \bar{x}\right)\end{cases}
$$

These assignment functions are all decreasing with distance to the city centre, as is shown in Figure A-2. For scenario $A$, we get the result mentioned in the text, namely that when distributions of heterogeneity are identical, the gradient of the assignment function is constant. As such, scenario $B$, which offers relatively more land at the periphery, has an assignment function which is less decreasing. This scenario implies a greater distance of the centre for households with the same unit travel costs. Conversely, scenario $C$ produces a more decreasing assignment function than scenario $A$. Another way of interpreting the assignment functions is to draw a vertical line in Figure A-2, showing that households at a given distance have higher unit transport costs in scenario $B$ then in scenario $A$, and lastly in scenario $C$.

The optimality condition for household choices $p^{\prime}(x)=\tau$ implies that the derivative of the equilibrium price with respect to distance is given by the assignment function. The relationship between price and distance is therefore found by integrating the assignment function at a given distance $\mathrm{x}$ :

$$
\begin{cases}p_{A}(x)= & k_{A}+(\bar{\tau} / \bar{x}) \times\left(x^{2} / 2\right) \\ p_{B}(x)= & k_{B}+(\bar{\tau} / \bar{x}) \times\left(x^{2}-x^{3} / 3 \bar{x}\right) \\ p_{C}(x)= & k_{C}+(\bar{\tau} / \bar{x}) \times\left(x^{3} / 3 \bar{x}\right)\end{cases}
$$

These price functions are both decreasing and convex (cf. Figure A-3, with $k_{A}=k_{B}=k_{C}=0$ ). The assignment model also makes it possible to find the convexity of prices as a function of the distance to the city centre on the basis of linear transport costs, a standard result of the urban economy literature which has strong empirical validity. Because living close to the city centre is desirable, the relative scarcity of construction close to the city centre in scenario $B$ leads to higher prices. Conversely, the three construction scenarios have identical effects at the boundary of the urban area due to fixing the building permits issued $\rho$ to 1 and normalization of the integration constants at 0 . Figure A-4 shows the price differences between the scenarios for all distances to the centre. The symmetrical nature of the distributions implies that the price differences between scenarios $A$ and $B$ are strictly equal to the price differences between scenarios $C$ and $A$. The curves are therefore superimposed. statistics indicate that the instruments are strong compared to the thresholds typically used (approximately $F=10$, according to Angrist \& Pischke, 2008). Furthermore, the sign of Student's $t$ statistics, having the same sign as the estimated coefficients, show that the effects of the instruments are consistent with the assumptions presented in Box 3.

\section{Results}

Estimations of inverse demand functions - land prices as a function of construction, respectively measured in terms of the number of housing units authorised, floor areas authorised and artificialised areas according to 
Table 2

Fisher and Student's statistics for the instrumental variables

\begin{tabular}{|c|c|c|c|c|}
\hline & \multicolumn{4}{|c|}{ Dependent variables } \\
\hline & Number of housing units & Floor areas & Artificialised areas & Land areas \\
\hline No spatial fixed effects & $\mathrm{F}=154.1^{* \star *}$ & $\mathrm{~F}=291.2^{\star \star \star}$ & $\mathrm{F}=130.5^{\star \star *}$ & $\mathrm{~F}=265.0^{* \star *}$ \\
\hline SSC & $-3.819^{* * *}$ & $-4.68^{\star * *}$ & -1.055 & $-10.447^{\star \star \star}$ \\
\hline AGRI & $-13.751^{\star \star *}$ & $-13.976^{\star \star *}$ & $-12.304^{\star \star *}$ & $-18.988^{\star \star *}$ \\
\hline INDUS & $9.595^{\star \star \star}$ & $13.782^{\star \star \star}$ & $8.032^{\star \star \star}$ & $7.841^{\star \star *}$ \\
\hline SLOPE & $-3.146^{\star \star \star}$ & $-12.7^{\star \star *}$ & $-6.277^{\star \star \star}$ & $-0.529^{* * *}$ \\
\hline $\begin{array}{l}\text { Fixed effects } \\
\text { for urban areas }\end{array}$ & $\mathrm{F}=230.7^{\star \star *}$ & $\mathrm{~F}=354.4^{\star \star *}$ & $\mathrm{~F}=143.8^{* \star *}$ & $F=287.6^{\star \star \star}$ \\
\hline SSC & -0.349 & -1.43 & -0.24 & $-5.483^{\star \star \star}$ \\
\hline AGRI & $-14.591^{* * *}$ & $-15.034^{\star * *}$ & $-8.799^{\star \star *}$ & $-18.637^{\star \star \star}$ \\
\hline INDUS & $14.027^{\star \star *}$ & $20.07^{\star \star *}$ & $11.969^{\star \star \star}$ & $13.318^{\star * \star}$ \\
\hline SLOPE & $-6.207^{\star \star *}$ & $-7.49^{* * *}$ & $-7.694^{\star \star *}$ & $-3.862^{\star \star \star}$ \\
\hline $\begin{array}{l}\text { Fixed effects } \\
\text { in employment zones }\end{array}$ & $\mathrm{F}=129.8^{* * *}$ & $\mathrm{~F}=249.2^{* * *}$ & $\mathrm{~F}=105.3^{\star * *}$ & $F=167.2^{\star * \star}$ \\
\hline SSC & $-2.327^{\star * *}$ & $-3.278^{* * *}$ & $-2.043^{\star \star *}$ & $-3.06^{* \star *}$ \\
\hline AGRI & $-13.885^{\star * *}$ & $-14.643^{* * *}$ & $-10.062^{\star * \star}$ & $-17.896^{\star \star \star}$ \\
\hline INDUS & $13.679^{* * *}$ & $19.729^{* \star *}$ & $11.504^{* \star \star}$ & $12.878^{* \star \star}$ \\
\hline SLOPE & $-5.676^{\star * *}$ & $-7.046^{* \star *}$ & $-7.648^{\star \star *}$ & $-3.571^{* * *}$ \\
\hline
\end{tabular}

Note: The table shows Fisher's F's and Student's t's for 12 regressions, corresponding to 4 construction measures, each modelled with no fixed spatial effects, with fixed effects by urban area or with fixed effects by employment zone. The sample includes all municipalities that contain at least one observation in the EPTB. In each of the regressions, the average plot size, the population density, the mean elevation, the mean slope, and the mean year of EPTB observations are included in the control. Fisher's F's correspond to joint nullity tests of the coefficients associated with the instruments and Student t's to individual significance tests. The agricultural opportunity cost variable (AGRI) is positive for all municipalities, the shrinkage or swelling of clay hazard (SSC), the number of former industrial sites (INDUS) and the portion of the population living on slopes steeper than 10\% (SLOPE) respectively comprise 8111 (34.8\%), 21,779 (93.44\%) and $9655(41.4 \%)$ null values, which are nevertheless distributed homogeneously. Less than 3,000 municipalities have zero values for the three variables at the same time.

Reading note: Fisher's statistics reject the joint nullity of instrument coefficients in all cases. Student's statistics show that, apart from the SSC variable in urban area fixed-effect models, the instruments have a significant impact on construction measures ( ${ }^{* *}$ means significant at the $1 \%$ threshold), a negative impact for SSC, AGRI and SLOPE and a positive impact for INDUS

Coverage: Metropolitan France.

Sources: EPTB (SDES), Sit@del2 (SDES), Insee, BD ALTI (IGN), INRA, Cerema, Basias (BRGM), SSP; authors' treatments.

Cerema - are shown in Tables 3,4 , and 5. The results for areas authorised for construction are shown in Table A 2 in the Appendix. The tables present the coefficients associated with equation (6), with and without spatial fixed effects for specifications with and without interaction with the location of the land. For all models without spatial fixed effects (columns (1) and (2) in the tables) the instruments used are the SSC hazard and the agricultural opportunity cost AGRI. These instruments are strong for all specifications, they are valid in the sense of the Sargan test when construction is measured by the number of housing units without interaction (model (1) in Table 3). For models that use Sit@del2 construction measures with spatial fixed effects (shown as (3) to (6) in the tables), the instruments used are the SSC hazard and the percentage of the population located on a slope SLOPE greater than $10 \%$,. The inclusion of fixed effects significantly decreases the power of the instruments, but the Sargan tests do not allow their validity to be rejected for all of the specifications (except for the model with the authorised surface areas presented in the Appendix, Table A2). For models that use Cerema's artificialised areas with spatial fixed effects (Table 5), the instruments used are the inhabitants residing on slopes, SLOPE and the number of former industrial sites INDUS. These instruments are strong in the sense of the conditional Fisher test for all specifications, and their validity cannot be rejected (except for model (5) where validity is rejected at $5 \%$ but not at $10 \%$ ). The tables also show Moran's I statistics, which test the null hypothesis of no spatial autocorrelation of the estimated residuals. They are calculated at the scale of EPTB observations with a spatial weight matrix based on the contiguity derived from the Delaunay triangulation. They indicate the presence of significant 
spatial autocorrelation which decreases with the inclusion of spatial fixed effects and interactions. The spatial autocorrelation of residuals does not call into question the validity of the instruments nor, therefore, the absence of bias in the estimators. Its effects on statistical inference are controlled by the use of a robust cluster inference. However, spatial autocorrelation indicates the presence of spatial effects not taken into account here, but which could be analysed in future research.

The effects of control variables are relatively stable across the specifications. The price elasticity of land area is about -0.9 for models without spatial fixed effects and about -0.7 for others. Elasticities as a function of density are more heterogeneous between the specifications but are, in all cases, positive (some of this heterogeneity is only apparent as it is linked to interactions with construction). This variable captures the quality effects of the location through proximity to jobs and services. A $1 \%$ increase in population density increases the unit price of land by about $0.7 \%$ in fixedeffect models for urban areas and about $0.35 \%$ in fixed-effect models for employment zones. The coefficients associated with elevation and slope are significantly modified following the inclusion of fixed effects. Elevation has a negative effect on price and the slope no longer has a significant negative effect (values not reported). Serviced land is on average $18 \%$ more expensive, the presence of an intermediary at the time of the sale significantly increases the price, with significant variations depending on the type of intermediary (reference method is non-response). Using an estate intermediary to purchase land leads to a price increase of $23 \%$, this effect is halved with the inclusion of spatial fixed effects. Similar results are obtained when the intermediary is a constructor whereas the absence of an intermediary decreases the price, this is not always significant however.

The sign of the estimated elasticities is robust to the construction measure, the inclusion of spatial fixed effects and the instruments used. The elasticities estimated in the models without interactions ((1), (3) and (5) in each of the tables) are all significant and negative, which confirms the theoretical results: all other things equal, increasing construction decreases the price of building land. The estimated elasticities, however, show strong heterogeneity between the specifications, from -0.191 for the effect of the estimated number of authorized housing units with fixed effects by employment zone (model (5) of Table 3 )

\section{Box 3 - Instrumental variables for construction}

Four instrumental variables are assumed to influence construction without being related to land prices. The number of instruments is therefore greater than the endogenous explanatory variables to be instrumented: the models are over-identified, which makes it possible to use Sargan tests for their validity. The validity of the instruments is conditionally defined by the endogenous explanatory variable used to measure construction and the controls included in the regressions. The same instrument may be valid for some construction measures but not for others. Likewise, a valid instrument for a model without fixed effects may be invalid after the inclusion of fixed effects. This is especially the case with agricultural opportunity cost, which is exogenous at the national level but correlates to the residuals of the price equation within urban areas and employment zones. Descriptive statistics for the instruments are shown at the bottom of Table 1.

\section{Shrinkage/swelling of clay hazard (SSC)}

The SSC hazard is a characteristic of soils which affects construction due to ground stability effects. It increases construction costs and is the second largest natural disaster compensation item affecting individual houses. It therefore causes additional insurance costs, while the fact that it is natural in origin makes it non-sensitive to land prices. This is a construction datum that cannot be modified in areas where land prices are high. SSC hazard maps are produced by the BRGM and available online (http:// www.georisques.gouv.fr/dossiers/alea-retrait-gonflement-des-argiles). Higher hazard levels affect $2 \%$ of metropolitan France $\left(10,600 \mathrm{~km}^{2}\right)$, medium hazard levels affect $15 \%\left(83,800 \mathrm{~km}^{2}\right)$, and low levels affect $44 \%\left(241,300 \mathrm{~km}^{2}\right)$. Areas that are a priori non-clayey, cover $39 \%$ of metropolitan France $\left(212,800 \mathrm{~km}^{2}\right)$. We use the portion of the municipal area with medium or high SSC hazards to instrument construction. To our knowledge, this instrument is original in the literature. Given its impact on construction and insurance costs, negative effects in the first stage of instrumentation are expected.

Share of the population living on steep slopes (SLOPE)

As with the SSC hazard, the slope of a plot hinders construction due to its impact on costs, while its 
Box 3 - (contd.)

natural origin makes it a potential instrument. The distribution of slopes at the national scale is calculated using the BD ALTI model, available at a resolution of 75 meters on the IGN website (http://professionnels. ign.fr/bdalti). The distribution of the slopes was combined with the 200 metre gridded population data from Insee (https://www.insee.fr/fr/statistiques/2520034) to calculate, at the municipal level, the portion of the population living on slopes between 10 and $15 \%$, and the portion of the population living on slopes greater than $15 \%$. A similar procedure to strengthen the power of topography for identification is being implemented by Saiz (2010). The idea of using the slope to explain construction is also present in Burchfield et al. (2006) and Hilber and Vermeulen (2016), where it is measured as the difference between the maximum altitude and the minimum altitude of the spatial unit, unless better data is available. A negative effect of this variable is expected in the first stage.

\section{Standard gross agricultural income (AGRI)}

Housing and agriculture compete for the scarce land resources. It follows that the agricultural production that would have occurred in the absence of construction constitutes an opportunity cost of said construction. However, this effect is difficult to measure because housing construction influences agricultural activity, and therefore the measure of opportunity cost (Cavailhès et al., 2011a). The instrumental variable AGRI must therefore represent the agricultural value of the land regardless of the effects of land prices over the period the prices are studied (1995-2014). To do this, we consider an earlier measure (1988) of the agricultural specialization of each region, the farms being classified according to their main technical-economic orientation, OTEX ${ }^{(a)}$. It is then possible to calculate local agricultural growth rates, which are exogenous to the local evolution of land prices, by multiplying the 1988 specialization by the national growth rates of the same OTEX over the period 1989-2014. By noting $l_{i s}^{88}$ the portion of OTEX $s$ in region $j$ in 1988 and $g_{s}$ the 1989-2014 national growth rate for OTEX $s$, the instrument is written as:

$$
\widehat{A G R I}_{j}=\sum_{s} I_{j s}^{88} \cdot g_{s}
$$

The literature attributes the origin of the use of such instruments to Bartik (1991) (characterized as shift and share by Baum-Snow \& Ferreira, 2015). The source of identification comes from initial agricultural specializations that impact the resistance of agriculture to construction. The validity of this instrument is based on the a priori assumption that agricultural specializations in 1988 do not depend on recent land dynamics (or any other variable that could be correlated with these dynamics). This type of instrument has been extensively used in the literature (see in particular Saiz, 2010; Hilber \& Vermeulen, 2016; Combes et al., 2016a) for local labour markets (demand variations), but not for land markets (variations in the offer). A negative effect of this instrument is expected in the first stage of instrumentation.

\section{Number of old industrial sites (INDUS)}

Like agriculture, industry is facing national and international shocks that affect its profitability regardless of the local context, in particular the land market. Industries are facing technological shocks that lead to cessation of business, so freeing up construction land (gas plants, printing plants, etc.). Former industrial activities and service activities have been systematically inventoried since 1994. The data collected for these inventories are archived in a national database, Basias (Base des Anciens Sites Industriels et Activités de Service) ${ }^{(b)}$. We can use the number of old industrial sites as an instrument at the municipal level. Due to effects of externality and the local labour market, the presence of a former industrial site can have a negative effect on construction and housing prices. We can, however, evaluate the net effect in the first stage as, on the one hand, release of the land should have a positive effect on construction and, on the other, externalities should have a negative effect. The estimation of a positive effect in the first stage indicates that the effects of externalities are relatively less important.

(a) OTEX classification of farms is done by the SSP (Service de la Statistique et de la Prospective, Ministère de l'Agriculture et de l'Alimentation) using standard gross production (SGP). The classification distinguishes 11 activities (field crops, market gardening and horticulture, viticulture, fruits, milk, cattle breeding and meat, milk, combined cattle breeding and meat, other herbivores, granivores, polyculturepolyseeding, other). SGP is calculated by valuing the cultivated areas and herds belonging to each farm according to coefficients which do not constitute observed financial results. They must be considered as orders of magnitude defining the potential production of the farm per hectare or head of livestock present, excluding all types of assistance. (b) Available online http://www.georisques.gouv.fr/dossiers/inventairehistorique-des-sites-industrie/s-et-activites-en-service-basias\#/ to -0.743 for the effect of floor areas authorised for construction with fixed effects by large urban area (model (3) in Table 4). Most of the estimated elasticities, however, do not significantly differ from -0.3. It appears that, among the construction measures from Sit@del2, the floor area construction produces the most significant effects on prices.
The construction of floor areas (cf. Table 4) has larger effects (in levels) on the price of land relative to the number of housing units (Table 3) and the surface area of the land authorized for construction (Appendix, Table A-2). They therefore appear to be more relevant levers for public policies that seek to create supply shocks. Cerema's artificialised 
Table 3

Inverse demand equations in number of authorised housing units

\begin{tabular}{|c|c|c|c|c|c|c|}
\hline & \multicolumn{6}{|c|}{ Dependent variable: Log of price per ha of land, two-stage least squares estimate } \\
\hline & (1) & $(2)$ & (3) & (4) & $(5)$ & (6) \\
\hline $\begin{array}{l}\text { Population density } \\
(\log )\left[\beta_{1}\right]\end{array}$ & $\begin{array}{l}0.434^{* * *} \\
(0.040)\end{array}$ & $\begin{array}{l}0.703^{* * *} \\
(0.038)\end{array}$ & $\begin{array}{l}0.621^{* * *} \\
(0.087)\end{array}$ & $\begin{array}{l}0.638^{* * *} \\
(0.045)\end{array}$ & $\begin{array}{l}0.337^{* * *} \\
(0.071)\end{array}$ & $\begin{array}{l}0.364^{* * *} \\
(0.052)\end{array}$ \\
\hline $\begin{array}{l}\text { Constructed housing units } \\
\text { (log) }\left[\beta_{2}\right]\end{array}$ & $\begin{array}{c}-0.302^{* * *} \\
(0.056)\end{array}$ & $\begin{array}{l}-0.101^{* *} \\
(0.045)\end{array}$ & $\begin{array}{c}-0.552^{* * *} \\
(0.108)\end{array}$ & $\begin{array}{c}-0.363^{* * *} \\
(0.055)\end{array}$ & $\begin{array}{l}-0.191^{* *} \\
(0.088)\end{array}$ & $\begin{array}{l}-0.006 \\
(0.062)\end{array}$ \\
\hline $\begin{array}{l}\text { Housing units } x \text { density } \\
(\log )\left[\beta_{3}\right]\end{array}$ & & $\begin{array}{c}-0.043^{* * *} \\
(0.004)\end{array}$ & & $\begin{array}{c}-0.043^{* * *} \\
(0.003)\end{array}$ & & $\begin{array}{c}-0.045^{\star * *} \\
(0.003)\end{array}$ \\
\hline Surface area of the plot (log) & $\begin{array}{c}-0.932^{* * *} \\
(0.015)\end{array}$ & $\begin{array}{c}-0.926^{* * *} \\
(0.011)\end{array}$ & $\begin{array}{c}-0.753^{* * *} \\
(0.017)\end{array}$ & $\begin{array}{c}-0.752^{* * *} \\
(0.009)\end{array}$ & $\begin{array}{c}-0.694^{* * *} \\
(0.015)\end{array}$ & $\begin{array}{c}-0.695^{\star * *} \\
(0.011)\end{array}$ \\
\hline Serviced land $(0-1)$ & $\begin{array}{l}0.187^{* * *} \\
(0.009)\end{array}$ & $\begin{array}{l}0.182^{* * *} \\
(0.007)\end{array}$ & $\begin{array}{l}0.203^{* * *} \\
(0.007)\end{array}$ & $\begin{array}{l}0.201^{* * *} \\
(0.004)\end{array}$ & $\begin{array}{l}0.188^{* * *} \\
(0.005)\end{array}$ & $\begin{array}{l}0.186^{* * *} \\
(0.004)\end{array}$ \\
\hline Agency $(0-1)$ & $\begin{array}{l}0.236^{* * *} \\
(0.012)\end{array}$ & $\begin{array}{l}0.233^{* * *} \\
(0.010)\end{array}$ & $\begin{array}{l}0.113^{* * *} \\
(0.010)\end{array}$ & $\begin{array}{l}0.114^{* * *} \\
(0.007)\end{array}$ & $\begin{array}{l}0.095^{* * *} \\
(0.008)\end{array}$ & $\begin{array}{l}0.095^{\star * *} \\
(0.007)\end{array}$ \\
\hline Constructor $(0-1)$ & $\begin{array}{l}0.027^{* * *} \\
(0.010)\end{array}$ & $\begin{array}{l}0.026^{* * *} \\
(0.009)\end{array}$ & $\begin{array}{c}0.013 \\
(0.009)\end{array}$ & $\begin{array}{l}0.011^{*} \\
(0.006)\end{array}$ & $\begin{array}{l}0.021^{* * *} \\
(0.007)\end{array}$ & $\begin{array}{c}0.019 * * * \\
(0.006)\end{array}$ \\
\hline Other intermediary (0-1) & $\begin{array}{c}-0.00004 \\
(0.010)\end{array}$ & $\begin{array}{l}-0.003 \\
(0.008)\end{array}$ & $\begin{array}{l}0.029 * * * \\
(0.008)\end{array}$ & $\begin{array}{c}0.027^{* * *} \\
(0.006)\end{array}$ & $\begin{array}{c}0.031^{* * *} \\
(0.007)\end{array}$ & $\begin{array}{c}0.028^{* * *} \\
(0.006)\end{array}$ \\
\hline No intermediary $(0-1)$ & $\begin{array}{c}-0.050^{* * *} \\
(0.009)\end{array}$ & $\begin{array}{c}-0.051^{* * *} \\
(0.008)\end{array}$ & $\begin{array}{l}-0.018^{* *} \\
(0.009)\end{array}$ & $\begin{array}{c}-0.019^{* * *} \\
(0.006)\end{array}$ & $\begin{array}{l}-0.007 \\
(0.007)\end{array}$ & $\begin{array}{l}-0.008 \\
(0.006)\end{array}$ \\
\hline COND. F & $109.379^{\star * *}$ & $109.379^{\star * *}$ & $29.245^{\star * *}$ & $29.245^{\star * *}$ & $29.064^{\star * \star}$ & $29.064^{\star * *}$ \\
\hline SARGAN & 0.137 & $0^{* * *}$ & 0.245 & 0.97 & $0.058^{*}$ & 0.74 \\
\hline SSC F & $30.782^{\star * *}$ & $30.782^{\star \star *}$ & $16.809^{* * *}$ & $16.809^{* * *}$ & $22.98^{\star * \star}$ & $22.98^{* * *}$ \\
\hline AGRI F & $103.325^{\star \star \star}$ & $103.325^{\star \star \star}$ & & & & \\
\hline SLOPE F & & & $47.946^{\star * *}$ & $47.946^{\star * *}$ & $19.135^{\star \star \star}$ & $19.135^{\star \star \star}$ \\
\hline Moran's I & $0.556^{* \star *}$ & $0.514^{* \star *}$ & $0.413^{\star * *}$ & $0.260^{\star \star \star}$ & $0.315^{\star \star \star}$ & $0.252^{\star \star \star}$ \\
\hline Fixed effects & & & UA & UA & $E Z$ & $E Z$ \\
\hline Observations & 279,215 & 279,215 & 279,215 & 279,215 & 279,215 & 279,215 \\
\hline Residual standard deviation & 0.685 & 0.578 & 0.607 & 0.418 & 0.46 & 0.411 \\
\hline
\end{tabular}

Notes: All models include indicator variables for the year of purchase of the land, and elevation and slope deciles for the plots. Included fixed effects are for large urban areas (UA, N = 230) and employment zones (EZ, N = 320). Box 3 presents the instruments, SSC for shrinkage/ swelling of clay, AGRI for the exogenous agricultural opportunity cost and SLOPE for housing units located on slopes greater than $15 \%$. Fisher's tests are identical side by side because the first steps of instrumentation are identical. The additional online complement table shows the ordinary least squares estimates and coefficients estimated in the first step of instrumentation. The strength of the instruments is measured by Ficher's statistics (COND. F, Sanderson \& Windmeijer, 2016). The table shows the critical value (p-value) of the SARGAN associated with the null hypothesis of validity of the instruments. The Moran l's are calculated using the estimated residuals and test their spatial autocorrelation on the basis of contiguity matrices. statistical inference is obtained using 1,000 permutations. For the variables relating to the presence of an intermediary, the reference method is non-response. Standard deviations are clustered at the common level. ${ }^{*} p<0.1 ;{ }^{* *} p<0.05 ;{ }^{* * *} p<0.01$.

Coverage: Metropolitan France.

Sources: EPTB (SDES), Sit@del2 (SDES), Insee, BD ALTI (IGN), Cerema, Basias (BRGM), SSP; authors' treatments.

areas show the most stable effects between the specifications, between -0.288 and -0.348 . The values of these elasticities are close to the elasticities obtained for the construction of floor areas, apart from model (3) in Table 4 , the high value of which can be explained by the low explanatory power of the instruments. The conditional Fisher test is, however, significant.
The estimated elasticity of -0.3 confirms that the construction of new housing can reduce the price of building land; however, this value is relatively small in absolute value, indicating that this lever is only moderately effective. Online complement tables C-1, C-2, C-3 and $\mathrm{C}-4$ show the elasticities estimated by models that do not take into account the endogeneity of construction. These models are estimated 
using OLS and show that the coefficients of the construction effect on the building land prices are positive (regardless of the construction measure or the presence of spatial fixed effects). This result is related to the location of construction, preferably in the places requested and therefore valued (Geniaux et $a l ., 2015)$. Our instrumental variable identification strategy corrects the endogeneity bias and estimates the negative effects of construction demand on the price of building land. This change in sign of the elasticities illustrates the importance of controlling the coefficients obtained by OLS of the endogeneity of construction resulting from the simultaneity of the observed equilibria. The tables in the Online complement also present the first steps of instrumentation. For a given construction variable and fixed effect type, models both with and without interactions are based on these same first steps.

In each of Tables $3,4,5$, and A2, columns (2), (4) and (6) show the interaction coefficients between construction and a location measure based on population density. The coefficients associated with interaction show high stability between the specifications for a given construction measure and, to a lesser extent, between the construction measures

Table 4

Inverse demand equations for authorised floor areas

\begin{tabular}{|c|c|c|c|c|c|c|}
\hline & \multicolumn{6}{|c|}{ Dependent variable: Log of price per ha of land, two-stage least squares estimate } \\
\hline & (1) & (2) & (3) & (4) & (5) & (6) \\
\hline $\begin{array}{l}\text { Population density } \\
\text { (log) }\left[\beta_{1}\right]\end{array}$ & $\begin{array}{c}0.426^{* * *} \\
(0.038)\end{array}$ & $\begin{array}{l}0.908^{* * *} \\
(0.054)\end{array}$ & $\begin{array}{c}0.746^{\star * \star} \\
(0.132)\end{array}$ & $\begin{array}{l}0.763^{* * \star} \\
(0.057)\end{array}$ & $\begin{array}{c}0.356^{\star \star *} \\
(0.082)\end{array}$ & $\begin{array}{l}0.388^{* \star *} \\
(0.057)\end{array}$ \\
\hline $\begin{array}{l}\text { Authorised floor areas } \\
\text { (log) }\left[\beta_{2}\right]\end{array}$ & $\begin{array}{l}-0.300^{\star \star \star} \\
(0.054)\end{array}$ & $\begin{array}{c}-0.093^{* *} \\
(0.046)\end{array}$ & $\begin{array}{c}-0.743^{* * *} \\
(0.173)\end{array}$ & $\begin{array}{l}-0.546^{\star \star \star} \\
(0.073)\end{array}$ & $\begin{array}{l}-0.225^{* *} \\
(0.106)\end{array}$ & $\begin{array}{l}-0.038 \\
(0.071)\end{array}$ \\
\hline $\begin{array}{l}\text { Authorised surface areas } x \text { Density } \\
(\log )\left[\beta_{3}\right]\end{array}$ & & $\begin{array}{c}-0.044^{* \star *} \\
(0.004)\end{array}$ & & $\begin{array}{l}-0.044^{\star \star \star} \\
(0.003)\end{array}$ & & $\begin{array}{c}-0.046^{* * *} \\
(0.003)\end{array}$ \\
\hline Surface area of the plot $(\log )$ & $\begin{array}{l}-0.928^{* * *} \\
(0.014)\end{array}$ & $\begin{array}{c}-0.921^{* * *} \\
(0.011)\end{array}$ & $\begin{array}{c}-0.765^{\star * *} \\
(0.022)\end{array}$ & $\begin{array}{l}-0.764^{\star \star \star} \\
(0.010)\end{array}$ & $\begin{array}{c}-0.695^{\star * *} \\
(0.015)\end{array}$ & $\begin{array}{l}-0.696^{* \star *} \\
(0.011)\end{array}$ \\
\hline Serviced land $(0-1)$ & $\begin{array}{l}0.188^{* * *} \\
(0.009)\end{array}$ & $\begin{array}{l}0.183^{* *} \\
(0.007)\end{array}$ & $\begin{array}{l}0.217^{\star \star *} \\
(0.011)\end{array}$ & $\begin{array}{l}0.215^{\star \star *} \\
(0.005)\end{array}$ & $\begin{array}{l}0.191^{* * *} \\
(0.007)\end{array}$ & $\begin{array}{l}0.189^{\star * *} \\
(0.005)\end{array}$ \\
\hline Agency $(0-1)$ & $\begin{array}{l}0.233^{* * *} \\
(0.012)\end{array}$ & $\begin{array}{l}0.231^{* * *} \\
(0.010)\end{array}$ & $\begin{array}{l}0.122^{* * *} \\
(0.012)\end{array}$ & $\begin{array}{l}0.123^{* *} \\
(0.007)\end{array}$ & $\begin{array}{c}0.097^{\star * *} \\
(0.008)\end{array}$ & $\begin{array}{l}0.098^{\star * *} \\
(0.007)\end{array}$ \\
\hline Constructor $(0-1)$ & $\begin{array}{l}0.026^{* *} \\
(0.010)\end{array}$ & $\begin{array}{l}0.025^{* * *} \\
(0.009)\end{array}$ & $\begin{array}{l}0.010 \\
(0.011)\end{array}$ & $\begin{array}{c}0.008 \\
(0.006)\end{array}$ & $\begin{array}{l}0.021^{* * *} \\
(0.007)\end{array}$ & $\begin{array}{l}0.018^{* * *} \\
(0.006)\end{array}$ \\
\hline Other intermediary $(0-1)$ & $\begin{array}{l}0.005 \\
(0.010)\end{array}$ & $\begin{array}{c}0.002 \\
(0.008)\end{array}$ & $\begin{array}{l}0.036^{* * *} \\
(0.010)\end{array}$ & $\begin{array}{l}0.034^{* * *} \\
(0.006)\end{array}$ & $\begin{array}{l}0.033^{* *} \\
(0.007)\end{array}$ & $\begin{array}{l}0.031^{* * *} \\
(0.006)\end{array}$ \\
\hline No intermediary (0-1) & $\begin{array}{c}-0.047^{\star \star *} \\
(0.009)\end{array}$ & $\begin{array}{c}-0.047^{\star \star *} \\
(0.008)\end{array}$ & $\begin{array}{l}-0.019^{*} \\
(0.010)\end{array}$ & $\begin{array}{l}-0.020^{\star \star \star} \\
(0.006)\end{array}$ & $\begin{array}{l}-0.006 \\
(0.007)\end{array}$ & $\begin{array}{l}-0.008 \\
(0.006)\end{array}$ \\
\hline COND. F & $120.393^{\star * \star}$ & $120.393^{\star \star \star}$ & $17.05^{\star \star \star}$ & $17.05^{\star \star \star}$ & $22.721^{\star \star \star}$ & $22.721^{\star \star \star}$ \\
\hline SARGAN & $0.016^{* *}$ & $0^{* * *}$ & 0.18 & 0.927 & 0.292 & 0.784 \\
\hline SSC F & $28.986^{* * *}$ & $28.986^{\star * *}$ & $9.827^{* *}$ & $9.827^{\star *}$ & $16.792^{* * *}$ & $16.792^{* \star *}$ \\
\hline AGRI F & $119.481^{* * *}$ & $119.481^{* * *}$ & & & & \\
\hline SLOPE F & & & $28.985^{* * *}$ & $28.985^{* * *}$ & $21.48^{\star * *}$ & $21.48^{* * *}$ \\
\hline Moran's I & $0.551^{* * *}$ & $0.514^{\star \star *}$ & $0.445^{\star \star \star}$ & $0.260^{\star \star \star}$ & $0.328^{\star \star *}$ & $0.252^{\star \star *}$ \\
\hline Fixed effects & & & UA & UA & $E Z$ & EZ \\
\hline Observations & 279,215 & 279,215 & 279,215 & 279,215 & 279,215 & 279,215 \\
\hline Residual standard deviation & 0.682 & 0.578 & 0.702 & 0.418 & 0.473 & 0.411 \\
\hline
\end{tabular}

Notes: cf. Table 3

Coverage: Metropolitan France.

Sources: EPTB (SDES), Sit@del2 (SDES), Insee, BD ALTI (IGN), Cerema, Basias (BRGM), SSP; authors' treatments. 
themselves. The interaction effects are all negative and significant, which confirms the results of the theoretical model. As accessibility of jobs and services (approximated by population density) is a desirable feature of the land plots, increasing construction has stronger price effects in absolute terms in more densely populated areas. For construction measured in number of housing units and authorized floor areas, the cross effects of density amount to -0.045 , whereas for construction measured in land area (according to Cerema and Sit@del2) they are in the order of -0.075 . This indicates that a $10 \%$ increase in construction decreases the price of building plots by $0.45 \%$ and $0.75 \%$ respectively in the top $10 \%$ most dense areas. Table 6 reports the different elasticities of construction for different density values, they come from models with effects fixed to employment zones (i.e. column (6) of the results tables). The median values are close to the elasticities obtained in the models without interactions (i.e. $\beta_{2}$ in columns (1) of the results tables). The values of these elasticities remain low, apart from the floor areas which always have a stronger effect on prices. It appears, for all construction measures, that the elasticity is higher in municipalities in the ninth density decile (387 inhab. $/ \mathrm{km}^{2}$ ) compared to those of the first decile (26 inhab. $\left./ \mathrm{km}^{2}\right)$, about 0.1 in absolute value.

Table 5

Inverse demand equations for artificialised areas

\begin{tabular}{|c|c|c|c|c|c|c|}
\hline & \multicolumn{6}{|c|}{ Dependent variable: Log of price per ha of land, two-stage least squares estimate } \\
\hline & (1) & (2) & (3) & (4) & (5) & (6) \\
\hline Population density $(\log )\left[\beta_{1}\right]$ & $\begin{array}{l}0.318^{\star * *} \\
(0.018)\end{array}$ & $\begin{array}{l}1.204^{* * *} \\
(0.087)\end{array}$ & $\begin{array}{c}0.331^{\star * *} \\
(0.020)\end{array}$ & $\begin{array}{c}0.297^{\star \star *} \\
(0.013)\end{array}$ & $\begin{array}{c}0.317^{* \star *} \\
(0.022)\end{array}$ & $\begin{array}{c}0.278^{\star \star *} \\
(0.014)\end{array}$ \\
\hline Artificialised areas $(\log )\left[\beta_{2}\right]$ & $\begin{array}{c}-0.288^{\star * *} \\
(0.052)\end{array}$ & $\begin{array}{c}0.053 \\
(0.052)\end{array}$ & $\begin{array}{c}-0.348^{* * *} \\
(0.047)\end{array}$ & $\begin{array}{l}0.080^{*} \\
(0.041)\end{array}$ & $\begin{array}{c}-0.319^{\star * *} \\
(0.050)\end{array}$ & $\begin{array}{c}0.131^{* * *} \\
(0.045)\end{array}$ \\
\hline Surface areas $x$ Density $(\log )\left[\beta_{3}\right]$ & & $\begin{array}{c}-0.074^{\star * *} \\
(0.007)\end{array}$ & & $\begin{array}{c}-0.068^{\star \star *} \\
(0.005)\end{array}$ & & $\begin{array}{c}-0.071^{* * *} \\
(0.005)\end{array}$ \\
\hline Surface area of the plot $(\log )$ & $\begin{array}{c}-0.874^{* * *} \\
(0.008)\end{array}$ & $\begin{array}{c}-0.870^{\star \star *} \\
(0.006)\end{array}$ & $\begin{array}{c}-0.694^{* * *} \\
(0.006)\end{array}$ & $\begin{array}{c}-0.683^{* \star *} \\
(0.005)\end{array}$ & $\begin{array}{c}-0.690^{* \star *} \\
(0.007)\end{array}$ & $\begin{array}{c}-0.676^{\star \star \star} \\
(0.005)\end{array}$ \\
\hline Serviced land (0-1) & $\begin{array}{c}0.216^{\star \star \star} \\
(0.014)\end{array}$ & $\begin{array}{l}0.211^{* * *} \\
(0.010)\end{array}$ & $\begin{array}{c}0.221^{* \star *} \\
(0.008)\end{array}$ & $\begin{array}{l}0.202^{\star \star \star} \\
(0.005)\end{array}$ & $\begin{array}{l}0.221^{* * *} \\
(0.008)\end{array}$ & $\begin{array}{c}0.201^{* * *} \\
(0.005)\end{array}$ \\
\hline Agency (0-1) & $\begin{array}{l}0.205^{\star \star \star} \\
(0.010)\end{array}$ & $\begin{array}{c}0.203^{* \star *} \\
(0.009)\end{array}$ & $\begin{array}{l}0.084^{* * *} \\
(0.008)\end{array}$ & $\begin{array}{c}0.086^{\star \star \star} \\
(0.006)\end{array}$ & $\begin{array}{l}0.083^{* * *} \\
(0.008)\end{array}$ & $\begin{array}{l}0.083^{* * *} \\
(0.006)\end{array}$ \\
\hline Constructor (0-1) & $\begin{array}{l}0.037^{* * *} \\
(0.010)\end{array}$ & $\begin{array}{c}0.036^{\star * *} \\
(0.009)\end{array}$ & $\begin{array}{c}0.030^{* * *} \\
(0.008)\end{array}$ & $\begin{array}{c}0.026^{* \star *} \\
(0.006)\end{array}$ & $\begin{array}{l}0.031^{* * *} \\
(0.008)\end{array}$ & $\begin{array}{c}0.027^{* * *} \\
(0.006)\end{array}$ \\
\hline Other intermediary $(0-1)$ & $\begin{array}{c}0.003 \\
(0.009)\end{array}$ & $\begin{array}{c}0.002 \\
(0.008)\end{array}$ & $\begin{array}{l}0.027^{* \star *} \\
(0.008)\end{array}$ & $\begin{array}{c}0.025^{\star \star *} \\
(0.006)\end{array}$ & $\begin{array}{l}0.032^{\star \star *} \\
(0.008)\end{array}$ & $\begin{array}{c}0.029^{* \star *} \\
(0.006)\end{array}$ \\
\hline No intermediary (0-1) & $\begin{array}{c}-0.059^{* * *} \\
(0.010)\end{array}$ & $\begin{array}{c}-0.059^{* * *} \\
(0.008)\end{array}$ & $\begin{array}{c}-0.026^{* * *} \\
(0.008)\end{array}$ & $\begin{array}{c}-0.019^{\star \star \star} \\
(0.006)\end{array}$ & $\begin{array}{l}-0.019^{* *} \\
(0.008)\end{array}$ & $\begin{array}{c}-0.013^{\star *} \\
(0.006)\end{array}$ \\
\hline COND. F & $74.724^{* * *}$ & $74.724^{\star * *}$ & $73.864^{* \star *}$ & $73.864^{* * *}$ & $69.139^{\star * \star}$ & $69.139^{* * *}$ \\
\hline SARGAN & $0.003^{\star *}$ & $0^{* \star *}$ & 0.587 & 0.616 & $0.008^{* *}$ & 0.616 \\
\hline SSC F & $18.301^{* * *}$ & $18.301^{* * *}$ & & & & \\
\hline AGRI F & $80.942^{\star * *}$ & $80.942^{* \star *}$ & & & & \\
\hline INDUS F & & & $70.67^{\star \star *}$ & $70.67^{\star \star \star}$ & $68.617^{* * *}$ & $68.617^{\star \star *}$ \\
\hline SLOPE F & & & $66.463^{\star \star *}$ & $66.463^{\star \star \star}$ & $56.178^{\star \star \star}$ & $56.178^{\star \star \star}$ \\
\hline Moran's I & $0.551^{* * *}$ & $0.513^{* * *}$ & $0.462^{\star \star *}$ & $0.260^{\star \star \star}$ & $0.358^{* \star *}$ & $0.252^{\star * *}$ \\
\hline Fixed effects & & & UA & UA & EZ & EZ \\
\hline Observations & 279,215 & 279,215 & 279,215 & 279,215 & 279,215 & 279,215 \\
\hline Residual standard deviation & 0.67 & 0.578 & 0.544 & 0.418 & 0.527 & 0.41 \\
\hline
\end{tabular}

Notes: cf. Table 3.

Coverage: Metropolitan France.

Sources: EPTB (SDES), Sit@del2 (SDES), Insee, BD ALTI (IGN), Cerema, Basias (BRGM), SSP; authors' treatments. 
Table 6

Summary table for the elasticities of inverse demand for building land

\begin{tabular}{|l|c|c|c|c|c|}
\hline \multirow{4}{*}{} & \multicolumn{5}{|c|}{ Municipal population density in 1990 (inhab./km²) } \\
\cline { 2 - 6 } & D1 & Q1 & Median & Q3 & D9 \\
& 26.5 & 44.3 & 85.2 & 178.2 & 387.1 \\
\hline Number of housing units authorised & -0.241 & -0.263 & -0.291 & -0.323 & -0.356 \\
& {$[-0.28 ;-0.20]$} & {$[-0.31 ;-0.22]$} & {$[-0.33 ;-0.25]$} & {$[-0.37 ;-0.28]$} & {$[-0.40 ;-0.31]$} \\
Authorised floor areas & -0.503 & -0.525 & -0.553 & -0.585 & -0.618 \\
& {$[-0.55 ;-0.46]$} & {$[-0.57 ;-0.48]$} & {$[-0.60 ;-0.51]$} & {$[-0.63 ;-0.54]$} & {$[-0.67 ;-0.57]$} \\
Developed areas & -0.152 & -0.175 & -0.204 & -0.237 & -0.272 \\
& {$[-0.23 ;-0.08]$} & {$[-0.25 ;-0.10]$} & {$[-0.28 ;-0.13]$} & {$[-0.31 ;-0.16]$} & {$[-0.35 ;-0.2]$} \\
Land areas & -0.237 & -0.260 & -0.288 & -0.32 & -0.354 \\
& {$[-0.28 ;-0.19]$} & {$[-0.30 ;-0.22]$} & {$[-0.33 ;-0.24]$} & {$[-0.36 ;-0.28]$} & {$[-0.4 ;-0.31]$} \\
\hline
\end{tabular}

Note: The models used to calculate the elasticities include fixed effects for the employment zones, these are the $(6)$ columns of Tables $3,4,5$ and A2. The confidence intervals of the elasticities are at the $95 \%$ threshold and calculated using the asymptotic delta method with a clustered variance/covariance matrix at the municipal scale. D1 and D9 represent the thresholds of the first and last deciles of municipal population density, $\mathrm{Q} 1$ and $\mathrm{Q} 3$ are the thresholds of the first and last quartiles.

Reading note: a $10 \%$ increase in the number of dwellings decreases the price of land by $2.41 \%$ in a municipality in the lower population density decile and by $3.56 \%$ in a municipality in the upper decile.

Coverage: Metropolitan France.

Sources: EPTB (SDES), Sit@del2 (SDES), Insee, BD ALTI (IGN), Cerema, Basias (BRGM), SSP; authors' treatments.

* *

In a context of significant increases in the price of built land and the costs of new housing construction, this article shows that the issuance of building permits does have significant negative effects on the price of land. This means that household demand is price elastic. However, the measured effect on prices is relatively small, the elasticity of inverse demand is, on average, less than 0.5 (in absolute value). These small estimated values vary with two important determinants, the construction measure and the location of the land. Firstly, the price response is larger (in absolute terms) for a relative change in floor areas authorised for construction than for the same relative change in the number of housing units authorised, or the artificialised area. Secondly, whatever the measure of construction, the denser the area of location, the more the variations will have an impact on prices. These results are to be put in perspective with households' preferences. An increase in available floor area appears to be a construction quality which is highly valued by households; this therefore has a more important role to play in lowering land prices. This interpretation is also valid for the location of the construction, where, more than the total quantity, the proximity of the housing units to jobs and services is a decisive element to consider in order to implement an effective supply shock.
This article highlights two important determinants for reducing the weight of land in new housing construction costs. Others should also be studied, such as zoning and infrastructure land policies, as well as strategies used by owners of building land. The issuance of building permits is not the only regulatory tool available to policy-makers. The effects of planning documents - which constrain the use of land - on land prices, and the establishment of density limits for construction, should also be subject to economic assessments. However, our results provide additional explanations for the weak correlations observed between construction and the prices of land and housing - low elasticity of inverse demand - whereas the academic and specialized literature usually invokes supply restrictions as stemming from regulatory constraints on construction (zoning in particular). Furthermore, the link between the price of land and density also depends on the types of housing built on it, which would also merit a special study.

Finally, it should be borne in mind that lower land prices due to construction do not necessarily improve households' well-being. The virtuous effects on the price of building land are of a low order of magnitude and must be compared to the hidden costs and the externalities (positive and negative) of construction. As proximity to jobs and services is valued by households, and existing housing units are generally better located than available land 
plots, our results on the effects of construction on prices must be compared with those for reconstruction, demolition, renovation and mobilization of vacant housing. These aspects are only partially taken into account in this analysis which only covers those relating to reconstruction which requires a building permit. Regarding trade-offs between the construction of new housing and existing housing stocks, amenities such as gardens and open spaces are also relevant. While household preferences for the latter were strong enough to reduce their demand for the existing, with smaller housing stocks, reconstruction and renovation would have little or no effect on prices. Lastly, construction in desirable locations may face physical, regulatory or strategic land availability issues that prevent construction and limit the virtuous effect of this price lever. Follow-ups of this study may seek to measure the impact of construction on the value of existing housing stocks or, more specifically, to analyse constraints related to land availability.

\section{BIBLIOGRAPHY}

Angrist, J. D. \& Pischke, J.-S. (2008). Mostly harmless econometrics: An empiricist's companion. Princeton: Pinceton University Press.

Atelier parisien d'urbanisme (2007). Comment produire du logement accessible au centre de l'agglomération métropolitaine? Les leviers d'action sur le prix du foncier et de l'immobilier. Note de synthèse.

https://www.apur.org/sites/default/files/documents/247.pdf (consulté le 26/07/2018).

Ay, J.-S. (2011). Hétérogénéité de la terre et rareté économique. Thèse de doctorat, INRA Dijon et Université de Bourgogne.

Bartik, T. J. (1991). Who Benefits from State and Local Economic Development Policies? Kalamazoo, MI: W.E. Upjohn Institute for Employment Research.

Baum-Snow, N. \& Ferreira, F. (2015). Causal inference in urban and regional economics. In: Duranton, G., Vernon Henderson, J. et Strange, W. C. (Eds.), Handbook of Regional and Urban Economics, vol. 5, chapter 1, 3-68. Amsterdam: North Holland.

Béchet, B., Le Bissonnais, Y. \& Ruas, A. (2017). Sols artificialisés et processus d'artificialisation des sols, Déterminants, impacts et leviers d'action. Expertise collective de l'Institut national de la recherche agronomique.

http://institut.inra.fr/Missions/Eclairer-les-decisions/ Expertises/Toutes-les-actualites/Sols-artificialiseset-processus-d-artificialisation-des-sols\#
Bénard, V. (2007). Le logement : crise publique, remèdes privés. Paris : Éditions Romillat.

Bisault, L. (2009). Des territoires de plus en plus artificialisés. La maison individuelle grignote les espaces naturels. Agreste Primeur, 219.

agreste.agriculture.gouv.fr/IMG/pdf/primeur 219.pdf

Bonnet, O., Bono, P.-H., Chapelle, G. \& Wasmer, É. (2015). Réflexions sur le logement, la hausse des prix de l'immobilier et les inégalités en réponse à l'ouvrage de Thomas Piketty, Le capital au XXI ${ }^{e}$ siècle. Revue d'Économie Politique, 125, 317-346.

https://doi.org/10.3917/redp.253.0317

Burchfield, M., Overman, H. G., Puga, D. \& Turner, M. A. (2006). Causes of Sprawl: A Portrait from Space. The Quarterly Journal of Economics, 121(2), 587-633.

https://academic.oup.com/qje/article-pdf/121/2/ 587/5324419/121-2-587.pdf

Caldera, A. \& Johansson, Å. (2013). The price responsiveness of housing supply in OECD countries. Journal of Housing Economics, 22(3), 231-249.

https://doi.org/10.1016/j.jhe.2013.05.002

Cavailhès, J., Hilal, M. \& Wavresky, P. (2011a). L'influence urbaine sur le prix des terres agricoles et ses conséquences pour l'agriculture. Économie et statistique, 444, 99-125.

https://doi.org/10.3406/estat.2011.9645 
Cavailhès, J., Mesrine, A. \& Rouquette, C. (2011b). Le foncier agricole : une ressource sous tensions. Économie et statistique, 444, 3-18. https://doi.org/10.3406/estat.2011.9639

Chapelle, G. (2017). Land and the housing market: three essays on the role of land and its implications for public policies. Thèse de doctorat, Institut d'études politiques de Paris.

Charmes, E. (2007). Le malthusianisme foncier. Etudes foncières, 125, 12-16.

Combes, P.-P., Duranton, G. \& Gobillon, L. (2016a). The Costs of Agglomeration: House and Land Prices in French Cities. CEPR Discussion Paper $\mathrm{N}^{\circ}$ DP9240.

https://ssrn.com/abstract=2210209

Combes, P.-P., Duranton, G. \& Gobillon, L. (2016b). The Production Function for Housing: Evidence from France. CEPR Discussion Paper $\mathrm{N}^{\circ}$ DP11669.

https://ssrn.com/abstract $=2877274$

Comby, J. (2015). Le logement malade du foncier. La revue foncière, 3, 24-27.

www.revue-fonciere.com/RF03/RF3Comby.pdf

Cornuel, D. (2017). Marché du logement et aides publiques. Paris : Éditions L'Harmattan.

Courtoux, A. \& Claveirole, C. (2015). La bonne gestion des sols agricoles: un enjeu de société. Les avis du Conseil économique sociale et environnemental. Les éditions des Journaux officiels. http://www.lecese.fr/sites/default/files/pdf/ Avis/2015/2015_14_gestion_sols_agricoles.pdf (consulté le 26/07/2018)

Duranton, G. \& Puga, D. (2015). Urban land use. In: Duranton, G., Vernon Henderson, J. et Strange, W. C. (Eds.), Handbook of Regional and Urban Economics, vol. 5, chapter 8, 467-560. Amsterdam: North Holland.

Epple, D., Gordon, B. \& Sieg, H. (2010). A new approach to estimating the production function for housing. American Economic Review, 100, 905-924.

https://ssrn.com/abstract $=1959733$

Fondation Abbé Pierre (2016). L'état du mal-logement en France. $21^{\mathrm{e}}$ rapport annuel. http://www.fondation-abbe-pierre.fr/nospublications/etat-du-mal-logement/les-rapportsannuels/2 1 e-rapport-sur-letat-du-mal-logementen-france-2016 (consulté le 26/07/2018)
Fondation pour la nature et l'homme (2017). Préserver les sols, supports de vie. Le Mag de la transition. http://www.fondation-nature-homme.org/magazine/ preserver-les-sols-supports-de-la-vie/ (consulté le 26/07/2018)

Geniaux, G., Napoléone, C.\& Leroux, B. (2015). Les effets prix de l'offre foncière. Revue d'Économie Régionale \& Urbaine, 2015(1), 273-320. https://doi.org/10.3917/reru.151.0273

Glaeser, E. \& Gyourko, J. (2018) The Economic Implications of Housing Supply. Journal of Economic Perspectives, 32(1), 3-30. https://doi.org/10.1257/jep.32.1.3

Grieson, R. E. \& White, J. R. (1981). The Effects of Zoning on Structure and Land Markets. Journal of Urban Economics, 10(3), 271-285. https://doi.org/10.1016/0094-1190(81)90001-2

Gyourko, J. \& Molloy, R. (2015). Regulation and Housing Supply. In: Duranton, G., Vernon Henderson, J. et Strange, W. C. (Eds.), Handbook of Regional and Urban Economics, vol. 5, chapter 19, 1289-1337. Amsterdam: North Holland.

Hilber, C. A. \& Vermeulen, W. (2016). The Impact of Supply Constraints on House Prices in England. Economic Journal, 126(591), 358-405. https://doi.org/10.1111/ecoj.12213

Knoll, K., Schularick, M. \& Steger, T. (2017). No Price Like Home: Global House Prices, 1870-2012. American Economic Review, 107(2), 331-353. https://www.aeaweb.org/articles/pdf/doi/ 10.1257/aer.20150501

Kuminoff, N. V., Smith, V. K. \& Timmins, C. (2013). The New Economics of Equilibrium Sorting and Policy Evaluation Using Housing Markets. Journal of Economic Literature, 51(4), 1007-1062. https://www.jstor.org/stable/23644816

Landvoigt, T., Piazzesi, M. \& Schneider, M. (2014). Housing Assignment with Restrictions: Theory and Evidence from Stanford University's Campus. American Economic Review, 104(5), 7-72. https://www.aeaweb.org/articles/pdf/doi/ 10.1257/aer.104.5.67

Lecat, G. (2006). Analyse économique de la planification urbaine. Thèse de doctorat, INRA Dijon et Université de Bourgogne.

Levasseur, S. (2013). Éléments de réflexion sur le foncier et sa contribution au prix de l'immobilier. Revue de l'OFCE, 128, 365-394.

https://www.ofce.sciences-po.fr/pdf/revue/15-128.pdf 
Quigley, J. M. \& Rosenthal, L. A. (2005). The effects of land use regulation on the price of housing: What do we know? What can we learn? Cityscape, 8(1), 69-137.

https://urbanpolicy.berkeley.edu/pdf/QR2005.pdf

Repentin, T. \& Braye, D. (2005). Les facteurs fonciers et immobiliers de la crise du logement. Rapport d'information parlementaire $\mathrm{N}^{\circ} 442$ (2004-2005). https://www.senat.fr/rap/r04-442/r04-442.html (consulté le 26/07/2018)

Saiz, A. (2010). The Geographic Determinants of Housing Supply. The Quarterly Journal of Economics, 125(3), 1253-1296.

https://academic.oup.com/qje/article-pdf/ 125/3/1253/5373851/125-3-1253.pdf

Sanderson, E. \& Windmeijer, F. (2016). A weak instrument F-test in linear IV models with multiple endogenous variables. Journal of Econometrics, 190(2), 212-221.

https://www.sciencedirect.com/science/article/ pii/S0304407615001736?via\%3Dihub

Sattinger, M. (1993). Assignment models of the distribution of earnings. Journal of Economic Literature, 31(2), 831-880. https://www.jstor.org/stable/pdf/2728516.pdf? refreqid $=$ excelsior $\% 3 \mathrm{Adb} 472 \mathrm{a} 358 \mathrm{f} 3489 \mathrm{~d} 2 \mathrm{f} 5078$ $610 \mathrm{c} 6 \mathrm{f} 76313$

Sociétés d'aménagement foncier et d'établissement rural (2018). Comment les Safer protègent-elles les terres agricoles et l'environnement?

http://www.safer.fr/protection-terres-agricoles.asp (consulté le 26/07/2018)

Trannoy, A. \& Wasmer, É. (2013). Comment modérer les prix de l'immobilier? Les notes $d u$ conseil d'analyse économique $\mathrm{N}^{\circ} 2$.

http://www.cae-eco.fr/IMG/pdf/cae-note002.pdf (consulté le 26/07/2018)

Turner, M. A., Haughwout, A. \& van der Klaauw, W. (2014). Land use regulation and welfare. Econometrica, 82(4), 1341-1403. https://onlinelibrary.wiley.com/doi/epdf/10.3982/ ECTA9823

Vermont, B. (2016). Prix des terrains à bâtir : une analyse spatiale. THÉMA, service de l'économie, de l'évaluation et de l'intégration du développement durable (SEEIDD). 
Table A1

Descriptive statistics for discrete variables in the final sample

\begin{tabular}{|c|c|c|c|}
\hline & Frequency & Percentage (\%) & Cumulative percentage (\%) \\
\hline \multicolumn{4}{|c|}{ Year land was purchased } \\
\hline 1995 & 521 & 0.2 & 0.2 \\
\hline 1996 & 69 & 0.0 & 0.2 \\
\hline 1997 & 85 & 0.0 & 0.2 \\
\hline 1998 & 106 & 0.0 & 0.3 \\
\hline 1999 & 171 & 0.1 & 0.3 \\
\hline 2000 & 277 & 0.1 & 0.4 \\
\hline 2001 & 292 & 0.1 & 0.5 \\
\hline 2002 & 362 & 0.1 & 0.7 \\
\hline 2003 & 553 & 0.2 & 0.9 \\
\hline 2004 & 829 & 0.3 & 1.2 \\
\hline 2005 & 1520 & 0.5 & 1.7 \\
\hline 2006 & 5060 & 1.8 & 3.5 \\
\hline 2007 & 31287 & 11.2 & 14.7 \\
\hline 2008 & 29,742 & 10.7 & 25.4 \\
\hline 2009 & 22,360 & 8.0 & 33.4 \\
\hline 2010 & 32,178 & 11.5 & 44.9 \\
\hline 2011 & 40,852 & 14.6 & 59.5 \\
\hline 2012 & 45,738 & 16.4 & 75.9 \\
\hline 2013 & 37,576 & 13.5 & 89.4 \\
\hline 2014 & 27,172 & 9.7 & 99.1 \\
\hline 2015 & 2481 & 0.9 & 100 \\
\hline \multicolumn{4}{|l|}{ Serviced land } \\
\hline No & 105,239 & 37.7 & 37.7 \\
\hline Yes & 173,992 & 62.3 & 100 \\
\hline \multicolumn{4}{|c|}{ Intermediary for the purchase } \\
\hline Not known & 6439 & 2.3 & 2.3 \\
\hline Agency & 66,264 & 23.7 & 26 \\
\hline Constructor & 46,294 & 16.6 & 42.6 \\
\hline Other & 49,608 & 17.8 & 60.4 \\
\hline None & 110,626 & 39.6 & 100 \\
\hline \multicolumn{4}{|c|}{ Socio-Professional Category } \\
\hline Farmer & 2481 & 0.9 & 0.9 \\
\hline Artisan & 18,111 & 6.5 & 7.4 \\
\hline Manager & 52,224 & 18.7 & 26.1 \\
\hline Intermediary & 27,430 & 9.8 & 35.9 \\
\hline Office worker & 124,106 & 44.5 & 80.4 \\
\hline Blue-collar worker & 36,291 & 13 & 93.4 \\
\hline Retiree & 18,588 & 6.7 & 100 \\
\hline \multicolumn{4}{|c|}{ Age on filing of the building permit } \\
\hline$<30$ & 75,542 & 27.1 & 27.1 \\
\hline $30-39$ & 107,629 & 38.5 & 65.6 \\
\hline $40-49$ & 49,352 & 17.7 & 83.3 \\
\hline $50-59$ & 27,610 & 9.9 & 93.2 \\
\hline$>60$ & 19,098 & 6.8 & 100 \\
\hline
\end{tabular}

Coverage: Metropolitan France.

Sources: EPTB (SDES). 
Table A2

Inverse demand equations for buildable areas

\begin{tabular}{|c|c|c|c|c|c|c|}
\hline & & ent variable: & f price per $h$ & and, two-ste & ast squares & \\
\hline & (1) & (2) & (3) & (4) & (5) & (6) \\
\hline Population density $(\log )\left[\beta_{1}\right]$ & $0.307^{* \star *}$ & $1.378^{* \star *}$ & $0.573^{\star \star \star}$ & $0.604^{\star * *}$ & $0.334^{\star * \star}$ & $0.388^{\star \star *}$ \\
\hline & $(0.016)$ & $(0.111)$ & $(0.111)$ & $(0.043)$ & $(0.069)$ & $(0.045)$ \\
\hline Constructible areas $(\log )\left[\beta_{2}\right]$ & $-0.245^{\star \star \star}$ & $0.115^{\star *}$ & $-0.933^{* * *}$ & $-0.614^{* * *}$ & $-0.357^{* *}$ & -0.075 \\
\hline & & $(0.053)$ & $(0.270)$ & $(0.107)$ & $(0.161)$ & $(0.102)$ \\
\hline Surface areas $x$ Density $(\log )\left[\beta_{3}\right]$ & & $-0.079^{* * *}$ & & $-0.080^{\star \star *}$ & & $-0.084^{* * *}$ \\
\hline & & $(0.008)$ & & $(0.006)$ & & $(0.006)$ \\
\hline Surface area of the plot (log) & $-0.857^{\star \star \star}$ & $-0.854^{\star * *}$ & $-0.701^{* * *}$ & $-0.701^{* * *}$ & $-0.680^{* * *}$ & $-0.683^{* \star *}$ \\
\hline & $(0.007)$ & $(0.006)$ & $(0.012)$ & $(0.005)$ & $(0.009)$ & $(0.006)$ \\
\hline Serviced land (0-1) & $0.177^{\star * *}$ & $0.173^{* \star *}$ & $0.204^{* * *}$ & $0.203^{* * *}$ & $0.188^{\star \star *}$ & $0.188^{* * *}$ \\
\hline & $(0.008)$ & $(0.006)$ & $(0.012)$ & $(0.005)$ & $(0.006)$ & $(0.004)$ \\
\hline Agency (0-1) & $0.226^{\star * *}$ & $0.225^{\star * *}$ & $0.131^{* \star *}$ & $0.133^{\star \star *}$ & $0.102^{* * *}$ & $0.107^{* * *}$ \\
\hline & $(0.011)$ & $(0.009)$ & $(0.017)$ & $(0.008)$ & $(0.010)$ & $(0.008)$ \\
\hline Constructor (0-1) & $0.032^{\star \star *}$ & $0.031^{* * *}$ & 0.009 & 0.006 & $0.020^{* *}$ & $0.016^{\star * *}$ \\
\hline & $(0.010)$ & $(0.009)$ & $(0.013)$ & $(0.006)$ & $(0.008)$ & $(0.006)$ \\
\hline Other intermediary (0-1) & -0.001 & -0.003 & $0.029^{* * *}$ & $0.027^{* \star *}$ & $0.031^{* * *}$ & $0.028^{* * *}$ \\
\hline & $(0.009)$ & $(0.008)$ & $(0.011)$ & $(0.006)$ & $(0.007)$ & $(0.006)$ \\
\hline No intermediary $(0-1)$ & $-0.046^{\star \star *}$ & $-0.046^{* * *}$ & $-0.020^{*}$ & $-0.021^{* * *}$ & -0.008 & $-0.011^{*}$ \\
\hline & $(0.009)$ & $(0.008)$ & $(0.012)$ & $(0.006)$ & $(0.008)$ & $(0.006)$ \\
\hline COND. F & $99.741^{* * *}$ & $99.741^{* * *}$ & $4.656^{* \star *}$ & $4.656^{* \star *}$ & $6.68^{* * *}$ & $6.68^{* * *}$ \\
\hline SARGAN & $0^{\star \star \star}$ & $0^{* * *}$ & $0^{\star * *}$ & $0.074^{*}$ & $0^{* * *}$ & 0.832 \\
\hline SSC F & 1.153 & 1.153 & 0 & 0 & 2.214 & 2.214 \\
\hline AGRI F & $128.142^{* * *}$ & $128.142^{\star \star *}$ & & & & \\
\hline SLOPE F & & & $16.421^{\star \star \star *}$ & $16.421^{\text {***}}$ & $22.262^{\star \star \star}$ & $22.262^{\star \star \star}$ \\
\hline Moran's I & $0.532^{* * *}$ & $0.513^{\star \star *}$ & $0.356^{\star \star *}$ & $0.258^{\star * *}$ & $0.353^{\star \star *}$ & $0.250^{\star \star \star}$ \\
\hline Fixed effects & & & UA & UA & $E Z$ & $E Z$ \\
\hline Observations & 279,215 & 279,215 & 279,215 & 279,215 & 279,215 & 279,215 \\
\hline Residual standard deviation & 0.65 & 0.579 & 0.807 & 0.418 & 0.512 & 0.411 \\
\hline
\end{tabular}

Notes: cf. Table 3.

Coverage: Metropolitan France.

Sources: EPTB (SDES), Sit@del2 (SDES), Insee, BD ALTI (IGN), Cerema, Basias (BRGM), SSP; authors' computations. 



\title{
New or old, why would housing price indices differ? An analysis for France
}

\author{
Thomas Balcone* and Anne Laferrère*
}

\begin{abstract}
In France, housing price indices have been computed since 1996 for second-hand dwellings (Indices Notaires-Insee) and since 2013 for new dwellings (Indice des prix des logements neufs). The evolution and volatility of the two indices differ. We explore why, using notarial data and surveys on new home sales $(E C L N)$ and the price of building land $(E P T B)$. The computation methods and the scopes of the indices contribute relatively little to the differences. The location of new and old housing differs, but this still explains only part of the differences. Decomposing a home value between that of land and that of buildings reveals that the share of land is higher for second-hand than for new dwellings. Land and second-hand dwellings price indices evolve in a very similar way. Structures prices have a greater influence on the price index of new homes. Nevertheless, construction costs are sensitive to the trend in land prices. The counter-cyclical construction of social housing may have contributed to reduce the volatility of new homes prices.
\end{abstract}

JEL Classification: C43, C81, E31, R31

Keywords: indices, hedonic models, housing demand

Reminder:

The opinions and analyses in this article

are those of the author(s)

and do not

necessarily reflect

their institution's

or Insee's views.

\begin{abstract}
*Insee at the time this research began (thomas.balcone@enseignementsup.gouv.fr; anne.laferrere@dauphine.fr).
We are grateful to the Scientific Board of the Indices Notaires-Insee, to Ronan Le Saout and Benjamin Vignolles for helpful discussions. The latter also provided his computation of the distance variable in EPTB. We thank Cédric Cailly for his help with the EPTB data and Insee and SDES (Service de la donnée et des études statistiques, of the ministère de la Transition écologique et solidaire) for allowing access to restricted data (convention $\left.n^{\circ} 2014065 N F\right)$. We are also grateful to the notaries for providing the data used for the methodology comparison. Last but not least, two referees provided invaluable critics and comments. We alone remain responsible for errors.

Received on 8 June 2017, accepted after revisions on 17 May 2018
\end{abstract}

To cite this article: Balcone, T. \& Laferrère, A. (2018). New or old, why would housing price indices differ? An analysis for France. Economie et Statistique / Economics and Statistics, 500-501-502, 69-95. https://doi.org/10.24187/ecostat.2018.500t.1946 
$\mathbf{H}$ ousing price indices have been published quarterly in France since 1996 for second-hand dwellings ${ }^{1}$. The sales prices are recorded by notaries and used to compute the so-called Indices Notaires-Insee (INI hereafter), at the national and various local levels ${ }^{2}$. Since 2013, an index for new dwellings has been computed by Insee, the Indice de prix des logements neufs (IPLN) relying on price data from a survey on the commercialisation of new dwellings $\left(E C L N^{3}\right)$. It soon appeared that the evolution of INI and IPLN indices were somewhat different. Over the 2006-2015 period, the volatility of the INI index was more than twice that of the IPLN index. This article aims at exploring why.

A first section summarizes the current methods of computation of the new and second-hand housing price indices and points to the differences in evolution of these two indices. Next, two potential sources of methodological differences are examined: the effect of the computation methods and that of the exclusion of individually built single-family houses (IP) from the IPLN index, i.e. the different scope of the two indices. We complement the IPLN index with an index for those individually built single-family houses, using another rich data source, the Enquête sur le prix des terrains à bâtir (EPTB); it allows computing a new, extended housing index. We call it IPLN++. Eliminating such differences in method and scope does not suppress the differences in time evolution and volatility. We then turn to some other sources of differences between the indices. The markets for new and second-hand homes differ; in particular, new homes are not located in the same areas as existing homes: they are mostly built in the periphery of cities, where land is available and cheaper. Hence the share of land in the home value would be smaller for new homes than for old ones and it might influence price evolution. We conduct two types of experiments. The first draws from the limited geographical information provided by the data used in computing the two indices, INI and IPLN. The distance to the city centre is not known, only the municipality. We compute a second-hand price index for dwellings situated in the same municipalities as the new ones. The difference between the two indices is somewhat reduced but not eliminated. Secondly, drawing from the Enquête sur le prix des terrains à bâtir (EPTB), separate indices for land and structure are computed and compared to the INI and to the IPLN. Land price evolution seems to be driving second-hand housing prices more than construction prices. The latter have more influence on new homes prices than land prices. However, the construction costs are also sensitive to the general trend in land prices. Looking for other potential explanations, two features are striking: the difference between the two indices is particularly important during the 2008-2009 crisis; and the prices for second-hand dwellings are more volatile than those of new dwellings. Looking at time series of sales and constructions suggests that the countercyclical building of social housing might have contributed to the lower volatility of new homes prices.

\section{Current methods of computation of new and second-hand dwellings price indices in France}

The approach to the second-hand (old) dwellings price index is that of hedonic imputation, while that for the new dwellings price index is that of a time dummies hedonic model.

\section{Second-hand dwellings: the Indice Notaires-Insee (INI)}

The second-hand dwellings price index (INI) is computed by a hedonic method based on the estimation of disaggregated models in homogeneous zones, separately for houses (181 zones) and flats (112 zones). Price zones are determined with an ascending hierarchical classification based on various statistics at the neighbourhood or canton level adding a criterion of geographic contiguity outside Île-de-France. The data consist of transaction prices collected by the notaries (see Gouriéroux and Laferrère (2009) and Clarenc et al. (2014) for details). Each quarter, the models are used to estimate the price of a fixed reference basket of dwellings in each zone. The reference basket is made up of two years of transactions and updated every two years. Hence the index is an index of transactions, not of the whole stock; but the "basket" is large enough not to be biased by short-term changes in the market ${ }^{4}$.

\footnotetext{
1. Second-hand in the fiscal sense, i.e. aged more than 5 years or being sold for the second time.

2. See: https:/wwwinsee.fr/fr/statistiques/series/102770558. Excel files are also attached to each quarterly publication. See https://www.insee.fr/ fr/statistiques?debut $=0$ \& theme $=30$ \& conjoncture $=56$.

3. Enquête sur la commercialisation des logements neufs conducted by the SDES. See Balcone $(2013,2018)$ for details.

4. $1 / 20^{\text {th }}$ of the extreme values are omitted from the computation.
} 
The basic model is as follows (omitting zone indices):

$$
\begin{aligned}
\log p_{i}= & \log p_{0}+\sum_{a=1}^{2} \mu_{a} Y_{a, i}+\sum_{m=1}^{12} \theta_{m} M_{m, i} \\
& +\sum_{k=1}^{K} \beta_{k} X_{k, i}+\varepsilon_{i}
\end{aligned}
$$

where:

- $p_{i}$ is the price (per $\mathrm{m}^{2}$ for flats) of dwelling $i$;

- $Y_{a, i}$ is a dummy for the year of sale of dwelling $i$;

- $M_{m, i}$ is a dummy for the month of sale of dwelling $i$;

- $X_{k, i}$ are $K$ characteristics of dwelling $i$, including physical characteristics (size, number of rooms, of bathrooms, of floors - interacted with existence of a lift for flats -, garage), date of construction, plot size for houses, etc., and neighbourhood dummies, proxying for local amenities;

- $p_{0}$ is the price of the "reference" dwelling defined by the omitted characteristics in $(1)^{5}$.

Similar models can be estimated at each date $t$, allowing estimating the price of the reference basket at each date. In practice the models are only revised every two years ${ }^{6}$. The ratio of the estimated values of the reference basket between $t$ and $t-1$, provides the index. Indices are then chained from period to period. The sub-indices by zones and type of dwellings are aggregated at higher geographic levels for publication ${ }^{7}$. Aggregation uses geometric means when the geographic level is infra-département, that is a small enough zone where the consumer is assumed to make her residential choices, and arithmetic means at higher geographic levels, with weights reflecting transaction values ${ }^{8}$.

\section{New dwellings: the Indice de prix des logements neufs (IPLN)}

The data source is the ECLN. The survey covers all building permits of 5 units or more: single-family units that are part of a development (called "individuel groupé", IG), and all multi-family units (in apartment buildings, called "collectif", Coll). Individually built single-family units, i.e. units built one by one, called "individuel pur" (IP), are left out of the index because, except when they are built by a developer and sold "clefs en main", no proper sale price is recorded. This is consistent with the scope of the European new dwellings index 9 . The ECLN survey only covers dwellings built for the private market. Subsidized construction for the social sector is left out. Table 1 compares the scope of housing price indices to that of all new home constructions and sales during the period 2006-2012. Social housing represented about $14 \%$ of new construction, and $18 \%$ when adding the increasing part of social housing built by private developers. Social housing is left out of the index computation because no costs or prices are recorded. The IPLN index covers $61 \%$ of all new housing units aimed at the private market and $98 \%$ of those for which a price is recorded.

For one newly built private dwelling sold, nearly four second-hand dwellings are sold. This is why price indices for second-hand dwellings can be computed at various geographical levels, and separately for houses and flats, while the IPLN, the official price index for new dwellings, has been computed only at the national level. Besides, because of the difference in the number of available recorded prices, the indices are computed with different methodologies: hedonic imputation for the $I N I$ and adjacent two-period time dummies for the IPLN.

Each quarter, the model is estimated on two successive quarters of data. The data are available only at the level of a construction program, not at the dwelling level. The following information is provided by type of construction ("individuel groupé", IG or "collectif", Coll ${ }^{10}$ ) for each class of number of rooms (from 1 to 6 or more): the total number of sold dwellings, the average size in $\mathrm{m}^{2}$ and the average price of the sold dwellings ${ }^{11}$.

\footnotetext{
5. For instance the reference house is $100 \mathrm{~m}^{2}$ on a $610 \mathrm{~m}^{2}$ plot, has 4 rooms, 2 levels, a garage, one bathroom, of unknown construction date and is sold in December of year 2 of the reference period. $R^{2}$ ranges from 0.25 to 0.85 . 6 . The model estimated over the period 2009-2010, was used to compute the indices for the period 2012-2013.

7. Only the sub-indices in cities or départements with enough transactions get the Notaires-Insee label.

8. By construction such models only allow getting different price evolutions by zones, separately for houses and apartments. They assume that the price evolution of a given basket of homes is the same within a zone, or whatever the number of rooms, or the date of construction. Details of the method can be found in Clarenc et al., 2014 at https://www.insee.fr/frl information/2569926.

9. See Owner-Occupied Housing regulation (EU Commission regulation $N^{\circ}$ 93/2013).

10. And whether the sold dwellings are private ordinary dwellings or part of residences offering specific collective services.

11. Hence, only the mean characteristics of the sold dwellings of a program are available. For similar houses, it is not a big issue. For apartments, some important characteristics, such as the level in the building, are unknown. It is of no consequences if the relative price of the omitted variable is constant and the frequency of the characteristics is also constant over time.
} 
Table 1

Newly built or sold second-hand dwellings and prices indices coverage

\begin{tabular}{|c|c|c|c|c|c|}
\hline & $\begin{array}{l}\text { Number } \\
\text { of dwellings }\end{array}$ & $\begin{array}{l}\text { Share of all } \\
\text { dwellings } \\
\text { (in \%) }\end{array}$ & Type of dwellings & $\begin{array}{c}\text { Share of new } \\
\text { dwellings by type } \\
\text { (in } \% \text { ) }\end{array}$ & Indices \\
\hline New dwellings built for: & 372,866 & 33 & - & - & - \\
\hline \multirow{3}{*}{ the private market } & \multirow{3}{*}{304,580} & \multirow{3}{*}{27} & "Pure" single-family units (IP) & 39 & \multirow{3}{*}{ IPLN } \\
\hline & & & "Grouped" single-family units (IG) & 12 & \\
\hline & & & Flats ("collective") + Residences & 49 & \\
\hline \multirow{3}{*}{ the non- private market } & \multirow{3}{*}{68,286} & \multirow{3}{*}{6} & "Pure" single-family units & 1 & \\
\hline & & & "Grouped" single-family units & 25 & \\
\hline & & & Flats & 74 & \\
\hline Sales of second-hand dwellings & 740,571 & 67 & & & INI \\
\hline Total & $1,113,438$ & 100 & & & \\
\hline
\end{tabular}

Note: Annual average over 2006-2012. Units built with permits of 2 to 4 units are in principle included in "Grouped" single-family units or in "collective" dwellings, but they are excluded of the ECLN survey and consequently from the scope of the IPLN (they represent only $2 \%$ of new dwellings for the private market). Homes transmitted by bequest or gift are excluded.

Sources: Sit@del2 for total new constructions. The number of constructions for the non-private market is estimated from the number of homes built by the social sector including homes built in "VEFA" (dwellings sold before they are built - vente en l'état futur d'achèvement) by the private sector for the public sector (see CDC, 2015). Sales of second-hand homes are estimated from CGEDD, from DGFiP (MEDOC) and notaries database (http://www.cgedd.developpement-durable.gouv.fr/nombre-et-montant-des-ventes-immobilieres-a1003.html). See Friggit (2014) for the method.

The hedonic model is the following:

$$
\begin{aligned}
\forall t=T-1, T \text { and } & \forall i=1, \ldots, n b_{-} o b s(t), \\
\ln \left(\bar{p}_{i, t}\right)=\alpha & +\beta_{S} \ln \left(S_{i, t}\right) \\
& +\sum_{k=1}^{K} \beta_{k} I_{i, t, k}+\delta_{T} D_{i, t, T}+\varepsilon_{i, t}
\end{aligned}
$$

where:

- $\bar{p}_{i, t}$ is the average price of dwellings of program $^{12} i$ sold in quarter $t$;

- $S_{i, t}$ is the average size in $\mathrm{m}^{2}$ of the dwellings of program $i$ sold in quarter $t$;

- $I_{i, t, k}$ is a vector of characteristics of the dwellings: type of construction (IG or Coll), number of rooms, dummies for "standing", presence of a swimming pool, air conditioning, balcony for flats, etc. Location is taken into account through 14 dummies for areas that are homogeneous in terms of price per square meter ${ }^{13}$, and dummies for some characteristics of the municipality (e.g. sea ${ }^{14}$, ski or hiking resorts);

- $D_{i, t, T}$ is a time dummy for quarter $T$.

The quarterly change in the index is obtained by the exponential of the coefficient of the quarter dummy. Contrary to second-hand dwellings, there is only one model for the whole of France ${ }^{15}$. Moreover, houses and flats are not separated because of the small number of quarterly observations in the $E C L N^{16}$. Balcone
(2013, 2018) describes the computation method in details. The main differences between the new and second-hand dwellings price indices are summed up in Table 2.

\section{Comparing price indices of new and second-hand dwellings}

Over the 2006-2015 period, the new and existing second-hand dwellings indices evolved differently (Figures I to III): the average difference in absolute value between the quarterly growth rates of the two indices is not negligible (1.2 percentage points). The same is true for the annual growth rates $(2.4$ percentage points). Actually, both indices follow the same trend except over the crisis 2008 Q4-2010 Q1 period and again in 2014_Q4 (Figure III). In 2008 Q4, the INI falls by 4 points, it falls by another 4 points in 2009 Q1, and by 2 points in

12. More exactly, the price corresponds to a program and a class of number of rooms.

13. The 14 zones have been computed by a ascending hierarchical classification based on 8 large regions (ZEAT) and 9 urban unit sizes, from $d$ welling prices and sizes. An urban unit is a municipality or group of municipalities with a continuously built zone (i.e. less than 200 meters between two constructions) with more than 2,000 inhabitants.

14. The law Littoral $n^{\circ} 86-2$ (1986) defined the classification. A municipality is coastline "littorale (or maritime)" if on the seaside, near ocean or salty marshes; "arrière-pays littoral" is a non-coastline municipality within a coastline canton (a group of municipalities with at least one coastline municipality)

15. Metropolitan France excluding Corsica.

16. Over the period 2006_Q1-2012_Q3, the average quarterly number of observations is 8194 "programs $x$ number of rooms", corresponding to 26105 new dwellings. In the regression each observation is weighted by the corresponding number of sold dwellings. 
Table 2

Main differences between the new and second-hand dwellings indices

\begin{tabular}{|l|l|l|}
\hline & \multicolumn{2}{|c|}{ IPLN } \\
\hline Data & $\begin{array}{l}\text { Survey on the commercialisation of new dwellings: } \\
\text { ECLN }\end{array}$ & $\begin{array}{l}\text { Transactions registered in the Notaries databases: BIEN (Base } \\
\text { d'informations économiques notariales) database for Île-de-France } \\
\text { and Perval (Min.not ADSN) database for the Province. }\end{array}$ \\
\hline Method & Adjacent two-period time dummy hedonic model & Hedonic imputation \\
\hline Geographical effect & $\begin{array}{l}14 \text { dummies for zones + municipality } \\
\text { characteristics, in a single model }\end{array}$ & $\begin{array}{l}\text { One hedonic model for each of the 293 zones + neighbourhood } \\
\text { dummies }\end{array}$ \\
\hline
\end{tabular}

Figure I

New dwellings (IPLM) and second-hand dwellings (INI) price indices, 2006-2015

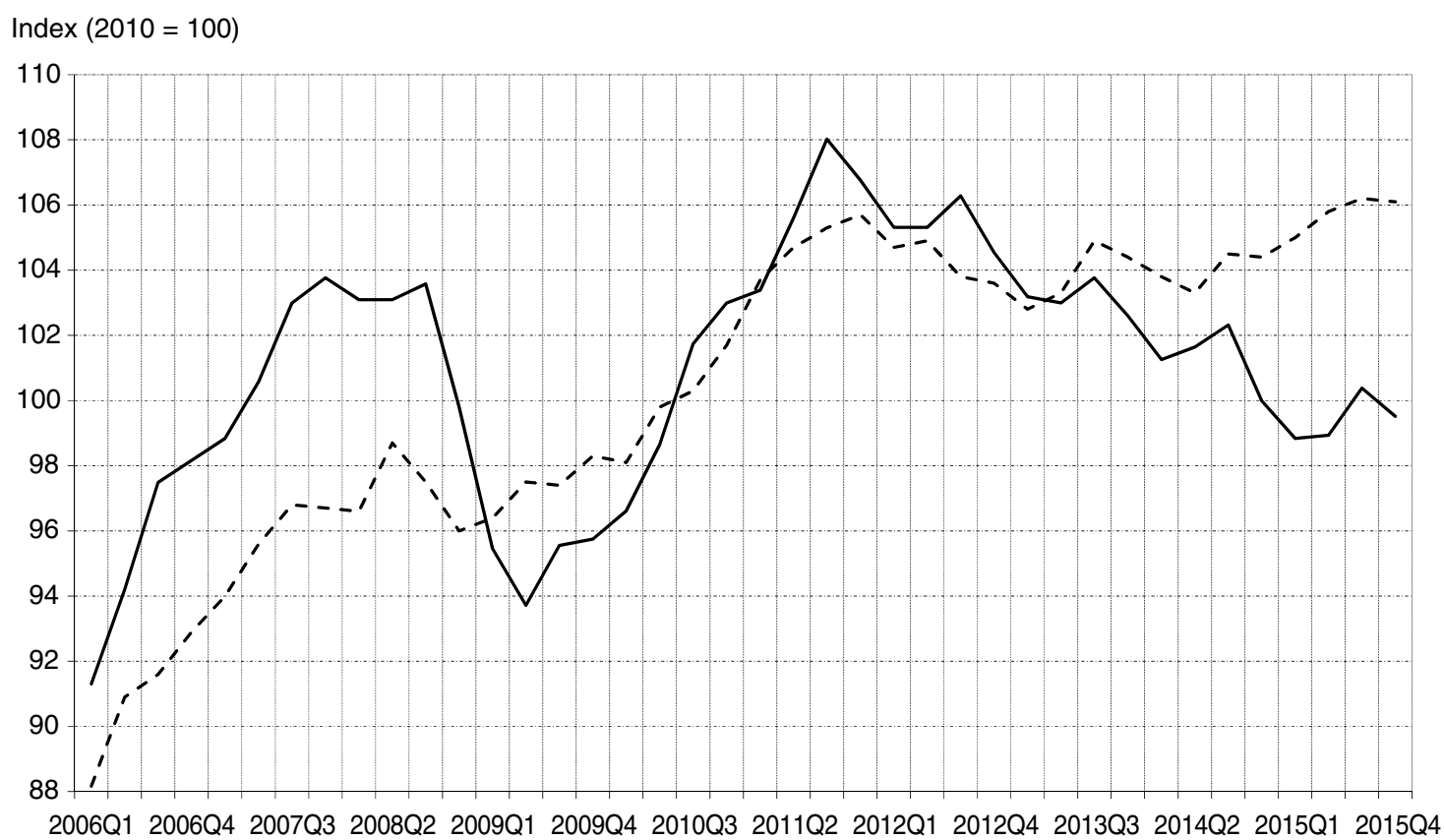

2006Q1 2006Q4 2007Q3 2008Q2 2009Q1 2009Q4 2010Q3 2011Q2 2012Q12012Q4 2013Q3 2014Q2 2015Q1 2015Q4

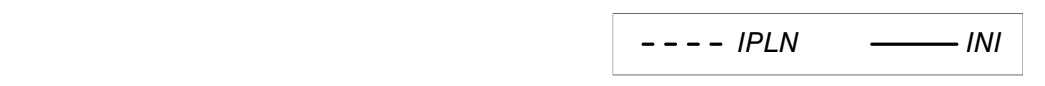

Sources: ECLN, BIEN and Perval data bases (see Table 2); authors' computation.

2009_Q2. The IPLN only drops by 2 points in 2008_Q4. In 2014_Q4 the INI falls by 2 points, while the IPLN does not change. The index for second-hand dwellings appears twice more volatile than the index for new dwellings (IPLN): the standard deviation of its annual evolution rate over this period was $4.59 \%$, when it was $2.31 \%$ for the $I P L N$.

\section{Potential methodological sources of differences between the IPLN and $I N I$ indices}

A first possible source of differences between the evolutions of the two indices comes to mind: the bias due to different methods, adjacent two-period time dummy method on a single model versus hedonic imputation method at a disaggregated geographical level. This has been explored in details by Balcone (2013, 2018). The next section summarizes his results. The period of observation is restricted to 2006-2010 because of the availability of the Notaries data for this simulation.

\section{The difference in computation methods has little effect}

Taking the second-hand dwellings sales data used for computing the INI, Balcone (2013) used the same adjacent two-period time dummy hedonic model as the one used for the 
Figure II

Quarterly growth rate of the new dwellings (IPLM) and the second-hand dwellings (INI) price indices, 2006-2015

(\%)

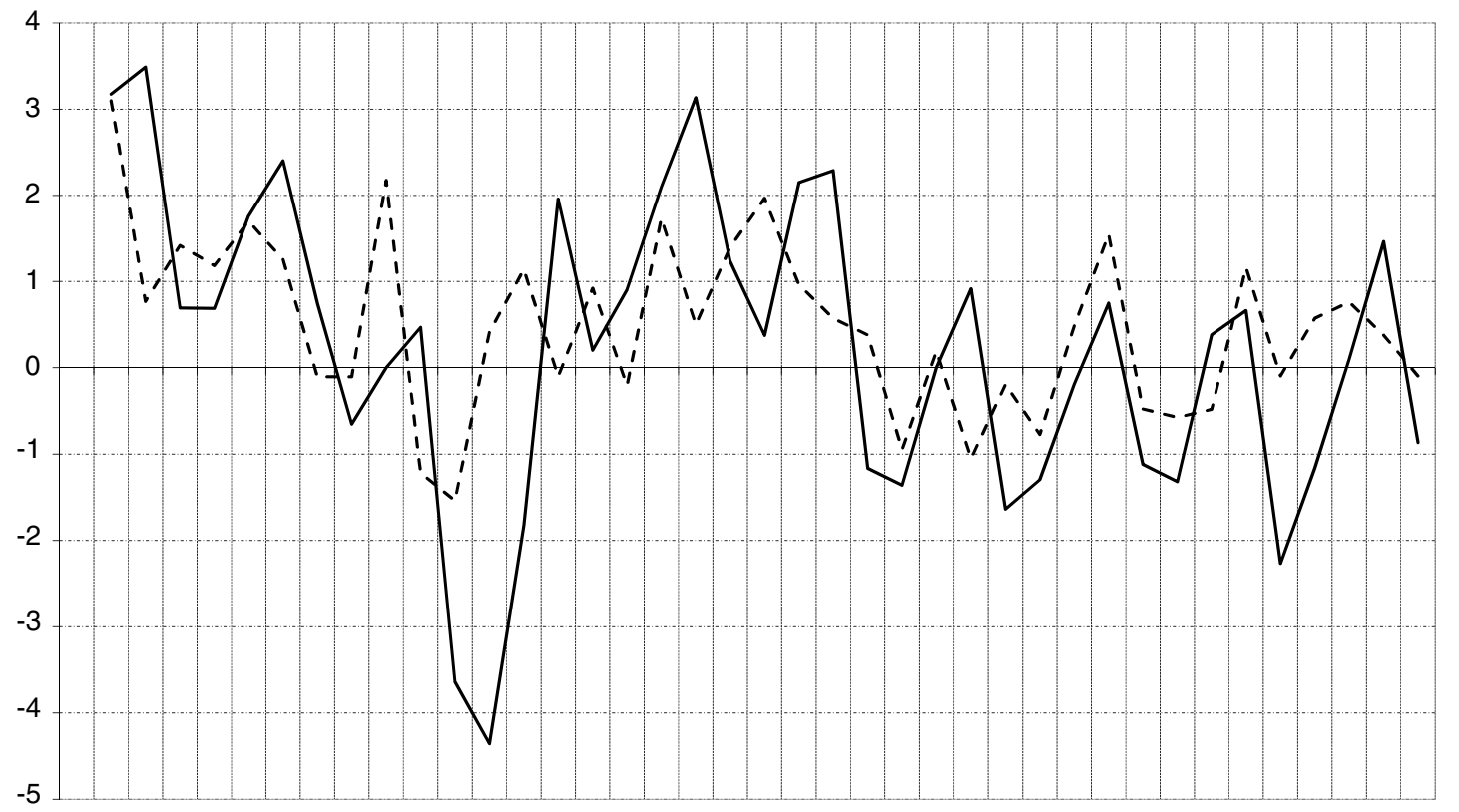

2006Q1 2006Q4 2007Q3 2008Q2 2009Q1 2009Q4 2010Q3 2011Q2 2012Q1 2012Q4 2013Q3 2014Q2 2015Q1 2015Q4

$$
---I P L N \quad \text { INI }
$$

Sources: ECLN, BIEN and Perval data bases (cf. Table 2); authors' computation.

Figure III

Annual growth rate of the new dwellings (IPLM) and the second-hand dwellings (INI) indices, 2006-2015

(\%)

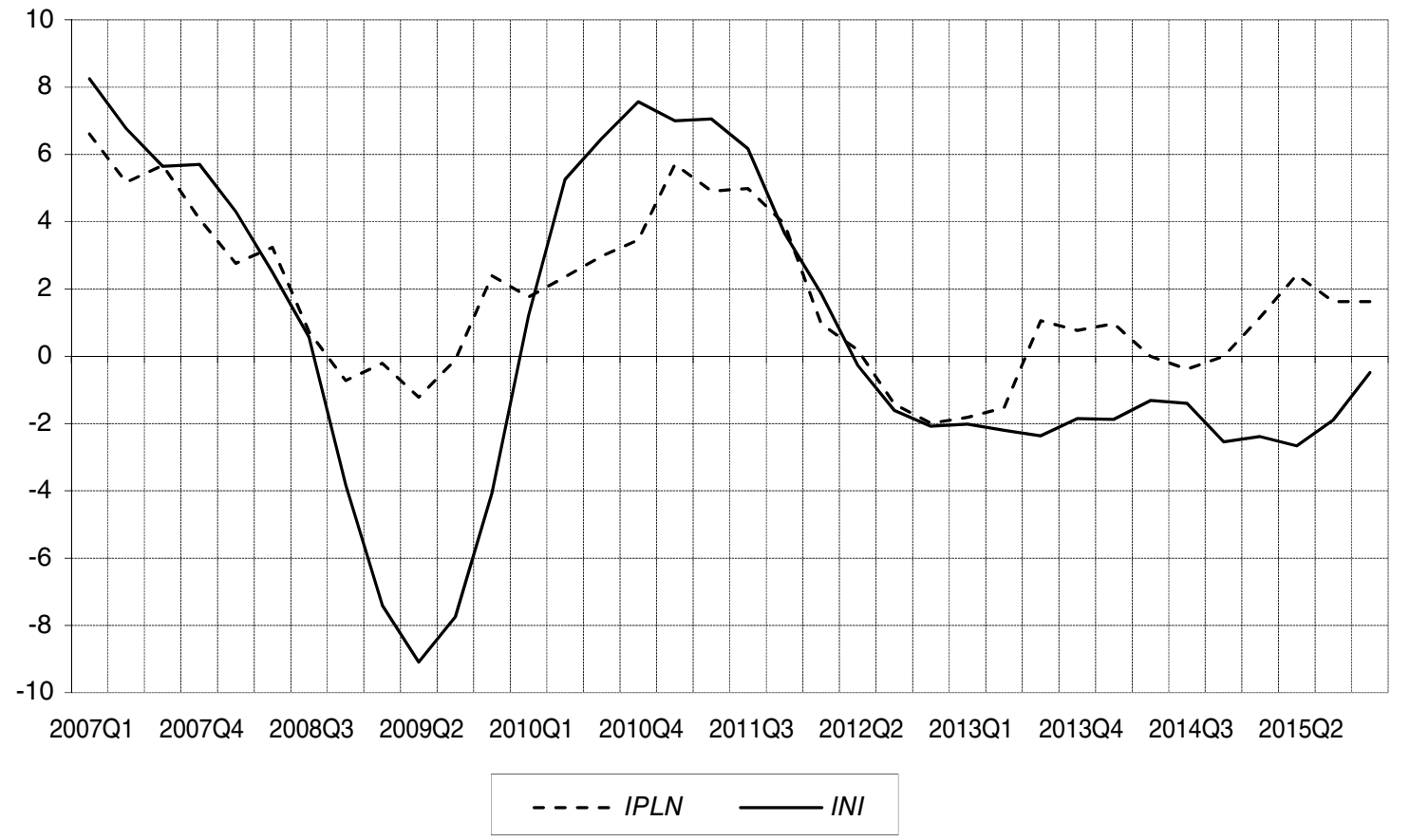

Note: Annual growth is the year-on-year evolution of the quarterly index.

Sources: ECLN, BIEN and Perval data bases (cf. Table 2); authors' computation. 
new dwellings index. Two indices were computed: one for houses and one for flats. To get closer to the smaller number of explanatory variables in $E C L N$, the number of explanatory variables was reduced compared to model (1), the geographical dummies were the same as in model (2) and a single model was used for the whole country.

Such experimental time dummy indices for second-hand houses and flats are compared to the $I N I$ indices. Since the only source of difference between these two sets of indices is the computation method, the gap between the indices is used to assess the potential bias due to different methods. For houses, the absolute value of the difference between the two indices is not higher than 2.6 index points (Figure IV-A), even if seasonal changes in the "time dummy" index are more pronounced than in the INI (Figure IV-B). The annual profiles are similar, and differences are most often no more than 1 percentage point (not shown). The difference is larger ( 2 percentage points) in 2009 Q3 in the middle of the crisis. The difference in the computation methods clearly cannot account for the difference between second-hand and new price indices for houses. For second-hand flats, the absolute value of the difference between the two indices is not higher than 2.6 index points (Figure V-A). Moreover, the evolution rates of both indices are also close (Figure V-B).

The results, both for second-hand houses and flats, lead to conclude that even if the computation method implemented for the INI is very different from a simplified adjacent twoperiod time dummy method, the final difference at the national level is surprisingly small. The time dummy method would lead to a less volatile index, as was the case for the IPLN compared to the $I N I$. For instance for houses over the period 2006-2010, the standard deviation of the annual evolution rate is $5.90 \%$ for the $I N I$ and $5.58 \%$ for the "time dummy" index. However, the method does not explain the gap between the INI and the IPLN that was observed during the 2008_Q4-2010_Q1 crisis period.

\section{Adding individually built single-family homes to the IPLN}

As shown in Table 1, the effective scope of new and second-hand dwellings indices differs: IPLN covers only the "individuel groupe"
(IG) and "collectif" (Coll) dwellings whereas INI also includes "individuel pur" (IP). To get a comprehensive new dwellings index, we use another rich data source, the EPTB survey ${ }^{17}$. It covers the building permits of "individually built" single-family houses (IP) and provides the prices and features of land plots (size in $\mathrm{m}^{2}$, whether it was purchased or not, purchase date, servicing works done or not, etc.). It also provides the expected price of the construction, and some of the house features: floor space, nature of the main coordinator of the works, type of heating system. We keep 344,847 observations for which land was purchased between 2006 and 2012, was located in metropolitan France ${ }^{18}$, and for which the size of the purchased plot is equal to that registered in the building permit ${ }^{19}$. From these data, a quality-adjusted price index for new IP singlefamily houses is computed using the adjacent two-period time dummy method.

\section{An "individually built" single-family houses price index}

Since the $E P T B$ data are richer than the $E C L N$, the location effect is taken into account by estimating one hedonic model per region. Dummies for municipal amenities are included: coastline, estuary, touristic "arrière-pays littoral" or ski or alpine resort. We also control for the type of urban unit: if the municipality is a single urban unit, it is a "ville isolée"; if it belongs to an urban unit made of several municipalities, it is then either a city centre or a suburb ${ }^{20}$; municipalities outside urban units are called rural. We finally add the straight-line distance in kilometers between the municipality where the land is bought and the closest urban centre ${ }^{21}$. Moreover, differences of quality between houses are taken into account by adding dummies for the construction characteristics. The hedonic model (3) used for each of the 21 regions $r$ is the following (omitting the region index):

\footnotetext{
17. Enquête sur le prix des terrains à bâtir conducted annually by the ministère de la Transition écologique et solidaire.

18. Excluding Corsica, as for the new dwellings index

19. The registered plot size is the total underlying land (ground floor + gardens and outhouses). We exclude the $4.6 \%$ cases where the individual buys just an extension of a plot which was his already, and the $5.2 \%$ cases where he buys a large plot, then divides it and uses only part of it for the building. Then the mean price per square meter may be lower because only part of the purchased land may have building permission, the remaining corresponding to farmland for instance.

20. Definitions can be found at : $h$ ttp://www.insee.fr/en/methodes/default. asp?page=definitions/ville-centre-et-banlieue.htm.

21. The urban center (pôle) is an urban unit offering at least 10,000 jobs and not located in the crown of another urban centre. The crown from an urban cluster covers all the municipalities in the urban area to the exclusion of its urban centre.
} 
Figure IV

Second-hand houses: "time dummy" and INI indices, 2006Q1-2010Q4

A - Indices

Index $(2009=100)$

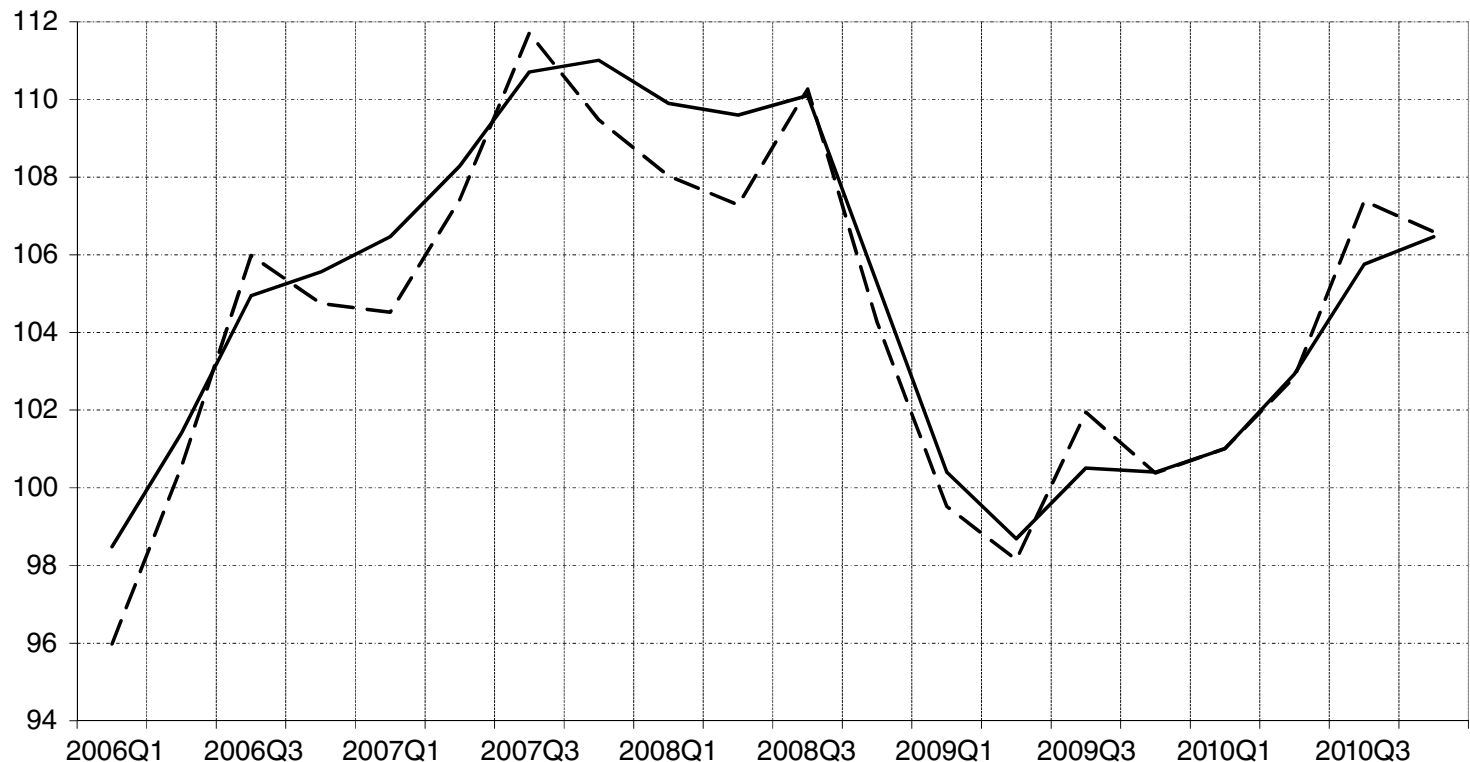

- - - "time dummy" index

\section{B - Quarterly growth rates}

(\%)

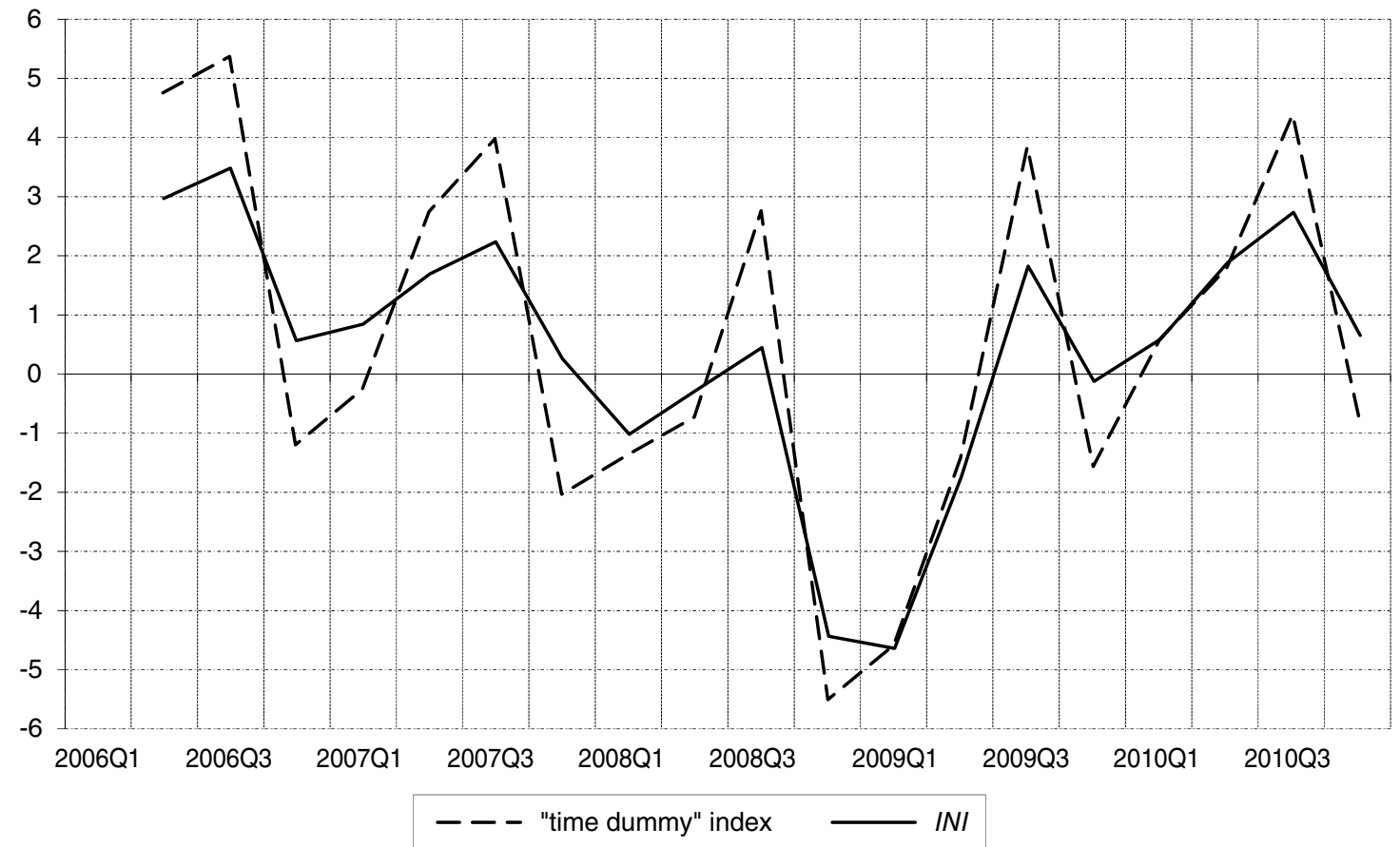

Sources: ECLN, BIEN and Perval data bases (cf. Table 2); authors' computation. 
Figure $\mathrm{V}$

Second-hand flats: "time dummy" and INI indices, 2006Q1-2010Q4

A - Indices

Index $(2009=100)$

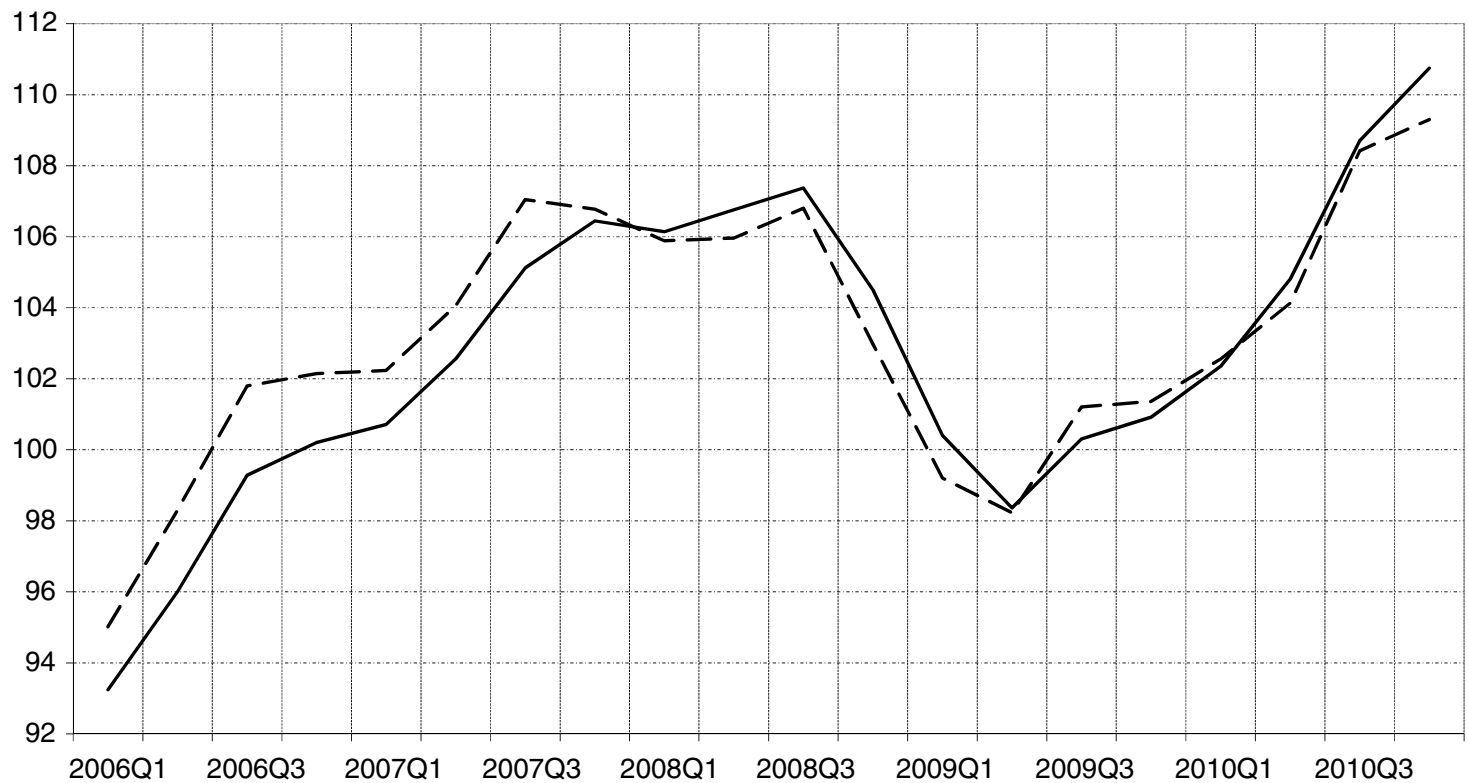

- - - "time dummy" index $\longrightarrow$ INI

B - Quarterly growth rates

(\%)

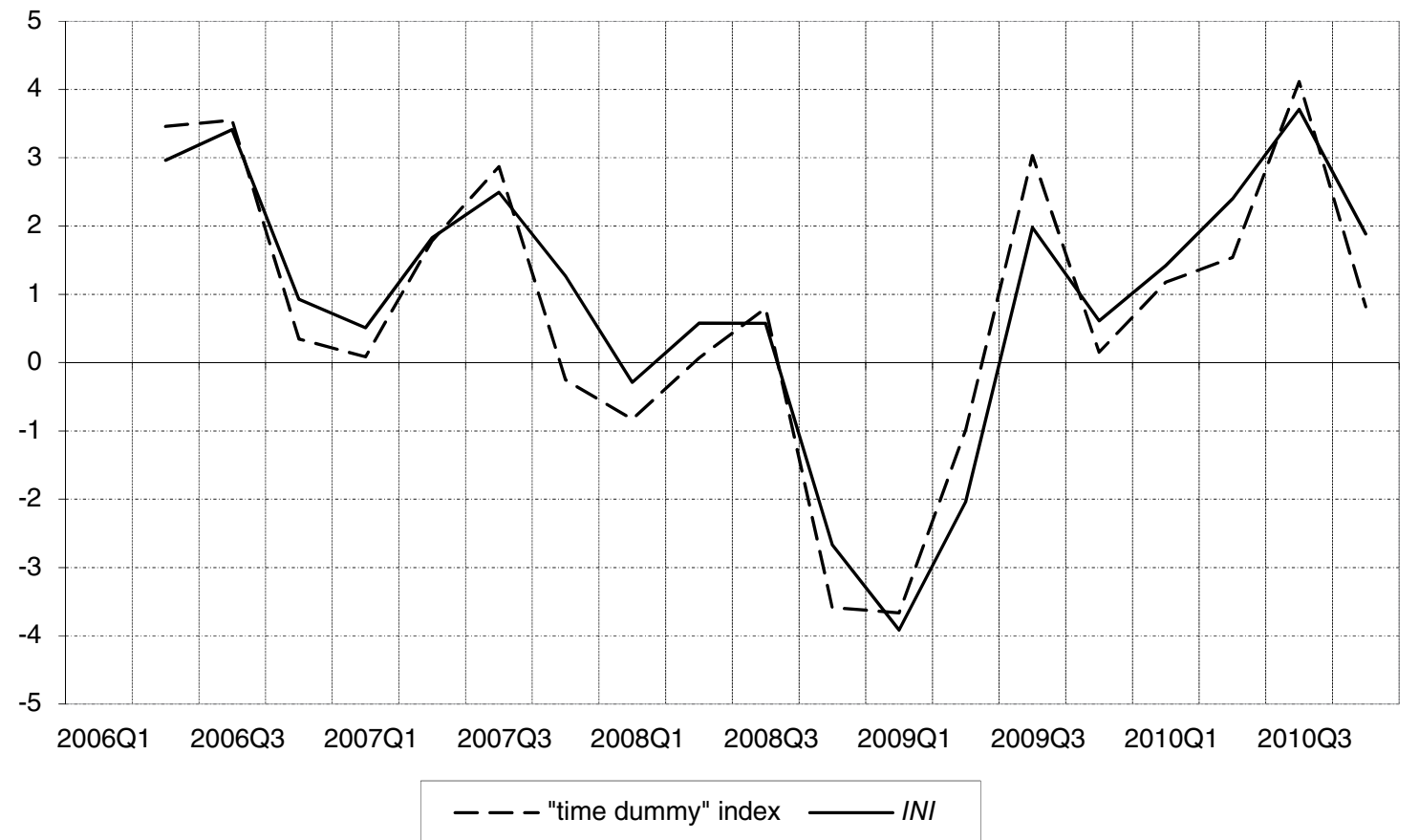

Sources: ECLN, BIEN and Perval data bases (cf. Table 2); authors' computation. 


$$
\begin{aligned}
\forall A=2007, \ldots, 2012, \forall a=A-1, A, \forall i \\
\begin{aligned}
\ln \left(p_{-} V_{i, a}\right) & =\alpha_{A, r}+\beta_{s_{-} L}^{A} \ln \left(s_{-} L_{i, a}\right) \\
& +\beta_{s h o n}^{A} \ln \left(\operatorname{shon}_{i, a}\right)+\beta_{d i s t}^{A} \operatorname{dist}_{i, a} \\
& +\sum_{k=1}^{K} \beta_{k}^{A} I_{i, a, k}+\delta_{A, r} D_{i, a, A}+\varepsilon_{i, a}
\end{aligned}
\end{aligned}
$$

Where, for plot $i$ in year $a$ :

- $p_{-} V_{i, a}$ is the house value, the sum of the land price and the construction price;

- $s_{-} L_{i, a}$ is the plot size in $\mathrm{m}^{2}$;

- shon $_{i, a}$ is the size in $\mathrm{m}^{2}$ of the house $\mathrm{e}^{22}$;

- dist ${ }_{i, a}$ is the distance to the nearest urban centre;

- $I_{i, a, 1}, \ldots, I_{i, a, k}, \ldots, I_{i, a, K}$ is a vector of $\mathrm{K}$ dummies for the characteristics of the land and of the structure : the geographical dummies described above to which we add whether the plot was serviced ("viabilisé"), or was bought through an intermediary or not and its type, degree of finish of the structure (totally fitted, ready to decorate, only "clos et couvert"), heating mode (gas, electricity, renewables, etc.), type of builder (architect, developer, artisan, self-building, other);

- $D_{A}$ is year $A$ dummy.

From the models, we compute, for each of the 21 regions $r$ an annual constant quality price index for year $A, 100=A-1, I_{-} V_{r, A / A-1}$ :

$I_{-} V_{r, A / A-1}=\exp \left(\hat{\boldsymbol{\delta}}_{A, r}\right) * 100$

where $\hat{\delta}_{A, r}$ is the OLS estimator of $\delta_{A, r}$.

The national index for year $A(100=A-1)$, $I_{-} V_{A / A-1}$ is the weighted average of the 21 regional indices:

$$
I_{-} V_{A / A-1}=\sum_{r=1}^{21} w_{-} V_{r, A-1} * I_{-} V_{r, A / A-1},
$$

where $w_{-} V_{r, A-1}$ is the share of the expenses for single-family units in region $r$, in year A-1 (see Appendix 1). This index is chained to get a national annual price index for new "individually built" single-family houses for year A, $100=2006, \forall \mathrm{A}=2007, \ldots, 2012$,
$I_{-} V_{A / 2006}=\left(\prod_{i=0}^{A-2007} \frac{I_{-} V_{A-i / A-i-1}}{100}\right) * 100$

\section{A comprehensive price index for new homes}

The index for newly built single-family houses is then aggregated to the current official IPLN index to get a comprehensive price index for new homes, adding "individuel pur", "individuel groupé", and "collectif", that we call $I P L N++$. This is done for each year. Over the period where the comparison is possible the IPLN index and the comprehensive price index $I P L N++$ are extremely close (Figures VI and VII). Extending the scope of the price index of new homes to include single-family units does not modify it significantly. The comprehensive index $I P L N++$ does not get closer to the INI. The gap even slightly increases: the average absolute difference in the annual growth rates of the two indices is now $2.0 \%$, whereas it was $1.8 \%$ with the current official IPLN.

Since the effect of the methodology has been ruled out, we hypothesize that the differences in evolution of the prices of new and secondhand dwellings come from deeper differences between the two markets. New homes are not located in the same areas as old ones; they are mostly built in the periphery of cities, where land is available and cheaper. This leads to reflect on the decomposition of the price of a home into that of the structure and that of the land, and introduce the notion of land leverage, the share of land in the home value. Then two types of experiment are conducted. The first one draws from the limited geographical information provided by the data used to compute the two indices, INI and IPLN. The distance to the city centre is not known, only the municipality. We compute the evolution of a price index for second-hand dwellings situated in the same municipalities as those newly constructed. The difference in the evolution of the two indices is somewhat reduced but not eliminated. Secondly, drawing from the EPTB survey, separate indices for land and structure are computed. Land prices seem to be driving second-hand housing prices more than construction prices. Conversely, structure prices have more influence on changes in new homes' prices. Still, the evolution of the construction cost index seems also sensitive to the general trend in land prices.

22. Floor area (GFA) replaced the net ground area (SHON) on $1^{\text {st }}$ March 2012 


\section{Figure $\mathrm{VI}$}

The INI, the official IPLN and the IPLN++ comprehensive price index

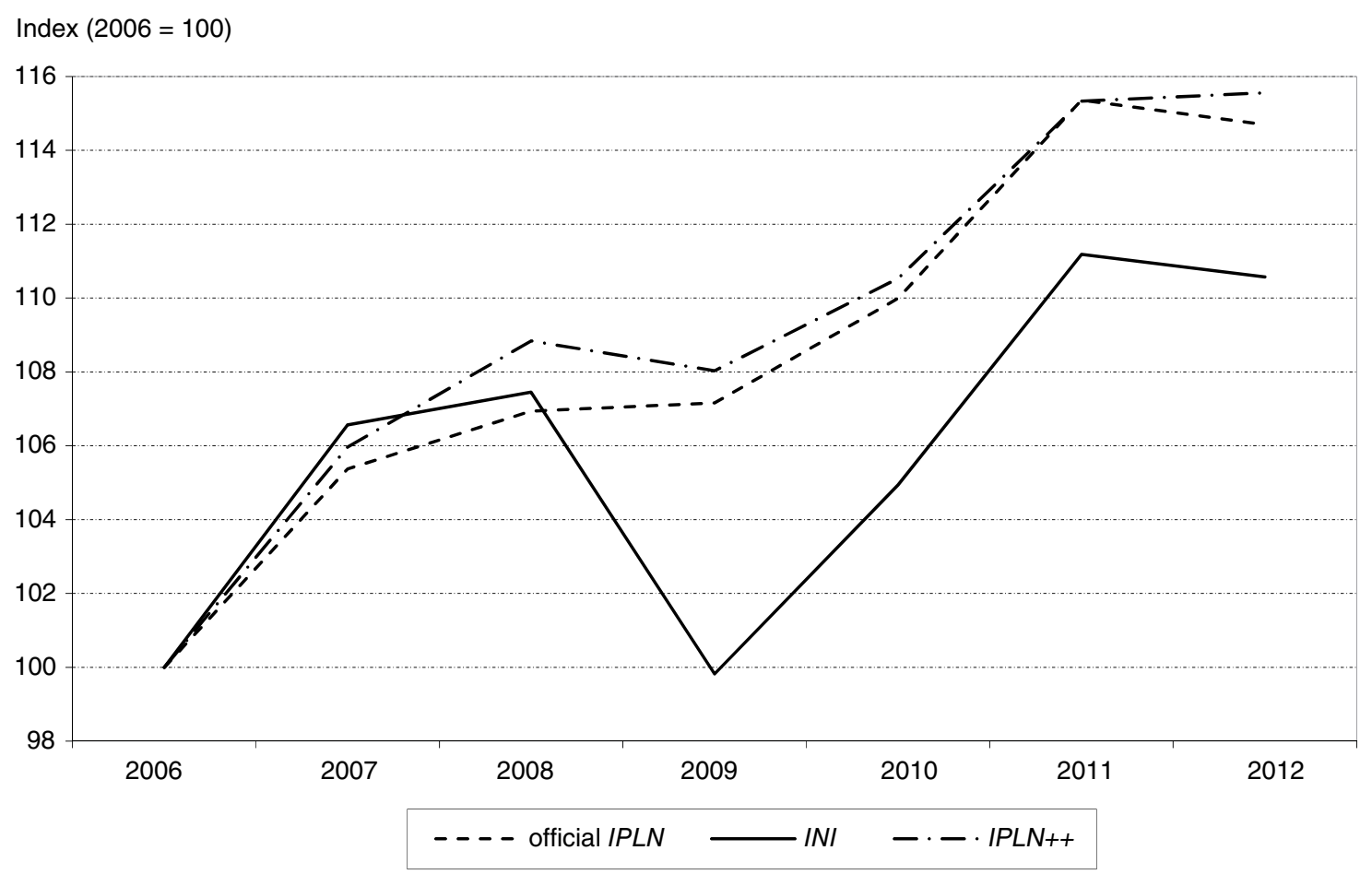

Sources: ECLN, BIEN and Perval data bases (see Table 2); authors' computation.

Figure VII

Growth rates of the INI, the official IPLN and the IPLN++ comprehensive price index

(\%)

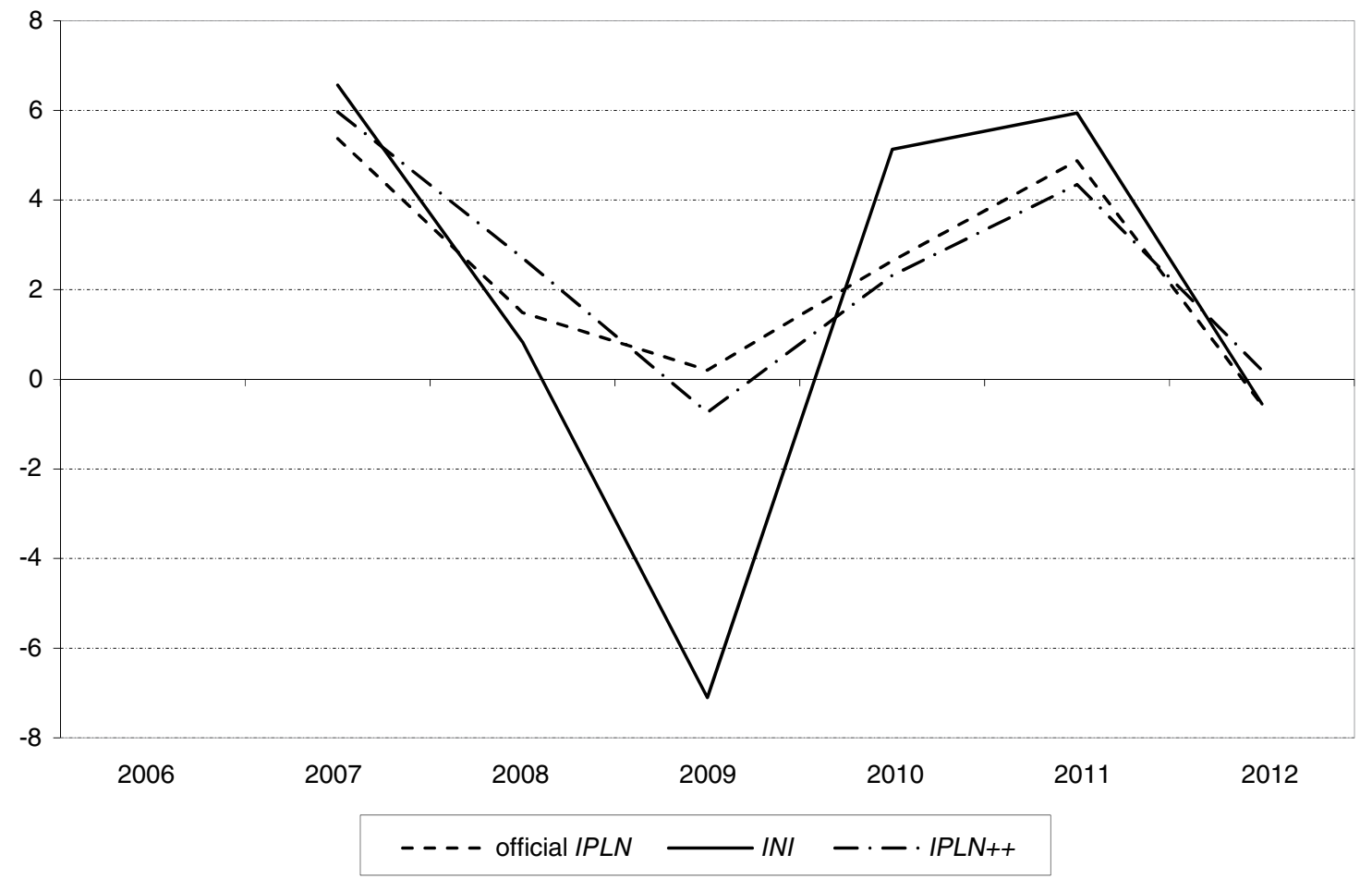

Sources: ECLN, BIEN and Perval data bases (cf. Table 2); authors' computation. 


\section{Other potential explanations: building on land}

As new buildings become old, structures quality declines while land quality might stay constant, improve (if, say, new public services, industries or transportation are emerging or developing in the area) or decline (if new sources of pollution, congestion or noise appear, or if industries disappear, or as a result of climate change). Depending on the depreciation rates of the structure and changes in land quality, the value of the "existing" dwellings will decline or increase. Supply and demand play a role, so do improvement and rehabilitation of the structure.

\section{Separating structure from land}

We start from the idea ${ }^{23}$ that at time $t$ the total value of a new house, $V$, can be separated into the land value, $L$, and the value of the building, the structure $S$ :

$V_{t}=L_{t}+S_{t}$

Let $g_{L}, g_{S}$, and $g_{V}$, denote the percentage change (say between $t$ and $t+1$ ) in the land, structure, and overall property values, respectively. With these appreciation rates, the value of the same property at date $t+1$ can be expressed in two ways:

$V_{t+1}=V_{t}\left(1+g_{v}\right)$

and

$V_{t+1}=L_{t}\left(1+g_{L}\right)+S_{t}\left(1+g_{S}\right)$,

with $g_{S}<0$ if the structure depreciates over time and the sign of $g_{L}$ depending on the evolution of land value over time.

$L_{t}\left(1+g_{v}\right)+S_{t}\left(1+g_{v}\right)=L_{t}\left(1+g_{L}\right)+S_{t}\left(1+g_{S}\right)$

$L_{t}\left(g_{v}-g_{L}\right)+S_{t}\left(g_{v}-g_{S}\right)=0$

$g_{v}\left(L_{t}+S_{t}\right)=g_{S} S_{t}+g_{L} L_{t}+g_{s} L_{t}-g_{s} L_{t}$

$g_{v}\left(L_{t}+S_{t}\right)=g_{S}\left(L_{t}+S_{t}\right)+L_{t}\left(g_{L}-g_{s}\right)$

$g_{v}=g_{S}+\left(g_{L}-g_{S}\right)\left(L_{t} / L_{t}+S_{t}\right)$

If we define the land share (or land leverage)

$\alpha_{t}=L_{t} / L_{t}+S_{t}\left(0<\alpha_{t}<1\right)$,

we can write:

$g_{v}=\alpha_{t} g_{L}+\left(1-\alpha_{t}\right) g_{S}$
From such mechanical decomposition we draw two conjectures $\mathrm{H} 1$ and $\mathrm{H} 2$.

The land share, i.e. the contribution of land in a home value, increases (decreases) over time as soon as $g_{L}>g_{S}\left(g_{S}>g_{L}\right)$. It is easy to show that:

$\alpha_{t+1}=L_{t+1} /\left(L_{t+1}+S_{t+1}\right)$

$=L_{t}\left(1+g_{L}\right) /\left[L_{t}\left(1+g_{L}\right)+S_{t}\left(1+g_{S}\right)\right]$

$\alpha_{t+1}>L_{t} /\left(L_{t}+S_{t}\right)$ if $g_{L}>g_{S}$

The land share in a new house value increases over time if the structure depreciates. Hence our first conjecture.

H1: In the same location, the land share in the value of second-hand homes will be higher than in the value of new homes if structures depreciate more, or appreciate less than land.

New homes are not located in the same areas as old ones: they are mostly built in the periphery of cities, where land is cheaper. This would predict that:

H1bis: In general the land leverage will be lower for new homes than for existing homes.

For a given net depreciation rate of structure $g_{S}$ and for the same $g_{L}$ the land leverage will influence the evolution of the home value.

Equation (5) shows that the change in the house value between $t$ and $t+1$ is the weighted mean of the evolution of land and that of structure values, where the weights are function of the share of land in the total value of the house in period $t$. If we differentiate, $d g_{v} / d \alpha_{t}=g_{L}-g_{S}$, the difference is positive (resp. negative) when $g_{L}>g_{S}\left(\right.$ resp. $\left.g_{L}<g_{S}\right)$.

H2: Price indices for second-hand dwellings, with a higher land leverage, would be more volatile than for new dwellings ${ }^{24}$. This seems to be the case at the turning point in 2009 when we compare the INI and the IPLN indices. Then the shock in demand seems to affect land values more than the value of structures.

Recalling that, for owner-occupiers, the home is both a consumption good and an investment suggests an economic interpretation.

23. Inspired among others by Bostic et al. (2007), Diewert (2011), Davis and Heathcote (2007), Davis and Palumbo (2008), Diewert et al. (2015). 24. Davis and Palumbo (2008) write: "Volatility is likely an increasing function of land's share in home value." 
Residential land value reflects more the investment dimension of the property, while the value of the structure would reflect more its consumption dimension. In a boom period, and even more in case of a price bubble, land prices would change faster than structure prices. In a recession, the consumption dimension does not change, the number of transactions drops, and the investment dimension, reflected in land prices, declines more as land prices absorb more of the shocks than the structure.

To test these ideas we conduct two types of experiment. The first relies on the different location of new and old homes. The data do not provide the distance to the city centre, only the municipality, but the sheer number of municipalities in France makes it more informative than in a country with smaller numbers of larger units. The first experiment consists in computing a second-hand price index for dwellings situated in the same municipalities as the new ones. Our second experiment will compute separate indices for land and for structure from the $E P T B$ data.

\section{The different location of new construction explains only part of the difference}

To correct as much as possible for the different locations of new versus second-hand dwellings, when the precise locations (for instance the distance to the city center) are not known, the second-hand transactions observed were re-sampled to mimic the locations of new dwellings. More precisely "geographical clones" of the new dwellings were created by drawing a sub-sample of second-hand transactions in the same municipalities as new constructions. The only difference between such "clones" and the original database is then the municipality distribution of dwellings. Thus, indices calculations carried out with the same methodology (the adjacent two-period time dummy hedonic model) on these two samples would allow assessing if the difference in the municipality location of new and second-hand dwellings can explain the differences between their price evolutions.

For this exercise, houses and flats are separated, hence the IPLN was recomputed separating houses and flats. The method is detailed in Appendix 2. We focus here on the annual growth rates of three indices. Two are computed for second-hand houses (or flats): the "clone" and the "time dummy" indices; the third is the IPLN, also separating houses and flats (Table 3 ).

The three annual growth rates together with the two standard deviations confidence interval linked to the annual growth rate of the "clone" index for houses are plotted in Figure VIII. Over the 2006-2010 period, the difference in absolute value between the growth rate of the "geographical clone" price index and that of the new houses is almost 1.6 times lower on average than the gap between the growth rate of the second-hand "time dummy" index and that of the new houses index (2.22 versus 3.65 percentage points). The drop during the crisis period is smaller in the "clone" locations. Thus, the difference in the municipality distributions of new and second-hand houses seems to explain some of the gap between the second-hand "time dummy" index and the new houses index over the period 2006-2010. However, this must be put into perspective, because the average growth rate of the new houses price index $(1.86 \%)$ is within the two standard deviations confidence interval of the "clone" price index growth rate $[0.81 \% ; 1.95 \%]$ and that of the second-hand "time dummy" price index is very close to the lower bound $(0.78 \%)$.

The results for flats show an even smaller location effect, which seems plausible as new flats are built in denser areas, hence in locations more similar to those of second-hand flats (Appendix 2).

Table 3

The methods and the samples used to compute the three indices

\begin{tabular}{|l|l|l|}
\hline Index & Method & Sample \\
\hline \multirow{2}{*}{ "Clone" index } & & $\begin{array}{l}\text { Second-hand dwellings (from notaries databases) geographical "clones" } \\
\text { of the new dwellings (from the ECLN database) }\end{array}$ \\
\cline { 1 - 1 } Second-hand "time dummy" index & Adjacent two-period time \\
New dwellings index (IPLN) & & All second-hand dwellings used to compute the Indice Notaires-Insee \\
\cline { 1 - 1 } & & New dwellings of the ECLN database \\
\hline
\end{tabular}


Figure VIII

Annual growth rates: new houses, "clone" second-hand houses, and "time dummy" indices, 2006-2010

(\%)

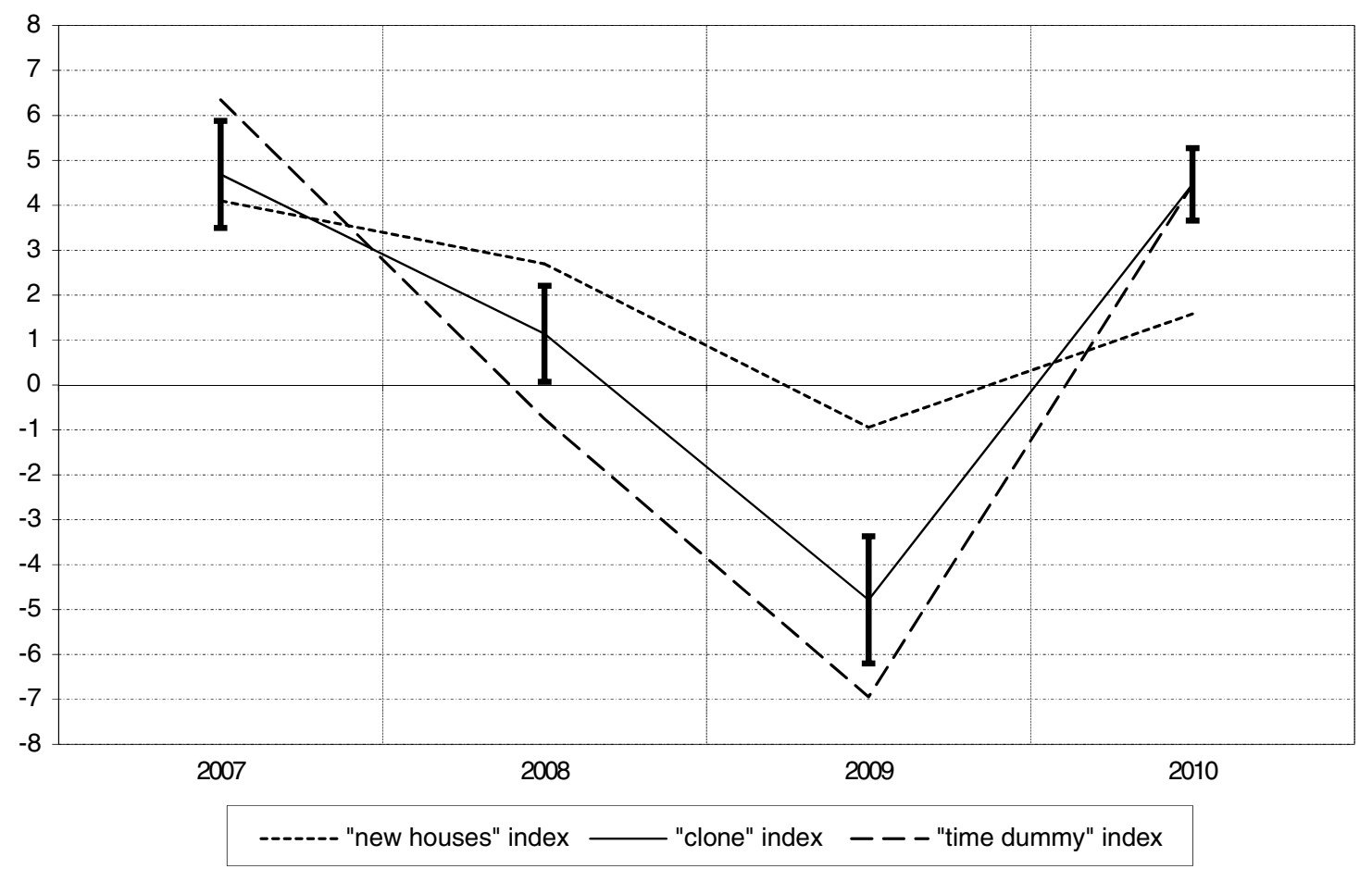

Reading note: For the "clone" index, the error bars are equal to two standard deviations. The closer the "clone" index to the new houses index, the more the difference in the municipality distributions of the new and second-hand houses can explain the gap between the second-hand houses index ("time dummy" index) and the new houses one.

Sources: ECLN, BIEN and Perval data bases (cf. Table 2); authors' computation.

We conclude that over the 2006-2010 period, the differences in municipality location have a negligible influence in 2007 and 2010 and that, even in 2008 and 2009, they do not fully explain the difference in the evolution of the two indices. It must be underlined that the correction for municipality location ignores the differences of locational distribution within a municipality. This difference is likely to be important because of the location of available land. If this could have been taken it into account, the correction might have been more effective. This leads us to the next step of our investigation.

\section{Decomposing a house price into land price and structure price}

Our second experiment draws on the EPTB and computes separate indices for land (building plots - terrains à bâtir) and structure for new "individually built" single-family houses ("individuel pur"). We compare all the indices to a construction cost index, in order to better understand the price dynamics of new homes.
In what was presented above (see section Separating structure from land), the evolution in value was not distinguished from the evolution in price. In other words, we abstracted from potential changes in home quality ${ }^{25}$. If we only consider newly built houses at each date, we can formally write the same suite of equations as above but now $g_{S}$ is the evolution of the cost of the (same quality) new structure. Equation (5) can be interpreted as giving the evolution of a constant quality new house. With the sign of $g_{S}$ depending on the evolution of construction cost (for a constant quality house) over time, and that of $g_{L}$ depending on the evolution of the price of plots for new construction. As above, the price evolution of a new house between $t$ and $t+1$ is the weighted sum of the price evolution of land and that of the structure. The land share $\alpha_{t}$ can be written as follows:

$\alpha_{t}=\left(g_{v}-g_{S}\right) /\left(g_{L}-g_{S}\right)$

25. We are very grateful to a referee for pointing that we had overlooked this delicate issue. 
It can be computed at each date.

We have to check that $0<\alpha_{t}<1$ for the validity of the computation. It can be easily shown that this condition is met if and only if:

$g_{S}<g_{v}<g_{L} \quad g_{L}<g_{v}<g_{S}$

We check below (Figure IX) that conditions (7) are met for successive cross sections of new homes.

To study how a house price is decomposed into the price of land and that of the structure we use the EPTB survey (see above). We now compute two quality-adjusted indices: a land price index and a structure price index. The adjacent period year dummy method is similar to that of the new "individually built" single-family houses price index (IPLN(IP)) computed with model (3). Only location variables and building plots characteristics are used for the land price index; building plot characteristics are dropped from the hedonic model for the structure price index, while structure characteristics are included. As for the "individually built" single-family houses index above, the models are computed at the regional level. The national indices for a year $A$ are the weighted average of the 21 regional indices, where the weights are respectively the shares of plot expenses and construction expenses in region $r$ in year $A-1$ (see Appendices 3 and $4)$. Then the indices are chained to get national annual price indices for land and structure from 2006 to 2012.

The annual evolutions of the indices for the price of land and for the price of structure are roughly similar over the period (Figures IX and $\mathrm{X}$ ). However, the changes in land price are more pronounced at each date than in structure price, except in 2010, after the crisis. For instance in 2007 , the increase is $10.9 \%$ for land, and only $4.5 \%$ for structure. In 2009 , the structure prices hardly decline $(-0.7 \%)$ when land prices decline by $3 \%$. In terms of volatility, defined as above as the standard deviation of the annual rates of change in price indices, land prices are 2.5 times more volatile than structure prices $(4.34 \%$ versus $1.73 \%)$. Oikarinen (2013) also found that land prices appeared to be more volatile than construction costs in the Helsinki Metropolitan Area between 1988 and 2008.

Nevertheless, the changes in structure prices appear to be closer than expected to those in land price. It may be because we have included the location characteristics of the house in the hedonic model for structure prices. The reason for this inclusion is that the cost of construction can vary with location, for instance with distance to providers of material. The location variables are proxies for such variation. As a robustness check we removed all location variables from the hedonic models of the structure price index; the decline in the structure price index in 2009 was unchanged (not shown). As Davis and Palumbo (2008) noted in their footnote 18 , there is a positive covariance over time between real land prices and construction costs that also affects home prices.

Using (6) we compute the estimated land leverage $\alpha_{t}$ from the evolution of the prices of land, structure and houses (Figure XI). The land leverage increases before the crisis of 2009 to much more than $50 \%(+77.4 \%$ between 2007 and 2008), which we interpret as a sign of the impending price bubble. In 2007 and 2008 (and probably for years before, that unfortunately we cannot observe) the price evolution of construction is less than that of land $\left(g_{S}<g_{v}<g_{L}\right)$. Then the crisis hits and the price of residential land declines by $3 \%$. However, the price evolution of construction is also influenced by the crisis, and it also declines in 2009, then rebounds in 2010 , with the result of increasing the estimated (i.e. ex post) land share in 2009. At the end of the period, the mean share does not rise much and stays around $31-32 \%$ while the estimated $\alpha$ is $36 \%$ in 2010 , and $43 \%$ in 2011.

Our method also allows computing the evolution of land share $\alpha_{t}$ by region, since hedonic models were computed in each region. The peak in land share is strikingly important in Île-de-France, reaching $74 \%$ in 2008 . It was $56 \%$ in Provence-Alpes-Côte d'Azur, 52\% in Rhône-Alpes (Figure XI). They are the three richest French regions. The bursting of the price bubble on second-hand homes was more important in those regions: between 2008_Q4 and 2009_Q2 prices dropped by $7.8 \%$ in Ile-de-France and Rhône-Alpes, by $7.2 \%$ in Provence-Alpes-Côte d'Azur and only by $6.6 \%$ in the whole of the Province. By contrast no bubble appears in Basse-Normandie. At the end of the period, in 2011, land share is higher in Provence-Alpes-Côte d'Azur - it kept rising after 2008 - than in Rhônes-Alpes. 
Figure IX

"New land" and "new structure" price indices for new "individually built" single-family homes and IPLN(IP) Index $(2006=100)$

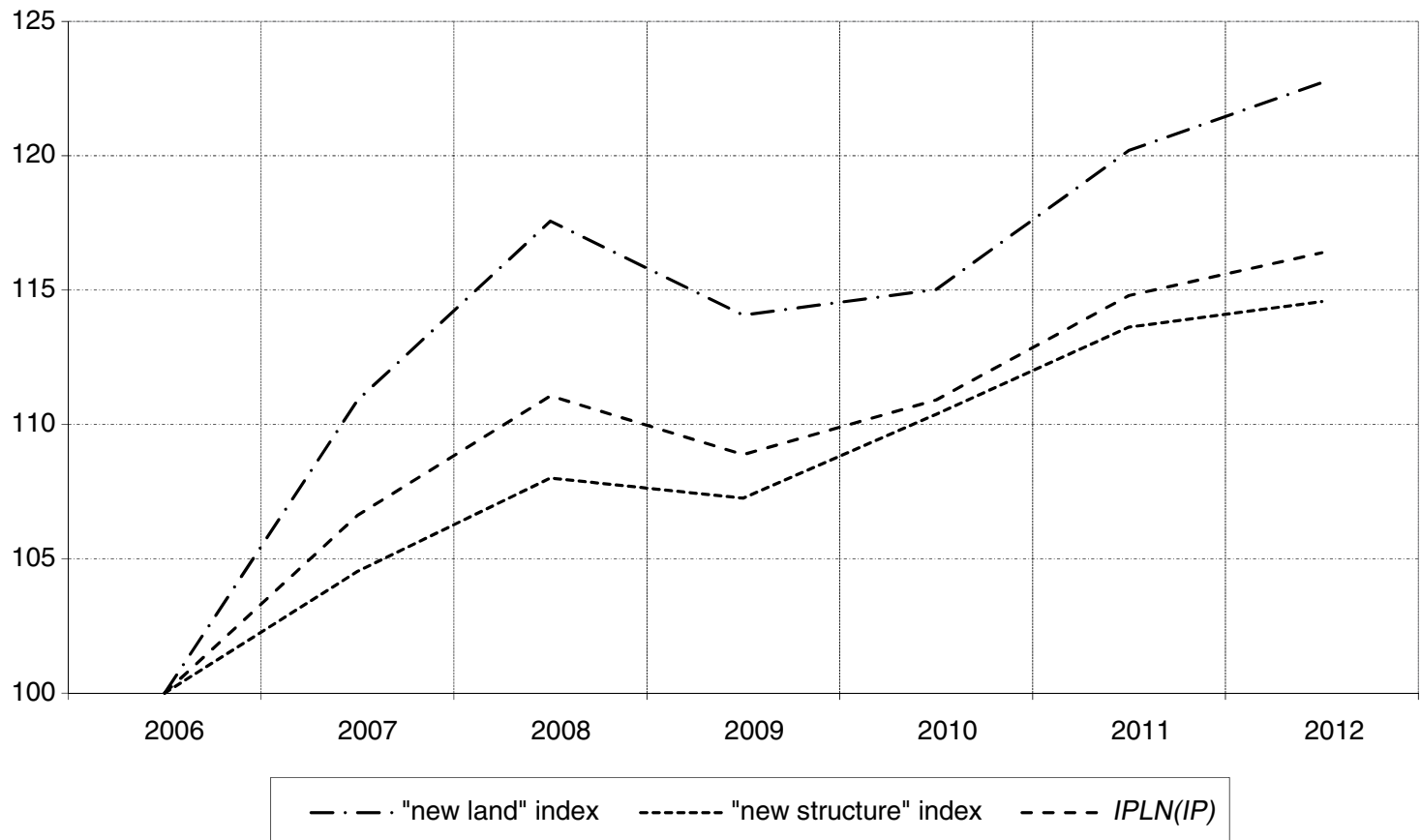

Sources: Authors computation from EPTB.

Figure $X$

Growth rates of "new land" and "new structure" price indices for new "individually built" single-family homes and of IPLN(IP), and estimated national share of land

Growth rate (\%)

Land share (\%)

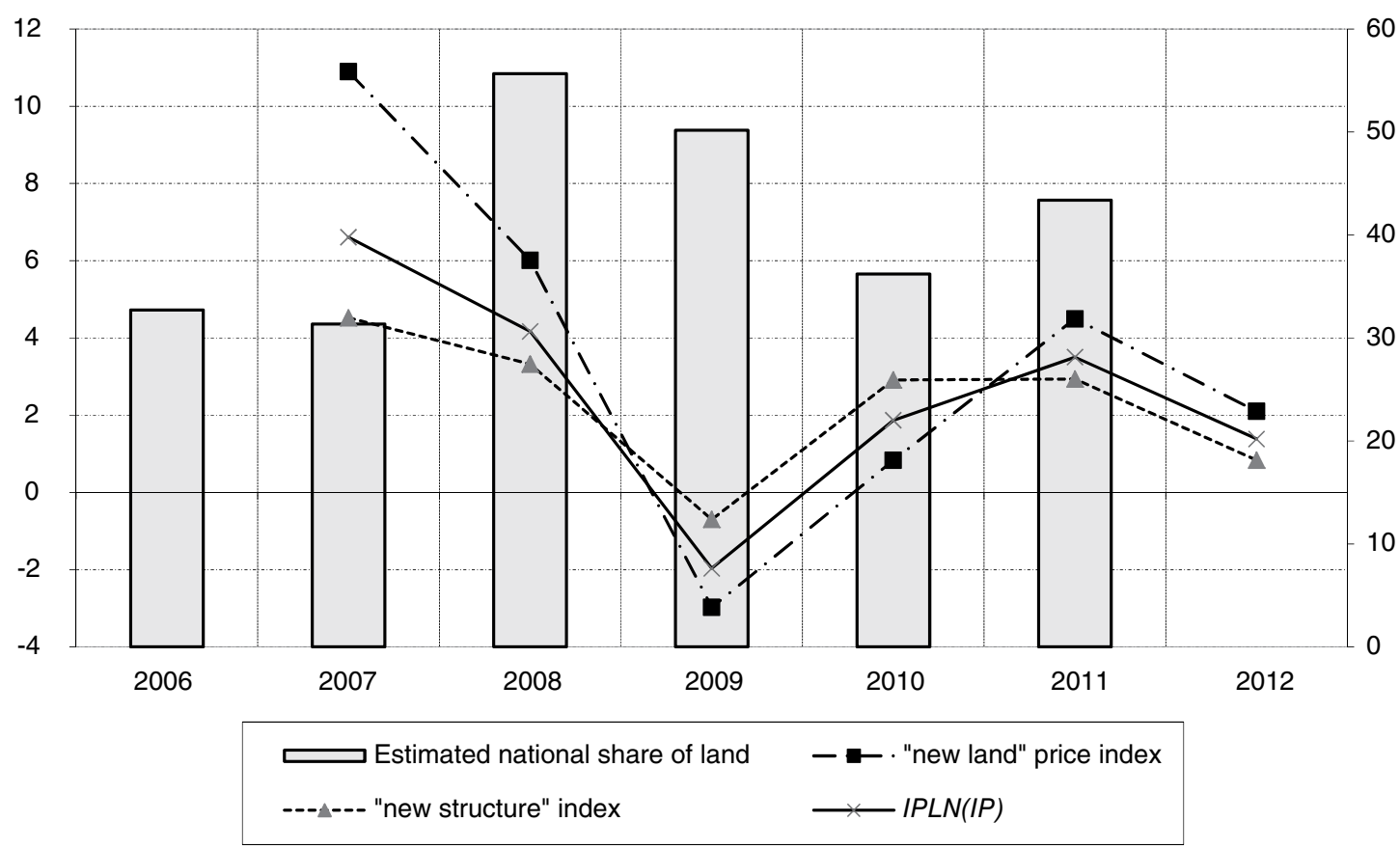

Reading note: Land share went as high as $56 \%$ in 2008, then dropped by about 20 percentage points in 2010 (right axis). Sources: Authors' computation from EPTB. 


\section{Figure XI \\ Estimated share of land under new houses in selected regions}

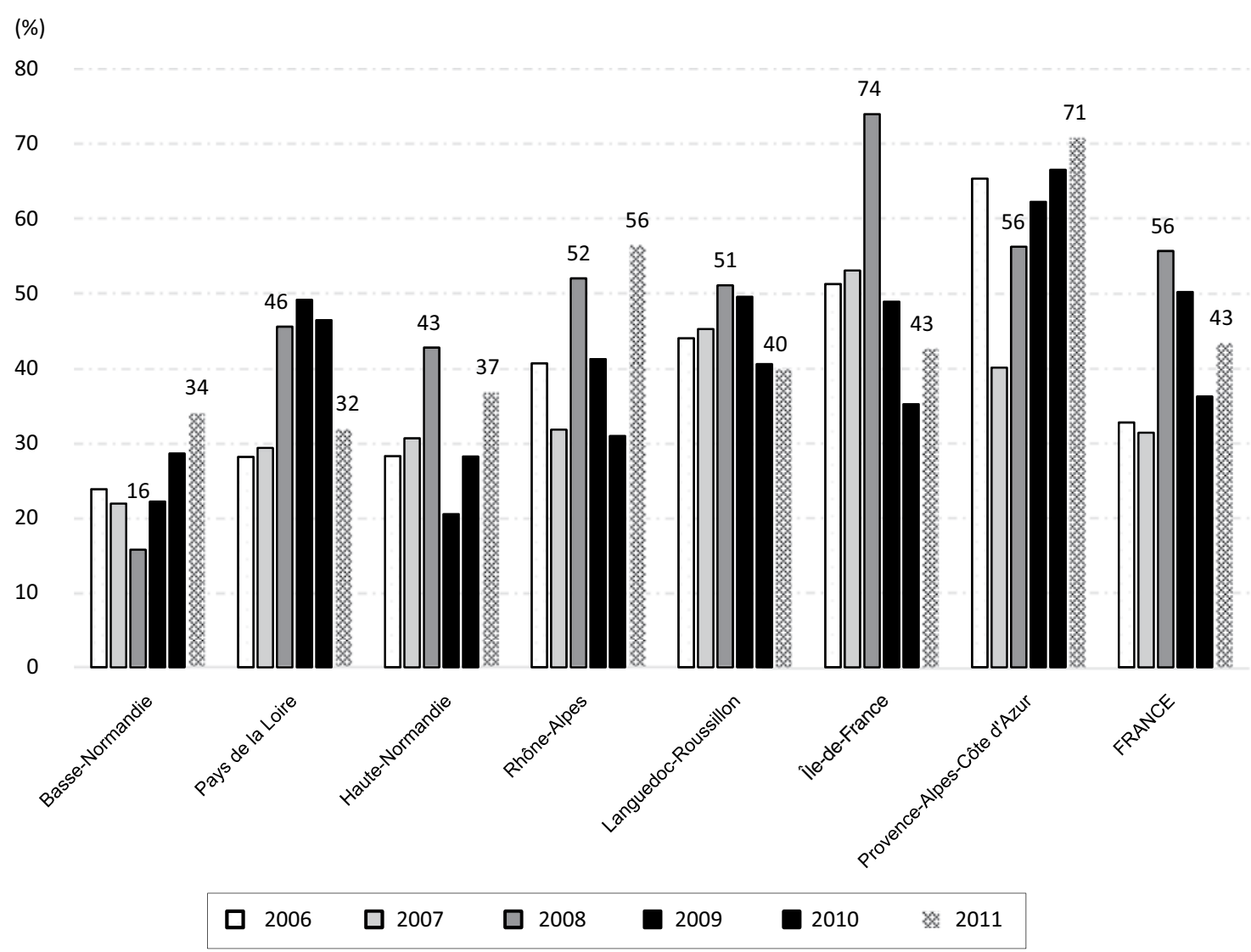

Sources: Authors' computation from EPTB.

\section{Land price index and the Indice Notaires-Insee for existing houses vs structure price index and the comprehensive price index}

The four price indices, namely the "new land", "new structure", the $I P L N++$ for new dwellings and the $I N I$ for existing dwellings, have roughly similar evolution over the whole period 2006-2012 (Figure XII). The "new land" price index evolution and that of the INI have more marked and synchronized evolutions during the bust period of 2009 , respectively $-3 \%$ and $-6 \%$ than the structure and comprehensive new dwellings indices (only $-1 \%$ ) (Figure XIII).

What partly drives the evolution of the housing market is the demand for location, i.e. the demand for land. If the land share under existing dwellings is higher than the land share under new dwellings, it could explain why land prices have grown faster than structure prices these last years. As Oikarinen (2013) wrote: "Since land prices appear to be more volatile than construction costs, it is anticipated that greater share of the land value component leads to more volatile housing prices." According to our estimation, the volatility of the price of the land under new single-family houses is more than twice that of the structure itself. This, for us, is part of the explanation of the greater volatility of the price index for second-hand dwellings (INI) compared to the IPLN (Table 4).

It can also be noticed that when the land price index is around 123 in 2012, the structure price index is around 115. It may seem surprising that the structure price index has increased so much over a period of six years. It could be that productivity did not improve in construction or, as some have argued, that wages, traditionally low in that sector have improved. It is also probable that the quality of homes has improved and that this is not taken into account fully in our hedonic model for lack of detailed information on house characteristics. New stringent norms of construction also play a role. Note however that our structure price index is very similar to the index of 


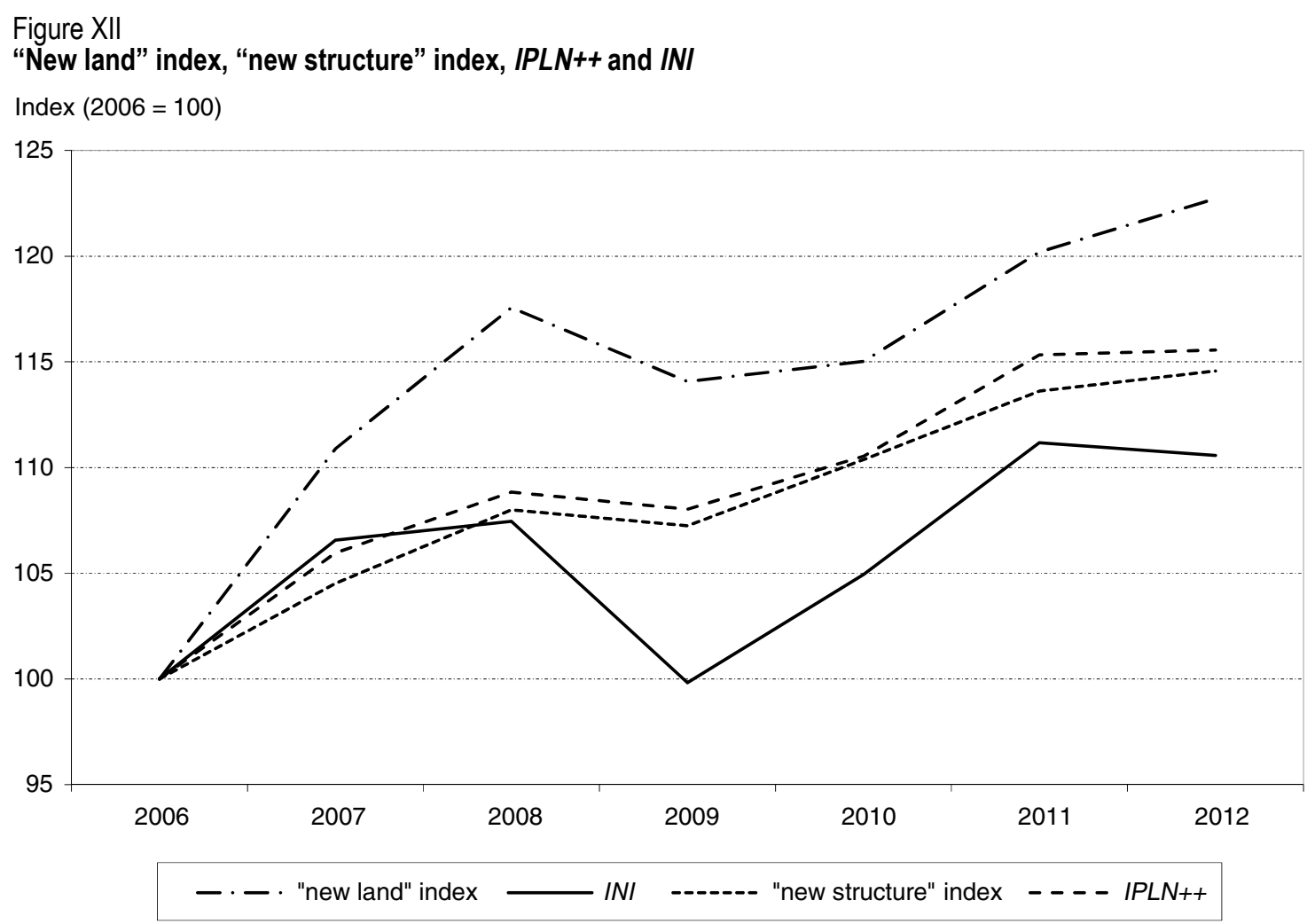

Sources: EPTB, ECLN, BIEN and Perval data bases (cf. Table 2); authors' computation.

Figure XIII

Growth rates of the "new land" index, "new structure" index, IPLN++ and INI

(\%)

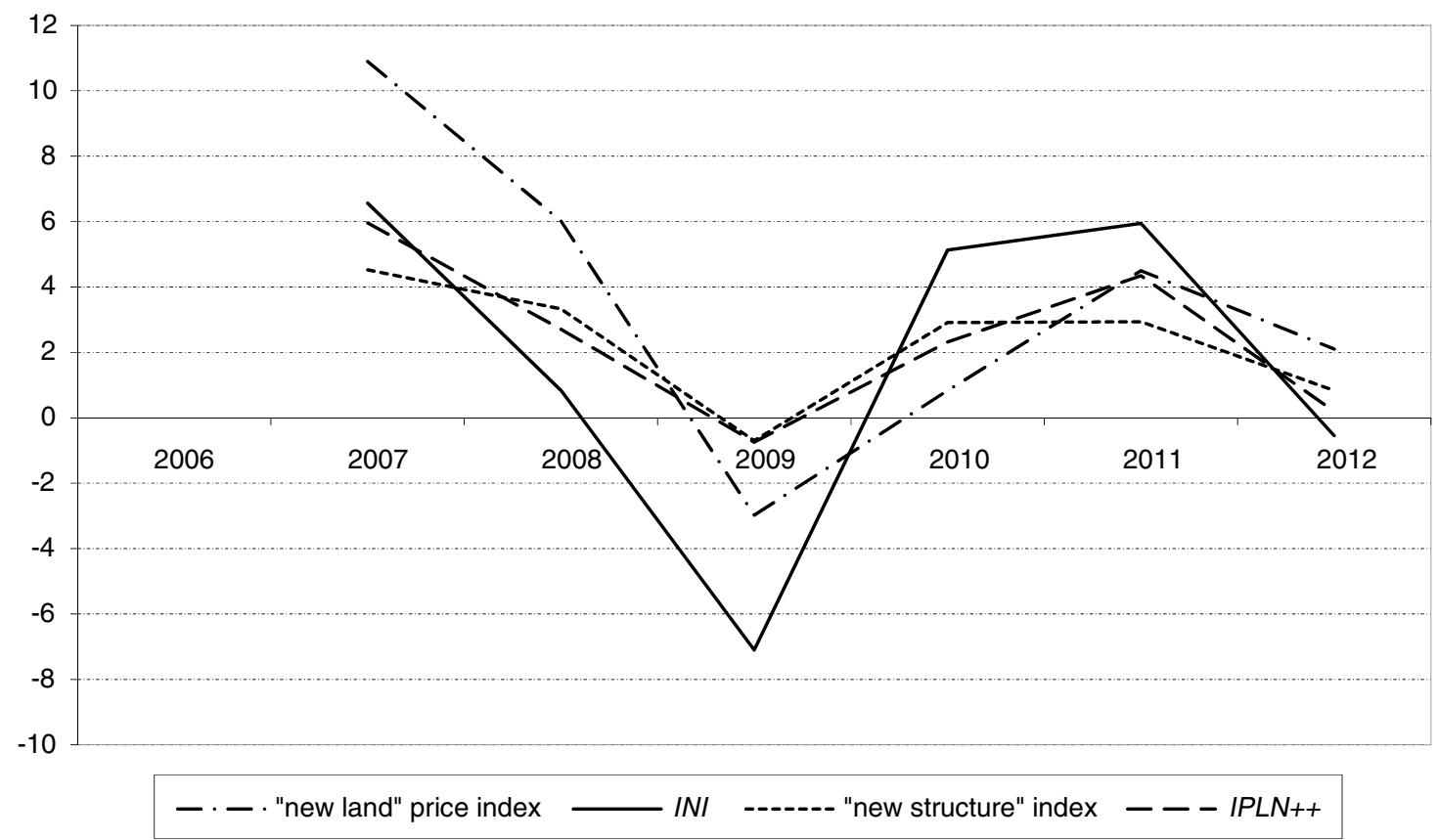

Sources: EPTB, ECLN, BIEN and Perval datsa bases (cf. Table 2); authors' computation. 
Table 4

Volatility of the various housing price indices over 2007-2012

\begin{tabular}{|l|c|}
\hline Index & Volatility 2007-2012 (in \%) \\
\hline INI & 4.77 \\
"New land" & 4.34 \\
IPLN(IP) & 2.65 \\
IPLN++ & 2.28 \\
IPLN & 2.22 \\
"New structure" & 1.73 \\
\hline
\end{tabular}

Note: Volatility is defined as the standard deviation of the annual rates of evolution in price indices.

construction cost (BT01), which is supposed to be a constant quality index (see Appendix 5).

\section{Demand and supply of new construction}

The price index for new dwellings is less volatile than the price index for second-hand dwellings. We did not find any related study on the relative volatility of new versus second-hand housing price indices. Richmond and Roener (2012) about US data wrote just the reverse of what we find: "Fluctuations in the price of new homes are known to be stronger than those of second-hand homes". They do not provide references. Volatility may be linked to the variability in new housing investment. For Topel and Rosen (1988), the short run supply price elasticity of investment in single-family homes is smaller than the long run elasticity, which is as high as 3 , and the two elasticities converge quickly. The low volatility in France would mean that the construction cycle is longer and much less reactive to prices than in the US.

We relate the variation in prices to the variation in the number of sales, relying on annual numbers of sales and constructions as quarterly numbers are not available. Figure XIV presents the estimated number of sales of second-hand homes and compares it to the total number of new constructions, separately for private homes (defined as those sold at market price) and non-private homes (social housing, either not sold or sold below market price thanks to various subsidies). It is not straightforward to compute such numbers because social housing is more and more built in "VEFA" (that is, dwellings sold before they are built - vente en l'état futur d'achèvement) by private developers who sell them at a discount, either to social housing agencies or to individual low-income buyers. As in Table 1, we combine information from building permits (logements commencés) in Sit@del2 and that of subsidised operations from CDC (2015) on the number of social dwellings produced.

More interesting here than the exact number of homes built are the diverging trends in construction of private and non-private homes. In 2008 , the number of sales declined by $17 \%$ for second-hand homes when the price evolution started to slow down; the number of homes built for the private market also declined markedly $(-24 \%)$ but the number of publicly financed new constructions increased by $16 \%$ (25\% when the "VEFA" sales are included). The prices evolution of new homes slowed down less than second-hand homes. In 2009, the crisis year, when second-hand home prices declined by $9 \%$ in annual rhythm in quarter 2 , the number of sales declined for second-hand homes $(-12 \%)$, the number of homes built for the private market also declined (-24\%); the number of publicly financed new construction increased significantly $(+22 \%,+27 \%$ including "VEFA") and increased even more in 2010 (cf. Figure XIV). Such countercyclical movement in subsidized construction does not compensate the overall decline, since publicly financed housing represents only $18 \%$ of new constructions (cf. Table 1). But the rather sustained demand for new homes may have helped maintain their prices: one element of explanation could be that builders, since the SRU law of 2000, must include a certain percentage of subsidized homes in a new project, so the price they can sell a home on the subsidized sector market influences the price on the private market. This could contribute to explain the more moderate decline in new homes prices compared to second-hand homes prices during the crisis $^{26}$.

26. Developing this interesting topic is left to future research 
Figure XIV

Number of new constructions built for the private and for the non-private market, and of second-hand sales

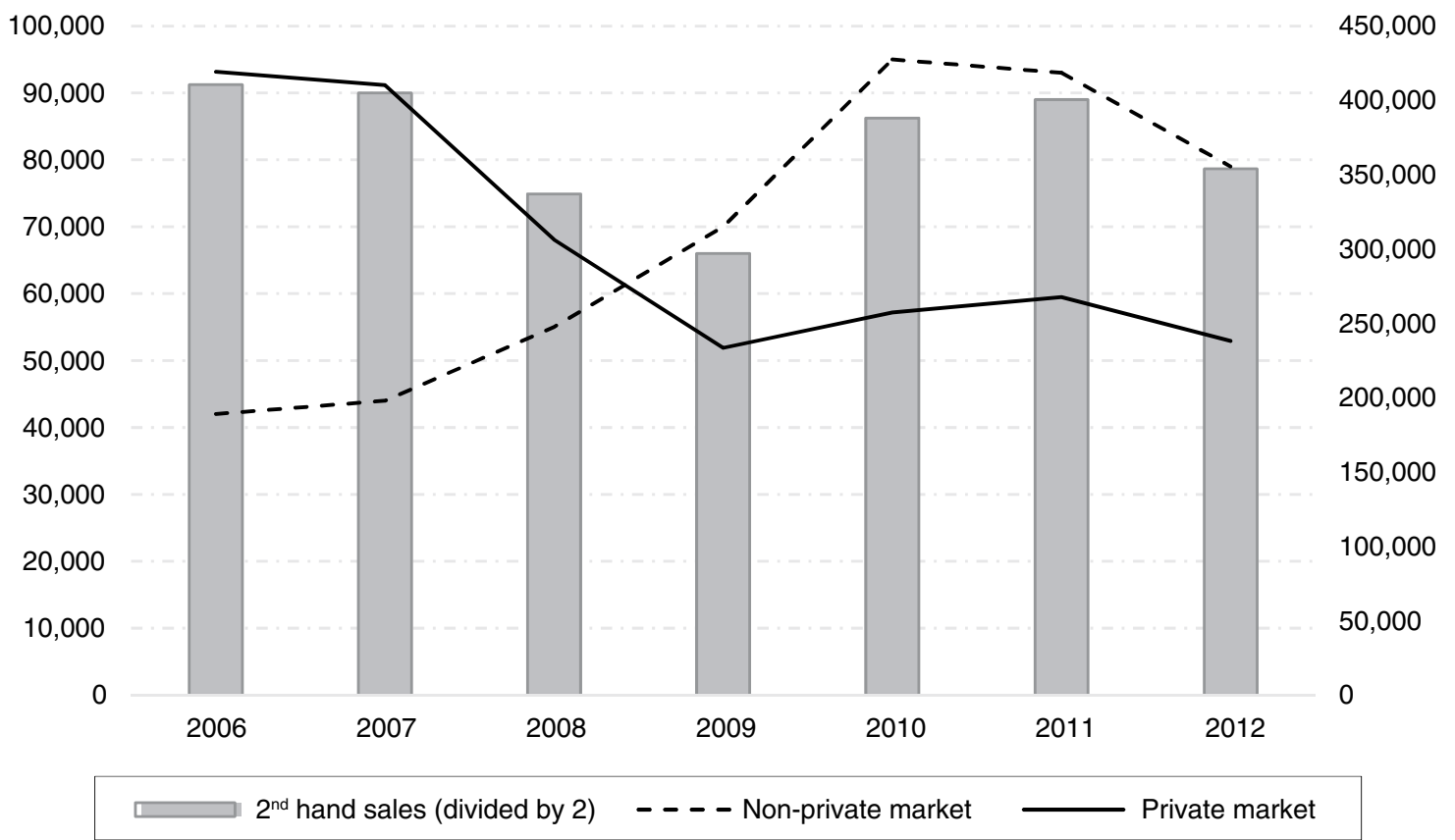

Note: "Non-private market" includes housing owned in private-public partnerships (logements non conventionnés appartenant à une Société d'économie mixte)

Reading Note: While new constructions of homes for the private market (line, right vertical axis) declined in 2008 and 2009 , as did the number of second-hand home sales (bars, right axis - numbers are divided by 2 in order to fit in the picture), the construction for the subsidized sector (line, left vertical axis) increased.

Sources: SOeS, Survey on social rental housing (Enquête sur le parc locatif social, EPLS) and Register of rental social housing (Répertoire des logements locatifs des bailleurs sociaux, RPLS).

Another potential factor of the evolution of new homes prices is the new fiscal incentive to invest in "buy to rent", called dispositif Scellier created in $2009^{27}$. Contrary to former public policy schemes (known as Robien, Borloo and Périssol, from the names of the person who promoted them) the Scellier was focused on new homes, with an explicit aim of promoting construction and increasing housing supply. It ended in 2012. In 2009 the Scellier represented two-third of new homes construction (Rapport de la Commission des Finances ${ }^{28}$ ) and $70 \%$ in 2010 . However we are not aware of any study of its net effect on housing construction compared to former schemes ${ }^{29}$. These schemes have been shown to have price effects (Bono \& Trannoy, 2012), and they may have contributed to the reduced decline in new homes prices in 2009. Concluding on causality is beyond the scope of this paper.

Many buyers of homes are also sellers of their former home. This explains why the demand for housing and prices evolve in the same direction. This suggests another non-exclusive explanation for the more modest evolution of new homes prices compared to second-hand housing prices. Homeowners who want to move have a tendency to wait in periods of price decline because of down-payment constraints or loss aversion (Stein, 1995). This partly explains the huge decline in the number of sales of second-hand dwellings in 2009 , in line with the decline in prices. Home builders cannot afford to lower their prices, and the buyers of new homes are more often first-time buyers than homeowners. They are less influenced by the decline in prices of second-hand homes and may have settled on the price at the time the construction was started. Indeed, according to the Enquete Logement 2013 (Insee), 61\% of those who recently purchased a newly built home ${ }^{30}$ were first-time buyers (39\% already owned their home), while they were only $52 \%$ among those who bought a second-hand home (and $48 \%$ already homeowners). First-time buyers are more likely to buy newly built homes than buyers

\footnotetext{
27. We are grateful to a referee for the suggestion

28. http://www.assemblee-nationale.fr/13/rap-info/i3631.asp. Quoted by Levasseur (2011).

29. Grislain-Letrémy and Trevien (2016) conclude to an absence of effect of rent subsidy to tenants on rental supply.

30. Defined here as a home built less than 5 years ago.
} 
who already owned a home $(32.5 \%$ versus $29.2 \%$ ) (Insee, 2017, p. 117). Hence, new home buyers may be less likely than second-hand homes buyers to wait for a period of price decline for their purchase, because they do not suffer from a decline in the price of their own home. For them, the purchase may be a more long-term operation. This may contribute to explain the more moderate reaction of new home prices compared to secondhand homes.

To summarize, during the crisis years (2008-2009) the relative decline in the number of constructions was larger than the decline in the number of sales of second-hand homes, but the price shock was lower. However, among new homes, the number built as social housing has increased, especially during the crisis years. This, together with public policy schemes supporting new home construction and the behaviour of buyers and developers, may have attenuated the demand shock, hence limited the price decline. In other words, the different characteristics of the markets for new and second-hand homes may explain the lower sensitivity of new home prices in downturns, and their lower overall volatility.

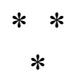

The starting motive of this paper was to look for reasons why the price evolutions of new and second-hand dwellings would differ, and more precisely, in France, why the official IPLN price index for new homes and the Indice Notaires-Insee (INI) for second-hand homes differ, with the second being more volatile than the first. Two first sources of differences were explored. First, the hedonic $I N I$ was recomputed using the more simple IPLN two-period time-dummy method. The difference accounts for 1 to 2 percentage points of growth rate, less than the difference to be explained (2.4 percentage points over the 2006-2015 period), especially at the turning point of 2009. Second, we extended the scope of the IPLN by complementing it with an index for new individually built single-family houses ("individuel pur"), which represent around $39 \%$ of new constructions for the private market: using data on the construction of single-family houses built individually on plots that have been purchased separately
$(E P T B)$, we compute an alternative comprehensive price index $I P L N++$ including such individually built houses. The new comprehensive index did not differ much from the current IPLN.

We then turned to other sources of differences in the markets for second-hand and new homes. New homes are mostly built in the periphery of cities, where land is available and cheaper, while old ones are closer to city centres. Decomposing the value of a house between land and structure shows that the price evolution of a house, new or secondhand, is the weighted sum of the price evolution of land and that of the built structure, where the weights are function of the share of land in the total value of the property. The share of land in a home value, the land leverage, is smaller for newly built homes than for second-hand ones. When the structure depreciates over time, this might influence price evolution. We show that the higher the land leverage, the higher the volatility of the index. This would explain what is observed on French data: the index for second-hand dwellings, with a higher land leverage, is more volatile than the new dwellings index.

The decomposition led to conduct two experiments. We computed a second-hand price index for dwellings situated in the same municipalities as the new ones. The difference between the two indices is somewhat reduced but not eliminated. Then separated price indices for land and structure were computed. Land price and second-hand housing price evolutions appear very similar, and their volatilities are close. Structure prices have more influence on new homes price indices. However construction prices also reacted to the demand shocks during the crisis. An output of the computation provides land shares and their evolution over time. They increased before the crisis, especially in the richest regions where demand was high.

Coming back to the differences in volatility of the two indices, particularly large during the 2008-2009 crisis, time series of sales and constructions suggest that the countercyclical building of social housing might have contributed to support new home prices and explains their lower volatility. More work is clearly to be done on the differences in the markets for new homes and for second-hand homes, to explore why the former might be less reactive than the latter in terms of prices. 


\section{BIBLIOGRAPHY}

Balcone, T. (2013). Mémoire de master de statistique publique. Miméo, ENSAI.

Balcone, T. (2018). Élaboration d'un indice de prix des logements neufs dans le cadre de la nouvelle réglementation Européenne 93/2013. InseeDocument de travail DSDS (à paraître).

Bono, P.-H. \& Trannoy, A. (2012). Évaluation de l'impact du dispositif Scellier sur les prix fonciers. Document de travail.

https://halshs.archives-ouvertes.fr/halshs-00796188/ document

Bostic, R.C., Longhofer, S.D. \& Redfearn, C.L. (2007). Land leverage: decomposing home price dynamics. Real Estate Economics, 35(2), 183-208. http://dx.doi.org/10.1111/j.1540-6229.2007.00187.x

CDC (Caisse des Dépôts), 2015. Logements sociaux produits en VEFA : retour d'expérience. Éclairages, Étude $\mathrm{N}^{\circ} 7$.

https://www.prets.caissedesdepots.fr/IMG/pdf/ eclairages_numero_7.pdf

Clarenc, P., Côte, J.-F., David, A., Friggit, J., Gallot, P., Gregoir, S., Laferrère, A., Nobre, A., Rougerie, C. \& Tauzin, N. (2014). Les indices Notaires-Insee de prix des logements anciens. Insee Méthode, 128.

https://www.insee.fr/fr/information/2569926

Davis, M.A. \& Heathcote, J. (2007). The Price and Quantity of Residential Land in the United States. Journal of Monetary Economics, 54(8), 2595-2620. https://doi.org/10.1016/j.jmoneco.2007.06.023

Davis, M.A. \& Palumbo, M.G. (2008). The Price of Residential Land in Large U.S. Cities. Journal of Urban Economics, 63(1), 352-384. https://doi.org/10.1016/j.jue.2007.02.003

Diewert, W. E. (2011). Alternative Approaches to Measuring House Price Inflation. WP, University of British Columbia.

Diewert, W. E., Haan, J. de \& Hendriks, R. (2015). Hedonic Regressions and the Decomposition of a House Price Index into Land and Structure Components. Econometric Reviews, 34(1-2), 106-126. https://doi.org/10.1080/07474938.2014.944791
Friggit, J. (2014). Évaluation du nombre de mutations de logements à titre onéreux et gratuit par statut d'occupation. Rapport du Conseil Général de l'environnement et du Développement durable $\mathrm{N}^{\circ}$ 008187-02.

www.ladocumentationfrancaise. fr/var/storage/rapports-publics/144000669.pdf

Gouriéroux, C. \& Laferrère, A. (2009). Managing Hedonic Housing Price Indices: the French Experience. Journal of Housing Economics, 18(3), 206-213.

Grislain-Letrémy, C. \& Trevien, C. (2016). The Impact of Housing Subsidies on the Rental Sector the French example, Working paper.

Insee (2017). Propriétaires occupants, acquisitions et accession. Insee Référence - Les conditions de logement en France, pp. 116-117. https://www.insee.fr/fr/statistiques/2586377

Levasseur, S. (2011). Dispositif Scellier : un bilan contrasté pour un coût élevé. Ofce, Le Blog. http://www.ofce.sciences-po.fr/blog/dispositif-scellier-un-bilan-contraste-pour-un-cout-eleve/

Oikarinen, E. (2010). An Econometric Examination on the Share of Land Value of Single-family Housing Prices in Helsinki. Research on Finnish Society, 3, 7-18.

Richmond, P. \& Roehner, B. (2012). The predictable outcome of speculative house price peaks. Evolutionary and Institutional Economics Review, 9(1), 125-139.

https://doi.org/10.14441/eier.A2012005

Stein, J. C. (1995). Prices and Trading Volume in the Housing Market: A Model with DownPayment Effects. The Quarterly Journal of Economics 110, 379-406.

https://www.jstor.org/stable/2118444? seq=1 \#page_scan_tab_contents

Topel, R. \& Rosen, S. (1988). Housing Investment in the US. Journal of Political Economy, 96(4), 718-740. 
APPENDIX 1

WEIGHTS FOR THE NEW “INDIVIDUALLY BUILT" SINGLE-FAMILY HOUSE PRICE INDEX IPLN (IP)

$w_{-} V_{A-1}^{r}$ is the share (in \%) of the expenses for single-family units in region $r$ in the total expenses of year A-1 :

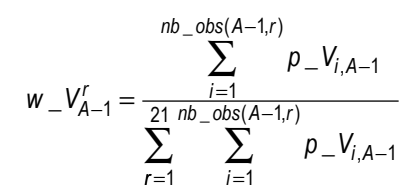

$(\ln \%)$

\begin{tabular}{|l|c|r|r|r|r|r|r|}
\hline Region & $2006-2007$ & 2008 & 2009 & 2010 & 2011 & 2012 & Mean \\
\hline ÎLE-DE-FRANCE & 8.95 & 7.97 & 8.12 & 6.23 & 3.54 & 4.43 & 6.88 \\
CHAMPAGNE-ARDENNE & 2.55 & 2.53 & 2.74 & 2.51 & 1.81 & 1.67 & 2.34 \\
PICARDIE & 2.52 & 2.34 & 2.13 & 2.90 & 2.81 & 3.16 & 2.63 \\
HAUTE-NORMANDIE & 2.84 & 3.13 & 2.73 & 3.32 & 3.67 & 3.70 & 3.17 \\
CENTRE & 4.38 & 4.24 & 3.96 & 4.81 & 5.39 & 4.56 & 4.53 \\
BASSE-NORMANDIE & 3.10 & 3.37 & 3.22 & 3.22 & 3.42 & 3.65 & 3.30 \\
BOURGOGNE & 2.24 & 2.44 & 2.01 & 2.38 & 2.22 & 2.45 & 2.28 \\
NORD-PAS-DE-CALAIS & 3.91 & 4.01 & 3.46 & 3.55 & 3.72 & 3.92 & 3.78 \\
LORRAINE & 3.04 & 2.74 & 2.45 & 2.66 & 2.76 & 2.87 & 2.79 \\
ALSACE & 2.63 & 2.75 & 3.10 & 2.44 & 1.68 & 2.00 & 2.46 \\
FRANCHE-COMTÉ & 2.17 & 2.11 & 1.99 & 2.06 & 2.67 & 2.34 & 2.22 \\
PAYS DE LA LOIRE & 13.24 & 12.45 & 13.96 & 13.12 & 12.48 & 11.26 & 12.82 \\
BRETAGNE & 8.87 & 8.12 & 8.19 & 8.50 & 9.77 & 9.91 & 8.89 \\
POITOU-CHARENTES & 4.07 & 6.76 & 8.03 & 6.17 & 5.05 & 4.62 & 5.54 \\
AQUITAINE & 6.12 & 6.15 & 6.49 & 6.85 & 7.86 & 7.70 & 6.75 \\
MIDI-PYRÉNÉES & 5.86 & 5.45 & 5.25 & 5.57 & 7.02 & 6.53 & 5.93 \\
LIMOUSIN & 1.22 & 1.33 & 1.19 & 1.26 & 1.36 & 1.37 & 1.28 \\
RHÔNE-ALPES & 9.37 & 9.94 & 10.26 & 9.89 & 11.09 & 11.49 & 10.20 \\
AUVERGNE & 2.19 & 2.21 & 2.40 & 2.41 & 2.44 & 2.47 & 2.33 \\
LANGUEDOC-ROUSSILLON & 5.22 & 4.91 & 4.58 & 5.59 & 5.44 & 5.25 & 5.17 \\
PROVENCE-ALPES-CÔTE D'AZUR & 5.53 & 5.03 & 3.75 & 4.57 & 3.80 & 4.67 & 4.70 \\
All & 100.00 & 100.00 & 100.00 & 100.00 & 100.00 & 100.00 & 100.00 \\
\hline
\end{tabular}

Note: 2006 and 2007 have the same weight because 2006 is the first year for which data are available. Sources: EPTB; authors' computation. 


\section{CONSTRUCTION OF THE GEOGRAPHICAL “CLONE” INDICES FOR THE SECOND-HAND DWELLINGS}

The clone database is built up in the following way. The number of new dwellings transactions in $E C L N$ and the number of second-hand dwellings transactions in the Notaries' databases are computed for each triplet 'year (instead of quarter to have enough observations) - type of dwelling (houses, only "Individuel groupé" in ECLN, or flats) - municipality (arrondissement for Paris, Marseille and Lyon)' over the 2006_Q1-2010_Q4 period.

Only triplets for which sales of both new and second-hand dwellings exist are kept. We thus miss $6 \%$ of the new dwellings sold during the period, i.e. for them no "clone" second-hand dwelling is sold. To check the effect of the selection of the non-missing triplets, we re-compute the index leaving out those $6 \%$. The annual index does not differ by more than 0.6 index point over the period. Then, for each triplet, a sample of "clones" of new dwellings among the corresponding second-hand dwellings is randomly drawn (with replacement). This "clone" population has the same municipality distribution as the new dwellings. For each triplet (year; type of dwelling; municipality), the number of "clones" is equal to the number of new dwellings. An index for the "clones" population is computed over the period 2006-2010 using the same adjacent two-period time dummies hedonic model as that used for new dwellings. To get a better estimation of the annual growth rate of the "clone" index, 50 different samples of "clones" dwellings are drawn. Thus, we focus on the mean and the standard deviation of the annual growth rates of 50 "clone" indices. However, to simplify, we speak of the "clone" index. Two indices are computed: one for "clones" houses, another for "clones" flats. The year is now the elementary time level.

We concentrate, for houses and flats, on the annual growth rates of the three following indices: the "clone", the "time dummy" and the new dwellings indices (recomputed separately for houses and flats) (see table 3).

For flats, the "clone" index growth rate is very close to that of the second-hand "time dummy" index. The difference in absolute value between the annual growth rates of these two indices is on average less than 0.70 percentage points over the $2006-2010$ period $(0.68$ percentage points, Figure A2.I). If we put aside year 2009, the gap falls below 0.50 percentage points, even if, again, the crisis year is less marked in the "clones" locations.

\section{Figure A2.I}

\section{Annual growth rates: new flats, "clone" second-hand flats and "time dummy" indices, 2006-2010}

(In \%)

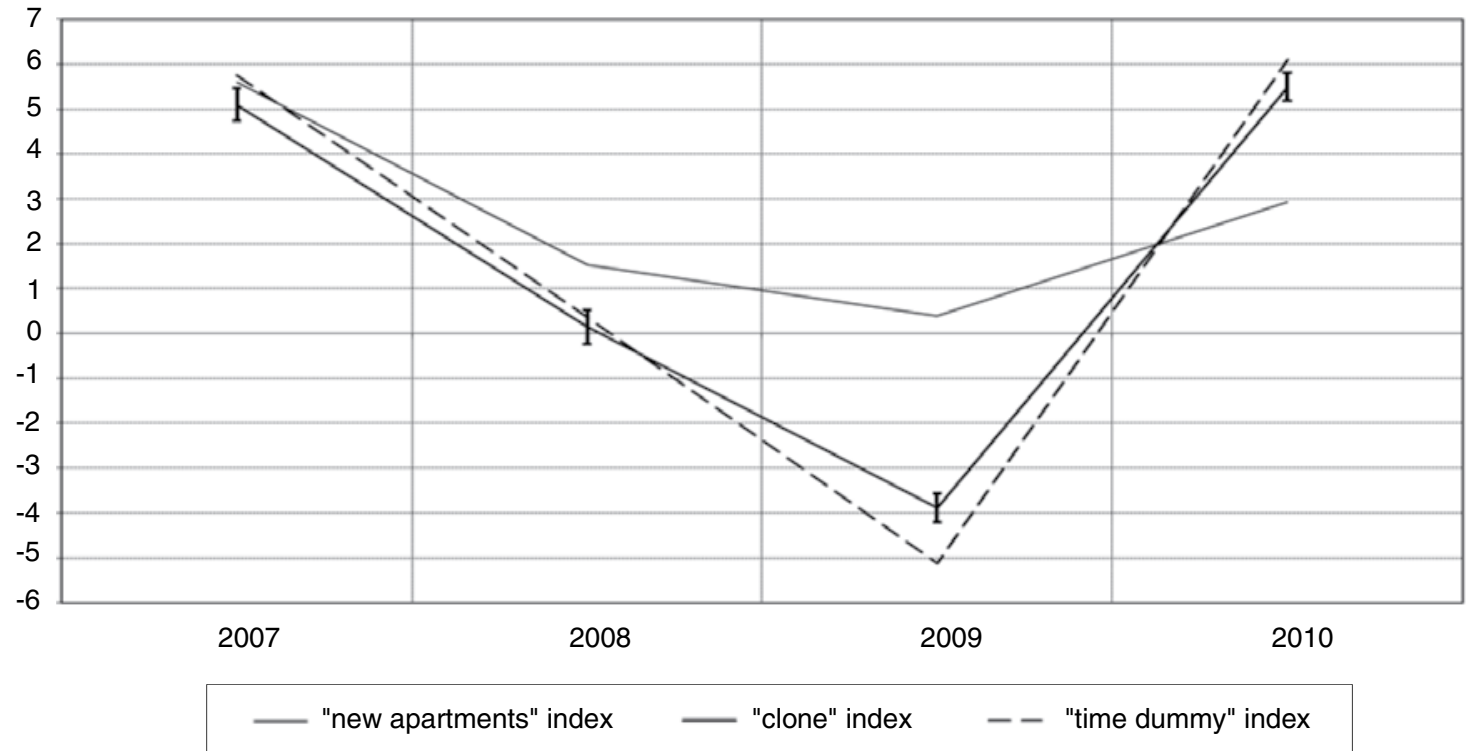

Note: For the "clone" index, the error bars are equal to two standard deviations

Reading note: The closer the "clone" index to the new flats index, the more the difference in the municipality distributions of the new and second-hand flats can explain the gap between the second-hand flats index ("time dummy" index) and the new flats index.

Sources: ECLN, BIEN and Perval data bases (see Table 2); authors' computation. 


\section{WEIGHTS FOR THE RESIDENTIAL LAND PRICE INDEX}

The weights $w_{-} L_{A-1}^{r}$ are the share (in \%) of the expenses for plots in region $r$ in the total expenses of year $A-1$ :

$$
w_{-} L_{A-1}^{r}=\frac{\sum_{i=1}^{n b \_o b s(A-1, r)} p_{-} L_{i, A-1}}{\sum_{r=1}^{21} \sum_{i=1}^{n b} p_{-}{ }_{-} L_{i, A-1}(A-1, r)}
$$

\begin{tabular}{|c|c|c|c|c|c|c|c|}
\hline Region & 2006-2007 & 2008 & 2009 & 2010 & 2011 & 2012 & Mean \\
\hline ÎLE-DE-FRANCE & 13.64 & 11.94 & 11.74 & 9.36 & 5.09 & 6.38 & 10.26 \\
\hline CHAMPAGNE-ARDENNE & 1.93 & 2.02 & 2.20 & 2.11 & 1.53 & 1.46 & 1.88 \\
\hline PICARDIE & 2.23 & 2.16 & 1.93 & 2.69 & 2.71 & 3.08 & 2.43 \\
\hline HAUTE-NORMANDIE & 2.42 & 2.95 & 2.69 & 3.22 & 3.70 & 3.56 & 2.99 \\
\hline CENTRE & 3.82 & 3.79 & 3.52 & 4.38 & 5.09 & 4.18 & 4.09 \\
\hline BASSE-NORMANDIE & 2.17 & 2.43 & 2.34 & 2.47 & 2.74 & 3.02 & 2.48 \\
\hline BOURGOGNE & 1.67 & 1.84 & 1.60 & 1.88 & 1.88 & 2.07 & 1.80 \\
\hline NORD-PAS-DE-CALAIS & 3.67 & 3.90 & 3.32 & 3.50 & 3.62 & 3.82 & 3.64 \\
\hline LORRAINE & 2.33 & 2.00 & 1.88 & 2.12 & 2.27 & 2.39 & 2.19 \\
\hline ALSACE & 2.47 & 2.60 & 3.04 & 2.33 & 1.64 & 1.95 & 2.36 \\
\hline FRANCHE-COMTÉ & 1.44 & 1.41 & 1.41 & 1.52 & 2.00 & 1.77 & 1.57 \\
\hline PAYS DE LA LOIRE & 11.71 & 11.13 & 12.87 & 11.80 & 11.24 & 10.08 & 11.51 \\
\hline BRETAGNE & 7.06 & 6.64 & 6.88 & 7.14 & 8.14 & 8.21 & 7.30 \\
\hline POITOU-CHARENTES & 3.08 & 5.22 & 6.20 & 4.70 & 4.03 & 3.76 & 4.30 \\
\hline AQUITAINE & 6.01 & 6.14 & 6.51 & 7.04 & 8.39 & 8.11 & 6.89 \\
\hline MIDI-PYRÉNÉES & 5.81 & 5.37 & 5.03 & 5.41 & 7.15 & 6.40 & 5.85 \\
\hline LIMOUSIN & 0.64 & 0.73 & 0.68 & 0.76 & 0.90 & 0.87 & 0.75 \\
\hline RHÔNE-ALPES & 11.19 & 12.28 & 12.60 & 11.93 & 13.17 & 13.51 & 12.27 \\
\hline AUVERGNE & 1.47 & 1.54 & 1.70 & 1.72 & 1.91 & 1.85 & 1.66 \\
\hline LANGUEDOC-ROUSSILLON & 6.93 & 6.47 & 6.23 & 7.32 & 7.13 & 6.61 & 6.80 \\
\hline PROVENCE-ALPES-CÔTE D'AZUR & 8.31 & 7.42 & 5.64 & 6.62 & 5.67 & 6.90 & 6.98 \\
\hline All & 100.00 & 100.00 & 100.00 & 100.00 & 100.00 & 100.00 & 100.00 \\
\hline
\end{tabular}

Note: 2006 and 2007 have the same weight because 2006 is the first year for which data are available. Sources: EPTB; authors' computation. 
The weights $w_{-} S_{A-1}^{r}$ are the share (in \%) of the construction expenses in region $r$ in the total expenses of year $A-1$ :

$$
w_{-} S_{A-1}^{r}=\frac{\sum_{i=1}^{n b} p_{-} \text {obs }(A-1, r)}{\sum_{r=1}^{21} \sum_{i=1}^{n b} S_{i, A-1} p_{-}(A-1, r)}
$$

\begin{tabular}{|l|c|c|c|c|c|c|c|}
\hline Region & $2006-2007$ & 2008 & 2009 & 2010 & 2011 & 2012 & Mean \\
\hline ÎLE-DE-FRANCE & 6.70 & 6.00 & 6.29 & 4.70 & 2.81 & 3.48 & 5.24 \\
CHAMPAGNE-ARDENNE & 2.85 & 2.78 & 3.01 & 2.70 & 1.94 & 1.77 & 2.56 \\
PICARDIE & 2.66 & 2.43 & 2.23 & 3.00 & 2.86 & 3.19 & 2.72 \\
HAUTE-NORMANDIE & 3.04 & 3.22 & 2.74 & 3.37 & 3.66 & 3.76 & 3.26 \\
CENTRE & 4.64 & 4.46 & 4.17 & 5.02 & 5.53 & 4.74 & 4.74 \\
BASSE-NORMANDIE & 3.55 & 3.84 & 3.66 & 3.59 & 3.74 & 3.95 & 3.70 \\
BOURGOGNE & 2.51 & 2.74 & 2.22 & 2.63 & 2.38 & 2.63 & 2.52 \\
NORD-PAS-DE-CALAIS & 4.02 & 4.06 & 3.53 & 3.58 & 3.76 & 3.97 & 3.85 \\
LORRAINE & 3.38 & 3.11 & 2.74 & 2.92 & 2.98 & 3.11 & 3.09 \\
ALSACE & 2.70 & 2.82 & 3.13 & 2.50 & 1.70 & 2.03 & 2.51 \\
FRANCHE-COMTÉ & 2.52 & 2.46 & 2.29 & 2.32 & 2.98 & 2.62 & 2.53 \\
PAYS DE LA LOIRE & 13.98 & 13.10 & 14.51 & 13.76 & 13.07 & 11.83 & 13.46 \\
BRETAGNE & 9.73 & 8.85 & 8.85 & 9.17 & 10.54 & 10.74 & 9.66 \\
POITOU-CHARENTES & 4.55 & 7.52 & 8.95 & 6.89 & 5.53 & 5.03 & 6.15 \\
AQUITAINE & 6.17 & 6.15 & 6.47 & 6.75 & 7.62 & 7.49 & 6.69 \\
MIDI-PYRÉNÉES & 5.88 & 5.49 & 5.36 & 5.65 & 6.96 & 6.59 & 5.97 \\
LIMOUSIN & 1.50 & 1.63 & 1.45 & 1.51 & 1.58 & 1.61 & 1.54 \\
RHÔNE-ALPES & 8.50 & 8.79 & 9.09 & 8.90 & 10.11 & 10.50 & 9.20 \\
AUVERGNE & 2.54 & 2.55 & 2.76 & 2.74 & 2.69 & 2.78 & 2.65 \\
LANGUEDOC-ROUSSILLON & 4.39 & 4.14 & 3.75 & 4.74 & 4.64 & 4.58 & 4.38 \\
PROVENCE-ALPES-CÔTE D'AZUR & 4.19 & 3.85 & 2.79 & 3.57 & 2.92 & 3.58 & 3.58 \\
All & 100.00 & 100.00 & 100.00 & 100.00 & 100.00 & 100.00 & 100.00 \\
\hline
\end{tabular}

Note: 2006 and 2007 have the same weight because 2006 is the first year for which data are available. Sources: EPTB; authors' computation. 
APPENDIX 5

COMPARISON OF THE "NEW STRUCTURE" PRICE INDEX AND THE CONSTRUCTION COST INDEX

To check the validity of our "new structure" price index we compare it to the BT01 index of construction cost (Indice national du bâtiment, tous corps d'état). The two profiles are strikingly similar (Figure A5). The rates of evolution differ by as much as 2 percentage points in 2008 , but less than 1 pct point in the other years. Even with a far from prefect hedonic model, we seem to recover a plausible structure price index from the EPTB survey covering only single-family homes. What drives the construction costs evolution is left for future research.

\section{Figure A5}

Growth rates of the "new structure" price index and the BT01 index

(In \%)

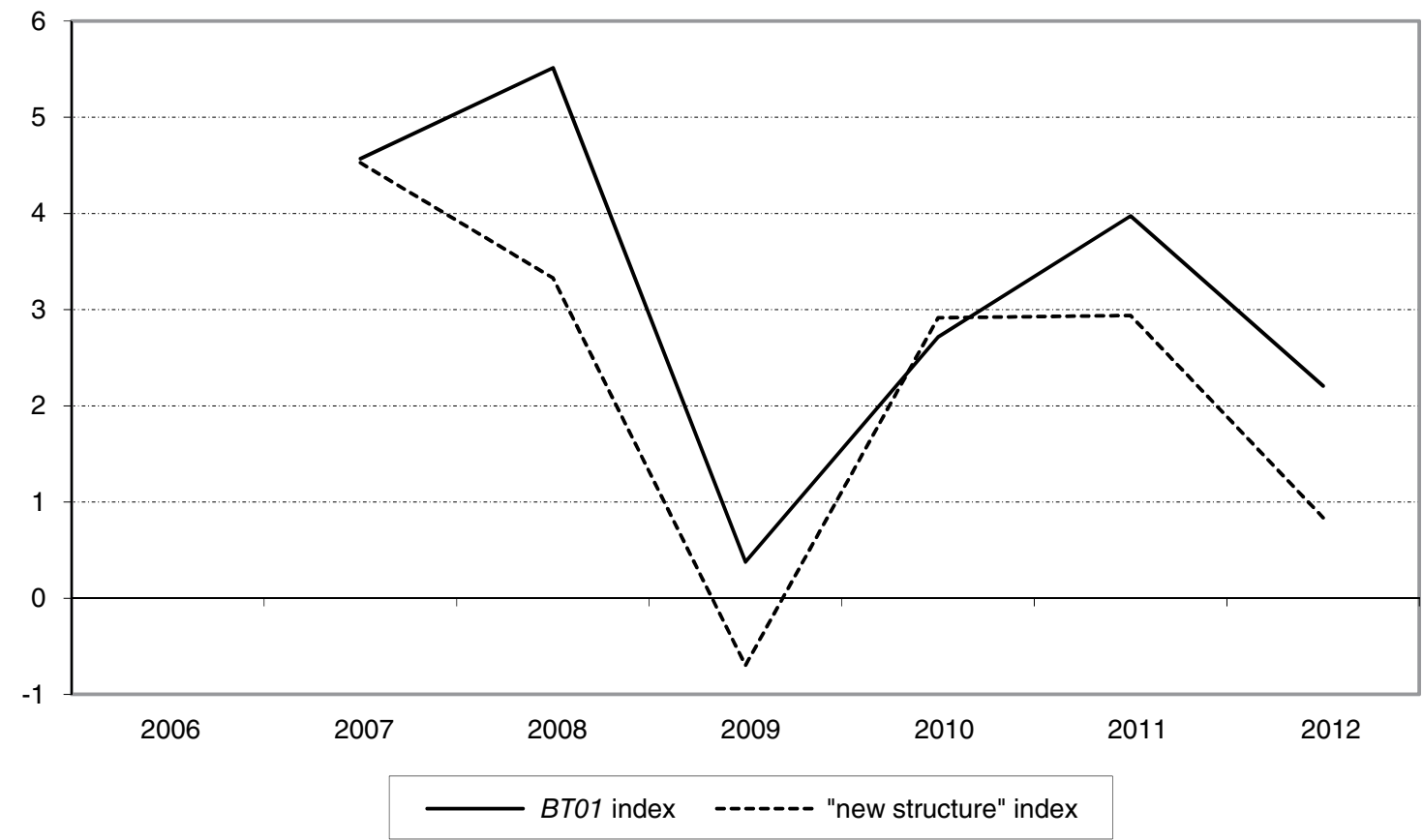

Sources: Insee; authors' computation from EPTB. 



\title{
Accessibility, local pollution and housing prices. Evidence from Nantes Métropole, France
}

\author{
Dorothée Brécard*, Rémy Le Boennec** and Frédéric Salladarré***
}

\begin{abstract}
In this empirical article, we analyze the extent to which accessibility and environmental variables are capitalized in apartment prices in Nantes Métropole, France. Using a sample of 5,590 transactions in 2002, 2006, 2008 from the Perval database, we estimate a spatial hedonic price model that takes into account spatial autocorrelation and spatial heterogeneity. Special attention is also paid to the construction of environmental quality variables (noise exposure, air pollution). We find that apartment prices depend positively on proximity to Nantes city centre but that the public transport network (urban or non-urban) has no significant influence. Noise reduction is valued, but only at low or marginal levels of significance. Last, air quality does not significantly influence apartment prices. These results can be related to good accessibility and environmental quality in Nantes Métropole which probably makes households less sensitive to these issues than in other geographical contexts. This seems to provide little support for sustainable urban mobility plans favoring better accessibility, unless public authorities also target the greater awareness of the use of virtuous modes of transport.
\end{abstract}

JEL Classification: C21, Q51, Q53, R31

Keywords: hedonic price model, accessibility, air quality, noise exposure, spatial econometrics

\section{Reminder:}

The opinions and analyses in this article

are those of the author(s)

and do not

necessarily reflect

their institution's

or Insee's views.

\footnotetext{
* Université de Toulon, LEAD (brecard@univ-tIn.fr)

** Institut VEDECOM et Laboratoire Genie Industriel, CentraleSupélec, Université Paris-Saclay (remy.leboennec@vedecom.fr)

*** Univ Rennes, CNRS, CREM - UMR 6211 \& LEMNA (frederic.salladarre@univ-rennes1.fr)

This research was funded by the Agence Nationale de la Recherche, as part of the "Evaluation of environmental impacts of different urban transport plan scenarios and their socio-economic consequences in Nantes Métropole" (ANR-08 VILL-0005). We would like to thank Patrice Mestayer and Bernard Bourges for their co-ordination of the Eval-PDU project, and Julie Bulteau, Marc Baudry, Yannick Le Pen and Bernard Fritsch for their contribution to the first part of this project.

Received on 15 June 2017, accepted after revisions on 24 July 2018
} 
$\mathbf{E}$ lected the European Union's Green capital in 2013, Nantes is now part of "Green cities fit for life". Nantes also ranks in the top French cities in which to live, according to a number of different French surveys ${ }^{1}$. One of its strengths is its environmental performance, thanks to urban transport networks, air quality, a quiet environment and the development of green spaces in the city. To what extent do households value these determinants of their living environment? This issue is particularly relevant with respect to the effectiveness of local policies, which are in theory aimed at enhancing the inhabitants' well-being via improvements in accessibility, air quality and calm, amongst other quality-of-life factors.

The theoretical urban economics literature suggests that accessibility and environmental amenities are key in household location decisions. The analysis of the determinants of household location relative to Central Business Districts (CBDs) reveals a trade-off between housing centrality - cheaper for the same surface area further from the centre - and transport costs - higher further away from the centre - (Alonso, 1964; Ogawa \& Fujita, 1980; Le Boennec, 2014). When there are multiple CBDs, the fall in housing prices with distance to the city centre may no longer be monotonic (Osland \& Pryce, 2012; Le Boennec \& Sari, 2015). Location choice also takes amenities into account (Fujita, 1989; Takahashi, 2017; Lemoy et al., 2017), while negative external environmental factors (noise, congestion and air pollution) discourage location (Kanemoto, 1980; Schindler et al., 2017).

The hedonic pricing method has been widely used since the seminal article of Rosen (1974) to provide monetary values for housing's intrinsic and extrinsic attributes. As house prices depend on intrinsic (number of rooms, living surface area) and extrinsic (proximity to public transport, social quality of the neighborhood, amenities and pollution) attributes, the housing market can indirectly provide a monetary value for these attributes. The price difference between two dwellings that are identical with the exception of one attribute should reflect the value of the gain or loss of well-being induced by that attribute: public transport, an amenity or environmental quality. The hedonic pricing method is therefore especially relevant for the provision of new insights into households' willingness-to-pay for greater accessibility and environmental quality.
Empirical work using stated preferences has also underlined the significance of these amenities in housing decisions. Households select the environments with transport and amenities that are consistent with their preferences (Bhat et al., 2008; Cao \& Cao, 2014). The role of preferences is revealed in residential location choices (Lund, 2006; Walker \& Li, 2007). Preferences are related to the life cycle, in the sense that certain life events (for example, the birth of a child) may change preferences and thus drive individuals to move (Clark \& Onaka, 1983; Rabe \& Taylor, 2010).

A wide-ranging empirical literature has used the hedonic approach in order to assess the values of both intrinsic and extrinsic house attributes. Although the bulk of the work using the hedonic pricing method has been carried out in the United States and Canada, the European literature has been growing since the early 2000s and even more recently; it is the same in Asia. In France, Cavailhès (2005) highlights that housing values rise with amenities and accessibility in the rental market in 287 French urban centres. He underlines that these higher values depend greatly on the social quality of the neighborhood. Capitalization of access to public transport in apartment prices has been shown in Nantes (Fritsch, 2007) and Paris (Nguyen-Luong \& Boucq, 2011). The roles of environmental amenities (such as green spaces) and environmental damage (such as noise exposure) have also been highlighted in Grenoble (Saulnier, 2004), in the majority of the urban centres studied by Cavailhès (2005), in Paris (Bureau \& Glachant, 2010), in Angers (Choumert \& Travers, 2010; Travers et al., 2013), on the French Atlantic coast (Pouyanne et al., 2011; Le Berre et al., 2017) and in Nantes (Le Boennec \& Sari, 2015; Le Boennec \& Salladarré, 2017).

Location and accessibility attributes often count among the major determinants of housing prices. Still, it is not always the case depending on the local context, whereas in most cases, the positive or negative relationship between accessibility to certain amenities or transport facilities and real-estate capitalization has to be clarified. Concerning environmental quality variables, there exist very few French hedonic studies providing insights

\footnotetext{
1. See for instance the 2018 Express ranking, where Nantes is in first place, as was the case in 2017 (https://www.lexpress.fr/emploi/le-palmares-2018-des-villes-ou-il-fait-bon-vivre-et-travailler_1984924.html, accessed 20/03/2018).
} 
on the potential influence of air pollution or noise exposure on the price of dwellings (see the following Literature review section). Even scarcer are the studies where corresponding data could be calculated for every dwelling transaction. Investigating such original variables, the present article provides new insights into the effects of greater accessibility and environmental quality on apartment values in a local context: the conurbation of Nantes Métropole.

To implement the hedonic model, we rely on an original cross-sectional database partially obtained from numerical simulations. These were carried out as part of a wide multidisciplinary research project, using a chain of physically-based models. The starting point of these was traffic data in Nantes Métropole (Mestayer et al., 2012), and noise exposure and air quality around dwellings were calculated. These environmental data were matched to our geo-referenced database, which includes data on apartment transactions in the 24 communes of Nantes Métropole in 2002, 2006 and 2008 , and distances to a set of reference points.

As housing observations constitute a type of data characterized by location attributes, we apply spatial econometrics in relation to hedonic price modeling. The spatial dependence between observations in our sample is then taken into account at various points in space. In order to deal with spatial autocorrelation and spatial heterogeneity, we use the instrumental variables and Generalized Method of Moments approaches (GMM) proposed by Kelejian and Prucha (2010) to estimate annual spatial autoregressive models with unknown heteroscedasticity in the disturbances. This recent multi-step estimation method has a spatial autoregressive process in the dependent variable and disturbance term.

In line with the existing hedonic literature, our results confirm that intrinsic attributes have an impact on housing prices. Concerning extrinsic attributes, the results are far more mixed: if greater accessibility to Nantes city centre increases apartment prices as expected, we find no significant impact of the public transport networks (both urban and non-urban) on prices. The specific influence of environmental quality variables is very limited as well: we find that airborne pollutants do not reduce housing prices; noise pollution does, but it only leads to slightly lower prices for noisy compared to quiet apartments. Some of these results are quite surprising and will be discussed further.

The remainder of the article is structured as follows. The next section reviews the current literature pertaining to the effect of noise, air pollution and accessibility on housing values. Then we present our database. Another section explains the econometric model and the spatial dependence tests, and the next is dedicated to the analysis of the results. Last, we provide some concluding remarks and policy recommendations.

\section{Literature review}

Although empirical work using the hedonic pricing method is relatively unanimous regarding the impact of various intrinsic attributes on housing values, results are more divided on the effects of extrinsic attributes, which crucially depend on dwelling location and neighborhood. The scope of this review is limited to the extrinsic attributes that will be investigated in the present article, namely local pollution (noise and air) and access to urban and non-urban public transport.

\section{Noise}

As a negative externality, noise tends to reduce housing values. Nelson (2004) considers the effects of noise exposure in dwellings close to 23 airports in the United States and Canada. He finds an average drop in house prices of $0.58 \%$ per additional decibel (dB), with greater noise sensitivity in Canada. The literature review in Nelson (2008) emphasizes that the Noise Depreciation Index (NDI) has a median value of $0.74 \%$ per $\mathrm{dB}$ for aircraft noise and $0.54 \%$ for traffic noise. Andersson et al. (2010) show a larger negative effect of road noise than railway noise in the Swedish municipality of Lerum, with a respective fall of $1.2 \%$ and $0.4 \%$ in property prices per additional $\mathrm{dB}$. This figure rises to $1.7 \%$ for road noise and $0.7 \%$ for railway noise when the total noise level is over $55 \mathrm{~dB}$. This drop is also about $0.5 \%$ per additional $\mathrm{dB}$ from the rail network in Seoul, Korea (Chang \& Kim, 2013). In the same line, apartments located in calmer districts in Paris, France, are worth 1.5\% more on average (Bureau \& Glachant, 2010). However, the relationship between noise exposure and housing values is not always obvious. Le Boennec and Sari (2015) find only a weak relationship between exposure to road and rail 
noise and house prices in Nantes Métropole $(-0.23 \%$ per additional $d B)$. Depending on the context, noise is sometimes even not significant, as found in Grenoble, France (Saulnier, 2004) and by Cavailhès (2005) in the majority of the French urban centres.

\section{Air pollution}

The relationship between air pollution and housing values has been extensively investigated since the seminal article of Ridker and Henning (1967), who established a negative effect of sulphur pollution in the St. Louis metropolitan area, United States. Air quality variables produce widely-differing effects on housing values in hedonic analyses (Smith \& Huang, 1993; Boyle \& Kiel, 2001). Decker et al. (2005) find a negative impact of a high concentration of restricted pollutants in Nebraska, United States. However, the same pollutants are not significant in the other American State of Massachusetts (Bui \& Mayer, 2003). French studies have also revealed a not significant link between air pollution and housing values: between nitrogen dioxide levels and rents in Grenoble (Saulnier, 2004) and air pollution and rents in French urban centres (Cavailhès, 2005). Kim et al. (2003) show that a permanent $4 \%$ improvement in air quality, through lower sulfur dioxide pollution $\left(\mathrm{SO}_{2}\right)$, is valued at $1.43 \%$ of mean house price in Seoul, whereas $\mathrm{NO}_{\mathrm{x}}$ pollution does not play any role in housing values. These contrasting results likely reflect heterogeneity in housing markets. Using a particular air-quality index, Le Boennec and Salladarré (2017) find that house buyers in Nantes Métropole are generally not sensitive to air pollution, except for those who previously lived in an air-polluted area. The mixed results could also come from differences in air quality measurement. For instance, Anselin and Le Gallo (2006) show that discrete ozone categories produce better results than the associated continuous variable in the estimation of the effect of air quality on housing values in Southern California.

\section{Transportation}

Empirical work on access to public transport (urban and non-urban) has produced contrasting results. This is emphasized by Bowes and Ihlanfeldt (2001) for Atlanta, United States. Railway station proximity is likely to increase house prices via improved accessibility and the presence of neighborhood shops, which is an advantage for nearby inhabitants. However, railway stations produce noise and air pollution, and disturb the landscape. The global net effect is therefore negative for properties close to the railway station (within a quarter of mile) and positive for properties farther away (between one and three miles). Other work has also found this concave effect of proximity to railway stations, such as Billings (2011) for light rail in Charlotte, United States, and Mohammad et al. (2017) for the subway in Dubai, United Arab Emirates. However, the positive accessibility effect dominates the negative externality effect for light rail in most of the studies focusing on other cities in the United States (for a detailed survey see Efthymiou \& Antoniou, 2013, and Dubé et al., 2013) and cities in Asian countries (Pan \& Zhang, 2008; Chen \& Haynes, 2015; Li et al., 2016; Diao et al., 2017).

Similar results have been obtained in European cities. Efthymiou and Antoniou (2013) show that proximity to subway, tram, suburban and bus stations in Athens, Greece, increases apartment prices, whereas proximity to the old urban railway, national rail stations, airports and ports reduces prices. Martínez and Viegas (2009) find that subway proximity increases property values in Lisbon, Portugal, with access to two subway lines being valued more than access to a single line. In Paris, while proximity to a railway station increases prices (Bureau \& Glachant, 2010), proximity to a subway station reduces them. This is in line with Nguyen-Luong and Boucq (2011), who find $5 \%$ lower prices for apartments located within 200 meters of the third line of the Paris tram. Interestingly, Fritsch (2007) uncovers similar results in Nantes, where tram lines tend to reduce housing values in areas near the city centre and increase housing values farther away ${ }^{2}$.

The meta-analyses of Debrezion et al. (2007) and Mohammad et al. (2013) show that the effects of rail projects or existing infrastructures on housing values also depend on a number of other factors, such as the type of rail service, the age of the rail system (with older networks having more lines and so being more attractive to users), the characteristics and locations of the stations, and the geographical location and access to roads. In particular, Mohammad et al.

2. Fritsch (2007) does however use a very particular definition of district accessibility: this is considered to be high (respectively medium and low) when the apartment is located in an IRIS where more than $50 \%$ (respectively from 20 to $50 \%$ and less than $20 \%$ ) of the IRIS surface is within 300 meters as the crow flies of a tram stop. 
(2013) show that commuter rail has larger positive effects on land and property values than light rail, and that access to roads reduces the valuation of rail. Moreover, the impact of rail is higher in European and East Asian cities compared to those in North America.

\section{Description of the data}

The determinants of Nantes Métropole apartment prices are analyzed using cross-sectional data. Nantes Métropole is an urban community bringing together 24 communes of the Loire-Atlantique département in the Pays de la Loire région. It is located in the West of France, $380 \mathrm{~km}$ from Paris, and covers over $523 \mathrm{~km}^{2}$. It is crossed by one major river (the Loire), and two other rivers (the Erdre and the Sèvre). It counts 600,000 inhabitants, half of whom live in the central commune of Nantes. There were over 2.3 million daily trips in 2015 in this territory, $55 \%$ of which were by car (both drivers and passengers) and $15 \%$ by public transport. The total traveled distances were $21 \mathrm{~km}$ a day, corresponding to a total travel time of $67 \mathrm{~min}$ utes $^{3}$. The database allows us to link the prices of apartments that were sold in Nantes Métropole to their intrinsic and extrinsic attributes (accessibility, geographical and socio-economic environment and environmental quality). All of the descriptive statistics appear in Table 1.

The data come from the notaries' Perval database, providing information on the 25,000 transactions of apartments and houses in Nantes Métropole in 2002, 2006 and 20084. It is worth noting that all housing transactions in any part of France are covered by two notarial databases: Perval and by the BIEN database for Paris (Gouriéroux \& Laferrère, 2009). The data were geo-referenced as part of the multidisciplinary research project. We use here data on the 5,590 apartment transactions, after cleaning the data from missing information. As real-estate transaction data cannot be treated as continuous over time, the three years are considered separately. The data provide information on the transaction (date, price, nature of the transfer, etc.), the location of the apartment (commune, cadastral plan section, etc.) and its intrinsic attributes (surface area, number of main rooms, bathrooms, etc.). Regarding the surface area, all the observations were kept with the exception of one apartment, whose surface area was under $9 \mathrm{~m}^{2} .{ }^{5}$
The geographical and socio-economic environment of the apartments is described by contextual data from the French National Institute of Statistics and Economic Studies (Insee). These data are at the "Aggregated blocks for statistical information" level (Ilots Regroupés pour l'Information Statistique or IRIS): apartment and house density, the unemployment rate, median income in the IRIS, the percentage of the population who are over 60 , foreigners, and have higher education, and the presence of a so-called Sensitive Urban Zone (Zone Urbaine Sensible or ZUS) in the IRIS or the contiguous IRIS.

Both general and specific accessibility attributes were geo-referenced as part of the multidisciplinary research project. These include the Euclidian distance to a set of reference places (railway stations, campus, etc.), to public transport networks (bus, tram and non-urban train), green spaces, rivers and Nantes city centre. The three watercourses constitute natural geographical barriers. This is notably the case for the Loire that workers living South of the river have to cross, as the majority of jobs are found to the North. Only $17 \%$ of housing transactions took place South of the Loire, considering the three years of transaction. $88 \%$ of apartments are inside the ring road, located on average around $6 \mathrm{~km}$ from the city centre. The natural environment is generally of good quality: $87 \%$ of apartments are located less than 600 meters from a green space (the average surface area of the latter is a little over $4 \mathrm{ha}$ ). Apartments are well-served by public transport: $46 \%$ are within $2 \mathrm{~km}$ of a railway station, $25 \%$ have a bus stop less than 100 meters away, and $48 \%$ have a tram stop less than 500 meters away ${ }^{6}$.

\footnotetext{
3. Source: Travel Survey in Loire-Atlantique département, January 2016. 4. Our descriptive data reveal a price of $€ 1,866$ per square meter for 2008 apartment transactions. This figure was $€ 1,511$ in 2002 (in constant Euros), and $€ 1,984$ in 2006. The two-year fall in price between 2006 and 2008 is thus $-5.9 \%$. On the contrary, prices per square meter rose $31.3 \%$ between 2002 and 2006. The real-estate market in France did not fall as sharply as in Spain, Ireland or the United States, for example. This favorable outcome is partly due to the dynamic long-term housing demand in France (and especially in large urban areas like Nantes Métropole), which is a result of demographics. Another reason may be the high level of public spending in France, which helped to preserve households' purchasing power during the global financial crisis.

5. The French decree of 2002, 30 January specifies the minimal surface area that a dwelling owner is allowed to rent to be qualified as decent: this minimal surface area is $9 \mathrm{~m}^{2}$. Moreover, the Loi Carrez (Carrez law) aims at certifying the surface area of dwellings that are sold in France (to be occupied by the owner or not): this certification is mandatory from $8 \mathrm{~m}^{2}$. This is thus not a surprise if the Perval database contains 95 observations less than $20 \mathrm{~m}^{2}$, as Nantes is an attractive city for students studying in the large university of Nantes and other institutions of higher education. This situation is comparable in France not only in Paris, but also in other large metropolises throughout the territory (Lyon, Toulouse, Montpellier, Rennes, Lille, etc.).

6. These percentages are quite similar for the three years under consideration.
} 
Table 1

Descriptive statistics

\begin{tabular}{|c|c|c|c|c|c|c|c|c|c|c|c|c|c|}
\hline \multirow[b]{2}{*}{ Variable } & \multirow[b]{2}{*}{ Definition } & \multicolumn{4}{|c|}{2002} & \multicolumn{4}{|c|}{2006} & \multicolumn{4}{|c|}{2008} \\
\hline & & Mean & SD & Min & $\operatorname{Max}$ & Mean & SD & Min & $\operatorname{Max}$ & Mean & SD & Min & $\operatorname{Max}$ \\
\hline Surface area & Living surface area in $\mathrm{m}^{2}$ & 64.49 & 24.67 & 11.00 & 241.00 & \begin{tabular}{|l|}
62.03 \\
\end{tabular} & 24.97 & 12.00 & 242.00 & 61.56 & 25.03 & 13.00 & 250.00 \\
\hline Constr $<1948$ & Construction before 1948 & 0.03 & 0.16 & 0.00 & 1.00 & 0.05 & 0.22 & 0.00 & 1.00 & 0.05 & 0.21 & 0.00 & 1.00 \\
\hline Constr[1948-1969] & Construction 1948-1969 & 0.18 & 0.39 & 0.00 & 1.00 & 0.20 & 0.40 & 0.00 & 1.00 & 0.20 & 0.40 & 0.00 & 1.00 \\
\hline Constr[1970-1980] & Construction 1970-1980 & 0.19 & 0.39 & 0.00 & 1.00 & 0.20 & 0.40 & 0.00 & 1.00 & 0.19 & 0.39 & 0.00 & 1.00 \\
\hline Constr[1981-1991] & Construction 1981-1991 & 0.14 & 0.35 & 0.00 & 1.00 & 0.15 & 0.36 & 0.00 & 1.00 & 0.12 & 0.33 & 0.00 & 1.00 \\
\hline Constr>1991 & Construction after 1991 & 0.46 & 0.50 & 0.00 & 1.00 & 0.40 & 0.49 & 0.00 & 1.00 & 0.44 & 0.50 & 0.00 & 1.00 \\
\hline Sale bef. completion & Sale before completion & 0.34 & 0.47 & 0.00 & 1.00 & 0.22 & 0.41 & 0.00 & 1.00 & 0.22 & 0.42 & 0.00 & 1.00 \\
\hline No parking space & 0 parking space & 0.04 & 0.19 & 0.00 & 1.00 & 0.06 & 0.23 & 0.00 & 1.00 & 0.08 & 0.28 & 0.00 & 1.00 \\
\hline One parking space & 1 parking space & 0.82 & 0.39 & 0.00 & 1.00 & 0.83 & 0.37 & 0.00 & 1.00 & 0.80 & 0.40 & 0.00 & 1.00 \\
\hline$>$ One parking space & 2 parking spaces or more & 0.15 & 0.36 & 0.00 & 1.00 & 0.11 & 0.31 & 0.00 & 1.00 & 0.12 & 0.32 & 0.00 & 1.00 \\
\hline ZUS & Location in a ZUS & 0.04 & 0.20 & 0.00 & 1.00 & 0.06 & 0.24 & 0.00 & 1.00 & 0.06 & 0.25 & 0.00 & 1.00 \\
\hline Contiguous ZUS & $\begin{array}{l}\text { Location in an IRIS } \\
\text { contiguous to a ZUS }\end{array}$ & 0.14 & 0.35 & 0.00 & 1.00 & 0.17 & 0.38 & 0.00 & 1.00 & 0.16 & 0.37 & 0.00 & 1.00 \\
\hline House density & $\begin{array}{l}\text { House density in the } \\
\text { IRIS in ha }\end{array}$ & 6.51 & 4.62 & 0.00 & 16.43 & 7.11 & 4.79 & 0.00 & 17.54 & 6.69 & 4.68 & 0.00 & 17.07 \\
\hline Median income & $\begin{array}{l}\text { Median income in the } \\
\text { IRIS in } €\end{array}$ & 18,765 & 3,215 & 8,170 & 28,059 & 18,481 & 3,636 & 8,441 & 29,015 & 18,917 & 3,472 & 8,565 & 28,799 \\
\hline Distance centre & $\begin{array}{l}\text { Distance to the city } \\
\text { centre in } \mathrm{m}\end{array}$ & 3,166 & 1,994 & 177 & 13,209 & 3,330 & 2,063 & 43 & 13,213 & 3,332 & 2,176 & 55 & 13,445 \\
\hline Dist. railway station & $\begin{array}{l}\text { Distance to the closest } \\
\text { railway station in } \mathrm{m}\end{array}$ & 2,529 & 1,635 & 93 & 10,048 & 2,457 & 1,559 & 110 & 10,221 & 2,574 & 1,755 & 129 & 10,078 \\
\hline Dist. bus & $\begin{array}{l}\text { Distance to the closest } \\
\text { bus stop in } m\end{array}$ & 165 & 105 & 15 & 609 & 158 & 93 & 16 & 633 & 169 & 101 & 18 & 612 \\
\hline Tram $<500 \mathrm{~m}$ & $\begin{array}{l}\text { Presence of a tram stop } \\
\text { less than } 500 \mathrm{~m} \text { away }\end{array}$ & 0.47 & 0.50 & 0.00 & 1.00 & 0.47 & 0.50 & 0.00 & 1.00 & 0.49 & 0.50 & 0.00 & 1.00 \\
\hline Private road & Location on a private road & 0.30 & 0.46 & 0.00 & 1.00 & 0.32 & 0.47 & 0.00 & 1.00 & 0.28 & 0.45 & 0.00 & 1.00 \\
\hline Green spaces & $\begin{array}{l}\text { Green-space surface } \\
\text { area less than } 300 \mathrm{~m} \\
\text { away in } \mathrm{m}^{2}\end{array}$ & 13,307 & 23,672 & 0.00 & 123,856 & 15,646 & 25,210 & 0.00 & 140,907 & 15,471 & 24,382 & 0.00 & 140,907 \\
\hline Max. noise & $\begin{array}{l}\text { Maximum noise } \\
\text { in } 24 \text { hours in } \mathrm{dB}\end{array}$ & 61.86 & 10.50 & 22.55 & 87.38 & 62.32 & 11.19 & 14.54 & 94.40 & 62.56 & 11.58 & 8.36 & 86.68 \\
\hline Benzene & Maximum concentration of & 0.20 & 0.09 & 0.04 & 0.74 & 0.20 & 0.10 & 0.04 & 0.90 & 0.20 & 0.09 & 0.03 & 0.67 \\
\hline $\mathrm{CO}$ & ditto & 346.5 & 25.8 & 301.4 & 469.2 & 346.6 & 26.3 & 300.8 & 534 & 346.5 & 25 & 297.8 & 493 \\
\hline VOCs & ditto & 10.44 & 3.21 & 3.27 & 27.7 & 10.38 & 3.24 & 3.07 & 31.02 & 10.43 & 3.22 & 2.64 & 24.65 \\
\hline $\mathrm{NO}_{2}$ & ditto & 22.14 & 3.53 & 11.29 & 33.58 & 22.00 & 3.67 & 11.32 & 39.46 & 22.07 & 3.67 & 10.43 & 35.82 \\
\hline $\mathrm{NO}_{x}^{2}$ & ditto & 34.18 & 8.80 & 14.84 & 74.17 & 34.19 & 9.05 & 14.69 & 94.76 & 34.19 & 8.62 & 13.16 & 77.33 \\
\hline $\mathrm{PM}_{10}$ & ditto & 19.09 & 0.85 & 17.28 & 23.36 & 19.11 & 0.87 & 17.25 & 25.00 & 19.10 & 0.83 & 17.13 & 23.34 \\
\hline $\mathrm{PM}_{2.5}$ & ditto & 11.99 & 0.67 & 10.55 & 15.27 & 12.00 & 0.69 & 10.54 & 16.65 & 12.00 & 0.66 & 10.44 & 15.39 \\
\hline $\mathrm{SO}_{2}$ & ditto & 1.88 & 0.24 & 1.06 & 2.54 & 1.87 & 0.25 & 1.05 & 2.51 & 1.86 & 0.29 & 1.04 & 2.44 \\
\hline
\end{tabular}

Note: $\mathrm{SD}=$ Standard deviation.

Coverage: 5,590 apartment transactions in the 24 communes of Nantes Métropole in 2002, 2006 and 2008 (respectively 1,943, 1,981 and 1,666 observations).

Sources: Perval 2002, 2006 and 2008.

Last, environmental quality variables were constructed as part of the research project. There are two of these. First, the exposure of apartments to road and rail noise: minimum, mean and maximum noise levels in the three periods of the day (daytime, evening, night-time), and over 24 hours. Second, the concentrations of eight airborne pollutants that are primarily associated with road traffic: sulfur dioxide $\left(\mathrm{SO}_{2}\right)$, nitrogen oxide $\left(\mathrm{NO}_{\mathrm{x}}\right)$, nitrogen dioxide $\left(\mathrm{NO}_{2}\right)$, particulate matter $\left(\mathrm{PM}_{10}\right.$ and $\mathrm{PM}_{2.5}$ ), carbon monoxide (CO), benzene, Volatile Organic Compounds (VOCs). The minimum, mean and maximum annual concentration levels of these were calculated.
Exposure to road and rail noise was calculated from traffic data as the standardized noise level, in accordance with Appendix 1 of the European Directive 2002/49/CE relating to the assessment and management of environmental noise ${ }^{7}$. The minimum, mean and maximum noise values were calculated for each of the three periods of the day. These were then compiled to produce the corresponding levels for the synthetic noise index using the weights advocated by the Directive (Le Boennec \& Salladarré, 2017). It is worth noting that about

7. http://www.developpement-durable.gouv.fr/MG/pdf/Texte_de_la_Directive2002-49_CE-2.pdf. 
half of apartments are not subject to noise problems, at any point during the day (below $65 \mathrm{~dB}$ as the maximum noise over 24 hours) ${ }^{8}$.

The Atmospheric Dispersion Modelling System urban model (ADMS) includes a number of emission sources simultaneously. We included road emissions, as they are expected to be major contributors, as well as residential and tertiary emissions. A variety of meteorological data were also taken into account to reflect seasonality (Le Boennec \& Salladarré, 2017). Correlations were calculated to take into account the potential links between the pollutants. The air pollution criteria are strongly correlated for each year of transaction (the correlations between pollutants are at least equal to 0.75 ). This may be due to underlying factors which could be observed through a factor analysis9. Using the Kaiser criterion, one factor emerges from the analysis for each year, and more than $95 \%$ of the variance is explained by this factor. Finally, we use the factor score of all pollution criteria for each year to construct the air pollution variable ${ }^{10}$. Most of the mean values of air pollution for the central city of Nantes and its metropolitan area are below the annual Air Quality Guideline (AQG) of the World Health Organization $(2000 ; 2006)$. However, around $15 \%$ of dwellings are on average above this threshold. We retain a dummy variable reflecting these $15 \%$ of locations concerned with air pollution.

In order to emphasize potential clusters of prices among close observations, we perform Local Indicators of Spatial Autocorrelation, or LISA, on apartment transactions (Figures I-A, I-B and I-C). The LISA statistics measure the degree of similarity of each observation to its neighbors (Anselin, 1995, 2005). We calculate separate LISA statistics for each of the three transaction years, using GeoDa. A variety of spatial weight matrices were tested ${ }^{11}$.

The results show comparable clustering patterns of prices for the three transaction years. Around half of the samples present significant patterns of local clustering $(57.9 \%$ in $2002,52.1 \%$ in 2006 and $48.8 \%$ in 2008). Positive spatial autocorrelation in our samples is emphasized in the form of clusters of high prices on one side, and clusters of low prices on the other side. Clusters of high prices are found for $11.8 \%$ of all transactions. The corresponding apartments are located on the one hand in the Western districts of the central part of the city and, on the other hand, in the
Northern part. These districts generally have high household incomes and benefit from good amenities (green spaces and private roads). On the contrary, clusters of low housing values emerge in the peripheral districts of the conurbation $(21.2 \%$ of the observations), where social housing is found in the form of tower blocks dating from the 1960s and 1970s. When negative spatial autocorrelation occurs, it can be found mainly in intermediate districts: a majority of the $20 \%$ of transactions with low-high or high-low clustering values can be found between central and peripheral districts, indicating that in such areas, a minority of cheap (respectively costly) apartments have costly (respectively cheap) apartments in their neighborhood.

Nearly half of the remaining transactions $(47 \%)$ do not have significant LISA values, so that highlighting local spatial autocorrelation for these observations is delicate. These transactions are also mostly located in intermediate districts of the city. However, these results should be taken with caution. There are other techniques, like scan tests, that may prove to be more sensitive in the detection of local clustering patterns (Hanson \& Wiczoreck, 2002). Indeed, while LISA statistics are expected to systematically suggest clustering patterns, they may also emphasize single significant observations, as they are calculated for each transaction. However, as we do not want to advocate a maximum number of observations per cluster (which is a requirement for scan-test processing), we prefer to rely on LISA statistics (López et al., 2015). Therefore, we retain for each transaction year five dummies corresponding to the five clustering patterns of prices emphasized by LISA statistics (high-high, low-low, low-high and high-low apartment prices, and not significant values). In the next section, the inclusion of these variables in our model will be tested.

8. Exposure to airborne noise was not taken into account, as only a few apartment transactions in our sample were located in the air corridor.

9. The Bartlett test of sphericity concludes that a factor analysis is relevant for each year. The Kaiser-Meyer-Olkin measure of sampling adequacy is 0.82 in 2002, 0.81 in 2006, and 0.80 in 2008, indicating that the sampling method is adequate.

10. Cronbach's alpha statistic determines the internal consistency of items in a survey instrument to determine its reliability. This statistic is 0.76 in 2002 and 2006 and 0.77 in 2008. According to Nunnally (1978), a score of 0.70 obtained on a substantial sample is an acceptably reliable coefficient. 11. We retain the weight matrices we use afterwards for the spatial estimation. The LISA maps were thus produced using 60 nearest neighbors in 2002, 100 in 2006 and 40 in 2008. 
Figure I

LISA cluster maps for the apartment prices in Nantes Métropole (2002, 2006 and 2008)

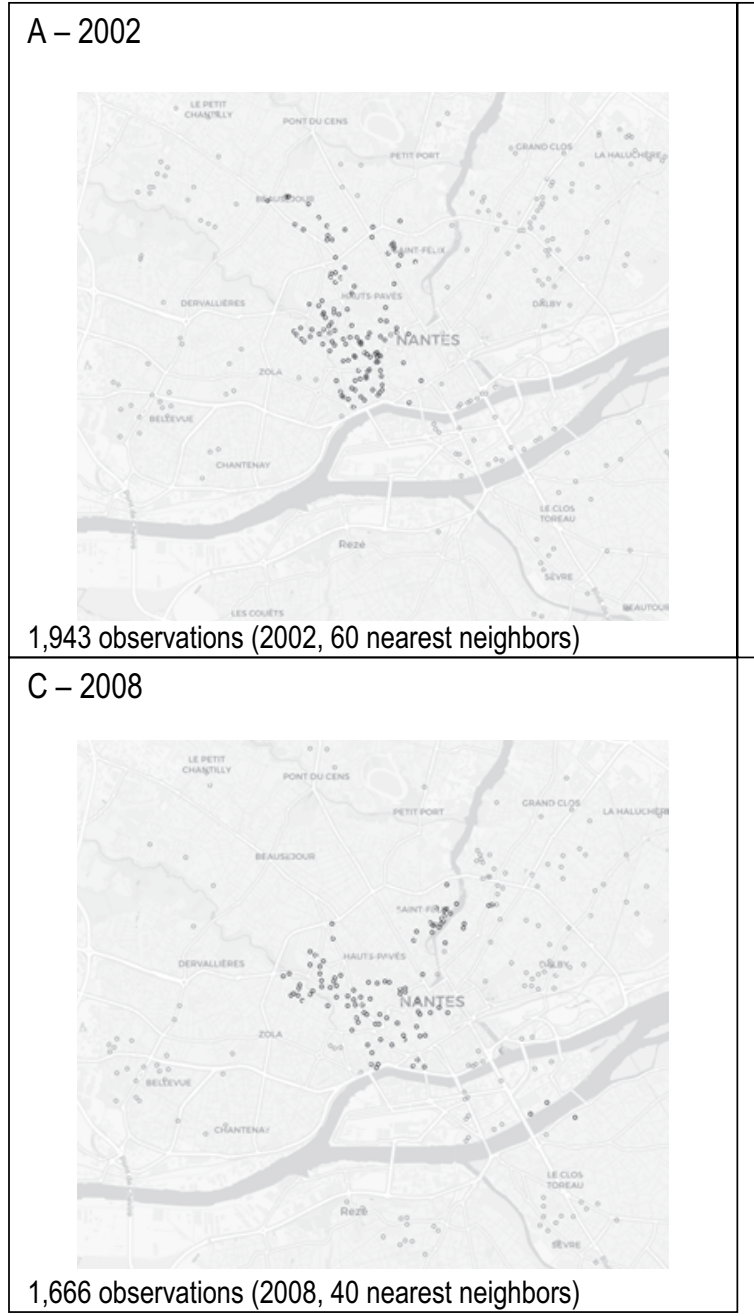

\section{Empirical model}

We use the apartment price as the dependent variable. From the descriptive analysis of the data, we postulate that this price can be explained by the intrinsic attributes of the dwelling, and extrinsic attributes such as proximity to public transport, which is a source of both amenities and pollution. We use the following hedonic price model to estimate housing price effects:

$p_{i}=\alpha_{0}+\sum_{c=1}^{C} \beta_{c} x_{c i}+\sum_{q=1}^{Q} \gamma_{q} y_{q i}+\sum_{r=1}^{R} \delta_{r} z_{r i}+\sum_{s=1}^{S} \phi_{s} v_{s i}+\varepsilon$

Here $p_{i}$ is the $\log$ of the price of transaction $I, x_{c}$ are the $C$ intrinsic attributes of the apartment sold, $y_{q}$ the contextual variables, $z_{r}$ the
B- 2006

1,981 observations (2006, 100 nearest neighbors)

Note: High-High (in black): the observed values of the transaction and its neighbors are high; Low-Low (in grey): the values of the transaction and its neighbors are low. Not represented: Low-High: the value of the transaction is low but those of its neighbors are high; High-Low: the value is high but those of its neighbors are low. LISA statistics are significant at the $5 \%$ level.

Source: Authors (GeoDa). accessibility characteristics et $v_{s}$ the environmental quality variables. $\alpha, \beta, \gamma, \delta$, and $\phi$ are the corresponding parameters to be estimated, and $\varepsilon_{i}$ is a residual error term assumed to be independent and identically distributed. All of the intrinsic and extrinsic variables described (Table 1) were included in the empirical model. Among the intrinsic attributes, the surface area and its square were additionally considered to test for a potential nonlinear relationship with the price ${ }^{12}$.

As the assumption of independence between observations is often violated, hedonic price models frequently use spatial econometric

12. The surface area and its square were centered to reduce the correlations between the variables. 
methods applied to geo-referenced data (Cliff et al., 1975; Anselin, 1988; Le Gallo, 2002, 2004). We tested the assumption of spatial dependence (i.e. cross-unit interactions), which implies that the structure of the correlation matrix between apartments located in different places is determined by the relative position of these apartments in geographical space. In other words, the values observed in one place depend on those elsewhere.

First, following the empirical strategy in Chasco et al. (2018), an Ordinary Least Squares (OLS) regression of the variables presented in Table 1 is estimated for each year. In addition, quarterly period dummies are included as temporal effects, as well as five submarket dummies corresponding to the five clusters of prices emphasized in the preceding section (on this point, see López et al., 2015). Table 2 provides OLS estimates and a number of regression diagnostics to test nonnormality, heteroscedasticity, and especially spatial dependence. Each model explains more than $80 \%$ of the apartment price variance. According to the AIC and BIC criteria, the spatial submarket dummies improve the model fit.
The models are not greatly affected by multicollinearity, as shown by the low value of the mean Variance Inflation Factor or VIF index (which is under 5 for all variables). However, the condition index is above the acceptable limit of 30-40 (Belsley, 1991). The Shapiro-Wilk and Cook-Weisberg tests indicate non-normality in the error terms. According to the Breusch-Pagan test for heteroscedasticity, we can reject the assumption of homoscedasticity for the three models, suggesting a functional form of heteroscedasticity. As a special case of the Breusch-Pagan test where the assumption of normally-distributed errors is relaxed, the White test provides similar results and shows the existence of an unspecified form of heteroscedasticity.

A number of tests were carried out to analyze the spatial autocorrelation that represents the correlations between the value at a location and those at neighboring locations. The Moran's I Error Test is significant, suggesting a problem with spatial autocorrelation in the residuals. The Lagrange Multiplier (LM) tests for spatial autocorrelation as well as their robust counterparts were calculated for an inverse distance matrix and different sets of nearest-neighbor

Table 2

Empirical estimation of apartment prices - OLS results and regression diagnostics

\begin{tabular}{|c|c|c|c|}
\hline Model & 2002 & 2006 & 2008 \\
\hline Surface area & $\begin{array}{l}0.0161^{* *} \\
(0.0004)\end{array}$ & $\begin{array}{l}0.0145^{\star *} \\
(0.0003)\end{array}$ & $\begin{array}{l}0.0152^{\star \star} \\
(0.0003)\end{array}$ \\
\hline Surface $^{2}$ & $\begin{array}{r}-0.0062^{\star *} \\
(0.0005)\end{array}$ & $\begin{array}{r}-0.0055^{\star *} \\
(0.0004)\end{array}$ & $\begin{array}{r}-0.0053^{* *} \\
(0.0006)\end{array}$ \\
\hline Constr $<1948$ & $\begin{array}{r}-0.2395^{\star *} \\
(0.0400)\end{array}$ & $\begin{array}{r}-0.1124^{* *} \\
(0.0295)\end{array}$ & $\begin{array}{r}-0.1331^{* *} \\
(0.0360)\end{array}$ \\
\hline Constr[1948-1969] & $\begin{array}{r}-0.2384^{* *} \\
(0.0199)\end{array}$ & $\begin{array}{r}-0.1758^{* *} \\
(0.0150)\end{array}$ & $\begin{array}{r}-0.2157^{\star \star *} \\
(0.0157)\end{array}$ \\
\hline Constr[1970-1980] & $\begin{array}{r}-0.2696^{* *} \\
(0.0209)\end{array}$ & $\begin{array}{r}-0.1571^{* *} \\
(0.0150)\end{array}$ & $\begin{array}{r}-0.2190^{* \star} \\
(0.0165)\end{array}$ \\
\hline Constr[1981-1991] & $\begin{array}{r}-0.1201^{* *} \\
(0.0185)\end{array}$ & $\begin{array}{r}-0.0748^{* *} \\
(0.0159)\end{array}$ & $\begin{array}{r}-0.1185^{\star *} \\
(0.0163)\end{array}$ \\
\hline Sale before completion & $\begin{array}{l}0.1847^{\star *} \\
(0.0172)\end{array}$ & $\begin{array}{l}0.1869^{\star *} \\
(0.0134)\end{array}$ & $\begin{array}{l}0.2007^{\star \star *} \\
(0.0148)\end{array}$ \\
\hline No parking space & $\begin{array}{r}-0.1539^{* *} \\
(0.0553)\end{array}$ & $\begin{array}{r}-0.0916^{* *} \\
(0.0261)\end{array}$ & $\begin{array}{r}-0.1609^{* \star} \\
(0.0301)\end{array}$ \\
\hline$>$ One parking space & $\begin{array}{l}0.0370^{* *} \\
(0.0119)\end{array}$ & $\begin{array}{c}0.0377^{\star *} \\
(0.0144)\end{array}$ & $\begin{array}{r}0.0074 \\
(0.0163)\end{array}$ \\
\hline ZUS & $\begin{array}{r}-0.0913^{* *} \\
(0.0331)\end{array}$ & $\begin{array}{r}-0.0693^{* *} \\
(0.0199)\end{array}$ & $\begin{array}{r}-0.0161 \\
(0.0239)\end{array}$ \\
\hline Contiguous ZUS & $\begin{array}{r}-0.0387^{* *} \\
(0.0144)\end{array}$ & $\begin{array}{r}-0.0262^{* *} \\
(0.0099)\end{array}$ & $\begin{array}{r}-0.0359 * * \\
(0.0129)\end{array}$ \\
\hline Median income & $\begin{array}{l}0.2976^{* *} \\
(0.0394)\end{array}$ & $\begin{array}{c}0.1662^{\star *} \\
(0.0282)\end{array}$ & $\begin{array}{l}0.2492^{* *} \\
(0.0342)\end{array}$ \\
\hline Private road & $\begin{array}{r}-0.0155 \\
(0.0107)\end{array}$ & $\begin{array}{r}-0.0320^{* *} \\
(0.0085)\end{array}$ & $\begin{array}{r}-0.0128 \\
(0.0098)\end{array}$ \\
\hline Green spaces & $\begin{array}{c}0.0042^{* *} \\
(0.0011)\end{array}$ & $\begin{array}{r}0.0005 \\
(0.0009)\end{array}$ & $\begin{array}{l}0.0018+ \\
(0.0011)\end{array}$ \\
\hline Distance centre & $\begin{array}{r}-0.0575^{\star *} \\
(0.0121)\end{array}$ & $\begin{array}{r}-0.0582^{\star *} \\
(0.0103)\end{array}$ & $\begin{array}{r}-0.0891^{* *} \\
(0.0129)\end{array}$ \\
\hline
\end{tabular}


Table 2 (contd.)

\begin{tabular}{|c|c|c|c|}
\hline Model & 2002 & 2006 & 2008 \\
\hline Dist. railway station & $\begin{array}{l}0.0486^{* *} \\
(0.0091)\end{array}$ & $\begin{array}{l}0.0290^{* *} \\
(0.0072)\end{array}$ & $\begin{array}{l}0.0234^{*} \\
(0.0097)\end{array}$ \\
\hline Distance to bus stop & $\begin{array}{r}0.0873^{*} \\
(0.0403)\end{array}$ & $\begin{array}{r}-0.0078 \\
(0.0066)\end{array}$ & $\begin{array}{r}0.0138 \\
(0.0086)\end{array}$ \\
\hline Tram $>500 m$ & $\begin{array}{l}-0.0306 \\
(0.0683)\end{array}$ & $\begin{array}{r}0.0071 \\
(0.0098)\end{array}$ & $\begin{array}{l}-0.0021 \\
(0.0104)\end{array}$ \\
\hline Max. noise & $\begin{array}{r}-0.0007+ \\
(0.0004)\end{array}$ & $\begin{array}{r}-0.0014^{* *} \\
(0.0004)\end{array}$ & $\begin{array}{r}-0.0013^{* *} \\
(0.0004)\end{array}$ \\
\hline Air pollution & $\begin{array}{l}0.0321+ \\
(0.0182) \\
\end{array}$ & $\begin{array}{r}0.0244 \\
(0.0152) \\
\end{array}$ & $\begin{array}{l}0.0308^{*} \\
(0.0153)\end{array}$ \\
\hline \multicolumn{4}{|l|}{ Temporal effects } \\
\hline Second quarter & $\begin{array}{r}0.0186 \\
(0.0155)\end{array}$ & $\begin{array}{r}0.0242^{*} \\
(0.0101)\end{array}$ & $\begin{array}{r}0.0045 \\
(0.0123)\end{array}$ \\
\hline Third quarter & $\begin{array}{l}0.0420^{\star *} \\
(0.0134)\end{array}$ & $\begin{array}{l}0.0411^{* *} \\
(0.0104)\end{array}$ & $\begin{array}{r}-0.0024 \\
(0.0129)\end{array}$ \\
\hline Fourth quarter & $\begin{array}{l}0.0475^{\star \star} \\
(0.0147)\end{array}$ & $\begin{array}{l}0.0459^{* *} \\
(0.0121)\end{array}$ & $\begin{array}{l}-0.0163 \\
(0.0131) \\
\end{array}$ \\
\hline \multicolumn{4}{|l|}{ Spatial submarkets } \\
\hline Submarket 2 (High-High) & $\begin{array}{l}0.1310^{* *} \\
(0.0210)\end{array}$ & $\begin{array}{l}0.1596^{* *} \\
(0.0182)\end{array}$ & $\begin{array}{l}0.1223^{\star *} \\
(0.0203)\end{array}$ \\
\hline Submarket 3 (Low-Low) & $\begin{array}{r}-0.0607^{* *} \\
(0.0140)\end{array}$ & $\begin{array}{r}-0.0281^{* *} \\
(0.0106)\end{array}$ & $\begin{array}{r}-0.0544^{* *} \\
(0.0121)\end{array}$ \\
\hline Submarket 4 (Low-High) & $\begin{array}{l}-0.0628^{*} \\
(0.0254)\end{array}$ & $\begin{array}{r}-0.0613^{* *} \\
(0.0237)\end{array}$ & $\begin{array}{r}-0.0770^{* *} \\
(0.0225)\end{array}$ \\
\hline Submarket 5 (High-Low) & $\begin{array}{l}0.0805^{*} \\
(0.0136)\end{array}$ & $\begin{array}{l}0.1103^{* *} \\
(0.0129)\end{array}$ & $\begin{array}{l}0.0467^{\star *} \\
(0.0148)\end{array}$ \\
\hline Constant & $\begin{array}{l}8.6513^{* *} \\
(0.3920) \\
\end{array}$ & $\begin{array}{r}10.4452^{* *} \\
(0.2829) \\
\end{array}$ & $\begin{array}{l}9.8130^{* *} \\
(0.3516) \\
\end{array}$ \\
\hline Observations & 1,943 & 1,981 & 1,666 \\
\hline R-squared & 0.832 & 0.822 & 0.823 \\
\hline \multicolumn{4}{|l|}{ Model fit } \\
\hline AIC & -664.96 & -1293.05 & -886.97 \\
\hline $\mathrm{BIC}$ & -508.95 & -1136.49 & -735.26 \\
\hline $\begin{array}{l}\text { AIC (Model without spatial } \\
\text { submarkets) }\end{array}$ & -560.98 & -1159.39 & -806.98 \\
\hline $\begin{array}{l}\text { BIC (Model without spatial } \\
\text { submarkets) }\end{array}$ & -427.25 & -1025.20 & -676.94 \\
\hline \multicolumn{4}{|l|}{ Multicollinearity } \\
\hline Mean VIF & 1.78 & 1.58 & 1.59 \\
\hline Condition index & 86.6 & 77.0 & 66.7 \\
\hline \multicolumn{4}{|l|}{ Error normality } \\
\hline Shapiro-Wilk W test & $0.848^{* *}$ & $0.905^{\star *}$ & $0.970^{* *}$ \\
\hline \multicolumn{4}{|l|}{ Heteroscedasticity } \\
\hline Breusch-Pagan & $51.84^{* *}$ & $63.40^{* *}$ & $159.35^{\star *}$ \\
\hline White's test & $735.38^{* *}$ & $590.22^{* *}$ & $521.81^{* *}$ \\
\hline \multicolumn{4}{|l|}{ Spatial error } \\
\hline Moran's I Error Test & $14.09^{\star \star}$ & $11.04^{\star *}$ & $18.54^{\star *}$ \\
\hline RLM Error (5 nn) & $109.64^{* *}$ & $72.00^{\star *}$ & $206.16^{* *}$ \\
\hline RLM Error (10 nn) & $112.41^{* *}$ & $69.39^{\star *}$ & $327.88^{* *}$ \\
\hline RLM Error (20 nn) & $108.95^{* *}$ & $98.69^{* *}$ & $373.45^{* *}$ \\
\hline RLM Error (40 nn) & $107.88^{* *}$ & $93.33^{* *}$ & $333.30^{* *}$ \\
\hline RLM Error (60 nn) & $86.56^{\star *}$ & $71.68^{* *}$ & $260.49^{* *}$ \\
\hline RLM Error (100 nn) & $76.48^{\star *}$ & $42.66^{\star *}$ & $254.27^{\star *}$ \\
\hline \multicolumn{4}{|l|}{ Spatial lag } \\
\hline RLM Lag (5 nn) & $3.28^{*}$ & 1.49 & $4.43^{* *}$ \\
\hline RLM Lag (10 nn) & $4.44^{*}$ & 2.69 & 0.53 \\
\hline RLM Lag (20 nn) & $5.96^{* *}$ & 3.04 & $9.38^{* *}$ \\
\hline RLM Lag (40 nn) & $9.46^{\star *}$ & 0.23 & $24.08^{* *}$ \\
\hline RLM Lag (60 nn) & $13.12^{* *}$ & 3.50 & $7.49^{\star *}$ \\
\hline RLM Lag (100 nn) & $7.52^{\star *}$ & $4.98^{*}$ & $17.02^{*}$ \\
\hline
\end{tabular}

Note: ** Significant at $1 \%$, ${ }^{*}$ Significant at $5 \%$ and + Significant at $10 \%$. RLM are the Robust Lagrange Multiplier tests for spatial error and spatial lag models. $5 \mathrm{nn}$ (nearest neighbors), $10 \mathrm{nn}, 20 \mathrm{nn}, 40 \mathrm{nn}, 60 \mathrm{nn}$ and $100 \mathrm{nn}$ are the 5, 10, 20, 40,60 and 100 nearest-neighbor weight matrices, respectively. High-High: The observed values of the transaction and its neighbors are high; Low-Low: the values of the transaction and its neighbors are low. Low-High: the value of the transaction is low but those of its neighbors are high; High-Low: the value is high but those of its neighbors are low. Coverage: 5,590 apartment transactions in the 24 communes of Nantes Métropole in 2002, 2006 and 2008 (respectively 1,943, 1,981 and 1,666 observations).

Sources: Perval 2002, 2006 and 2008; authors' estimations. 
matrices $(5,10,20,40,60 \text { and } 100)^{13} .60$ nearest neighbors were chosen for 2002, 100 for 2006, and 40 for $2008^{14}$. The robust LM test for spatial errors is significant, as well as the robust LM test for the spatial lag. The first is always higher than the second. However, these results must be taken with caution due to the non-normality of the error terms.

In accordance with the results of the LM tests, we use a spatial model containing spatial lags in the dependent variable, exogenous variables and disturbance term. The spatially-lagged variable allows for spatial spillovers in the dependent variable; it uses a spatial weight matrix to express the potential spatial interaction between the locations of each pair of apartments ${ }^{15}$. Moreover, a spatial autoregressive process is included in the error term, allowing for spatial spillovers ${ }^{16}$. Finally, the model is specified as follows:

$$
\begin{aligned}
p_{i} & =\alpha_{0}+\lambda \sum_{j=1}^{n} w_{i j} p_{j}+\sum_{c=1}^{C} \beta_{c} x_{c i}+\sum_{q=1}^{Q} \gamma_{q} y_{q i} \\
& +\sum_{r=1}^{R} \delta_{r} z_{r i}+\sum_{s=1}^{S} \phi_{s} v_{s i}+u_{i} \\
u_{i} & =\rho \sum_{j=1}^{n} m_{i j} u_{j}+\varepsilon_{i}
\end{aligned}
$$

where $\lambda$ is the spatial autoregressive parameter, $\rho$ the spatial error parameter, and $w_{i j}$ and $m_{i j}$ are the spatial weight matrices ${ }^{17}$. In modeling the price of each apartment as depending on a weighted average of the prices of other apartments, the model determines the outcomes simultaneously, which implies that the OLS estimator is not consistent (Anselin, 1988). This endogeneity due to the spatial lag requires the use of an instrument matrix.

As the error terms are not normally distributed, the Maximum Likelihood estimator (ML) is not relevant ${ }^{18}$. Moreover, the model residuals are affected by spatial correlation and heteroscedasticity. Heteroscedasticity is likely due to spatial heterogeneity, as the housing market is generally not uniform over space ${ }^{19}$. Despite the introduction of spatial submarket dummies to reduce spatial heterogeneity, there is still disturbance heteroscedasticity. We consequently use the GMM estimator proposed by Kelejian and Prucha (2010) for the spatial autoregressive parameter in the disturbance process, as this estimator allows for heteroskedastic error terms. The model is estimated in the first step by the Two Stage Least Square method (2SLS) using the instrument matrix. In the second step, the autoregressive parameter $\rho$ is estimated using the GMM estimation based on the 2SLS residuals from the first step. To account for spatial correlation, the regression model is reestimated in the third step by the 2SLS method, after applying a Cochrane-Orcutt type transformation to the model (for further details, see Kelejian and Prucha, 2010).

\section{Results}

The results of this model are reported in Table 3.

The parameter $\lambda$ is positive and significant, indicating spatial autoregressive dependence in apartment prices. The parameter $\rho$ is positive and significant, so that the unobserved components of the model are spatially linked. The spatial submarkets variables are globally significant ${ }^{20}$.

\section{The effects of apartments' intrinsic and contextual attributes}

The role of intrinsic characteristics of dwellings in real-estate capitalization that we find in Nantes Métropole is globally consistent with other work on French data (Cavailhès, 2005; Bono et al., 2007; Fritsch, 2007; Bureau \& Glachant, 2010; Trannoy \& Wasmer, 2013). Among these attributes, the surface area plays a major role. In order to investigate potential nonlinear relationships, we add the squared surface area to the surface area, and find a concave relationship between the latter and the price of the apartment. Such a result could indicate a saturation effect of buyer preferences when a dwelling surface area lies above a certain threshold. We emphasize that this threshold is located between 200 and $220 \mathrm{~m}^{2}$ according to the year of transaction.

\footnotetext{
13. As LM-Error and LM-Lag were always significant, robust tests were used because both $L M$-Error and $L M$-Lag have power against the other alternative. 14. The average distance between each observation and its $k$-th nearest neighbor is $1.1 \mathrm{~km}$ in 2002 (60 th nearest neighbor), $1.4 \mathrm{~km}$ in 2006 (100 th nearest neighbor) and $1 \mathrm{~km}$ in 2008 (40 th nearest neighbor). 15. The $\mathrm{n} \times \mathrm{n}$ spatial weight matrix is row standardized: each row sums to one. 16. The AIC and BIC criteria conclude that the inclusion of the spatial autoregressive and spatial error parameters improves the model fit in each year. 17. In our specification, $\mathrm{w}_{\mathrm{i}}=\mathrm{m}_{\mathrm{i}}$.

18. The quasi-ML estimator in the model proposed by Lee (2004) does not carry over to the case where the disturbances are heteroskedastic.

19. LeSage (1999) shows, for example, that the mean and variance of house prices change with the distance from the central business district. 20. We tested our models without the submarket dummies to see if they reduced the impact of other explanatory variables, notably accessibility and environmental quality variables. Our results proved to be similar.
} 
Table 3

Estimation of the spatial hedonic price model for apartments in Nantes Métropole, 2002, 2006 and 2008

\begin{tabular}{|c|c|c|c|}
\hline Variables & Model 2002 & Model 2006 & Model 2008 \\
\hline Surface area & $\begin{array}{l}0.0163^{* *} \\
(0.0004)\end{array}$ & $\begin{array}{l}0.0146^{* *} \\
(0.0003)\end{array}$ & $\begin{array}{l}0.0156^{\star \star} \\
(0.0003)\end{array}$ \\
\hline Surface2 & $\begin{array}{r}-0.0063^{* *} \\
(0.0006)\end{array}$ & $\begin{array}{r}-0.0056^{* *} \\
(0.0004)\end{array}$ & $\begin{array}{r}-0.0057^{\star *} \\
(0.0006)\end{array}$ \\
\hline Constr $<1948$ & $\begin{array}{r}-0.2370^{* *} \\
(0.0426)\end{array}$ & $\begin{array}{r}-0.1194^{* *} \\
(0.0289)\end{array}$ & $\begin{array}{r}-0.1243^{* *} \\
(0.0351)\end{array}$ \\
\hline Constr[1948-1969] & $\begin{array}{r}-0.2401^{* *} \\
(0.0198)\end{array}$ & $\begin{array}{r}-0.1769^{\star *} \\
(0.0150)\end{array}$ & $\begin{array}{r}-0.2161^{* \star} \\
(0.0159)\end{array}$ \\
\hline Constr[1970-1980] & $\begin{array}{r}-0.2561^{* *} \\
(0.0210)\end{array}$ & $\begin{array}{r}-0.1548^{* *} \\
(0.0149)\end{array}$ & $\begin{array}{r}-0.2089^{* *} \\
(0.0168)\end{array}$ \\
\hline Constr[1981-1991] & $\begin{array}{r}-0.1169^{* *} \\
(0.0179)\end{array}$ & $\begin{array}{r}-0.0747^{\star *} \\
(0.0157)\end{array}$ & $\begin{array}{r}-0.1226^{\star *} \\
(0.0161)\end{array}$ \\
\hline Sale before completion & $\begin{array}{l}0.1489^{* *} \\
(0.0190)\end{array}$ & $\begin{array}{l}0.1755^{\star \star} \\
(0.0134)\end{array}$ & $\begin{array}{l}0.2053^{\star *} \\
(0.0175)\end{array}$ \\
\hline No parking space & $\begin{array}{r}-0.1629^{* *} \\
(0.0559)\end{array}$ & $\begin{array}{r}-0.0928^{* *} \\
(0.0256)\end{array}$ & $\begin{array}{r}-0.1623^{* *} \\
(0.0292)\end{array}$ \\
\hline >One parking space & $\begin{array}{c}0.0388^{* *} \\
(0.0117)\end{array}$ & $\begin{array}{c}0.0366^{*} \\
(0.0143)\end{array}$ & $\begin{array}{r}0.0115 \\
(0.0153)\end{array}$ \\
\hline ZUS & $\begin{array}{l}-0.0568 \\
(0.0436)\end{array}$ & $\begin{array}{r}-0.0922^{* *} \\
(0.0213)\end{array}$ & $\begin{array}{r}0.0305 \\
(0.0331)\end{array}$ \\
\hline Contiguous ZUS & $\begin{array}{r}-0.0237 \\
(0.0179)\end{array}$ & $\begin{array}{r}-0.0322^{* *} \\
(0.0122)\end{array}$ & $\begin{array}{r}-0.0194 \\
(0.0179)\end{array}$ \\
\hline Median income & $\begin{array}{l}0.1414^{\star *} \\
(0.0480)\end{array}$ & $\begin{array}{l}0.1010^{\star *} \\
(0.0313)\end{array}$ & $\begin{array}{l}0.1869^{\star *} \\
(0.0446)\end{array}$ \\
\hline Private road & $\begin{array}{r}-0.0409^{* *} \\
(0.0143)\end{array}$ & $\begin{array}{r}-0.0258^{\star \star} \\
(0.0087)\end{array}$ & $\begin{array}{l}-0.0085 \\
(0.0103)\end{array}$ \\
\hline Green spaces & $\begin{array}{l}0.0039^{* *} \\
(0.0015)\end{array}$ & $\begin{array}{r}-0.0004 \\
(0.0009)\end{array}$ & $\begin{array}{r}0.0004 \\
(0.0014)\end{array}$ \\
\hline Distance centre & $\begin{array}{r}-0.0648^{* *} \\
(0.0211)\end{array}$ & $\begin{array}{l}-0.0367^{\star} \\
(0.0156)\end{array}$ & $\begin{array}{r}-0.0956^{* \star} \\
(0.0227)\end{array}$ \\
\hline Dist. railway station & $\begin{array}{l}0.0235+ \\
(0.0127)\end{array}$ & $\begin{array}{r}0.0122 \\
(0.0102)\end{array}$ & $\begin{array}{r}0.0174 \\
(0.0185)\end{array}$ \\
\hline Distance to bus stop & $\begin{array}{r}0.0052 \\
(0.0099)\end{array}$ & $\begin{array}{l}-0.0096 \\
(0.0066)\end{array}$ & $\begin{array}{r}-0.0040 \\
(0.0094)\end{array}$ \\
\hline Tram $>500 m$ & $\begin{array}{r}-0.0020 \\
(0.0177)\end{array}$ & $\begin{array}{r}0.0009 \\
(0.0112)\end{array}$ & $\begin{array}{l}-0.0127 \\
(0.0137)\end{array}$ \\
\hline Max. noise & $\begin{array}{l}-0.0006 \\
(0.0005)\end{array}$ & $\begin{array}{r}-0.0013^{* *} \\
(0.0004)\end{array}$ & $\begin{array}{l}-0.0010^{*} \\
(0.0005)\end{array}$ \\
\hline Air pollution & $\begin{array}{r}0.0182 \\
(0.0195) \\
\end{array}$ & $\begin{array}{l}0.0260+ \\
(0.0150)\end{array}$ & $\begin{array}{r}0.0087 \\
(0.0168) \\
\end{array}$ \\
\hline \multicolumn{4}{|l|}{ Temporal effects } \\
\hline Second quarter & $\begin{array}{l}0.0271+ \\
(0.0149)\end{array}$ & $\begin{array}{l}0.0290^{* *} \\
(0.0099)\end{array}$ & $\begin{array}{l}-0.0101 \\
(0.0118)\end{array}$ \\
\hline Third quarter & $\begin{array}{l}0.0425^{* \star} \\
(0.0129)\end{array}$ & $\begin{array}{l}0.0448^{* *} \\
(0.0103)\end{array}$ & $\begin{array}{l}-0.0170 \\
(0.0127)\end{array}$ \\
\hline Fourth quarter & $\begin{array}{l}0.0527^{* *} \\
(0.0140)\end{array}$ & $\begin{array}{l}0.0509^{* *} \\
(0.0119)\end{array}$ & $\begin{array}{r}-0.0254 \\
(0.0128)\end{array}$ \\
\hline \multicolumn{4}{|l|}{ Spatial submarkets } \\
\hline Submarket $2(H H)$ & $\begin{array}{c}0.0711^{*} \\
(0.0338)\end{array}$ & $\begin{array}{l}0.1041^{* *} \\
(0.0209)\end{array}$ & $\begin{array}{r}0.0309 \\
(0.0294)\end{array}$ \\
\hline Submarket 3 (LL) & $\begin{array}{l}0.0308+ \\
(0.0180)\end{array}$ & $\begin{array}{r}-0.0087 \\
(0.0115)\end{array}$ & $\begin{array}{r}0.0254 \\
(0.0167)\end{array}$ \\
\hline Submarket $4(\mathrm{LH})$ & $\begin{array}{r}-0.1171^{* *} \\
(0.0296)\end{array}$ & $\begin{array}{r}-0.0959^{* *} \\
(0.0254)\end{array}$ & $\begin{array}{r}-0.1538^{* \star} \\
(0.0286)\end{array}$ \\
\hline Submarket 5 (HL) & $\begin{array}{l}0.1449^{\star \star} \\
(0.0177)\end{array}$ & $\begin{array}{l}0.1224^{* *} \\
(0.0135)\end{array}$ & $\begin{array}{l}0.0869^{* \star} \\
(0.0169)\end{array}$ \\
\hline Constant & $\begin{array}{l}6.0400^{* *} \\
(0.7397) \\
\end{array}$ & $\begin{array}{l}6.9313^{*} \\
(0.9531) \\
\end{array}$ & $\begin{array}{l}6.9271^{* *} \\
(1.3387)\end{array}$ \\
\hline Lambda & $\begin{array}{l}0.3803^{* \star} \\
(0.0671)\end{array}$ & $\begin{array}{l}0.3566^{* *} \\
(0.0788)\end{array}$ & $\begin{array}{l}0.3163^{\star \star} \\
(0.1108)\end{array}$ \\
\hline Rho & $\begin{array}{l}0.6481^{* *} \\
(0.0652)\end{array}$ & $\begin{array}{l}0.5671^{\star *} \\
(0.0983)\end{array}$ & $\begin{array}{l}0.7699 * * \\
(0.0644)\end{array}$ \\
\hline Observations & 1,943 & 1,981 & 1,666 \\
\hline
\end{tabular}

Note: ** Significant at $1 \%,{ }^{*}$ significant at $5 \%$ and + significant at $10 \%$.

$H H$ : The observed values of the transaction and its neighbors are high; $L L$ : the values of the transaction and its neighbors are low. $L H$ : the value of the transaction is low but those of its neighbors are high; $H L$ : the value is high but those of its neighbors are low.

Coverage: 5,590 apartment transactions in the 24 communes of Nantes Métropole in 2002, 2006 and 2008 (respectively 1,943, 1,981 and 1,666 observations).

Sources: Perval 2002, 2006 and 2008; authors' estimations. 
Several other intrinsic attributes also influence apartment prices in Nantes Métropole. Post-1991 buildings sell at higher prices than older ones. Buyers' perceptions of potentially worse apartments, with less efficient thermal and acoustic insulation than more recent ones, could lie behind this result ${ }^{21}$. In the same way, new apartments (sold before completion) also benefit from considerably higher prices. The number of parking spaces also significantly influences the price: apartments with no parking spaces sell at lower prices than apartments with one parking space, whereas apartments with two or more parking spaces sell at higher prices. Buyers would then seem to consider parking on a public road at home to be delicate.

Housing values are also usually determined by the geographical and socio-economic environment of the dwellings. Still, certain contextual attributes have no clear impact on the apartment prices in Nantes Métropole. Being located in a ZUS or an IRIS contiguous to a ZUS thus reduces the transaction prices in 2006 , although these two variables are not significant in 2002 and 2008. This result can be interpreted as potentially showing the usefulness of urban-renewal programs in improving the image of these districts and their neighborhood. Conversely, in line with Bureau and Glachant (2010), median IRIS income is positively correlated with apartment prices.

\section{The effects of location and accessibility variables}

As the location and accessibility variables were constructed in the framework of the multidisciplinary research project, these attributes were expected to be more informative. Indeed accessibility variables, especially proximity to transport networks, often play a role in hedonic studies in Europe and elsewhere, as we highlighted in the Literature review section. Still these effects are not always significant; if they are, they may highlight either the expected accessibility effect yielded by the transport facility (inducing real-estate capitalization) or, conversely, a negative externality effect notably due to the higher noise levels endured (causing a drop in housing prices). Last, such effects remain dependent on the local context in the sense that, as we will see, the existing transport networks in the city may be considered more or less dense by the buyers. It thus seems important to confirm or refute the partial results of Fritsch concerning the tram influence in Nantes (2007). To this end, we discuss the results obtained through the construction of accessibility variables intended to complete the hierarchy of public transport networks: from above (commuter rail) and from below (the bus network).

In the first place, the proximity to Nantes city centre unsurprisingly plays a positive role. We verify that there is no evidence of a nonlinear effect between this distance and the price of the apartment. This linear relationship is both in line with theoretical (Fujita, 1989) and empirical literature: notably in Paris (Bureau \& Glachant, 2010), and in Bordeaux city centre (Gaschet \& Pouyanne, 2011).

Concerning the construction of the accessibility variables to public transport, we follow specific strategies according to the network. As bus stops can be found in the peripheral municipalities of Nantes Métropole, the variable "distance of the apartment from the nearest bus stop" can be introduced in a continuous form. Conversely, as the locations of tram stops are more correlated with the distance to the city centre (no tram stops outside the ring road), we choose to use a dummy variable ("Presence of a tram stop less than 500 meters away"). The threshold of 500 meters approximately reflects the median value of the distribution. Concerning non-urban public transport (commuter rail), it should be noted that only $12 \%$ of transactions are located less than one kilometer from the central railway station. These particular locations could be viewed as a premium by the buyers.

However, proximity to the closest railway station does not play the expected accessibility role, with not significant estimated coefficients. This may reflect the minor role played by the non-urban railway network in urban mobility in France. Moreover, in Nantes Métropole, this likely is due to the good accessibility to urban public transport, which is expected to provide a better service than commuter rail inside the conurbation, notably in terms of frequency and daily operating times.

The assumption of a greater interest of the apartment buyers towards the urban transport networks is however not verified: we find no significant influence of the bus and tram networks on apartment prices in Nantes Métropole

21. Unfortunately, no information was available on the state of the apartment at the time of transaction. 
either. The estimated bus coefficients are insignificant in all three transaction years. However, this absence of valuation may simply be due to the high density of urban transport networks in the city in general, which makes immediate proximity to a bus stop superfluous from the buyer's point of view.

The four tramlines were established to help make radial trips to Nantes city centre using public transport. The three first lines were opened between 1985 and 2000 . As the third line was extended to the North of Nantes in 2004 and the fourth line was opened in 2006 (the "busway" line as a Bus Rapid Transit), these trips to the city centre were made possible from various points of the ring road. However, in the same way as above, our results show that being located in a 500-m radius around a tram stop does not significantly affect apartment prices in Nantes Métropole, with coefficients never significant for any transaction year ${ }^{22}$. Unlike Fritsch (2007), we therefore cannot conclude, for apartment transactions in Nantes Métropole, for the existence of either an accessibility effect of the tram network, or a negative effect from being located too close to a tram stop (in particular given the noise expected). This result is in line with those of Travers et al. (2014), who show that the "busway" line has no significant impact on housing prices in the municipalities of Nantes Métropole crossed by this new line (Nantes, Vertou and Saint-Sébastien-sur-Loire).

Concerning the remaining location variables, we do not emphasize any clear influence on apartment prices either. In two distinct ways, being on a private road and benefiting from large green-space surface areas around the apartment can be considered as amenities. However, despite the expected quiet environment, location on a private road (which is the case for $30 \%$ of the observations) is actually associated with lower prices in 2002 and 2006; this is likely due to the difficulty of access when roads are narrow. Concerning green spaces, the existence of a surface area within 300 meters around the apartment is significant only in 2002 . However, a positive influence of green spaces close by has been highlighted in a number of French cities: Paris (Bureau \& Glachant, 2010) and Angers (Choumert \& Travers, 2010). Our results here are more mixed insofar as green spaces do not significantly affect housing prices in 2006 and 2008, probably because Nantes, in recent years, has been one of the most active French cities with respect to green spaces and public expenditure per capita ${ }^{23}$.

\section{The effects of environmental quality variables}

Households are expected to value an improvement in environmental quality in urban centres, where it is generally considered deficient. Moreover, like accessibility, these attributes can be modified by sustainable urban mobility plans (Ellison et al., 2013). For these reasons, environmental quality variables (noise exposure and air pollution) were also constructed as part of the multidisciplinary research project, as potential factors of valorization or depreciation of the dwellings.

We retain in our models the noise variable that refers to the maximum noise level from roads and railways over a 24-hour period. Our results prove to be quite robust, as they are comparable whatever the noise variable introduced: day-time, evening or night-time; maximum, mean or minimum level. In the end, noise exposure reduces the price of apartments in 2006 and $2008^{24}$. For a noise exposure of 55 to $60 \mathrm{~dB}$, our results suggest a lower price of $0.28 \%$ per additional decibel. This coefficient is lower than that in Boiteux's report (2001): the figures there are $0.4 \%$ for the same $\mathrm{dB}$ interval, and $1.1 \%$ for over $75 \mathrm{~dB}$. In a previous study, Le Boennec and Sari (2015) find a comparable effect of noise on house prices in Nantes Métropole ( $-0.23 \%$ per additional decibel), again a lower value than in Boiteux's report. Our result may be due to the quiet environment found in Nantes Métropole in general.

Concerning the potential influence of air quality on the price of apartments in Nantes Métropole, it should be noted that only about $15 \%$ of dwellings are on average above the annual Air Quality Guideline (AQG) of the WHO (2000, 2006). However, even for this subsample of apartments, we do not find any positive relationship between air quality and the price. This result is confirmed for the apartments with better air quality. This general absence of relationship could reflect that real-estate capitalization is better explained by subjective perceptions of environmental attributes rather than objective data, as shown in Chasco and Le Gallo (2013). The explanation is double. First, the largely invisible and

22. Other threshold distances were tested, without success.

23. In the 2017 ranking of the Observatory of Green cities, Nantes was second of the 50 most-populated French cities.

24. The estimated price of an apartment that exchanged hands in 2008 is thus $€ 117,170$ above $62 d B$, whereas it is $€ 121,391$ below this threshold. 
intangible nature of air quality generally renders objective measures non influent, except in the case when the pollution is odorous or visible. Second, air pollution is seen as ephemeral, even though its effects on health are tangible (Le Boennec \& Salladarré, 2017). Last, lower air quality is more difficult to perceive when average air quality is high.

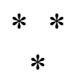

Our hedonic pricing analysis of apartment transactions in Nantes in 2002, 2006 and 2008 highlights the only moderate degree of real-estate capitalization with respect to accessibility to the city centre, air quality and noise reduction.

We confirm that housing prices in Nantes Métropole depend above all on the intrinsic attributes of the apartments and their socio-economic environment. In contrast, our results regarding accessibility are not particularly strong. In line with Travers et al. (2014), who find no real-estate capitalization for the "busway" line in Nantes Métropole, our results show no significant accessibility effect of urban and non-urban transport networks (bus, tram and train). Such an absence of a clear relationship between public transport and housing prices may be interpreted in two different ways. This may reflect sufficientlygood connections to the city centre from the buyer's point of view, regardless of the location of the apartment (given that the vast majority of apartments are located inside the ring road). Conversely, this may indicate the lack of buyers' interest in public transport in general, in that the corresponding modal share does not exceed $15 \%$ of total trips (as in comparable French Métropoles). Indeed, over 60\% of public transport users are under 25 and so are probably not active in the housing market.

The effects of environmental quality are not obvious either. On the one hand, the noise from road and rail is perceived negatively: we emphasize that apartment prices fall with noise exposure, although the effect is only small in size. On the other hand, we show that the concentration of airborne pollutants does not reduce apartment prices, even for the mostexposed dwellings. The explanation may lie in the fact that individuals are generally more sensitive to noise than air pollution. Such an attitude is consistent with the environmental economics theory that takes air pollution as a negative externality that individuals do not take into account when they purchase on the housing market. Environmental and public health policies thus have a role to play. A contextual interpretation may be provided in addition: environmental quality is generally good in Nantes Métropole, so households are probably less sensitive through housing valuation. The method we use to elaborate the environmental quality variables may also play a role: different results could have been found through the use of observed noise and air pollution values, unfortunately not available, instead of the values calculated from traffic data.

Do these results finally make the case for voluntarist public policies in favor of public transport? The 2010 Grenelle 2 French Law advocates tax policies regarding real-estate capital gains from selling property with transport facilities close by. However, our results suggest that these polices may be useless if awareness policies towards transport users are not implemented at the same time: local authorities should thus continue to emphasize the individual and collective benefits in order to make larger groups of individuals aware of the use of public transport. This could be carried out jointly with improvements in the quality of service (including carpooling options when bus lines are not profitable) and consequent investments in mobility platforms (mobile apps) in order to facilitate daily trips for everyone.

As hedonic price models cannot take into account all of the elements that affect housing prices, our results should be treated with caution. First, access to street and road networks could not be examined as potential premiums, as these variables were not geo-referenced in the framework of the research project. There are in addition many other factors that play a role in the perceptions of the quality of the living environment, such as security, the quality of schools, job opportunities, and proximity to the sea or other unique natural resources. All of these factors may be reflected in the housing market; however, as our models explain over $80 \%$ of the variance in apartment prices, these remaining factors should only have a relatively minor role to play in Nantes. More generally, a permanently high demand-tosupply ratio reveals the lack of apartments on the market. In this case, certain apartment attributes may be regarded as secondary by buyers, as can be seen in Nantes Métropole and other attractive cities. 
Alonso, W. (1964). Location and Land Use. Toward a General Theory of Land Rent. Cambridge: Harvard University Press.

Andersson, H., Jonsson, L. \& Ögren, M. (2010). Property Prices and Exposure to Multiple Noise Sources: Hedonic Regression with Road and Railway Noise. Environmental and Resource Economics, 45(1), 73-89.

https://oi.org/10.1007/s10640-009-9306-4

Anselin, L. (1988). Spatial Econometrics: Methods and Models. Boston : Kluwer Academics.

Anselin, L. (1995). Local Indicators of Spatial Association-LISA. Geographical analysis, 27(2), 93-115.

https://doi.org/10.1111/j.1538-4632.1995.tb00338.x

Anselin, L. (2005). Exploring Spatial Data with GeoDa: A Workbook. Spatial Analysis Laboratory, Department of Geography. Center for Spatially Integrated Social Science. Urbana, Champaign, IL : University of Illinois.

www.csiss.org/clearinghouse/GeoDa/geodawork book.pdf

Anselin, L. \& Le Gallo, J. (2006). Interpolation of Air Quality Measures in Hedonic House Price Models: Spatial Aspects. Spatial Economic Analysis, 1(1), 31-52.

https://doi.org/10.1080/17421770600661337

Belsley, D. (1991). Conditioning Diagnostics: Collinearity and Weak Data in Regression. New York : Wiley.

Billings, S. B. (2011). Estimating the value of a new transit option. Regional Science and Urban Economics, 41(6), 525-536.

https://doi.org/10.1016/j.regsciurbeco.2011.03.013

Bhat, C., Garrow, L., Mokhtarian, P. L. \& Cao, X. (2008). Examining the impacts of residential self-selection on travel behavior: A focus on methodologies. Transportation Research Part B: Methodological, 42(3), 204-228.

https://doi.org/10.1016/j.trb.2007.07.006

Boiteux, M. (2001). Transports : choix des investissements et coût des nuisances. Commissariat Général du Plan. Paris: La Documentation Française. www.ladocumentationfrancaise.fr/var/storage/ rapports-publics/014000434.pdf
Bono, P.-H., Gravel, N. \& Trannoy, A. (2007). L'importance de la localisation dans la valorisation des quartiers marseillais. Économie publique/ Public economics, 20(1).

http://journals.openedition.org/economiepublique/6202

Bowes, D. R. \& Ihlanfeldt, K. R. (2001). Identifying the Impacts of Rail Transit Stations on Residential Property Values. Journal of Urban Economics, 50(1), 1-25.

https://doi.org/10.1006/juec.2001.2214

Boyle, M. \& Kiel, K. (2001). A Survey of House Price Hedonic Studies of the Impact of Environmental Externalities. Journal of Real Estate Literature, 9(2), 117-144.

https://doi.org/10.5555/reli.9.2.23u082061q53qpm3

Bui, L. M. T. \& Mayer, C. J. (2003). Regulation and Capitalization of Environmental Amenities: Evidence from the Toxic Release Inventory in Massachusetts. Review of Economics and Statistics, 85(3), 693-708.

https://doi.org/10.1162/003465303322369821

Bureau, B. \& Glachant, M. (2010). Évaluation de l'impact des politiques Quartiers verts et Quartiers tranquilles sur les prix de l'immobilier à Paris. Economie \& prévision, 192(1), 27-44. https:/www.cairn.info/revue-economie-et-prevision2010-1-page-27.htm

Cao, X. \& Cao, J. (2014). The Impacts of LRT, Neighbourhood Characteristics, and Self-selection on Auto Ownership: Evidence from Minneapolis-St. Paul. Urban Studies, 51(10), 2068-2087. https://doi.org/10.1177\%2F0042098013505887

Cavailhès, J. (2005). Le prix des attributs du logement. Economie et Statistique, 381-382, 91-123. https://www.insee.fr/fr/statistiques/fichier/ 1376579/es381-382e.pdf

Chang, J. S. \& Kim, D.-J. (2013). Hedonic estimates of rail noise in Seoul. Transportation Research Part D: Transport and Environment, 19, 1-4. https://doi.org/10.1016/j.trd.2012.11.002

Chasco, C. \& Le Gallo, J. (2013). The Impact of Objective and Subjective Measures of Air Quality and Noise on House Prices: a Multilevel Approach for Downtown Madrid. Economic Geography, 89(2), 127-148.

https://doi.org/10.1111/j.1944-8287.2012.01172.x 
Chasco C., Le Gallo, J. \& López, F. A. (2018). A scan test for spatial groupwise heteroscedasticity in cross-sectional models with an application on houses prices in Madrid. Regional Science and Urban Economics, 68, 226-238. https://doi.org/10.1016/j.regsciurbeco.2017.10.015

Chen, Z. \& Haynes, K. E. (2015). Impact of high speed rail on housing values: An observation from the Beijing-Shanghai line. Journal of Transport Geography, 43, 91-100. https://doi.org/10.1016/j.jtrangeo.2015.01.012

Choumert, J. \& Travers, M. (2010). La capitalisation immobilière des espaces verts dans la ville d'Angers. Revue économique, 61(5), 821-836. https://doi.org/10.3917/reco.615.0821

Clark, W. A. V. \& Onaka, J. (1983). Life Cycle and Housing Adjustment as Explanations of Residential Mobility. Urban Studies, 20(1), 47-57. https://doi.org/10.1080\%2F713703176

Cliff, A. D., Haggett, P., Ord, J. K., Basset K. A. \& Davies, R. B. (1975). Elements of Spatial Structure: A Quantitative Approach. Cambridge: Cambridge University Press. https://doi.org/10.1111/j.1745-7939.1977.tb00848.x

Debrezion, G., Pels, E. \& Rietveld, P. (2007). The Impact of Railway Stations on Residential and Commercial Property Value: a Meta-Analysis. The Journal of Real Estate Finance and Economics, 35(2), 161-180.

Decker, C. S., Nielsen, D. A. \& Sindt, R. P. (2005). Residential Property Values and Community Right-to-Know Laws: Has the Toxics Release Inventory Had an Impact? Growth and Change, 36(1), 113-133.

https://doi.org/10.1111/j.1468-2257.2005.00269.x

Diao, M., Leonard, D. \& Sing, T. F. (2017). Spatial-difference-in-differences models for impact of new mass rapid transit line on private housing values. Regional Science and Urban Economics, 67, 64-77.

https://doi.org/10.1016/j.regsciurbeco.2017.08.006

Dubé, J., Thériault, M. \& Des Rosiers, F. (2013). Commuter rail accessibility and house values: The case of the Montreal South Shore, Canada, 19922009. Transportation Research Part A: Policy and Practice, 54, 49-66.

https://doi.org/10.1016/j.tra.2013.07.015

Efthymiou, D. \& Antoniou, C. (2013). How do Transport Infrastructure and Policies Affect House
Prices and Rents? Evidence from Athens, Greece. Transportation Research Part A: Policy and Practice, 52, 1-22.

https://doi.org/10.1016/j.tra.2013.04.002

Ellison, R. B., Greaves, S. P. \& Hensher, D. A. (2013). Five years of London's low emission zone: Effects on vehicle fleet composition and air quality. Transportation Research Part D: Transport and Environment, 23, 25-33. https://doi.org/10.1016/j.trd.2013.03.010

Fritsch, B. (2007). Tramway et prix des logements à Nantes. L'Espace géographique, 36(2), 97-113. https://doi.org/10.3917/eg.362.0097

Fujita, M. (1989). Urban Economic Theory: Land Use and City Size. Cambridge: Cambridge University Press.

Gouriéroux, C. \& Laferrère, A. (2009). Managing hedonic housing price indexes: The French experience. Journal of Housing Economics, 18(3), 206-213.

https://doi.org/10.1016/j.jhe.2009.07.012

Gaschet, F. \& Pouyanne, G. (2011). Nouvelles centralités et valeurs immobilières : vers un découplage des centralités résidentielles et économiques? Revue d'Économie Régionale \& Urbaine, 3, 499-525.

https://doi.org/10.3917/reru.113.0499

Hanson, C. E. \& Wieczorek, W. F. (2002). Alcohol mortality: a comparison of spatial clustering methods. Social Science \& Medicine, 55(5), 791-802.

https://doi.org/10.1016/S0277-9536(01)00203-9

Kanemoto, Y. (1980). Theories of Urban Externalities. Amsterdam: North-Holland.

Kelejian, H. H. \& Prucha, I. R. (2010). Specification and estimation of spatial autoregressive models with autoregressive and heteroskedastic disturbances. Journal of Econometrics, 157(1), 53-67. https://doi.org/10.1016/j.jeconom.2009.10.025

Kim, C. W., Phipps, T. T. \& Anselin, L. (2003). Measuring the benefits of air quality improvement: a spatial hedonic approach. Journal of environmental economics and management, 45(1), 24-39. https://doi.org/10.1016/S0095-0696(02)00013-X

Le Berre, I., Thériault, M., Maulpoix, A. \& Gourmelon, F. (2017). Moderation effect of planning on housing development along the French Atlantic coast: Findings from an event 
history hazard model. Journal of Land Use Science, 12(4), 271-291.

https://doi.org/10.1080/1747423X.2017.1322154

Le Boennec, R. (2014). Externalité de pollution versus économies d'agglomération : le péage urbain, un instrument environnemental adapté? Revue d'Économie Régionale \& Urbaine, 1, 3-31. https://doi.org/10.3917/reru.141.0003

Le Boennec, R. \& Salladarré, F. (2017). The impact of air pollution and noise on the real estate market. The case of the 2013 European Green Capital: Nantes, France. Ecological Economics, 138, 82-89. https://doi.org/10.1016/j.ecolecon.2017.03.030

Le Boennec, R. \& Sari, F. (2015). Nouvelles centralités, choix modal et politiques de déplacements : le cas nantais. Les Cahiers Scientifiques du Transport, 67, 55-86.

http://afitl.ish-lyon.cnrs.fr/tl_files/documents/ CST/N67/LeBoennec67pdf.pdf

Le Gallo, J. (2002). Économétrie spatiale : l'autocorrélation spatiale dans les modèles de régression linéaire. Economie \& prévision, 4(155), 139-157. https://www.cairn.info/revue-economie-et-prevision-2002-4-page-139.htm

Le Gallo, J. (2004). Hétérogénéité spatiale. Economie \& prévision, 1(162), 151-172.

https://www.cairn.info/revue-economie-etprevision-2004-1-page-151.htm

Lee, L.F. (2004). Asymptotic distributions of maximum likelihood estimators for spatial autoregressive models. Econometrica, 72(6), 1899-1925. https://doi.org/10.1111/j.1468-0262.2004.00558.x

Lemoy, R., Raux, C. \& Jensen, P. (2017). Exploring the polycentric city with multi-worker households: An agent-based microeconomic model. Computers, Environment and Urban Systems, 62, 64-73. https://doi.org/10.1016/j.compenvurbsys.2016.10.008

LeSage, J. (1999). Spatial Econometrics. The Web Book of Regional Science. Regional Research Institute. Morgantown: West Virginia University.

Li, S., Yang, J., Qin, P. \& Chonabayashi, S. (2016). Wheels of Fortune: Subway Expansion and Property Values in Beijing. Journal of Regional Science, 56(5), 792-813. https://doi.org/10.1111/jors. 12284

López, F. A., Chasco, C. \& Le Gallo, J. (2015). Exploring scan methods to test spatial structure with an application to housing prices in Madrid. Papers in Regional Science, 94(2), 317-346.

https://doi.org/10.1111/pirs.12063

Lund, H. (2006). Reasons for Living in a Transit-Oriented Development, and Associated Transit Use. Journal of the American Planning Association, 72(3), 357-366.

https://doi.org/10.1080/01944360608976757

Martínez, L. \& Viegas, J. (2009). Effects of transportation accessibility on residential property values: Hedonic Price Model in the Lisbon, Portugal, metropolitan area. Transportation Research Record: Journal of the Transportation Research Board, (2115), 127-137.

https://doi.org/10.3141/2115-16

Mestayer, P. et al. (2012). Environmental Impact Assessment of Urban Mobility Plan: a Methodology Including Socio-Economic Consequences. In: Urban Environment (pp. 15-26). Amsterdam: Springer Netherlands.

Mohammad, S. I., Graham, D. J., Melo, P. C. \& Anderson, R. J. (2013). A meta-analysis of the impact of rail projects on land and property values. Transportation Research Part A: Policy and Practice, 50, 158-170.

https://doi.org/10.1016/j.tra.2013.01.013

Mohammad, S. I., Graham, D. J. \& Melo, P. C. (2017). The effect of the Dubai Metro on the value of residential and commercial properties. Journal of Transport and Land Use, 10(1), 263-290. https://www.jtlu.org/index.php/jtlu/article/view/750/847

Nelson, J. P. (2004). Meta-analysis of airport noise and hedonic property values: problems and prospects. Journal of Transport Economics and Policy, 38(1), 1-28.

https://ssrn.com/abstract $=610523$

Nelson, J. P. (2008). Hedonic property value studies of transportation noise: aircraft and road traffic. In: Baranzini, A., Ramirez, J., Schaerer, C., Thalmann, P. (Eds.), Hedonic methods in housing markets, pp. 57-82. New York: Springer.

Nguyen-Luong, D. \& Boucq, E. (2011). Évaluation de l'impact du T3 sur les prix de l'immobilier résidentiel. Rapport d'IAU-IFSTTAR pour le Ministère de l'Environnement et du Développement Durable, des Transports et du Logement (MEDDTL).

Nunnally, J.C. (1978). Psychometric Theory. New York: McGraw-Hill. 
Ogawa, H. \& Fujita, M. (1980). Equilibrium land use patterns in a nonmonocentric city. Journal of regional science, 20(4), 455-475.

https://doi.org/10.1111/j.1467-9787.1980.tb00662.x

Osland, L. \& Pryce, G. (2012). Housing Prices and Multiple Employment Nodes: Is the Relationship Nonmonotonic? Housing Studies, 27(8), 1182-1208.

https://doi.org/10.1080/02673037.2012.728571

Pan, H. \& Zhang, M. (2008). Rail transit impacts on land use: Evidence from Shanghai, China. Transportation Research Record: Journal of the Transportation Research Board, (2048), 16-25.

Pouyanne, G., Lyser, S., Gaschet, F. \& DacharyBernard, J. (2011). L'impact de la littoralisation sur les marchés fonciers. Une approche comparative des côtes basque et charentaise. Économie et Statistique, 444(1), 127-154.

https://www.insee.fr/fr/statistiques/1377853?som maire $=1377863$

Rabe, B. \& Taylor, M. (2010). Residential mobility, quality of neighbourhood and life course events. Journal of the Royal Statistical Society: Series A (Statistics in Society), 173(3), 531-555.

Ridker, R. G. \& Henning, J. A. (1967). The determinants of residential property values with special reference to air pollution. The Review of Economics and Statistics, (1967), 246-257.

Rosen, S. (1974). Hedonic Prices and Implicit Markets: Product Differentiation in Pure Competition. Journal of Political Economy, 82(1), 34-55.

Saulnier, J. (2004). Une application des prix hédonistes : influence de la qualité de l'air sur le prix des logements ? Revue d'économie politique, 114(5), 613-636.

Schindler, M., Caruso, G. \& Picard, P. (2017). Equilibrium and first-best city with endogenous exposure to local air pollution from traffic. Regional Science and Urban Economics, 62, 12-23.

https://doi.org/10.1016/j.regsciurbeco.2016.10.006
Smith, V. K. \& Huang, J. C. (1993). Hedonic models and air pollution: twenty-five years and counting. Environmental and Resource Economics, 3(4), 381-394. https://doi.org/10.1007/BF00418818

Takahashi, T. (2017). Determination of neighbourhood housing amenities: Asymmetric effects of consumers' choices and multiple equilibria. Papers in Regional Science, 96(3), 555-570. https://doi.org/10.1111/pirs.12213

Trannoy, A. \& Wasmer, É. (2013). La politique du logement locatif. Notes du conseil d'analyse économique $\mathrm{N}^{\circ} 10,1-12$.

http://www.cae-eco.fr/La-politique-du-logementlocatif.html

Travers, M., Appéré, G. \& Larue, S. (2013). Évaluation des aménités urbaines par la méthode des prix hédoniques: une application au cas de la ville d'Angers. Économie et statistique, 460(1), 145-163. https://www.insee.fr/fr/statistiques/1377435? sommaire $=1377437$

Travers M., Giffon S. \& Appéré, G. (2014). Le financement de la mobilité durable. Prix de l'immobilier et nouvelles lignes de transports collectifs en site propre : quels impacts ? Collection « Analyse et connaissance » $\mathrm{N}^{\circ}$ 107, DREAL Pays de la Loire.

Walker, J. L. \& Li, J. (2007). Latent lifestyle preferences and household location decisions. Journal of Geographical Systems, 9(1), 77-101. https://doi.org/10.1007/s10109-006-0030-0

World Health Organization (2000). Air quality guidelines for Europe. Copenhagen, Denmark: WHO Regional Office for Europe.

www.euro.who.int/_data/assets/pdf_file/0005/ 74732/E71922.pdf

World Health Organization (2006). Air quality guidelines. Global update 2005. Particulate Matter, Ozone, Nitrogen Dioxide and Sulfur Dioxide. Copenhagen, Denmark: WHO Regional Office for Europe.

www.euro.who.int/_data/assets/pdf_file/0005/ 78638/E90038.pdf 



\title{
Rising inequalities in access to home ownership among young households in France, 1973-2013
}

\author{
Carole Bonnet*, Bertrand Garbinti** and Sébastien Grobon***
}

\begin{abstract}
Amongst young households (ages 25 to 44), inequalities in first-time home-ownership and in the amount of acquired real estate assets have increased between the most modest and the most affluent groups over the past forty years. According to Insee's Housing surveys, $32 \%$ of young low-income households were homeowners in 1973, as compared to only $16 \%$ in 2013. Beyond the role of macroeconomic and institutional factors (real estate prices, interest rates, term of loans granted, etc.), a decomposition of changes in ownership rates over the period using the "Oaxaca-Blinder" method highlights the role of changes in family structures (increasing proportion of single-parent families, decline in the share of couples with children in the most modest households) and the sharp decline in small rural home ownership. Family support - gift assistance, inheritance and other forms of aid - also played an important part in the 2000s: four out of ten recent homeowners benefited from it, two out of ten even receiving direct financial assistance for their purchase. This support increased significantly among wealthier households during the 2000s, contributing to a widening gap with the share of homeowners in the least well-off populations.
\end{abstract}

JEL Classification: D63, D64, J10, R21

Keywords: home ownership, real estate wealth, family transfers, gift assistance, Oaxaca decomposition, inequalities

\section{Reminder:}

The opinions and analyses in this article

are those of the author(s)

and do not

necessarily reflect

their institution's

or Insee's views.

\footnotetext{
*Ined (carole.bonnet@ined.fr)

** Banque de France and Crest (bertrand.garbinti@ensae.fr)

*** Insee and Ined (sebastien.grobon@insee.fr)
}

The analyses presented here are not necessarily those of the Banque de France or the Eurosystem. The authors would like to thank Magali Beffy, Romain Roussel and Augustin Vicard for their comments on a first version of this work carried out at Drees, as well as Catherine Bonvalet, Anne Laferrère and Thomas Piketty.

Received on 02 June 2017, accepted after revisions on 18 April 2018

Translated from the original version: « Hausse des inégalités d'accès à la propriété entre jeunes ménages en France, 1973-2013 » 
$\mathbf{I}_{\mathrm{n}}^{\mathrm{n}}$ France, many public policies aim to promote first-time home ownership (Worms, 2009), particularly since the 1977 reform which "tends to make home ownership 'the logical outcome' of any upward residential path" (Bonvalet \& Bringé, 2013). Few studies have succeeded in giving an economic legitimacy to this political drive to encourage first-time home ownership ${ }^{1}$ (Bozio et al., 2016); however, most do highlight the positive externalities associated with ownership status, or the economic advantages of owning one's home as a reserve of wealth. Household well-being, in particular, would be higher amongst homeowners, and home ownership would generate externalities that might increase children's chances of success (Spilerman \& Wolff, 2012; Haurin et al., 2002). Being the main asset of the majority of households ${ }^{2}$, real estate reportedly provides insurance against risks of falling income during individuals' active periods or upon retirement (Angelini et al., 2013), risks of increases in house prices (Agarwal et al., 2016), or even of rising inflation (Malmendier \& Steiny, 2016).

The issue of the inequality in real estate assets has been the subject of renewed interest in the academic field in recent years. First of all, following the research carried out by Piketty (2014) and Piketty and Zucman (2014), debate has emerged on the measurement of real estate wealth and its effect on the measurement of wealth inequality ${ }^{3}$. Secondly, the results of the Eurosystem's Household Finance and Consumption Survey $\left(\mathrm{HFCS}^{4}\right)$ called attention to the connection between net wealth inequality and the share of homeowning households: the countries where inequalities are the greatest are also those with the lowest share of home-owning households (for example, Germany and Austria), especially among households belonging to the poorest half of the population in terms of accumulated wealth (Kaas et al., 2015; Garbinti \& Savignac, 2018). We look here at the change in inequalities in access to real estate ownership in France, paying particular attention to the initial acquisitions made by young households.

Analysing inequalities in first-time home ownership requires considering all the determinants of access to property, beyond public policies alone. In particular, the macroeconomic factors - such as real estate prices or borrowing terms (interest rates, term of loans) - significantly affects first-time home-ownership, which increases during periods of economic expansion and declines when unemployment rises (Arnold \& Boussard, 2017). However, these effects do not impact all households uniformely regardless of their characteristics, thus encouraging the microeconomic approach which we develop here. Arnold and Boussard also point out that first-time home-ownership by young households held steady despite the 2008 crisis, in particular thanks to the provision of own capital, including the gift assistance received, larger under these circumstances. However, this steady rate of first-time home ownership among all young households seems to have come along with an increase in disparities within this population. Some studies have suggested this trend without, however, looking at young households in detail. Fack (2007), for example, indicates that between 1973 and 2002 the percentage of homeowners amongst the poorest households declined while it steadily increased in the better-off households. Clerc et al. (2011) point out that "between middle managers or professions and workers or employees, inequalities [in access to home ownership] have widened considerably since the early 1990s, particularly among young people". This widening gap was also discussed before the start of the 1990s, by Meron and Courgeau (2004) as well as by Bugeja (2011).

The role of family gift assistance and assistance in housing purchases definitely has a bearing on these trends. Several studies have highlighted the positive role of family transfers (in the broad sense: financial support, gift assistance and inheritances) in the acquisition

\footnotetext{
1. As Bozio et al. (2016) report, many studies focusing on the positive externalities of ownership show correlations, but not causality. We refer the reader to this report for a complete listing of research on this issue. 2. In 2015 , real estate accounts on average for $61 \%$ of households' gross wealth, and in half of home-owning households, real estate represents more than $80 \%$ of their total gross wealth (Ferrante et al., 2016).

3. Some authors argue that real estate wealth should be measured on the basis not of market values but on the present value of income flows from housing services (Bonnet et al. 2014) on the grounds that in periods of real estate bubbles, market values are thought to artificially increase the value of total assets. Others (Carbonnier, 2015; Garbinti et al., 2016) stress that during these periods, the use of market values causes total wealth inequalities to be underestimated, as more real estate wealth is attributed to the middle class: the choice is more transparent, but also more "conservative".

4. The HFCS Survey (coordinated by the European Central Bank) provides harmonised information on the composition and breakdown of household wealth (in both gross and net terms) (http://www.ecb.europa. eu/pub/economic-research/research-networks/html/researcher hfcn. en.html). The data regarding France are taken from the Household Wealth Survey (Insee) run as part of a partnership with the Banque de France.
} 
of housing ${ }^{5}$, in France as well as in other countries $^{6}$. On French data, the important role of family transfers is confirmed by Spilerman and Wolff (2012), Le Bayon et al. (2013) and Arrondel et al. (2014), particularly in the period of sharp increases in real estate prices since the early 2000s (Le Bayon et al., 2013; Arrondel et al., 2014), while gift assistance and inheritances are mainly made by households from higher social categories such as managers or intermediate professions (Garbinti et al., 2012).

The contribution of this article is twofold. First of all, we analyse the increase in disparities in first-time home-ownership among young households (defined here as households whose reference person is aged 25 to $44^{7}$ ) over the last forty years (from 1973 to 2013) according to their standard of living. Secondly, we study the role played by family assistance in purchasing a home, over the longest period available. These changes have so far been little or not documented. All the available Insee Housing Surveys (Box) are used: they make it possible to supplement the French research described above on the extent of gift assistance and inheritances, carried out on the basis of the Household Wealth survey in which the first purchase is not distinguished from other purchases. However, the first purchase of a home is more sensitive to the rise in property prices, while subsequent purchases benefit from a resale effect of the property owned. In addition, the role of family financial support is much more decisive at the time of a first purchase: in 2002, family support contributed to individual capital for a quarter of the first-time buyers, providing $18 \%$ in volume, as compared to only $7 \%$ of other buyers and $3 \%$ in capital volume (Bosvieux, 2005). For these reasons, we focus on the first acquisition when we measure the role of gift assistance and inheritances in the recent period. This focus on the critical moment of the first acquisition sheds light on the rest of the analysis, which considers the change in the share of owner households as a whole.

\footnotetext{
5. Note the exception of Kolodziejczyk and Leth-Petersen (2013) who, on Danish data, find very little effect of transfers on first-time home ownership. 6. Based on American data, Engelhardt and Mayer (1998) conclude that family transfers can have an impact in three ways: a reduction in the time needed to acquire housing, a reduction in the amount borrowed, and the higher value of the property purchased. Luea (2008) indicates that beneficiaries of intergenerational transfers have a $20 \%$ greater chance of acquiring housing than those who do not. The same effect of transfers on ownership is also shown in Barrett et al. (2015), for which the benefit of gift assistance increases the ownership rate (by 4 to 8 percentage points). Duffy and Roche (2007) deem meanwhile that transfers represent $21 \%$ of the initial contribution for the purchase of a home.

7. Our results are robust to the choice of a different age group, for example ages 25-40. While the levels vary slightly, the trends are the same.
}

\section{Box - Data, scope and definitions}

The nine waves of the Insee Housing surveys, reference in France for the study of housing characteristics, first-time home-ownership and its determinants, are used here. They cover the period from 1973 to 2013, with one wave approximately every five years.

The information makes it possible to distinguish whether the purchase is a first-time acquisition: a question is explicitly asked from the 2002 survey on; as for the previous surveys, a home purchase is assumed to occur for the first time when no real estate sale is reported to finance the purchase of the main place of residence. We are particularly interested in "recent first-time homeowners", defined as households that acquired their dwelling in the four years preceding the survey. Almost all of them $(97 \%)$ were in the process of repaying a loan (first-time buyers), while the others were full-owners after a recent purchase.

We restrict the analysis to households in which the reference person is between ages 25 and 44 and is not a student. These households accounted for $67 \%$ of recent homeowners (excluding students) in 1973 and $78 \%$ in 2013. To ensure comparability between the different years of the Housing survey, only homes located in mainland France were included.
To study the relationship between home ownership and the standard of living, households are distinguished by standard of living quartiles, computed over the young household population as defined above. Households belonging to the first standard of living quartile (Q1), i.e. the bottom $25 \%$ of the distribution, are referred to as the "least well-off", and those belonging to the last standard of living quartile (Q4) are called the "most well-off". The standard of living is computed here using the equivalence scale equal to the square root of household size ${ }^{(a)}$.

Among the variables that can help explain differences in first-time home ownership, family assistance is of particular interest, especially when it is financial and takes place at the time of purchase, but also in its other forms, either indirect financial (through a gift or inheritance received previously, or with no apparent link to the purchase), or non-financial. Studying family assistance over a long period proves difficult, due to a change in the wording of the respective questions before and after 2002 , causing a series break ${ }^{(b)}$. The analyses on this point therefore focus on the period 2002-2013.

(a) This scale is used in particular by the OECD. Our conclusions remain identical with the "OECD-modified" scale (the one used by Eurostat and Insee).

(b) We detail this point precisely in Appendix 1 


\section{The gap in home ownership among young households has widened over the past 40 years}

\section{Home ownership increases among wealthier households and decreases among the most modest}

In $1973,32 \%$ of young low-income households were homeowners. The figure was only $16 \%$ in 2013 (Figure I). In contrast, the share of owners among young well-off households increased over the period: in $2013,66 \%$ of them were owners, as compared to $45 \%$ in 1973. The overall stability in the proportion of young homeowners since the $1990 \mathrm{~s}$, around $45 \%$, thus masks a highly unequal long-term trend.

The increase in real interest rates from the mid-1980s to the mid-1990s, followed by the doubling of property prices between 1996 and 2010, slowed down access to the property market especially for modest households (Arnault \& Crusson, 2012), and housing poli$\operatorname{cies}^{8}$, in particular all subsidies for access to ownership, did not halt this dynamic. They may even have accentuated it (Bonvalet \& Bringé, 2013). Zero-interest loans, for example, although they reduce the loan to property value ratio (Labonne \& Welter-Nicol, 2015), did not reach the most modest populations (Gobillon \& Le Blanc, 2005).

\section{Value of acquired real estate assets: the gaps also increased over the period}

The growing difference between the percentages of homeowners by standard of living quartile is coupled with a difference in the value of homes purchased ${ }^{9}$. The difference between the average purchase price of housing units in the first quartile and the last quartile appears to be much higher from the 1990s onwards (in euros 2013, $€ 77,000$ on average over the period 1992-2013, as compared to $€ 45,000$ between

8. One example is the housing policy reform of 1977, which created two types of loans: the home ownership loan (PAP), subject to income conditions, replaced by the interest-free loan in 1995 (PTZ), which was extended in 2005; and the State agreed loan (PC), granted at a preferential rate with no conditions on resources, which was replaced in 1993 by the social accession loan (PAS), subject to income conditions.

9. Measured in constant euros 2013

\section{Figure I}

Share of homeowners among young households by standard of living quartile, 1973-2013

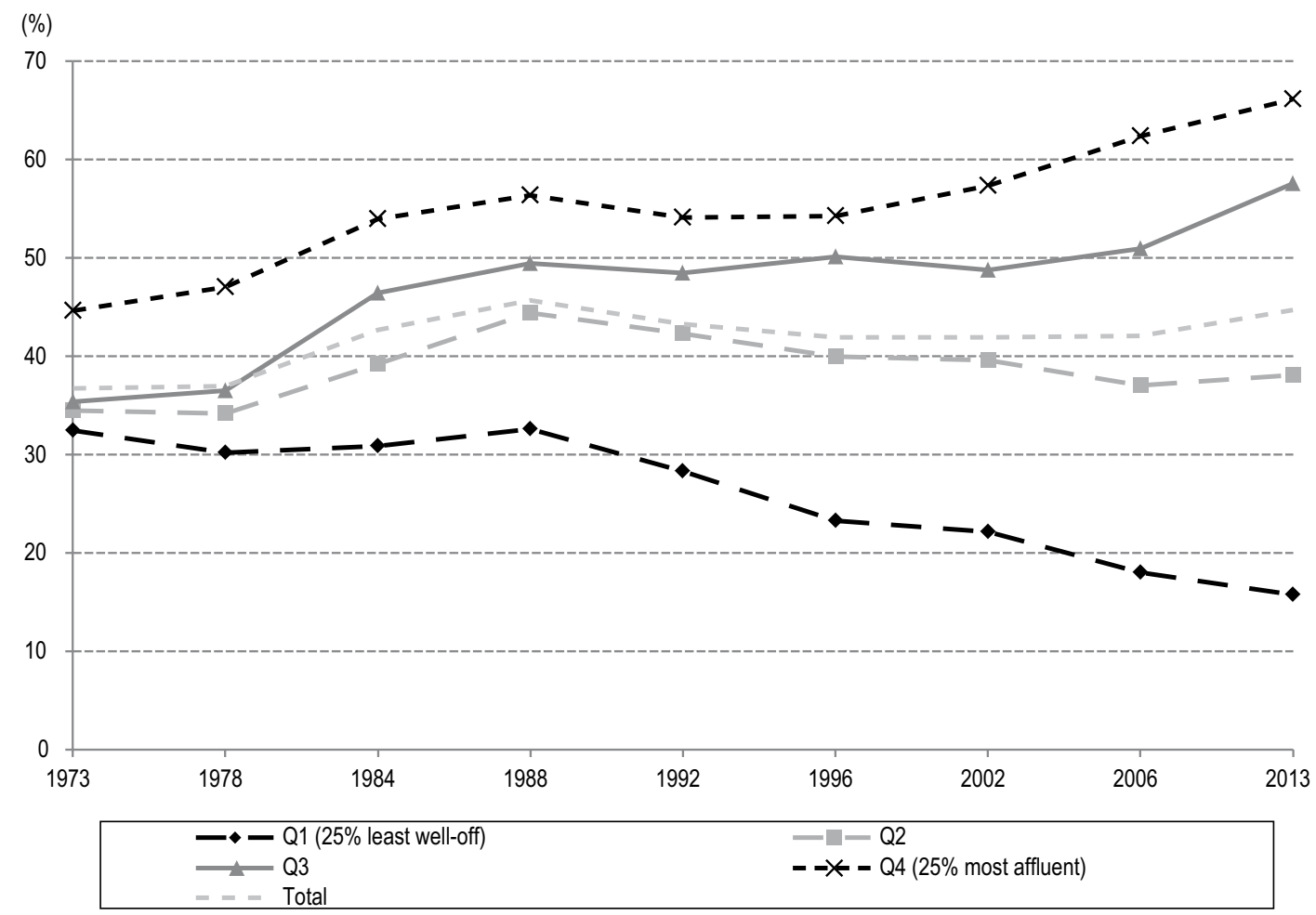

Reading note: Among those aged $25-44,32 \%$ of households in the first standard of living quartile (Q1, the lowest $25 \%$ ) owned their home in 1973 compared to $16 \%$ in 2013. Out of the wealthiest (Q4, the wealthiest $25 \%$ ), the share of owners rose from $43 \%$ in 1973 to $66 \%$ in 2013 . Coverage: households whose reference person is aged 25 to 44, excluding students, residing in mainland France. Sources: Insee, Housing surveys 1973-2013. 
1973 and 1988). After large differences in 1992 and 1996 (€87,000 and $€ 89,000$ in euros 2013), this difference decreases slightly (in euros 2013: $€ 61,000$ in 2013) but remains at higher levels than in the previous period.

However, since the late 1990s, as house prices rose, the ratio between average purchase prices fell both between the first three income quartiles (which reach a comparable level at the end of the period) and between the better-off and the worse-off. The average price of housing purchased by the better-off is thus more than twice as high as that purchased by the worse-off in 1992 and 1996, when this price ratio is at its highest. The gap then narrowed until 2013, when it reached the lowest level of the period, namely an average purchase price one-third higher for the better-off (35\% in 2013, versus a gap of $82 \%$ in 2002 and $71 \%$ in 2006). The difference in average purchase prices thus seems very polarised at the end of the period: the wealthiest quarter buys properties that are significantly more expensive than the rest of the population, while the average prices of properties purchased are very close for the rest of the young first-time owners (Figure II).
While the least well-off do purchase a home, when they can, at prices as high as those paid by young middle-class households ${ }^{10}$, fewer and fewer of them are able to become homeowners overall. The share of recent new homeowners decreased significantly in the first quartile (Figure III).

By combining these changes in house prices and the number of buyers ${ }^{11}$, it is possible to calculate the flow of the amount of real estate assets acquired by quartile of standard of living. This flow is measured as the product of the number of young recent first-time homeowners in the quartile by the average price of homes purchased in that quartile.

Figure IV shows that the most modest households have acquired a property portfolio that is much lower than that acquired by the better-off.

10. That is, those whose living standard is between the $1^{\text {st }}$ and the $3^{\text {rd }}$ quartile (Q2 and Q3).

11. For each survey year, the number of buyers is defined as the (weighted) number of young households having bought their property during the last four years.

\section{Figure II \\ Change in average prices (in euros 2013) of the first dwellings purchased recently, by standard of living quartile}

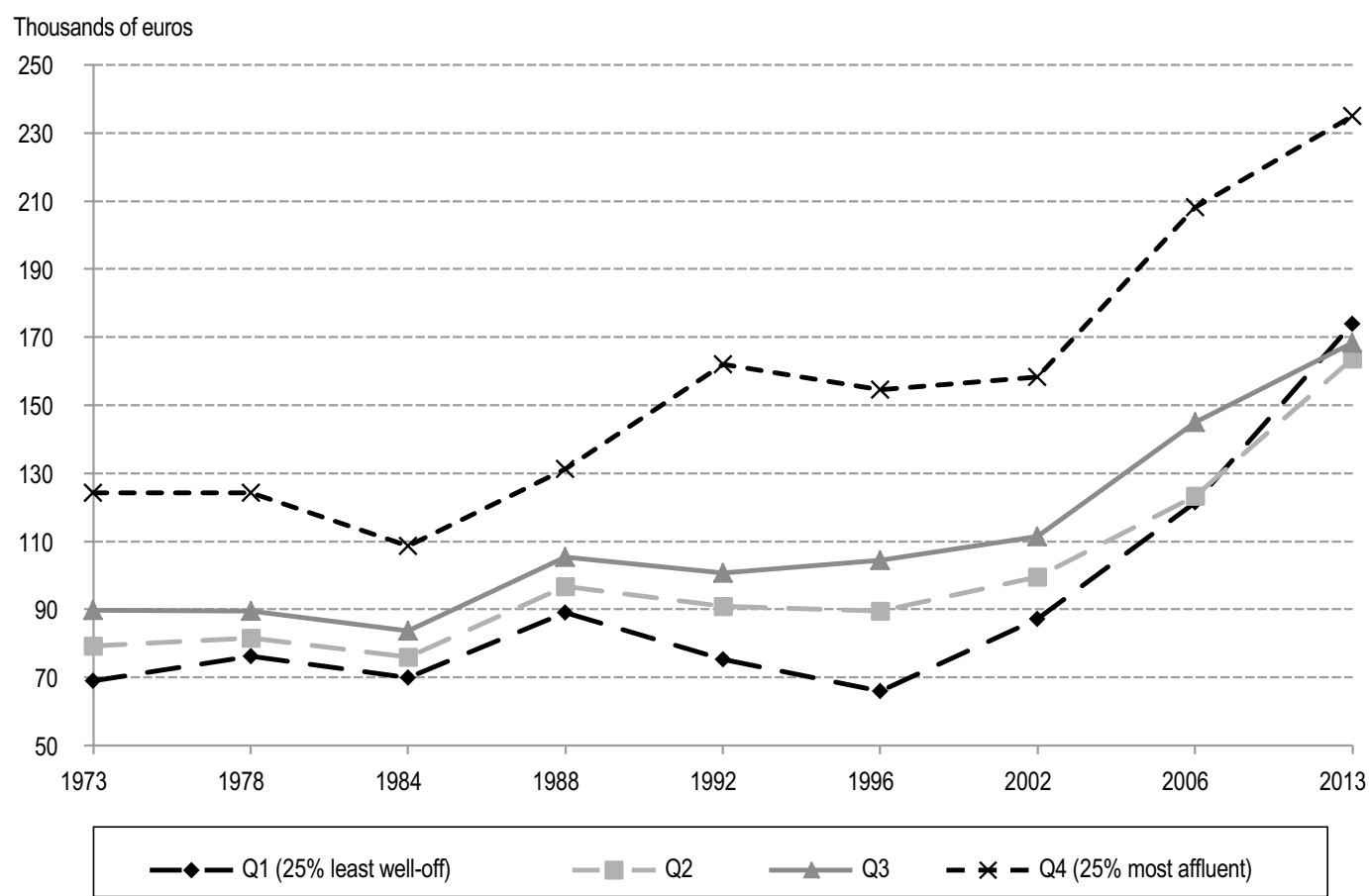

Coverage: Households whose reference person is between ages 25 and 44, excluding students, first recent owners, residing in mainland France. Sources: Insee, Housing surveys 1973-2013. 
Figure III

Share of recent first homeowners by standard of living quartile

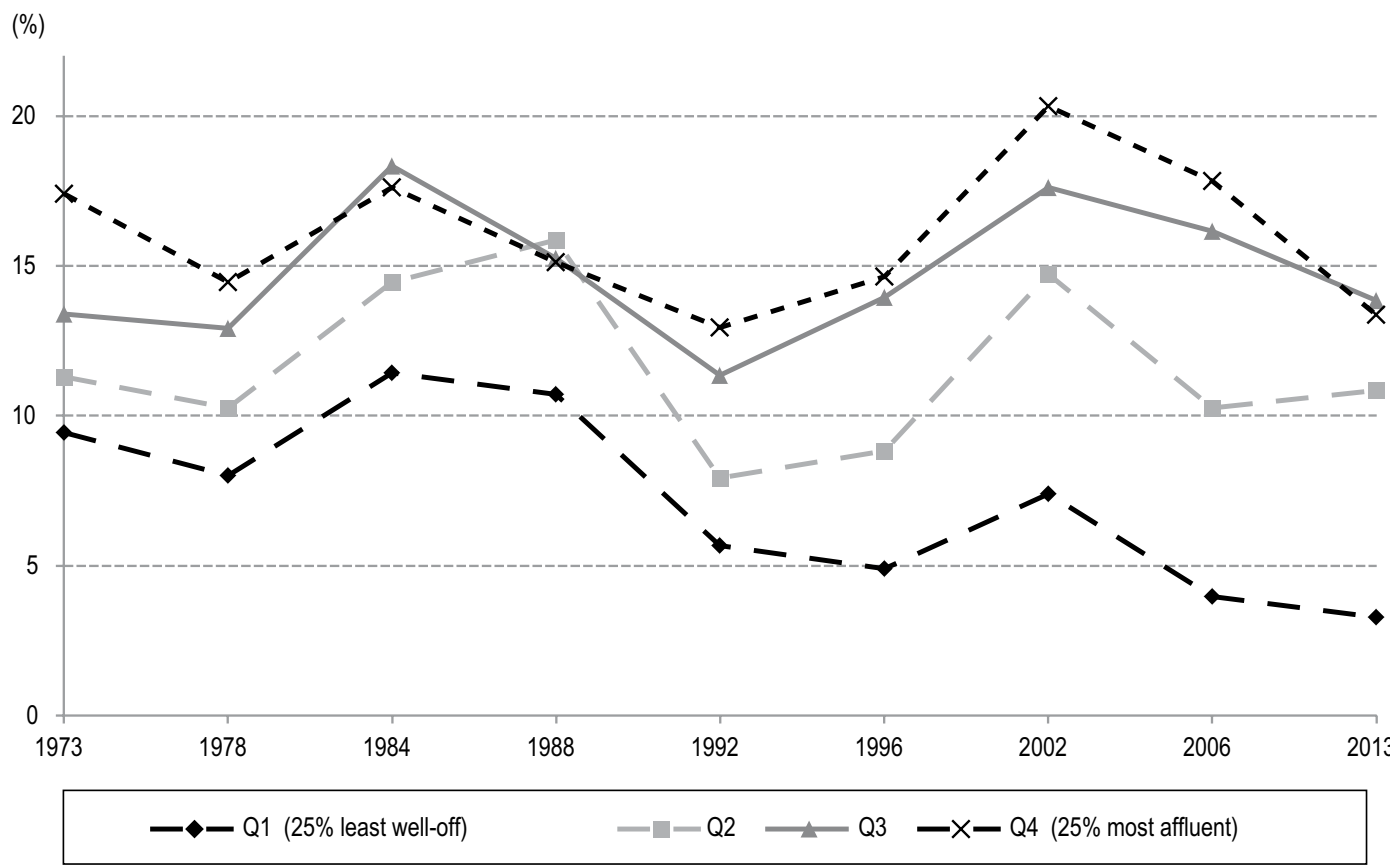

Note: The first recent owners are households who became owners of their main residence for the first time in the four years preceding the survey (see Box).

Coverage: Households whose reference person is aged 25 to 44 , excluding students, first recent owners, residing in metropolitan France. Sources: Insee, Housing surveys 1973-2013.

Figure IV

Trend in total amount of real estate acquired, by standard of living quartile (in millions of constant euros 2013)

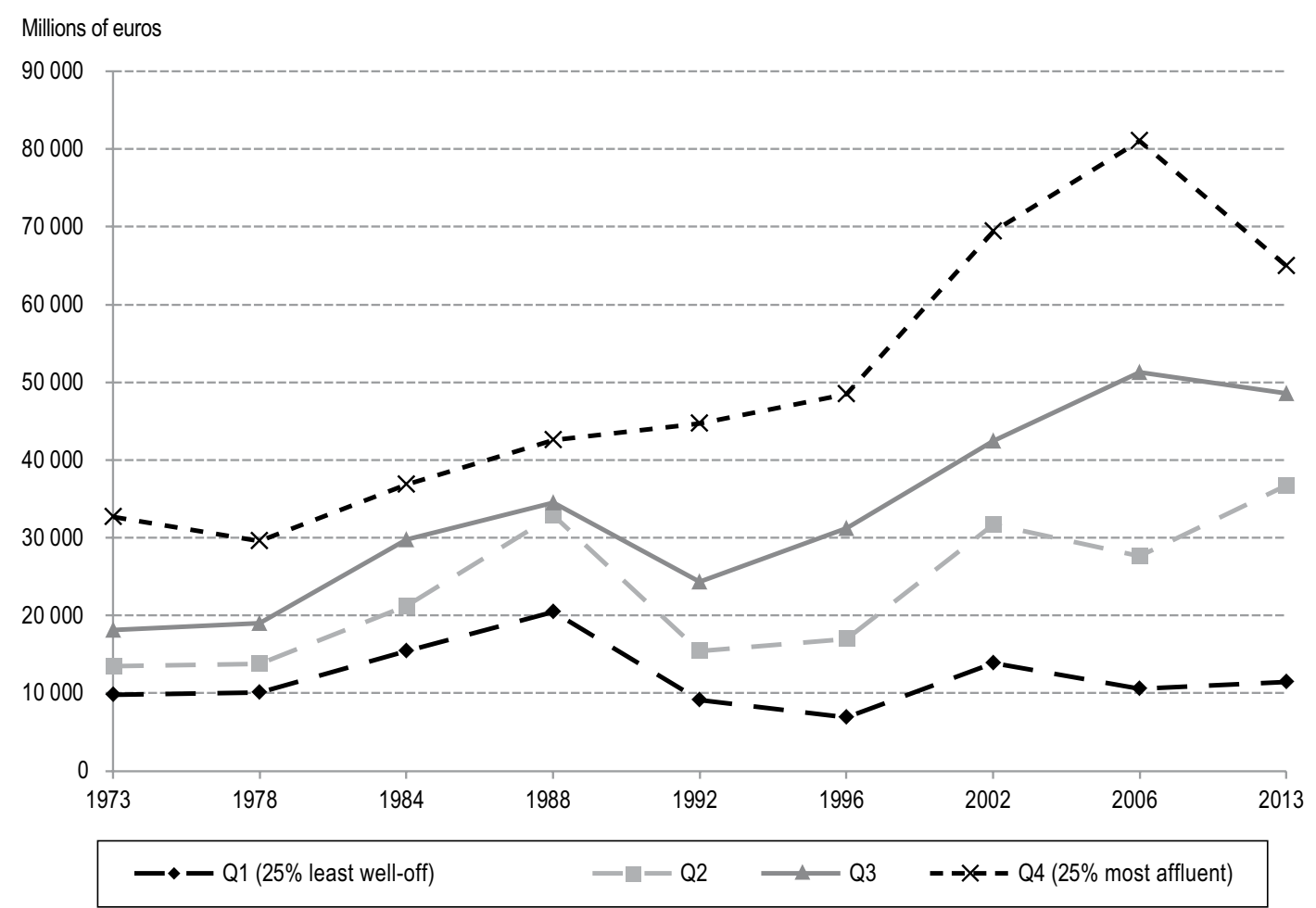

Note: The amount of real estate assets acquired is defined as the product of the number of first owner households in the quartile (weighted number of households) and the average purchase price of the quartile.

Coverage: Households whose reference person is between ages 25 to 44, excluding students, first recent owners, residing in mainland France. Sources: Insee, Housing surveys 1973-2013. 
In 2013, this acquired real estate wealth is thus five times lower for the least well-off young households than for those enjoying the top standard of living. While the ratio was only around 2 to 3.5 until the early $1990 \mathrm{~s}$, it has risen sharply since then and has varied from 5 to 8 over the last twenty years. It can also be noted that, in the $1^{\text {st }}$ quartile, the total amount of assets acquired shows only slight variations (in constant euros), while it increases overall in the last quartile ${ }^{12}$.

\section{Family support, location and family configurations: three important factors for understanding the differentiated changes in ownership rates among young households}

The growing importance of the flow of gift assistance and inheritances in France as well as in other European countries and the United States ${ }^{13}$ has been documented in various works. This growth in the share of family transfers in national income and private wealth is stirring interest as to how they are used and how they affect the economy and wealth of younger generations. In a context of sharply rising property prices in France in the 2000s, the influence exerted by family transfers on the acquisition of the main residence raises questions. We will begin by giving some orders of magnitude relating to the link between the help received from the family and the acquisition of the first main place of residence. Then, prompted by our historical approach, we will question the role that certain changes have played over a longer period of time. Many socio-demographic factors can explain the differentiated changes in the shares of owner households according to the standard of living presented above - the assistance received from the family is one of the central elements, but other explanations are possible. Among the factors explaining home ownership, it seems important to detail the evolution of the places of residence, on which both the price of housing and, over a long period, the type of property (farms or urban housing) depends, as well as family configurations - the share of lone individuals and single-parent families, less often owners on average, having increased over the period in the population of young households (Chardon et al., 2008).

\section{Family financial support decisive for access to property and more often received by wealthy young households}

The Housing surveys include two questions on family transfers. The first concerns the aid received at the time of the purchase of the property and is therefore only asked of owners. Another question is asked of the entire sample about possible exceptional cash inflows during the last four years preceding the survey, including inheritances or gift assistance (see detailed wording in the Online complement C1).

At the time of purchase, nearly four in ten first-time homeowners were assisted by their families

Family financial support often comes in the form of gift assistance received at the time of purchase; $20 \%$ of the first recent home-owners ages 25 to 44 benefited from it in 2002. This proportion rose during the $2000 \mathrm{~s}$, reaching $27 \%$ in 2013 (Figure V). Family financial support at the time of purchase can also come in other forms, also identified in the Housing survey (see Online complement $\mathrm{C} 1$ ). It can be previous gift assistance, which is not declared as direct aid at the time of purchase ${ }^{14}$, exceptional cash income due to gift assistance or an inheritance in the four years preceding the survey (excluding direct or indirect aid declared elsewhere) or other types of support such as a loan, a transfer of loan entitlements accrued through a housing savings plan, or the payment of rent or the provision of housing in the years preceding the purchase.

When all these forms of financial support are considered, nearly four out of ten recent first-time homeowners say they were helped by their family at the time of purchase. This proportion remains stable between 2002 and 2013, with the higher frequency of gift assistance in 2013 being offset by the decline in other forms of aid (cf. Figure V). The proportion of first-time homeowners reporting having received financial assistance for their purchase by a recent inheritance remained stable at $6 \%$ over the entire period.

12. The drop in the last quartile of living standards in 2013 is linked to the fall in the number of buyers not offset by the rise in the average price of housing.

13. See for example Piketty (2011), Alvaredo et al. (2017).

14. As the questionnaire allows multiple answers to these different questions on family assistance, we present here a variable constructed so that the answers to the different modalities are exclusive. 


\section{Figure $\mathrm{V}$ \\ Changes in forms of family financial support received by young recent first-time homeowners over the period 2002-2013}

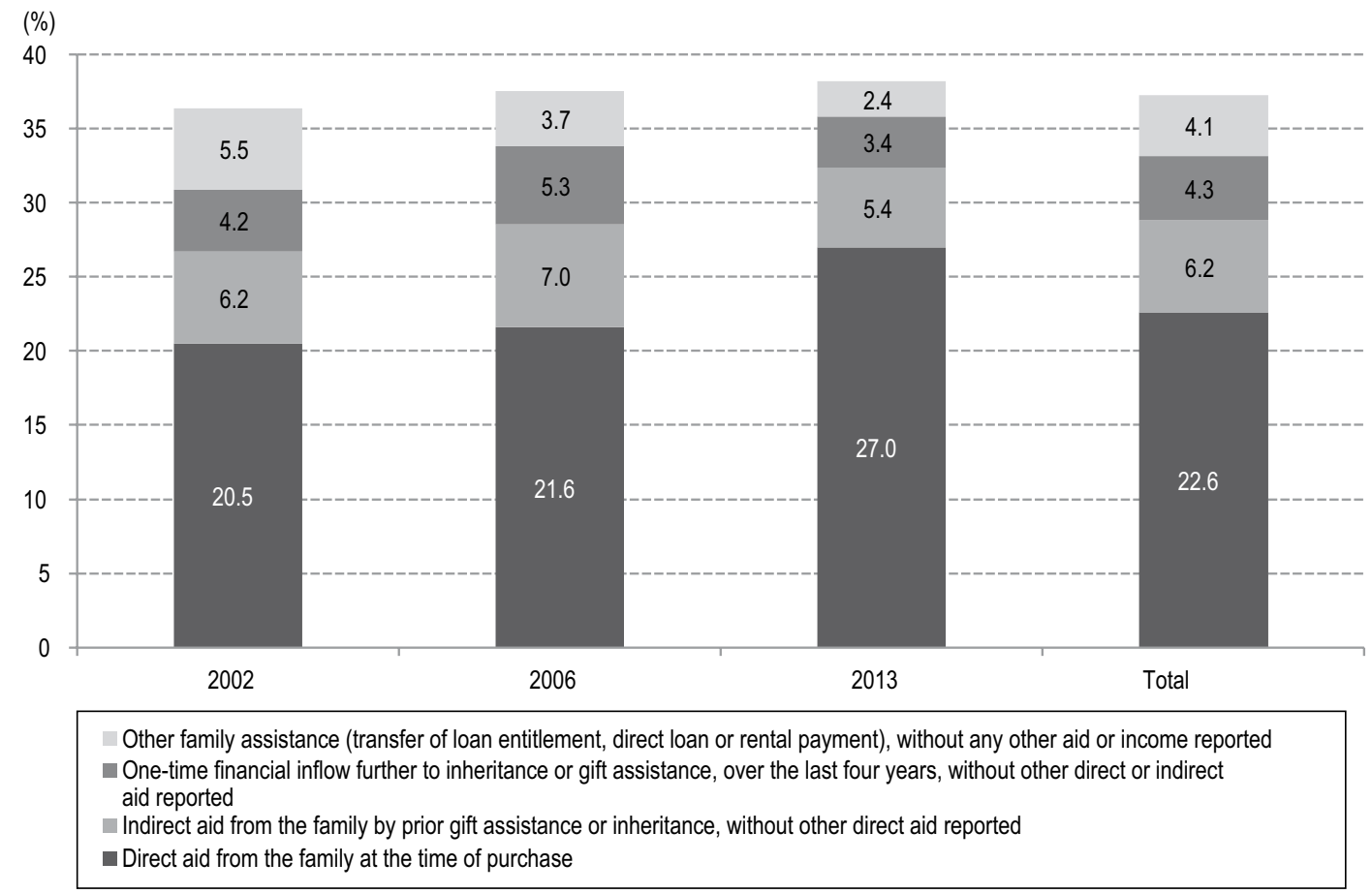

Reading note: In 2002, among the first recent homeowners aged 25 to $44,20 \%$ were directly assisted by their family at the time of purchase. Coverage: Households whose reference person is aged 25 to 44, excluding students, first recent owners, residing in mainland France. Sources: Insee, Housing surveys 2002-2013.

Figure $\mathrm{VI}$

Forms of family financial support received by young recent first-time homeowners by standard of living quartile

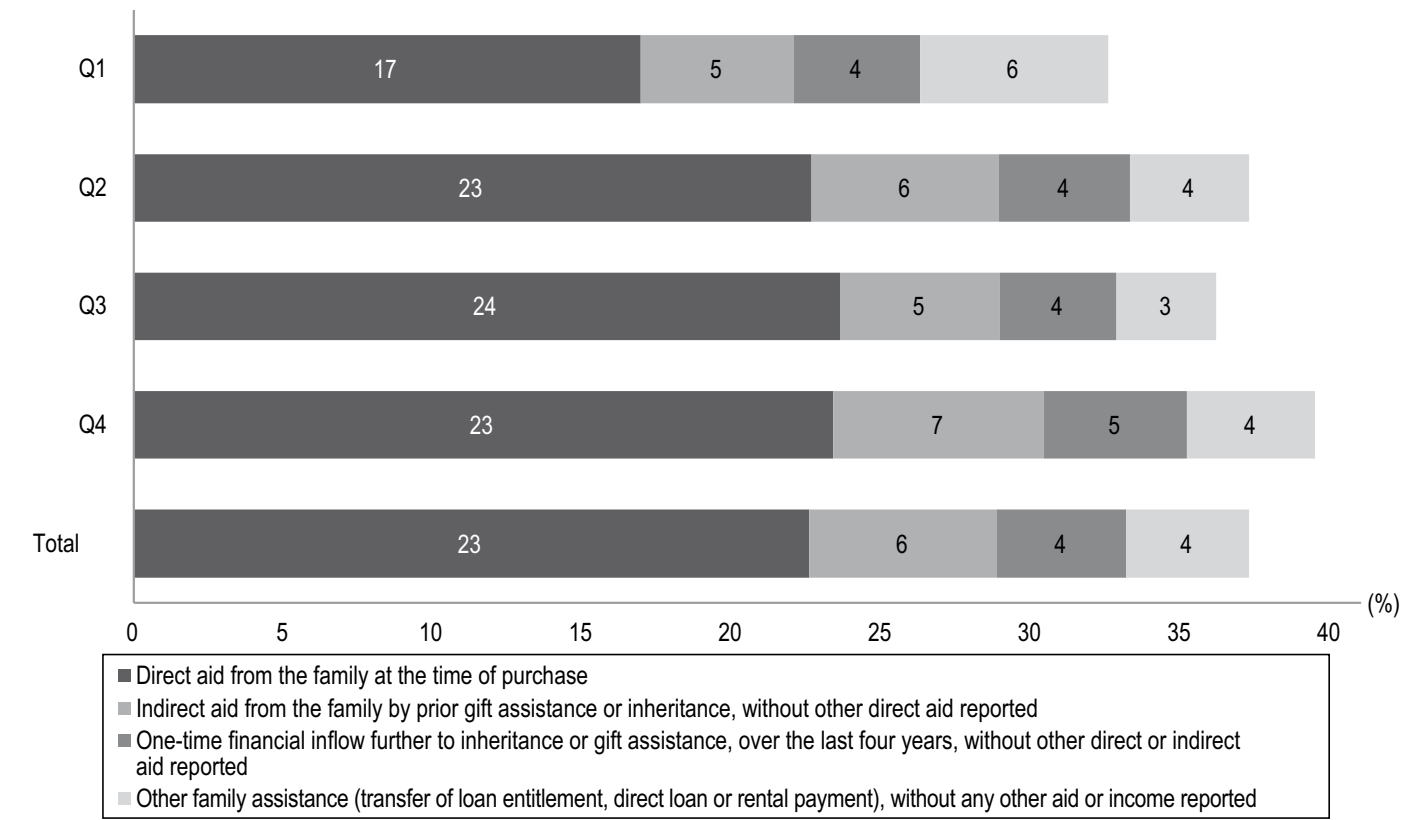

Reading note: $16 \%$ of recent homeowning households ages $25-44$ in the top standard of living quartile were assisted directly by their families at the time of purchase through gift assistance, compared to $24 \%$ of the better-off.

Coverage: Households whose reference person is between ages 25 and 44, excluding students, first recent owners, residing in mainland France. Sources: Insee, Housing surveys 2002-2013. 
This order of magnitude, with four out of ten first-time homeowners assisted by their family at the time of purchase, applies to the most modest (Q1) as well as to the wealthiest (Q4) (Figure VI), with a slightly higher proportion of households assisted in the bottom quartile (39\% versus $33 \%$ ). Some differences can be found in the forms of assistance received. The share of households that received gift assistance is lower in the first quartile, at around $16 \%$, compared to $24 \%$ in the last quartile. The most modest receive more assistance in a form other than gift assistance or inheritance.

Receiving gift assistance at the time of purchase is associated with acquiring a home at a higher price, especially for less well-off households. Thus, among households in the top two quartiles of living standards, those who received assistance purchased housing at $20 \%$ more than those who did not receive assistance. The gap is $11 \%$ for households at the top of the distribution.

Becoming a homeowner is more common among recipients of family assistance

By combining the answers to the question on direct assistance received at the time of purchase and the answers to the question on possible exceptional cash receipts in the form of inheritances and gift assistance (see Online complement $\mathrm{C} 1$ ), the correlation between receiving a family transfer and becoming a first-time home owner can be estimated (Table 1$)^{15}$.
The probability of having become a homeowner in the four years preceding the survey, rather than remaining a tenant, is 32 points higher for a household that receives financial support from its family (cf. Table 1). As regards the difference in the probability of access to home ownership, the effect of gift assistance on the probability of becoming a first-time homeowner is the highest for young households in the middle quartiles of the income distribution, but the odds ratio of home ownership is the highest for the poorest.

Thus, the probability for modest households ( $1^{\text {st }}$ quartile) renting their home in the four years up to the survey and not having received gift assistance, of buying their first main place of residence is $4 \%$. This probability rises to $28 \%$ for those who received gift assistance, i.e. an increase of 24 points, and a 7-fold increase in the odds of becoming a first-time homeowner. This seems considerable but is linked to the fact that only a small proportion of the poorest receive financial assistance from their families. Moreover, the study dealing with young households, certainly more sensitive to the assistance received in the purchase process, first of all, and being based on the Housing

15. Using a variable to build our gift assistance variable applicable only to buyers could cause the effect of the gift assistance on the purchase to be overestimated. Online complement $\mathrm{C} 1$ presents the results obtained by excluding the aids that are declared received at the time of purchase, i.e. by using only the answers to the question on exceptional cash inflows (as in Bonnet et al., 2016). As expected, while the likelihood of home ownership is then lower, the conclusions on quartile differences in standards of living are similar. Similarly, in the Oaxaca-Blinder decomposition presented below, we look at the trend in this variable which is not likely to be biased.

\section{Table 1}

Probability of buying one's first main place of residence in the last four years, according to whether gift assistance or an inheritance was received, by standard of living quartile (logistic regression)

\begin{tabular}{|c|c|c|c|c|c|}
\hline \multirow{3}{*}{$\begin{array}{l}\text { Standard of living } \\
\text { quartiles }\end{array}$} & \multirow{3}{*}{$\begin{array}{l}\text { Total } \\
\text { (in \%) }\end{array}$} & \multirow{3}{*}{$\begin{array}{l}\text { Received gift } \\
\text { assistance } \\
\text { (A) } \\
\text { (in \%) }\end{array}$} & \multirow{3}{*}{$\begin{array}{c}\text { Did not receive } \\
\text { gift assistance } \\
\begin{array}{c}\text { (B) } \\
\text { (in \%) }\end{array}\end{array}$} & \multicolumn{2}{|c|}{ Effect of gift assistance* } \\
\hline & & & & $\begin{array}{l}\text { Differences in probability of } \\
\text { first-time home ownership }\end{array}$ & $\begin{array}{l}\text { Ratio of probability of first- } \\
\text { time home ownership }\end{array}$ \\
\hline & & & & $\begin{array}{c}\text { (B)- }(\mathrm{A}) \\
\text { (in points) }\end{array}$ & $(B) /(A)$ \\
\hline $1^{\text {st }}$ quartile & 6 & 4 & 28 & 24 & 7.0 \\
\hline $2^{\text {nd }}$ quartile & 17 & 13 & 53 & 40 & 4.1 \\
\hline $3^{\text {rd }}$ quartile & 27 & 22 & 58 & 36 & 2.6 \\
\hline $4^{\text {th }}$ quartile & 34 & 28 & 60 & 32 & 2.1 \\
\hline Total & 19 & 15 & 47 & 32 & 3.1 \\
\hline
\end{tabular}

* The differences reported in this table are significantly different from zero at the $1 \%$ threshold, the odds ratios are significantly different from 1 at the $1 \%$ threshold.

Note: The control variables used are age, living in a couple versus alone, urban unit and number of children. Weighted regression on 16,912 households: 6,519 in Q1, 4,220 in Q2, 3,328 in Q3 and 2,845 in Q4.

Reading note: Without a donation, renters in the lowest $25 \%$ of households have a $4 \%$ chance of becoming homeowners, compared to a $28 \%$ chance of becoming homeowners if they received a donation, a difference of 24 points. The probability of first-time home ownership is thus multiplied by 7 .

Coverage: Households whose reference person is aged 25 to 44 , excluding students, residing in mainland France, tenants 4 years before the survey date. Sources: Insee, Housing surveys 2002-2013. 
survey, that focuses on property purchase and financing issues, secondly, also contribute to this strong correlation between family assistance and access to home ownership.

The effect of gift assistance is also important for young households in the second and third quartiles of living standards. The difference in probability of first-time home ownership is 40 and 36 points in both cases, the higher, but the odds ratios are multiplied by 4 in the second quartile and 3 in the third. The best-off see their chances of access multiplied by only 2 if their family helps them (cf. Table 1).

\section{Gift assistance received accounts on average for one-fifth of the price of the housing purchased}

Although property prices almost doubled in the 2000 s, the share accounted for by gift assistance in the purchase price of housing remains fairly stable over the period. Thus, the assistance received represents between $22 \%$ and $19 \%$ of the price of housing on average, and on average between $15 \%$ and $12 \%$ (Table 2 ).

This relative stability in a context of property price growth may cover different mechanisms. Some families may have adapted their assistance to rising property prices, households may have bought cheaper (possibly lower quality) goods or, finally, some households may have been forced out of the market, not benefiting from sufficient family assistance to acquire housing.

If we consider beneficiaries by standard of living, the percentage of the price of housing covered by family gift assistance is slightly lower at the top of the distribution (19\%) than at the bottom $(23 \%)$, this for all the surveys over 2002-2013 combined. The average price of housing purchased by the most modest households is $€ 139,000$ (constant Euros 2013), compared with $€ 193,000$ at the top of the living standards distribution.

\section{The share of modest owners is declining sharply in rural areas}

It is in rural areas that the distribution of ownership between the poorest and the wealthiest has undergone the most marked changes (Figure VII). While the least well-off ( $1^{\text {st }}$ quartile of standard of living) accounted for more than one-third $(36 \%)$ of rural homeowners in the 1970 s, they now represent only $11 \%$ of rural homeowners in 2013 (Figure VII-A). During the same period, the percentage of the best-off (last quartile) rose from $16 \%$ to $28 \%$ and, more broadly, that of the better-off half of the population (Q3 and Q4) from 37\% to 64\% of homeowners in rural areas. The vast majority of home ownership in urban areas consists of the best-off population since the 1970s, and this phenomenon has increased slightly over the period (Figure VII-B). The best-off quarter of the population (Q4) accounted for $38 \%$ of homeowners at the beginning of the period, and $42 \%$ in 2013 . In the same period, the share of the least well-off homeowners in urban areas, already marginal in 1973 (15\%), was halved from $15 \%$ to $8 \%$.

More generally, the location of all households according to their standard of living has changed

Table 2

Change in amount of gift assistance (in euros 2013)

\begin{tabular}{|c|c|c|c|c|}
\hline & & 2002 & 2006 & 2013 \\
\hline \multirow{4}{*}{$\begin{array}{l}\text { Amount of gift assistance } \\
\text { (in constant euros 2013) }\end{array}$} & $25 \%$ lowest & 8,900 & 11,800 & 10,000 \\
\hline & Median & 17,900 & 25,900 & 25,000 \\
\hline & Mean & 28,700 & 35,700 & 39,800 \\
\hline & $25 \%$ highest & 35,900 & 47,100 & 50,000 \\
\hline \multirow{2}{*}{$\begin{array}{l}\text { Proportion of gift } \\
\text { assistance in price } \\
\text { of dwelling (in \%) }\end{array}$} & Median & 15 & 14 & 12 \\
\hline & Mean & 22 & 19 & 19 \\
\hline \multicolumn{2}{|c|}{ Total numbers } & 342 & 373 & 180 \\
\hline
\end{tabular}

Note: Amounts are rounded to the nearest 100 euros.

Reading note: The median amount of gift assistance received by those aged 25-44 who became owners for the first time during the last four years preceding the survey was 17,900 euros in 2002 (amount in euros 2013) and 25,000 euros in 2013. The amount of gift assistance received at the time of purchase represents approximately one-fifth of the price of the unit over the entire period.

Coverage: Households whose reference person is aged 25 to 44 , excluding students, first recent owners to receive gift assistance at the time of purchase and entered its amount in the survey (i.e. $20.3 \%$ of the first recent owners aged 25 to 44 ), residing in mainland France.

Sources: Insee, Housing surveys 2002-2013. 
over the period studied, accompanying changes in the labour market, which may partly contribute to the respective changes in access to home ownership in rural and urban areas. Over the period, we note in particular that the modest categories increasingly live in large cities and the Paris agglomeration (44\% in 2013 against 25\% in 1973), at the expense of rural areas, whose share in the most modest households housing (Q1) fell from 35\% in 1973 to $14 \%$ forty years later (Table 3). Better-off households live slightly more often in rural areas in 2013, and in large cities, with the exception of Paris $(24 \%$ in cities with more than 200,000 inhabitants, as compared to $16 \%$ in 1973$)^{16}$.
Thus, rural areas are marked both by a decline in the proportion of small farms whose owners could have a modest standard of living, and the arrival of wealthier categories wishing for better quality of life, especially in peri-urban areas. In urban areas, already marked by strong inequalities at the beginning of the period, it

16. The research carried out by Cavailhès (2005) effectively sheds light on these trends, showing that the income elasticity of demand for available living space is higher than that of demand for ease of access among managers, and the reverse among workers. For the author, these results "suggest that workers located in the city centre place greater emphasis on accessibility than on the surface of their housing, and conversely, that the preference for the outskirts, seen in managers, reflects greater concern about having space".

\section{Figure VII}

Proportion of rural and urban homeowners by standard of living quartile
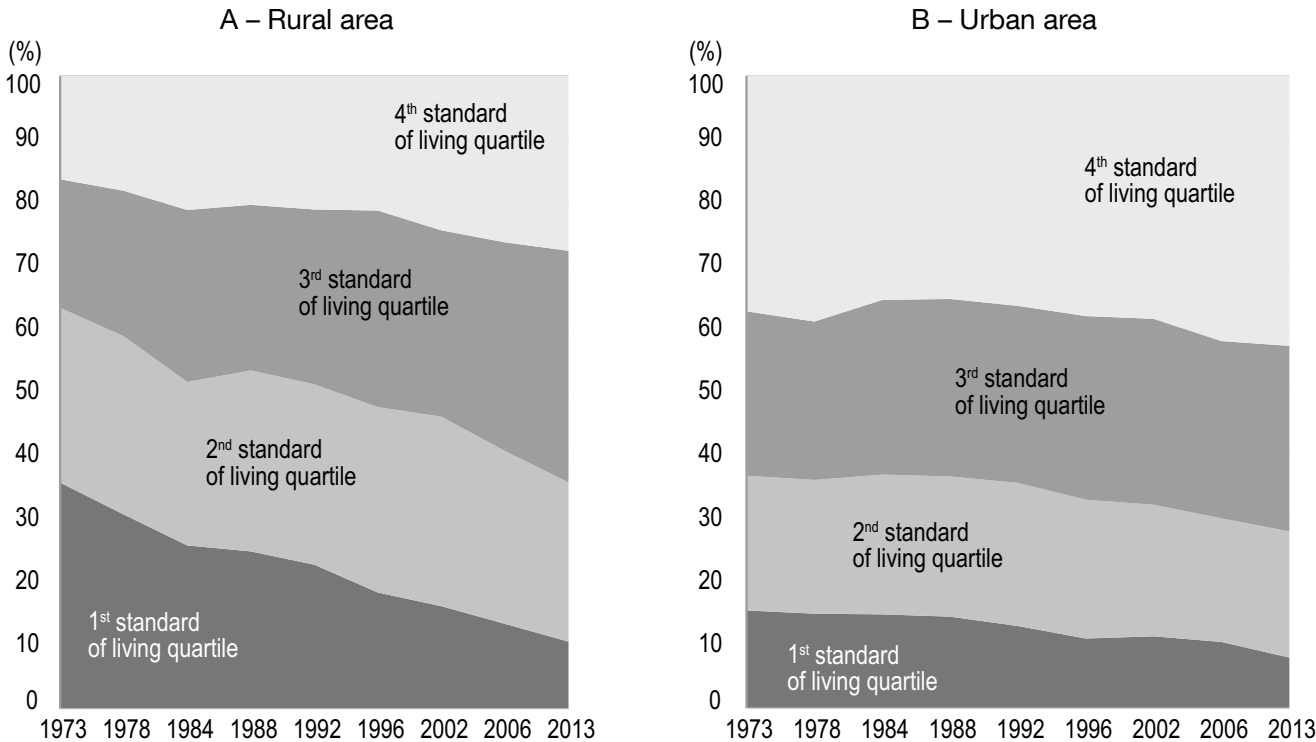

Coverage: Households of owners whose reference person is aged between 25 and 44, excluding students, residing in mainland France. Sources: Insee, Housing surveys 1973-2013.

Table 3

Change in the location of households according to their standard of living quartile, 1973 and 2013

\begin{tabular}{|c|c|c|c|c|c|c|c|c|c|c|}
\hline & \multicolumn{2}{|c|}{ Q1 } & \multicolumn{2}{|c|}{ Q2 } & \multicolumn{2}{|c|}{ Q3 } & \multicolumn{2}{|c|}{ Q4 } & \multicolumn{2}{|c|}{ Total } \\
\hline & 1973 & 2013 & 1973 & 2013 & 1973 & 2013 & 1973 & 2013 & 1973 & 2013 \\
\hline Rural municipality & 35 & 14 & 24 & 23 & 18 & 26 & 14 & 18 & 23 & 20 \\
\hline $\begin{array}{l}\text { Urban unit with less than } \\
10,000 \text { inhabitants }\end{array}$ & 11 & 11 & 11 & 14 & 10 & 13 & 7 & 8 & 10 & 12 \\
\hline $\begin{array}{l}\text { Urban unit with } 10,000 \\
\text { to } 49,999 \text { inhabitants }\end{array}$ & 14 & 12 & 14 & 11 & 14 & 10 & 11 & 9 & 13 & 10 \\
\hline $\begin{array}{l}\text { Urban unit with } 50,000 \\
\text { to } 199,999 \text { inhabitants }\end{array}$ & 15 & 19 & 17 & 14 & 17 & 13 & 14 & 11 & 16 & 14 \\
\hline $\begin{array}{l}\text { Urban unit with } 200,000 \\
\text { to } 1,999,999 \text { inhabitants }\end{array}$ & 17 & 28 & 19 & 24 & 19 & 23 & 16 & 24 & 18 & 25 \\
\hline Paris conurbation & 8 & 16 & 15 & 14 & 22 & 15 & 38 & 30 & 21 & 19 \\
\hline Total & 100 & 100 & 100 & 100 & 100 & 100 & 100 & 100 & 100 & 100 \\
\hline
\end{tabular}

Coverage: Households whose reference person is aged 25 to 44 , excluding students, residing in mainland France.

Sources: Insee, Housing surveys 1973 and 2013. 
is difficult for the modest categories to gain access to property, while access for the more affluent extends to very large cities outside the Paris conurbation.

Fewer couples with children and more single-parent families among the least well-off

From the 1970 s to the 2000 s, the family structure of young households in the first quartile of living standards changed profoundly, with a sharp rise in the proportion of single-parent families $(31 \%$ in 2013 , compared to $9 \%$ in 1978) and, conversely, a sharp fall in the proportion of couples with children, from $79 \%$ in 1978 to $37 \%$ of modest households in 2013 . Unlike single-parent families, couples with children have a higher than average propensity to own their own home, a trend that could partly explain the decline in home ownership rates among the poorest over the long-term (Table 4).

\section{A strong contribution of structural change and family support to changing inequalities in home ownership}

Changes in the ownership rate may stem from changes in household characteristics (age, location, family structure, share of gift assistance received, etc.) and changes in the propensity to become a homeowner. In order to better quantify the role that changes in these various factors may have played in changes in the rate of home ownership among young households, we propose a decomposition of the "Oaxaca-Blinder" type (Oaxaca, 1973; Blinder, 1973).

The "Oaxaca-Blinder" decomposition applied to the change in inequalities in home ownership rates

The general principle of this decomposition is to distinguish, in a gap, that which is due to a structural difference ("explained" by the observed characteristics) from what is a change in the effect of these characteristics ("unexplained" difference). Here, we try to distinguish what, in the change in the percentage of homeowners, is due to changes in the observable characteristics of households, from what comes from changes in the effect of given characteristics on home ownership.

We denote $\bar{P}_{a}$ the probability of becoming an owner in year $a, \bar{X}_{a}$ the vector of the means of the characteristics in year $a$ and $\beta_{a}$ the vector of the coefficients estimated for year $a$. The change in ownership rate between 1978 and 2013 can then be written:

$$
\begin{aligned}
\bar{P}_{2013}-\bar{P}_{1978} & =\left(\bar{X}_{2013}-\bar{X}_{1978}\right) \beta_{2013} \\
& +\bar{X}_{1978}\left(\beta_{2013}-\beta_{1978}\right)
\end{aligned}
$$

$\left(\bar{X}_{2013}-\bar{X}_{1978}\right) \beta_{2013}$ represents the effect of changes in household structure (age, marital status, etc.) and corresponds to the so-called "explained" part of the change. In addition to the socio-demographic characteristics of the young household population, whose role is analysed over a long period, we introduce gift assistance and inheritances to study their importance during the $2000 \mathrm{~s}$. The term $\bar{X}_{1978}\left(\beta_{2013}-\beta_{1978}\right)$ represents changes in the propensity to become homeowners (for

Table 4

\begin{tabular}{|c|c|c|c|c|c|c|c|c|c|c|}
\hline & \multicolumn{2}{|c|}{ Q1 } & \multicolumn{2}{|c|}{ Q2 } & \multicolumn{2}{|c|}{ Q3 } & \multicolumn{2}{|c|}{ Q4 } & \multicolumn{2}{|c|}{ Ensemble } \\
\hline & 1978 & 2013 & 1978 & 2013 & 1978 & 2013 & 1978 & 2013 & 1978 & 2013 \\
\hline Single-parent family & 9 & 31 & 6 & 11 & 3 & 4 & 1 & 2 & 5 & 12 \\
\hline Couples with children & 79 & 37 & 75 & 50 & 68 & 58 & 61 & 53 & 71 & 49 \\
\hline Couples without children & 6 & 7 & 6 & 10 & 14 & 14 & 22 & 22 & 12 & 13 \\
\hline Person living alone & 4 & 23 & 11 & 27 & 13 & 21 & 13 & 20 & 10 & 23 \\
\hline Other households & 2 & 2 & 2 & 2 & 2 & 3 & 3 & 3 & 2 & 3 \\
\hline Total & 100 & 100 & 100 & 100 & 100 & 100 & 100 & 100 & 100 & 100 \\
\hline
\end{tabular}

Structure by type of household, by standard of living, 1978 and 2013

Coverage: Households whose reference person is aged 25 to 44 , excluding students, residing in mainland France.

Sources: Insee, Housing surveys 1978 and 2013. 
given household characteristics), which may stem from changes in behaviour, linked to changes in preferences, from public policies that may influence the latter, or the economic environment.

\section{Structural changes especially among young low-income households}

Between 1978 and 2013, the probability of becoming a homeowner fell by 14 percentage points among young low-income households, from $30 \%$ to $16 \%$ (see Table 5). Over $60 \%$ of this decline is attributable to the changing structure of this population over time. This confirms the key role of the two factors examined above: family configurations (including the share of single-parent families and couples with children) and location (mainly in rural areas).
First of all, the family structures of young low-income households varied greatly during this period, as seen above: the percentage of single-parent families increased more than threefold and the number of couples with children was cut in half (see Table 4). This explains more than half of the structural effect $(61 \%)$. Secondly, the proportion of households living in rural areas has fallen considerably: it has also been halved among young low-income households (cf. Table 3). This decrease makes the other half of the structural effect (table 5).

For young households in the lowest quartile of living standards, the evolution over the same period is diametrically opposite. Their likelihood of becoming homeowners increased by almost 20 percentage points, of which only one-tenth can be explained by structural effects. Most of this increase comes from the

Table 5

Decomposition in change in ownership rate ("Oaxaca-Blinder" method)

\begin{tabular}{|c|c|c|c|c|}
\hline & \multicolumn{2}{|c|}{$\begin{array}{c}1978-2013 \\
\text { With the variable on assistance/inheritance }\end{array}$} & \multicolumn{2}{|c|}{$\begin{array}{l}2002-2013 \\
\text { With the variable on gift assistance/inheritance }\end{array}$} \\
\hline & Q1 & Q4 & Q1 & Q4 \\
\hline & \multicolumn{4}{|c|}{ Total ownership rate } \\
\hline 1978 & \multirow[t]{2}{*}{30.2} & \multirow[t]{2}{*}{47.0} & & \\
\hline 2002 & & & 22.1 & 57.3 \\
\hline 2013 & 15.7 & 66.2 & 15.7 & 66.2 \\
\hline \multirow[t]{2}{*}{ Gap } & -14.4 & 19.2 & -6.4 & 8.9 \\
\hline & \multicolumn{4}{|c|}{ Explained and unexplained share } \\
\hline Unexplained share & 37.9 & 89.7 & 48.0 & 63.1 \\
\hline \multirow[t]{2}{*}{ Explained share } & 62.1 & 10.3 & 52.0 & 36.9 \\
\hline & \multicolumn{4}{|c|}{ Decomposition of explained share } \\
\hline Inheritance or gift assistance & & & 9.6 & 35.8 \\
\hline Ages 25-29 & -7.3 & 122.9 & 6.7 & 21.9 \\
\hline Ages 30-34 & -2.2 & 26.2 & -1.8 & 4.0 \\
\hline \multicolumn{5}{|l|}{ Ages 35-39 ans (ref.) } \\
\hline Ages 40-44 & -4.9 & 26.0 & -8.2 & 8.5 \\
\hline Paris & 6.0 & -18.0 & 2.1 & 12.2 \\
\hline Large cities & 5.5 & 0.0 & 10.0 & -3.2 \\
\hline \multicolumn{5}{|l|}{ Medium-sized cities (ref.) } \\
\hline Rural & 41.5 & 43.9 & 34.9 & 3.3 \\
\hline Single-parent families & 13.7 & -2.9 & 9.6 & -0.2 \\
\hline \multicolumn{5}{|l|}{ Couples without children (ref.) } \\
\hline Lone individuals & 11.6 & -40.2 & 8.9 & 5.6 \\
\hline Couples with children & 36.1 & -57.9 & 28.1 & 12.2 \\
\hline Total & 100 & 100 & 100 & 100 \\
\hline
\end{tabular}

Note: Columns 2 and 3 show the results for the years 1978-2013, without the gift assistance and inheritance variable, while the two following ones relate to years 2002-2013, including the gift and inheritance variable, available only for this period (cf. box). The third and fifth columns include the best-off, the second and fourth the most modest.

Reading note: The change in population structure explains $62 \%$ of the change in the ownership rate between 1978 and 2013 in the 1 st quartile. Almost half of this $62 \%$ is due to changes in the share of households living in rural areas (42\%) and more than half to changes in family patterns (61\%).

Coverage: Households whose reference person is between ages 25 and 44, excluding students, residing in mainland France.

Sources: Insee, Housing surveys 1978-2013. 
increase in the probability of buying among the reference population. The relative fall observed in large conurbations, and especially in Paris, appears significant (see Appendix 2, Table A2-2) and probably reflects a greater rise in property prices in these areas, though the observed increase in the probability of becoming homeowners remains valid. This may seem surprising at a time when housing prices are rising, and could be due to the possibly greater role of family assistance received by these households.

\section{The growing role of financial support from the family}

In order to bring out this role, we now introduce into the decomposition the variable reflecting the receipt of gift assistance or an inheritance. As we have reliable information on this issue only for 2002-2013, we focus on a shorter period of time.

As to young households in the $1^{\text {st }}$ quartile of living standards, the probability of buying their main place of residence decreased by 6 percentage points between 2002 and 2013. We can confirm here that more than half of this decline $(52 \%)$ is due to changes in the structure of the population (family structure, in particular, and place of residence). The share of households that report having received assistance from their family stagnated or even decreased slightly over the period, from $8 \%$ to $7 \%$ (see Appendix 2, Table A2-3). In addition, the link between receipt of assistance and home ownership has lessened slightly over the period, although it remains largely significant and positive. This seems consistent with the decline in average household purchasing capacity for real estate observed during the 2000s (Arnold \& Boussard, 2017), and could indicate that the amounts of aid received were unable to offset the rise in real estate prices over this period.

It is among the wealthiest young households that the change in the role of gift assistance and inheritance is the most noticeable. Between 2002 and 2013, their probability of home ownership increased by 9 percentage points. $13 \%$ of this increase is explained by the increasing role played by these aids ${ }^{17}$. The share of wealthy young households assisted by their families rose from $20 \%$ to $24 \%$ (see Appendix 2, Table A2-4), which is the largest increase out of all the explanatory variables introduced. Adding the receipt of gift assistance or inheritance to the analysis increases the explained share of the difference in homeowners' rate from $24 \%$ to $37 \%$ (see Appendix 2, Table A2-5), thus underlining the importance of this type of assistance for the better-off households ${ }^{18}$. Finally, 63\% of the gap remains unexplained, a larger share than in the sample of the least well-off households (in which only $48 \%$ remain unexplained). This may reflect the effects of economic conditions, changes in the purchasing behaviour of the better-off or the effect of public policies to foster first-time home ownership from which the better-off might benefit. In particular, the zero interest loan (prêt à taux zero, PTZ), created 1996, has been rather poorly targeted and many households in the $4^{\text {th }}$ standard of living quartile have been able to benefit from it, as noted by Gobillon and Le Blanc (2004; 2005). Their theoretical modelling of the effect of the PTZ on the purchase decision is almost directly transferable to our question of the effect of donations on access to property: family transfers, like the PTZ, essentially loosen the budgetary constraint and increase the maximum budget devoted to housing, which increases the chances of accessing a property at least as satisfactory as the one the household could have rented. This assistance received by the households, whether public or family, also make it possible to reduce the user cost of capital (of which the interest rate), which can make a loan more attractive in comparison with the payment of a rent, and thus influence the trade-off between purchase and rental.

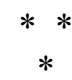

The apparent stability of home ownership among young households aged 25 to 44 between 1973 and 2013 masks growing disparities between the best and the least well-off. These disparities appear more marked than those already highlighted in previous research on all households (Laferrère et al., 2017). This difference results from the combined effect of the scope of our study, restricted to young households, and the choice of a social position indicator defined on quartiles of living standards rather than on socio-professional categories. This choice makes it possible to avoid the

17. This $13.2 \%$ results from multiplying the share explained by the share of inheritances and gifts in this explained share, i.e., $36.9 \% \times 35.8 \%$. 18. Conversely, the explained share did not change in the least well-off households when this variable is introduced. It should also be noted that the other coefficients remain similar after these variables are introduced (see Appendix 2, Table A2-5). 
problem of variations in occupational structure across cohorts, and to explain the disparities by the differential socio-demographic changes that affected households according to their financial wealth. The decomposition of the change in ownership rates inequality between the least and the best well-off highlights the important role played by changes in family structures (increasing proportion of single-parent families and decline in the share of couples with children among the least well-off) and in the location of households (sharp fall in the share of households living in rural areas), particularly among the least well-off. In contrast, changes in the socio-demographic composition of the quartiles of standard of living contribute less to the change in ownership rates among young well-off households. For them, the role of family assistance increased considerably over the period 2002-2013. However, some of the evolutions remain unexplained by the variables considered, perhaps reflecting changes in behaviours or the role of macroeconomic factors, including the housing market.

While it is not possible to study the contribution of changes in family assistance on first-time home ownership over the entire period covered by the Housing surveys, it is plausible, in view of the results for the period 2002-2013, that family financial support also played an important part; this would have to be analysed in more detail with other data, in the context of the trend in inequalities since the 1970s. We initiated this work drawing on the Household Wealth survey (see Appendix 3 ), over the period 1998-2014. Comparing changes in ownership rates with those in gift assistance and inheritances received by owners consistently shows concurrent shifts in the disparities in first-time home ownership and family transfers from as early as 1998 . The share of young owner households in the first quartile of standard of living fell slightly, while it rose very markedly in the last quartile. At the same time, the share of young households that received family financial assistance rose noticeably among the wealthiest, while it stagnated among the least well-off households.

Highlighting this role of intergenerational transfers invites further analysis of their impact on inequality between young households in two directions. First of all, beyond home ownership in the strict sense, family transfers could influence the characteristics of the housing purchased: households receiving family assistance could acquire more spacious, better-quality, better-located, better-equipped housing, etc.. Secondly, analysis of inequalities in terms of objective characteristics of the housing acquired (such as the value of the main residence or the surface area) could be furthered by a study of their appreciation by the household (ratings of the housing and the neighbourhood). This would provide a subjective measure of housing quality and adequacy with individual preferences, which could be analysed in relation to location and occupancy status. Research could then focus on whether family assistance, in addition to influencing first-time home ownership, facilitates mobility and access to housing likely to improve well-being.

\section{BIBLIOGRAPHY}

Agarwal, S., Hu, L. \& Huang, X. (2015). Rushing into the American dream? House prices growth and the timing of homeownership. Review of Finance, 20(6), 2183-2218.

https://doi.org/10.1093/rof/rfv063

Alvaredo, F., Garbinti, B. \& Piketty, T. (2017). On the Share of Inheritance in Aggregate Wealth: Europe and the USA, 1900-2010. Economica, 84, 239-260.

https://doi.org/10.1111/ecca.12233
Angelini, V., Laferrere, A. \& Weber, G. (2013). Home-ownership in Europe: How did it happen? Advances in Life Course Research, 18(1), 83-90. https://doi.org/10.1016/j.alcr.2012.10.006

Arnault, S. \& Crusson, L. (2012). La part du logement dans le budget des ménages en 2010. Alourdissement pour les locataires du parc privé. Insee Première $\mathrm{N}^{\circ} 1395$.

https://www.insee.fr/fr/statistiques/1281118 
Arnold, C. \& Boussard, J. (2017). L'accès à la propriété en recul depuis la crise de 2008. Insee Références - Les conditions de logement en France, pp. 41-53. https://www.insee.fr/fr/statistiques/2586022? sommaire $=2586377$

Arrondel, L., Garbinti, B. \& Masson, A. (2014). Inégalités de patrimoine entre générations : les donations aident-elles les jeunes à s'installer? Économie et Statistique, 472-473, 65-100.

https://www.insee.fr/fr/statistiques/1377767? sommaire $=1377781$

Barrett, G., Cigdem, M., Whelan, S. \& Wood, G. (2015). The relationship between intergenerational transfers, housing and economic outcomes. AHURI Final Report 250, Australian Housing and Urban Research Institute Limited, Melbourne. https://www.ahuri.edu.au/research/final-reports/250

Blinder, A. (1973). Wage Discrimination: Reduced Form and Structural Estimates. The Journal of Human Resources, 8(4), 436-455. https://doi.org/10.2307/144855

Bonnet, C., Garbinti, B. \& Grobon, S. (2016). Accès à la propriété : les inégalités s'accroissent depuis quarante ans. Études et Résultats $\mathrm{N}^{\circ} 961$.

http://drees.solidarites-sante.gouv.fr/etudes-etstatistiques/publications/etudes-et-resultats/article/ acces-a-la-propriete-les-inegalites-s-accroissentdepuis-quarante-ans

Bonnet, O., Bono, P.-H., Chapelle, G. \& Wasmer, É. (2014). Le capital logement contribue-t-il aux inégalités? Retour sur Le Capital au $\mathrm{XXI}^{\mathrm{e}}$ siècle de Thomas Piketty. LIEPP Working Paper $\mathrm{N}^{\circ} 25$.

https://www.sciencespo.fr/liepp/fr/content/ le-capital-logement-contribue-t-il-aux-inegalites

Bonvalet, C. \& Bringé, A. (2013). Les effets de la politique de logement sur l'évolution des taux de propriétaires en France. Revue européenne des sciences sociales, 151(1), 153-177. https://journals.openedition.org/ress/2342

Bosvieux, J. (2005). Accession à la propriété : des acquéreurs plus nombreux mais prudents. Économie et Statistique, 381-382, 41-61.

https://www.insee.fr/fr/statistiques/1376575? sommaire $=1376587$

Bozio, A., Monnet, M. \& Romanello, L. (2016). Analyse des dispositifs d'aide à l'accession à la propriété. Rapport IPP $\mathrm{N}^{\circ} 16$.

http://www.ipp.eu/publication/decembre-2016analyse-dispositifs-aide-accession-a-la-propriete/

Bugeja, F. (2011). Les inégalités d'accès à la propriété et leurs déterminants institutionnels.
Étude comparative entre la France et le Royaume-Uni (1980-2005). Revue française de sociologie, 52(1), $37-69$.

https://doi.org/10.3917/rfs.521.0037

Carbonnier, C. (2015). L'impact des prix de l'immobilier sur les inégalités et leur mesure. Revue économique, 66(6), 1029-1044. https://doi.org/10.3917/reco.pr2.0052

Cavailhès, J. (2005). Le prix des attributs du logement. Économie et Statistique, 381-382, 91-123. https://www.insee.fr/fr/statistiques/1376579? sommaire $=1376587$

Chardon, O., Daguet, F. \& Vivas, E. (2008). Les familles monoparentales : des difficultés à travailler et à se loger. Insee Première $\mathrm{N}^{\circ} 1195$. https://www.insee.fr/fr/statistiques/1281271

Clerc, M.-E., Monso, O. \& Pouliquen, E. (2011). Les inégalités entre générations depuis le baby-boom. Insee Références - L'Économie française - Comptes et Dossiers, pp. 47-67.

https://www.insee.fr/fr/statistiques/1373852? sommaire $=1373855$

Duffy, D. \& Roche, M. J. (2007). Getting a Helping Hand: Parental Transfers and First-Time Homebuyers. Economics, Finance and Accounting Department Working Paper series, 1740507 National University of Ireland, Maynooth.

https://ideas.repec.org/p/may/mayecw/n1740507.html

Engelhardt, G. V. \& Mayer, C. J. (1998). Intergenerational transfers, Borrowing constraints and Saving behavior: Evidence from the Housing Market. Journal of Urban Economics, 44, 135-57. https://doi.org/10.1006/juec.1997.2064

Fack, G. (2007). Formation des inégalités, politiques du logement et ségrégation résidentielle. Thèse de doctorat.

Ferrante, A., Guillas, D. \& Solotareff, R. (2016). Entre 2010 et 2015 , les inégalités de patrimoine se réduisent légèrement. Insee Première $\mathrm{N}^{\circ} 1621$. https://www.insee.fr/fr/statistiques/2496232

Garbinti, B., Lamarche, P. \& Salembier, L. (2012). Héritages, donations et aides aux ascendants et descendants. Insee Références - Les revenus et le patrimoine des ménages, pp. 57-69.

https://www.insee.fr/fr/statistiques/1373963? sommaire $=1373966$

Garbinti, B., Goupille-Lebret J. \& Piketty, T. (2016). Accounting for Wealth Inequality Dynamics: Methods, Estimates and Simulations for France (1800-2014). WID world Working Paper, 2016/5. 
Garbinti, B. \& Savignac, F. (2018). Le rôle de l'immobilier dans les inégalités de patrimoine en zone euro : les enseignements de l'enquête Household Finance and Consumption. Rue de la Banque $\mathrm{N}^{\circ} 55$.

https://publications.banque-france.fr/le-role-delimmobilier-dans-les-inegalites-de-patrimoine-enzone-euro-les-enseignements-de-lenquete

Gobillon, L. \& Le Blanc, D. (2005). Quelques effets économiques du prêt à taux zéro. Économie et Statistique, 381-382, 63-89.

https://www.insee.fr/fr/statistiques/1376577? sommaire $=1376587$

Gobillon, L. \& Le Blanc, D. (2004). L'impact des contraintes d'emprunt sur la mobilité résidentielle et les choix entre location et propriété. Annales d'économie et de statistique, 74, 15-45.

Haurin, D., Parcel, R. \& Hautin, R. (2002). Does homeownership affect child outcomes? Real Estate Economics, 30(4), 635-666. https://doi.org/10.1111/1540-6229.t01-2-00053

Kaas, L., Kocharkov, G. \& Preugschat, E. (2015). Wealth inequality and homeownership in Europe. Working Paper Series of the Department of Economics, University of Konstanz, 2015-2018. https://ideas.repec.org/p/knz/dpteco/1518.html

Kolodziejczyk, C. \& Leth-Petersen, S. (2013). Do First Time House Buyers Receive Financial Transfers from Their Parents? Scandinavian Journal of Economics, 115(4), 1020-45. https://doi.org/10.1111/sjoe.12032

Labonne, C. \& Welter-Nicol, C. (2015). Cheap Credit, Unaffordable Houses? ACPR et Banque de France, Débats économiques et financiers, 20. https://acpr.banque-france.fr/cheap-creditunaffordable-houses

Laferrère, A., Pouliquen, E. \& Rougerie, C. (2017). Le logement en France depuis 30 ans. Insee Références - Les conditions de logement en France, pp. 11-22.

https://www.insee.fr/fr/statistiques/fichier/2586003/ LOGFRA17a_VE_logement.pdf

Le Bayon, S., Levasseur, S. \& Madec P. (2013). Achat de la résidence principale. Le profil des ménages français dans les années 2000. Revue de l'OFCE / Débats et politiques, 128, 451-482.

https://www.ofce.sciences-po.fr/pdf/revue/18-128.pdf

Luea, H. M. (2008). The impact of financial help and gifts on housing demand and cost burdens. Contemporary Economic Policy, 26(3), 420-432. https://doi.org/10.1111/j.1465-7287.2008.00106.x

Malmendier, U. \& Steiny, A. (2016). Rent or buy? The role of lifetime experiences of macroeconomic shocks within and across countries. CEPR Network Event on Household Finance, 6-7/05/2016.

Méron, M. \& Courgeau, D. (2004). Home Ownership and Social Inequality in France. In : Kurz, K. \& Blossfeld, H.-P. (Ed.), Home ownership and social inequalities in comparative perspective, pp. 61-78. Stanford: Stanford University Press.

Oaxaca, R. (1973). Male-Female Wage Differentials in Urban Labor Markets. International Economic Review, 14(3), 693-709.

https://doi.org/10.2307/2525981

Piketty, T. (2011). On the Long-Run Evolution of Inheritance: France 1820-2050. The Quarterly Journal of Economics, 126 (3), 1071-1131.

https://doi.org/10.1093/qje/qjr020

Piketty, T. (2014). Capital in the Twenty-First century. Harvard: Harvard University Press.

Piketty, T. \& Zucman, G. (2014). Capital is Back: Wealth-Income Ratios in Rich Countries 1700-2010. The Quarterly Journal of Economics, 129(3), 1155-1210. https://doi.org/10.1093/qje/qju018

Spilerman, S. \& Wolff, F.-C. (2012). Parental wealth and resource transfers: How they matter in France for home-ownership and living standards. Social Science Research, 41, 207-223. https://doi.org/10.1016/j.ssresearch.2011.08.002

Worms, B. (2009). Les politiques d'aide à l'accession à la propriété à l'épreuve de la crise. Informations sociales, 155, 120-130.

https://www.cairn.info/revue-informations-sociales2009-5-page-120.htm 


\section{UNDERSTANDING THE ROLE OF FAMILY FINANCIAL ASSISTANCE OVER THE LONG TERM, USING THE HOUSING SURVEYS}

Several questions make it possible to describe the financial support received from families when buying. However, it was not possible to construct a homogeneous series over an extended period, in particular because of the significant change in the order and nature of the questions in the 2002 survey. Starting in 2002, individuals were first asked about their various loans and the related amounts. Then, when "the total amount of the initial loans is less than the purchase price", they are asked how they formed their individual contribution.
This introduces a significant break in the level of family assistance measured between 1996 and 2002 (figure A1-I). The use of this variable between 1996 and 2002 would have led to the conclusion that there had been a sharp increase in the share of first-time homeowners assisted by their families. However, it is very likely that some of this increase will actually be observed, in particular because of the significant rise in property prices from the end of the 1990s.

Figure A1-I

Change in the share of first-time homeowners assisted by their families

$(\%)$

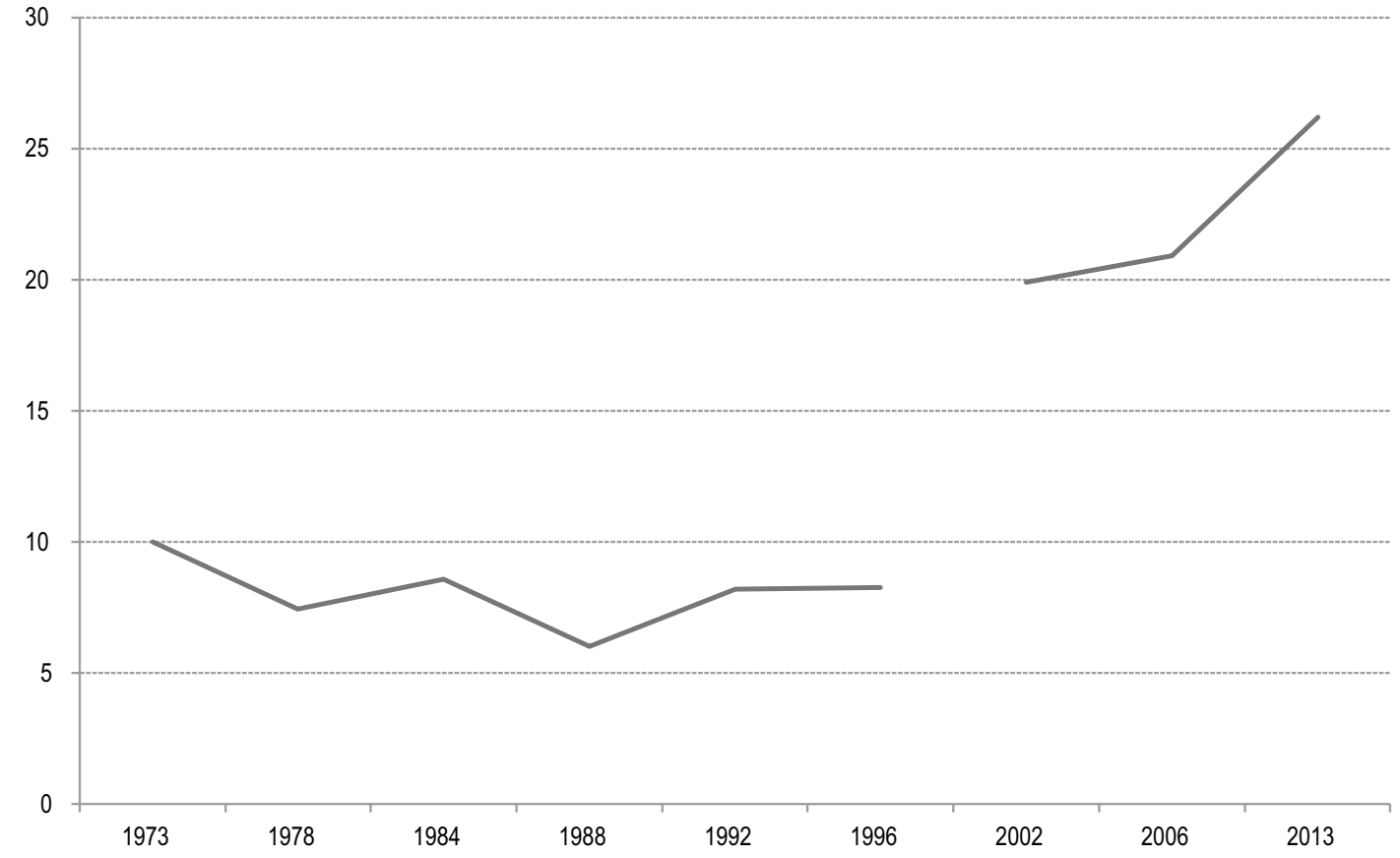

Coverage: Households whose reference person is between ages 25 and 44, first recent owners, residing in mainland France. Sources: Insee, Housing surveys 1973-2013. 
OAXACA-BLINDER DECOMPOSITIONS: REGRESSION RESULTS

Table A2-1

Decomposition of changes in home ownership rates in the first standard of living quartile, 1978-2013

\begin{tabular}{|c|c|c|c|c|c|c|}
\hline & \multicolumn{2}{|c|}{1978} & \multicolumn{2}{|c|}{2013} & \multicolumn{2}{|c|}{ Decomposition } \\
\hline & Average & Coefficient & Average & Coefficient & Structure effects & $\begin{array}{c}\text { Changes in relative } \\
\text { chances } \\
\text { of purchasing }\end{array}$ \\
\hline Ages 25-29 & 0.26 & $-0.23^{\star \star \star}$ & 0.22 & $-0.09^{\star * *}$ & $0.01^{* *}$ & $0.04^{\star \star *}$ \\
\hline Ages 30-34 & 0.27 & $-0.11^{\star \star \star}$ & 0.24 & $-0.02(\mathrm{~ns})$ & $0.002^{*}$ & $0.02^{* *}$ \\
\hline Ages 35-39 (ref.) & & & & & & \\
\hline Ages 40-44 & 0.24 & $0.11^{* * *}$ & 0.30 & $0.06^{\star *}$ & $0.004^{* *}$ & $-0.01(\mathrm{~ns})$ \\
\hline Paris & 0.07 & $-0.16^{* * *}$ & 0.17 & $-0.01(\mathrm{~ns})$ & $-0.005^{* * *}$ & $0.01^{* * *}$ \\
\hline Large cities & 0.29 & $-0.05^{\star *}$ & 0.37 & $-0.06^{* * *}$ & $-0.005^{\star \star \star}$ & $-0.002(n s)$ \\
\hline Medium-sized cities (ref.) & & & & & & \\
\hline Rural & 0.30 & $0.23^{* * *}$ & 0.14 & $0.26^{* * *}$ & $-0.04^{* * *}$ & 0.008 (ns) \\
\hline Single-parent families & 0.09 & $0.01(\mathrm{~ns})$ & 0.31 & $-0.06^{* *}$ & $-0.01^{* *}$ & -0.007 (ns) \\
\hline Couples without children (ref.) & & $-0.04(\mathrm{~ns})$ & & & & \\
\hline Lone individuals & 0.04 & $-0.04(\mathrm{~ns})$ & 0.23 & $-0.06^{* *}$ & $-0.01^{* *}$ & $-0.003(\mathrm{~ns})$ \\
\hline Couples with children & 0.79 & $0.11^{* * *}$ & 0.37 & $0.07^{* *}$ & $-0.03^{* \star *}$ & $-0.03(\mathrm{~ns})$ \\
\hline Constant & & $0.24^{* \star *}$ & & $0.16^{* * *}$ & & $-0.08(\mathrm{~ns})$ \\
\hline Total ownership rate & 0.30 & & 0.16 & & -0.09 & -0.05 \\
\hline
\end{tabular}

Note: Rural cities $=$ rural cities or cities with less than 20,000 inhabitants; large cities = more than 200,000 inhabitants; medium-sized cities = 20,000 to 199,999 inhabitants (reference category).

Reading note: The home ownership rate decreased from $30 \%$ to $16 \%$ between 1978 and 2013 , or 14 percentage points. The structural effects account for 9 points of this decline and the change in the relative chances of buying (ie unexplained share) 5 points.

Coverage: First standard of living quartile in households whose reference person is between ages 25 and 44 , excluding students, residing in mainland France, years 1978 and 2013.

Sources: Insee, Housing surveys 1978 and 2013.

Significance determined from the following p-value and thresholds: *** $1 \%$ ** $5 \%$ * $10 \%$; ns $=$ not significant.

Table A2-2

Decomposition of changes in home ownership rates in the last standard of living quartile, 1978-2013

\begin{tabular}{|c|c|c|c|c|c|c|}
\hline & \multicolumn{2}{|c|}{1978} & \multicolumn{2}{|c|}{2013} & \multicolumn{2}{|c|}{ Decomposition } \\
\hline & Average & Coefficient & Average & Coefficient & Structure effects & $\begin{array}{c}\text { Changes in relative } \\
\text { chances } \\
\text { of purchasing }\end{array}$ \\
\hline Ages $25-29$ & 0.22 & $-0.293^{* \star *}$ & 0.14 & $-0.28^{\star \star \star}$ & & \\
\hline Ages 30-34 & 0.28 & $-0.177^{\star \star \star}$ & 0.24 & $-0.106^{\star \star *}$ & $0.005^{\star *}$ & $0.018(\mathrm{~ns})$ \\
\hline Ages 35-39 (ref.) & & & & & & \\
\hline Ages $40-44$ & 0.26 & $0.032^{\star *}$ & 0.36 & $0.056^{*}$ & $0.005^{\star \star}$ & $0.007(\mathrm{~ns})$ \\
\hline Paris & 0.24 & $0.084^{*}$ & 0.30 & $-0.17^{\star \star \star}$ & $-0.004^{* *}$ & $-0.068^{* \star *}$ \\
\hline Large cities & 0.28 & $0.047^{\star *}$ & 0.28 & $-0.075^{\star \star *}$ & $0(n s)$ & $-0.034^{* \star *}$ \\
\hline Medium-sized cities (ref.) & & & & & & \\
\hline Rural & 0.13 & 0.239 (ns) & 0.18 & $0.111(\mathrm{~ns})$ & $0.009^{\star * *}$ & $-0.02^{\star \star *}$ \\
\hline Single-parent families & 0.01 & $0.089^{*}$ & 0.02 & $-0.128^{\star \star \star}$ & $-0.001(\mathrm{~ns})$ & $-0.004^{*}$ \\
\hline Couples without children (ref.) & & & & & & \\
\hline Lone individuals & 0.13 & $-0.089^{* \star *}$ & 0.20 & $-0.109^{\star \star *}$ & $-0.008^{\star \star *}$ & $-0.002^{* \star *}$ \\
\hline Couples with children & 0.61 & 0.134 (ns) & 0.53 & 0.172 (ns) & $-0.011^{* * *}$ & $0.023(\mathrm{~ns})$ \\
\hline Constant & & 0.441 (ns) & & $0.69(\mathrm{~ns})$ & & $0.249^{\star \star *}$ \\
\hline Total ownership rate & 0.47 & & 0.66 & & 0.02 & 0.17 \\
\hline
\end{tabular}

Note: cf. tableau A2-1.

Coverage: Fourth standard of living quartile of households whose reference person is aged 25 to 44 , excluding students, residing in mainland years 1978 and 2013

Sources: Insee, Housing surveys 1978 and 2013. 
Table A2-3

Decomposition of changes in ownership rate in the first standard of living quartile, 2002-2013, taking into account family transfers

\begin{tabular}{|c|c|c|c|c|c|c|}
\hline & \multicolumn{2}{|c|}{2002} & \multicolumn{2}{|c|}{2013} & \multicolumn{2}{|c|}{ Decomposition } \\
\hline & Average & Coefficient & Average & Coefficient & Structure effects & $\begin{array}{c}\text { Changes in relative } \\
\text { chances } \\
\text { of purchasing }\end{array}$ \\
\hline $\begin{array}{l}\text { Inheritance or gift assis- } \\
\text { tance }\end{array}$ & 0.08 & $0.408^{\star \star \star}$ & 0.07 & $0.384^{\star \star *}$ & & \\
\hline Ages $25-29$ & 0.20 & $-0.157^{\star \star \star}$ & 0.22 & $-0.075^{* \star *}$ & $-0.002(\mathrm{~ns})$ & $0.017^{* \star \star}$ \\
\hline Ages 30-34 & 0.25 & $-0.077^{\star \star *}$ & 0.24 & $-0.025(\mathrm{~ns})$ & $0.001(\mathrm{~ns})$ & $0.012(\mathrm{~ns})$ \\
\hline \multicolumn{7}{|l|}{ Ages 35-39 (ref.) } \\
\hline Ages 40-44 & 0.25 & $0.072^{\star \star \star}$ & 0.30 & $0.043^{\star * *}$ & $0.003^{\star \star *}$ & $-0.008^{\star \star *}$ \\
\hline Paris & 0.15 & $-0.076^{\star \star \star}$ & 0.17 & $-0.003(\mathrm{~ns})$ & -0.001 (ns) & $0.012^{\star *}$ \\
\hline Large cities & 0.32 & $-0.064^{* * *}$ & 0.37 & $-0.056^{* \star *}$ & $-0.003^{* * *}$ & $0.003(\mathrm{~ns})$ \\
\hline \multicolumn{7}{|l|}{ Medium-sized cities (ref.) } \\
\hline Rural & 0.20 & $0.162^{* \star *}$ & 0.14 & $0.242^{\star \star *}$ & $-0.012^{* * *}$ & $0.014^{* * *}$ \\
\hline Single-parent families & 0.26 & $-0.081^{* \star *}$ & 0.31 & $-0.049^{*}$ & $-0.003^{\star \star}$ & 0.009 (ns) \\
\hline \multicolumn{7}{|l|}{$\begin{array}{l}\text { Couples without children } \\
\text { (ref.) }\end{array}$} \\
\hline Lone individuals & 0.19 & $-0.078^{* * *}$ & 0.23 & $-0.065^{\star \star *}$ & $-0.003^{\star * *}$ & $0.003^{\star \star *}$ \\
\hline Couples with children & 0.48 & $0.087^{\star * *}$ & 0.37 & $0.075^{\star \star}$ & $-0.009^{* * *}$ & $-0.005(\mathrm{~ns})$ \\
\hline Constant & & $0.216^{\star \star \star}$ & & $0.13^{* * *}$ & & $-0.086^{*}$ \\
\hline Total ownership rate & 0.22 & & 0.16 & & -0.03 & -0.03 \\
\hline
\end{tabular}

Note: cf. Table A2-1.

Coverage: First standard of living quartile in households whose reference person is between ages 25 to 44 , excluding students, residing in mainland France, years 2002 and 2013

Sources: Insee, Housing surveys 2002 and 2013.

Table A2-4

Decomposition of changes in ownership rate in the last standard of living quartile, 2002-2013, taking into account family transfers

\begin{tabular}{|c|c|c|c|c|c|c|}
\hline & \multicolumn{2}{|c|}{2002} & \multicolumn{2}{|c|}{2013} & \multicolumn{2}{|c|}{ Decomposition } \\
\hline & Average & Coefficient & Average & Coefficient & Structure effects & $\begin{array}{c}\text { Change in relative } \\
\text { chances } \\
\text { of purchasing }\end{array}$ \\
\hline $\begin{array}{l}\text { Inheritance or gift assis- } \\
\text { tance }\end{array}$ & 0.20 & $0.149^{\star \star \star}$ & 0.24 & $0.119^{\star \star *}$ & & \\
\hline Ages 25-29 & 0.16 & $0.53^{* * *}$ & 0.14 & -0.097 (ns) & $0.007^{* *}$ & 0.001 (ns) \\
\hline Ages 30-34 & 0.25 & $0^{* * *}$ & 0.24 & $-0.102^{\star * \star}$ & 0.001 (ns) & $-0.004(\mathrm{~ns})$ \\
\hline Ages 35-39 (ref.) & & & & & & \\
\hline Ages 40-44 & 0.32 & $0.26^{* \star *}$ & 0.36 & $0.637^{\star \star *}$ & $0.003^{* *}$ & $-0.01(n s)$ \\
\hline Paris & 0.33 & $-0.28^{\star \star \star}$ & 0.30 & $0^{* \star *}$ & $0.004^{* *}$ & $-0.029^{* *}$ \\
\hline Large cities & 0.27 & $-0.101^{\star * *}$ & 0.28 & $0^{* \star *}$ & $-0.001(\mathrm{~ns})$ & -0.01 (ns) \\
\hline Medium-sized cities (ref.) & & & & & & \\
\hline Rural & 0.17 & $-0.125^{\star \star *}$ & 0.18 & $-0.284^{* * *}$ & $0.001(\mathrm{~ns})$ & $-0.001(\mathrm{~ns})$ \\
\hline Single-parent families & 0.02 & $-0.071^{\star \star \star}$ & 0.02 & $-0.094^{\star \star \star}$ & 0 (ns) & $-0.002(\mathrm{~ns})$ \\
\hline Couples without children (ref.) & & & & & & \\
\hline Lone individuals & 0.22 & -0.065 (ns) & 0.20 & $-0.08^{\star * *}$ & 0.002 (ns) & $-0.001(\mathrm{~ns})$ \\
\hline Couples with children & 0.51 & $-0.099^{* * *}$ & 0.53 & $-0.054^{* *}$ & 0.004 (ns) & 0.008 (ns) \\
\hline Constant & & $0.158^{* * *}$ & & $0.122^{\star * \star}$ & & $0.107^{\star *}$ \\
\hline Total ownership rate & 0.57 & & 0.66 & & 0.03 & 0.06 \\
\hline
\end{tabular}

Note: cf. tableau A2-1

Coverage: Fourth standard of living quartile in households whose reference person is between ages 25 and 44 excluding students, residing in mainland France, years 2002 and 2013.

Sources: Insee, Housing Surveys 2002 and 2013. 
Table A2-5

Summary of the decomposition of changes in ownership rates in the first and last quartile of living standards, 2002-2013, with or without the variable "gift assistance or inheritance"

\begin{tabular}{|c|c|c|c|c|}
\hline & \multicolumn{2}{|c|}{ Q1 (2002-2013) } & \multicolumn{2}{|c|}{ Q4 (2002-2013) } \\
\hline & $\begin{array}{l}\text { With the variable } \\
\text { "gift assistance } \\
\text { or inheritance" }\end{array}$ & Without the variable & $\begin{array}{l}\text { With the variable } \\
\text { "gift assistance } \\
\text { or inheritance" }\end{array}$ & Without the variable \\
\hline & \multicolumn{4}{|c|}{ Ownership rate } \\
\hline 2002 & \multicolumn{2}{|c|}{22.1} & \multicolumn{2}{|c|}{57.3} \\
\hline 2013 & \multicolumn{2}{|c|}{15.7} & \multicolumn{2}{|c|}{66.2} \\
\hline Gap & \multicolumn{2}{|c|}{-6.4} & \multicolumn{2}{|c|}{8.9} \\
\hline & \multicolumn{4}{|c|}{ Explained and unexplained share } \\
\hline Explained & 52.0 & 50.8 & 36.9 & 24.2 \\
\hline \multirow[t]{2}{*}{ Unexplained } & 48.0 & 49.2 & 63.1 & 75.8 \\
\hline & \multicolumn{4}{|c|}{ Decomposition of explained share } \\
\hline $\begin{array}{l}\text { Inheritance } \\
\text { or gift assistance }\end{array}$ & 9.6 & & 35.8 & \\
\hline Ages 25 to 29 & 6.7 & 7.4 & 21.9 & 33.5 \\
\hline Ages 30 to 34 & -1.8 & -1.8 & 4.0 & 5.9 \\
\hline Ages 35 to 39 (ref.) & & & & \\
\hline Ages 40 to 44 & -8.2 & -9.4 & 8.5 & 13.2 \\
\hline Paris & 2.1 & 2.6 & 12.2 & 18.2 \\
\hline Large cities & 10.0 & 10.9 & -3.2 & -4.4 \\
\hline Medium-sized cities (ref.) & & & & \\
\hline Rural & 34.9 & 39.9 & 3.3 & 4.8 \\
\hline Single-parent families & 9.6 & 11.7 & -0.2 & -0.4 \\
\hline Couples without children (ref.) & & & & \\
\hline Lone individuals & 8.9 & 9.7 & 5.6 & 9.4 \\
\hline Couples with children & 28.1 & 29.1 & 12.2 & 20.0 \\
\hline Total & 100 & 100 & 100 & 100 \\
\hline
\end{tabular}

Coverage: First and fourth standard of living quartile in households where the reference person is between ages 25 and 44, excluding students, residing in mainland France.

Sources: Insee, Housing surveys 2002-2013. 


\section{TRENDS IN GIFT ASSISTANCE AND INHERITANCES RECEIVED BY HOMEOWNERS FROM THE 1998 AND 2014 HOUSEHOLD WEALTH SURVEYS}

Insee's Household Wealth surveys allow to confirm the findings of the Housing surveys on the growing importance of the role of intergenerational transfers, by extending the period before 2002. The Household Wealth surveys from 1998 and 2014(i) can be used to this end. However, since these surveys contain significantly fewer observations than the Housing surveys ${ }^{(i i)}$, the degree of precision is reduced, particularly on a subsample such as young households broken down into standard of living quartiles. Thus, rather than computing breakdowns of the same type as those carried out with the Housing surveys, we put in parallel, in Figure A3-I, the trends in ownership rates and in gift assistance and inheritances received by homeowners.

(i) It is only possible to calculate a household standard of living for the 1998 to 2014 surveys, as only income brackets are available in previous years. (ii) About 10,000 households in mainland France in the Household Wealth surveys, as compared to 40,000 in the Housing surveys

Figure A3-I

\section{Trends in gift assistance and inheritances received by owners (based on Household Wealth surveys)}

$80 \%$

First quartile

Last quartile

$70 \%$

$60 \%$

$50 \%$

$40 \%$

$30 \%$

$0 \%$

$$
\begin{aligned}
& \text { Gift assistance or inheritances } \\
& \text { received by owners }
\end{aligned}
$$

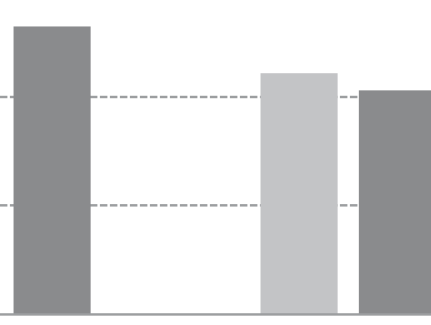

Owners

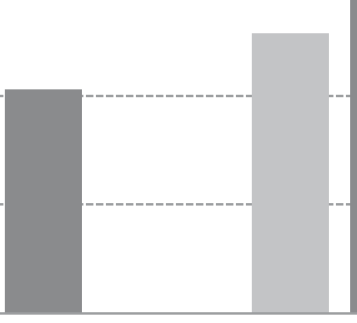

Gift assistance or inheritances received by owners

$$
\begin{array}{|l|l|}
\square 1998 \quad \square 2014 \\
\hline
\end{array}
$$

Coverage: Households whose reference person is between ages 25 and 44, excluding students, residing in mainland France. Sources: Insee, Household Wealth surveys 1998 and 2014. 


\title{
The dynamisation and subsequent vulnerability of the Dutch owner-occupied sector. An analysis of 1986-2012
}

\author{
Kees Dol* and Harry van der Heijden*
}

\begin{abstract}
This article investigates the backgrounds to changing residential mobility of Dutch owner-occupiers from 1986-2006 and during the 2008-2018 crisis. The Oaxaca-Blinder decomposition is used to disentangle the main factors at work. Households of all age groups and family types have become more mobile in 1986-2006, with the highest increase amongst the youngest age groups. Nonetheless, ageing of owner-occupiers has dampened the growth between 1986 and 2006, because older owner-occupiers usually move less frequently than younger age groups. Had this ageing process not taken place, the overall increase in mobility would have been much higher (about 3.5 percentage points) than the 1.4 percentage point observed. The overall compositional effect remains negative despite a shift from traditional families with children towards more singles and couples without children, who are more mobile. During the crisis of 2008-2012, high residential mobility rates amongst the young age groups took a sharp negative turn. Combined with their increased presence among owner-occupiers, this implies that the contemporary Dutch owner occupied sector is more vulnerable to economic shocks.
\end{abstract}

JEL Classification: R21, R31

Keywords: residential mobility, owner-occupation, housing systems

Reminder:

The opinions and analyses in this article

are those of the author(s)

and do not

necessarily reflect

their institution's

or Insee's views.
*Delft University of Technology, Faculty of Architecture and the Built Environment (c.p.dol@tudelft.nl; h.m.h.vanderheijden@tudelft.nl)

Received on 12 June 2017, accepted after revisions on 13 June 2018 
$\mathbf{T}$ he Dutch owner-occupied housing sector has grown substantially in the past three decades, from about $45 \%$ of all dwellings in the mid-1980s until nearly $60 \%$ in 2015 (Statistics Netherlands, 2016). The start of the Global Financial Crisis in 2008 marked a stabilisation of the proportion of owneroccupiers. In absolute terms, the Dutch owneroccupied sector doubled from about 2.1 million units in 1986 to 4.2 million units in 2012. As a result, the characteristic Dutch housing career, where households trade up in a number of consecutive steps from smaller to larger dwellings, increasingly takes place in the owner-occupied sector. Whereas in the 1980s, typical housing careers commenced with a couple of steps in the rental sector before households entered into owner occupation, the contemporary housing career usually starts in the rental sector, but it continues in the owneroccupied sector at a much earlier stage in the life cycle (Feijten \& Mulder, 2002; Mulder \& Wagner, 1998). Today, an increasing proportion of households even starts their housing career in the owner-occupied sector. As Dutch housing careers have become more focused on the owner-occupied sector, the composition of the population of owner-occupiers has drastically changed. Whereas the owner-occupied sector was dominated by families with children (around 60\%) in the 1980s, this share has declined to less than $40 \%$ in 2012 . At the same time the Dutch population has aged and the large cohort of baby boomers, who were the first generation of "new home owners" in the 1970s and 1980s, are currently in their late fifties and early sixties (see for example Blijie et al., 2013; Helderman, 2004). Many baby boomers are currently empty nesters, also impacting on a higher share of households without children in their household.

There is a general agreement that housing careers of contemporary Dutch owneroccupiers involve more residential moves and therefore more dynamism exists in the individual housing histories of new generations of owner-occupiers. However, the question arises whether the proportion of all owneroccupiers that recently moved around 2005, differs much from the proportion of recent movers in the 1980s. The motivation for a more detailed investigation emanates from the fact that alongside an influx of more young, dynamic households in the owner-occupied sector, the potential effects of demographic ageing should not be overlooked. For instance, simply because older owner-occupiers have a lower propensity to move than their younger counterparts, ageing of a significant share of owner-occupiers has the potential to negatively affect the overall percentage of owneroccupiers that have moved recently. In this article, such factors are referred to as "compositional effects". We explicitly state that compositional changes, such as population ageing, have the potential to negatively affect the overall percentage of owner-occupiers that have moved recently. Another main factor to take into account is that population cohorts behaviour can change over time, i.e. "behavioural effects". For instance, contemporary (older) owner-occupiers may have a higher chance of having moved recently than their counterparts of the 1980s, which would materialise into more dynamism in the owner-occupied sector.

We also aim to investigate a second theme that is related to the particular evolution of the Dutch owner-occupied housing market. As indicated, contemporary Dutch households enter the owner-occupied sector at a younger age, on average, than their counterparts in the 1980s. While Dutch households of the 1980s usually lived in a rental dwelling for a prolonged time before buying a singlefamily dwelling for long time residence, today a sequence of relatively short residences in an owner-occupied apartment is not unusual for young households. High leverage (mortgaged loans) among young households has become a characteristic of the new dynamic market, which has the potential to make it more vulnerable to economic crises than the "traditional system". The main argument behind this is that the sequences of residential moves in the earlier life course can be obstructed, because of the risk of a remaining debt (Van der Heijden et al., 2011). We aim to investigate in more detail the vulnerability of the contemporary Dutch owner-occupied housing system during the recent crisis of 2008-2013.

The article is organised as follows. The next section provides the theoretical backgrounds to the typical Dutch owner-occupied housing market and compares it to some other countries. Then section 3 elaborates on the quantitative methodology and the data which are used. In section four we present the results and section five reflects on the main findings.

\footnotetext{
1. We rather not use "cohort effect" because it might refer to either behavioural or compositional effects or both. 


\section{Theoretical backgrounds}

In this literature review, we first deal with a more detailed description of the formation of a "dynamic" owner-occupied sector in the Netherlands as opposed to the more "static" system in several other countries. Did mobility in the owner-occupied sector increase as a result of changes in the behaviour of owneroccupiers? We draw on the Structure of Housing Provision approach as developed in the late 1980 s by researchers who analysed variations in international housing systems. Then we continue with an overview of the relation between household characteristics and mobility. This will assist in analysing the effects of changing demographic composition on mobility in the Dutch owner-occupied sector. These insights are based on the research schools that link residential mobility (and migration) to the career and life course perspective.

\section{The Dutch owner-occupied housing market in an international perspective: Static versus dynamic}

From the early 1980s and onwards, international variations in housing systems in the Western World sparked interest in the academic community. It led to detailed comparative analysis of housing policy systems (for example Boelhouwer \& Van der Heijden, 1992), while explanations of differences in tenure status across countries were put forward referring to national political ideologies and welfare regimes, with the most notable contributions by Kemeny $(1992,1995,2006)$. Another branch of research focused more on an analysis of the way that housing is provided. This body of research became known as the Structure of Housing Provision (SPH) approach, which investigated the role of all (social) actors involved in housing provision (Ball et al., 1988; Martens, 1990; Barlow \& Duncan, 1994). As such, the SPH approach has provided detailed overviews of those political-economic structures that finance, subsidise and build dwellings in the different tenures. It departs from the idea that there are no universal ways of housing provision and all national systems need to be scrutinised individually. Based on the work of Ball et al. (1988) and Martens (1990), Van der Heijden et al. (2011) propose two ideal-typical systems in the owner-occupied sector. The first one is a system with a relatively low degree of mobility in the owner-occupied sector. This is connected to an owner-occupied housing provision practice where prospective home owners buy a plot of land and hire an architect and subcontractors to design and build the dwelling; hence the term "self-provided" or self-commissioned housing. In most cases this involves building detached dwellings on plot of land. In case the household needs more space, a move is often not necessary because the house can be modified. In sum, new construction is targeted primarily towards first time buyers and a great part of the household's housing career can take place within one single dwelling. As a consequence, housing careers in the owner-occupied sector will involve only one or two moves. In this kind of market, owner-occupied dwellings are regarded as consumer goods. Because household mobility is rather low and housing construction in the owner-occupied sector is largely targeted towards first time buyers, the influence of economic trends on the housing market will be relatively limited. Such systems of owner-occupied housing provision are found in Germany, Belgium and France (Barlow \& Duncan, 1994; Van der Heijden et al., 2011). Based on the relative immobility in these owner-occupied sectors, Van der Heijden et al. (2011) refer to "static" owneroccupied housing systems. However, we need to emphasize that this does not by any means assume that all static systems are similar. The structure of the Belgian and the German owner-occupied housing system can both be characterized as "static", but the overall housing system in Germany is dominated by private rental and families move to their detached dream house when they are in their late thirties, whereas Belgians often start in a selfprovided (or renovated) detached dwelling at a much younger age.

In the second system, the dynamic owneroccupied market, there is much more mobility of owner-occupiers, which can be linked to a specific form of owner-occupied housing provision. The provision of new owner-occupied housing takes place through speculative developers, who buy land, draw up a housing plan, commence building and sell the dwellings; hence speculative developers. They mostly build dwellings at the upper end of the market, where the margins are greater, because affluent consumers tend to buy more spacious dwellings with more luxury materials and equipment. The newly constructed dwellings are mostly bought by people who move in from a smaller existing owner-occupied dwelling. Thus, via upward mobility on the "housing 
ladder" in existing owner-occupied dwellings, the construction of new dwellings at the upper end of the market ultimately results in an existing dwelling becoming available for a first-time buyer at the lower end of the market (Van der Heijden et al., 2011). This process leads to relatively high levels of mobility and a large number of transactions of existing owner-occupied dwellings.

Van der Heijden et al. (2011) argue that it is likely that a dynamic owner-occupied system is sensitive to economic cycles because it relies on households who already own a good dwelling to move to a larger, more expensive property. In case of economic prosperity, many households who reaped the economic benefits from such an upturn may aim to make another step onto the housing ladder and buy another, more spacious and/or luxury dwelling. Rising house prices, or the expectation of further increases in the price of owneroccupied dwellings, stimulates the demand for such properties and fuels the number of transactions, because it can lead to a high return on investment. During an economic downturn, however, mobility can be severely affected because households anticipate on downward house prices, so they delay their move. As a result, fewer dwellings are sold, mobility decreases and eventually house prices will fall. Especially the upper end of the market will be hit hard. The declining demand from households that normally make a "luxury" move to a newly constructed dwelling at the upper end of the market, impacts on investment decisions by speculative housing developers. Housing production in the owner-occupied sector will decrease substantially and the remaining production will be targeted more to first time buyers.

The owner-occupied housing markets of the UK and the Netherlands are dynamic in character. In the Netherlands the formation of this dynamic system started during the 1970s, when increasing prosperity allowed new middle classes to access the owner-occupied market and the share of owner-occupied housing within the Dutch housing stock increased from around $40 \%$ in the mid- 1980 s to $55 \%$ in 2005 (Ministerie BZK, 2010). In the mid-1980s, the starting point of our research (because of data availability), there were already signs of more dynamism (housing ladders) and this developed further during the 1990s and 2000s. The period from the mid-1980s until the start of the economic crisis in 2008 was characterized by rising house prices and increasing numbers of transactions of existing dwellings (Ministerie $\mathrm{BZK}, 2010)$. This increase in the number of transactions can partly be explained by the growth of the owner-occupied sector. But even when we correct for this growth by looking

\section{Figure I \\ Transactions of existing owner-occupied dwellings as a percentage of the stock of owner-occupied housing in the Netherlands, 1985-2016.}

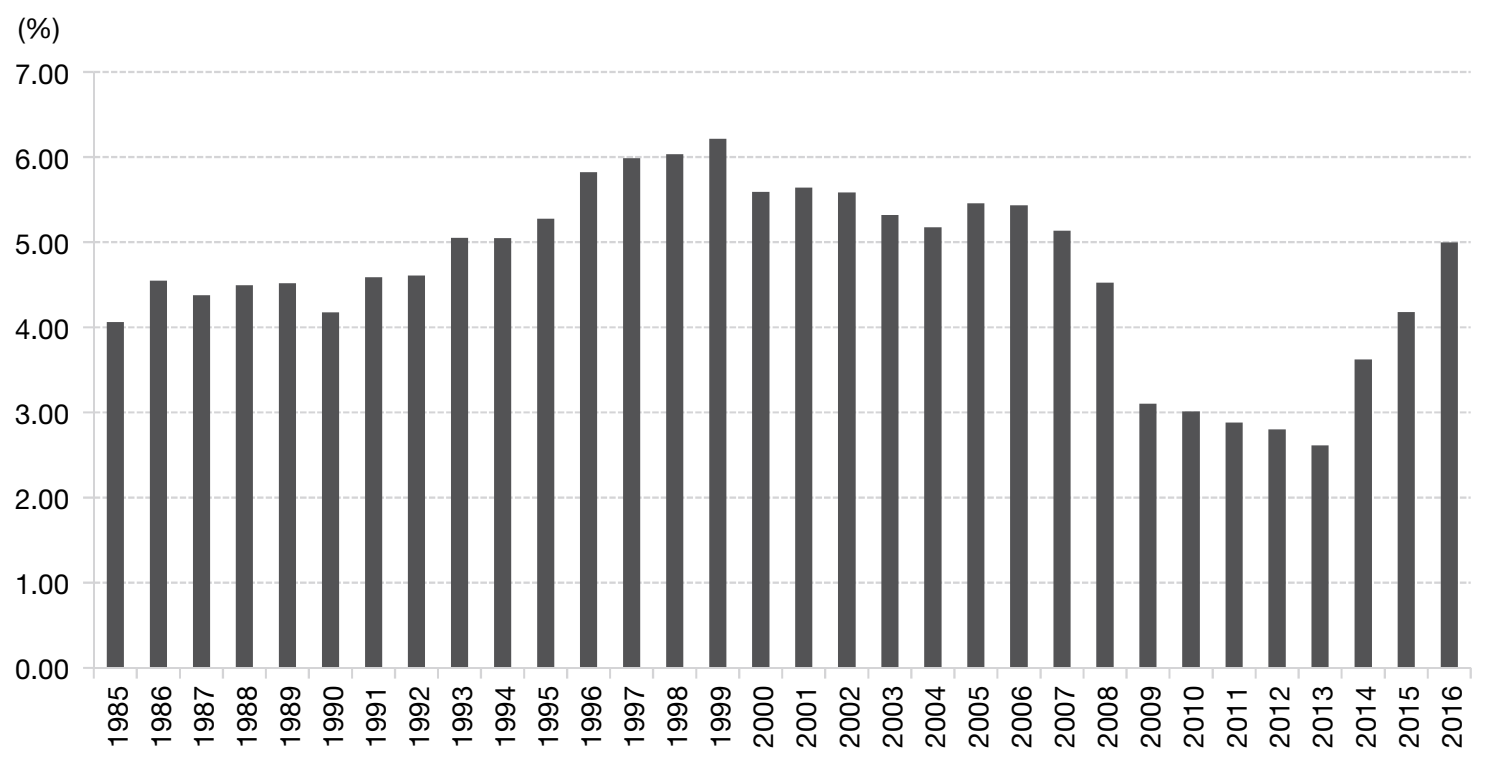

Source: CBS (Statistics Netherlands); Kadaster; NVM; authors' calculations. 
at the percentage of existing owner-occupied dwellings that was sold per year (Figure I), it is clear that mobility increased since the mid-1980s until the start of the economic crisis in 2008. During the crisis mobility fell sharply but since 2014 the owner-occupied housing market is recovering from the crisis.

During the economic crisis, housing production in the Netherlands fell from nearly 80,000 dwellings in 2008 to less than 50,000 dwellings in 2013 (Statistics Netherlands). Within the production of owner-occupied housing, the focus of housing developers changed from the more expensive dwellings to cheaper dwellings, targeted towards first time buyers (Figure II). In recent years, the focus has changed back, towards the production of more expensive dwellings again.

The question is whether the dynamisation of the Dutch owner-occupied housing system has been caused by changes in the behaviour of owner-occupiers, in the sense that they have become more mobile through time. For instance, it addresses the question to what extent older households behaved differently in the 1980s than older households in the 2000s.

Another main question is whether the growth and dynamisation of the Dutch owner-occupied sector been caused by an influx of specific household types who are more mobile than traditional owner-occupiers (i.e. families with children). If this is the case, the increase of residential mobility might be explained by a greater presence of these new groups on the market for owner-occupied housing. We will discuss the relation between household characteristics and residential mobility in the next section.

\section{Residential mobility and the life course}

In the past two decades, researchers have accumulated a vast body of literature on residential mobility. From the early 1990s the residential mobility literature has used the sociological notion of life courses (see for example Mulder, 1993; Mulder \& Hooimeijer, 1999; Feijten \& Mulder, 2002). It acknowledges that household change/events and employment careers strongly relate to housing careers. Whereas the traditional household and employment careers were highly predictable in the post war era, they have become more fragmented in the recent decades and this reflects in more diverse housing careers (Beer \& Faulkner, 2011). Despite this fragmentation, it is still possible to identify a number of relatively standardised household and housing careers,

Figure II

Transactions of newly build owner-occupied dwellings by price segment in the Netherlands, 2005-2017

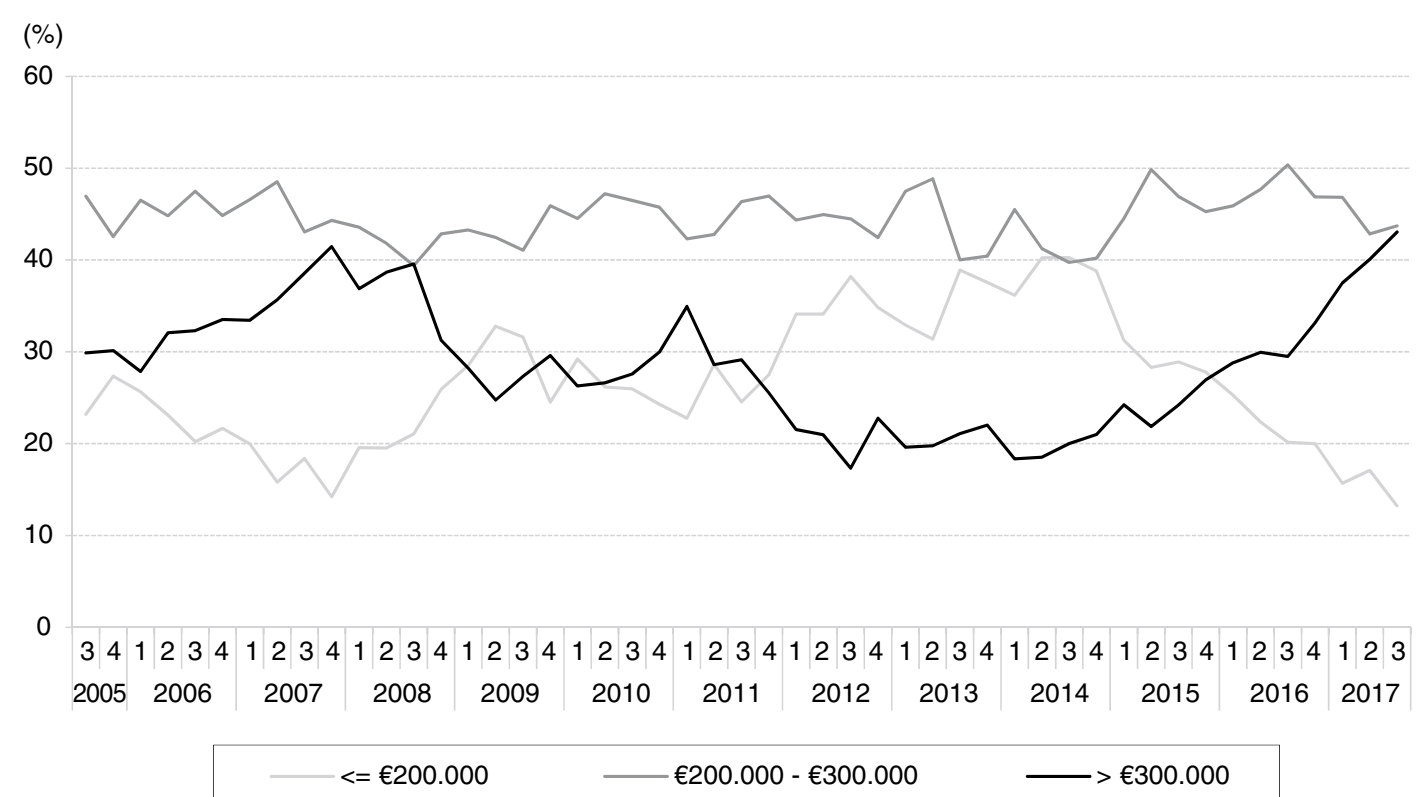

Source: Monitor newly build dwellings (Neprom, NVB). 
but there are now also many more individualised trajectories. For instance, Clark et al. (2003), using detailed longitudinal datasets for the USA, found that about $75 \%$ of all housing careers fall within 11 (standard) trajectories, while the other $25 \%$ are much more diverse. For the Dutch situation, such studies have not been performed, due to lack of long time longitudinal data, but there is a substantial body of literature on cross sectional data and this clearly shows that propensities to move vary by household characteristics. In case the demographic make-up, i.e. household characteristics of the Dutch owner-occupiers change, this may partly explain changes in residential mobility. In other words, are changes in the overall propensity of home owners mobility explained by "compositional effects"? For the Dutch (and other) context, the main findings are that age is negatively related to the propensity to move. Furthermore, household characteristics are relevant. The literature shows that family-couples with children often have relatively small chances to move as they are often in a stable phase of the life course (see for example Helderman et al., 2004). Indeed, decisions of residential moves may be difficult to make since they involve all the family. For singles, such decisions are easier made. Income can be regarded as another important factor in residential mobility. For those that wish to trade up within the owner-occupied sector to another larger dwelling, sufficient income is an important condition. There is also a theoretical relation between educational levels and the propensity to move. Those households with higher education might have a much broader geographical search field because their employment search field is also broader than less educated people for whom it may be difficult to find adequate jobs locally (Green $\&$ Shuttleworth, 2015).

In the Netherlands, home ownership has increased and a larger part of the entire housing career of households now takes place in the owner-occupied sector. Many young single households now live in owner-occupied apartments, rather than in a rental apartment. Also, older people who move out of a (large) single family dwelling, now live in an owneroccupied apartment. Given the variation on the propensity to move by household characteristics, this demographic transformation of the last decades in the Dutch owner-occupied sector may well have impacted on residential mobility in this sector.
Similar to Cooke (2011), we will analyse both the compositional and behavioural effects on residential mobility among Dutch home owners over the long run. In a second step, we turn to the short-term effect and investigate the mechanisms that lead to the massive decline of mobility within the typical Dutch "dynamic" housing market during the last crisis.

\section{Methodology}

The first objective of this article is to investigate to what extent the more dynamic housing careers of the new generations that entered the Dutch owner-occupied sector materialise into significantly higher rates of recent moves of the total population of owneroccupiers. As elaborated in the introduction, two main factors are at play here: composition and behaviour. While an influx of more "dynamic" households, such as young people in the early phases in their housing career, might have caused a larger proportion of recent moves amongst the population of owneroccupiers, demographic ageing of a large group of owner-occupiers may have had a dampening effect. These are the compositional effects as a result of changes in the composition of the population of owner-occupiers. The second main factor that might influence the proportion of households that recently moved, relates to changes in behaviour. For instance, the cohorts of older households of the 1980s may well have been much less mobile than their "modern" counterparts of the early 2000s. Furthermore, younger households who currently move into the owner-occupied sector often opt for relatively short residences in apartments, while their counterparts of the 1980s usually bought a single-family dwelling with the intention of a long-time residence.

A much-used method in economics to disentangle compositional and behavioural effects is the so-called "Oaxaca-Blinder" decomposition method. It was designed to explain gender and racial wage differences by using micro level data (Blinder, 1973; Oaxaca, 1973). The method can also be used for the analysis of change over time, using cross-sectional micro level data at two points in time. Of course, different points in time need to have sufficient distance because, most often, the composition of a population does not change a great deal over the shorter run, even over ten years. Over the past four decades, statistical agencies in several countries have accumulated 
a series of cross section micro databases on housing and residential mobility. This now offers the possibility to perform an analysis over a longer period of time. Examples are an analysis of long distance migration trends in the USA (Cooke, 2011) and the tenure shift in New Zealand (Bourassa \& Shi, 2017), but such studies are still rare. However, one drawback of the Oaxaca-Blinder method is that it is only fit for using micro level data and it cannot include external effects such as fluctuations in the GDP and or interest rates ${ }^{2}$. Changes in external effects when comparing data from different years may affect the behavioural component, then making it difficult to characterize long-term trends of residential mobility (cleared of external factors). Therefore, we need to carefully select two databases in times that compare in terms of overall economic development (Box).

As mentioned earlier, the second objective of this study is to explore in more detail the vulnerability of the contemporary (particular) Dutch owner-occupied sector to economic crisis (Van der Heijden et al., 2011). Here we just compare a cross section from around 2005 with the era shortly after the start of the crisis. The composition of the population will not have changed much in such a short time, so comparing two separate regression models in order to investigate which household types were most affected in terms of residential mobility can be regarded as sufficient.

We now turn to the presentation of the Oaxaca-Blinder method. As indicated we will investigate the entire proportion of owneroccupiers that moved in the past two years. This proportion is denoted as $Y$. We want to separate, in the difference between the proportions having moved in the past two years between 1986 and 2006, whether this is related to changes in the composition of the population of owner-occupiers and/or to changes in their behaviours. $Y$ is estimated separately for 1986 and 2006; $X$ is a vector of observable

2. This will be clear when the method is presented.

\section{Box - Data and variables}

The Dutch national institution responsible for statistics (Statistics Netherlands) has been conducting a housing survey every three to four years since 1981 (National Housing Demand survey, WBO, before 2006, then Netherlands' Housing survey, WoON). The data include detailed information on housing and household characteristics. It also provides information on the previous dwellings of recent movers, whether the household intends to move, and housing preferences. In the article, residential mobility refers to "recent moves", that is, residential moves occurred within the two past years for households who are owner-occupiers at the time of survey. The data are based on household interviews, but since 2006, more information has been added from register data. This has improved the information on household income but also created some problems for comparisons with previous datasets.

The first part of the analysis aims to disentangle compositional and behavioural effects of the change in residential mobility of home owners in the long run. Here we need to find two years that are comparable in terms of economic circumstances (see the section on methodology). We are aware that it is impossible to find a perfect match in terms of economic situation. However, we assess that the economic background is quite comparable between the data of 1986 and 2006. In both periods the Dutch economy (and house prices) was recovering after an economic slowdown and GDP growth reached levels between $2 \%$ and $3 \%$. The notion of "recent moves" referring to moves occurred in the past two years, so the 1986 data refer to residential moves occurred in 1984-1985; for the 2006 dataset, it refers to moves occurred in 2003-2004 because the year 2005 was not fully covered.

Selecting the years was less complicated for the second part of the analysis. We used the data from 2006 and compare it with the data from 2012, when the economic crisis had resulted in a massive decline of housing transactions in the owner-occupied sector (see also Van der Heijden et al., 2011).

The analysis retains the main household characteristics that the literature has regularly found to have significant effects (age, household type, income) on mobility. We use age groups rather than the continuous age variable (age of the household head) because it can be more informative on the behaviour of cohorts over time. For the household income, we had the problem of the change in data collection in 2006. Therefore, we constructed income quintiles (based on the income distribution of the entire household population) rather than use the detailed income values. This also avoids to have to adjust for inflation. Furthermore, the 1986 database only provides net household incomes, while the later databases contain disposable incomes. Some caution is thus needed, but using quintiles improves the comparability to a great extent. 
characteristics (structure by age group, household type and income), $\beta$ is the vector of the estimated coefficients, that is, the effect of given characteristics on having moved, analysed as related to behaviour.

The difference, between 1986 and 2006, in the estimated probability of having moved can be written as follows:

$$
\bar{Y}_{2006}-\bar{Y}_{1986}=(\alpha+\hat{\beta} \bar{X})_{2006}-(\alpha+\hat{\beta} \bar{X})_{1986}
$$

Without going into the details of the mathematical elaboration, this is developed into the final form of the Oaxaca-Blinder decomposition (see Jann, 2008):

$$
\begin{aligned}
\bar{Y}_{2006}-\bar{Y}_{1986} & =\left(\bar{X}_{2006}-\bar{X}_{1986}\right) \hat{\beta}_{1986} \\
& +\bar{X}_{1986}\left(\hat{\beta}_{2006}-\hat{\beta}_{1986}\right) \\
& +\left(\bar{X}_{2006}-\bar{X}_{1986}\right)\left(\hat{\beta}_{2006}-\hat{\beta}_{1986}\right)
\end{aligned}
$$

The first part corresponds to the compositional effect, where the effects of changes in the population structure (composition) are calculated keeping behaviours (the $\beta$-parameters) constant. The second part represents the behavioural effect, that is, the effect of changes in the $\beta$-parameters, calculated keeping the population structure constant. The third part corresponds to interaction effects, or in other words, it shows whether changes in the population structure correlate with changes in behaviour. However, interactions can be quite complicated to interpret in these particular models. As such, a first step is to investigate whether the interaction effects are relevant at all and if not (which they are often), we proceed with a model without an interaction term.

Furthermore, we estimate a linear probability model rather than a commonly used logistic regression model. An overriding motive for many researchers to use a logistic regression model is that it avoids predicted outcomes potentially falling outside the 0 to 1 dichotomy. But the use of logistic regressions as soon as the dependent variable is a binary variable has been increasingly debated (see e.g. Hellevik, 2009). The main advantage of the linear probability model is the ease of interpretation, which is certainly relevant in our study with the Oaxaca-Blinder decomposition method, because it produces more complex output in the form of both compositional and behavioural effects.

A second main drawback of the linear probability model is that variance is related to the value of the independent variable(s). This implies heteroscedasticity, which can lead to biased standard errors and p-values. While we are mainly interested in the coefficients' patterns and do not aim to find a strong model to be used for scenario building or as input for other models, we need to know the precision of the estimated coefficients and their statistical significance. At any rate, heteroscedasticity has no consequence on the predicted coefficients, but the tests of significance may be affected (see for instance Hellevik, 2009). A common way of dealing with heteroscedasticity is to construct weights (i.e. larger weights for smaller predicted values and vice versa $^{3}$ ) and run a Weighted Least Squares (WLS) regression. The drawback is that such weights potentially change the estimated coefficients of the original model. Our approach is to estimate WLS models in order to investigate whether the significant predicted values are not too much influenced by heteroscedasticity and if so, we will warn about this.

Finally, we use a deviation model for the categorical variables. Indeed, with categorical variables, one of the categories must be omitted (the reference) to avoid collinearity. However, the choice of the reference category may affect the estimation of behavioural effects in the Oaxaca-Blinder detailed decomposition (cf. Jann, 2008). Using a deviation model (where the sum of the coefficients is constrained to zero and the coefficients are expressed as a deviation from the mean effect) avoids this.

\section{Results}

As mentioned earlier in the introduction, the percentage of owner-occupiers increased rapidly from the 1980s and onwards (Table 1). The rental sector declined in relative terms but remained stable in absolute terms at 3.0 million dwellings. The main factors behind the increase of owner-occupation were a change in the policy focus from widespread support of the (social) rental sector with large scale building programs, towards the owner-occupation sector. Whereas "brick \& mortar" and operations subsidies for social rental dwellings

3. In fact, the database already includes a weight factor. 
were virtually abolished in the $1990 \mathrm{~s}$, owner-occupiers were able to benefit from a very generous tax relief on paid mortgage interest. Under these conditions, the private rental sector, which did not benefit from any government support, has not been considered a viable alternative for many households. Furthermore, changing household preferences, as a result of increasing prosperity, focused more on single family (terraced) houses with gardens. In the last decade, Dutch governments have increasingly restricted access to the (affordable) social rental sector because they fear that it creates an unbalanced playing field for market parties, especially those parties that invest in the private rental market. At the same time, there is still a great unbalance between the unsubsidized private rental sector and the heavily fiscally stimulated owneroccupied sector, which either draws or pushes many households into owner-occupation.

As our main objective is to analyse the change in the proportion of owner-occupiers that recently moved, we first give an overview of this change. Overall, Table 2 shows that the percentage of recently moved owner-occupiers has increased from 1986 to 2006, but it is not dramatically higher. With regard to the shorter term, where the backgrounds to the sensitivity of the Dutch owner-occupied system to a (housing) crisis will be investigated, the main indicator in Table 2 is quite straightforward. The percentage of recent moves in the owneroccupied sector has declined by about $30 \%$. In fact, the decline is greater, when compared to the transaction levels at the height of the real estate boom in 2007 (Figure 3).

As a first step towards the Oaxaca-Blinder decomposition, Table 3 gives information on the changing composition of the population of owner-occupiers. As mentioned in the introduction, the dominance of traditional families with children has altered drastically in favour of single persons, couples and single parent households. Ageing of the Dutch population is also visible in the data for owner-occupiers 1986 and 2006. With regard to income distributions in the owner-occupied sector, 1986 and 2006 show a somewhat striking difference. Overall, home ownership has become more concentrated in the middle classes (quintiles 3 and 4), while the lowest quintile shows a marked decline. However, it needs to be noted that owner-occupation levels have increased among all household types, except for the very lowest income quintile. So, for young households (20-34), the percentage of owner-occupiers increased from about $35 \%$ to nearly $50 \%$ and for the age groups between 35 and 65 it increased from nearly $50 \%$ to

Table 1

Tenure structure of Dutch households

\begin{tabular}{|l|c|c|c|}
\hline & \multicolumn{2}{|c|}{$($ In \%) } \\
\hline Owner-occupied & 1986 & 2006 & 59 \\
Rental & 43 & 56 & 41 \\
Total & 57 & 44 & 100 \\
\hline Total (units) & 100 & 100 & $7,140,758$ \\
\hline
\end{tabular}

Coverage: Households living in private homes (excluding special types of housing such as houseboats).

Sources: CBS (Statistics Netherlands), Housing surveys WBO 1986, WoON 2006; authors' calculations.

Table 2

Households that recently moved*

\begin{tabular}{|l|c|c|r|}
\hline & 1986 & 2006 & 2012 \\
\hline In the owner-occupied sector & 10.7 & 12.1 & 8.5 \\
In the rental sector & 19.6 & 15.7 & 19.1 \\
\hline Total & 15.8 & 13.7 & 12.8 \\
\hline
\end{tabular}

Coverage: Households living in private homes (excluding special types of housing such as houseboats).

Sources: CBS (Statistics Netherlands), Housing surveys WBO 1986, WoON 2006, 2012; authors' calculations. 
well over $60 \%$. The same applies to single person and single parent households who still have relatively low chances of being home owners (circa 33\%), but it has definitively increased. An increase is also visible for the other household types and currently a vast majority of couples $(65 \%)$ and couples with children $(75 \%)$ is owner-occupier.

Although we argued earlier that many young (dynamic) people have turned to the owneroccupied sector, thereby possibly raising the proportion of recent moves, the percentage of young people in the entire owneroccupied population has declined. In fact, the large cohorts of households aged 35-44 in the 1980s, including baby boomers, are now ageing and form a major share of the population of owner-occupiers in the age group 55-64. Furthermore, there is now a much higher share of non-traditional family households, who are expected to be more mobile. However, some couples (without children) and single person households increasingly belong to the age groups above 55 years empty nesters who are usually less mobile. These general shifts in the structure of the population of owner-occupiers are thus compositional factors that can give some clue as to how residential mobility amongst owneroccupiers has changed. Behavioural changes are addressed in the next section.

\section{Analysing mobility changes between 1986 and 2006}

The results of the Oaxaca-Blinder decomposition of the overall change in recently moved owner-occupiers, can be somewhat complicated to interpret without having some basic understanding of the behavioural changes for different household characteristics. For a general overview of the changes in the behaviour per household characteristic, we run separate linear regression models for the probability to move per household characteristic for the years 1986 and 2006. Note that this is a deviation model, where the sum of the coefficients for the categories per variable is equal to zero. We highlight the largest changes in Table 4. Overall, both regression outcomes confirm that there is a negative relation between age and the propensity to move. The results also confirm that households without children have higher propensities to move. With regard to income, there is no clear pattern while the coefficients are also not significant. Such findings confirm the expectation from the theoretical framework

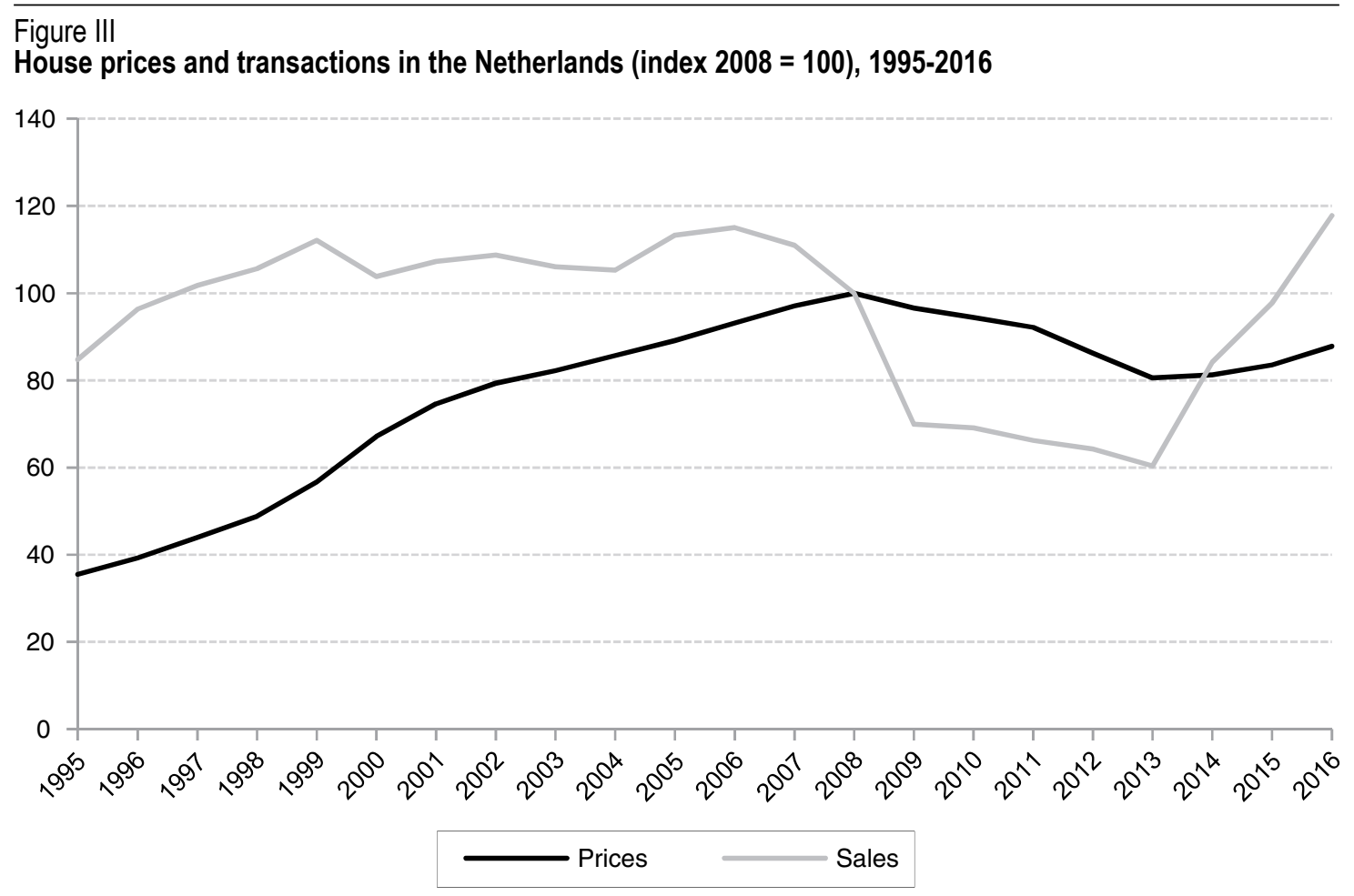

Sources: CBS (Statistics Netherlands). 
that on the one hand, a shift towards more non-family households (no children) in the owner-occupied sector potentially has a positive impact on the overall mobility level of owner-occupiers, while demographic ageing will have a negative impact.

A comparison of the estimated coefficients in the two models shows an overall increase of the chances to have moved in the past two years for virtually all household characteristics. This is visible in the rather large change in the constant, whereas most of the changes in the coefficients of the household characteristics do not "compensate" for this. The probability of having moved may have decreased for some combinations of characteristics (e.g. the association of the 65-75 age group and the type of household living alone) but, for most household profiles, an increase is visible.

As discussed earlier, a main concern regarding linear probability models is the possibility of unrealistic outcomes below 0 or above 1 . Table 4 shows that such an outcome may be true for a couple of household profiles, but such households are quite rare in practice. Furthermore, alternative estimations with logistic regression models gave comparable patterns in coefficients and significance levels. For an additional check, the main results of the Oaxaca-Blinder linear decomposition will be compared to the results of the logit decomposition as proposed by Fairlie (2005).

Tables 3 and 4 already provide some indication on the drivers of the overall change in owneroccupiers mobility; this is further analysed now with the Oaxaca-Blinder decomposition. The overall probability to move as estimated by the model is $10.25 \%$ in 1986 and increases to $12.63 \%$ in 2006 and this increase is significant (Table 5). The decomposition shows that compositional changes in the population of owner-occupiers had a negative impact on the probability to move. This is in line what

Table 3

Household characteristics of Dutch owner-occupiers

\begin{tabular}{|c|c|c|c|}
\hline & 1986 & 2006 & 2012 \\
\hline \multicolumn{4}{|l|}{ Household type } \\
\hline Single person & 15 & 20 & 22 \\
\hline Couple (without children) & 25 & 35 & 35 \\
\hline Couple with children & 57 & 41 & 39 \\
\hline Single parent & 3 & 4 & 4 \\
\hline Total & 100 & 100 & 100 \\
\hline \multicolumn{4}{|l|}{ Age group } \\
\hline $20-34$ & 22 & 16 & 14 \\
\hline $35-44$ & 30 & 27 & 23 \\
\hline $45-54$ & 21 & 25 & 26 \\
\hline $55-64$ & 18 & 20 & 24 \\
\hline $65-75$ & 9 & 12 & 13 \\
\hline Total & 100 & 100 & 100 \\
\hline \multicolumn{4}{|c|}{ Income quintiles (based on quintiles of all households) } \\
\hline Quintile 1 (lowest) & 12 & 7 & 6 \\
\hline Quintile 2 & 13 & 13 & 14 \\
\hline Quintile 3 & 19 & 20 & 22 \\
\hline Quintile 4 & 24 & 28 & 27 \\
\hline Quintile 5 (highest) & 32 & 32 & 31 \\
\hline Total & 100 & 100 & 100 \\
\hline Total owner-occupiers & $2,132,316$ & $3,778,335$ & $4,214,420$ \\
\hline
\end{tabular}

Coverage: Owner-occupier households (private homes excluding special types of housing such as houseboats).

Sources: CBS (Statistics Netherlands), Housing surveys WBO 1986, WoON 2006; authors' calculations. 
was already suspected based on Table 3 . The behavioural effect is positive and explains the general increase of the probability of Dutch owner-occupiers to move $e^{4}$. This also confirms the patterns revealed in Table 4. A further comparison of these results with a decomposition using estimates from a logistic regression (Fairlie) shows similar general results, with a negative parameter of $-1.15 \%$ for the composition part and $+3.57 \%$ for the behavioural part.

These first findings are further explored in the detailed Oaxaca-Blinder decomposition, which calculates the effects for each individual variable (see Table 6). Overall, demographic ageing has a negative effect on recent moves $(-0.0236$, all ages). This is visible for all the age categories, which is consistent with the evolutions shown in Table 3 on compositional change. Although higher proportions of younger people turn to the owneroccupied sector, the percentage of younger, more mobile owner-occupiers has substantially declined. This has a negative impact on the overall proportion of owner-occupiers that moved recently, because young owneroccupiers have higher chances of moving than their older counterparts (cf. also Table 4). The negative impact of demographic ageing on residential mobility is partly offset by a positive impact of changing household characteristics $(+0.0116)$. The main contribution comes from the relative decline of couples with children. This confirms the general assumption that a weaker domination of traditional, "immobile" family households in the Dutch owner-occupied sector lead to an overall increase in mobility. With regard to income quintiles, the structural effects are mostly not significant.

4. As indicated in the methodology section, we first tried a decomposition model with interaction effects (third part of the Oaxaca-Blinder equation). The model with interactions gives little added value and will only be shortly discussed.

Table 4

Linear regression of owner occupiers probability to have moved in the previous two years

\begin{tabular}{|l|c|c|c|c|c|}
\hline \multirow{2}{*}{20 -34 } & \multicolumn{2}{|c|}{1986} & \multicolumn{2}{|c|}{2006} & $1986-2006$ \\
\cline { 2 - 6 } $35-44$ & $\beta$-parameter & $p$-value & $\beta$-parameter & $p$-value & Difference coefficients \\
$45-54$ & 0.166 & 0.000 & 0.245 & 0.000 & 0.079 \\
$55-64$ & 0.023 & 0.000 & 0.038 & 0.000 & 0.015 \\
$65-75$ & -0.033 & 0.000 & -0.051 & 0.000 & -0.017 \\
\hline Single person & -0.070 & 0.000 & -0.106 & 0.000 & -0.037 \\
Couple (no children) & -0.086 & - & -0.126 & - & -0.040 \\
Couple with children & 0.041 & 0.000 & 0.015 & 0.001 & -0.026 \\
Single parent & 0.027 & 0.000 & 0.035 & 0.000 & 0.008 \\
\hline Quint1 & -0.046 & 0.000 & -0.048 & 0.000 & -0.002 \\
Quint2 & -0.022 & & -0.002 & & 0.019 \\
Quint3 & -0.016 & 0.024 & -0.007 & 0.269 & 0.009 \\
Quint4 & 0.005 & 0.375 & 0.006 & 0.173 & 0.001 \\
Quint5 & -0.011 & 0.026 & -0.004 & 0.268 & 0.007 \\
\hline Constant & 0.002 & 0.675 & -0.006 & 0.079 & -0.008 \\
F-value & 0.020 & - & 0.011 & - & -0.009 \\
R-square & 0.100 & 0.000 & 0.136 & 0.000 & 0.036 \\
\hline N & 143.477 & 0.000 & 401.269 & 0.000 & - \\
\hline Note: & 0.092 & - & 0.126 & - & - \\
\hline
\end{tabular}

Note: Significance levels must be taken with caution in linear probability models (due to heteroscedasticity). The results from alternative WLS estimations (not reported) show that the household type might be not significant. Note that with the deviation model, the coefficients of the last category are calculated separately for each categorical variable (the sum of the coefficients being equal to zero).

Coverage: Owner-occupier households (private homes excluding special types of housing such as houseboats).

Sources: CBS (Statistics Netherlands), Housing surveys WBO 1986, WoON 2006; authors' calculations. 
We now turn to the behavioural effects. First of all, the constant indicates a general trend towards more mobility $(+0.0359)$. The coefficients per household characteristic show that the variation around this constant is quite small, which indicates that the proportion of recent movers has increased across the board. Although in our analysis we cannot distinguish between new entrants (first time buyers) and those who move within the sector, this overall dynamisation is a clear sign of the formation of housing ladders, where households move from smaller to larger dwellings and, at a later age, move "back" to an apartment. The particularly large coefficient for young households also supports the general idea that young people enter the sector at a younger age and move much more frequently within the sector during this phase of life. The only parameter for which a somewhat smaller increase (keeping in mind the intercept) is visible is for single person households. Even though we control for age and income, this might still be a sign of more heterogeneity within the population of single households, who are not only young and with lower incomes, but increasingly are elderly single. With regard to income the change is not significant for any of the quintiles.

In a preliminary analysis we also estimated a model with interaction effects $\left(\bar{X}_{2006}-\bar{X}_{1986}\right)\left(\hat{\beta}_{2006}-\hat{\beta}_{1986}\right)$, but this did not add much information. At best, it shows one significant interaction between a decline in the percentage of young households (20-34) and a strong increase of the mobility behaviour, but we do not assume any causal effect. The fact that the overall proportion of younger owneroccupiers declines is related to demographic ageing, while the increase of mobility "just" relates to their aforementioned earlier entry in the sector and more subsequent moves.

One last remark must be made with regard to the behavioural effects of the youngest age group (20-35). The positive behavioural effect shown in Table 6 for this group is related to entrance into the owner-occupied sector at a younger age, and higher chances to move onwards within the owner-occupied sector before the age 35 . In case both the age of entry into the sector and the chance to move within the sector before age 35 had remained unchanged between 1986 and 2006, there would be no behavioural effect. However, in such a scenario there is still a possibility that the parameter for the behavioural effect shows a change resulting from short term changes in the size of birth cohorts. For instance, a (sudden) decline of a birth cohort will materialise in a smaller influx from the rental sector or from parental homes. This will subsequently lead to a smaller proportion of recently moved young households in the owner-occupied sector. If birth rates are stable or only gradually change, behavioural effects should just be interpreted as changes in the age of entry into the owner-occupied sector and different chances to move within the owner-occupied sector before the age of 35. In the Dutch case, there was a drastic decline of births from 1970-1975 (from around 240,000 to 170,000), which has the potential to materialise in a negative behavioural effect. After 1975, birth rates stabilised. It needs to be noticed that many of the 1970-1975 generation were already in the owner-occupied sector in around 2005, but the sudden decline in this cohort may have had a negative impact on the proportion of young households that moved within the sector (before age 35). This combination of a

Table 5

Oaxaca-Blinder decomposition of owner-occupiers probability to move in the previous two years 1986 versus 2006 (general effects)

\begin{tabular}{|l|c|c|c|}
\hline & Probability to move (\%) & Standard Error & p-value \\
\hline Prediction model 1986 & 10.25 & 0.00236 & 0.000 \\
Prediction model 2006 & 12.63 & 0.00248 & 0.000 \\
Difference & 2.38 (pct. points) & 0.00342 & 0.000 \\
\hline Decomposition of change & \multicolumn{3}{|l|}{} \\
Composition (structure) & -1.19 & 0.00142 & 0.000 \\
Behaviour & 3.57 & 0.00354 & 0.000 \\
\hline
\end{tabular}

Reading note: The change in the estimated probability to move of 2.38 pct. points between 1986 and 2006 results from a negative effect of changes in the structure of the population (-1.19 pct. points) and a positive effect of changes in behaviour (3.57 pct. points).

Coverage: Owner-occupier households (private homes excluding special types of housing such as houseboats).

Sources: CBS (Statistics Netherlands), Housing surveys WBO 1986, WoON 2006; authors' calculations. 
possible negative impact on the behavioural effect and the increase in the actual estimated effect of the parameter (cf. Table 6) supports the idea that young households have become more dynamic.

\section{Vulnerability of the system? Changing mobility of owner-occupiers 2006-2012}

We now turn to an analysis of the crisis period. The main topic of interest here is to investigate how the crisis affected the contemporary Dutch owner-occupied housing market. Again we memorise that more households spend a larger part of their housing career in the owneroccupied sector. Whereas in the mid-1980s the owner-occupied sector was dominated by "static" family households, there are now more households that start their housing career in a small owner-occupied dwelling and subsequently make a couple of moves on the housing ladder after (or during) household and income changes. The literature also mentions that a crisis can significantly obstruct these moves on the housing ladder as a result of income-employment uncertainty and negative equity. With regard to the latter point, it must also be mentioned that young Dutch households were able to take out as much as $130 \%$ of the value of the dwelling. Buying a highly leveraged apartment with the intention of moving on after a few years certainly poses a risk of negative equity. Furthermore, according to the theoretical framework, it can be expected that those households that are already well housed, but who in principle consider moving to a more luxury dwelling, may put those ambitions on the longer run during a crisis.

These general expectations seem to hold to a great extent with regard to age when comparing regression models of 2006 and 2012 . First of all, the intercept indicates an overall

Table 6

Detailed Oaxaca-Blinder decomposition for owner occupiers probability to move in the previous two years 1986 versus 2006

\begin{tabular}{|l|c|c|c|c|}
\hline \multirow{2}{*}{} & \multicolumn{2}{|c|}{ Compositional effects $\left(\bar{X}_{2006}-\bar{X}_{1986}\right) \hat{\beta}_{1986}$} & \multicolumn{2}{c|}{ Behavioural effects $\bar{X}_{1986}\left(\hat{\beta}_{2006}-\hat{\beta}_{1986}\right)$} \\
\cline { 2 - 4 } & Coefficient & $p$-value & Coefficient & p-value \\
\hline $20-34$ & -0.0144 & 0.00 & 0.0149 & 0.00 \\
$35-44$ & -0.0013 & 0.00 & 0.0044 & 0.03 \\
$45-54$ & -0.0019 & 0.00 & -0.0039 & 0.00 \\
$55-64$ & -0.0044 & 0.00 & -0.0065 & 0.00 \\
$65-75$ & -0.0015 & 0.00 & -0.0047 & 0.00 \\
Total age & -0.0236 & - & 0.0041 & - \\
\hline Single person & 0.0011 & 0.00 & -0.0038 & 0.02 \\
Couple (no children) & 0.0033 & 0.00 & 0.0023 & 0.25 \\
Couple with children & 0.0072 & 0.00 & -0.0010 & 0.82 \\
Single parent & 0.0000 & 0.34 & 0.0007 & 0.16 \\
Total household type & 0.0116 & - & -0.0018 & - \\
\hline Quint1 (low) & 0.0002 & 0.29 & 0.0009 & 0.31 \\
Quint2 & -0.0001 & 0.23 & 0.0002 & 0.87 \\
Quint3 & -0.0001 & 0.11 & 0.0014 & 0.33 \\
Quint4 & -0.0001 & 0.32 & -0.0022 & 0.21 \\
Quint5 (high) & 0.0001 & 0.13 & -0.0028 & 0.18 \\
Total income & 0.0001 & - & -0.0026 & - \\
\hline Constant & - & - & 0.0359 & 0.00 \\
\hline Total & -0.0119 & 0.0357 & 0.00 \\
\hline
\end{tabular}

Note: cf. Table 4

Coverage: Owner-occupier households (private homes excluding special types of housing such as houseboats).

Sources: CBS (Statistics Netherlands), Housing surveys WBO 1986, WoON 2006, 2012; authors' calculations. 
decline of residential mobility (see Table 7). This decline is even higher for households below 45 years and especially for those under 35. The overall decline is somewhat lower for those above 45. With regard to household type, the only change of interest is the parameter for single person households. It is positive, but small. For income quintiles, the change is positive and quite strong for the lowest quintile, while it is negative and rather low for the highest quintile(s).
This positive change for the lowest income quintile sparks some extra interest because it was discussed among housing market experts during the crisis. One debate revolved around the issue of highly leveraged young households who were virtually locked up in their dwelling because of negative equity, while another focused on the possibilities for first time buyers. Whereas falling house prices might provide opportunities for first time buyers, credit

Table 7

Linear regression of owner-occupiers probability to move in the two previous years

\begin{tabular}{|l|c|c|c|c|c|}
\hline & \multicolumn{2}{|c|}{2006} & \multicolumn{2}{|c|}{2012} & $2006-2012$ \\
\hline & $\beta$-parameter & $p$-value & $\beta$-parameter & $p$-value & $\beta$-parameter change \\
\hline $20-34$ & 0.245 & 0.000 & 0.217 & 0.000 & -0.028 \\
$35-44$ & 0.038 & 0.000 & 0.019 & 0.000 & -0.019 \\
$45-54$ & -0.051 & 0.000 & -0.042 & 0.000 & 0.009 \\
$55-64$ & -0.106 & 0.000 & -0.085 & 0.000 & 0.021 \\
$65-75$ & -0.126 & - & -0.109 & - & 0.017 \\
\hline Single person & 0.015 & 0.001 & 0.007 & 0.049 & -0.007 \\
Couple (no children) & 0.035 & 0.000 & 0.038 & 0.000 & 0.003 \\
Couple with children & -0.048 & 0.000 & -0.045 & 0.000 & 0.003 \\
Single parent & -0.002 & - & 0.000 & - & 0.002 \\
\hline Quint1 & -0.007 & 0.269 & 0.009 & 0.071 & 0.016 \\
Quint2 & 0.006 & 0.173 & 0.008 & 0.039 & 0.002 \\
Quint3 & -0.004 & 0.268 & -0.010 & 0.001 & -0.006 \\
Quint4 & -0.006 & 0.079 & -0.011 & 0.000 & -0.003 \\
Quint5 & 0.011 & - & 0.004 & - & -0.007 \\
\hline Constant & 0.136 & 0.000 & 0.107 & 0.000 & -0.029 \\
\hline F-value & 401.269 & 0.000 & 491.629 & 0.000 & - \\
R square & 0.126 & - & 0.130 & - & - \\
\hline N & 26,779 & - & 36,235 & - & - \\
\hline No: cf Tab & & & & & \\
\hline
\end{tabular}

Note: cf. Table 4

Coverage: Owner-occupier households (private homes excluding special types of housing such as houseboats).

Sources: CBS (Statistics Netherlands), Housing surveys WBO 1986, WoON 2006, 2012; authors' calculations.

Table 8

Original housing sector of recently moved owner occupiers (in the previous two years)

\begin{tabular}{|l|c|c|c|}
\multicolumn{5}{|c|}{ (In \%) } \\
\hline Origin & 1986 & 2006 & 2012 \\
\hline From parent/student house & 34 & 22 & 33 \\
From rental house & 40 & 30 & 29 \\
From owner-occupied house & 26 & 48 & 38 \\
\hline Total & 100 & 100 & 100 \\
\hline
\end{tabular}

Coverage: Owner-occupier households (private homes excluding special types of housing such as houseboats).

Sources: CBS (Statistics Netherlands), Housing surveys WBO 1986, WoON 2006, 2012; authors' calculations. 
restrictions self-imposed by mortgage lend$\mathrm{ers}^{5}$ or government policies to restrict high loan-to-value ratios could become problematic for potential first-time buyers to benefit from house price declines. However, the actual moves of first time buyers into the owner-occupied housing market indicated that there was actually no strong decline (Boumeester et al., 2015).

Rather, the results presented in Table 7 suggest that the mobility of low-income households has not been as affected by the crisis as might have been expected. It appears there is a distinction between first time-buyers, who had better opportunities to buy a dwelling and existing young owner occupiers, who were 'stuck' in their dwelling because of high leverage. A limitation here is that we cannot take into account their residential origin in our models: this information is only available for households that have moved recently (in the previous two years).

For those who moved in the previous two years, Table 8 shows a marked increase between 2006 and 2012 of the percentage of first time buyers coming from their parents' home or from a student dwelling, while the share of first time buyers coming from a rental dwelling remains more or less the same. Owner-occupiers' mobility within this sector dramatically declines. It gives substance to the idea of Van der Heijden et al. (2011), that a more dynamic home ownership sector with much mobility on the housing ladder can be seriously affected by a crisis. Table 8 also shows that in 1986, before the expansion of the owner-occupied sector. The percentages of first time buyers from the rental sector were also high, while mobility within the owneroccupied sector was much lower, suggesting a more static system, dominated by families who did not move much.

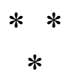

The first part of this article investigated how mobility levels in the Dutch owner-occupied sector changed in a context where this sector grew substantially, both as a proportion of the entire housing stock and in absolute size. Our main assumption was that the Dutch owner-occupied sector can be characterised as "dynamic"
(Van der Heijden et al., 2011) and that its dynamisation is visible since the mid-1980s. The backgrounds to this assumption have been under investigated. There is room to explain the dynamisation through a changing composition of the owner-occupiers population, i.e. an influx of dynamic (young) household in the owner-occupied sector. In addition, behavioural changes might also have played a role, for instance older people in the 1980s being less mobile than the contemporary older population. We used the Oaxaca-Blinder method, to disentangle the compositional and behavioural effects. Overall, there has been an increase in mobility through changing behaviour of owneroccupiers from 1986 to 2006 . There is remarkable little variation by household characteristics on this part, although it can be said that younger owner-occupiers are more mobile than before. Changes in the composition of the household structure in the owneroccupied sector had a negative impact on mobility. Although we expected more mobility because of an influx of younger households, overall ageing of the (owner-occupied sector) population is responsible for this negative compositional effect. However, the change towards a more diversified composition in terms of household types somewhat counterbalances this ageing effect. In fact there was a marked decline in the share of traditional, less mobile, family households.

In the second part of the study, we aimed to connect to the hypothesis that the changing structure of the owner-occupied sector population might also make it vulnerable to an economic downturn. Households in dynamic owner-occupied markets make several moves on the "housing ladder" during their housing career, in contrast to less mobile systems. During a crisis, the process stops and the entire system can come to a halt, further affected by the withdrawal of speculative developers from the market for new construction. There was previously little information as to how this decline plays out at the household level and we aimed to fill this gap. Which household types are more vulnerable to a crisis? The analysis shows that especially the younger households moved less. This may be partly due to the fact that many young Dutch home owners have high debt and did not wish or were unable to move after the decline in house prices. However, the overall pattern in 2012 still shows that young

5. See for instance the work of Fostel and Geanakoplos (2008). 
households have the highest mobility rates. In fact, many young home owners who entered the owner-occupied market as (low income) first time buyers, benefited from house price declines.

Here we have investigated the developments in the Netherlands. In order to gain more insights into the evolution and mechanisms of static and dynamic housing markets, similar research would be needed in other countries. First of all it might be interesting to investigate how other dynamic home ownership systems, such as the UK and the USA, relate to the Netherlands. A comparative analysis of such dynamic markets static systems, such as Belgium, Germany and possibly France (see Barlow, 1992) is another avenue for future research.

\section{BIBLIOGRAPHY}

Ball, M., Harloe, M. \& Martens, M. (1988). Housing and Social Change in Europe and the USA. London and New York: Routledge.

Barlow, J. \& Duncan, S. (1994). Success and Failure in Housing Provision, European Systems Compared. Oxford, New York and Tokyo: Pergamon and Elsevier Science Ltd.

Barlow, J. (1992). Self-promoted housing and capitalist suppliers: The case of France. Housing Studies, 7(4), 255-267.

https://doi.org/10.1080/02673039208720741

Beer, A. \& Faulkner, D. (2011). Housing transitions through the life course: Aspirations, needs and policy. Bristol: Policy Press.

Blijie, B., Groenemeijer, L., Gopal, K. \& van Hulle, R. (2013). Wonen in ongewone tijden. De resultaten van het Woononderzoek Nederland 2012. (Living in unusual times. The results of the Housing survey Netherlands 2012). Den Haag: Ministerie van Binnenlandse Zaken en Koninkrijksrelaties.

Blinder, A. (1973). Wage Discrimination: Reduced Form and Structural Estimates. The Journal of Human Resources. 8(4), 436-455.

https://www.jstor.org/stable/144855

Boelhouwer, P. \& Van der Heijden, H. (1992). Housing systems in Europe: Part 1. A comparative study of housing policy. Housing and Urban Policy Studies 1. Delft: Delft University Press.

Boumeester, H., Dol, K. \& Mariën, G. (2015). Verhuiswensen en feitelijk gedrag op de Nederlandse woningmarkt 2006-2011. Verhuis- en slaagratio's op basis van Verhuismodule WoON 2006 en 2009. (Moving intentions and actual behaviour on the Dutch housing market 2006-2011. Relocation- and succeeding ratio's based on the Relocation module Housing demand Survey 2006 and 2009) Delft: Delft University of Technology, OTB Research for the Built Environment.

Bourassa, S. C. \& Shi, S. (2017). Understanding New Zealand's decline in homeownership. Housing Studies, 32(5), 693-710. https://doi.org/10.1080/02673037.2016.1228851

Clark, W. A. V., Deurlo, M. C. \& Dieleman, F. M. (2003). Housing Careers in the United States, 1968-93: Modelling the Sequencing of Housing States. Urban Studies, 40(1), 143-160. https://doi.org/10.1080/00420980220080211

Cooke, T. J. (2011). It is not Just the Economy: Declining Migration and the Rise of Secular Rootedness. Population, Space and Place, 17, 193-203. https://doi.org/10.1002/psp.670

Fairlie, R. W. (2005). An Extension of the Blinder-Oaxaca Decomposition Technique to Logit and Probit models. Journal of Economic and Social Measurement, 30(4), 305-316.

https://www.researchgate.net/publication/ 279548723_An_Extension_of the_Blinder-Oaxaca Decomposition_Technique_to_Logit_and_Probit_ Models

Feijten, P. \& Mulder, C. H. (2002). The Timing of Household Events and Housing Events in the Netherlands: a Longitudinal Perspective. Housing Studies, 17(5), 773-792.

https://doi.org/10.1080/0267303022000009808

Fostel, A. \& Geanakoplos. J. (2008). Leverage Cycles and the Anxious Economy. American Economic Review, 98(4), 1211-1244.

https://ssrn.com/abstract $=1328564$ 
Green, A. \& Shuttleworth, I. (2015). Labour markets and internal migration. In: Smith, D. P., Finney, N., Halfacree, K. \& Walford, N., (Eds.) Internal Migration: Geographical Perspectives and Processes, pp. 65-79. Farnham: Ashgate Publishers.

Helderman, A. C. (2007). Continuities in home ownership and residential relocations. PhD-thesis, Netherlands Geographical Studies 354. Amsterdam: University of Amsterdam.

Helderman, A. C., Mulder, C. H. \& Van Ham, M. (2004). The changing effect of home ownership on residential mobility in the Netherlands, 1980-98. Housing Studies, 19(4), 601-616. https://doi.org/10.1080/0267303042000221981

Helderman, A. C., Van Ham, M. \& Mulder, C. H. (2006). Migration and Home Ownership. Tijdschrift voor Economische en Sociale Geografie, 97(2), 111-125.

https://doi.org/10.1111/j.1467-9663.2006.00506.x

Hellevik, O. (2009). Linear versus logistic regression when the dependent variable is a dichotomy. Quality \& Quantity, 43(1), 59-74.

https://doi.org/10.1007/s11135-007-9077-3

Jann, B. (2006). FAIRLIE: Stata module to generate nonlinear decomposition of binary outcome differentials. Boston College Department of Economics - Statistical Software Components S456727. http://ideas.repec.org/c/boc/bocode/s456727.html.

Jann, B. (2008). The Blinder-Oaxaca decomposition for linear regression models. The Stata Journal, 8(4), 453-479.

https://www.stata-journal.com/sjpdf. html?articlenum $=$ st 0151

Kemeny, J. (1992). Housing and Social Theory. London/New York: Routledge.
Kemeny, J. (1995). From public housing to the social market: Rental policy strategies in comparative perspective. London/New York: Routledge.

Kemeny, J. (2006). Corporatism and housing regimes. Housing Theory and Society, 23(1), 1-18. https://doi.org/10.1080/14036090500375423

Martens, M. (1990). Ways of owning, a study of home ownership in Europe and the USA, PhD-thesis. Essex (UK): University of Essex.

Ministerie BZK (2010) Cijfers over Wonen, Wijken en Integratie 2010. (Data on Housing, Neigbourhoods and Integration 2010). Den Haag: Ministerie van Binnenlandse Zaken en Koninkrijksrelaties.

Mulder, C. H. (1993). Migration dynamics: A life course approach. Amsterdam: Thesis publishers.

Mulder, C. H. \& Hooimeijer, P. (1999). Residential Relocations in the Life Course. In: Van Wissen, L. J. G. \& Dijkstra, P. A. (Eds.). Population Issues. An Interdisciplinary Focus, pp. 159-186. New York: Plenum.

Mulder, C. H. \& Wagner, M. (1998). First-time Home-ownership in the Family Life Course: a West German-Dutch Comparison. Urban Studies, 35(4), 159-186.

https://doi.org/10.1080/0042098984709

Oaxaca, R. (1973). Male-Female Wage Differentials in Urban Labor Markets. International Economic Review, 14(3), 693-709.

https://www.jstor.org/stable/2525981

Van der Heijden, H., Dol, K. \& Oxley, M. (2011). Western European housing systems and the impact of the international financial crisis. Journal of Housing and the Built Environment, 26(3), 295-313. https://doi.org/10.1007/s10901-011-9230-0 


\title{
Consumption, household portfolios and the housing market in France
}

\author{
Valérie Chauvin* and John Muellbauer**
}

\begin{abstract}
Consumption and wealth may co-move because of shifts in credit conditions, interest rates, income expectations or demographics whose impact should be identified to disentangle wealth effects. The findings for France from a 6-equation model for consumption and the main elements of household portfolios are that marginal propensities to consume financial wealth are comparable to those in the US or the UK, but housing wealth effects are far weaker, and aggregate consumption falls with higher house prices relative to income. This is interpreted as the need for households in France then to save more if they wish to become homeowners or can expect rents to increase in the future. The estimates suggest that during the French house price boom between 1996 and 2008, offsets from the negative effect of higher house prices and higher debt neutralized the positive effects of higher housing wealth and easier credit on consumption, evading the amplifying feedbacks, via consumption, of the US boom.
\end{abstract}

Codes JEL / JEL Classification: E21, E27, E44, E51, E58

Keywords: consumption, credit conditions, household debt, housing collateral, monetary transmission

Reminder:

The opinions and analyses in this article

are those of the author(s)

and do not

necessarily reflect

their institution's

or Insee's views.

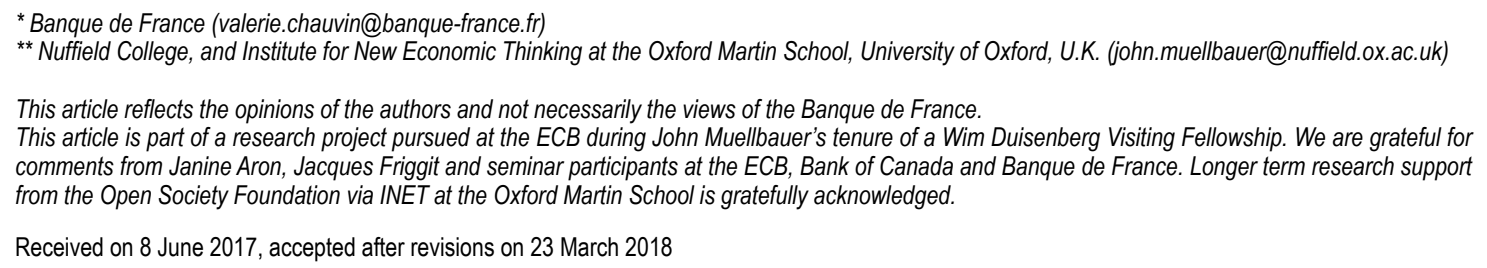

*Banque de France (valerie.chauvin@banque-france.fr)

** Nuffield College, and Institute for New Economic Thinking at the Oxford Martin School, University of Oxford, U.K. (john.muellbauer@nuffield.ox.ac.uk)

This article reflects the opinions of the authors and not necessarily the views of the Banque de France.

This article is part of a research project pursued at the ECB during John Muellbauer's tenure of a Wim Duisenberg Visiting Fellowship. We are grateful for comments from Janine Aron, Jacques Friggit and seminar participants at the ECB, Bank of Canada and Banque de France. Longer term research support from the Open Society Foundation via INET at the Oxford Martin School is gratefully acknowledged.

Received on 8 June 2017, accepted after revisions on 23 March 2018 
$\mathbf{T}$ he US sub-prime crisis, which triggered the global financial crisis, began with a major over-valuation of asset prices, especially of housing. The consequence of overvaluation, eventually, is falling house prices, triggering the down-phase of a financial accelerator. Falling house prices reduce residential investment and lower consumer spending in countries where housing collateral is an important driver of consumption, such as the US and the UK. Falling house prices increase bad loans and lower the capital of financial firms. This impairs the ability of banks to extend credit. The credit-crunch feeds back further on residential investment and household spending, increasing unemployment and reducing GDP, which further reduces the demand for housing and the capital of financial firms.

Macro-evidence has accumulated for the role of leverage and of real estate connected financial instability (Cerutti et al., 2017 and Mian et al., 2017). Mian and Sufi $(2014,2018)$ have provided extensive microeconomic evidence for the role of credit shifts in the US sub-prime crisis and the constraining effect of high household debt levels. Jordà et al. (2016) have drawn attention to the increasing role of real estate collateral in bank lending in most advanced countries and in financial crises. The IMF's October 2017 Financial Stability Report (IMF, 2017) provides further evidence, highlighting the critical role of mortgage debt and nonlinear effects, finding more pronounced effects at high debt ratios, and larger effects in countries with open capital accounts and fixed exchange rate regimes.

Beyer et al. (2017) note the importance of wealth effects and heterogeneity, including across countries. This is indeed a focus for the ECB's multi-country model, under construction, for the five largest members of the Eurozone. This model belongs to the class of macro-econometric models, newly popular with central banks, which do not impose the rational, representative agent micro of New Keynesian DSGE models and give more scope to empirical evidence. However, most versions of such models impose a net worth constraint on the effect on consumption function of wealth, and ignore shifting credit conditions. The multi-equation personal sector model here estimated for France evaluates whether those assumptions are valid.

Does France resemble the Anglo-Saxon economies where changes in house or financial asset prices translate into changes in consumption, an amplifying mechanism in the financial accelerator, and part of monetary policy transmission? Its institutional background is very different: in particular, home equity withdrawal opportunities are much rarer, the retirement system relies mostly on a pay-as-you-go system and stock-market participation is lower. Current literature reviewed in Online complement $\mathrm{C} 1$ generally accepts lower wealth effects in France. However, the macroeconomic estimates of the marginal propensity to consume (MPC) for net worth cover a wide range - from 0.4 cent per additional euro of net worth to 4.6 - largely the result of specification problems such as omitting controls for permanent income (i.e. expectations of income growth) and credit conditions (whose large changes are documented in Online complement C3). On microeconomic data, Arrondel et al. (2014) report a MPC for financial wealth which is at the lower end of the range, with 0.5 cent per euro and large disparities between households and types of wealth.

Since household spending, saving and portfolio decisions are related and driven by common shocks and shifts in the economic and demographic environment, it is important to model these decisions jointly in a sub-system of equations when using a macroeconomic approach. In the present article, we follow Aron et al. (2012) with a "credit-augmented" permanent income form of the consumption function. This encompasses the textbook permanent income model as a special case but captures shifts in credit availability and balance sheet heterogeneity. As no direct measure of time-varying access to credit is available, we use a latent variable method to measure credit conditions in a six-equation system for France for consumption, housing loans, consumer credit, liquid assets, house prices and permanent income estimated from 1981Q2 to 2016Q4. This can be seen as a translation into macro-time series of Mian and Sufi's (2018) "credit-driven household demand channel".

The outline of the article is as follows. The econometric specification of consumption equation is presented. Then the empirical approach is presented, with the specification of the empirical models finally selected. Conclusions are drawn. An appendix and online complements give respectively details on the data used and further literature background.

\section{Macro theory, the consumption function and the modelling framework}

Blanchard (2018) argues that in contrast to dynamic stochastic general equilibrium models, 
"Partial equilibrium modelling and estimation are essential to understanding the particular mechanisms of relevance to macroeconomics". In particular, Hendry and Muellbauer (2018) criticize the representative agent New Keynesian DSGE models for being insufficiently stochastic - trivializing the role of uncertainty and heterogeneity, insufficiently dynamic - missing key lags in relationships, insufficiently general equilibrium - ignoring important feed-back loops, seen for example in the global financial crisis, and insufficiently Keynesian - missing co-ordination failures in labour and financial markets.

\section{Consumption function}

Households actually face idiosyncratic and uninsurable income uncertainty, and uncertainty interacts with credit or liquidity constraints. The asymmetric information revolution in economics in the 1970s for which Akerlof, Spence and Stiglitz shared the Nobel prize explains this economic environment. Research by Deaton (1991, 1992), Carroll (1992, 2000, 2001, 2014), and a new generation of heterogeneous agent models imply that household horizons then tend to be both heterogeneous and shorter - with "hand-to-mouth" behavior even by quite wealthy households (Kaplan et al, 2014). Kaplan et al. (2018) have incorporated these insights into a DSGE model, though without endogenising housing, and Hedlund et al. (2017) into a DSGE model with a frictional housing market. Kaplan and Violante (2018) spell out further implications of heterogeneous agent models, the limitations of existing models and unresolved research questions, for example on asset pricing and labour market income risk. They acknowledge that current versions of the heterogeneous agent New Keynesian model "miss the potentially large wealth effects on consumption for wealthy households that can arise from changes in asset prices", an issue on which the present paper provides empirical evidence. There is also mounting empirical evidence on the cash-flow channel of monetary policy transmission, consistent with heterogeneity and liquidity constraints (La Cava et al. (2016) for micro-evidence on Australia, Aron et al. (2012) for macro-evidence for the UK).

Contributions to behavioral economics by Thaler and on financial illiteracy (Clark et al., 2017 as an example) reject the hypothesis of a shared rational behavior. Alternative expectations mechanisms, radical uncertainty and structural breaks, such as shifts in credit market architecture in particular, have not, so far, been incorporated in DSGE models useful for central bank policy making. They do however, feature in the quantitative partial equilibrium model of the household sector estimated on aggregate data presented below. To obtain general equilibrium results, this module would have to be inserted into a larger macro-econometric model, including specifications of policy feedback rules.

The simplest textbook permanent income form of the consumption function is as follows, using the log-linear approximation as in Muellbauer and Lattimore (1995):

$$
\ln \left(c_{t} / y_{t}\right)=\alpha_{0}+\ln \left(y_{t}^{p} / y_{t}\right)+\gamma A_{t-1} / y_{t}
$$

where $c$ is consumption, $y$ is non-property income, $y^{p}$ is permanent non-property income, and $A$ is net worth. The marginal propensity to spend out of net worth is $\gamma$.

If real interest rates are variable, standard consumption theory suggests that the real interest rate $r_{t}$ enters the model with the usual interpretation of inter-temporal substitution and income effects. Extending the model further to include probabilistic income expectations suggests the introduction of a measure of income uncertainty. With income uncertainty, the discount factor, $\delta$, in expected income growth as measured by $\ln \left(y_{t}^{p} / y_{t}\right)$ should incorporate a risk premium, allowing the possibility that households may discount the future more heavily than by the real rate of interest.

Furthermore, different types of assets may imply different marginal propensities to consume. One reason is that owner-occupied housing wealth differs fundamentally from financial assets since a roof over one's head gives shelter (has utility value) as well as having an asset value, see Buiter (2010) and Aron et al. (2012). The second reason is that, with credit constraints, housing wealth has a collateral role (see Muellbauer (2007) or Aron et al. (2012) for further discussion). A third reason is that illiquid financial assets as well as housing are subject to asset price volatility and/or trading costs or restrictions (Kaplan et al., 2014; Kaplan et al., 2018).

Finally, the consumption to income ratio varies with the incidence of credit constraints, as well as with age, see Fesseau et al. (2009) for French evidence for demographic effects on consumption. 
The long-run version ${ }^{1}$ of the credit-augmented generalized aggregate consumption function is:

$$
\begin{aligned}
\ln \left(c_{t} / y_{t}\right) & =\alpha_{0 t}+\alpha_{1 t} r_{t}+\alpha_{2} r l_{t}+\alpha_{3 t} E_{t} \ln \left(y_{t}^{p} / y_{t}\right) \\
& +\gamma_{1} N L A_{t-1} / y_{t}+\gamma_{2} I F A_{t-1} / y_{t}+\gamma_{3 t} H A_{t-1} / y_{t} \\
& +\gamma_{4 t} \ln \left(h p_{t-1} / y_{t-1}\right)+y_{5} \operatorname{demog}_{t}
\end{aligned}
$$

Here $r$ is a real interest rate for borrowing and $r l$ a real interest rate on liquid assets. Net worth, $A$, is replaced by a tripartite division into liquid assets minus $\operatorname{debt}^{2} N L A$, illiquid financial assets $I F A$, gross housing wealth $H A$, with different marginal propensities. $h p$ is an index of house prices, and demog the proportion of adults in the pre-retirement age group on consumption. With numerical indicators such as credit conditions indices $(C C I s)$ for the mortgage market $(M C C I)$ and for consumer credit loans (CRCCI), it is possible to make each potentially time-varying parameter a linear function of the CCIs and to test hypotheses about time variation.

The intercept $\alpha_{0 t}$ increases with greater availability of non-housing loans and of mortgages, as the need to save for a down-payment is reduced or as the lengthening of mortgage maturities improves short- to medium-term net cash-flows. The coefficient measuring the sensitivity of down-payment requirements to house prices relative to income, $\gamma_{4 t}$, should become less negative if the down-payment constraint becomes less binding. However, a relaxation of the debt-service ratio constraint could increase the fraction of households subject to the down-payment constraint. If access to home equity loans increases, the coefficient, $\gamma_{3 t}$, measuring the marginal propensity to spend out of housing wealth, should increase. Expectations of future income growth, captured in $E_{t} \ln \left(y_{p} / y_{t}\right)$ should have a larger effect on consumption when credit constraints ease, while greater income insecurity should have the opposite effect. It is also possible that $\alpha_{1}$ the sensitivity of consumption to the real interest rate on borrowing might be affected by credit conditions.

Consumption equation (2) satisfies long-run homogeneity in income and assets: doubling both, doubles consumption. The long run coefficient on $\ln y$ is set to 1 . This means that the income endogeneity issues raised by Hall (1978) are not of concern for the measurement of the long-run income and asset effects.

The modelling philosophy follows an encompassing approach. Bontemps and Mizon (2008), given uncertainty about which of several competing models is correct, recommend constructing an encompassing model, which generates each of the competing models under particular testable parameter restrictions. For example, equation (1) is a special case of equation (2) under a number of restrictions. As presented in the empirical section, the data strongly reject these restrictions.

\section{Modelling framework for household portfolios}

Household portfolios are key determinants for consumption. The house price index as well as mortgage and consumer debt and liquid assets are endogenised in the model. They are determined by current and permanent income (with a positive coefficient, + ), credit conditions (+ for debt and house prices, - for liquid assets), uncertainty (-), and characteristics of the age composition of population. They are also determined by arbitrage opportunities, represented here by their corresponding interest rates, real or nominal (- for debt and house prices, + for liquid assets) and the evolution of other assets (the impact of which is ambiguous, whether assets are complements or substitutes $)^{3}$. House price and mortgage debt equations also include housing user and transaction costs (-). The modelling framework for the house price index and the mortgage debt are detailed further here, see Online complement C5 for consumer debt and liquid assets equations.

The theory background for the house price equation is an inverted log-linear demand function, where real house prices, $r h p$, are determined by household demand, conditional on the lagged housing stock.

$$
\begin{aligned}
\ln r h p_{t}= & h_{0 t}+h_{1 t} \ln n m r_{t}+h_{2 t} \ln \text { user }_{t}+h_{3}\left(\ln \left(y_{t} / h s_{t-1}\right)\right. \\
& +h_{4 t} E_{t} \ln \left(y_{t}^{p} / y_{t}\right)+h_{5} \text { demog }_{t}+h_{6} L A_{t-1} / y_{t} \\
& +h_{7} I_{t-1} / y_{t}+h_{8} \text { spillover }_{t-1}+h_{9} \text { trans }_{t}
\end{aligned}
$$

Here $h_{0 t}$ should increase with mortgage credit conditions. The nominal mortgage rate is $\mathrm{nmr}$,

1. The dynamic version includes partial adjustment, and changes in the unemployment rate - an income uncertainty proxy -, and changes in income and interest rates. Models of this type have been estimated for the UK, US and Japan in Aron et al. (2012), Canada in Muellbauer et al. (2015), South Africa in Aron and Muellbauer (2013), and Germany in Geiger et al. (2016). 2. It is possible to disaggregate net worth into four main elements, with a separate coefficient on debt. However, netting debt off liquid assets is supported by the evidence, while netting debt off gross housing wealth, a restriction sometimes found in the literature, is strongly rejected.

3. Avouy-Dovi et al. (2014) show how financial assets may be complements or substitutes with a model for French households' portfolio detailed in six categories. Liquid assets are substitute for other assets, but not for insurance and pension funds. 
and user cost, measured by interest rates minus expected appreciation, plus a risk premium, is $u s e r$. The parameter $h_{3}$ measures minus the inverse of the price elasticity of demand for housing, and is attached to the $\log$ ratio of income to the housing stock, which imposes the constraint that the income elasticity of demand for housing is one. The coefficient $h_{4 t}$ captures the relative effect of permanent to current income, analogously to a similar term in the consumption function. The remaining terms respectively represent the effects of demography, liquid and illiquid financial assets, spillover effects from other housing markets, transactions costs and income uncertainty.

Mortgage and consumer debt are driven by the purpose of the debt, i.e. house prices and the long-run solution from the consumption function in equation (2) respectively. Higher house prices should increase the demand for mortgages because for a given level of housing demand, higher house prices require greater levels of debt:

$$
\begin{aligned}
& \ln (\text { mdebt } \left.t_{t} / y_{t}\right)=m_{0 t}+m_{1 t} \ln n m r_{t}+m_{2 t} \ln \text { user }_{t} \\
& \quad+m_{3 t} E_{t} \ln \left(y_{t}^{p} / y_{t}\right)+m_{4 t} \ln \left(h p_{t-1} / y_{t-1}\right)+m_{5} \text { demog }_{t} \\
& \quad+m_{6 t} \ln \left(L A_{t-1} / y_{t}\right)+m_{7} \ln \left(I F A_{t-1} / y_{t}\right)+m_{9} \text { trans }_{t}
\end{aligned}
$$

Credit market liberalisation should impact in several ways on these long-run relationships, broadly corresponding to effects described on consumption. A direct, positive effect on debt should result from the different facets of credit liberalisation, which included relaxation of the down-payment and debt-service constraints in the 1980s and longer duration for housing credits in the 2000s, which also reduced debt-service cash-flows. Thus, $m_{0 t}$ should increase with $M C C I$, though housing equity loans to existing owners remained marginal in France. Real interest rates may matter more with liberalisation, making $m_{2 t}$ more negative for example, while nominal ones perhaps matter less, making $m_{1 t}$ less negative. Income expectations may matter more after liberalization, shifting $m_{3 t}$. Higher house prices relative to income should increase demand for mortgages but this might well be more pronounced if liberalisation relaxes the down-payment constraint, shifting $m_{4 i}$. Demography, asset to income ratios and transactions costs are represented in the next four terms in (4). To the extent that bank funding is less constrained by household deposits in a more liberal regime, there may be time variation in $m_{6 t}$

\section{Empirical findings}

Six equations are estimated jointly by maximum likelihood methods for French quarterly data from 1981 to 2016, for consumption, house prices, mortgage loans, consumer credit, and liquid assets ${ }^{4}$, permanent income (Box), with credit conditions for both consumer credit and mortgage loans estimated as latent variables ${ }^{5}$. They entail potentially important, highly non-stationary demographic effects. Empirical identification of the latent variables relative to demography is not a trivial exercise. Fortunately, there is institutional and other information on the nature and timing of credit market liberalisation and there are priors on the direction of interest rate and income effects on house prices and household balance sheets. Micro information on holdings of debt and liquid assets by age of household and on household saving rates (hence consumption to income ratios) by age is also used to impose sign restrictions and upper bounds on potential demographic effects.

\section{Estimates for the two credit conditions indices}

There are no data to measure credit conditions directly in France before 2003. This article adopts a "latent variable approach", where credit conditions indicators for housing and non-housing loans are proxied by spline functions guided by institutional information on credit market liberalization. Both indices are specified as a linear combination of ogive dummies, which make a smooth transition from zero to one over eight quarters, and lagged inflation rates, relevant for consumer credit. When inflation risk, proxied by the lagged annual inflation rate, is high, lenders are less likely to extend credit for fear of negative returns. The disinflation that really took hold in 1984 would therefore have been likely to ease credit constraints. In all, 13 dummies (resp. 6) are used to describe the shape of the mortgage credit (resp. consumer credit) conditions index $M C C I$ (resp. CRCCI) shown in Figure I (see also Online complement C2).

Since the stock of consumer credit rises from extremely low levels in 1981, unlike consumption and liquid assets, potentially influenced

\footnotetext{
4. For the estimations of the consumer credit and liquid assets equations, see Online complement $\mathrm{C5}$.

5. Duca and Muellbauer (2013) name this type of equation system a Latent Interactive Variable Equation System (LIVES).
} 


\section{Box - The permanent income forecasting equation: modelling and estimates}

Following Campbell (1987), expected income growth is defined as a moving average of forward-looking real per capita income over ten years with discount factor $\delta$ a measure of permanent income, minus current income.

The expression for the log ratio of permanent to current non-property income per head is

$\ln \left(y_{t}^{p} / y_{t}\right)=\left(\sum_{s=1}^{k} \delta^{s-1} E_{t} \ln y_{t+s}\right) /\left(\sum_{s=1}^{k} \delta^{s-1}\right)-\ln y_{t}$ The quarterly discount factor is set at $\delta=0.95$.

Forecast permanent income follows linear trends, allowing for an unanticipated negative shift after the global financial crisis, economic variables and demography. This approach can be seen as a reduced form representation of the forecast effects of the capital stock and of total factor productivity and of cyclical deviations around capacity on future incomes. The expected signs of coefficients are indicated in parentheses: the economic variables include changes in nominal and levels of real interest rates (-), current real per capita income (-), because of reversion to trend, changes in log real per capita income, possibly indicating some growth momentum $(+)$, household survey expectations of future living standards $(+)$, the unemployment rate (-) (e.g. because it weakens the power of workers in wage negotiations), the log stock market index in real terms (+) (it indicates expectations of productivity growth and is one of the drivers of capital investment which expands future capacity), log real oil prices (-) and the log real exchange rate (-), indicating worsening competitiveness, and finally the ratio of the working age population divided by the total population (+).

The relevant variables were chosen by first carrying out a model selection exercise for data from 1972 to 2016 for forecasting income over 1, 4 and 8-quarter horizons, incorporating a split trend around 2009. This exercise suggested the relevance of longer lags than normally considered in econometric forecasting. Since permanent income is a moving average of future income, it is plausible that moving averages of the drivers would also be relevant and many of the variables enter in that form. The parameter estimates are shown in Table $A$ below and the fit is visualised in Figure A. The long lags shown for many variables are consistent with a slowly evolving capital stock, reacting to economic influences on investment. Because of these long lags, the residuals are highly auto-correlated, though the model does seem to capture reasonably well cyclical fluctuations. Goodness of fit, however, is not necessarily an unmixed blessing since households are bound to make serious forecast errors: rather the aim is to capture what their views might have been, given the kind of information to which households would have ready access. In contrast to the unforecastable financial crisis, the effects of repeated variations in interest rates, equity prices, oil prices, exchange rates and unemployment might have been sensibly evaluated. They could have operated through the medium of professional forecasters, business economists, central banks and organisations such as the IMF and the OECD.

Two alternative methods of dealing with income growth beyond the end of the sample in 2016 were considered. One uses forecasts from Oxfordeconomics.com in which future trend growth is of the order of $1.2 \%$; the other assumes linear trend growth of real per capita income ranging from $0.6 \%$ to $1 \%$ per annum. The results are robust to alternative assumptions, and $0.8 \%$ growth is assumed.

\section{Figure $\mathrm{A}$}

Actual values of log ratio of permanent to current income against fitted values and modified fitted values used in the consumption equation

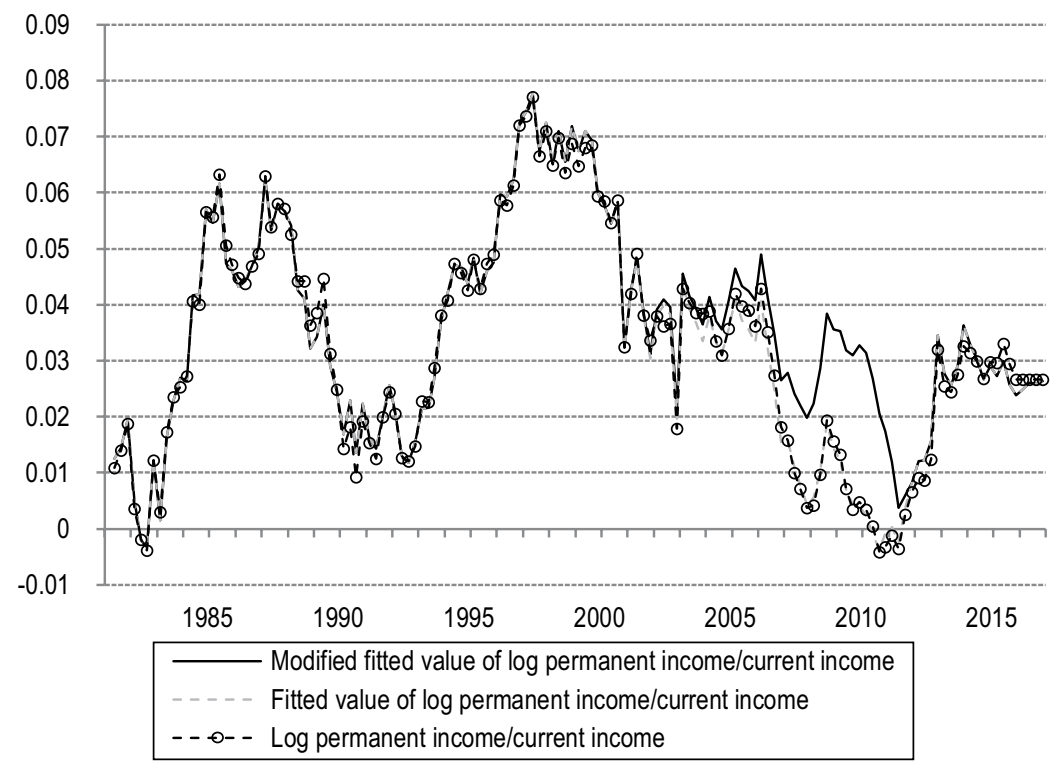


Box (contd.)

Table A

Estimates for the income growth forecasting model

\begin{tabular}{|c|c|c|c|c|}
\hline \multirow[t]{2}{*}{ Dependent Variable $=\log$ (permanent income/current income) } & \multicolumn{2}{|c|}{ 1981Q2-2016Q4 } & \multicolumn{2}{|c|}{ 1981Q2-2008Q3 } \\
\hline & Coefficient & $t$-ratio & Coefficient & t-ratio \\
\hline \multicolumn{5}{|l|}{ Variables } \\
\hline Constant & 1.74 & $37.3^{\star * *}$ & 1.68 & $18.7^{\star * *}$ \\
\hline Time trend & 0.00318 & $34.1^{* \star *}$ & 0.00299 & $21.8^{* \star *}$ \\
\hline Split trend from 2009Q4, discounted present value & -0.00200 & $22.3^{* * \star}$ & -0.00231 & $-5.4^{* \star *}$ \\
\hline Log (real per capita income) & -1.10 & $-42.4^{* * *}$ & -1.02 & $-39.5^{* * *}$ \\
\hline 4-quarter change in log (real per capita income) & 0.17 & $6.0^{\star \star \star}$ & 0.11 & $3.2^{* \star \star}$ \\
\hline Log working age pop./total population & 0.59 & & 0.59 & \\
\hline Survey expectations of future conditions & 0.0052 & $3.8^{* \star \star}$ & 0.0040 & 1.1 \\
\hline Real interest rate $\mathrm{ma4}_{t-1}$ & -0.08 & & -0.08 & \\
\hline Real interest rate $\mathrm{ma4}_{t-5}$ & -0.19 & $-6.3^{* \star *}$ & -0.18 & $-7.1^{* \star *}$ \\
\hline Real interest rate $\mathrm{ma}_{t-9}$ & -0.19 & $-7.1^{* \star *}$ & -0.18 & $-7.9^{* * *}$ \\
\hline 4-quarter change in T-bill rate & -0.073 & $-9.2^{\star \star \star}$ & -0.027 & $-1.6^{*}$ \\
\hline 4-quarter change in T-bill rate ${ }_{t-4}$ & -0.041 & $-6.7^{* * *}$ & -0.016 & -1.2 \\
\hline Log real stock market index ma4 ${ }_{t-1}$ & 0.015 & $7.3^{\star \star *}$ & 0.013 & $5.9^{\star \star \star}$ \\
\hline unemployment rate $\mathrm{ma}_{t-1}$ & -0.0034 & $-5.5^{* * *}$ & -0.0020 & $-2.2^{* *}$ \\
\hline unemployment rate $\mathrm{ma4}_{t-5}$ & -0.0022 & $-4.3^{\star \star *}$ & -0.0014 & $-3.4^{* * *}$ \\
\hline Log real oil price ma4 $t_{t-1}$ & -0.0071 & $-5.5^{\star \star *}$ & -0.0044 & $-2.5^{* *}$ \\
\hline Log real oil price ma4 ${ }_{t-5}$ & -0.0059 & $-4.2^{* \star *}$ & -0.0058 & $-3.7^{\star \star \star}$ \\
\hline Log real exchange rate ma4 $4_{t-1}$ & -0.038 & $-4.5^{\star \star *}$ & -0.032 & $2.2^{* \star}$ \\
\hline Log real exchange rate $\mathrm{ma}_{t-5}$ & -0.033 & $-3.0^{* \star *}$ & -0.045 & $-3.5^{\star \star *}$ \\
\hline \multicolumn{5}{|l|}{ Diagnostics } \\
\hline Equation standard error & \multicolumn{2}{|c|}{0.00184} & \multicolumn{2}{|c|}{0.00161} \\
\hline DW & \multicolumn{2}{|c|}{0.54} & \multicolumn{2}{|c|}{0.42} \\
\hline R-squared & \multicolumn{2}{|c|}{0.992} & \multicolumn{2}{|c|}{0.993} \\
\hline
\end{tabular}

Note: $t$-ratios are corrected for heteroscedasticity and autocorrelation. Statistical significance at the $10 \%, 5 \%$, and $1 \%$ levels is denoted by *

${ }^{* *}$, and ${ }^{* * *}$ respectively ma4: moving average of order 4 .

Sources: Insee; Banque de France; authors' calculations.

If the downturn in economic growth after the global financial crisis, implying a shift in the trend, had been fully anticipated, then, given the 10-year horizon, already in 2000, household expectations would have been beginning to build in the shift in trend that began at the end of 2009 . To fit the data, the permanent income model therefore incorporates the present discounted value of the shift in trend that began at the end of 2009. However, households could not have had this information in real time, so that generated permanent income up to 2009 Q3 omits this component of the econometric model. We then assume that households' expectations gradually incorporated the downward revision of trend growth over the next 8 quarters so that from 2011Q4 they have fully adjusted. The effect of the adjustment is that households have increasingly a too optimistic view of permanent income before 2009. This is shown in Figure A, suggesting households over-estimated permanent income by around 3 percent in 2009. by $C R C C I$, it is implausible to use the same linear form in each equation. Hence while $C R C C I$ enters the other equations linearly, in the consumer credit equation it enters as: $\ln \left(0.5+C R C C I_{t}\right)$. For log consumer debt, the marginal effect of $C R C C I$ then declines as $C R C C I$ rises, while for the other $(\log )$ variables, the marginal effect is constant (Figure I).

Though unsecured consumer debt was already rising dramatically before, credit controls were relaxed in 1984, when MCCI begins to rise strongly, and further deregulation took place later in the 1980s, when both indices rise. In the early 1990s, in common with many other countries, some French banks were in trouble with bad loans partly due to excess lending to real estate developers in the late $1980 \mathrm{~s}$, to households' nominal income deceleration following disinflationary monetary policy, and to the stresses caused by interest rate rises resulting from German unification. There is a close negative correlation from 1991 to 2016 between the lagged ratio of non-performing loans to total loans to the private sector, and our estimated MCCI (Figure II). The relation is particularly close when credit conditions tighten in 1991-1996 and 2010-2014. 
Towards the end of the 1990s, as banks recovered, credit flows improved, competition in credit markets increased with the expected arrival of the common currency and, as discussed in Online complements $\mathrm{C} 3$ and $\mathrm{C} 4$ conditions on securitisation of loans loosened, while terms of housing loans were extended from an average of 11.8 years in 1989 to 14.3 years in 1999 and 18.4 years in 2009. Given the maximum debt burden of loans allowed by banks to households,

\section{Figure I}

Estimated mortgage and consumer credit conditions indices in France

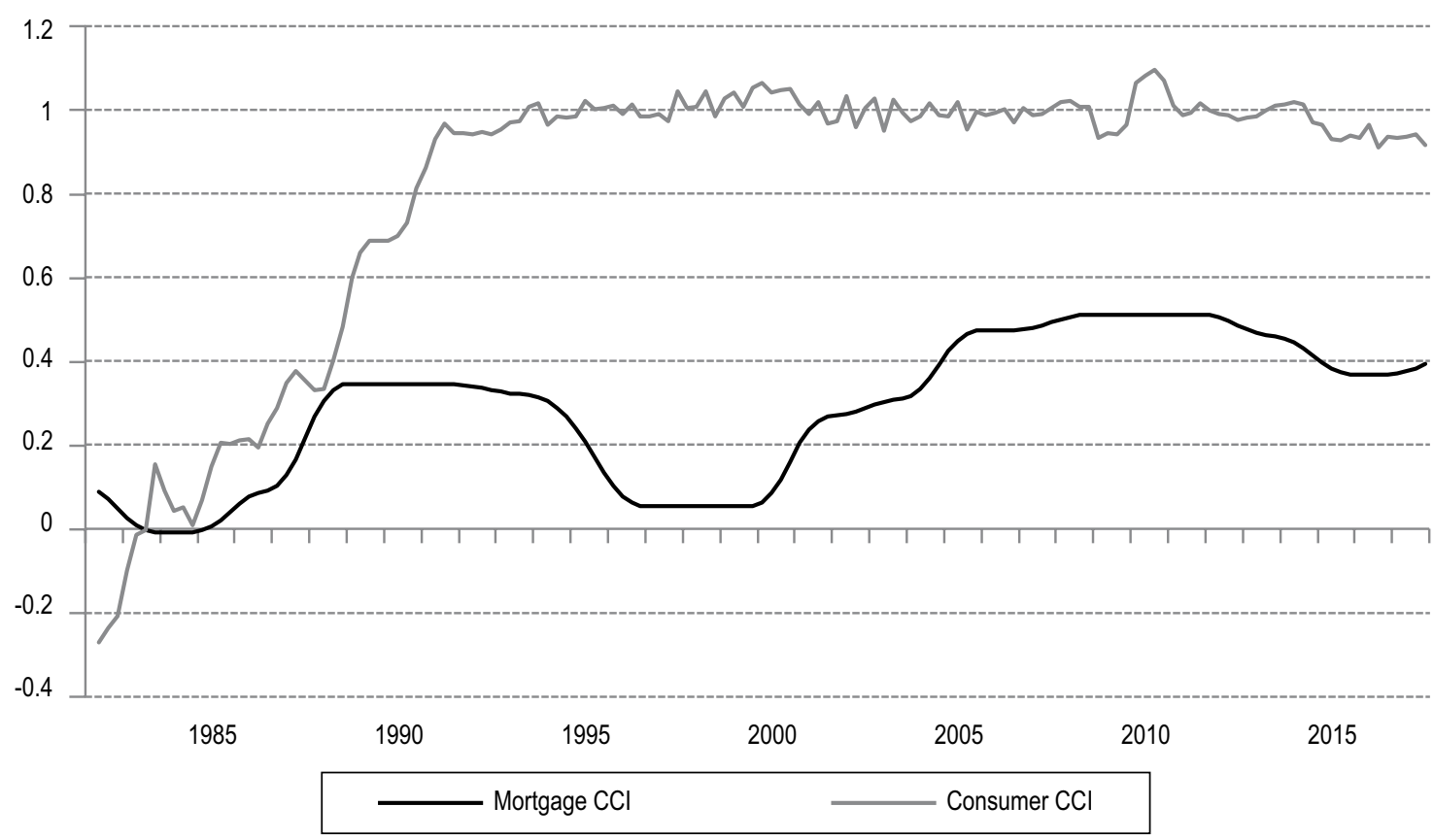

Sources: Insee; authors' calculations (see Online complement C2).

Figure II

Non-performing loan ratio (8-quarter moving average, lagged 2 quarters) and estimated mortgage credit conditions index in France

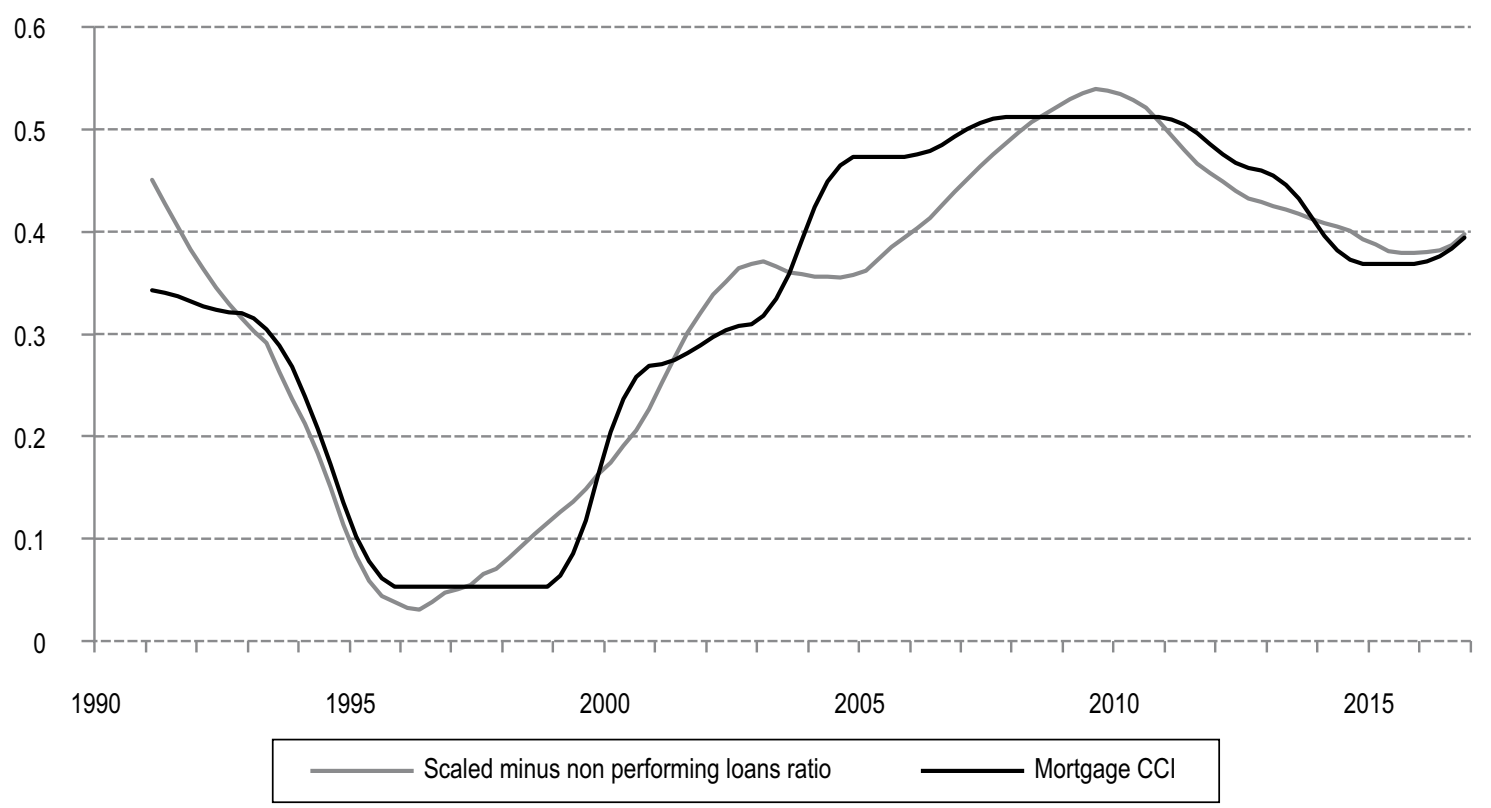

Sources: Insee; Banque de France; authors' calculations (see Online complement C2). 
the level of interest rates and of income, this meant an increase of nearly $20 \%$ in the borrowing capacity of households. This shows up as a considerable liberalisation on housing loans before declining once more after 2010 as the bad loans ratio rose. There seems to have been little change in credit availability for consumer credit since about 1990 (Figures I and II).

\section{Consumption}

The general form of the consumption equation was set out in equation (2). The estimated speed of adjustment at 0.56 is high, indicating a strong reaction of consumption to the long run determinants (Table 1). The main difference with US and UK estimates comes from effects of house prices and housing wealth.

The real interest rate enters as a weighted average of the real interest rate on unsecured debt and mortgage debt, weighted by the lagged debt to income ratios. It has a strongly significant negative effect. The coefficient on the ratio of permanent to current income is a little over one half, substantially below the "text-book" permanent income hypothesis of one, despite the fact that permanent income, by its construction already embodies a far shorter horizon. The coefficient on net liquid assets is substantially larger than that on illiquid financial wealth, the latter containing a large saving for retirement element ${ }^{6}$. The restriction that the debt coefficient is minus that on liquid assets is easily accepted. The apparently small size of the illiquid financial wealth effect with a marginal propensity to consume (MPC) of 0.022 is partly due to the inclusion of the control for permanent income, which is strongly affected by the stock market ${ }^{7}$. These results are consistent with those based on micro data for France. Using the French Wealth Survey and the Household Budget Survey, Arrondel et al. (2014) report a MPC for financial wealth ranging from 0 for the wealthiest owning mostly illiquid assets to 0.11 for the less wealthy owning mostly liquid assets.

Housing wealth/income has a positive effect, but with an MPC (0.013) smaller than that for illiquid financial assets, and with a strong offsetting negative effect from log house prices/ income. The two measures are quite correlated, so that their separate coefficients are not very accurately estimated. If the negative house price/income effect is omitted, housing wealth/ income becomes insignificant, with a t-ratio below 1 but other coefficients are little affected.
This answers the question of whether there is an aggregate housing wealth effect on consumption in France: the simplest interpretation is that there is such an effect for owners, but that it is offset, when housing becomes less affordable, by lower consumption of tenants, including those saving for a housing deposit. Such a hypothesis is confirmed by Arrondel et al. (2014), who find a MPC for housing wealth ranging from 0.007 to 0.011 for homeowners on microdata.

An interaction between mortgage credit conditions and log house prices/income proved negative and on the margin of significance. This result indicates the importance of distinguishing the down-payment from other constraints on borrowers. Easing only the former would entail a positive coefficient on the interaction. Easing only the latter is likely to drive larger fractions of potential first-time buyers to save more for a given down-payment ratio, resulting in a negative interaction effect. However, the overall implications for consumption from this more complex specification are almost the same as those discussed below for the 1996 to 2008 period.

Estimating demographic effects on consumption, given the other controls, of which balance sheets are themselves likely to be influenced by demography, potentially runs into a "spurious regression" problem as most demographic variables are integrated of order $2^{8}$. Cross-section studies tend to find the highest saving rates for households in the pre-retirement age bracket. This suggests using the proportion of adults in this age group, defined as the proportion of those aged 40 to 59 plus 0.4 of those aged 60-64, since the retirement age was 60 over most of our sample. The coefficient on this variable approximately represents minus the difference between the saving rate of this group of adults, about $40 \%$ of adults, compared to the remainder of adults. It seems hard to believe that this could be more than 0.4, an upper bound ${ }^{9}$. Between 1981 and 2016 , the $3 \%$ increase in this proportion would then imply a $1.2 \%$ decline in the consumption to income ratio. The freely estimated coefficient is

6. The estimated coefficient is 0.14 . However, the ratio to income of net liquid assets has a strong downward trend. Introducing a small trend effect, for example, from increased life expectancy for those aged 60 or more, which should also reduce the consumption to income ratio, it is easy to accept a coefficient of 0.12 , close to US and UK estimates. Fortunately, such a modification has little effect on other estimates.

7. This is consistent with Poterba (2000), who argues that so-called wealth effects in consumption functions, excluding controls for expected income, are a mix of genuine wealth effects and expectations.

8. Requiring twice differencing to make them stationary.

9. Cross-section evidence shows more moderate differences in saving rates out of income by age. Such evidence is only a rough quide since gross differences in saving rates by age are attenuated by wealth differences. 
within one standard error of -0.4 and we therefore calibrate the coefficient to this value.

The coefficient on the mortgage credit conditions index is normalised at 1 in the house price equation. When the MCCI has an impact of $+1 \%$ on house prices, then its estimated impact on consumption is $+0.06 \%$, everything else being equal. In the consumer loans equation, the term $\ln \left(0.5+C R C C I_{t}\right)$ has a coefficient normalised to 1 . For high values of $C R C C I$, a rise with a $1 \%$ impact on consumer credit implies an impact on consumption of around $0.08 \%$, other things being equal. The quantitative long-run contributions to the log-ratio of consumption to income of the two credit conditions indices are shown in Figure III-A.

From 1983 to 1990 increasing access to consumer credit is estimated to have increased the consumption to income ratio by around $6 \%$, with another $2.5 \%$ or so from increased access to mortgages. However, the negative offset from the rise in the overall debt to income ratio, as reflected in the decline in the ratio of liquid assets minus debt, accounted for around 3\% over that period.
From the 1996 trough to the 2008 peak in the housing market and mortgage credit availability, the increase in mortgage credit availability accounts for a direct increase in the $\log$ consumption to income ratio of about $2.5 \%$ and an indirect increase via housing wealth of $3.5 \%$. But this is almost exactly balanced by a $3.5 \%$ negative effect from higher house prices relative to income and a $2.5 \%$ negative effect of lower net liquid assets relative to income, mainly driven by higher household debt.

The UK and the US also experienced mortgage credit liberalisation and a large rise in housing wealth from 1996 to 2007. Falls in the ratio of liquid assets minus debt to income also occurred in the US and the UK with similar negative effects on consumption to those in France, see Duca and Muellbauer (2013) and Hendry and Muellbauer (2018). But with far smaller down-payment requirements and easy access to home equity withdrawal, the net consumption effects, unlike in France, were large and positive in the US and the UK.

\section{Figure III-A}

\section{Long-run effects on log consumption/income in France}

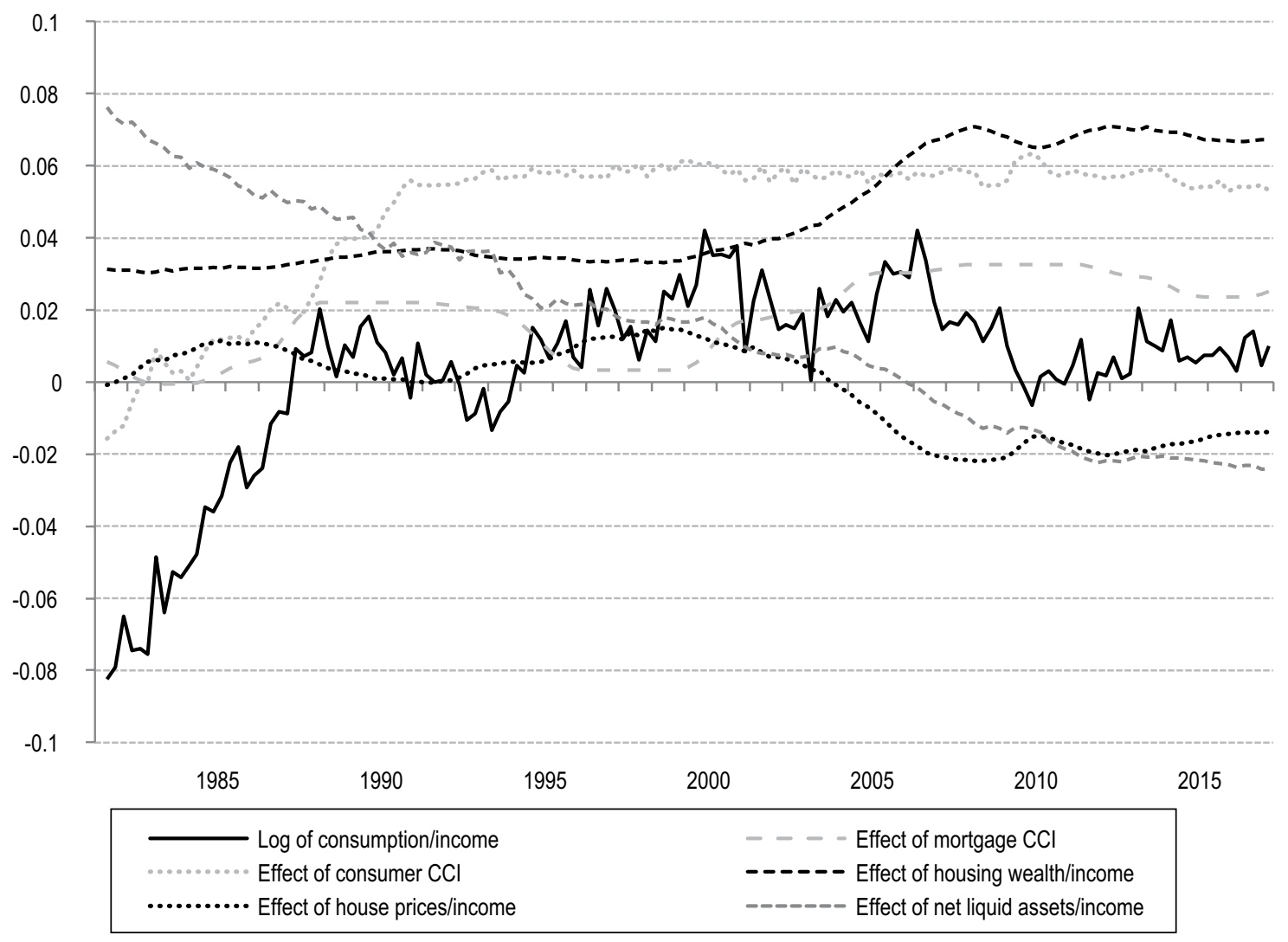

Sources: Banque de France; OECD; Insee; authors' calculations. 
Figure III-B illustrates the notable contributions of ratios to current income of permanent income and illiquid financial wealth, and of real interest rates, which rose in the 1980s and fell after the mid-1990s. The increasing share of adults in the pre-retirement age-group is reflected in the demographic trend.

The propensity to consume might depend on the type of income. It is accounted for in the form of a weighted average of log conventional household disposable income (HDI) and $\log$ non-property income, with weights $\omega$ and $1-\omega$. The estimated weight on log HDI is 0.5. Since HDI contains non-property income, the implied weight on the property component of income is around 0.33 with 0.67 on the non-property component ${ }^{10}$.

The short-run dynamics include five economic variables: the quarterly change in log real income enters with a negative coefficient, suggesting that a mix of current and last quarter's income is relevant for consumption. The change over four quarters in the unemployment rate has a significant negative effect, paralleling results for other countries, see Aron et al. (2012). Inflation over the two previous years has a negative effect ${ }^{11}$. A measure of the car scrapping scheme subsidy is strongly significant, with a positive effect, offset by a negative effect in the quarter after the subsidy ends ${ }^{12}$. The annual change in the housing transaction tax rate has a significant negative effect on consumption. The specification also included three impulse dummies for outliers ${ }^{13}$, which may represent other shocks, e.g. due to major strikes or floods. The results are robust to the exclusion of the impulse dummies though illiquid wealth is a little less significant. Parameter stability tests, for example estimating from 1986Q1 instead of 1981Q2, and estimating to 2008Q3, omitting the global financial crisis, support the reported estimates. The second column reports estimates to $2008 \mathrm{Q} 3^{14}$.

10. If income is measured just by non-property income, all the wealth coefficients rise. This is not surprising since the omitted property income is clearly linked with asset ownership. The negative effect of the log house price to income ratio increases.

11. It is unlikely that this could be a real balance effect since that is already strongly represented through the net liquid asset/income term. It could be another indicator of uncertainty about real income or indirectly picking up a small role for nominal interest rates, given the strong real interest rate effects in the equation.

12. The scheme operated for parts of the periods 1994-98 and 2009-13 and had the purpose of stimulating the car industry by offering a premium for scrapping of older models when purchasing a new one.

13. For 1984Q4, $1993 \mathrm{Q} 1$ and $1995 \mathrm{Q} 2$.

14. Since estimation of demographic effects needs long samples, the coefficients on the proportion of adults in the pre-retirement age group in the consumption equation and that on the log working age population in the permanent income equation are set to the full sample values.

\section{Figure III-B \\ Long-run effects on log consumption/income in France}

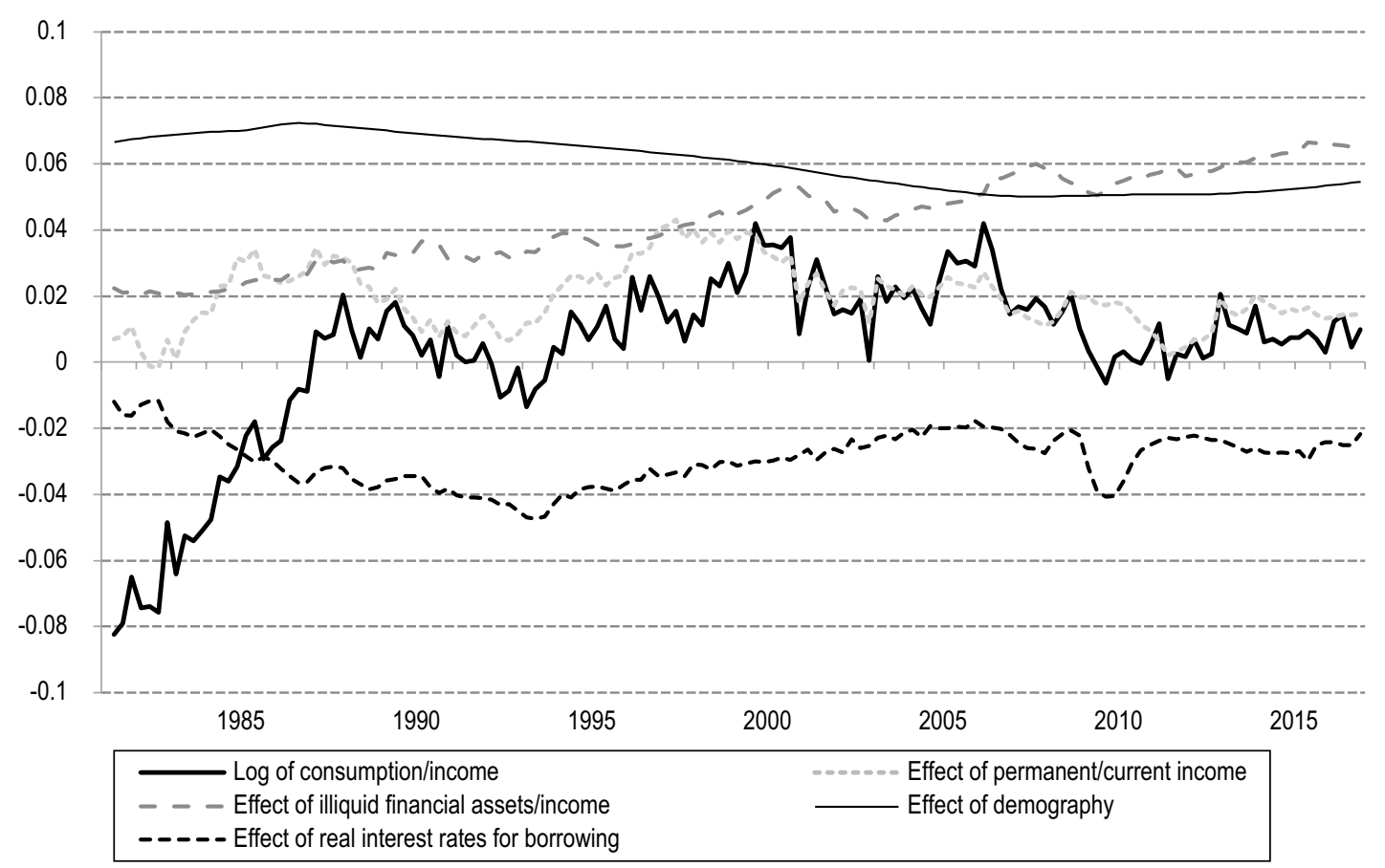

Sources: Banque de France; Insee; authors' calculations. 
The last column of Table 1 shows estimates for the consumption function obtained when the two credit conditions indicators are excluded. The speed of adjustment falls from 0.55 to 0.2 and the R-squared falls from to 0.71 to 0.57 . The coefficient on the log house price to income ratio switches from negative to positive, while that on the housing wealth to income ratio switches from positive to negative, though neither is significant. The marginal propensities to spend out of net liquid and illiquid financial assets both rise and are far less well determined. The direction of these biases can all be interpreted in terms of correlations with the omitted

Table 1

Estimates of the long-run solution of the French consumption function

\begin{tabular}{|c|c|c|c|c|c|c|c|}
\hline \multirow{2}{*}{ Dependent Variable $=\Delta \ln c_{t}$} & \multirow{2}{*}{ Symbol } & \multicolumn{2}{|c|}{ 1981Q2-2016Q4 } & \multicolumn{2}{|c|}{ 1981Q2-2008Q3 } & \multicolumn{2}{|c|}{$\begin{array}{l}\text { 1981Q2-2016Q4 } \\
\text { Excluding } \mathrm{CCls}^{(\mathrm{a})}\end{array}$} \\
\hline & & Coefficient & t-ratio & Coefficient & $t$-ratio & Coefficient & t-ratio \\
\hline Speed of adjustment & $\lambda$ & $0.56^{\star * *}$ & 11.1 & $0.63^{* * *}$ & 10.3 & $0.20^{\star * *}$ & 5.0 \\
\hline \multicolumn{8}{|l|}{ Long-run coefficients for log c/y } \\
\hline Constant & $\alpha_{0}$ & $0.08^{*}$ & 1.7 & $0.12^{\star *}$ & 2.2 & -0.11 & -0.9 \\
\hline Mortgage credit conditions index: $\mathrm{MCCl}$ & $\alpha_{0 c}$ & $0.064^{* \star *}$ & 5.3 & $0.078^{\star * *}$ & 4.8 & 0 & Fix \\
\hline Consumer credit CCl: $\mathrm{CRCCI}$ & $\alpha_{00 c}$ & $0.058^{\star \star \star}$ & 5.4 & $0.066^{* * *}$ & 4.9 & 0 & Fix \\
\hline Real interest rate ${ }_{t}$, weighted by debt/income & $\alpha_{1}$ & $-0.72^{\star * \star}$ & -7.5 & $-0.65^{\star \star *}$ & -4.8 & $-1.17^{\star \star *}$ & -4.0 \\
\hline Forecast future income growth: $E \ln (y p e r m / y)_{t}$ & $\alpha_{3}$ & $0.55^{\star \star \star}$ & 9.9 & $0.59^{\star * *}$ & 11.3 & $0.48^{\star \star *}$ & 3.1 \\
\hline Net liquid assets ${ }_{t-1} / y_{t}$ & $\gamma_{1}$ & $0.14^{\star \star *}$ & 4.4 & $0.13^{* * *}$ & 4.3 & $0.18^{* *}$ & 2.0 \\
\hline Illiquid financial assets $t_{t-1} / y_{t}$ & $\gamma_{2}$ & $0.022^{\star \star \star}$ & 3.3 & $0.017^{\star \star \star}$ & 3.4 & $0.040^{* *}$ & 2.3 \\
\hline Housing wealth $t_{t-1} /$ income $_{t-1}$ & $\gamma_{3}$ & $0.013^{\star *}$ & 2.2 & $0.015^{\star \star \star}$ & 2.7 & -0.013 & -0.9 \\
\hline Log house prices $_{t-1} /$ income $_{t-1}$ & $\gamma_{4}$ & $-0.062^{* *}$ & -2.5 & $-0.081^{\star \star \star}$ & -3.1 & 0.070 & 1.2 \\
\hline Ratio of pre-retirement age group/adults & $\gamma_{5}$ & -0.4 & fix & -0.4 & fix & -0.4 & fix \\
\hline Weight on $H D I$ & $\omega$ & 0.5 & fix & 0.5 & fix & 0.5 & fix \\
\hline \multicolumn{8}{|l|}{ Diagnostics } \\
\hline Equation standard error & & \multicolumn{2}{|c|}{0.00324} & \multicolumn{2}{|c|}{0.00306} & \multicolumn{2}{|c|}{0.0390} \\
\hline DW & & \multicolumn{2}{|c|}{1.93} & \multicolumn{2}{|c|}{1.86} & \multicolumn{2}{|c|}{1.85} \\
\hline R-squared & & \multicolumn{2}{|c|}{0.705} & \multicolumn{2}{|c|}{0.760} & \multicolumn{2}{|c|}{0.573} \\
\hline
\end{tabular}

(a) Excluding the two credit conditions indicators.

Note: Statistical significance at the $10 \%, 5 \%$, and $1 \%$ levels is denoted by ${ }^{*}$ ** , and ${ }^{* * *}$ respectively. Maximum likelihood estimation of 6 -equation system in TSP (Time Series Processor) 5.1. Equation standard errors are RMSEs of the residuals.

Sources: Banque de France; Insee; OECD; authors' calculations.

Table 2

Estimates of the long-run credit conditions and wealth effects for Germany, UK and US

\begin{tabular}{|c|c|c|c|c|c|c|c|}
\hline & Symbol & $\begin{array}{l}\text { German estimate } \\
\text { 1981:3-2012:4 }\end{array}$ & $t$-ratio & $\begin{array}{c}\text { UK estimate } \\
\text { 1967:1 - 2005:4 }\end{array}$ & $t$-ratio & $\begin{array}{l}\text { US estimate } \\
\text { 1971:4 - 2011:1 }\end{array}$ & $t$-ratio \\
\hline $\begin{array}{l}\text { Mortgage credit conditions index: } \\
\mathrm{MCCl}\end{array}$ & $\alpha_{0 c}$ & 0.073 & 5.8 & 0.050 & 3.6 & - & - \\
\hline $\begin{array}{l}\text { Consumer credit CCl: } \\
\mathrm{CRCCl}\end{array}$ & $\alpha_{00 c}$ & 0.024 & 1.0 & - & - & 0.089 & 7.7 \\
\hline Net liquid assets $t_{t-1} / y_{t}$ & $\gamma_{1}$ & 0.09 & 4.1 & 0.11 & 8.0 & 0.10 & 7.6 \\
\hline Illiquid financial assets $/ y_{t-1} y_{t}$ & $\gamma_{2}$ & 0.016 & 2.5 & 0.022 & 8.0 & 0.017 & 8.6 \\
\hline Housing wealth $t_{t-1} /$ income $_{t-1}$ & $\gamma_{3}$ & 0.001 & 0.1 & - & - & - & - \\
\hline$M C C /{ }^{*}$ Housing wealth ${ }_{t-1} /$ income $_{t-1}$ & $\gamma_{3 c}$ & & & 0.043 & 10.3 & 0.055 & 5.4 \\
\hline log house prices $t_{t-1} /$ income $_{t-1}$ & $\gamma_{4}$ & -0.069 & -3.2 & - & - & - & - \\
\hline
\end{tabular}

Notes: German estimate from a special version of the equation in Geiger et al. (2016); UK estimate from Aron et al. (2012); US estimate from Duca and Muellbauer (2013).

Sources: Cited papers. 
credit conditions. Forcing wealth effects to enter in a single net worth to income ratio and omitting the log house price to income ratio fares even worse, with the coefficient on the net worth to income ratio estimated to be negative. No wonder previous estimates of aggregate French consumption functions find unstable wealth effects (Chauvin \& Damette, 2011). As argued in Hendry and Muellbauer (2018), the net worth constraint and the omission of shifts in credit conditions correspond to a gross misspecification, particularly for economies where large shifts have occurred in credit architecture.

Comparable estimates of long-run credit conditions and wealth effects for Germany, the UK and the US, are shown in Table 2. They show no housing wealth or collateral effect in Germany but a comparable negative effect of log house prices/income as in France. Also, the small variation in credit conditions entail smaller effects than in France. In the UK and the US the interaction of mortgage credit conditions and housing wealth/income is crucial, suggesting no housing wealth or collateral effect before mortgage credit liberalisation.

\section{House prices}

In the house price equation, the credit conditions indicator for housing loans is identified except for a constant. This effect is normalised at one, at the intercept. The estimated quarterly speed of adjustment is 0.12 , similar to that found for Germany in Geiger et al. (2016) (Table A2-1). The elasticity of house prices w.r.t. to the nominal mortgage rate is $-0.38(t=-11.5)$. There is also an interest rate effect buried in the user cost measure, which turns out to interact with mortgage credit conditions. When MCCI is zero, there is no significant user cost effect. This finding is consistent with the large user cost effect found by Duca et al. $(2011,2016)$ for US house prices, given higher levels of leverage there.

The user cost variable is described in Appendix 1. It incorporates large transaction costs which are motivated by weak mobility in France. Together with a time-varying risk premium, this prevents user cost becoming negative after a period of large house price increases. Lagged house price appreciation relative to other countries was also explored but found insignificant.

The effect of income relative to the net housing stock is strongly significant and in line with Meen (2001) "central estimates". Indeed, the log of this measure has a freely estimated coefficient close to 2 and we impose this restriction, implying that the price elasticity of aggregate demand for housing in France is -1/2. It is a little less elastic than UK estimates, see Cameron et al. (2006), and substantially less elastic than German estimates, see Geiger et al. (2016) ${ }^{15}$. The hypothesis of an equal and opposite coefficient on log income and log housing stock, implying an income elasticity of demand for housing of one, is accepted by data, as is usually the case in this approach ${ }^{16}$. The relative weight of log permanent to current income of 0.52 is close to the 0.55 found in the consumption function.

The last elements in the long run solution are two demographic variables also found relevant in the mortgage equation: the ratio of children to adults and the proportion of adults in the pre-retirement age group. On the one hand, a higher ratio of children to adults suggests a rise in the number of families, increasing housing demand. On the other hand, cross-section data in Arrondel et al. (2016) show the highest incidence of mortgages by 10-year age brackets in the 40-49 and 50-59 brackets. To avoid the risk of spuriously large demographic effects, the size of the coefficient for the ratio of children to adults (resp. for the proportion of 40 to $60-64 \mathrm{~s}$ ) is limited to 2 (resp. 3). Those values are within one standard error of the freely estimated coefficient.

Short-term effects include the acceleration of the proportion of those aged 25 to 40 as well as that of unemployment rate over two quarters. Note that those variables are also in the short-term dynamics of mortgage equation, but by considering their change rather than their acceleration.

Since persistence in house price appreciation is already incorporated in the user cost, further short-term house price dynamics are checked using lagged acceleration in log nominal housing stock. Short-run dynamics also include the annual change in transactions costs - the level is not significant - and some impulse dummies. These capture the three quarters after the collapse of Lehman Bros.

Figure IV-A shows that the combination of lower nominal interest rates and liberalisation of credit market conditions explains a good deal of the upward trend since 1985 in real house

15. This is probably due to the Paris-dominated structure of the French economy in contrast to the far more decentralised German economy with multiple metropolitan centres, thus offering greater locational substitution possibilities. 16. Note that this model cannot estimate the elasticity of housing supply with respect to prices because the stock of houses is considered as given. 
prices, with credit crunches explaining most of the fall from 1990 to 1996 and after 2010. Demography, in the form of the fall in the ratio of children to adults, together with rising housing supply relative to income and population explains the fall in real house prices in the early 1980s, despite falling interest rates (Figure IV-B). Demography explains about half of the rise after 1995, when the increasing share of adults in the pre-retirement age group is more than compensating for the continued, but more moderate, decline in the child/adult ratio.

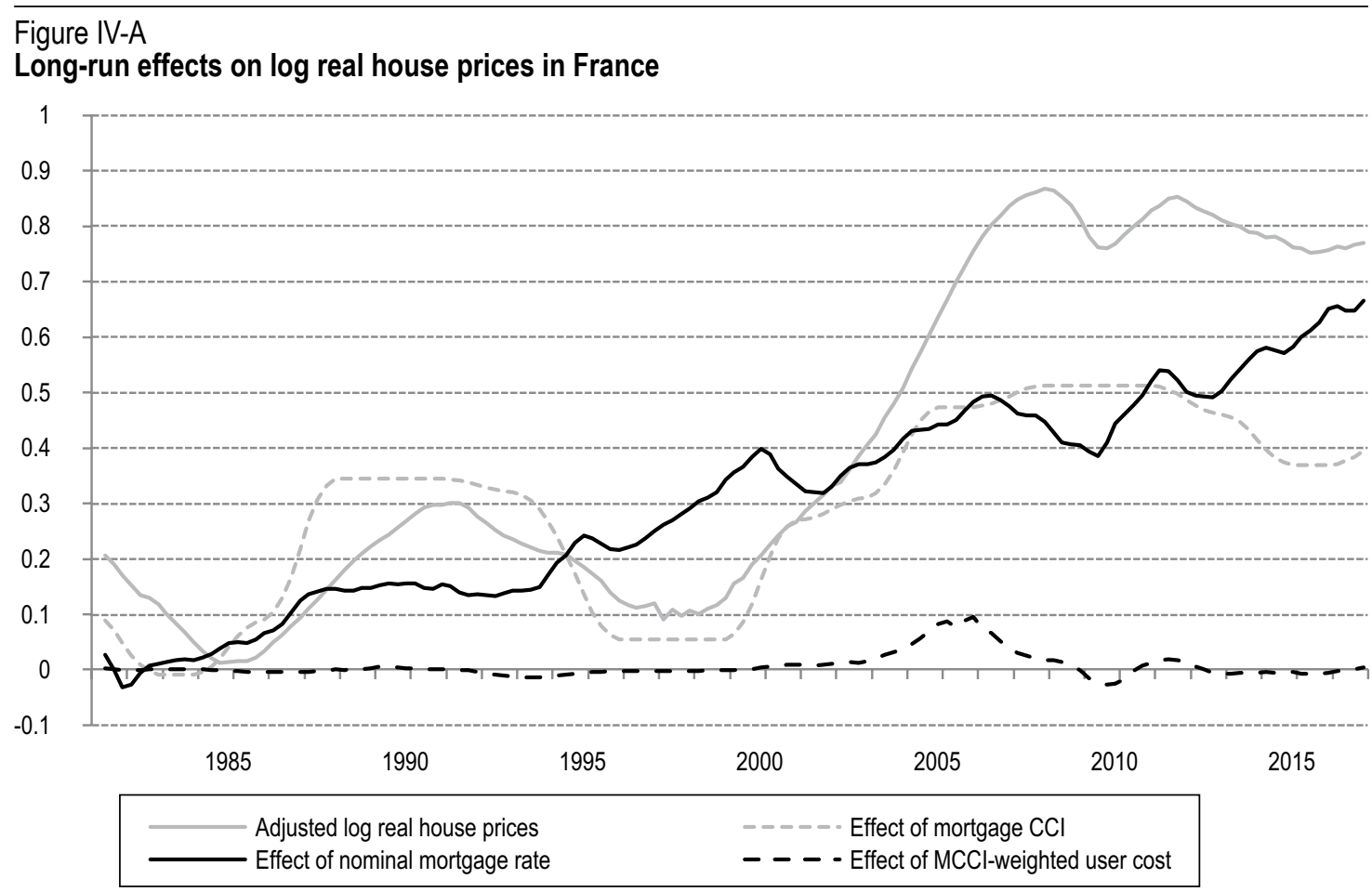

Sources: Banque de France; Insee; OECD; authors' calculations.

Figure IV-B

Long-run effects on log real house prices in France

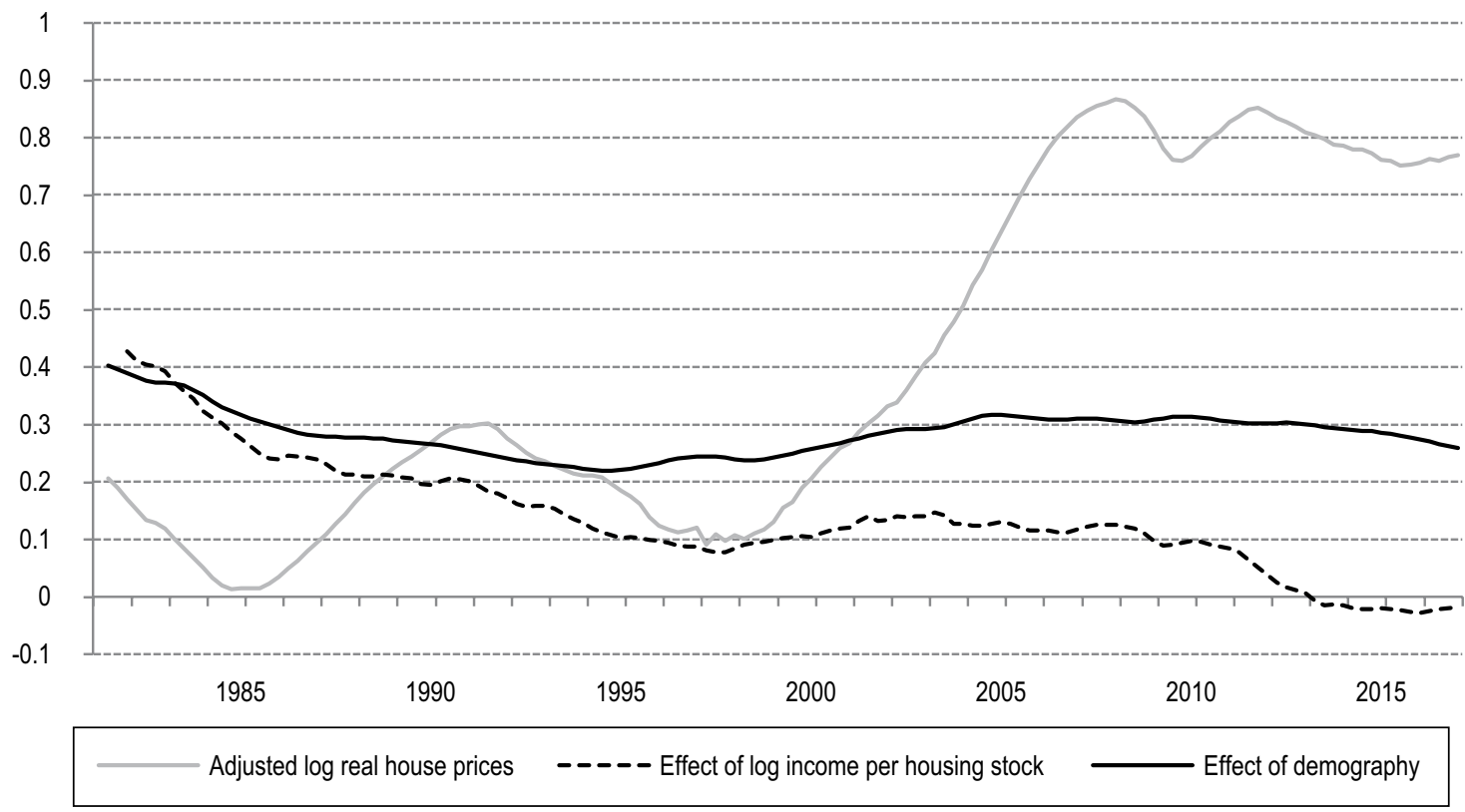

Sources: Banque de France; Insee; OECD; authors' calculations. 
Excluding the $M C C I$ term in the house price equation, leads to a collapse in the speed of adjustment from 0.12 to 0.026 , and a dramatic worsening in the fit and in autocorrelation of the residuals. Without restrictions, many of the estimated long-run effects would be absurd. To help define a sensible long-run solution, key coefficients are calibrated as shown in the table and demographic effects are generalised by including the proportion of adults aged 25 to 44 . The evidence is consistent with that of the studies surveyed in Online complement $\mathrm{C} 1$ excluding credit conditions, which reveal extreme fragility of estimated parameters, and in many cases magnitudes of elasticities far from economically plausible values. Even with calibrated demographics and interest rate effects, the freely estimated coefficient on $\log$ income per house would rise from a value of 2 to the absurd level of 12 (and a very low price elasticity of demand), while the speed of adjustment falls further.

\section{Mortgage stock}

Miles (1992) and Brueckner (1994) discuss the borrowing and saving decisions for housing and portfolio investment motives as well as the consequences of the relaxation of mortgage rationing for the mortgage stock. However, little systematic econometric work exists on household debt, see the reviews in Fernandez-Corugedo and Muellbauer (2006) and in Meen (1990). In France, as in most developed economies, mortgage debt accounts for the major proportion, often 70 to 80 percent of total household debt.

Given the long duration of mortgage contracts, the mortgage stock adjusts quite slowly to the long-run drivers, with a quarterly speed of adjustment of $0.077(t=15.8)$ (see Table A2-2). This is not far from estimates of around 0.065 found for the UK in Fernandez-Corugedo and Muellbauer (2006). In the long-run solution for the mortgage stock equation, the log of the nominal mortgage interest rates has a highly significant coefficient of $-0.46(t=-16.6)$. Such a strong effect is consistent with banks using the debt service ratio as a key lending criterion (Online complement $\mathrm{C} 4$ ). In the extreme case of every borrower at the maximum allowed by the ceiling on the debt service ratio, the coefficient on the nominal interest rate would be -1 . Neither the real interest rate nor a measure of the user cost of housing proved significant, though user cost has an indirect influence via its impact on house prices. Not surprisingly, mortgage credit conditions have a highly significant intercept effect, with a coefficient of 0.59 . The effect of the log house price to income ratio varies strongly with mortgage credit conditions, a highly significant interaction effect.

No effects could be detected of liquid or illiquid financial wealth or of permanent income on the stock of mortgages, and an income elasticity of one is accepted. The housing transactions cost has a clear negative effect on the level of mortgages. Demography has important effects, as suggested by recent international evidence on rates of housing investment by Monnet and Wolf (2016) interpreted as demand for housing. The ratio of children to adults and the ratio of adults in the pre-retirement age group (defined as above) both have strong positive effects, somewhat amplified from their role in the house price equation. The effect is calibrated at 1.5 of the effect in the house price equation, an acceptable restriction, below the freely estimated value. In the short-term dynamics, the change (but not the level) in the proportion in the age group 25 to 44 has a highly significant positive effect, $t=12.4$. Short run dynamics include a negative effect from the change in the unemployment rate over the two previous quarters, $t=-3.2$.

Figure V-A and V-B, which decompose part of the long-run solution, show that the loosening of housing loans conditions, the fall in nominal mortgage rates, the interaction of credit liberalisation with house price to income ratios and demography are the key to understanding the rise in the mortgage stock to income ratio. There is a modest positive effect from the decline in transactions cost and a notable effect from demography, in particular from the decline in the child to adult ratio, offset somewhat by the increasing proportion of adults in the pre-retirement age group.

When the mortgage credit conditions index is omitted from the housing loan stock equation, the speed of adjustment falls, but only modestly, and the equation standard error rises. The equation is now dominated by the $\log$ ratio of house prices to income, clearly a proxy for the omitted credit conditions effect, though the log of the nominal mortgage rate remains highly significant. 
Figure V-A

Long-run effects on log mortgage stock/income in France

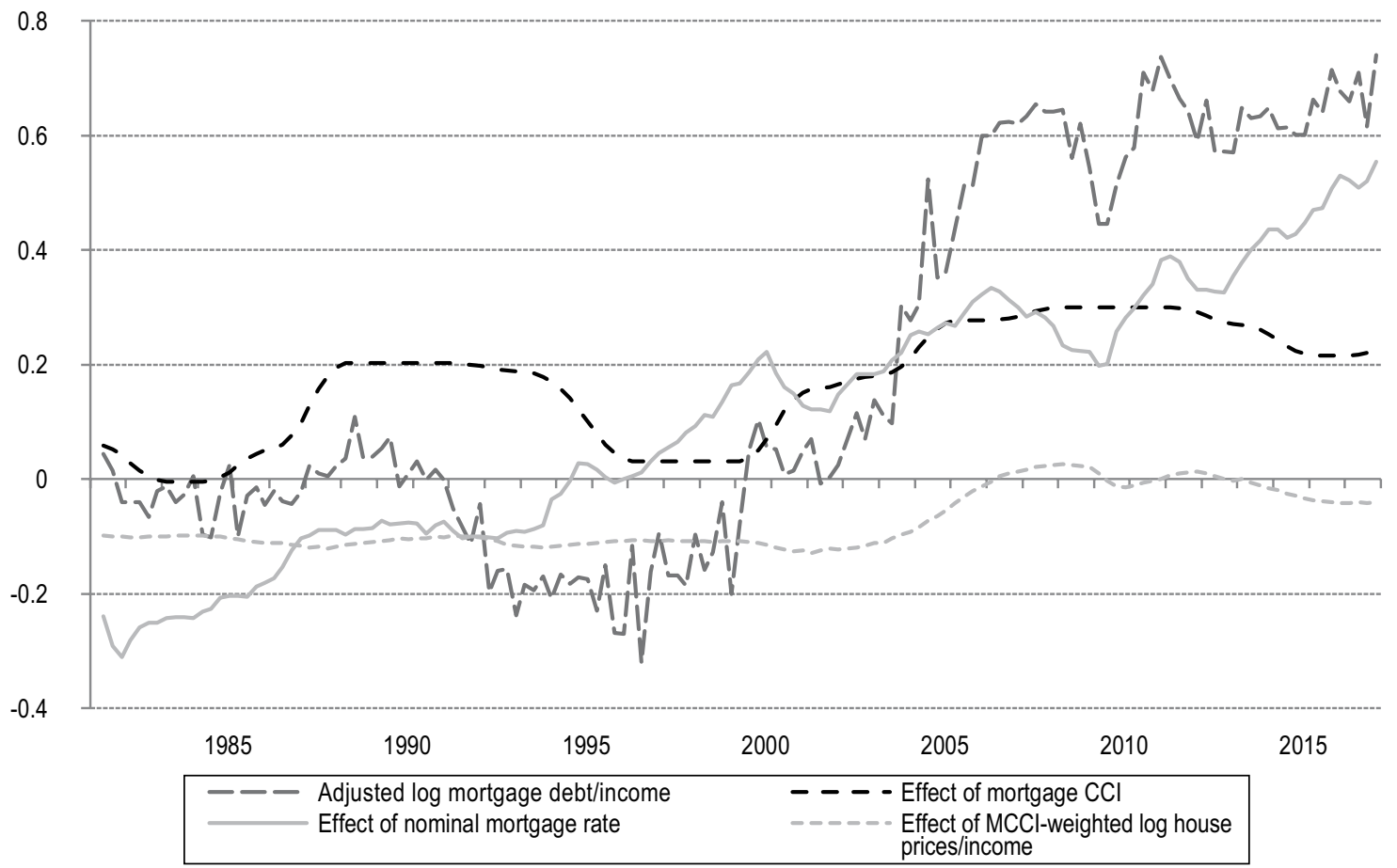

Note: Given the slow speed of adjustment, the dependent variable in the figures is $\ln \left(\right.$ debt $_{t-1} /$ income $\left._{t-1}\right)+\Delta \ln \left(\right.$ debt $\left._{t} / \pi\right)$ where $\pi$ is the speed of adjustment. Without the second term, the visualisation would show a strong lag between the long run drivers and the dependent variable.

Sources: Banque de France; Insee; authors' calculations.

Figure V-B

Long-run effects on log mortgage stock/income in France

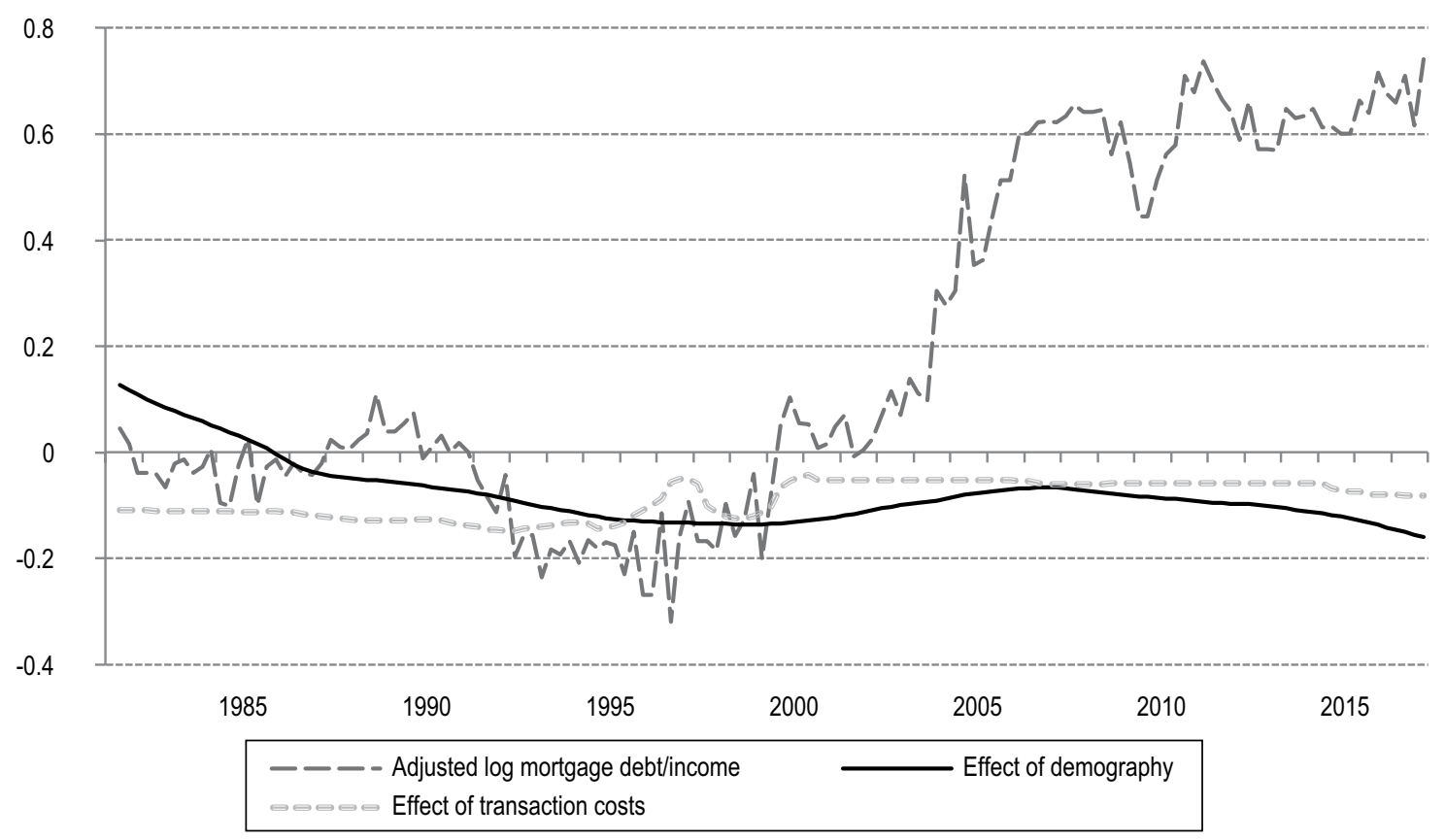

Note: Given the slow speed of adjustment, the dependent variable in the figure is $\ln \left(\right.$ debt $_{t-1} /$ income $\left._{t-1}\right)+\Delta \ln \left(\right.$ debt $\left._{t} / \pi\right)$. Without the second term, the visualisation would show a strong lag between the long run drivers and the dependent variable.

Sources: Banque de France; Insee; authors' calculations. 
The consumption functions of current central bank non-DSGE econometric policy models typically summarise household portfolios in a single net worth measure and neglect shifts in credit conditions. These assumptions greatly restrict the interactions of the household and financial sectors. The empirical evidence of this article for French quarterly data from 1981 to 2016 strongly rejects these assumptions.

Not all co-movements between consumption and wealth are wealth effects. Some result from common factors including shifts in credit conditions, interest rates, income expectations or demographics. These controls are essential to estimate well-identified wealth effects and to illuminate direct and indirect monetary policy transmission on consumption. To distinguish common factors driving consumption and household portfolios from causal relationships, it is necessary to model the main components of household portfolios. This includes modelling house prices, which derive from housing demand, given the housing stock. The model therefore included equations for consumption, house prices, mortgage debt, consumer credit, liquid assets, and permanent income. Controls included credit conditions both for housing and non-housing consumer credit, estimated as latent variables common to multiple equations, interest rates, income expectations and demographics.

Previous macro-econometric models excluding the two credit conditions indicators perform badly, particularly as far as consumption, house prices and consumer credit are concerned. The interpretation of the two latent variables in the system as credit availability indicators is a strong one. Financial liberalization relaxed French mortgage credit conditions from 1984. Subsequent variations are strongly inversely correlated with banks' non-performing loans. Permanent income matters for consumption but, consistent with undiversifiable income uncertainty and liquidity constraints, far less than under the strict permanent income hypothesis. For France, the marginal propensities to consume from financial wealth are comparable to those in the US, the UK and Germany, with a marginal propensity to consume out of liquid assets minus debt far greater than for illiquid financial assets. But, as in Germany, housing wealth or collateral effects in France are much weaker in aggregate, given the absence of home equity loans, than in the US or the UK. ECB (2009) points to this as a major factor in the high levels of heterogeneity across countries in housing wealth or collateral effects on consumption. Arrondel et al. (2014) support the evidence for small housing wealth effects for French homeowners, using microdata. Moreover, there is evidence of a negative effect on aggregate consumption of higher house prices. This can be interpreted as follows: with relatively strict financial regulation in France, higher house prices relative to income require younger households to save more if they wish to become homeowners, while other tenants can expect rent rises and so save more also.

During the French house price boom between 1996 and 2008, a small positive housing wealth effect on consumption and looser mortgage credit conditions, were thus offset by the negative effect of higher house prices and higher debt. France is therefore very different from the Anglo-Saxon economies where home equity loans produced large collateral effects of housing wealth on consumption. As a result, despite higher house prices, France did not experience an Anglo-Saxon-style consumption boom in which the financial accelerator via home equity loans proved powerful and destabilising. Another element in the US house price boom was an overshooting of house prices due to extrapolative expectations, likely to have been enhanced by high levels of gearing. The empirical evidence is that overshooting of French house prices due to extrapolative expectations has been on a relatively limited scale, consistent with relatively strict regulations, which limit gearing by French households. This suggests only a small potential risk factor for financial stability from this source.

House prices are quite sensitive to interest rates and, of course, to income and the supply of houses. Moreover, consumption is quite sensitive to interest rates making interest rates and income potential sources of fragility for the French housing and housing loans markets. However, with lower levels of illiquid financial asset holdings in France than in the US or the UK, the financial asset price mechanism for monetary transmission is likely to be weaker. These findings suggest that, incorporated in a larger econometric model, in which different scenarios could be simulated, this household sector model is useful for examining monetary policy issues, including financial stability. 


\section{BIBLIOGRAPHY}

Adda, J. \& Cooper R. (2000). Balladurette and Juppette: A Discrete Analysis of Scrapping Subsidies. Journal of Political Economy, 108(4), 778-806. https://doi.org/10.1086/316096

Aron, J. \& Muellbauer J. (2013). Wealth, Credit Conditions and Consumption: Evidence from South Africa. Review of Income and Wealth, 59(S1), 161-196.

https://doi.org/10.1111/roiw.12033

Aron, J., Duca J., Muellbauer, J., Murata, K. \& Murphy, A. (2012). Credit, Housing Collateral and Consumption: Evidence from Japan, the U.K. and the U.S. Review of Income and Wealth, 58(3), 397-423.

https://doi.org/10.1111/j.1475-4991.2011.00466.x

Arrondel, L., Bartiloro, L., Fessler P., Lindner, P., Mathä, T. Y., Rampazzi, C., Savignac, F., Schmidt, T., Schürz, M. \& Vermeulen, P. (2016). How Do Households Allocate Their Assets? Stylized Facts from the Eurosystem Household Finance and Consumption Survey. International Journal of Central Banking, 12(2), 129-220.

http://www.ijcb.org/journal/ijcb16q2a4.pdf

Arrondel, L., Lamarche, P. \& Savignac, F. (2014). Consommation et patrimoine des ménages : au-delà du débat macroéconomique. Économie et statistique, 472-473, 21-48.

https://doi.org/10.3406/estat.2014.10487

Avouyi-Dovi, S., Borgy, V., Pfister, C., Scharnagl, M. \& Sedillot, F. (2014). Households' Portfolio Choices: A comparison between France and Germany (1978-2009). In: Winkler, B.,Van Riet, A. et Bull, P. (Eds.) A Flow of Funds Perspective on the Financial Crisis. London: Palgrave MacMillan. https://doi.org/10.1057/9781137352989

Bernard, J.-B. \& Berthet, L. (2015). French Housholds Financial Wealth: Which Changes in 20 Years? Insee working paper $\mathrm{N}^{\circ} \mathrm{G} 2015-18$. https://www.insee.fr/en/statistiques/1304139

Beyer, A., Coeuré, B. \& Mendicino, C. (2017). Foreword - The Crisis, Ten Years After: Lessons Learnt for Monetary and Financial Research. Economie et Statistique / Economics and Statistics, 494-495-496, 45-64.

https://doi.org/10.24187/ecostat.2017.494t.1918
Blanchard, O. (2018). On the Future of Macroeconomic Models. Oxford Review of Economic Policy, 34(1-2), 43-54.

https://doi.org/10.1093/oxrep/grx045

Bontemps, C. \& Mizon, G. E. (2008). Encompassing: Concepts and Implementation. Oxford Bulletin of Economics and Statistics, 70(1), 721-775. https://doi.org/10.1111/j.1468-0084.2008.00528.x

Brueckner, J. K. (1994). The Demand for Mortgage Debt, Some Basic Results. Journal of Housing Economics, 3(4), 251-262.

https://doi.org/10.1006/jhec.1994.1012

Buiter, W. H. (2010). Housing wealth isn't wealth, Economics - The Open-Access, Open-Assessment E-Journal. Kiel Institute for the World Economy, 4(22), 1-29.

http://dx.doi.org/10.5018/economics-ejournal. ja.2010-22

Cameron, G., Muellbauer J. \& Murphy A. (2006). Was There A British House Price Bubble? Evidence from a Regional Panel. CEPR discussion paper $\mathrm{N}^{\circ} 5619$.

https://econpapers.repec.org/RePEc:cpr:ceprdp:5619

Campbell, J. Y. (1987). Does Saving Anticipate Declining Labor Income? An Alternative Test of the Permanent Income Hypothesis. Econometrica, 55(6), 1249-1273.

https://doi.org/10.2307/1913556

Carroll, C. D. (1992). The Buffer-Stock Theory of Saving: Some Macroeconomic Evidence. Brookings Papers on Economic Activity, 23(2), 61-135.

https://www.jstor.org/stable/pdf/2534582.pdf?refre qid=excelsior\%3Af98b10439495b153775671dbb8 $71 \mathrm{~b} 4 \mathrm{ca}$

Carroll, C. D. (2000). Requiem for the Representative Consumer? Aggregate Implications of Microeconomic Consumption Behavior, American Economic Review Papers and Proceedings, 90(2), $110-115$.

http://dx.doi.org/10.1257/aer.90.2.110

Carroll, C.D. (2001). A Theory of the Consumption Function with and without Liquidity Constraints, The Journal of Economic Perspectives, 15(3), 23-45. https://pubs.aeaweb.org/doi/pdfplus/10.1257/jep.15.3.23 
Carroll, C. D. (2014). Representing Consumption and Saving without a Representative Consumer. In: D. W. Jorgenson, J. S. Landefeld, and P. Schreyer (Eds). Measuring Economic Sustainability and Progress, pp. 115-134. University of Chicago Press: National Bureau of Economic Research http://www.nber.org/chapters/c12830

Cerutti, E., Dagher, J. \& Dell'Ariccia. G. (2017). Housing Finance and Real Estate Booms: A Cross-Country Perspective. Journal of Housing Finance, 38, 1-13. https://doi.org/10.1016/j.jhe.2017.02.001

Clark, R., Lusardi, A. \& Mitchell, O. S. (2017). Employee Financial Literacy and Retirement Plan Behavior: A Case Study. Economic Inquiry, 55(1), 248-259.

http://dx.doi.org/10.1111/ecin.12389

Chauvin, V. \& Damette, O. (2011). Effets de richesse: le cas francais. Économie et Statistique, 438-439-440, 111-140.

https://doi.org/10.3406/estat.2010.9595

Deaton, A. (1991). Saving and Liquidity Constraints. Econometrica, 59(5), 1221-1248.

https://www.jstor.org/stable/pdf/2938366.pdf?refreqid $=$ excelsior $\% 3 \mathrm{Ab} 2433935 \mathrm{~d} 363 \mathrm{f} 4 \mathrm{fl} 1 \mathrm{c} 41072569241 \mathrm{c} 6 \mathrm{~d} 1$

Deaton, A., (1992). Understanding Consumption. Oxford: Oxford University Press. https://doi.org/10.1002/jae.3950090109

Duca, J., Muellbauer, J., \& Murphy, A. (2011). House Prices and Credit Constraints: Making Sense of the US Experience. The Economic Journal, 121(552), 533-551.

https://doi.org/10.1111/j.1468-0297.2011.02424.x

Duca, J., \& Muellbauer, J. (2013). Tobin LIVES: Integrating Evolving Credit Market Architecture into Flow of Funds Based Macro-Models. In: B. Winkler, A. van Riet and P. Bull (Eds.), A flow-of-funds perspective on the financial crisis, Vol. 2. London: Palgrave-Macmillan. Also ECB Working Paper $\mathrm{N}^{\circ} 1581$, August 2013.

http://www.ecb.europa.eu/pub/pdf/scpwps/ ecbwp1581.pdf

Duca, J., Muellbauer, J., \& Murphy, A. (2016). How Mortgage Finance Reform Could Affect Housing. American Economic Review, 106(5), 620-624. https://doi.org/10.1257/aer.p20161083

ECB (2009). Housing Wealth and Private Consumption in the Euro Area. Monthly bulletin, January 2009 59-71. https://www.ecb.europa.eu/pub/pdf/other/ mb200901 pp59-71en.pdf?575d70264f5fb10af9129 2ae92c6ff25

Fernandez-Corugedo, E. \& Muellbauer J. (2006). Consumer Credit Conditions in the U.K. Bank of England working paper $\mathrm{N}^{\circ} 314$.

http://www.bankofengland.co.uk/research/Documents/workingpapers/2006/WP314.pd

Fesseau, M., Bellamy, V. \& Raynaud, E. (2009). Les inégalités entre ménages dans les comptes nationaux, Insee Premiere $\mathrm{N}^{\circ} 1265$.

https://www.insee.fr/fr/statistiques/1280709

Friggit, J. (2010). Le prix des logements sur le long terme. Rapport du Conseil général de l'Environnement et du Développement durable. http://www.cgedd.developpement-durable.gouv. $\mathrm{fr} / \mathrm{IMG} / \mathrm{pdf} /$ evolution-prix-immobilier-friggit cle0c611b.pdf

Geiger, F., Muellbauer, J. \& Rupprecht, M. (2016). The Housing Market, Household Portfolios and the German Consumer. ECB working paper $\mathrm{N}^{\circ} 1904$. https://www.ecb.europa.eu//pub/pdf/scpwps/ ecbwp1904.en.pdf

Gouriéroux, C. \&Laferrère, A. (2009). Managing Hedonic Housing Price Indexes: The French Experience. Journal of Housing Economics, 18(3), 206-213

https://doi.org/10.1016/j.jhe.2009.07.012

Hall, R. E. (1978). Stochastic Implications of the Life Cycle-permanent Income Hypothesis, Theory and Evidence. Journal of Political Economy, 86(6), 971-87.

https://doi.org/10.1086/260724

Hedlund, A., Karahan, F., Mitman, K. \& Ozkan, S. (2017). Monetary Policy, Heterogeneity, and the Housing Channel. Society for economics dynamics meeting paper $\mathrm{N}^{\circ} 1610$.

https://economicdynamics.org/meetpapers/2017/ paper_1610.pdf

Hendry, D. F. \& Muellbauer, J. (2018). The Future of Macroeconomics: Macro Theory and Models at the Bank of England. Oxford Review of Economic Policy, 34(1-2), 287-328.

https://doi.org/10.1093/oxrep/grx055

IMF (2017). Is growth at risk? Global Financial Stability Report, October 2017.

https://www.imf.org/en/Publications/GFSR/ Issues/2017/09/27/global-financial-stabilityreport-october-2017 
Jordà, O., Schularick, M. \& Taylor, A.M. (2016). The Great Mortgaging: Housing Finance, Crises and Business Cycles. Economic Policy, 31(85), 107-152.

https://doi.org/10.1093/epolic/eiv017

Kaplan, G., Violante, G. \& Weidner, J. (2014). The Wealthy Hand-to-Mouth. Brookings Papers on Economic Activity Spring, 45(1), 77-144.

https://www.brookings.edu/wp-content/ uploads/2016/07/2014a_Kaplan.pdf

Kaplan, G., Moll, B. \& Violante, G. (2018). Monetary Policy According to HANK. American Economic Review, 108(3), 697-743.

https://doi.org/10.1257/aer.20160042

Kaplan, G. \& Violante, G. (2018). Microeconomic Heterogeneity and Macroeconomic Shocks. Journal of Economic Perspectives (forthcoming).

La Cava, G., Hughson, H. \& Kaplan, G. (2016). The Household Cash Flow Channel of Monetary. Reserve Bank of Australia, Policy Research Discussion Paper.

https://www.rba.gov.au/publications/bulletin/2016/ sep/3.html

Meen, G. P. (1990). The Measurement of Rationing and the Treatment of Structural Change in the UK Mortgage Market. Journal of Applied Econometrics, 5(2), 167-187.

https://doi.org/10.1002/jae.3950050205

Meen, G. P. (2001). Modelling Spatial Housing Markets. New York: Springers US.

https://doi.org/10.1007/978-1-4615-1673-6

Mian, A., Sufi, A. \& Verner, E. (2017). Household Debt and Business Cycles Worldwide. The Quarterly Journal of Economics, 132(4),1755-1817.

https://doi.org/10.1093/qje/qjx017

Mian, A. \& Sufi, A. (2014). House of Debt: How They (and You) Caused the Great Recession, and How We Can Prevent It from Happening Again. Chicago: University of Chicago Press.
Mian, A. and Sufi, A. (2018). Finance and Business Cycles: the Credit-Driven Household Demand Channel. Journal of Economic Perspectives, 32(3), 31-58. https://doi.org/10.1257/jep.32.3.31.

Miles, D. (1992). Housing Markets, Consumption and Financial Liberalization in the Major Economies. European Economic Review, 36(5), 1093-1136. https://doi.org/10.1016/0014-2921(92)90048-2

Monnet, E. \& Wolf, C. (2016). Demographic Cycle, Migration and Housing Investment: a Causal Examination. Banque de France, Document de travail $\mathrm{N}^{\circ} 591$.

https://www.banque-france.fr/sites/default/files/ medias/documents/document-de-travail_591_2016.pdf

Muellbauer, J. (2007). Housing, Credit and Consumer Expenditure. in Housing, Housing Finance, and Monetary Policy. A Symposium Sponsored by the Federal Reserve Bank of Kansas City, Jackson Hole, Wyoming, 30 August 30-September 1, 2007, 267-334. Annual series: Federal Reserve Bank of Kansas City. https://www.kansascityfed.org/publicat/sympos/2007/PDF/Muellbauer_0415.pdf

Muellbauer, J., St. Amant P.\& Williams, D. (2015). Credit Conditions and Consumption, House Prices and Debt: What Makes Canada Different? Bank of Canada, Staff Working Paper 2015-40. http://publications.gc.ca/pub?id=9.806007\&sl $=0$

Muellbauer, J. \& Lattimore, R. (1995). The Consumption Function: a Theoretical and Empirical Overview. In: Pesaran, M. H. \& Wickens, M. (Eds.) Handbook of applied econometrics: macroeconomics, pp. 221-311. Oxford: Blackwell. https://doi.org/10.1111/b.9780631215585.1999.x

Poterba, J. (2000). Stock Market Wealth and Consumption. Journal of Economic Perspectives, 14(2), 99-118. https://doi.org/10.1257/jep.14.2.99

Wilhelm, F. (2005). L'évolution actuelle du crédit à l'habitat en France est-elle soutenable ? Bulletin de la Banque de France, août 2005.

https://www.banque-france.fr/fileadmin/user upload/banque_de_france/archipel/publications/ bdf_bm/etudes_bdf_bm/bdf_bm_140_etu_2.pdf 


\section{DATA, DEFINITIONS AND SOURCES}

C: Consumption is total consumption excluding financial services at constant prices (source: National accounts, Insee (National Institute of Statistics and Economics)).

$Y$ : Income is a geometric average of disposable non-property income and conventional disposable income of households (source: National accounts, Insee)

LA: Liquid assets include cash (coins and notes), current deposits, liquid saving accounts, short-term debt securities and short-term mutual funds (source: Financial national accounts, Banque de France).

NLA: Liquid assets net of debt (source: Financial national accounts, Banque de France).

IFA: Illiquid financial assets include all financial assets with the exception of liquid assets as defined above (source: Financial national accounts, Banque de France).

HA: Gross housing asset is available as annual data since 1978. It includes housing and land under building (source: National accounts, Insee).

Mdebt: The term "Mortgage debt" has been used in this article in place of housing loans (source: Banque de France). A long time series has been built by Wilhelm (2005). Mortgage loans in the strictly legal sense are a minority in housing loans in France and is not measured as such regularly in France. Most housing loans are indeed guaranteed by a specialized organisation that mutualizes risks on incomes $(62 \%$ of new loans in 2011 according to the French Supervisory Authority for banks and insurance companies, ACPR). Thus, housing properties are not the guarantee for most loans, but households' income. However when a housing loan is not repaid, households might be obliged to sell their home. Thus the impact on the housing market might not differ from that of a mortgage loan.

Cdebt: Consumer credit extends over any credit card debt, personal loans or overdrafts and loans for the purchase of durable goods other than housing (source: Banque de France) ${ }^{17}$.

Hp and rhp: House price and real house price (source: OECD): There has been an official house price index for all France, corrected for quality effects, only since 1996 from the notaries data (Gouriéroux \& Laferrère, 2009). Before, the only official index is a Parisian index since 1980 built by Insee. OECD publishes an index which is based on an annual index constructed by Friggit (2010) based on repeat sales information. Before 1997, actual annual log real house price changes at $\mathrm{t}-1$ are replaced by their fitted values from a regression on growth in mortgage debt, interest rates, inflation and income and the 4-quarter lag of the annual log real house price change.

Rdepr: Returns on liquid assets is measured by a weighted average of real interest rate on regulated saving accounts (source: Banque de France), zero for non-interest bearing deposits (which is the rule in France) and the after tax interest rate on money market fundssuch funds for households developed earlier in France than in most other European countries due to fiscal advantages (source: Bernard \& Berthet, 2015)
$\mathrm{Ncr}$ and $\mathrm{rcr}$ : nominal/real interest rates on consumer loans. Interest rates on consumer loans are the equally weighted average of rates on overdraft and proper consumer loans measured by the MIR (Monetary Financial Institution Interest Rates) survey harmonized over the euro zone level since 2003 (source: Banque de France). They were backcast by the average of minimum and maximum rates beforehand.

$\mathrm{Nmr}$ : Nominal interest rates for mortgage loans adjusted for tax relief on mortgage interests paid. Interest rates on housing loans are those of new loans agreed by banks with fixed rate, according to the survey on the cost of credit (source: Banque de France). Before 1980, they were backcast with information on minimum and maximum rates beforehand. Tax relief is taken from the National accounts for housing (source: Ministry for Housing).

User: The user cost measure is defined as the real after-tax mortgage interest rate minus expected real appreciation plus assumed annualised transactions costs of $4.5 \%{ }^{18}$ of the value and a lagged time varying risk premium. The time-varying risk premium is defined by the volatility of annual real house price changes in the last four years, with declining weights going back in time: (ad4lrhp $+0.7^{*}$ $\left.\operatorname{ad} 4 \operatorname{Irhp}(-4)+\left(0.7^{\star *} 2\right)^{*} \operatorname{ad} 4 \operatorname{Irhp}(-8)+\left(0.7^{\star *} 3\right)^{*} \operatorname{ad} 4 \operatorname{Irhp}(-12)\right) /(1+0.7$ $\left.+\left(0.7^{\star *} 2\right)+\left(0.7^{\star *} 3\right)\right)$ where ad4/rhp is the absolute value of the annual change in log real house prices, instrumented during the pre-1996 period of interpolated annual house price data.

Demog: Demographic data are annual data each $1^{\text {st }}$ January (source: Insee). They were interpolated and lagged accordingly. In the permanent income model, demography affects the ratio of the working age population for all ages, measured as an 8-quarter moving average, to the total population.

$H$ : The housing stock has been recursively computed on the principal of perpetual inventory using data from the housing stock in constant prices (source: National accounts, Insee). The level is set by the value of stock in 2010. Gross fixed capital formation is housing GFC in volume and the deterioration rate is that of national accounts.

$\theta$ : Income uncertainty is proxied by the 4-quarter change in the unemployment rate in the consumption equation, and 2-quarter changes in the other equations.

Trans: Transaction costs come from "valeur-immobilier-france" (source: Ministry of Housing).

The impact of car scrapping subsidies is computed following Adda and Cooper (2000) for the first wave and extrapolated according to the link with car registration for the second wave.

17. Like consumption and income, all nominal balance sheet data are deflated by the consumer price deflator and population.

18. For any one transaction, costs, including costs of moving, are much higher. The discounted present value spread out over a few years of ownership could plausibly be of the order of $4.5 \%$ per annum. This is consistent with low levels of mobility in France. 
Table A2-1

Estimates of long-run solution for the French house price equation

\begin{tabular}{|c|c|c|c|c|c|c|c|}
\hline \multirow{2}{*}{ Dependent Variable $=\Delta \ln h p_{t}$} & \multirow{2}{*}{ Symbol } & \multicolumn{2}{|c|}{ 1981Q2-2016Q4 } & \multicolumn{2}{|c|}{ 1981Q2-2008Q3 } & \multicolumn{2}{|c|}{$\begin{array}{l}\text { 1981Q2-2016Q4 } \\
\text { Excluding } M C C /^{\text {(a) }}\end{array}$} \\
\hline & & Coefficient & t-ratio & Coefficient & $t$-ratio & Coefficient & $t$-ratio \\
\hline Speed of adjustment & & $0.123^{\star * \star}$ & 12.6 & $0.126^{\star \star *}$ & 10.3 & $0.026^{* * *}$ & 10.8 \\
\hline \multicolumn{8}{|l|}{ Long-run coefficients } \\
\hline Constant & $h_{0}$ & $-5.95^{\star \star \star}$ & -51.8 & $-14.0^{* \star *}$ & -38.9 & $-8.8^{* \star *}$ & -25.9 \\
\hline Mortgage credit conditions index: $\mathrm{MCCl}$ & $h_{0 c}$ & 1 & fix & 1 & fix & 0 & fix \\
\hline Log nominal mortgage rate & $h_{1}$ & $-0.38^{\star \star *}$ & -12.4 & $-0.39^{\star \star *}$ & -9.1 & -0.38 & fix \\
\hline Log user $\operatorname{cost}^{\star} \mathrm{MCCl}$ & $h_{2}$ & $-0.07^{\star \star \star}$ & -2.8 & $-0.14^{*}$ & -1.8 & $-0.87^{\star \star \star(a)}$ & -8.4 \\
\hline Coefficient on risk premium in user cost & $h_{2 a}$ & $0.63^{* \star *}$ & 12.0 & $0.72^{* * *}$ & 10.2 & $0.96^{\star \star \star}$ & 16.5 \\
\hline Log (real income/housing stock) & $h_{3}$ & 2 & fix & 2 & fix & 2 & fix \\
\hline Log (permanent/current income) & $h_{4}$ & $0.52^{\star \star \star}$ & 3.8 & $0.41^{* * *}$ & 2.7 & 0.52 & fix \\
\hline Children/adults & $h_{5 a}$ & 2 & fix & 2 & fix & 3 & fix \\
\hline Pre-retirement adults/total adults & $h_{5 b}$ & 3 & fix & 3 & fix & 4 & fix \\
\hline Adults $25-44 /$ total adults & & 0 & fix & 0 & fix & $2.2^{* * *}$ & 3.2 \\
\hline \multicolumn{8}{|l|}{ Diagnostics } \\
\hline Equation standard error & \multicolumn{3}{|c|}{0.00234} & \multicolumn{2}{|c|}{0.00235} & \multicolumn{2}{|c|}{0.00482} \\
\hline DW & \multicolumn{3}{|c|}{1.83} & \multicolumn{2}{|c|}{1.72} & \multicolumn{2}{|c|}{0.84} \\
\hline R-squared & & \multicolumn{2}{|c|}{0.973} & \multicolumn{2}{|c|}{0.969} & \multicolumn{2}{|c|}{0.887} \\
\hline
\end{tabular}

(a) Not interacted with $\mathrm{MCCl}$

Note: Statistical significance at the $10 \%, 5 \%$, and $1 \%$ levels is denoted by *, ${ }^{* *}$, and ${ }^{* * *}$ respectively. Maximum likelihood estimation of the 6 -equation system in TSP (Time Series Processor) 5.1. Equation standard errors are RMSEs of the residuals.

Sources: Banque de France; Insee; authors' calculations.

Table A2-2

Estimates of the long-run solution for the mortgage stock equation

\begin{tabular}{|c|c|c|c|c|c|c|c|}
\hline \multirow{2}{*}{ Dependent Variable $=\Delta \ln$ mdebt $_{t}$} & \multirow[t]{2}{*}{ Symbol } & \multicolumn{2}{|c|}{ 1981Q2-2016Q4 } & \multicolumn{2}{|c|}{ 1981Q2-2008Q3 } & \multicolumn{2}{|c|}{$\begin{array}{l}\text { 1981Q2-2016Q4 } \\
\text { Excluding } M C C /^{(a)}\end{array}$} \\
\hline & & Coefficient & $t$-ratio & Coefficient & $t$-ratio & Coefficient & $t$-ratio \\
\hline Speed of adjustment & $\pi$ & $0.077^{\star \star *}$ & 15.8 & $0.088^{\star \star *}$ & 3.3 & $0.057^{* * *}$ & 10.8 \\
\hline \multicolumn{8}{|l|}{ Long-run coefficients for log (real mdebt/y) } \\
\hline Constant & $m_{0}$ & $-2.7^{* * \star}$ & -27.9 & $-2.9^{* * *}$ & -25.5 & $-7.1^{* * *}$ & -4.7 \\
\hline Mortgage credit conditions index: $\mathrm{MCCl}$ & $m_{o c}$ & $0.59^{\star \star *}$ & 12.2 & $0.55^{* * *}$ & 10.5 & 0 & - \\
\hline Log nominal mortgage rate & $m_{1}$ & $-0.46^{* * *}$ & -16.6 & $-0.38^{* * *}$ & -10.4 & $-0.59^{\star \star \star}$ & -12.3 \\
\hline $\log ($ house prices/y) & $m_{4}$ & 0 & - & 0 & - & 0.97 & 14.9 \\
\hline$M C C l \times \log ($ house prices/y $)$ & $m_{4 c}$ & $0.70^{\star \star *}$ & 5.6 & $0.86^{* * *}$ & 5.4 & 0 & - \\
\hline $\begin{array}{l}\text { Composite demographic effect from the } \\
\text { house price equation }\end{array}$ & $m_{5}$ & 1.5 & fix & 1.5 & fix & 1.5 & fix \\
\hline Transaction costs & $m_{9}$ & $-2.9^{\star \star *}$ & -4.2 & $-3.9^{* \star *}$ & -2.7 & $-5.1^{* * *}$ & -4.4 \\
\hline \multicolumn{8}{|l|}{ Diagnostics } \\
\hline Equation standard error & & \multicolumn{2}{|c|}{0.00322} & \multicolumn{2}{|c|}{0.00327} & \multicolumn{2}{|c|}{0.00374} \\
\hline DW & & \multicolumn{2}{|c|}{2.10} & \multicolumn{2}{|c|}{2.21} & \multicolumn{2}{|c|}{1.77} \\
\hline R-squared & & \multicolumn{2}{|c|}{0.902} & \multicolumn{2}{|c|}{0.906} & \multicolumn{2}{|c|}{0.870} \\
\hline
\end{tabular}

(a) Not interacted with $\mathrm{MCCl}$.

Note: Statistical significance at the $10 \%, 5 \%$, and $1 \%$ levels is denoted by *, ${ }^{* *}$, and ${ }^{* * *}$ respectively. Maximum likelihood estimation of the 6 -equation system in TSP (Time Series Processor) 5.1. Equation standard errors are RMSEs of the residuals.

Sources: Banque de France; Insee; OECD; authors' calculations. 


\title{
The impact of the 2014 increase in the real estate transfer taxes on the French housing market
}

\author{
Guillaume Bérard* and Alain Trannoy*
}

\begin{abstract}
This paper estimates the effects of an increase in the share of the real estate transfer taxes (RETT) rates going to the French départements from 3.80\% to $4.50 \%$. Not all the départements voted the RETT increase on the same date, which is the starting point of a natural experiment. Using a difference-in-differences design, we estimate two main effects. (1) An anticipation effect, one month before the implementation of the reform, in order to avoid the RETT increase. (2) A retention effect in the post-reform period. In the end, the net effect (retention minus anticipation) corresponds to an average drop in transactions of around $6 \%$ over the first three months after the reform, that is, approximately 15,000 transactions lost at national level. If we find a short term effect of the reform, we do not find evidence of a medium- or long-term effect.
\end{abstract}

JEL Classification: H71, R21, R31, R51

Keywords: local government, real estate market, transfer taxes, natural experiment

Reminder:

The opinions and analyses in this article

are those of the author(s)

and do not

necessarily reflect

their institution's

or Insee's views.

\section{*Aix-Marseille University, CNRS, EHESS, Centrale Marseille, AMSE (guillaume.berard@univ-amu.fr ; alain.trannoy@univ-amu.fr).}

We warmly thank Jacques Friggit and Gérard Forgeot for their help on the datasets, Stephen Bazen, Pierre Cahuc, Habiba Djebbari, Emmanuel Flachaire, Xavier Joutard, Barbara Petrongolo, Marc Sangnier, Patrick Sevestre and two referees for their helpful comments, Pierre-Yves Cusset for his support, and Gustave Kenedi for his corrections. All remaining errors are our own.

Received on 7 June 2017, accepted after revisions on 24 April 2018 
$\mathbf{T}$ he 2014 reform of the French real estate transfer taxes (RETT), allowing an increase in départements ${ }^{1}$ tax rate of 0.7 percentage point (from $3.80 \%$ to $4.50 \%$ of the tax base), aimed to raise their tax revenue, in a context of state grants reductions and increasing social spending. Not all départements implemented the RETT increase, and not at the same time, which is the starting point for a natural experiment. Even though it is not a purely random experiment, we show in the course of the paper that there was no departmental selection bias in choosing the tax increase: this choice was not correlated with the local housing market or political features.

The RETT, also called stamp duties land taxes, or droits de mutations in French ${ }^{2}$, are taxes levied on all ownership transfers of real estate or land (Box 1). The RETT are an important source of revenue for the French départements: they represent around $€ 10$ billion per year. However, while the RETT as the other transaction costs (notary and experts' fees) cannot be financed through mortgages and must be paid first by the buyer and in addition to the downpayment, the possible negative impact on the housing market was not evaluated or even discussed when the reform was implemented. In this study, we use open access data on the monthly number of transactions and real estate tax bases by département and implement a difference-in-differences framework using a quasi-myopic model $^{3}$ as developed by Malani and Reif (2015). We assume that there were two main effects due to this reform, (1) an anticipation effect from the buyers and sellers to avoid the tax increase (timing response), and (2) a retention effect in post-reform period: a classic depressing effect of a tax on the equilibrium quantity. Note that in the very short-run, this effect is composed of re-timing due to the anticipated transactions (intertemporal substitution by those who would have purchased a real estate property anyway), and of extensive margin responses (those who would have purchased a property in the absence of the reform). What we are looking for is the behavioral response in terms of timing and extensive margin of the agents (i.e. buyers and sellers). Finally, we evaluate the tax elasticity of the tax bases to the RETT.

We estimate that there was an anticipation effect of $26 \%$ on the volume of transactions, meaning that buyers and sellers reacted to the RETT increase, the month just before the implementation of the tax increase, by bringing forward their sale date. We also estimate the average monthly retention effect for the three months following the tax increase at around 14\% of the volume of transactions (assuming no effect on the sale price) - with $49 \%$ of this loss due to a pure extensive margin effect (and not to re-timing) - meaning that the tax increase had a negative impact on the housing market. All in all, the average monthly net effect corresponds to a drop in transactions of around $6 \%$ over a period of three months following the implementation date. None of the estimates after these three months are significantly different from zero. The corresponding rough estimate of the lost transactions is around 15,000. Therefore, there is some compelling evidence of a strong short-term effect, but no mediumor long-term effect. Furthermore, we estimate that the elasticity of the tax bases to the tax increase is about -0.42 , meaning that tax bases decreased by $0.42 \%$ for a $1 \%$ increase in the RETT rate (i.e. there is a loss in the tax bases which reduces the gains of tax revenues for the local budgets). Computing the Laffer rate, we conclude that départements' tax revenues are still on the increasing side of the Laffer curve. Note that our results are valid in a partial equilibrium framework: we do not estimate the possible general equilibrium resulting from the distortion of the housing market. Finally, we run a series of robustness checks such as a placebo test, a self-selection test and control for possible changes in local economic conditions, confirming that our results are unbiased and robust.

\section{Literature review}

Previous literature on the impact of the increase in the rate of the RETT is relatively recent, as the first empirical estimation was published in 1993, and other main theoretical and empirical evaluations were mostly done over the past four years. As this stream of papers follows a natural development, we present them in chronological order for a better understanding.

The first in-depth research on RETT was done by Benjamin et al. (1993), who analyze the effect of an increase of $45 \%$ in Philadelphia's transfer taxes in 1988. The specificity of the

\footnotetext{
1. Intermediary administrative unit.

2. In France, they are also referred as droits d'enregistrement et taxe de publicité foncière.

3. Econometric model with anticipation (see Box 3).
} 
transfer taxes of this city compared to French ones, is that the payment of the tax is shared equally between the seller and the buyer. The authors focus on the effect of the RETT increase on the sale price of residential property, using a hedonic model and micro data (around 350 transactions). Unfortunately, they could not estimate the impact on the volume of transactions. Nevertheless, they find a decrease in postreform prices equal to the tax increase, meaning that the burden of the tax increase rests on the seller, at least in the short-run.

The next paper, Ioannides and Kan (1996), is not directly related to the RETT's impact, but more generally to residential mobility, and to the decision of moving, and whether to rent or to own. This article develops a theoretical model of housing tenure choice and residential mobility which is used as a basis in many following papers. The authors find that home-owners are responsive to housing market conditions by adjusting their stock. Their empirical estimates suggest that proportional monetary transaction costs are not worse than lump-sum transaction costs in households' mobility decisions, and that housing price increases seem to discourage renters from moving and from owning after moving. Then, housing price appreciation is likely to have

\section{Box 1 - The real-estate transfer taxes system in France}

The RETT are levied on all transfers of ownership of real estate and land. The French law distinguishes between two types of transfers, (1) the droits de mutation à titre onéreux (DMTO), which are based on transfers of ownership further to a sale, and (2) the droits de mutation à titre gratuit, which are based on transfers of ownership further to a donation or inheritance. Unlike in the United Kingdom or some counties in the United States, the RETT in France are proportional and not progressive. However, different rates exist; they depend on the characteristics of the real estate, the denomination of the buyer and seller (i.e. individual or professional) and the type of transfer. The RETT are calculated on the tax base after abatements, which are very scarce and small; therefore, the tax base reflects the real estates' sale price in almost all cases.

Three tax regimes of RETT exist in France, with different applicable rates:

(1) Régime de droit commun. It applies to the DMTO on real estate exempted from Value Added Tax (VAT): established properties (more than 5 years old), new constructions (less than 5 years old) sold between individuals (except if the seller has bought it in off-plan $(V E F A)$ ), and the buildable lands sold between individuals. The applicable rate for this tax system is decomposed as follows: $3.80 \%$ goes to the départements (rate before the 2014 reform which we are interested in), $1.20 \%$ goes to the municipalities, and finally $2.37 \%$ applied to the départements' tax rate goes to the central government (for tax base and collection fees) (i.e. $0.09 \%$ of the tax base). Thus, the total rate for this regime was $5.09 \%$ before the reform, and is at $5.81 \%$ now for the départements which have implemented the reform.

(2) Régime dérogatoire. First, it applies to the DMTO subject to VAT: the new constructions and lands sold by a professional or the new constructions bought in off-plan and resold between individuals, at the rate of $0.715 \%$. Secondly, it applies to all the droits de mutation à titre gratuit, at the rate of $0.60 \%$. Within this tax regime, the part of transactions of droits de mutations à titre gratuit is roughly $40 \%$.

(3) Exonération des droits de mutation. This tax system applies only to the acquisition done by the State or local authorities, so there is a total tax exemption.

The average period between the signature of the preliminary sale agreement (between the seller and the buyer), and the bill of sale is 3 months. The minimum is 1 month due to the legal period of withdrawal.

The transaction costs (i.e. the RETT, the notary and experts' fees) of a house or land sale are paid by the buyer, and must be paid in full when the bill of sale is signed. Before the reform, the average rate of the transaction costs for real estate subject to the Régime de droit commun was around $7 \%$. These transaction costs are collected by the notary on behalf of the Treasury Department (Direction Générale des Finances Publiques - DGFiP).

Following this, all the transfers of ownership and their details (e.g. number of transactions, sale price, tax revenue, locality, owners' identities) are registered by the Service de publicité foncière, which depends on the Treasury Department, except for the Alsace-Moselle territory. Composed of the départements of Moselle (57), Bas-Rhin (67) and Haut-Rhin (68), this territory has its own registration utility: the Livre foncier. This situation is due to the particular legal status of this territory, inherited from the German annexation of 1870.

It is important to note that, in almost any case, the transaction costs cannot be financed through mortgages. In other words, the transaction costs must be paid first and in addition to the downpayment. Therefore, even a slight increase of the RETT could have a large impact on the behavior of the buyers, because it increases out-of-pocket contributions, and thus may have large impacts on the housing market.

(Sources: DGFiP and Légifrance, Bulletin officiel des Finances publiques - Impôts 2017) 
strong effects on the housing rental market. Using the same theoretical framework, Van Ommeren and Van Leuvensteijn (2005) assess the impact of an increase in transaction costs in the Netherlands that are close to the transfer taxes in France, as they are ad valorem transaction costs, mostly paid by the buyer. Using duration models, they find that a $1 \%$ increase in the transaction costs decreases mobility by $8 \%$, which is quite significant, but they did not conclude about the time length of this effect. They deduce that transaction costs could imply lock-in effects, leading to a negative impact on the housing market and the labor market. Their conclusion is that a decrease or an abolition of the buyer's transaction costs would improve home-owners' mobility.

A more recent study by Dachis et al. (2012) estimates the effect of the implementation of a progressive transfer taxes in Toronto $(1.1 \%$ on average), paid by the buyer. Unfortunately, they could not consider a potential anticipation effect. Combining difference-in-differences and regression discontinuity designs on a large sample, they estimate that the new tax decreased the volume of transactions by $14 \%$, and the sale price by a proportional amount to the transfer taxes. Their theoretical model predicts a welfare loss of about $\$ 1$ for every $\$ 8$ in tax revenue raised. They conclude that the RETT should be removed in favour of the property tax.

Davidoff and Leigh (2013) assess the Australian's progressive RETT reform. Instrumenting the endogenous RETT variable, they obtain similar results to Benjamin et al. (1993): increases in transfer taxes lower housing prices, suggesting that economic incidence falls on sellers. They also evaluate that such increases have a negative impact on owners' mobility, and that this effect increases over time. Besley et al. (2014) evaluate the impact on the housing market of a RETT holiday in the United Kingdom, using data on sale price and number of transactions. They develop detailed and convincing empirical evaluations as well as a bargaining model. They find a significant increase of around $8 \%$ in the volume of transactions following the tax holiday, but only in the short-run. Their theoretical model allows them to estimate that $60 \%$ of the tax decrease accrues to the buyer. Kopczuk and Monroe (2015) estimate the effect of a specific RETT on high value housing in New-York, called the mansion tax. They assess that this tax creates a notch (i.e. a discontinuity in the tax liability), with a surplus of selling below, and a large gap above the threshold. They estimate that the volume of missing transactions above the threshold is greater than the volume of transactions below. They conclude that this is due to the bargaining of buyers and sellers, and that this particular tax impacts negatively the search market around the notch, and is inefficient in terms of tax revenue.

Slemrod et al. (2017) estimate the behavioral responses to a change in the RETT's notch in Washington D.C. They provide a useful model of bargaining between sellers and buyers, with progressive tax. Using a difference-indifferences design, they find no evidence of a lock-in effect, but they estimate a slight timing effect, which corresponds to an anticipation effect to avoid the tax increase. Furthermore, they conclude that buyers and sellers are more able to adjust the sale price in response to the tax increase than to modify the sale date (which works only with progressive RETT). Finally, Best and Kleven (2018) also analyze some notches in the housing market in the United Kingdom, due to the progressive RETT. Their findings are similar to those of the previous article: there is some distortion of the housing market across marginal tax rates. Analyzing the same tax holiday as Besley et al. (2014), they find similar results regarding the volume of transactions: the elimination of $1 \%$ transfer taxes increased housing market activity by $20 \%$. Therefore, there are large timing and extensive margin responses from buyers and sellers due to the RETT modification.

To summarize, transaction costs have a negative impact on residential mobility. They lead to suboptimal equilibrium on the housing market: they distort owners and renters' choices between staying or moving and renting or owning. Empirical literature on RETT mainly resorts on difference-in-differences and regression discontinuity designs using the features of quasi-natural experiments. They proved that transfer taxes are highly distortionary in the short-run, in terms of volume, price and timing of transactions. Medium- and long-run effects are more ambiguous, and depend on the specificity of each legal system and local conditions. The specificity of the French case is that the RETT are proportional, they accrue to the buyer only, and it is a potential widespread reform that impacted the whole country. 


\section{Context of the reform in France}

As explained by all the official documents and newspapers, there are two main reasons why the government and the départements wanted to increase the RETT. (1) For several decades, a process of decentralization and fiscal autonomy of local authorities has been engaged. As a result, State grants decreased drastically. Moreover, in 2010, the State abolished the business tax, one of the main sources of tax revenue for local authorities. (2) The growth in the real estate market between 2000 and 2007 enabled départements to follow the pace of growth of local public expenditures until the financial crisis of 2007 . Then, with the economic downturn, the revenues generated by the transfer tax dropped. Simultaneously, the amount of social spending of the départements (RSA, APA and $\mathrm{PCH}^{4}$ especially) increased sharply, and both factors resulted in a financial stranglehold. Thus, in the framework of the Pacte de confiance et de responsabilité entre l'État et les collectivités territoriales, the Prime Minister and the local councilors discussed the possibility of an RETT's increase, to help the départements which were struggling with their finances.

Therefore, we can argue that the implementation or the non-implementation of the treatment was not due to a willingness to stimulate the housing market, or to help buyers and sellers through fiscal policy. This policy change was mainly driven by reasons entrenched in the financial turmoil of the départements, then it is as random. The draft Finance Act for 2014 was publicly announced on September 25,2013 , and relayed the information of a first agreement between the départements and the French Government about an increase in the RETT's Régime de droit commun (cf. Box 1). Most of the départements announced whether they would increase the RETT and when during the first semester of 2014.

At this stage, we can argue that both buyers and sellers of property were aware of the reform and its date of implementation, and whether the département where they intended to buy or sell would increase the tax ${ }^{5}$. They then could anticipate the reform by bringing forward the sale date, in order to avoid the tax increase.

The RETT reform was enacted on December 29, 2013, by the article 77 of the Finance Act for 2014, allowing the départements that are willing to do so (i.e. the implementation of a tax rise remains optional), to increase their part of RETT's Régime de droit commun by a maximum of 0.7 percentage point. It means that the rate of the RETT going to the départements can rise from $3.80 \%$ to $4.50 \%$ (i.e. an increase of $18.42 \%$ of the RETT departmental's part). Furthermore, at this time, the reform was enacted as temporary and should have been implemented only on the agreements finalized between March 2014 and February 2016; afterwards, the RETT should have gone back to $3.80 \%$ maximum. However, on December 29, 2014, the article 116 of the Finance Act for 2015 made permanent the possibility for the départements to rise their part of the RETT up to a rate of $4.50 \%$. The choice to increase the tax or not and the level falls to the local councilors. The $4.50 \%$ rate is an upper limit, and the départements can set whatever rate suits them between $1.20 \%$ and $4.50 \%$. However, in practice, every département that chose to raise the RETT has increased them by the maximum amount (i.e. up to $4.50 \%)^{6}$.

A first group of 61 départements implemented the reform on March 1, 2014, a second group of 20 départements on April 1, 2014, a third group of 2 départements on May 1, 2014, a fourth group of 7 départements on June 1,2014, a fifth group of 4 départements on January 1, 2015 and finally a group composed of 2 départements on January 1, 2016. However, this last group is not considered as treated in our estimates, as we stop the period of estimation in October 2015. Finally, 5 départements ${ }^{7}$ are still currently ${ }^{8}$ at $3.80 \%$.

From the full sample of départements (i.e. 101), we remove 9 départements, because of lack of data, or because we strongly suspect them to have heterogeneous housing market and/or unobservables that affect their housing market differently over time. Those départements are the 3 départements of Alsace-Moselle territory for the reasons already defined above (cf. also Box 1), the 5 overseas départements, and finally the département of Paris (75). Figure I

\footnotetext{
4. Revenu de solidarité active (RSA), Allocation personnalisée d'autonomie and Prestation de compensation du handicap.

5. An additional argument to demonstrate that they were aware of the reform, is that buyers and sellers usually mandate a real estate agent and/ or a notary for the matching process and afterwards some counsels about the documents (e.g. expert diagnostics, property tax notice), needed for the preliminary agreement. These brokers and experts are well-informed about the changes of the real estate legal context.

6. Except Côte d'Or (21) which increased them until 4.45\%; thus, we consider it as being at $4.50 \%$ in the estimates.

7. Indre (36), Isère (38), Morbihan (56), and two overseas départements Martinique (972) and Mayotte (976).

8. May 2017.
} 
shows a map of the implementation schedule of the reform.

\section{Purpose of the evaluation}

In the following evaluation, we focus on two main potential effects, although three effects may be distinguished:

(1) Anticipation effect. As the reform was publicly announced far ahead, we assume that the buyers and sellers were not caught off guard, and thus many of them may have chosen to bring forward the sale date in order to avoid the tax increase in their départements. This behavior can be referred to as a dynamic optimisation effect, or timing response. This period of anticipation should precede the implementation month. This assumption seems plausible when observing the trends in the number of transactions and the total tax base of the Régime de droit commun from January 2012 to October 2015 (Figure II). Indeed, some distinct peaks appear just before the date of implementation. We expect no effect on prices during the anticipation period. Two reasons can vindicate this guess. In the first place, as said in the previous sections, the sale price is set during the preliminary agreement, which is signed around 3 months before the sale date, and thus people who anticipated could have changed only the sale date and not the sale price set by agreement. Furthermore, as both the seller and the buyer are interested in avoiding the tax increase, no bargaining on price should have occurred.

(2) Retention effect. We expect the housing market to be impacted durably by the increase in the RETT, preventing some buyers from moving and accessing to ownership. Thus, a decrease in the volume of transactions should be observed. The retention effect should begin at the implementation date of the reform, and could have either persisted or diminished over time ("resilience of the market"). Note that in the very short-run, this effect is composed of re-timing due to the anticipated transactions (intertemporal substitution by those who would

\section{Figure I \\ Map of the RETT-increase implementation by Département}

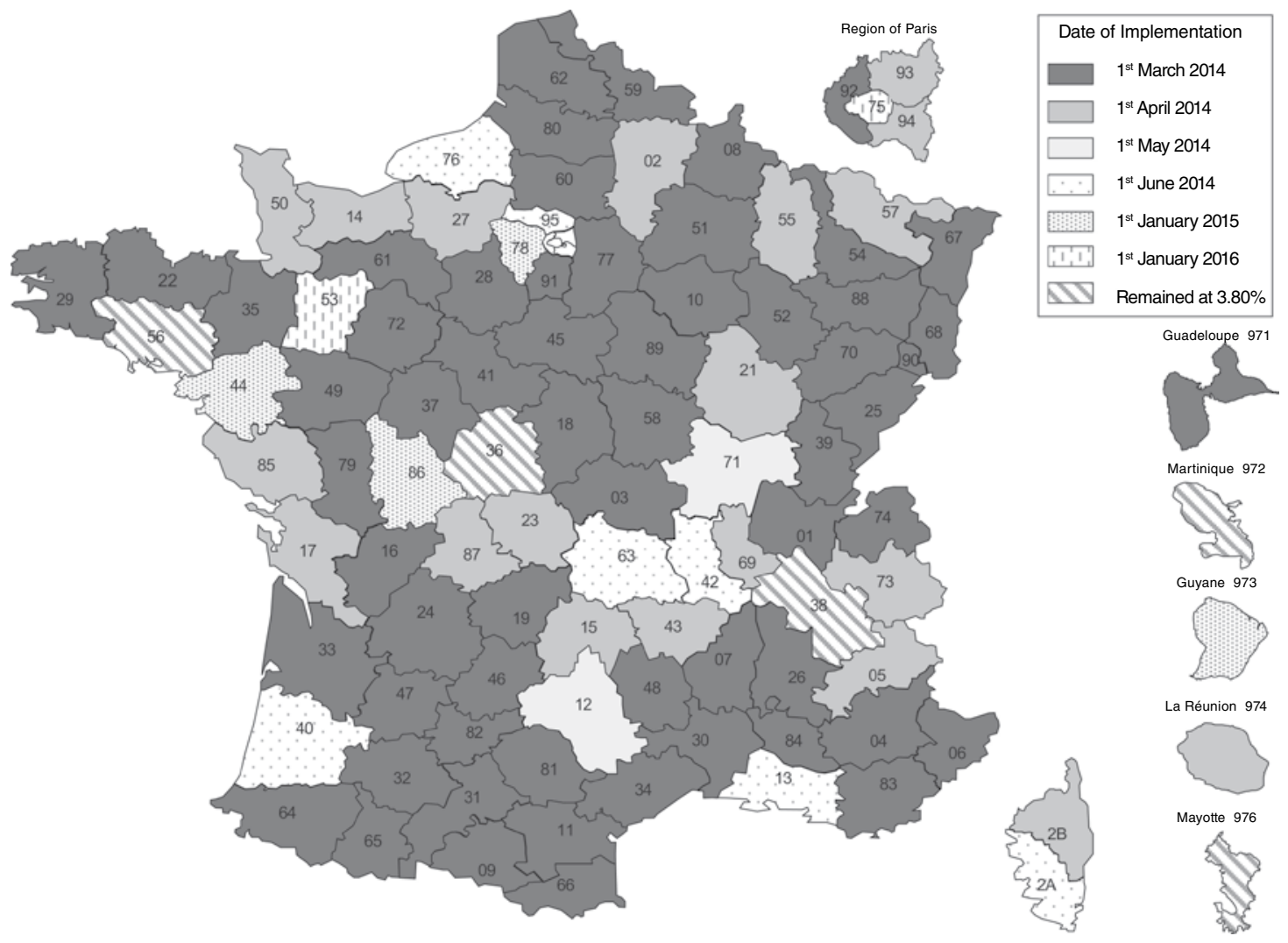

Notes: Map updated May 2017

Sources: DGFiP, Droits d'enregistrement : taux, abattements et exonérations 2017; authors' drawing. 


\section{Figure II \\ Monthly (12-month cumulative) number of transactions from January 2012 to October 2015, by sample and implementation groups}

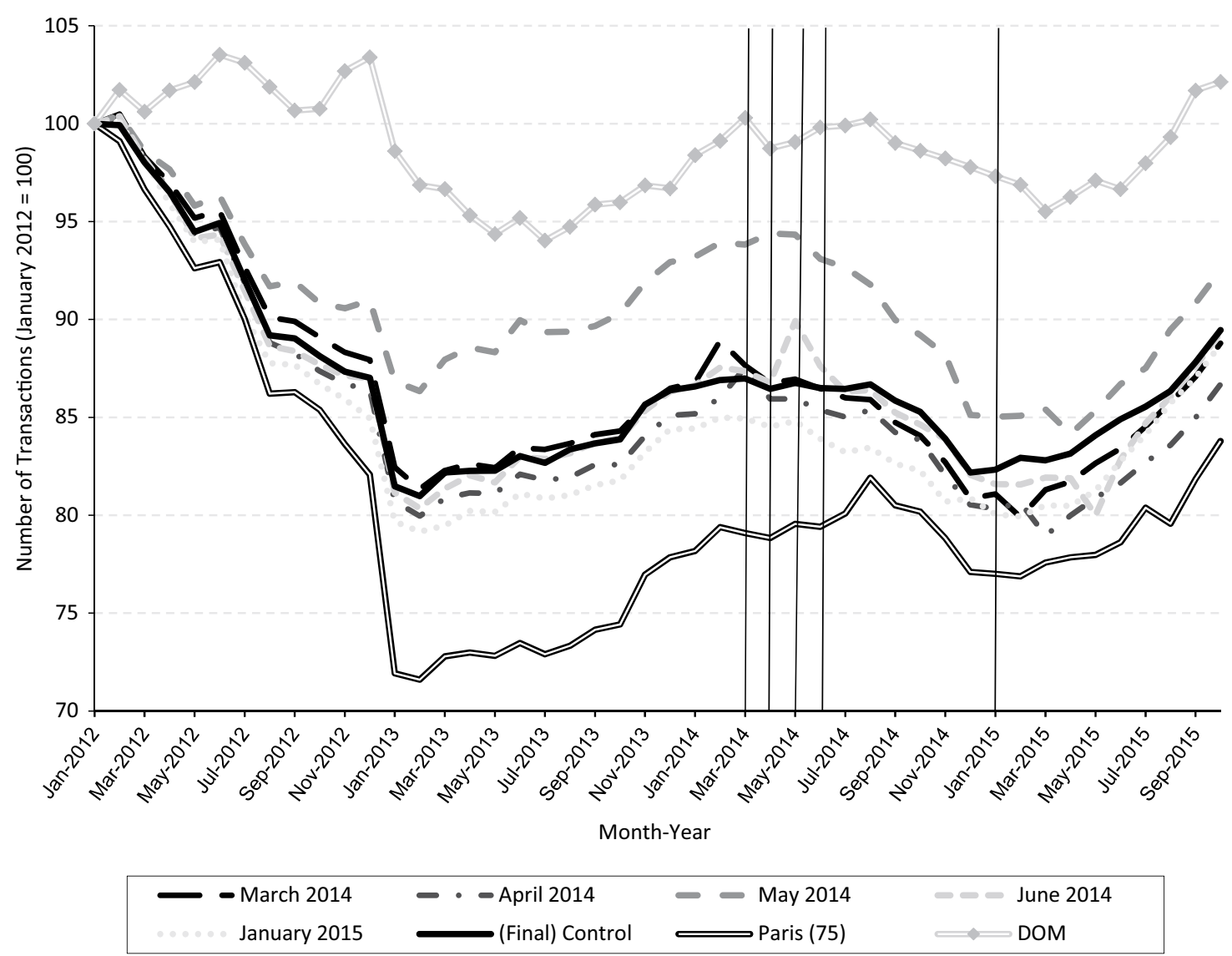

Notes: The number of transactions of the départements in each group are cumulated over the previous 12 months, and correspond to the number of transactions in the régime de droit commun registered by the DGFiP in each département. The départements of Moselle (57), Bas-Rhin (67), Haut-Rhin (68) and Mayotte (976), are excluded. Vertical lines correspond to the implementation dates.

Sources: CGEDD from DGFiP (MEDOC + Fidji), Nombre de ventes immobilières taxées au taux de droits commun par département from 2012 to 2015 .

have purchased a real estate anyway), and of extensive margin responses (those who would have purchased a real estate in the absence of the reform). If the extensive margin effect is dominating the timing effect, we may observe a lock-in effect (e.g. buyers could have chosen to renounce to buy, to postpone their purchase, or to rent rather than to become owners).

(3) Price effect. Theory also suggests a slight effect on sales prices: due to the extensive margin response, the demand must have decreased while the supply must have remained the same; therefore, the bargaining power of the buyers must be higher, the competition between sellers must increase, and some would be willing to decrease their selling price. However, this is a strong assumption knowing that the French housing market is price-sticky. In France, RETT must be paid by the buyers, and knowing that the housing market is rigid, sellers have a greater bargaining power. Then, unlike Philadelphia's RETT reform - where RETT's payment is divided in half between buyer and seller - studied by Benjamin et al. (1993) who estimated that housing prices decreased, it is less likely to observe the same phenomenon in France. Moreover, the RETT in France are proportional and not progressive. Hence, the agents have less interest in changing the sale price - compared to progressive RETT - and more in changing the sale date (Davidoff \& Leigh, 2013; Slemrod et al., 2017). Furthermore, the data we use are not very suited to test this price effect. We hence focus on the first two effects.

\section{Data}

To undertake this evaluation, we use two main variables, which are the number of transactions and the tax bases, both by département 
and month. The source of these variables is the Conseil général de l'environnement et $d u$ développement durable (CGEDD). The raw data on the RETT come from the Service de publicité foncière (datasets MEDOC and Fidji) and are compiled and modified by the CGEDD, before being made available at the departmental level in open access.

MEDOC provides the tax revenue by département and month, and is exhaustive. Fidji provides the tax revenue and the number of transactions also by département and month, but it presents the inconvenience to be not completely exhaustive $(1 \%$ of the transactions are missing). To solve this problem, the CGEDD uses both databases, and applies a correction coefficient ${ }^{9}$, in order to recover an estimation of the total number of transactions by départe$m e n t^{10}$. Next, the CGEDD computes the monthly total tax bases of each département, by dividing the tax revenue by the corresponding RETT rate, and publishes in open access two datasets.

The first one provides monthly data on the number of transactions of the Régime de Droit Commun by département, for the period from April 2004 up to now (from MEDOC + Fidji), but those data are computed on a 12-month cumulative basis. The second one provides monthly total tax bases (raw and 12-month cumulative) of the Régime de droit commun and the Régime dérogatoire separately and by département, for the period from January 2000 up to now (from $M E D O C$ ). The data on the Régime de droit commun (whereby the reform is implemented) are composed approximately of $95 \%$ of established properties (whose $15 \%$ of non-residential premises) and around 5\% of lands. We only use this second dataset because it is impossible at this stage to recover the simple monthly data for the first dataset.

Following this, we applied some correction to these raw datasets, in order to make them match to the months when the bill of sale is signed (and not to the months of tax revenue collection).

Our control variables include the unemployment rates, the number of new residential construction, population, property tax rates, and three local variables on the départements' finances. Data on the unemployment rates come from Insee ${ }^{11}$ and are quarterly data by département for metropolitan France, and yearly data for the overseas départements, both seasonally adjusted. In order to estimate monthly data, we made linear interpolation. Data on the new residential construction (monthly building permits by département) come from the database Sit@del2, and are compiled by Insee. The estimated population on January 1 of each year in each département, using the Insee annual census. The property tax rates voted each year by the départements, from the $\mathrm{DGFiP}^{12}$. Three local variables from the DGFiP-DGCL ${ }^{13}$ in order to "compute an index of good administration" of the local governments. These variables are the salary cost, the operating revenue (which the total local taxes revenues) and the social spending, all per capita, by département.

Finally, we also use other variables in order to check for possible unobservables that could affect the sample groups differently over time, not included as covariates in the estimates because they do not fit to our panel data. Indeed, these variables do not vary across the regressed period, then their effect ought to be captured by the département and month fixed effects. These data are two local variables from Insee, in order to make a comparison of the treated and control groups from their inherent housing market, which are: the share of social housing and secondary residence, within the total number of housings, by département.

\section{Empirical strategy}

In order to estimate the effects of the RETT increase, we use a difference-in-differences framework (Donald \& Lang, 2007). To undertake our difference-in-differences design (Box 2), we divide our sample in two groups: (1) the treatment group, composed of the départements that implemented the reform during the period from March 2014 to January 2015; (2) the control group, composed of the départements which had not yet implemented the reform at the estimated month (i.e. these départements were still on their pre-reform period) and of the 4 départements which remained at a RETT rate of $3.80 \%$ during our regressed time period: the (final) control group.

\footnotetext{
9. Number of Transactions Tdt $=$ Number of Transactions $_{\mathrm{dt}}$ (Fidji) $\times \frac{\operatorname{TaxBases}_{\mathrm{dt}}(\text { MEDOC })}{\text { Tax Bases }_{\mathrm{dt}} \text { (Fidji) }}$
}

10. Data on 4 départements are missing: the 3 départements of the Alsace-Moselle because we have no precise data due to its specific registration case (cf. Box 1); and data on Mayotte (976), because it is a French département only since 2011.

11. Institut national de la statistique et des études économiques. 12. It corresponds exactly to the property tax rates on built real estate.

13. Direction générale des collectivités locales. 


\section{Box 2 - Validity of the difference-in-differences design}

The most important hypothesis in the difference-indifferences framework is the common trend assumption, which assumes the evolution of the variable of interests would have been the same for the treatment and the control groups, without the reform. This assumption could be violated if there are some exogenous shocks or unobservables, which affect differently the groups over time. However, the trends of the outcome variables over the full sample period and the estimated period, show that they followed exactly the same trend and level until the reform, except for the département of Paris (75) and overseas départements (DOM). There is sometimes a slight difference in the trend of the May 2014 group (cf. Figures II and A). Those observations deserve further enquiry, which we perform below, and later in the robustness checks section.

\section{Figure $\mathrm{A}$}

Monthly (12-month cumulative) tax base of the Régime de droit commun trends from October 2000 to February 2016, by sample groups

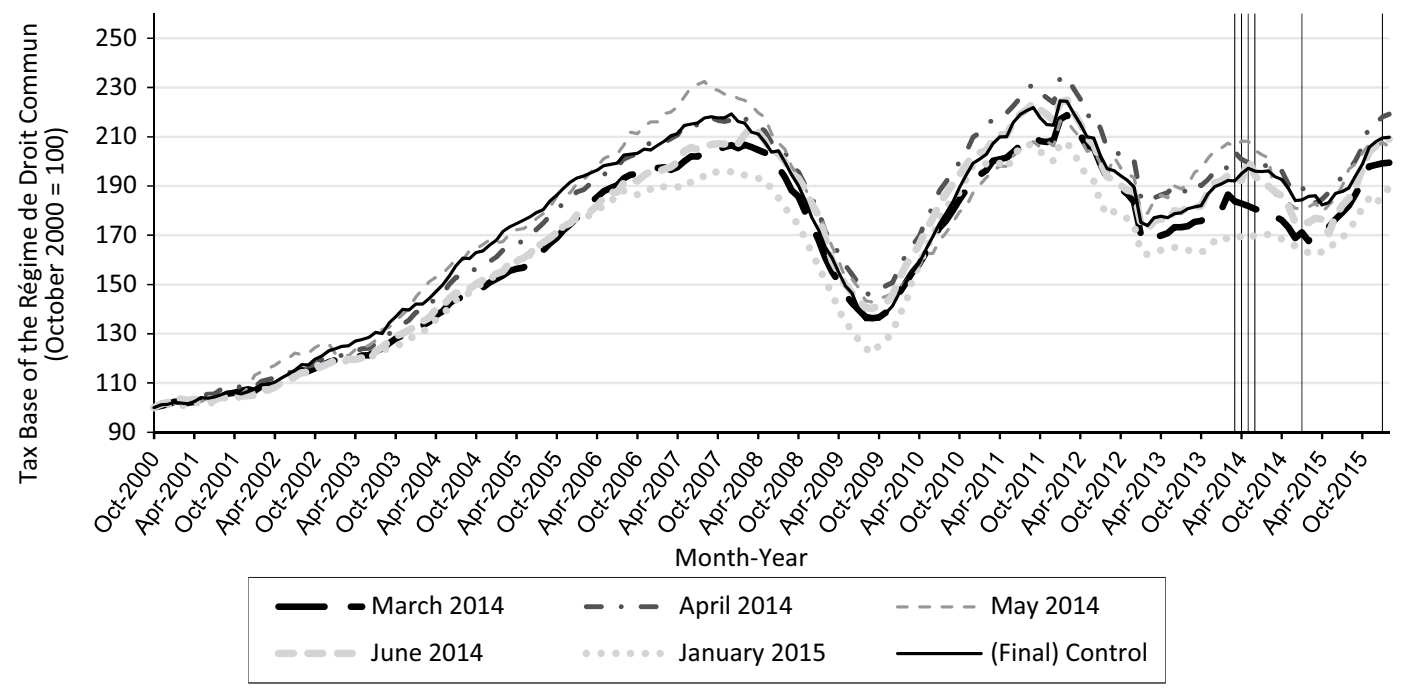

Notes: The total tax base of the départements in each group are cumulated over the previous 12 months, and corresponds to the tax revenue of the régime de droit commun registered by the DGFiP in each département, divided by the RETT rates. The départements of Moselle (57), Bas-Rhin (67), Haut-Rhin (68), Paris (75) and overseas départements (DOM), are excluded. Vertical lines correspond to the implementation dates.

Sources: CGEDD from DGFiP (MEDOC), Assiettes des droits de mutation immobiliers par département from 2000 to 2016.

\section{Test on possible self-selection: logit}

The binary logit is used to test whether there is a selection bias in the départements which implemented the tax increase, compared to the départements which did not (i.e. (final) control group). We use a binary logit over the period from January 2008 to December 2013.

$Y_{d t}=\sum_{x=1}^{9} \beta_{x} X_{d t}+\varepsilon$

In this equation, $Y_{d t}$ is equal to 1 if the département implemented the tax increase, 0 otherwise; $X_{d t}$ corresponds to one of the variables of interest or control, in a département $\mathrm{d}$, in period $\mathrm{t}$.

Estimates are reported in the online add-on C5. Estimates of the Table C5-1 show that the coefficients are close to zero, even if they are statistically significant. The choice to increase the tax is almost not correlated with these variables. It means that there is no selection bias of the treated départements. They did not do it because of a possible difference in the explaining variables, compared to the départements which chose to remain at $3.80 \%$.

\section{Placebo test}

The placebo test is used to check empirically the validity of the common trend assumption, by regressing our variable of interests in a pre-reform period, and prior the period used in the standard regressions (i.e. January 2012 to October 2015). To implement this test, we use the period from January 2008 to October 2011, and regress the month-based model (see below) on the outcome variables, using the same groups. We define our dummies for anticipation and retention as being the same than equation (2) below, but the periods are moved back of four years. For instance, for the départements which implemented the reform on March 1, 2014, the dummy for the anticipation effect $\left(T_{d}-1\right)$ is equal to 1 in February 2010, 0 otherwise.

Estimates are reported in the Online complement C5. Table C5-2 shows no coefficients significantly different from zero at the $10 \%$ level, in all the variables of interest; meaning that the trends of the treatment and control groups are the same before the implementation of the reform. Thus, the common trend assumption appears valid, and our difference-in-differences design can be implemented. 
The specificity of our difference-in-differences framework is that there is an attrition of the control group over the regressed period, and an increase of the treatment group (Table 1 and Figure III). We subdivide the treatment group in five subgroups (Table A1 in Appendix), where the treated départements are clustered by date of implementation (i.e. March 2014, April 2014, May 2014, June 2014 and January 2015), in order to estimate whether there have been some different effects and heterogeneous shocks between all groups and subgroups.

We limit our estimations to the period from January 2012 to October 2015, for two reasons. First, we choose to start from January 2012 to avoid a possible noise from the reduction of the period of transmission of the bill of sale by the notaries from 2 months to 1 month (which occurred in 2011). Second, we stop the study in October 2015 because on January 1, 2016, the Mayenne (53), one of the département of the (final) control group, implemented the tax increase. Consequently, its anticipation period should begin in November 2015 (date of its public announcement) (Box 3).

We estimate two models, respectively termed month-based model and parsimonious model.

\section{Month-Based Model}

The aim of this model is to see the dynamics of the anticipation and the retention effects in the pre-treatment and post-treatment periods. We attempt to estimate how quickly the outcome variables react to the reform of the RETT, and how they evolve over time (e.g. how long the retention effect lasts). In order to perform these estimations, we use monthly leads and lags: 6 month leads for the anticipation effect, and 20 month lags for the maximum retention effect (keeping in mind that 20 months is the full period of retention: March 2014 to October 2015). This model can be seen as a sensitivity check against the parsimonious model. The model with monthly regressors is shown in the following equation:

$$
\begin{aligned}
\log Y_{d t}= & \alpha_{d}+\lambda_{t}+\sum_{j=1}^{6} \beta_{A j} \text { Anticipation }_{d, t=T_{d}-j} \\
& +\sum_{k=0}^{\text {Oct. } 2015} \beta_{R k} \text { Retention }_{d, t=T_{d}+k}+\rho X_{d t}+\varepsilon_{d t}
\end{aligned}
$$

where $T_{d}$ is equal to the implementation month of the reform in a département $d$.

Table 1

\begin{tabular}{|c|c|c|c|c|}
\hline \multirow{2}{*}{\multicolumn{2}{|c|}{ Period (from) }} & \multicolumn{2}{|c|}{ Group } & \multirow{2}{*}{ Total } \\
\hline & & Treatment & Control & \\
\hline \multirow{5}{*}{ Treatment } & March 2014 & 58 & 34 & 92 \\
\hline & April 2014 & 76 & 16 & 92 \\
\hline & May 2014 & 78 & 14 & 92 \\
\hline & June 2014 & 85 & 7 & 92 \\
\hline & January 2015 & 88 & 4 & 92 \\
\hline
\end{tabular}

Size of the treatment and control groups over the estimated period, by date of implementation

Notes: Numbers correspond to the number of départements. Dates correspond to the month of implementation, and are different from the treatment subgroups.

\section{Box 3 - Standard event study model with anticipation}

To estimate properly the anticipation and retention effects, we use a standard event study model (see for instance Jacobson et al., 1993) as proposed in Malani and Reif (2015) that allows to estimate properly effects of a treatment, when there are expectations and anticipations from the treated population, as it is the case in our evaluation. Indeed, as explained in the previous cited papers, when there are anticipations, the full treatment effect depends on both the ex-ante and the ex-post effects. Therefore, they must be estimated simultaneously to avoid a bias in the estimations. They propose two models: (1) the quasi-myopic model which is based on a standard event study specification, and (2) the exponential discounting model. In this paper, our preferred model is the quasi-myopic model for two main reasons. First, the quasi-myopic model is easier to implement than the exponential discounting model and provides equal or better estimates when there is a finite and known period of anticipation, as in this natural experiment. Secondly, the exponential discounting model requires a structure on the error term, and in addition it assumes that people discount the future exponentially and have rational expectations, which is a strong assumption. 
Figure III

Maps of the treatment and control départements
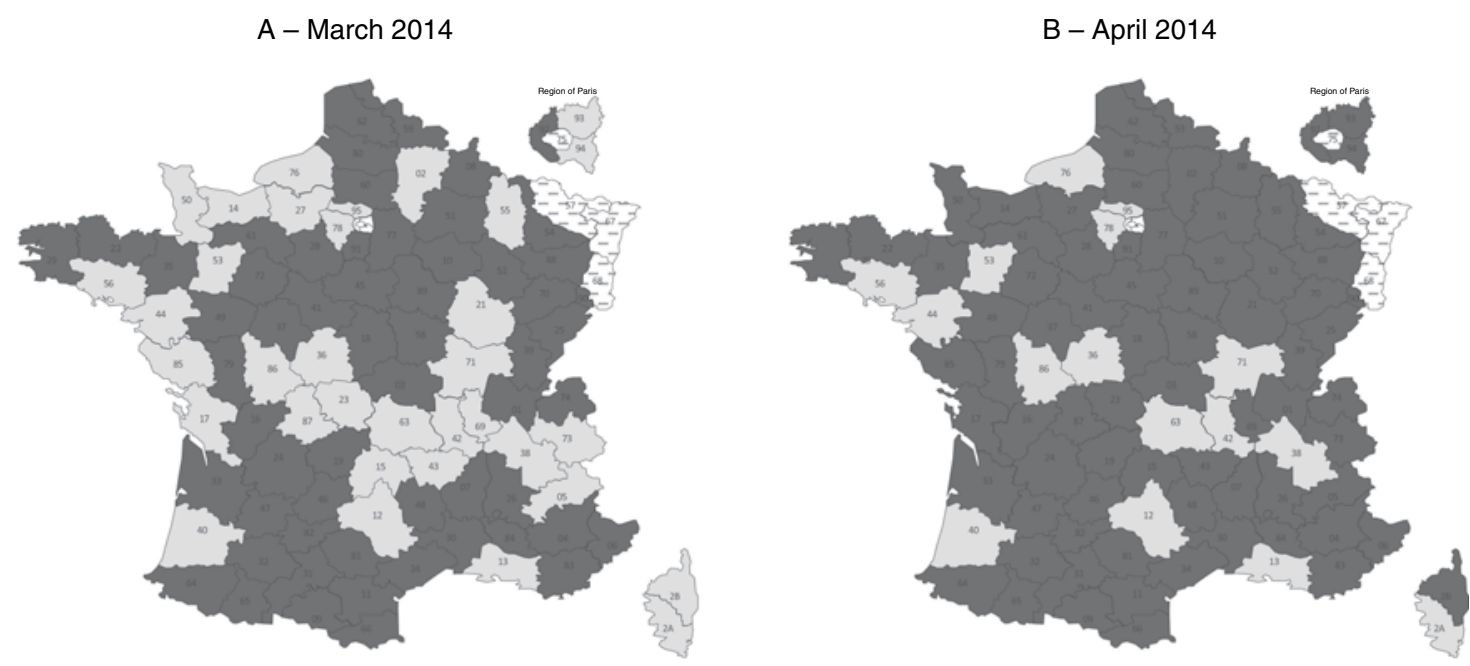

$$
\text { C - May } 2014
$$
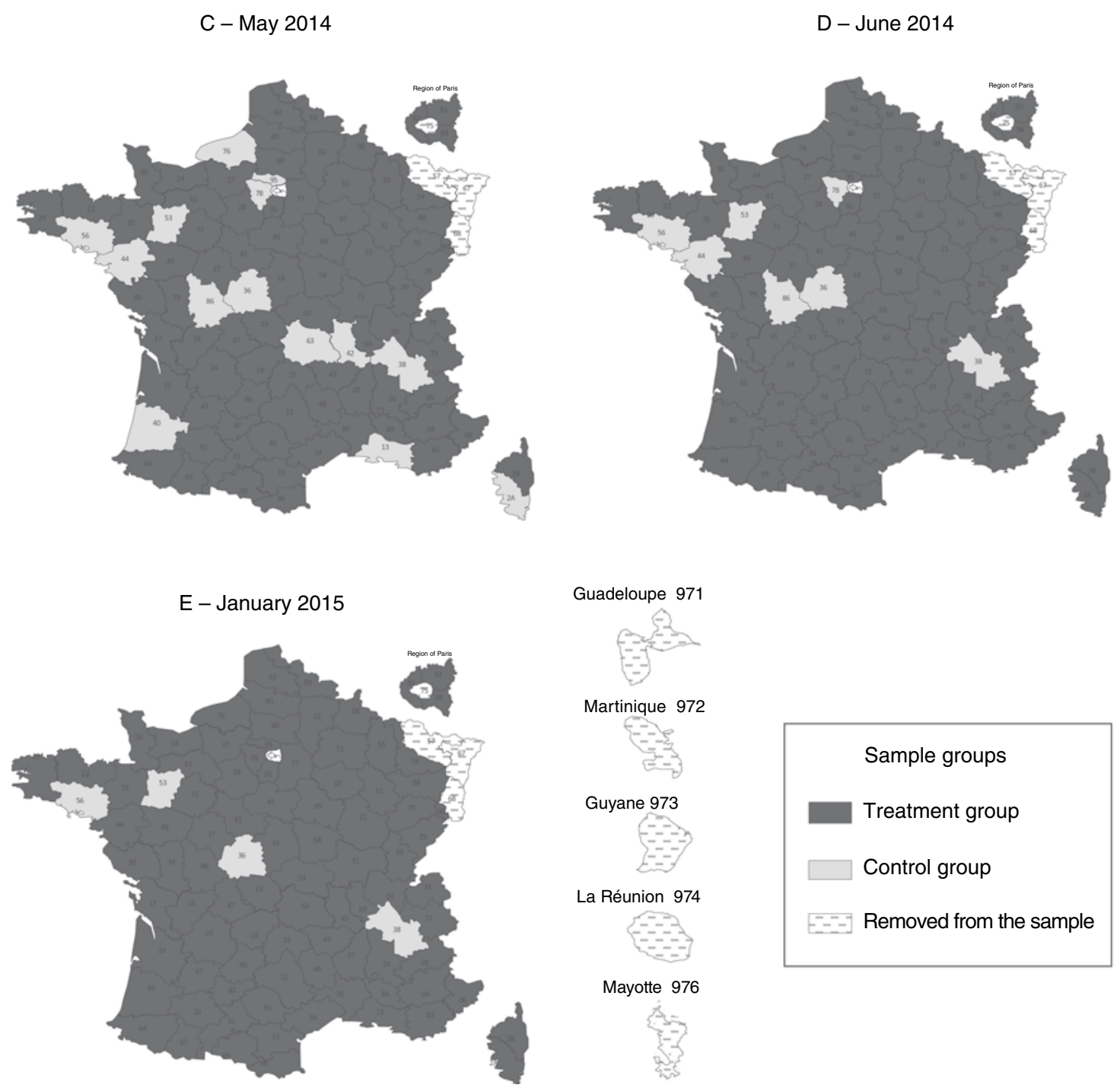

Guadeloupe 971
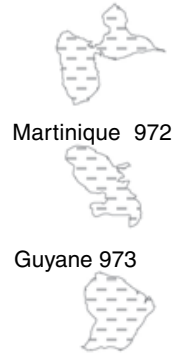

La Réunion 974

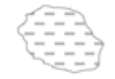

Mayotte 976 Sample groups

Treatment group

Control group

Removed from the sample

Notes: Dates correspond to the month of implementation, and are different from the treatment subgroups. Source: Authors' drawing. 
Anticipation $_{d, t=T_{d}-j}$ is a dummy variable equal to 1 if the observation in a département $\mathrm{d}$ occurs during one of the first 6 months preceding the implementation month for that département, 0 otherwise. For instance, in the départements that implemented the reform in March 2014, the variable Anticipation ${ }_{d, t=T_{d}-1}=1$ in February 2014, Anticipation ${ }_{d, t=T_{d}-2}=1$ in January 2014, and so on.

Retention $_{d, t=T_{d}+k}$ is a dummy variable equal to 1 if the observation in département $d$ occurs during one of the first 20 months following the implementation month for that département, including that month, 0 otherwise. For instance, in the départements that implemented the reform in March 2014, the variable Retention ${ }_{d, t=T_{d}+0}=1$ in March 2014, Retention $_{d, t=T_{d}+1}=1$ in April 2014, and so on. The anticipation effect in $T_{d}-j$ is estimated by $\hat{\beta}_{A j}$ and the retention effect in $T_{d}+k$ is estimated by $\hat{\beta}_{R k}$.

In addition, the models include $X_{d t}$, a vector of 7 time-variant control variables that could affect the outcome variable $Y_{d t}, \alpha_{d}$, which controls for département time-invariant characteristics (département fixed effects), and $\lambda_{t}$, which controls for differences across months shared by the sample groups (month-fixed effects). Finally, the error term $\varepsilon_{d t}$, clustered by département, and captures the département $\times$ month shocks to the variable $Y_{d t}$ (Wooldridge, 2005). This error term is assumed to be uncorrelated with the regressors, and problems could occur using a within estimator in a difference-indifferences framework, especially in the case of time-variant omitted variables that affect differently the sample groups.

\section{Parsimonious model}

The following model is similar to the regression developed by Best and Kleven (2018). It is our benchmark because it is parsimonious. Indeed, as shown in the estimates of the month-based model, the anticipation effect only occurs the month before the implementation, while the retention effect seems to last only in a short-term of 3 months after reform. After this short-term effect, the coefficients are non-different from zero, meaning that the housing market should have reached a new steady state. Then, we developed the following model in order to estimate the average effects of these three periods.

$$
\begin{aligned}
\log Y_{d t}= & \alpha_{d}+\lambda_{t}+\beta_{A 1} \text { Anticipation }_{d, t=T_{d}-1} \\
& +\beta_{2} \text { Retention }_{d, t \in\left[T_{d}, T_{d}+1, T_{d}+2\right]} \\
& +\beta_{3} \text { Post.Retention }_{d, t \in\left[T_{d}+3,\right. \text { Oct. 2015] }} \\
& +\rho X_{d t}+\varepsilon_{d t}
\end{aligned}
$$

where $T_{d}$ is equal to the implementation month of the reform in a département $d$.

Anticipation $_{d, t}=T_{d}-1$ is a dummy variable equal to 1 only the month preceding the implementation month (i.e. $T_{d}$ ) in a département $d, 0$ otherwise. For instance, in the départements that increased the RETT in March 2014, Anticipation $_{d, t=T_{d}-1}=1$ in February 2014; in the départements that implemented the reform in April 2014, Anticipation $_{d, t}=T_{d}-1=1$ in March 2014.

Retention $_{d, t \in\left[T_{d}, T_{d}+1, T_{d}+2\right]}$ is equal to 1 if a RETT increase is implemented in a département $\mathrm{d}$, and the month $t$ belongs to its 3 first months following the implementation date, 0 otherwise.

Post.Retention $_{d, t \in\left[T_{d}+3, \text { Oct. } 2015\right]}$ is equal to 1 if a RETT increase is implemented in a département $d$, and the month $t$ belongs to the period after the 3 first months following the implementation date, 0 otherwise.

The anticipation effect in $T_{d}-1$ is estimated by $\hat{\beta}_{A 1}$ (positive timing effect), the mean retention effect is estimated by $\hat{\beta}_{2}$ (negative effect due to re-timing + extensive margin response) and the mean effect post retention is estimated by $\hat{\beta}_{3}$. To interpret the raw coefficients, see Box 4.

\section{Results}

\section{Month-based model}

Table 2-A shows the estimates of the monthbased model, where the dependent variable is the total tax base of the Régime de droit commun, and are illustrated by Figure IV which shows a plot of the coefficient and confidence intervals (Table C-2 in the Online complement shows the detailed coefficients).

The estimates show an increase of around $25 \%$ the month just before the implementation 


\section{Box 4 - Interpreting results from a log-level model}

As all the models are estimated in log-level, and as our independent variables displayed in the tables of results are dummies, $(\exp (\beta)-1) \times 100$ can be interpreted as: by how many percent the dependent variable $Y$ has evolved in the situation where $D=1$, compared to $D=0$
( $D$ represents the dummy variable of the treatment). An admissible approximation is $\beta \times 100 \%$ when the coefficient is lower than 0.10 .

Note that all the results displayed in the tables are the raw estimated coefficients.

\section{Figure IV \\ Effect of the reform on the volume of transactions, month by month before and after the implementation date}

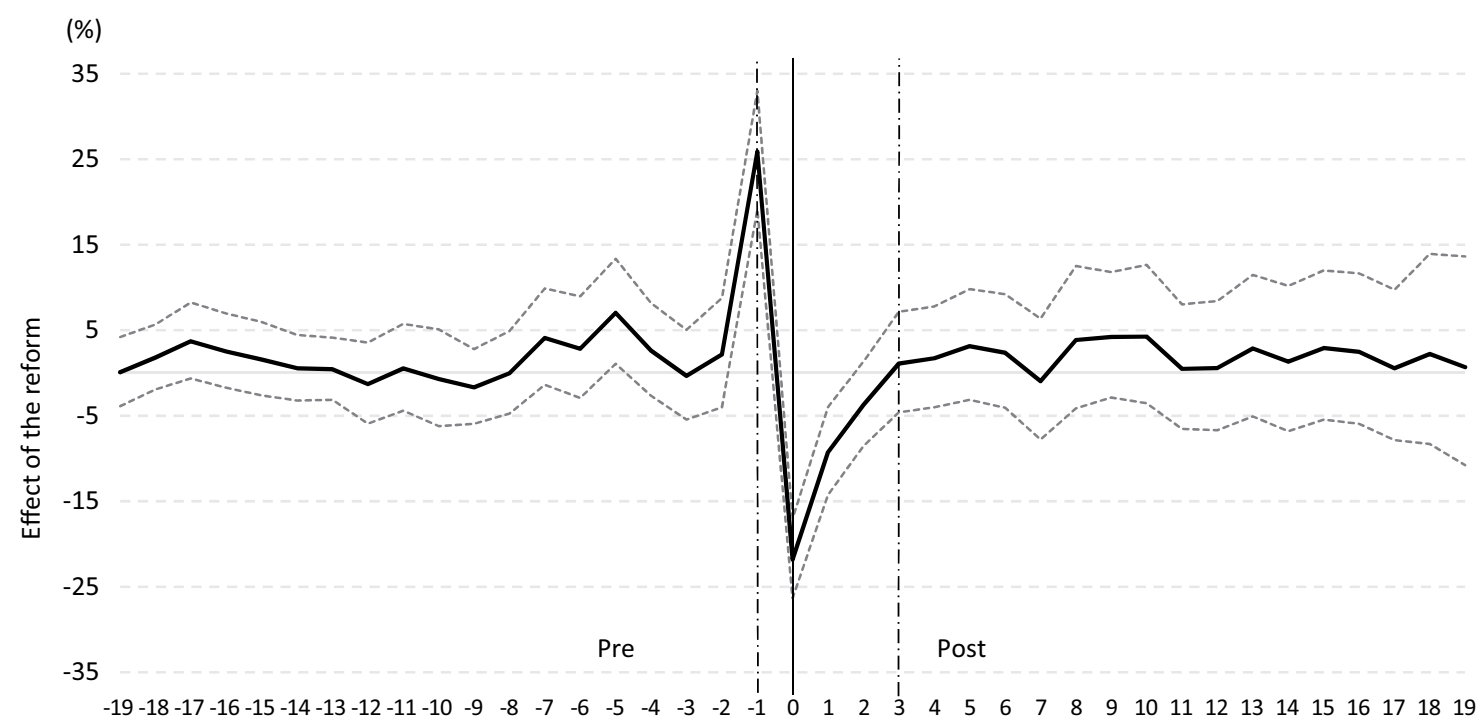

Month of implementation of the reform

$$
\text { — Estimated coefficients --------- Confidence interval (95\%) }
$$

Notes: Month 0 (solid vertical line) is the month of implementation of the reform in a given département; vertical dotted lines indicate statistically significant months As the month-based model is log-level, the "gross» coefficients should be calculated using the following method in order to be interpreted as a percentage, as shown in the graph above: $(\exp (\beta)-1) \times 100$. These effects are estimated from monthly total tax bases by département, thus represent the change in the volume of transactions assuming that prices was unchanged.

Reading note: One month after the implementation of the reform, the volume of transactions decreased by around $10 \%$ in the départements which increased the RETT.

Sources: CGEDD from DGFiP (MEDOC), Assiettes des droits de mutation immobiliers par département, Insee, Construction de logements (Sit@del2), Taux de chômage localisés, Estimation de population au 1er janvier, DGFiP, Taux de fiscalité directe locale (TFPB), DGFiP-DGCL, Les budgets primitifs des départements, from 2012 to 2015; authors' computation.

of the reform (i.e. $T_{d}-1$ ), significant at the $1 \%$ level. None of the other anticipation-period coefficients are significantly different from zero (except the coefficient for $T_{d}-5$, equal to $5.6 \%{ }^{14}$ ), meaning the anticipation effect is concentrated over the month just before the date of implementation. Both specifications suggest that buyers and sellers really agreed to escape the tax increase, and consequently, they brought forward the sale date of one month.
The estimates with the month-based model show a large decrease in the tax bases the first month of the RETT increase (i.e. $T_{d}$ ), of around $22 \%, 9.5 \%$ the second month after reform (i.e. $T_{d}+1$ ), and $4.6 \%$ the third month (i.e. $T_{d}+2$ ), all significant at the $1 \%$ and $5 \%$ level (Table 2-A). None of the other

14. This coefficient is quite puzzling and we speculate that it might correspond to a possible first anticipation during the last quarter of 2013, following the draft Finance Act. 
coefficients are significantly different from zero. It proves that most of the retention effect took place the first three months after the reform, and the effect vanished later on as the plot of estimated coefficients of the monthly effects shows (cf. Figure IV). The cumulated decrease in the months following the reform is higher than the increase of $25 \%$ in $T_{d}-1$ (see Figure V). This proves that the estimated fall in the number of transactions is not only due to re-timing (i.e. anticipated transactions that already occurred in $T_{d}-1$ ).

\section{Parsimonious model}

Table 2-B shows the estimates of the parsimonious model for different specifications, introducing one by one the monthly-fixed effect, the département fixed effect and the control variables. For the anticipation effect, once we introduce monthly fixed effects, that is, we are really adopting the difference-in-differences estimation strategy, neither the coefficients nor the standard errors really change with or without covariates (columns (4) to (6)). We find that there was an anticipation in $T_{d}-1$, of around $26 \%$, significant at the $1 \%$ level. The average monthly retention effect during the three months following the implementation is around $-14 \%$, and significant at the $1 \%$ level (columns (4) to (6)), while we see no effect significantly different from zero in the period post retention when introducing the monthly fixed effects (columns (4) to (6)).

\section{Net effect}

One may want to compute the net retention effect (Mian \& Sufi ${ }^{15}$, 2012; Best \& Kleven, 2018). Indeed, the retention effect which has been evaluated so far is magnified by the strong anticipation effect in $T_{d}-1$ which creates a "loss" of transactions the following month

15. We cannot implement the very same method proposed in this paper because of the different waves of the implementation process.

Table 2-A

Estimates for the month-based model

\begin{tabular}{|l|c|}
\hline & Total tax bases of the Régime de droit commun \\
\hline Anticipation effect $\left(T_{d}-5\right)\left(\hat{\beta}_{A 5}\right)$ & $0.055^{\star \star}$ \\
& $(0.027)$ \\
\hline Anticipation effect $\left(T_{d}-4\right)\left(\hat{\beta}_{A 4}\right)$ & 0.013 \\
\hline \multirow{2}{*}{ Anticipation effect $\left(T_{d}-3\right)\left(\hat{\beta}_{A 3}\right)$} & $(0.022)$ \\
\hline \multirow{2}{*}{ Anticipation effect $\left(T_{d}-2\right)\left(\hat{\beta}_{A 2}\right)$} & -0.013 \\
& $(0.021)$ \\
\hline \multirow{2}{*}{ Anticipation effect $\left(T_{d}-1\right)\left(\hat{\beta}_{A 1}\right)$} & 0.013 \\
\hline \multirow{2}{*}{ Retention effect $\left(T_{d}\right)\left(\hat{\beta}_{R 0}\right)$} & $(0.022)$ \\
\hline \multirow{2}{*}{ Retention effect $\left(T_{d}+1\right)\left(\hat{\beta}_{R 1}\right)$} & $0.22^{\star * *}$ \\
\hline \multirow{2}{*}{ Retention effect $\left(T_{d}+2\right)\left(\hat{\beta}_{R 2}\right)$} & $(0.021)$ \\
\hline \multirow{2}{*}{ Retention effect $\left(T_{d}+3\right)\left(\hat{\beta}_{R 3}\right)$} & $-0.25^{\star * *}$ \\
\hline \multirow{2}{*}{ Retention effect $\left(T_{d}+4\right)\left(\hat{\beta}_{R 4}\right)$} & $(0.030)$ \\
\hline Adjusted $R^{2}$ & $-0.10^{* * *}$ \\
\hline Observations & $(0.026)$ \\
\hline
\end{tabular}

Notes: For a better understanding, we present only estimates for the 5 months before and after reform. All coefficients are available in the Online Complement C2. This table reports estimates of equation 2, using within estimator. Outcome variable is in log in the estimation. In this table $T$ corresponds to the month of implementation of the reform in a département $d$. Standard errors, given in brackets, are clustered by département. Stars indicate significance level: * $p<0.1,{ }^{* *} p<0.05$ and ${ }^{* * *} p<0.01$.

Sources: CGEDD from DGFiP (MEDOC), Assiettes des droits de mutation immobiliers par département, Insee, Construction de logements (Sit@del2), Taux de chômage localisés, Estimation de population au 1er janvier, DGFiP, Taux de fiscalité directe locale (TFPB), DGFiP-DGCL, Les budgets primitifs des départements, from 2012 to 2015. 
Table 2-B

Estimates for the parsimonious model

\begin{tabular}{|l|c|c|c|c|c|c|}
\hline \multirow{2}{*}{} & \multicolumn{7}{|c|}{ Total tax bases of the Régime de droit commun } \\
\cline { 2 - 7 } & $(1)$ & $(2)$ & $(3)$ & $(4)$ & $(5)$ & $(6)$ \\
\hline \multirow{2}{*}{ Anticipation effect $\left(T_{d}-1\right)\left(\hat{\beta}_{A 1}\right)$} & $0.19^{* * *}$ & $0.19^{* * *}$ & $0.18^{* * *}$ & $0.23^{* * *}$ & $0.23^{* * *}$ & $0.23^{* * *}$ \\
& $(0.014)$ & $(0.016)$ & $(0.016)$ & $(0.021)$ & $(0.021)$ & $(0.021)$ \\
\hline \multirow{2}{*}{ Mean retention effect $\left(\hat{\beta}_{2}\right)$} & $-0.16^{* * *}$ & $-0.15^{* * *}$ & $-0.17^{* * *}$ & $-0.14^{* * *}$ & $-0.15^{* * *}$ & $-0.15^{* * *}$ \\
& $(0.011)$ & $(0.014)$ & $(0.013)$ & $(0.022)$ & $(0.021)$ & $(0.021)$ \\
\hline \multirow{2}{*}{ Mean effect post retention $\left(\hat{\beta}_{3}\right)$} & $0.031^{* * *}$ & $0.049^{* * *}$ & $0.036^{* * *}$ & -0.0099 & -0.018 & -0.016 \\
& $(0.0050)$ & $(0.010)$ & $(0.0099)$ & $(0.026)$ & $(0.025)$ & $(0.024)$ \\
\hline Adjusted R $\mathrm{R}^{2}$ & 0.055 & 0.067 & 0.070 & 0.64 & 0.64 & 0.65 \\
\hline Observations & 4,232 & 4,232 & 4,232 & 4,232 & 4,232 & 4,232 \\
\hline Monthly FE & No & No & No & Yes & Yes & Yes \\
\hline Département FE & No & No & Yes & No & Yes & Yes \\
\hline Control Variables & No & Yes & Yes & Yes & No & Yes \\
\hline
\end{tabular}

Notes: This table reports estimates of equation 3, using within estimator. Outcome variable is in log in the estimations. In this table $T_{d}$ corresponds to the month of implementation of the reform in a département $\mathrm{d}$. Standard errors, given in brackets, are clustered by département. FE indicates fixed effects. Stars indicate significance level: ${ }^{*} p<0.1,{ }^{* *} p<0.05$ and ${ }^{* \star *} p<0.01$.

Sources: cf. Table 2-A.

(i.e. re-timing). The upshot is an increase of the estimated negative effect.

The coefficient $\hat{\beta}_{A 1}=0.23(0.021)$ from equation (3) implies that the anticipation of the reform increase the volume of transactions by $26 \%$ the month just before the implementation, and the coefficient $\hat{\beta}_{2}=-0.15(0.021)$ implies that the average monthly activity was $14 \%$ lower in the treated départements the 3 months following the implementation. These estimates together imply that $-\hat{\beta}_{A 1} /\left(3 \hat{\beta}_{2}\right)=51 \%$ of the retention effect was a re-timing effect due to the anticipated transactions (intertemporal substitution by those who would have purchased a real estate anyway), and the remaining $49 \%$ was an extensive margin effect (those who would have purchased a real estate in the absence of the reform).

A new piece of evidence is brought by Figure V, which plots the cumulative sum of the coefficients from the month-based model starting from one month before the implementation month (i.e. $\left.T_{d}-1\right)$. It shows that the magnitude of the retention effect is higher than the one of the anticipation effect, and that in the months following the implementation date, the cumulative sum is always negative. Performing a Wald test on the sum of the coefficients from $T_{d}-1$ to $T_{d}+2$, we can reject at the $5 \%$ level the hypothesis that this add-up to zero $\left(\mathrm{H}_{0}\right)$. In fact, it is even true for a period of 5 months from $T_{d}-1$ to $T_{d}+3$ (Figure $\mathrm{V}$ and the double arrow), except for the month of implementation of the reform (i.e. $T_{d}$ ), which implies that the re-timing is almost completely absorbed in the first month of implementation. Beyond four months following the implementation date, we cannot reject that the evolution of the treatment and the control groups are similar.

The cumulative sum of the coefficients up to $T_{d}+2$ is equal to -0.18 . Dividing it by 3 (i.e. number of months of the retention effect), we find an average monthly net effect of $-5.8 \%$ over three months. The same computation up to $T_{d}+3(-0.17)$ gives an average monthly net effect of $-5.5 \%$ during four months. We have then strong evidence of a short-term effect.

Using the coefficients from the parsimonious model (cf. Table 2-B) and applying a similar computation $^{16}$, we find an average monthly net proportional change of $-7 \%$ during the three initial months following the implementation date.

Taking advantage of both estimations and giving more weight to the monthly estimation, we then conclude to a short-term drop between $5.5 \%$ and $7 \%$ per month during three months after the implementation date (i.e. approximatively $6 \%$ ), and no medium- or long-term response afterwards.

16. $(0.23+3 \times(-0.15)) / 3=-0.073$ 
Figure V

Cumulative effect of the reform on the volume of transactions, month by month before and after the implementation date

(\%)

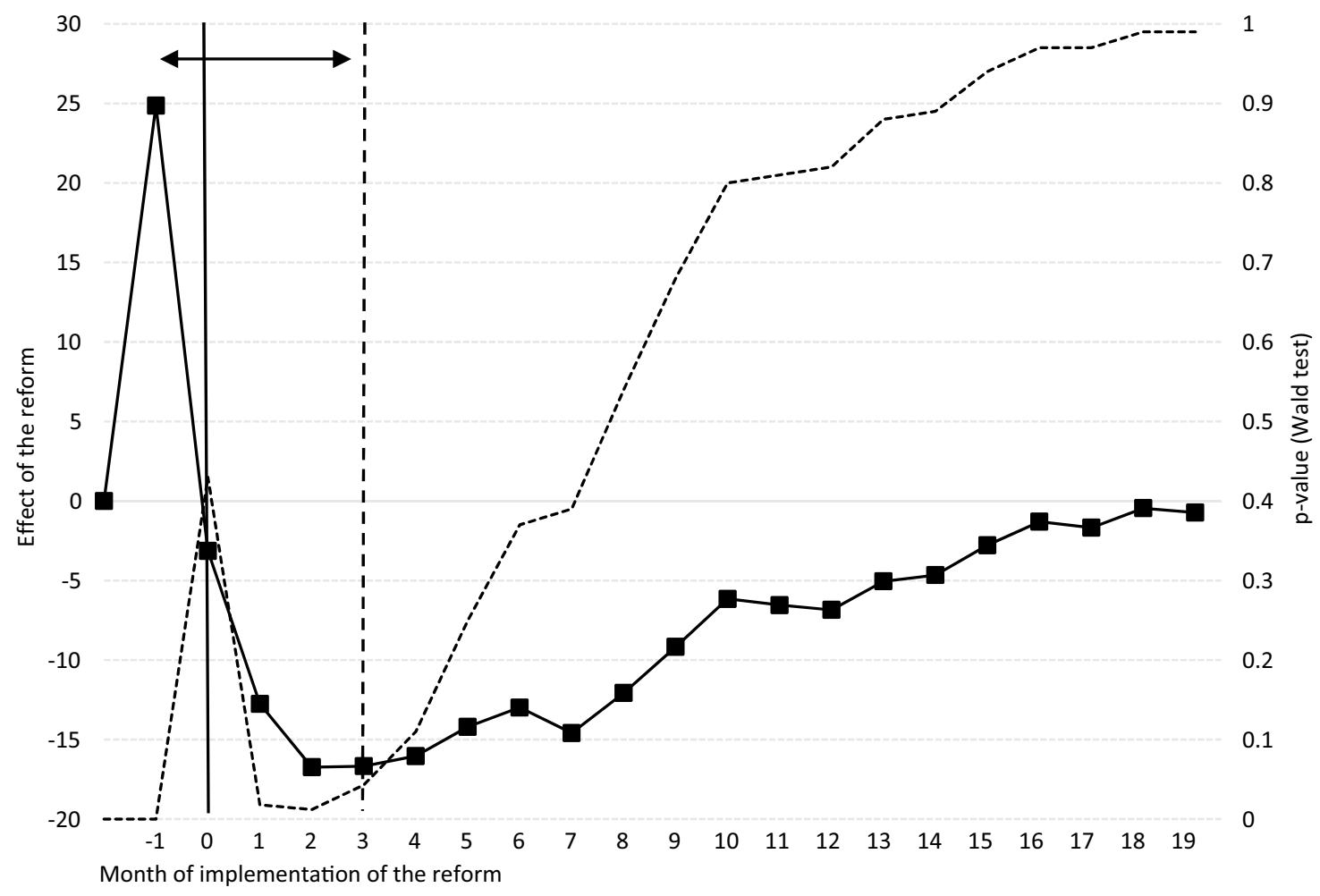

$\longrightarrow$ Cumulative effect ------- p-value

Notes: Month 0 corresponds to the month of implementation of the reform in a given département. This graph shows the cumulative sum from $T_{d}-1$ of the effects estimated in Table 2-A, and plotted in Figure IV (left axis), and the p-value of the Wald test (right axis). The double arrow figures out the period for which the Wald test rejects $\mathrm{H}_{0}$ (i.e. the sum of the coefficients is null).

Reading note: The value $-3.14 \%$ for month 0 is the percentage change from $T_{d}-1$ to $T_{d}$ (two months), and has the following interpretation: after two months since $T_{d}-1$, there is a cumulative fall of $3.14 \%$ of the monthly number of transactions, and the $p$-value is 0.43 for the Wald test.

Sources: CGEDD from DGFiP (MEDOC), Assiettes des droits de mutation immobiliers par département, Insee, Construction de logements (Sit@de/2), Taux de chômage localisés, Estimation de population au 1er janvier, DGFiP, Taux de fiscalité directe locale (TFPB), DGFiP-DGCL, Les budgets primitifs des départements, from 2012 to 2015; authors' computation.

This net monthly effect helps to provide a rough estimate of the number of missed transactions in 2014 due to the rise of the RETT. As shown in the following graph (Figure VI), the yearly number of transactions in the Régime de droit commun at the national level were around $1,050,000$ on the verge of 2014 . We could offer a rough estimate of the drop that would have occurred, were the implementation nationwide. We should observe a drop of the number of transactions of around $18 \%$ at the end of the three month period, that is $16,142 \simeq(-18 \%) \times \overline{\text { Number of Transactions }}_{0}$, where $\overline{\text { Number of Transactions }}_{0}$ is equal to the previous two years' average monthly number of transactions (i.e. 89,681).

In fact, only $93 \%{ }^{17}$ of the départements implemented the measure over the regressed period.
Then, the true effect is closer to 15,000 , which is approximatively $1 / 4$ of the drop that we can detect on Figure VI (see the circle, which brings about the total number of real estate transactions $\left.{ }^{18}\right)$. This computation surely underestimates the true effect since we ignore any interdependence between local markets. It should be considered as a lower bound of the true effect.

Unfortunately, we cannot conclude on the issue whether this loss in transaction of the three (four) initial months is reversed (i.e. the entire response to the reform is a timing response). On the one hand, a piece of evidence in favor of no recovering is the fact that the monthly coefficients are not significant after $T_{d}+2$ in the monthly regression

17. $94 / 101=0.93$.

18. Houses + non-residential premises + lands. 
Figure VI

12 month-moving-average total number of real-estate transactions

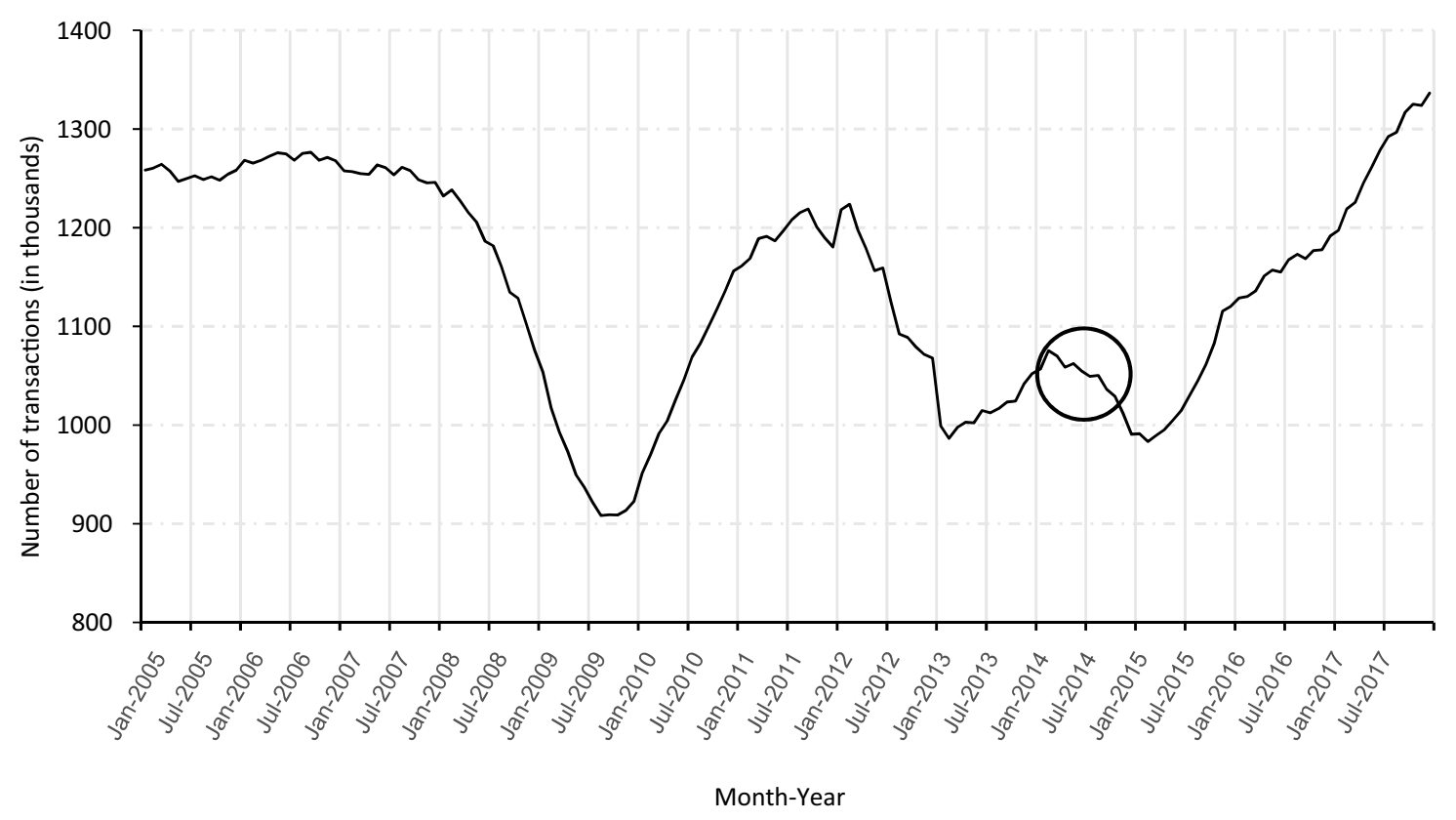

Notes: The number of transactions is cumulated over the previous 12 months, and corresponds to the number of transactions in the régime de droit commun registered by the DGFiP.

Coverage: France (Mayotte excluded).

Sources: CGEDD from DGFiP (MEDOC + Fidji), nombre de ventes immobilières taxées au taux du régime de droit commun par département from 2005 to 2017.

(cf. Table 2-A), contrary to Mian and Sufi (2012) who got statistically significant reversal coefficients. On the other hand, a piece of evidence in the other direction is the fact that looking at the Wald test of the nullity of the sum of the coefficients, we cannot reject the hypothesis that these coefficients add up to zero beyond five months (i.e. after $T_{d}+3$ ). However, we should not forget that the design of the implementation introduces a noise beyond $T_{d}+3$ due to the attrition of the control group (cf. Table 1), in addition to the decrease in magnitude of the effect, which reduces the statistical power. Furthermore, the statistical power of the cumulative effect weakens also mechanically as we extend the horizon by adding an extra noise for each month added, as shown by the pattern of the Wald test's p-value. So, we choose to let this issue unsettled at this stage, and we conclude that this point needs further investigations.

\section{Tax elasticity and the Laffer curve}

In this section we are interested in quantifying the response of the total tax bases to a onepercent increase in the tax. Since we found that the net effect is estimated to be around
$-6 \%$ whereas the increase in tax rates is about $14.15 \%{ }^{19}$ the elasticity is:

$$
\varepsilon_{T B}^{\tau}=\frac{\partial \log Y}{\partial \log \tau} \cong \frac{\frac{\Delta Y}{\Delta \tau}}{\frac{\Delta \tau}{\tau}} \cong \frac{-0.06}{0.1415}=-0.42
$$

This means that tax bases decreased by $0.42 \%$ for a $1 \%$ increase in the RETT's rate (i.e. there is a loss in the tax bases which reduces the gains of tax revenues for the local budgets). Following this, we want to compute $\bar{\tau}$ the rate from which the tax revenues of the départements would be maximum, then, begin to decline for each $\tau>\bar{\tau}$ (i.e. the maximum of the Laffer curve).

A small change in the tax rate changes $\mathrm{Y}$ by:

$$
\frac{\partial \tau . Y}{\partial \tau}=Y+\tau \frac{\partial Y}{\partial(1+\tau)}=Y\left(1-\frac{\tau}{1+\tau} \varepsilon\right)
$$

where $\varepsilon \equiv \varepsilon_{T B}^{1+\tau}=-\frac{\partial \log Y}{\partial \log (1+\tau)}$ is the elasticity of the tax bases with respect to tax-inclusive

19. RETT of the Régime de droit commun increased by 0.7 percentage point (due to the increase of the departmental's part, see box 1), jumping from $5.09 \%$ to $5.81 \%$, thus a rise of $14.15 \%$. 
prices. The Laffer rate sets the above expression to zero:

$$
\bar{\tau}=\frac{1}{\varepsilon-1}
$$

To compute this rate, we use the following expression:

$$
\varepsilon_{T B}^{1+\tau}=\varepsilon_{T B}^{\tau} \frac{1+\tau}{\tau} \cong 0.42 \frac{1+0.0509}{0.0509} \cong 8.7
$$

Then, replacing (7) in (6) implies that $\bar{\tau} \cong 13 \%$, and that the départements' tax revenues are still on the increasing part of the Laffer curve ${ }^{20}$.

\section{Discussion}

The main result - only a short-term effect of the reform - raises interesting issues. At first glance, when increasing tax, we should expect the market to be negatively impacted durably. Nevertheless, in our case, the extensive margin effect is estimated to last only 3 months, and we see no difference between treated and controlled départements beyond. We provide three possible explanations for this result. (1) It is possible to build theoretical model of housing investment where the long-term effect is ambiguous. (2) This short decrease could correspond to the shifting time of demand (people should buy anyway). Indeed, the average time for a housing contract in France is 3 months. So, perhaps that these three months of decrease correspond to the time spell for sellers to find new buyers, after that the first buyers gave up on buying when being informed of the tax increase. Moreover, those buyers could have decided to buy at lower price. They renounced to real estates that they were looking for, in order to buy some with lower characteristics and amenities a few months later. (3) It could be related to a cognitive bias from the agent. As developed by the Nobel Prize Richard Thaler, people do not feel price differences "equally" when prices are big. For instance, people are ready to pay a relatively important "cost" to save $€ 10$ for a small purchase (e.g. at a restaurant); at the same time, they think that a $€ 200,000$ and $\mathrm{a} € 205,000$ housing are almost of the same values, except the deviation is $€ 5,000$ !

Nevertheless, our study faces two main limitations. One is a possible spillover effect, due the fact that some buyers could have "voted with their feet" may introduce a bias. More precisely, some buyers who were willing to buy real estate in a treated département neighboring a controlled département, in an area close to the border, could have chosen to buy in the controlled département because of the reform. In further studies using micro data, this spillover effect could be estimated with a regression discontinuity design (Hahn et al., 2001; Imbens \& Lemieux, 2008), by clustering the neighboring treated and controlled départements. Defining a band of a few kilometers around the border to make the difference between treated and controlled, and between the housing markets in the center of the treated départements, compared to their housing market at this border. Nonetheless, we guess that this effect is small in magnitude, as real estate are heterogeneous goods, including their localization. The other is a possible lack of control variables, because we could not get all the desired data (monthly and by départements), especially the rent by département. Nevertheless, we attempt below to check for possible unobservables or heterogeneity between départements, and we assume that most of the possibly omitted covariates are time-invariant, thus captured by the fixedeffects estimator.

One could also argue that there is a selection bias, because the départements that did not implement the RETT increase, are different in some points to the others. That does not seem likely when looking at the trends of the outcome variables (cf. Figures II and A). Furthermore, when looking at the distributions and trends of the other local variables between groups (see Online complement $\mathrm{C} 1$ ), there is no marked difference between the treated and control groups. Population, property tax rates, index of "good administration" and their inherent housing market show no differences between groups, and between them and national statistics. Ultimately, what we are interested in here is the elasticity of buyers' and sellers' supply and demand in real estate, while the choice of the reform implementation falls to the local councilors. Those decision makers are elected, and thus one could think that there is a correlation between them and the population (composed of the buyers and sellers). However, the point in case is to know whether those elasticities are correlated with the choice to implement the reform or not. Such independence assumption is difficult to

20. Notice that the elasticity estimate would be higher using the gross estimates (rather than net estimates). 
check. Nonetheless, we attempt below to test for a possible bias from the political color of the local governments.

The main selection problem, in natural experiments including a local fiscal policy reform, is the political color of the local councilors that decided to implement (or not) the tax increase. Indeed, in our study one could argue that leftwing or right-wing départements might have implemented the reform differently. However, the proportion of left-wing and right-wing départements which implemented the tax increase (or not), is exactly the same as the distribution of left-wing and right-wing départements among the whole country (Table 3 ). Furthermore, in the 2015 departmental elections, 28 départements switched from the left-wing to the right-wing, and only one switched from the right-wing to the left-wing. The new political distribution of the local councils is: 34 for the left-wing and 67 for the right-wing. Therefore, the distribution has shifted between political wings, but no département has decided to decrease the RETT, while they have had the possibility to do so.

More elements are discussed in the Online complement $\mathrm{C} 4$.

\section{Robustness checks}

As suggested in Meyer (1995), we multiply the tests of robustness, in order to check the validity of our results. Developments and estimates are reported in the Online complement C5.

(1) Alternative dependent variable. Alternative dependent variable (total tax bases of the Régime dérogatoire) is used to test whether the results are biased because there was an exogenous shock affecting the housing markets of the two groups differently. Results of Table C5-3 show no coefficient significantly different from zero at the $10 \%$ level, for the substitute outcomes. Then, it appears that our results are not biased: there was no shock affecting differently the housing markets of the two groups during the regressed period.

(2) Estimations using different period. We check the validity of our results to the choice of the period and sample groups. Table C5-4 shows estimates close to the ones found in the main estimations. The main effect in which we are interest in being similar to our first estimates, they appear robust to the choice of the estimation period.

(3) Changes in local economic conditions. As the results that we obtain could be impacted by an exogenous economic shock, affecting the sample groups differently, we test for this kind of changes in the local economic conditions. To implement this test, we use the same method as in Benzarti and Carloni (2015). Results for both models presented in Tables C5-5 and C5-6 show only slight differences between the estimates and our main results. We can therefore conclude that our estimates are robust, and that no exogenous local economic shocks affected differently our groups.

(4) Regressing by treatment subgroups. We re-estimate the parsimonious model where we allow for a possible heterogeneity for the different subsets of treated groups. Results of this regression are displayed in Table C5-7. The anticipation effect is non-significant for the January subgroup and for the other

Table 3

Distribution of the départements' political color, by implementation or non-implementation of the RETT increase

\begin{tabular}{|l|c|c|c|c|}
\hline \multicolumn{2}{|c|}{} & \multicolumn{2}{|c|}{ Party } & \multirow{2}{*}{ Total } \\
\cline { 3 - 4 } \multicolumn{2}{|c|}{} & Left-Wing & Right-Wing & \\
\hline \multirow{2}{*}{ RETT $=4.50 \%$ (increased) } & number of départements used(a) & 60.4 & 39.6 & 100 \\
& $\%$ & 58 & 38 & 96 \\
\hline \multirow{2}{*}{ RETT = 3.80\% (unchanged) } & number of départements used(a) & 60 & 40 & 100 \\
& $\%$ & 60.4 & 2 & 5 \\
\hline \multirow{2}{*}{ Whole country } & number of départements used (a) & 61 & 39.6 & 100 \\
& & 40 & 101 \\
\hline
\end{tabular}

(a) The number of département used to compute the percentages.

Notes: The party of the local government corresponds to the political color when the RETT increase was voted. Then, it corresponds either to the 2011 or 2015 departmental elections.

Coverage: Whole France. This computation was made among all the départements (i.e. 101).

Sources: Ministère de l'Intérieur, résultats des élections cantonales 2011 et départementales 2015. 
subgroups spans a large range between $16 \%$ (May) and 45\% (April). The retention effect is also non-significant for the January subgroup and is comprised between $-10 \%$ (March) and $-17 \%$ (May) for the other subgroups. None of the coefficients of the post retention period are significantly different from zero. It is not very surprising that there is some heterogeneity in the local-market responses.

(5) Removing possibly heterogeneous groups. We may suspect a possible heterogeneity or unobservables that affect differently May 2014 and January 2015 groups over time. In order to test this hypothesis, we estimate our coefficients removing either January 2015 or May 2014 group or both, from the estimated sample. Tables C5-8 shows only slight differences between the estimates and our main results. We can conclude that our findings are robust to the choice of the sample, and to a possible bias from heterogeneous départements.

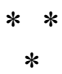

To conclude, we find evidence that the RETT increase had an impact on the housing market in line with the economic literature. We bring empirical evidence that two behavioral responses took place. We show extremely compelling estimates of a short-term timing response to an anticipated tax increase. People brought forward transactions to the month before the tax increase. The number of transactions rocketed by $26 \%$ the month preceding the implementation of the reform. Second, the volume of transactions fell by around $14 \%$ on average per month during the three months following the rate change, whose $51 \%$ of this loss is due to re-timing. The two effects do not cancel out. All in all, the average monthly net effect corresponds to a transaction drop of around $6 \%$ over the three months following the implementation date, assuming no sale-price changes. Such assumption appears realistic, as the RETT system in France is proportional and the RETT's payment accrues to the buyer. Buyers and sellers can more easily agree in changing the sale date rather than the sale price (Benjamin et al., 1993; Davidoff \& Leigh, 2013; Slemrod et al., 2017), a behavior supported by the large anticipation effect. Nonetheless, it is difficult without noncumulative monthly data on the number of transactions and hedonic estimation, to disentangle the effect on the volume of transactions from the price effect. We find compelling evidence of a sizable short-term effect - but no medium or long-run effect meaning that there is a strong "resilience" from the housing market (people should buy anyway). Moreover, we estimate that the short-term elasticity of the tax base to the tax rate is around -0.42 , meaning that there is a loss of $42 \%$ in the tax revenues with respect to a situation of no behavioral response, the first quarter after the reform. Computing the Laffer tax rate, we conclude that départements' tax revenues are still on the increasing side of the Laffer curve. Note that our results are valid for partial equilibrium. We do not estimate the possible other general equilibrium aspects resulting from the distortion of the housing market, such as changes in investment from the local governments or impact in the labor market. Applied to national transactions data, our estimate means that around 15,000 transactions were missing because of the transfer tax increase. This estimate is likely a lower bound of the true impact.

This evaluation can be extended in three ways: using the non-cumulative monthly data on the number of transactions; doing a precise estimation of the price effect through hedonic model (using the notarial databases BIEN - Base d'informations économiques notariales - and Perval); implementing a regression discontinuity design to estimate the possibility that buyers could have "voted with their feet" (i.e. spillover effect).

Finally, our results might be used to discuss the impact of future RETT reforms, and anticipate the effect on the housing market, in particular on buyers and sellers behavior. Even if the RETT rise was a "good deal" for the départements in terms of tax revenue, the distorting effect of the tax reform was assessed: some people who could have become owners or moved from a place to another, did not because of the reform (i.e. lock-in effect). Consequently, in line with the findings of Van Ommeren and Van Leuvensteijn (2005), we conclude that the RETT increase has a negative sizable (short-term) impact on mobility and well-being. 


\section{BIBLIOGRAPHY}

Benjamin, J. D., Coulson, N. E. \& Yang, S. X. (1993). Real Estate Transfer Tax and Property Values: The Philadelphia Story. The Journal of Real Estate Finance and Economics, 7(2), 151-157. https://doi.org/10.1007/bf01258324

Benzarti, Y. \& Carloni, D. (2015). Who Really Benefits from Consumption Tax Cuts? Evidence from a Large VAT Reform in France. Job Market Paper. https://papers.ssrn.com/sol3/papers.cfm?abstract_id $=2629380$

Besley, T., Meads, N. \& Surico, P. (2014). The Incidence of Transaction Taxes: Evidence from a Stamp Duty Holiday. Journal of Public Economics, 119, 61-70.

https://doi.org/10.1016/j.jpubeco.2014.07.005

Best, M. C. \& Kleven, H. J. (2018). Housing Market Responses to Transactions Taxes: Evidence from Notches and Stimulus in the UK. The Review of Economic Studies, 85 (1), 157-193. https://doi.org/10.1093/restud/rdx032

Dachis, B., Duranton, G. \& Turner, M. A. (2012). The Effects of Land Transfer Taxes on Real Estates Market: Evidence from a Natural Experiment in Toronto. Journal of Economics Geography, 12(2), 327-354.

https://doi.org/10.1093/jeg/lbr007

Davidoff, I. \& Leigh, A. (2013). How Do Stamp Duties Affect the Housing Market?. Economic Record, 89(286), 396-410.

https://doi.org/10.1111/1475-4932.12056

Donald, S. G. \& Lang, K. (2007). Inference with Difference-in-Differences and Other Panel Data. Review of Economics and Statistics, 89(2), 221-233. https://doi.org/10.1162/rest.89.2.221

Hahn, J., Todd, P. \& Van der Klaauw, W. (2001). Identification and Estimation of Treatment Effects with a Regression-Discontinuity Design. Econometrica, 69(1), 201-209.

https://www.jstor.org/stable/2692190?seq=1\#page _scan_tab_contents

Imbens, G. \& Lemieux, T. (2008). Regression Discontinuity Designs: A Guide to Practice. Journal of Econometrics, 142(2), 615-635. https://doi.org/10.3386/w13039
Ioannides, Y. M. \& Kan, K. (1996). Structural Estimation of Residential Mobility and Housing Tenure Choice. Journal of Regional Science, 36(3), 335-363.

https://doi.org/10.1111/j.1467-9787.1996.tb01107.x

Jacobson, L. S., LaLonde, R. J. \& Sullivan, D. G. (1993). Earnings Losses of Displaced Workers. The American Economic Review, 83(4), 685-709. https://www.jstor.org/stable/2117574

Kopczuk, W. \& Monroe, D. J. (2015). Mansion Tax: The Effect of Transfer Taxes on the Residential Real Estate Market. American Economic Journal: Economic Policy, 7(2), 214-257.

https://doi.org/10.3386/w20084

Malani, A. \& Reif, J. (2015). Interpreting Pre-Trends as Anticipation: Impact on Estimated Treatment Effects from Tort Reform. Journal of Public Economics, 124, 1-17.

https://doi.org/10.1016/j.jpubeco.2015.01.001

Meyer, B. (1995). Natural and Quasi-experiments in Economics. Journal of Business and Economic Statistics, 13(2), 151-161.

https://doi.org/10.3386/t0170

Mian, A. \& Sufi, A. (2012). The Effects of Fiscal Stimulus: Evidence from the 2009 'Cash for Clunkers' Program. The Quarterly Journal of Economics, 127(3), 1107-1142.

https://doi.org/10.3386/w16351

Slemrod, J. B., Weber, C. \& Shan, H. (2017). The Behavioral Response to Housing Transfer Taxes: Evidence from a Notched Change in D.C. Policy. Journal of Urban Economics, 100(C), 137-153. https://doi.org/10.1016/j.jue.2017.05.005

Van Ommeren, J. \& Van Leuvensteijn, M. (2005). New Evidence of the Effect of Transaction Tax Costs on Residential Mobility. Journal of Regional Science, 45(4), 681-702. https://doi.org/10.1111/j.0022-4146.2005.00389.x

Wooldridge, J. M. (2005). Fixed Effects and Related Estimators for Correlated Random-Coefficient and Treatment-Effect Panel Data Models. Review of Economics and Statistics, 87(2), 385-390.

https://doi.org/10.1162/0034653053970320 
Table A1

Sample groups with subdivision of the treatment group ${ }^{(a)}$ in subgroups by date of implementation

\begin{tabular}{|c|c|c|c|c|c|c|c|}
\hline \multicolumn{4}{|c|}{ March 2014} & \multicolumn{2}{|r|}{ April 2014} & \multicolumn{2}{|r|}{ May 2014} \\
\hline $\mathrm{N}^{\circ}$ & Département & $\mathrm{N}^{\circ}$ & Département & $\mathrm{N}^{\circ}$ & Département & $\mathrm{N}^{\circ}$ & Département \\
\hline 01 & Ain & 47 & Lot-et-Garonne & 02 & Aisne & 12 & Aveyron \\
\hline 03 & Allier & 48 & Lozère & 05 & Hautes-Alpes & 71 & Saône-et-Loire \\
\hline 04 & Alpes-de-Haute-Provence & 49 & Maine-et-Loire & 14 & Calvados & & \\
\hline 06 & Alpes-Maritimes & 51 & Marne & 15 & Cantal & & \\
\hline 07 & Ardèche & 52 & Haute-Marne & 17 & Charente-Maritime & & \\
\hline 08 & Ardennes & 54 & Meurthe-et-Moselle & $2 B$ & Haute-Corse & & \\
\hline 09 & Ariège & 58 & Nièvre & 21 & Côte-d'Or & & \\
\hline 10 & Aube & 59 & Nord & 23 & Creuse & & \\
\hline 11 & Aude & 60 & Oise & 27 & Eure & & \\
\hline 16 & Charente & 61 & Orne & 43 & Haute-Loire & & \\
\hline 18 & Cher & 62 & Pas-de-Calais & 50 & Manche & & \\
\hline 19 & Corrèze & 64 & Pyrénées-Atlantiques & 55 & Meuse & & \\
\hline 22 & Côtes-du-Nord & 65 & Hautes-Pyrénées & 69 & Rhône & & \\
\hline 24 & Dordogne & 66 & Pyrénées-Orientales & 73 & Savoie & & \\
\hline 25 & Doubs & 70 & Haute-Saône & 85 & Vendée & & \\
\hline 26 & Drôme & 72 & Sarthe & 87 & Haute-Vienne & & \\
\hline 28 & Eure-et-Loir & 74 & Haute-Savoie & 93 & Seine-St-Denis & & \\
\hline 29 & Finistère & 77 & Seine-et-Marne & 94 & Val-de-Marne & & \\
\hline 30 & Gard & 79 & Deux-Sèvres & & & & \\
\hline 31 & Haute-Garonne & 80 & Somme & & & & \\
\hline 32 & Gers & 81 & Tarn & & & & \\
\hline 33 & Gironde & 82 & Tarn-et-Garonne & & & & \\
\hline 34 & Hérault & 83 & Var & & & & \\
\hline 35 & Ille-et-Vilaine & 84 & Vaucluse & & & & \\
\hline 37 & Indre-et-Loire & 88 & Vosges & & & & \\
\hline 39 & Jura & 89 & Yonne & & & & \\
\hline 41 & Loir-et-Cher & 90 & Territoire-de-Belfort & & & & \\
\hline 45 & Loiret & 91 & Essonne & & & & \\
\hline 46 & Lot & 92 & Hauts-de-Seine & & & & \\
\hline \multicolumn{2}{|r|}{ June 2014} & \multicolumn{2}{|r|}{ January 2015} & & (Final) Control & \multicolumn{2}{|c|}{ Removed from the sample } \\
\hline $\mathrm{N}^{\circ}$ & Département & $\mathrm{N}^{\circ}$ & Département & $\mathrm{N}^{\circ}$ & Département & $\mathrm{N}^{\circ}$ & Département \\
\hline 13 & Bouches-du-Rhône & 44 & Loire-Atlantique & 36 & Indre & 57 & Moselle \\
\hline $2 \mathrm{~A}$ & Corse-du-Sud & 78 & Yvelines & 38 & Isère & 67 & Bas-Rhin \\
\hline 40 & Landes & 86 & Vienne & 53 & Mayenne & 68 & Haut-Rhin \\
\hline 42 & Loire & & & 56 & Morbihan & 75 & Paris \\
\hline 63 & Puy-de-Dôme & & & & & 971 & Guadeloupe \\
\hline 76 & Seine-Maritime & & & & & 972 & Martinique \\
\hline 95 & Val-d'Oise & & & & & 973 & Guyane \\
\hline & & & & & & 974 & La Réunion \\
\hline & & & & & & 976 & Mayotte \\
\hline
\end{tabular}

(a) Treatment group is composed of the subgroups: March 2014, April 2014, May 2014, June 2014 and January 2015. 


\title{
Does information to buyers affect the sales price of a property? Mandatory disclosure and the hedonic price model - A test on French data
}

\author{
Amélie Mauroux*
}

\begin{abstract}
Under the assumption of complete and perfect information, hedonic prices can be interpreted as marginal willingness to pay. This assumption may appear strong, especially in cases of exposure to natural risks. This assumption is tested for the French real estate market: we assess the impact of an informational shock-the implementation of the obligation to inform buyers and tenants (IAL) on $1^{\text {st }}$ June 2006 - on real estate prices. If the information available to buyers was perfect, there should not be any impact. A hedonic price model is estimated in difference-in-differences, using notarial data spatially matched with maps of regulated zones covered by flood risk prevention plans. The results do not show an impact of the introduction of the IAL on the average price of the houses concerned. However, for certain categories of properties (ground floor apartments) and certain municipalities (where the housing market is the least tense, such as the so-called "recentred" Robien zone C), the estimated impact is negative and significant, a sign that not all buyers were initially in a situation of complete and perfect information.
\end{abstract}

JEL Classification: Q58, Q54, R21.

Keywords: hedonic prices, quasi-experiment, risk perception, sellers' disclosure statements, public policy evaluation.

The author would like to thank Clément Carbonnier, Laurent Gobillon, Ronan Le Saout, Benjamin Vignolles and Bertrand Villeneuve for their comments on an initial version, as well as Vincent Marcus, Tedjani Tarayoun and Mariia Ostapchuk (SEEIDD) for their work at an early stage in the project. She also thanks the Direction de la Prévention des Risques Nature/s, in particular Jacques Faye, and the members of the Observatoire National des Risques Naturels. Finally, she thanks two anonymous referees for their comments and suggestions.

Received on 14 June 2017, accepted after revisions on 20 July 2018.

Translated from the original version: L'information aux acheteurs affect-t-elle le prix de vente des logements ? L'obligation d'information et le modèle de prix hédoniques - Un test sur données françaises

To cite this article: Mauroux, A. (2018). Does information to buyers affect the sales price of a property? Mandatory disclosure and the hedonic price model - a test on French data. Economie et Statistique / Economics and Statistics, 500-501-502, 201-220. https://doi.org/10.24187/ecostat.2018.500t.1952 
$\mathbf{H}$ edonic price theory (Rosen, 1974) is the reference conceptual framework used to analyse real estate prices. Under the assumptions of agents' rationality and buyers and sellers' complete and perfect information about all of a property's characteristics, hedonic prices can be interpreted as the marginal willingness to pay for those characteristics. However, this assumption can appear strong in some cases because of potential asymmetries of information between buyers and sellers (Pope, 2008a), or indeed a lack of information about certain characteristics. This is particularly true for exposure to environmental risks: in 2013, one inhabitant in five in a municipality exposed to a flood risk said that they were unaware of the risk when they moved in, while half of them said that they were aware but they considered the risk minimal (SOeS survey on the perception of risk exposure, see Pautard, 2014).

This paper attempts to test the assumption of complete and perfect information on the French property markets. To this end, it assesses the impact of an information shock the implementation, on $1^{\text {st }}$ June 2006, of the obligation to inform buyers and tenants on natural and technological risks (Information aux acquéreur et locataires in French, the IAL) - on the sales price of existing houses and on the perception of natural risks among the inhabitants of exposed zones. Since the coming into force of the IAL, buyers must be informed if the property they wish to acquire is exposed to risks when it is located within the boundaries of a risk prevention plan (PPR) or a seismic zone (see Box).

Studies testing the level of information and risk perception often use major natural disasters as an exogenous information shock insofar as they are the expression of the natural hazard (Montz \& Tobin, 1988, 1994; Bin \& Polasky, 2004; Harrison et al., 2001; Beron et al., 1997). Nonetheless, properties and their direct environment are also subject to material damage. As such, the estimated impact includes both the adjustment of risk perception and, at least in the short term, a deterioration in the quality of the properties and possibly even the increase in risk exposure if protective structures have been damaged ${ }^{1}$.

On the other hand, buyer disclosure mechanisms (such as the sellers' disclosure statement that currently exists in the USA), where the expected impact is to improve the agents' risk perception, do not modify either the specific characteristics of the property or those of its environment, nor do they alter the level of objective exposure to the risk. When they have not been anticipated, they may therefore be seen as an exogenous change of the quantity and/or quality of the information made available to buyers. The rare studies conducted into their impact conclude that there is a depreciative effect on residential property prices. Pope (2008a) demonstrated the depreciative effect $(-2.9 \%)$ on the value of houses in the most exposed zones following the introduction of a requirement to inform potential buyers about the noise caused by the Raleigh-Durham airport in North Carolina. Pope (2008b) also studied the impact of the 1996 introduction of the North Carolina Residential Disclosure Statement, a similar mechanism to the IAL. A difference-in-differences analysis points to a $4 \%$ depreciation in the price of houses located in federal flood risk zones when compared to houses exposed to less frequent risks, all other things being equal. However, in the United States, contrary to France ${ }^{2}$, insurance premiums take into account risk exposure so that flows from future insurance premiums are capitalized into North American real estate prices (MacDonald et al., 1990; Bin \& Landry, 2013). This mechanism therefore has an impact on buyers' risk perception and on their financial planning, so Pope's estimation does not strictly identify the impact of information.

The introduction of the IAL requirement for properties situated within the boundaries of a PPR provided an opportunity for a quasinatural experiment to identify the impact of a purely informational shock on house prices in the zones concerned and to test the assumption of complete and perfect information on the French real estate markets. A downward adjustment of prices after $1^{\text {st }}$ June 2006 in zones subject to the IAL requirement would indicate that at least a portion of buyers initially underestimated the risk and that the assumption of complete and perfect information was not therefore verified.

This paper only studies the flood risk. The impact of the enforcement of the IAL requirement on the housing prices within zones exposed to the flood risk (flood risk

\footnotetext{
1. See Mauroux (2015) for an analysis of the theoretical effects of a natural disaster on real estate markets.

2. In France, natural disaster insurance is a mandatory extension of the home insurance cover. However, the insurance premium is not linked to the level of exposure and stands at $12 \%$ of the amount of the home insurance premium all over France.
} 
prevention plan or PPRi) is estimated using a difference-in-differences hedonic price model (Parmeter \& Pope, 2013). Housing transactions located in municipalities concerned by the IAL requirement but outside the boundaries of PPRi are used as a counterfactual. It should be noted that, as we do not attempt to estimate the implicit price of exposure to natural risks, the results cannot be interpreted in terms of marginal willingness to pay.

\section{Box - The obligation of information to buyers and tenants (IAL)}

Since $1^{\text {st }}$ June 2006, any new buyer or tenant of a property of any kind must be notified by the seller or lessor of the existence of a natural and technological risk affecting the property and the easements to be respected (Articles L. 125-5 and R. 125-23 to 27 of the French Environment Code). The aim of this disclosure requirement (IAL, for Information des Acquéreurs et des Locataires in French) is to inform new occupants so that they can adapt their home or the property accordingly to be better prepared for crisis situations in the event of a natural disaster.

The disclosure requirement applies to real estate (built or non-built properties) located within the boundaries of a natural risk (PPRn) or technological risk (PPRt) prevention plan or within an la, Ib, II or III seismic zone indicated in Article 4 of the decree dated 14 May 1991(a).

The risk prevention plans establish risk zones at sub-municipal level based on a map defining the various zones according to their level of exposure to the given risk (avalanches, forest fires, floods, volcanoes, etc.). The PPR plans also include regulations that define, for each zone, the public utility easements and construction/urbanism rules that must be complied with, again according to level of exposure (non-build zones, zones where building is permitted subject to specific adaptations and zones where building is permitted without reservations). Zones are defined to a very fine geographic level (see, for example, the PPR map for the $5^{\text {th }}, 6^{\text {th }}$ and $7^{\text {th }}$ arrondissements of Paris, Online complement C1).

The owner or lessor of a property concerned must therefore provide a risk disclosure statement based on information that the département's prefect provides to the mayor of the municipality in which the property is located (see in Appendix 1 the form provided by the ministry in charge of risk prevention in 2006). This risk disclosure statement is accompanied by a map precisely locating the property and indicating whether or not it is affected by the notified risks and, if so, which ones. Outside these boundaries, the IAL is not mandatory even if the property is located within the territory of a municipality subject to a PPR.

The risk statement is drawn up by the time of signature of the initial sales agreement at the latest and given to the buyer with the other technical property audits (energy performance, asbestos situation, etc.). It may be updated at the time of sale in case of changes with respect to the risks since the initial sales agreement. It is then appended to the deed of sale and initialled by both parties (seller and buyer). If the seller fails to disclose information and to present a natural and technological risk statement, the buyer (or tenant) may withdraw from the sale or ask a judge to impose a lower price (Article 125-5 of the French Environment Code).

In 2006, 13,999 municipalities out of a total 36,705 , i.e. just over one third, were concerned by an IAL requirement (see Table A). 9,926 (or just under a third) were concerned by a PPRn; no PPRt had been approved at that point as the procedure was still very new. The PPRn was still at the prescription stage in 5,593 municipalities and had been approved in 4,333 (source: Gaspar). 5,895 municipalities were located in a seismic risk zone, 820 of which were covered by an approved PPRn $(1,002$ under a prescribed PPRn). The PPRn mainly covered flood risks $(70 \%)$, ground movement risks $(14 \%)$ and the shrinkage and swelling of clay soils, i.e. drought (11\%).

(a) New seismic zoning (modifying articles 563-1 to 8 of the French Environment Code) came into force on $1^{\text {st }}$ May 2011. The municipalities' seismic zone map is now established by Decree no. 2010-1255 dated 22 October 2010 on the delineation of seismic zones in France. Since 2011, owners and lessors must also inform future occupants if the property has suffered damage following a natural or technological catastrophe and, along with the sales contract, provide a statement listing any insurance claims paid of which they are aware. Since 2013, they must also state the property's situation within the boundaries of a mining risk prevention plan and, if the property is within the boundaries of a PPRt, whether work has been prescribed and, if so, whether it has been done.

Table A

Municipalities subject to a natural risk prevention plan and in a seismic zone in France in 2006

\begin{tabular}{|l|c|c|c|c|}
\hline & No PPR & Prescribed PPR & Approved PPR & Total \\
\hline Outside a seismic zone & 22,706 & 4591 & 3,513 & 30,810 \\
\hline Seismic zone & 4,073 & 1,002 & 820 & 5,895 \\
\hline Total & 26,779 & 5,593 & 4333 & 36,705 \\
\hline
\end{tabular}

Note: No PPRt had been approved in 2006 (there were six prescribed PPRt), hence all the approved PPR were PPRn.

Coverage: Whole of France.

Sources: Gaspar, CGDD calculations. 
The IAL was first analysed by Caumont (2014). He estimated the impact on house prices in the Nord-Pas-de-Calais coast of integrating the coastal flood risk into IAL disclosure requirement in October 2011. However, as the estimations are only conducted on the period following implementation of the IAL (October 2011 and June 2013), the impact of the informational shock is not identified. Here, the impact of enforcement of the IAL requirement on residential property prices is identified using temporal variability (before and after $1^{\text {st }}$ June 2006) and spatial variability (within and outside the PPRi boundaries covered by the IAL requirement) of the information provided to buyers.

Our paper is organized as follows: the first section focuses on the question of complete and perfect information within the framework of the hedonic price model. We then explain the econometric method and identification strategy, as well as the various sources of data used. Next, we turn to the results of estimations of the impact of IAL implementation on residential property prices and test their heterogeneity according to various factors involving risk perception (house's floor), memory of the risk (date of the last official declaration of natural disaster ) and tension on real estate markets, and then conduct placebo tests. The final section discusses the results and the limits of the study.

\section{Information and the hedonic price method}

Hedonic price theory (Rosen, 1974) is based on the central assumption that a housing unit can be defined as a set of characteristics and its total price is the sum of the implicit prices that the consumer is willing to pay for each of those characteristics ("hedonic prices"). Exposure to risk may be seen as a loss of amenity (a disamenity) for householders. For example, in the event of a natural disaster, the household will not only suffer material damage but also intangible damage (loss of items with sentimental value, stress, etc.). Under the assumption of complete and perfect information, the marginal price should therefore decrease with risk exposure and reciprocally, all other things being equal, the price should increase as household security increases (cf. Pope 2008b, p. 554, Figure 2). This is true even for households that are risk-neutral because they still bear the damage costs on uninsured properties $^{3}$. According to the theory, all other things being equal, the depreciation of the price of an insured house exposed to a natural risk, compared to an identical but non-exposed house, is equal to the uninsured damage and a risk premium, which reflects households' risk aversion (Mauroux, 2015).

Nonetheless, this result is only valid under the strong assumption of complete and perfect information available to sellers and buyers on the house price and characteristics. Uninformed buyers, or buyers who are informed but do not perceive the risk ${ }^{4}$, do not adjust their price offer for changes in the level of disamenity since they do not observe it; this is true regardless of their preferences for that particular characteristic. Without this assumption, the hedonic price model is not identified and the results of the estimate can no longer be interpreted as a marginal willingness to pay.

Under information asymmetry, if none of the buyers are informed about the risk, the maximum price at which they are prepared to purchase the property is, all other things being equal, constant regardless of the level of amenity loss. Conversely, if some of the buyers are informed, they will not be prepared to pay more than their maximum bid for significant levels of disamenity. Not all sellers will afford to wait for an uninformed buyer prepared to "over-pay" for the disamenity (this situation is described in Pope 2008b, p. 556, Figure 4). The higher the fraction of informed buyers, the lower the appeal for sellers of waiting for an uninformed buyer to put in an offer for the property, and thus the closer to the value of perfect information the implicit price for the disamenity will be.

To test the assumption of complete and perfect information on real estate markets, the selected strategy is to observe the markets' reaction to an information shock on a the attribute of a house or its environment. If the assumption is verified, this shock should not have any impact on prices.

3. In France, natural disaster insurance policies almost completely cover material damage to insured properties caused by a major event, the coverage rate of the "Cat Nat" CATastrophe NATurelle, or natural disaster) insurance scheme being close to $100 \%$ and the relatively low franchise $(450$ euros for a private individual). In the event of a flood, the material damage borne by households mainly corresponds to uninsured property.

4. Buyers may be informed about risk exposure and value security but fail to take the information into account for as much, or they may have misunderstood it (because it might be complex), may not trust the source of information or have perception biases leading them to underestimate the risk (e.g. availability heuristic or gamblers' fallacy: see below). 
Conversely, if we observe a price adjustment, this would indicate that households initially had a misguided perception of the given attribute, which would challenge the assumption of complete and perfect information. All other things being equal, we therefore expect the impact of the IAL to be nil among informed populations and to have a negative impact on the price of exposed houses, compared to non-exposed houses, among people who were not previously informed. At market level, the proportion of informed households should increase and, all other things being equal, the price of exposed properties should fall.

\section{Estimation method}

\section{Difference-in-differences identification strategy}

We assume that potential buyers' preferences and risk aversion are not altered by the IAL. The strategy used to identify the impact of the IAL on house prices is based on two sources of variation. The first is the discrete temporal shift in flood risk information available to potential buyers of a property situated in a municipality covered by a PPRi after the IAL requirement came into force on $1^{\text {st }}$ June 2006. Before then, information on the exposure of a property was available to the public, free of charge, but potential buyers had to bear search costs (time, visits to the council offices, etc.) to obtain it. On $1^{\text {st }}$ June 2006, these search costs were practically cancelled out because potential buyers now receive a risk statement and map showing them the property's position with regard to the regulated zones (see the Box and Appendix 1). The second source of variation is spatial variation in levels of exposure between regulatory PPRi zones and areas outside those zones; this allows us to identify which sellers are required to provide an IAL statement to potential buyers. PPRi zones are subject to regulations precisely because they are the most exposed geographic areas given their closeness to a source of risk, their vulnerability before a concentration of factors, etc. According to the experiment's terminology, properties situated within the boundaries of a PPRi zone have received a "treatment", i.e. the provision of information on risk exposure contained in IAL documents. The other properties in the municipality, located outside the boundaries of the PPRi zones, are not subject to the disclosure requirement. There are nonetheless part of the same local real estate markets and are affected by the same shocks. They are used as a control group 5 .

The difference-in-differences model identifies the impact of treatment on the treated, under the assumptions that, in the absence of treatment, the two groups would have undergone the same changes (common trend) and that the differences observed before treatment are constant over time (constant group fixed effect) ${ }^{6}$. This implies an assumption whereby the fact of being located within the boundaries of a PPRi has a constant effect on prices over time (no modification in agents' preferences as regards the risk after $1^{\text {st }}$ June 2006), and PPRi and non-PPRi zones do not form two separate markets but are subject to the same trends (no contextual shocks or specific trends). This assumption will be tested by a placebo test.

Identification of the difference-in-differences model is also based on the assumption that the treatment rate goes up from 0 to $100 \%$ in the treatment group after the treatment date (sharp design), and remains at $0 \%$ in the control group. However, even before the IAL came into force, some households were already aware of risk exposure (thanks to publicly available information). Similarly, after $1^{\text {st }}$ June 2006, we are unable to ascertain whether all future buyers of a property within a PPR zone actually received the risk statement and whether their perception bias ${ }^{7}$ was reduced. The impact of preventive information thus seems to fall under the definition of fuzzy design. Here, we assume that, for a potential buyer, the IAL resulted in an increase of the probability of being informed in risk zones, but we cannot affirm that this probability has risen from 0 to 1 . At the aggregate level, we assume that the IAL has increased the number of informed agents and that the hedonic price curve has shifted closer to the perfect information curve, though does not necessarily match it completely.

\footnotetext{
5. Because seismic zones are defined at municipal level, it is not possible to distinguish, within a single municipality, properties subject to the IAL requirement and those not subject to it to be used as a control group. Municipalities subject to a seismic risk were therefore excluded from the coverage of this study.

6. Another assumption for identification is that being treated is not determined by the result, the variable of interest: because the PPRi zones are based on an administrative decision according to flood risk exposure level, the price of the property sold has no impact on the fact that it is situated (or not situated) in a PPRi zone.

7. We use the term "perception bias" to refer to the difference between the perceived risk (subjective probability) and the objective risk. Savage (1954) introduced the notion of subjective probabilities as an extension of von Neumann and Morgenstern's expected utility model to formalise the fact that the agents do not necessarily base their decisions on objective probability but instead use a perceived probability.
} 
According to Chaisemartin and d'Haultfoeuille (2018), in the presence of fuzzy treatment and if none of the members of the control group is treated at any time, the difference-indifferences estimator of the variable is equal to the difference-in-differences estimator divided by the change in probability of being treated for the treated after treatment. To estimate the effect of treatment on the treated, we need to be able to observe the level of information among buyers of houses in PPRi zones before and after $1^{\text {st }}$ June or, at the very least, ascertain whether buyers were actually provided with risk statements. However, this information is not available in the notarial data and, as far as we know, there is no external survey able to inform us on awareness of environmental risk exposure at a sufficiently detailed geographic level or for the period in question ${ }^{8}$. We are not therefore able to estimate the exact effect of treatment on the treated. However, we may reasonably assume that the level of information has not fallen since the introduction of the IAL; the difference-in-differences estimator would thus provide a lower bound of the effect of treatment on the treated.

In addition, perception biases may also have been reduced for properties located out of PPRi zones. Following enforcement of the IAL requirement, demand for "safe" properties may have increased while supply has remained constant. The economic outcome of interest is thus the impact of the disclosure requirement on households who would not have otherwise been informed. In cases of fuzzy design and unlike the standard case, households can be treated in each group and for each period. Chaisemartin and d'Haultfoeuille (2018) have studied the form of the difference-indifferences estimator in such a case and detailed the conditions of identification. They put forward an alternative estimator, but using it requires knowing how information levels changed in the municipalities subject to a PPR, within and outside the regulated zones before and after June 2006. Under the likely assumption that the probability of being informed increases faster among the treatment group than in the control group, the difference-indifferences estimate is again a lower bound of the impact of treatment on the treated.

Finally, it is rather unlikely that the date of enforcement of the IAL and the rise in the proportion of informed buyers after $1^{\text {st }}$ June were anticipated by the sellers of exposed properties $^{9}$. If that were the case, we would expect buyers to try and anticipate the sale of properties exposed to a risk. The difference-indifferences model would then underestimate the fall in price consecutive to the disclosure of information.

\section{Choice of functional form}

We estimate a conventional hedonic price model (Rosen, 1974 ; Palmquist, 2005) in a difference-in-differences setting (Parmeter $\&$ Pope, 2013) ${ }^{10}$. We suppose that the implementation of the IAL requirement is a localised shock, in other words, a limited number of housing transactions are affected, meaning that, at least in the short term, the equilibrium on the real estate market is not modified and the hedonic price function remains constant (Bartik, 1988; Palmquist, 2005). Our aim is to estimate the marginal effect of a specific attribute as accurately as possible (Cassel \& Mendelsohn, 1985; Cropper et al., 1988); however, this paper does not attempt to estimate the marginal price to obtain marginal willingness to pay estimates for an attribute (safety as regards the flood risk in this case) ${ }^{11}$.

We have opted for a semi-log model. A model with an additive form for explanatory variables allows to directly interpret the differencein-differences regression results as the average effect of treatment on the treated (Ai \& Norton, 2003; Puhani, 2012).

\footnotetext{
8. The survey into the perception of exposure to risks conducted in 2007 and 2013 by the SOeS does not provide information on the exact location of the respondents' residence with regard to the regulated zones and does not therefore allow an estimation of the proportion of buyers informed about flood risk exposure in PPRi zones before and after 1 st June 2006. 9. Implementing decree 2005-134 dated 15 February 2005 provided that the IAL would become mandatory as from the first day of the fourth month following publication, in the official departmental statute book, of the prefectural decrees establishing the list of natural and technological risks, the municipalities concerned and the documents to which sellers and lessors can refer. The implementing decree provided for a maximum time frame of one year for publication of these lists, meaning an enforcement date of $1^{\text {st }}$ June 2005 at the earliest and 1 st June 2006 at the latest. A majority of the prefectural decrees were enacted in early 2006.

10. Endogeneity between price and quantity is a problem that is inherent to the hedonic price method, especially when estimating parameters of the supply function. To control endogeneity, some authors have used an instrumental variables model (Cavailhès, 2005: Travers et al., 2009). Parmeter and Pope (2014) demonstrate that when applied to pseudo-experiments, quasi-experimental methods such as difference-in-differences can be used to solve the endogeneity issue. The variable of interest in this paper is obtained by crossing a characteristic related to the property's location with a date, which is a priori exogenous. It is therefore highly unlikely that the fact of lying within the treatment zone after treatment is endogenous with the price. Here, the differences between the treated zone and the treatment zone are not significant (see Online complement $\mathrm{C} 2$ ). If we were able to identify endogeneity between the price and certain other characteristics of the properties, the risk of contamination between other potentially endogenous $X$ variables and the crossed interaction term would be low. 11. Apart from in cases of infinitesimal, exogenous change, quasi-experiment methods are not the most appropriate (Kuminoff \& Pope, 2014. Klaiber \& Smith, 2013)
} 
We thus estimate the following differencein-differences hedonic price model :

$$
\begin{gathered}
\log \left(p_{i j t}\right)=\alpha_{0}+\sum_{k} \alpha_{k} X_{i k}+\alpha_{d} d_{i c}+\sum_{j} c_{j} Z_{j} \\
+\sum_{t=2}^{12} \beta_{t} 1_{t}+\beta_{z} 1_{\text {Zrisque }}+\delta 1_{\text {Zrisque }} \times 1_{\text {ApJuin }}+\varepsilon_{i t}
\end{gathered}
$$

where $p_{i j t}$ is the price (excluding agency and notary fees) of the property sold in the month $t$ in the municipality $j, \alpha_{0}$ is a constant, $X_{k}$ is the vector of the housing unit's intrinsic characteristics, $d_{i c}$ the distance (in $\mathrm{km}$ ) of the house from the centre of the municipality, $Z_{j}$ the vector of the municipality's characteristics $j$ and $\varepsilon_{i t}$ an error term. $1_{t}$ is an indicator equal to 1 if sale of the property occurs in month $t$. These dummies are used to estimate the trend in housing transaction prices over time, supposedly common to all the treated zones and the control zone $^{12} .1_{\text {Zrisque }}$ takes the value 1 if the property lies within a PPRi zone, and otherwise 0 , and $1_{\text {ApJuin }}$ is given the value 1 if the transaction was completed after $1^{\text {st }}$ June $2006^{13}$, and otherwise 0 , so that $1_{\text {Zrisque }} \times 1_{\text {ApJuin }}$ is equal to 1 if the house was subject to the IAL requirement at the time of sale, and 0 otherwise.

The parameter of interest is $\delta$, the estimate of the price adjustment, in percentage, caused by the disclosure of information, all other things being equal, and at an unchanged level of exposure to the risk.

As a robustness check, we also estimate the following simple Box-Cox model (Box \& Cox, 1964), allowing greater flexibility in the hedonic price function.

$$
\begin{aligned}
& p_{i t}(\lambda)=\sum_{k \in K_{c}} \alpha_{k} X_{i k}(\lambda)+\sum_{k \in K_{d}} \alpha_{k} X_{i k} \\
& \text { with } Z(\lambda)=\frac{Z^{\lambda}-1}{\lambda} \text { si } \lambda \neq 0, Z(\lambda)=\ln (Z) \text { si } \lambda=0
\end{aligned}
$$

where $p_{i j t}$ is the price exclusive of agency and notary fees of the property $i$ sold in month $t$, $\lambda$ the transformation coefficient, $K_{c}$ indicates the continuous explanatory variables and $K_{d}$ the discrete variables.

Since the variables of interest are the discrete variables, we report the sign of the impact of these variables on the price estimated using the Box-Cox model. This model is not linear and the values calculated on the basis of the coefficients estimated before the treatment variables will no longer be equal to the effect of treatment on the treated (Ai \& Norton, 2003; Puhani, 2012). As the transformation function is an increasing monotonous function, the treatment still has the same sign as the coefficient and is only significant if the coefficient is too. The results of the Box-Cox estimation are therefore used to confirm or invalidate the sign and the significance of the results. Only their sign and significance will be interpreted.

We need to control for two known confounding influences. Firstly, a natural disaster in the year of the transaction will affect both the real estate market and perceptions of natural risks (Mauroux, 2015). It will thus be difficult to ascertain the extent to which the variations observed on markets in 2006 can be attributed to the information provided by the IAL or to material damage suffered by properties or public infrastructures. For this reason, municipalities subject to at least one official natural disaster classification in 2006 are excluded from the estimation sample ${ }^{14}$.

Another confounder is the effect of amenity which proximity to the source of risk can imply. For example, flood-risk areas are precisely at risk because they lie close to river banks. Such proximity may be highly valued by home owners due to the landscapes, the view and the recreational possibilities (Longuépée \& Zuindeau, 2001; Travers et al., 2008). Exposure to a natural risk, recognised here in the regulated PPRi zones, will be strongly correlated with environmental benefits which it may be impossible to observe. As a result, hedonic price estimates suffer from an omitted variable bias. To identify price variations due to the positive effect of amenity separately from those due to the negative impact of the risk, we need a variable that measures amenity (direct view of a river bank, altitude, distance from the coast, etc.) separately from

12. If the temporal trend is constant over the pre-treatment period $\left(\beta_{2}=\beta_{5}\right)$ and over the post-treatment period $\left(\beta_{6}=\beta_{12}\right)$, we find ourselves with a "conventional" difference-in-differences model with a before/ after indicator.

13. A preferred estimation model would be an event study analysis type model (also known as timing of event) with a crossed interaction term per month, rather than a before/after setting $\left(\sum_{t=2}^{12} \delta_{t} 1_{t} 1_{\text {inzppr }}\right.$ instead of $\delta 1_{\text {Zrisque }} \times 1_{\text {Apjuin }}$, with $\delta_{t}$ month-by-month treatment impacts). This model relaxes the assumption on uniformity of the effect of treatment on the treated in all observation periods and, thanks to the terms crossed before the treatment date $\left(\sum_{t-2}^{5} \delta_{t} 1_{t} 1_{\text {inzppr }}\right)$, allows to test the absence of a pre-trend between the treated and the control group $\left(\delta_{t}=0\right)$. The number of in PPRi zone transactions is, however, low in certain months, so an estimate of this specification would be based on few observations in the treatment zones. The selected specification increases the statistical power but is based on the assumptions of the absence of pre-trend and that-which cannot be tested-that the treatment effect on the treated is uniform over the whole period after $1^{\text {st }}$ June.

14. With the exception of shrinkage and swelling of clay soils. The consequences of this kind of disaster are often observed several months after the occurrence of a drought, so the date of classification as natural disaster often falls after the date of the event. 
the measurement of exposure (Pope 2008a; Pope 2008b; Longuépée \& Zuindeau 2001; Déronzier \& Terra, 2006). Nonetheless, if the characteristics of the properties concerning these amenities (distance, view, etc.) remain constant over time and between zones, the fixed "housing unit located within the regulated zone" effect will also reflect the effect of amenity on price. Buyers' preferences for environmental amenities do not really change with the introduction of the IAL requirement so the "before/after" difference in the difference-in-differences model will cancel out any constant effect over time between zones, regardless of whether the variable is observable or not. This is a particularly attractive model for treating omitted variable bias, which is a major issue with the hedonic price method.

\section{Data}

This study uses original data spatially matching notarial databases covering real estate transactions in 2006 with the regulated flood risk prevention plans (PPRi) official zoning and municipal data on land use and past natural disaster records.

The data on real estate transactions are taken from notarial databases for the year 2006 (the BIEN-notarial economic database-for Île-de-France, and the Perval database for other départements ${ }^{15}$ ). These very rich databases provide a detailed set of information on each transaction: sales price (exclusive of notarial and negotiating fees), address, plot surface area, number of rooms, type of housing unit, period of construction, with a garage or not, car parking, cellar, etc.). It also provides some information on the seller and buyer (age, nationality, place of residence, etc.).

The study is limited to private sales completed in 2006, involving private individuals and vacant homes (excluding unusual properties such as mills, former railway stations, etc., and excluding life leases), where the price, excluding notarial and agency fees, exceeded $€ 1,500$. We only retained standard apartments (with a maximum of nine rooms and a living area of at least $10 \mathrm{~m}^{2}$ ) and individual houses for which the land surface is indicated (with a maximum of twelve rooms and a living area of at least $\left.20 \mathrm{~m}^{2}\right)^{16}$.

The notarial data were spatially matched with maps of the regulated PPRi official zoning available on the Cartorisque website ${ }^{17}$ and the information taken from the Gaspar ${ }^{18}$ database on PPRs. To identify the units located within the regulated zones subject to the IAL requirement, the housing transactions in the notarial databases were geopositioned to the cadastral parcel using the Parcellaire $\AA$ database from the IGN. The $1_{\text {Zrisque }}$ indicator results from the matching of the coordinates obtained with the PPRi maps. This unique database is used to accurately determine whether or not the property is situated in a regulated PPRi zone and, for transactions after $1^{\text {st }}$ June 2006; whether the housing transaction is subject to the IAL requirement. At the time of matching, the Cartorisque GIS did not contain all the regulatory PPRi maps, which led to some "false zero" results (properties actually within a PPRi zone but appearing outside the PPRi in the dataset) during matching if the map wasn't available. To overcome biases in the estimates, the database was restricted to municipalities in which at least one recorded transaction within a PPRi zone in 2006, which made sure that the PPRi map for the municipality was available at the time of matching.

Municipal data from Insee and the Corine Land Cover geographic database have also been exploited to control the extrinsic attributes of the housing units and characterise the attractiveness of their immediate surroundings (municipal population, relative share of natural spaces in the municipality, etc.). The "as the crow flies" distance of the properties from the centre of the municipality is also included as a proxy of distance and accessibility of the town centre.

These data are completed by the list of official natural disaster classifications in the Gaspar register, and by indicators from the National

15. The Perval databases are produced by a company named Min.Not ADSN. The data used in this study were produced following work to ensure consistency between the fields and variable dictionaries used by BIEN and Perval, conducted by the SOeS (statistics department of the French ministry of Environment).

16. These criteria are recommended by the company Min.Not ADSN (the producer of Perval databases) for real estate statistics. A full description of these filters and their impact on the notarial data is provided by Vermont (2015).

17. Cartorisque is a geographic information system (SIG) that groups maps of major natural and technological risks (http://www.cartorisque. prim.net). In 2006, no PPRt has been approved; hence, only the PPRn maps in force for 2006 were used. The published information comes from the State's decentralised services, under the authority of the prefects concerned.

18. GASPAR - Gestion Assistée des Procédures Administratives relatives aux Risques naturels et technologiques/Assisted management of administrative procedures concerning natural and technological risks. Gaspar contains information on preventive or regulatory documents down to municipal level. 
Natural Risk Observatory (ONRN) on the per municipality average cost of flood damage claims paid out under the natural disaster ("Cat Nat") insurance scheme between 1995 and $2010^{19}$. These indicators are a proxy of the expected compensation for damage cost by households in the event of a flood. The ONRN publishes these indicators in amount brackets, which provides a scale of relative severity of damages from one municipality to another.

The estimation sample includes 18,350 transactions (of which 9,040 apartments and 9,310 houses); $19 \%$ are situated within a PPRi zone and $62.2 \%$ occurred after enforcement of the
IAL requirement on $1^{\text {st }}$ June 2006 (Table 1). The properties are located in 484 municipalities spread across 39 départements (Figure I). On average, these municipalities are relatively densely populated, more urban and have more public amenities and shops than all the municipalities subject to a PPRn and concerned by the IAL requirement.

19. The average cost of claims paid out by insurers under the natural disaster scheme for the flood risk in the broadest sense (flood and mudslides, flood due to rising groundwater and coastal flooding) in mainland France between 1995-2010. These average costs only concern insured properties other than motorised land vehicles and are net of any excess. Insured damages account for $60-90 \%$ of the total economic cost according to Letremy (2009) and Sigma Re (2014).

Table 1

Base used for the estimations

\begin{tabular}{|l|c|c|c|c|c|c|c|c|c|}
\hline & \multicolumn{3}{|c|}{ Outside PPRi zones } & \multicolumn{3}{c|}{ In PPRi zones } & \multicolumn{3}{c|}{ Total } \\
\cline { 2 - 10 } & $\begin{array}{c}\text { Before } \\
\text { 1st June }\end{array}$ & After & Total & $\begin{array}{c}\text { Before } \\
\text { 1st June }\end{array}$ & After & Total & $\begin{array}{c}\text { Before } \\
\text { 1st June }\end{array}$ & After & Total \\
\hline Apartments & 2,809 & 4,578 & 7,387 & 659 & 994 & 1,653 & 3,468 & 5,572 & 9,040 \\
& $(38.0)$ & $(62.0)$ & $(100)$ & $(39.9)$ & $(60.1)$ & $(100)$ & $(38.4)$ & $(61.6)$ & $(100)$ \\
\hline Houses & 2,771 & 4,699 & 7,470 & 694 & 1,146 & 1,840 & 3,465 & 5,845 & 9,310 \\
& $(37.1)$ & $(62.9)$ & $(100)$ & $(37.7)$ & $(62.3)$ & $(100)$ & $(37.2)$ & $(62.8)$ & $(100)$ \\
\hline Total & 5,580 & 9,277 & 14,857 & 1,353 & 2,140 & 3,493 & 6,933 & 11,417 & 18,350 \\
& $(37.6)$ & $(62.4)$ & $(100)$ & $(38.7)$ & $(61.3)$ & $(100)$ & $(37.8)$ & $(62.2)$ & $(100)$ \\
\hline
\end{tabular}

Note: The properties in the base used for the estimations are described in the Online complement $\mathrm{C} 1$

Coverage: Municipalities in mainland France in which at least one real estate transaction was recorded in 2006 and which was covered by a PPR in 2006, and outside seismic zoning and outside the scope of an official classification as "natural disaster" in 2006.

Sources: Perval and BIEN 2006 notarial databases, Cartorisque and Gaspar, author's calculations.

Figure I

Municipalities subject to a PPRi included in the study

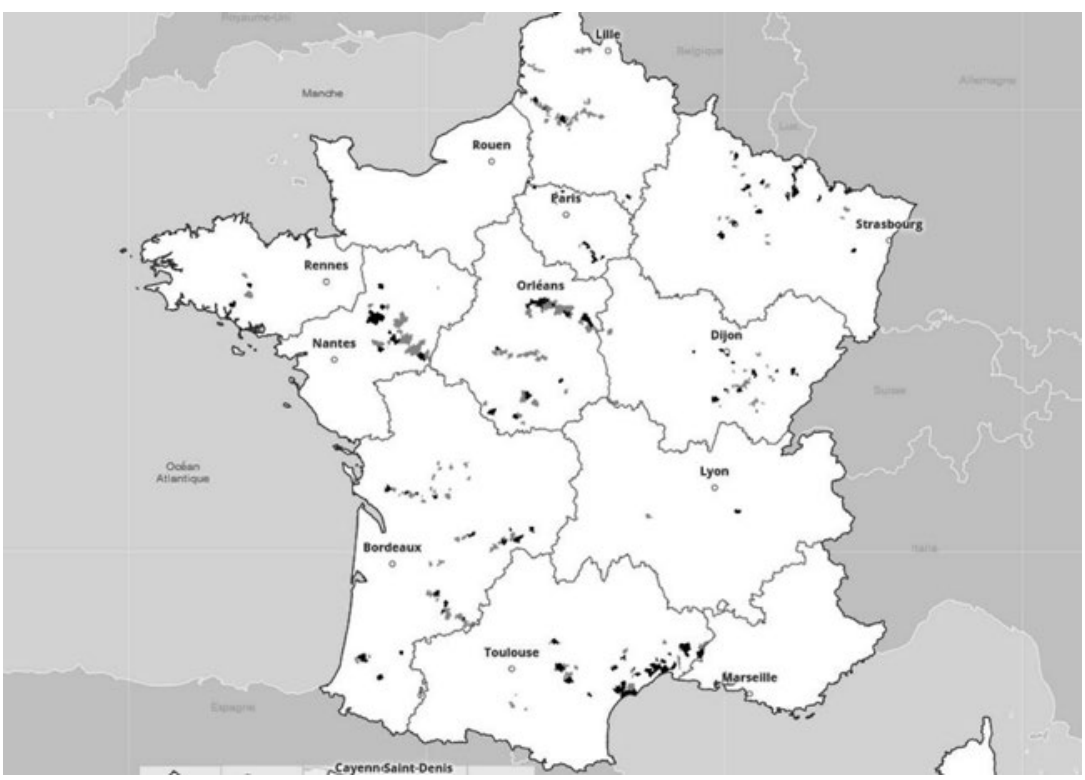

Sources: Perval and BIEN 2006 databases, Cartorisque, Géoref; author's calculations. 


\section{Impact of the IAL requirement on residential property prices}

Before and after $1^{\text {st }}$ June 2006, the average prices of apartments in PPRi zones are relatively similar to those outside the zones and are not significantly different at the $1 \%$ level (Table 2). These average prices are not corrected for the quality of the properties sold but nonetheless seem to follow the same general trend as that for apartments outside the PPRi zones (Figure II-A, lower curves, and II-B upper curves). After 2006, the per-squaremetre price is systematically lower in PPRi zones (except in July), and appears to increase at a slower rate than for apartments outside the PPRi zones. For individual houses, the price (in euros, excluding agency and notary fees) is almost always lower within than outside the PPRi zones (Figure II-A, upper curves,

Table 2

Selling price (in euros, excluding agency and notary fees) of properties according to the zoning and date of sale

\begin{tabular}{|c|c|c|c|c|c|c|c|}
\hline & \multirow[b]{2}{*}{$\begin{array}{l}\text { Outside a } \\
\text { PPRi zone }\end{array}$} & \multirow[b]{2}{*}{$\begin{array}{l}\text { In a PPRi } \\
\text { zone }\end{array}$} & \multicolumn{2}{|c|}{ Outside PPRi zones } & \multicolumn{2}{|c|}{ In PPRi zones } & \multirow[b]{2}{*}{$\begin{array}{l}\text { Difference-in-differences } \\
\text { (standard error) }\end{array}$} \\
\hline & & & $\begin{array}{l}\text { Before } \\
1^{\text {st }} \text { June }\end{array}$ & $\begin{array}{c}\text { After } \\
1^{\text {st }} \text { June }\end{array}$ & $\begin{array}{l}\text { Before } \\
1^{\text {st }} \text { June }\end{array}$ & $\begin{array}{l}\text { After } \\
1^{\text {st }} \text { June }\end{array}$ & \\
\hline \multicolumn{8}{|l|}{ Apartments } \\
\hline Average selling price & 107,574 & 102,760 & 105,603 & 108,784 & 99,050 & 105,220 & $\begin{array}{c}2,989 \\
(2,864)\end{array}$ \\
\hline Price per $\mathrm{m}^{2}$ & 1,987 & 1,904 & 1,898 & 2,041 & 1,831 & 1,953 & $\begin{array}{l}-21 \\
(40)\end{array}$ \\
\hline Number of transactions & 7,387 & 1,653 & 2,809 & 4,578 & 659 & 994 & $-1,434$ \\
\hline \multicolumn{8}{|l|}{ Houses } \\
\hline Average selling price & 170,104 & 161,476 & 159,903 & 176,119 & 152,317 & 167,023 & $\begin{array}{l}-1,509 \\
(4,248)\end{array}$ \\
\hline Price per $\mathrm{m}^{2}$ & 1,634 & 1,585 & 1,557 & 1,679 & 1,505 & 1,633 & $\begin{array}{c}7 \\
(36)\end{array}$ \\
\hline Number of transactions & 7,470 & 1,840 & 2,771 & 4,699 & 694 & 1,146 & $-1,476$ \\
\hline
\end{tabular}

Coverage: Municipalities in mainland France in which at least one real estate transaction was recorded in 2006 and which was covered by a PPR in 2006, and outside seismic zoning and outside the scope of an official "natural disaster classification" in 2006.

Sources: Perval and BIEN 2006 notarial databases, Cartorisque and Gaspar, author's calculations.

Figure II

Price (in euros, excluding agency and notary fees) of monthly transactions according to location and date of sale

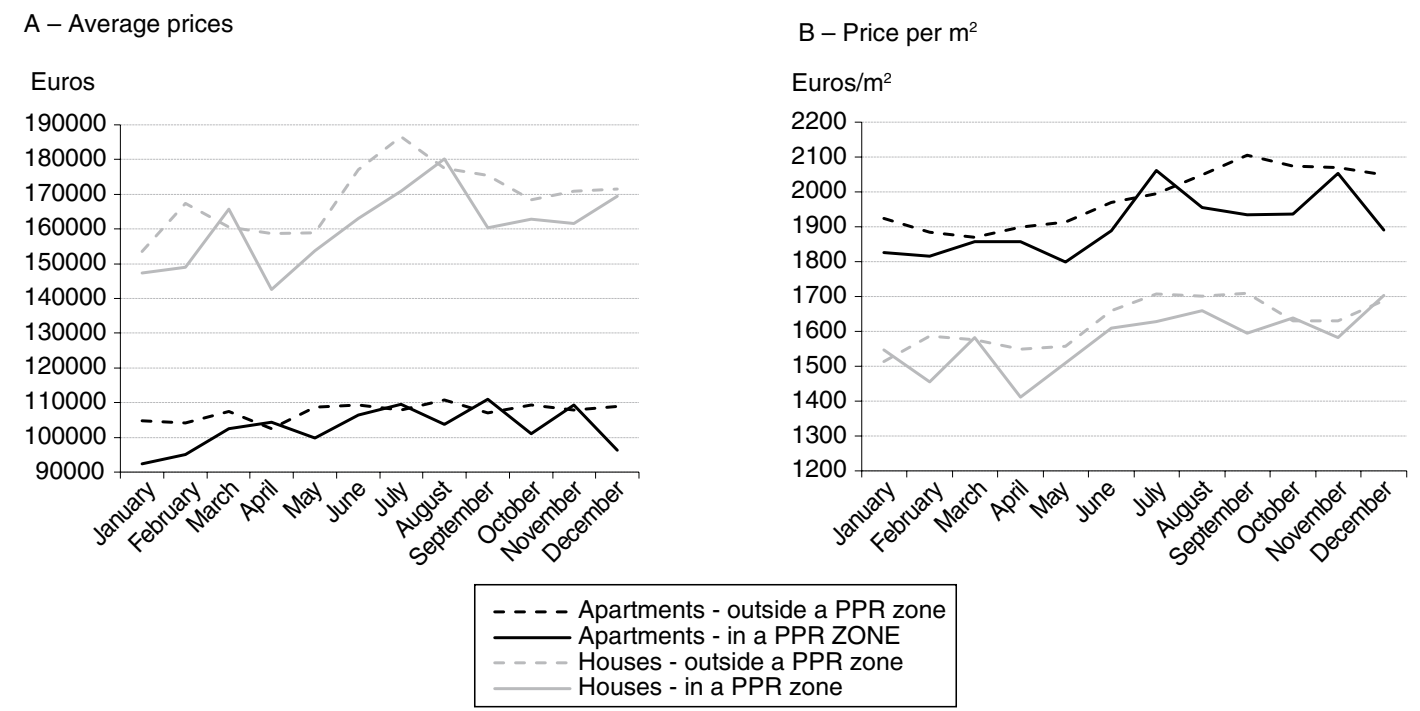

Coverage: Municipalities in mainland France in which at least one real estate transaction was recorded in 2006 and which was covered by a PPR in 2006, and outside seismic zoning and outside the scope of an official "natural disaster classification" in 2006.

Sources: Perval and BIEN 2006 notarial databases, Cartorisque and Gaspar, author's calculations. 
and II-B, lower curves). Analysis of the graph does not point to a change in the marked trend in house prices after the IAL came into force. The number of housing transactions in PPRi zones is relatively low (cf. Table 1), however, so average prices may be more volatile than outside these zones.

The estimation results obtained using the difference-in-differences hedonic price model by ordinary least squares (OLS) are reported in Table 3 (OLS and Box-Cox columns). The variables included in the estimation were selected after analysis of the multicollinearity ${ }^{20}$. For ease of reference, only the coefficients of interest are presented (the coefficients corresponding to the characteristics of the housing unit and their municipality have the expected sign and are globally highly significant, see the detailed results in Online complement $\mathrm{C} 3$ ). Before $1^{\text {st }}$ June 2006, the housing location within a PPRi zone rather than in the white (no-risk) zone of a flood-risk municipality had no significant effect on its price, once controlled for the

20. Multicollinearity was analysed using two methods: analysis of correlations between the explanatory variables, and analysis of the Variance Inflation Factor (VIF).

Table 3

Impact of the IAL on the average transaction prices (excluding agency and notary fees) within and outside PPRi zones, as a $\%$ of the price

\begin{tabular}{|c|c|c|c|c|c|c|}
\hline & \multicolumn{3}{|c|}{ Apartments } & \multicolumn{3}{|c|}{ Houses } \\
\hline Model & OLS & Box-Cox & $\begin{array}{c}\text { OLS } \\
\text { T1-T4 }\end{array}$ & OLS & Box-Cox & $\begin{array}{l}\text { OLS } \\
\text { T1-T4 }\end{array}$ \\
\hline Month of sale & & & & & & \\
\hline January & Réf. & Réf. & Réf. & Réf. & Réf. & Réf. \\
\hline February & $\begin{array}{c}-2.7^{\star \star \star} \\
(1.8)\end{array}$ & - & $\begin{array}{l}-2.4 \\
(1.8)\end{array}$ & $\begin{array}{l}5.6^{\star \star} \\
(2.2)\end{array}$ & $t^{* * *}$ & $\begin{array}{l}5.5^{\star *} \\
(2.2)\end{array}$ \\
\hline March & $\begin{array}{c}0.7 \\
(2.1)\end{array}$ & + & $\begin{array}{c}0.9 \\
(2.1)\end{array}$ & $\begin{array}{l}3.9^{*} \\
(2.1)\end{array}$ & $t^{*}$ & $\begin{array}{l}3.9^{*} \\
(2.1)\end{array}$ \\
\hline April & $\begin{array}{c}1.2 \\
(1.8)\end{array}$ & + & & $\begin{array}{l}3.1 \\
(2.1)\end{array}$ & $t^{*}$ & \\
\hline May & $\begin{array}{c}0.9 \\
(2.2)\end{array}$ & + & & $\begin{array}{l}4.6^{* \star} \\
(2)\end{array}$ & $t^{* *}$ & \\
\hline June & $\begin{array}{l}2.9^{*} \\
(1.6)\end{array}$ & $+^{*}$ & & $\begin{array}{c}10.5^{* * *} \\
(2.2)\end{array}$ & $+^{* * *}$ & \\
\hline July & $\begin{array}{l}5.3^{* *} \\
(2.2)\end{array}$ & $t^{\star * *}$ & & $\begin{array}{c}11.7^{* \star \star} \\
(1.9)\end{array}$ & $+* * *$ & \\
\hline August & $\begin{array}{c}7.7^{* * *} \\
(1.5)\end{array}$ & $t^{* * *}$ & & $\begin{array}{l}11.7^{7 * *} \\
(2)\end{array}$ & $t^{\star \star *}$ & \\
\hline September & $\begin{array}{l}4.2^{* *} \\
(1.8)\end{array}$ & $t^{* *}$ & & $\begin{array}{l}8.9^{* * *} \\
(2.1)\end{array}$ & $+* * *$ & \\
\hline October & $\begin{array}{c}6.0^{* * *} \\
(2.1)\end{array}$ & $t^{* * *}$ & $\begin{array}{c}6.8^{* \star *} \\
(2.2)\end{array}$ & $\begin{array}{l}11 . .^{1 * * \star} \\
(2)\end{array}$ & $t^{* \star *}$ & $\begin{array}{c}11.2^{* \star * \star} \\
(2.1)\end{array}$ \\
\hline November & $\begin{array}{l}4.7^{\star \star} \\
(1.8)\end{array}$ & $t^{* *}$ & $\begin{array}{l}5.4^{* *} \\
(2.1)\end{array}$ & $\begin{array}{c}7.1^{* * *} \\
(2.4)\end{array}$ & $t^{\star \star \star}$ & $\begin{array}{l}7^{\star * *} \\
(2.6)\end{array}$ \\
\hline December & $\begin{array}{c}7.8^{* \star *} \\
(2.3)\end{array}$ & $t^{* * *}$ & $\begin{array}{l}8.5^{\star * \star} \\
(2.5)\end{array}$ & $\begin{array}{c}9.9^{* * *} \\
(2.2)\end{array}$ & $+* * *$ & $\begin{array}{c}9.8^{\star \star *} \\
(2.2)\end{array}$ \\
\hline PPRi Zone & $\begin{array}{l}-0.6 \\
(2.7)\end{array}$ & - & $\begin{array}{l}-0.8 \\
(3.0)\end{array}$ & $\begin{array}{c}1.2 \\
(2.3)\end{array}$ & + & $\begin{array}{c}2.2 \\
(2.7)\end{array}$ \\
\hline $\begin{array}{l}\text { After } 1 \text { st June x PPRi Zone } \\
\text { (obligation of IAL) }\end{array}$ & $\begin{array}{l}-0.2 \\
(2.4)\end{array}$ & - & $\begin{array}{l}-0.3 \\
(3.3)\end{array}$ & $\begin{array}{c}0 \\
(0.02)\end{array}$ & - & $\begin{array}{c}0 \\
(0.03)\end{array}$ \\
\hline Lambda & 0 & 0.2 & 0 & 0 & 0.42 & 0 \\
\hline R2 & 0.59 & 0.59 & 0.57 & 0.51 & 0.51 & 0.5 \\
\hline Number of observations & 9,040 & 9,040 & 4,279 & 9,310 & 9,310 & 4,258 \\
\hline
\end{tabular}

Note: Significant at the $1 \%{ }^{* * *}, 5 \%$ **, $10 \%$ * level. Standard errors (in parenthesis) are computed by cluster so as to account for the possible spatial correlation of the residuals on local housing markets (unobserved variables, or local characteristics such as criminality, shocks (e.g. factory closing, etc.). The clusters retained are the municipalities.

Coverage: Municipalities in mainland France in which at least one real estate transaction was recorded in 2006 and which was covered by a PPR in 2006, and outside seismic zoning and outside the scope of an official "natural disaster classification" in 2006.

Sources: Perval and BIEN 2006 notarial databases, Cartorisque and Gaspar, author's calculations. 
quality of the property and the municipality's characteristics. On the whole, enforcement of the IAL has not had an effect on the difference in price between properties in zones regulated by a PPRi and those outside the PPRi zones: the estimates of the effect of treatment on the treated are very low for apartments and individual houses and never differ significantly from zero. An alternative difference-in-differences model estimating the effect of the IAL month-by-month in PPRi zones ${ }^{21}$ was also implemented (see Online complement C3, figures $\mathrm{C} 3-\mathrm{I}$ and $\mathrm{C} 3-\mathrm{II})$. The estimated coefficients are not significant for the months after June. Nor are they significant for the months preceding the coming into force of the IAL, which supports the assumption of the absence of a pre-trend in the treatment group.

There are several possible interpretations of these results. The first is that the disclosure requirement does not provide additional information for potential buyers. If buyers were already informed, market prices already included the "risk" factor before June 2006 and the IAL requirement have not changed anything in that respect. The assumption of complete and perfect information cannot therefore be rejected. The second possibility is that the information provided by the IAL is new for buyers and the proportion of informed buyers has increased, but the information contained in the IAL does not efficiently reduce perception biases (e.g. information not clear enough, too complex, etc.). The final interpretation possible is that the information is provided at too late a stage in the sales process, once price negotiations have been completed, so that it does not have a direct impact on price in the short term. We cannot rule out the fact that certain buyers decide against buying exposed properties; in this case, the short-term impact would be on sales, then in the medium term on prices through the supply and demand equilibrium.

A robustness check on the estimation period was conducted. According to expert opinion, the average time lapse between the initial sales agreement and signature of the final deed of sale is three months. If the sale takes place in June, the initial sales agreement may have been signed in March or April. In this case, the buyer only received a risk statement at the time of signature of the final deed of sale and it is unlikely that they would withdraw at that stage. To remove the possible bias due to the time lapse between signature of the initial sales agreement and of the deed of sale, the preceding model is estimated on the subsample of housing transactions from January to March (first quarter) and those from October to December (fourth quarter). The impact of introduction of the IAL on residential property prices (excluding fees) remains zero and non-significant (Table 3, "OLS T1-T4" column).

\section{Sensitivity of the results to the factors of perception and memory of the risk}

To refine the analysis, we now consider two factors likely to affect potential buyers' perception of the risk: firstly, the housing unit's floor (or number of storeys for a house) because its strong link with to the perception of flood risk vulnerability, and secondly the date of the last official classification as natural disaster in the municipality, because recent damage events can affect experience and local "memory" of the risk.

\section{Housing unit floor}

First, we test whether the IAL has had more impact on ground-floor apartments than on those on the upper floors or, for houses, on single-storey houses than on those with several storeys. Equation 1 is completed using the following terms

$$
\begin{array}{r}
\beta_{Z}^{R D C} 1_{\text {Zrisque }} 1_{R D C}+\sum_{t=2}^{11} \beta_{t}^{R D C} 1_{t} 1_{R D C} \\
+\delta^{R D C} 1_{\text {Zrisque }} 1_{\text {ApJuin }} 1_{R D C} .
\end{array}
$$

The coefficient $\delta^{R D C}$ is interpreted as an additional effect of the IAL on ground-floor or single-storey housing prices, with regard to the effect of the IAL on the price of housing units taken as reference, i.e. apartments on the upper floors or houses with several storeys. The assumption is that the perception of a property's vulnerability correlates strongly with its height position and that the ground floor of a building is perceived as the most exposed to flood risk. If this is the case, apartment buyers will not normally alter their decision for floors above the ground floor. For houses, the lower floor will suffer damage in the event of a flood, regardless of whether the building has a single storey or several storeys. However, a house with more than one storey provides a safe haven if water levels rise and may therefore appear safer than a single-storey house. We can therefore expect a greater price adjustment for single-storey houses.

\footnotetext{
21. $\delta 1_{\text {Apjuin }} 1_{\text {Zrisque }}$ is replaced by $\sum_{t=2}^{12} \delta_{t} 1_{t} 1_{\text {Zrisque. }}$.
} 
All other things being equal, enforcement of the IAL requirement led to a $9 \%$ fall in the price of ground-floor apartments in PPRi zones when compared to ground-floor apartments not subject to the IAL (Table 4). The difference-in-differences estimator for singlestorey houses is also negative (cf. Table 4), but not significant.

\section{Recent damage events in the municipality}

In behavioural economics and psychology, it is well documented that risk perception is very strongly influenced by experience and one's own history (Tallon \& Vergnaud, 2007). The sign for this correlation is nonetheless ambiguous. According to the "availability heuristic" assumption (Tversky \& Kahneman, 1973), an individual is all the more likely to overestimate (or respectively underestimate) the probability of a random event if they have recent experience (respectively, "distant") of a similar event and can easily (respectively, with difficulty) recall it. On the contrary, according to "gamblers' fallacy", agents consider that it is rather unlikely that an event that has just occurred will reoccur any time soon and, reciprocally, that after a long period with no occurrences, an event is more likely to occur to "correct" the low probability factor, even if the events are independent. If the municipality has not experienced a natural disaster for several years, the IAL may recall otherwise forgotten information. In the opposite case, it may reactive memories of recent events.

In our estimation sample, 33 municipalities suffered a natural disaster (excluding shrinkage and swelling of clay soils) in 2005, the year preceding the sale, and 230 at least once in the five years preceding the sale. Immediate memory of the risk is therefore potentially very heterogeneous within our estimation sample. The date of the last official classification as natural disaster is used as a proxy of the last major flood in the municipality. To the reference equation, we add the variables from the difference-in-differences model crossed with a dummy variable equal to 1 if the municipality was subject to at least one natural disaster classification in the year preceding the sale (in 2005), then at least one such classification in the five years preceding the sale. The crossed effect is interpreted as the additional effect of the IAL requirement compared to the reference situation, i.e. with no natural disaster classification in 2005 and, respectively, none in the five years preceding the sale.

In the municipalities that experienced a natural disaster in the year preceding the sale, enforcement of the IAL requirement had a significant depreciative effect of $-7 \%$ on the price of apartments subject to the IAL requirement

Table 4

Impact of the IAL on the average transaction prices (excluding agency and notary fees) within and outside the PPRi zones depending on the housing unit's storey, as a \% of the price

\begin{tabular}{|l|c|c|c|c|c|c|}
\hline & \multicolumn{3}{|c|}{ Apartments } & \multicolumn{3}{c|}{ Houses } \\
\hline Model & OLS & Box-Cox & OLS & OLS & Box-Cox & OLS \\
T1-T4 \\
\hline \multirow{2}{*}{ PPRi Zone } & -2.2 & - & -2.4 & 0.7 & + & 1,4 \\
& $(2.6)$ & & $(2.9)$ & $(2.6)$ & & $(3)$ \\
Ground floor apartments or single-storey houses x PPRi Zone & 1.4 & + & -1.3 & 1 & + & 1,6 \\
& $(2.8)$ & & $(3.1)$ & $(2.6)$ & & $(3,6)$ \\
After 1't June x PPRi Zone (obligation of IAL) & $10.1^{* *}$ & $+^{* *}$ & 10.3 & 2.7 & + & 4.7 \\
& $(4.2)$ & & $(7.4)$ & $(4.7)$ & & $(5.9)$ \\
Ground floor/single-storey x After 1st June x PPRi Zone & $-9.1^{*}$ & $-{ }^{\circ}$ & $-11.1^{\circ}$ & -7.3 & - & -10.3 \\
& $(4.9)$ & & $(7.6)$ & $(5.5)$ & & $(8.9)$ \\
\hline Lambda & 0 & 0.2 & 0 & 0 & 0.42 & 0 \\
\hline R2 & 0.59 & 0.59 & 0,57 & 0.51 & 0.52 & 0.51 \\
\hline Number of observations & 9,040 & 9,040 & 4,279 & 9,310 & 9,310 & 4,258 \\
\hline
\end{tabular}

Note: Significant at the $1 \%{ }^{* * *}, 5 \%$ **, $10 \%$ * level. Standard errors (in parenthesis) are computed by cluster (cf. Table 3). The estimation controls for the month of sale; the coefficients are presented in Table C4-1 of the Online complement C4.

Coverage: Municipalities in mainland France in which at least one real estate transaction was recorded in 2006 and which was covered by a PPR in 2006, and outside seismic zoning and outside the scope of an official "natural disaster classification" in 2006.

Sources: Perval and BIEN 2006 notarial databases, Cartorisque and Gaspar, author's calculations. 
when compared to similar properties that were not subject to it (Table 5). The same result is obtained if we take the two years prior to the sale into consideration (not reported here). Nonetheless, the OLS estimator is not significant at the $10 \%$ level (p-value of $12 \%$ ), so this result remains fragile. For individual houses, the effect is not significant.

Over a time frame of five years prior to the sale, enforcement of the IAL requirement has no impact on residential property prices, regardless of whether or not the municipality was affected by a natural disaster. The IAL therefore only appears to have an impact on the price of apartments when the last events are very recent, which is consistent with the availability heuristic assumption and undermines the assumption of complete and perfect information.

\section{Sensitivity of the results to the characteristics of local real estate markets}

The impact of disclosure to new buyers is estimated depending on tension on the local real estate market. Tension corresponds to the adequacy of supply of available houses with demand for housing within a territory. A zone is described as "tense" (respectively "slack") if the supply of available housing is not (resp. is) enough to cover demand. When supply is lower than demand, buyers' bargaining power is expected to be weaker because they have less choice and are probably less able to ask for a price drop after learning about the property's exposure to risk. Conversely, if supply is abundant when compared to demand, potential buyers find it easier to negotiate the price downwards or pull out of the sale.

Table 5

Impact of the IAL on the average transaction prices (excluding agency and notary fees) within and outside PPRi zones, by date of the last official classification as natural disaster, as a $\%$ of the price

\begin{tabular}{|c|c|c|c|c|c|c|}
\hline \multirow[b]{2}{*}{ Model } & \multicolumn{3}{|c|}{ Apartments } & \multicolumn{3}{|c|}{ Houses } \\
\hline & OLS & Box-Cox & $\begin{array}{c}\text { OLS } \\
\text { T1-T4 }\end{array}$ & OLS & Box-Cox & $\begin{array}{c}\text { OLS } \\
\text { T1-T4 }\end{array}$ \\
\hline \multicolumn{7}{|l|}{ At least one classification as "natural disaster" in2005 } \\
\hline PPRi Zone & $\begin{array}{c}0.5 \\
(3.1)\end{array}$ & - & $\begin{array}{c}0.2 \\
(3.8)\end{array}$ & $\begin{array}{c}1.4 \\
(2.5)\end{array}$ & & $\begin{array}{l}1.3 \\
(3)\end{array}$ \\
\hline At least one "Cat Nat" in 2005 x PPRi Zone & $\begin{array}{l}-3.4 \\
(5.3)\end{array}$ & - & $\begin{array}{l}-2.8 \\
(5.5)\end{array}$ & $\begin{array}{l}-1.5 \\
(7.1)\end{array}$ & - & $\begin{array}{c}6.2 \\
(6.2)\end{array}$ \\
\hline After $1^{\text {st }}$ June $x$ PPRi Zone & $\begin{array}{c}2.7 \\
(2.5)\end{array}$ & + & $\begin{array}{l}-3.0 \\
(4.2)\end{array}$ & $\begin{array}{c}0 \\
(2.6)\end{array}$ & - & $\begin{array}{c}0.9 \\
(3.7)\end{array}$ \\
\hline At least one "Cat Nat" in 2005 x PPRi Zone x After 1'st June & $\begin{array}{l}-7.1^{*} \\
(4.6)\end{array}$ & $-{ }^{*}$ & $\begin{array}{l}-0.7 \\
(6.2)\end{array}$ & $\begin{array}{l}-1.4 \\
(6.7)\end{array}$ & - & $\begin{array}{l}-9.8 \\
(7.2)\end{array}$ \\
\hline Lambda & 0 & 0.2 & 0 & 0 & 0.42 & 0 \\
\hline $\mathrm{R} 2$ & 0.59 & 0.59 & 0.57 & 0.51 & 0.52 & 0.51 \\
\hline Number of observations & 9,040 & 9,040 & 4,279 & 9,310 & 9,310 & 4,258 \\
\hline \multicolumn{7}{|l|}{ At least one classification as "natural disaster" in the 5 previous years } \\
\hline PPRi Zone & $\begin{array}{c}1.9 \\
(5.6)\end{array}$ & + & $\begin{array}{c}-1.4 \\
(7.6)\end{array}$ & $\begin{array}{l}5.9 \\
(4)\end{array}$ & $t^{* *}$ & $\begin{array}{c}4.7 \\
(4.8)\end{array}$ \\
\hline At least one "Cat Nat" in the 5 previous years x PPRi Zone & $\begin{array}{l}-3.1 \\
(5.9)\end{array}$ & - & $\begin{array}{c}0.9 \\
(7.7)\end{array}$ & $\begin{array}{l}-7.8 \\
(5.1)\end{array}$ & $-{ }^{* *}$ & $\begin{array}{l}-4.4 \\
(4.8)\end{array}$ \\
\hline After $1^{\text {st }}$ June x PPRi Zone & $\begin{array}{l}-2.0 \\
(4.8)\end{array}$ & - & $\begin{array}{c}-15.7^{\star *} \\
(7.7)\end{array}$ & $\begin{array}{c}-1.4 \\
(4.4)\end{array}$ & - & $\begin{array}{l}-1.6 \\
(5.8)\end{array}$ \\
\hline $\begin{array}{l}\text { At least one "Cat Nat" in the } 5 \text { previous years } x \text { PPRi Zone } x \text { After } 1^{\text {st }} \\
\text { June }\end{array}$ & $\begin{array}{l}2.3 \\
(5.8)\end{array}$ & + & $\begin{array}{l}15.9^{*} \\
(0.1)\end{array}$ & $\begin{array}{l}1.4 \\
(5.2)\end{array}$ & + & $\begin{array}{c}1.7 \\
(5.9)\end{array}$ \\
\hline Lambda & 0 & 0.2 & 0 & 0 & 0.42 & 0 \\
\hline $\mathrm{R} 2$ & 0.59 & 0.59 & 0.57 & 0.51 & 0.52 & 0.51 \\
\hline Number of observations & 9,040 & 9,040 & 4,279 & 9,310 & 9,310 & 4,258 \\
\hline
\end{tabular}

Note: Significant at the $1 \%{ }^{* * *}, 5 \%$ **, $10 \%$ * level. Standard errors (in parenthesis) are computed by cluster (cf. Table 3). The estimation controls for the month of sale; the coefficients are presented in Table C4-2 of the Online complement C4.

Coverage: Municipalities in mainland France in which at least one real estate transaction was recorded in 2006 and which was covered by a PPR in 2006, and outside seismic zoning and outside the scope of an official "natural disaster classification" in 2006.

Sources: Perval and BIEN 2006 notarial databases, Cartorisque and Gaspar; author's calculations. 
We use a French policy scheme known as the "Robien law 'recentred' zones" as proxies of tension on real estate markets in 2006; these zones were defined in August 2006 and split the territory into four areas according to market tension. Zone $\mathrm{A}$ is the most tense and most notably includes Paris and its conurbation, the Côte d'Azur and municipalities in the French Genevois territory; as the number of sales in a PPRi zone after $1^{\text {st }}$ June 2006 was very low for this "zone A" (4 out of 632 apartment sales, 7 out of 375 house sales), it is excluded from the estimation sample. Zone B1 covers conglomerations of over 250,000 inhabitants, the periphery of the Côte d'Azur, the overseas départements and Corsica; zone $\mathrm{B} 2$ includes other conglomerations of over 50,000 inhabitants and other expensive conglomerations near the borders, coasts and close to the Parisian conurbation; zone $\mathrm{C}$, which is the least tense, covers the rest of France.

To the reference equation, we add the terms of the difference-in-differences model crossed with an indicator equal to 1 if the municipality is located in zone $\mathrm{B} 1$, and those crossed with an indicator equal to 1 if the municipality is located in zone $\mathrm{C}$ (zone $\mathrm{B} 2$ is taken as the reference). The crossed effect for a given zone is interpreted as an additional effect of the IAL in that zone, compared to the effect on the price of properties in the zone taken as reference.

For apartments, enforcement of the IAL requirement did not have a significant effect on prices regardless of the zone considered. For houses, the IAL had an additional effect of $-9 \%$ (significant at the $10 \%$ level) on sales prices in zone $\mathrm{C}$ and $-8 \%$ (significant at a $13 \%$ level) in zone B1 (Table 6). The impact of the IAL in the reference zone (B2) is positive and significant but lower $(+6 \%)^{22}$, so the overall impact of the IAL on house prices in zones $\mathrm{C}$ and $\mathrm{B} 1$ is negative. Hence, in municipalities where the real estate market is the least tense, enforcement of the IAL requirement went hand-in-hand with a $3 \%$ decline in housing

22. This "Robien B2" zone corresponds to specific real estate markets, including expensive coastal zones and border zones. The positive amenity effect of the proximity of the coast shore or of a river can outweigh the negative effect of flood risk exposure.

\section{Table 6}

Impact of the IAL on the average transaction prices (excluding agency and notary fees) within and outside the PPRi zones according to real estate market tension, as a $\%$ of the price

\begin{tabular}{|c|c|c|c|c|c|c|}
\hline \multirow[b]{2}{*}{ Model } & \multicolumn{3}{|c|}{ Apartments } & \multicolumn{3}{|c|}{ Houses } \\
\hline & OLS & Box-Cox & $\begin{array}{c}\text { OLS } \\
\text { T1-T4 }\end{array}$ & OLS & Box-Cox & $\begin{array}{c}\text { OLS } \\
\text { T1-T4 }\end{array}$ \\
\hline Zone Robien B1 & $\begin{array}{l}12.0^{*} \\
(6.9)\end{array}$ & $t^{* * *}$ & $\begin{array}{c}7.5 \\
(7.2)\end{array}$ & $\begin{array}{c}0.05 \\
(0.05)\end{array}$ & + & $\begin{array}{c}7.5 \\
(5.7)\end{array}$ \\
\hline Zone Robien B2 & Ref. & Ref. & Ref. & Ref. & Ref. & Ref. \\
\hline Zone Robien C & $\begin{array}{c}-20.1^{* *} \\
(10.2)\end{array}$ & $--^{* \star *}$ & $\begin{array}{c}-18.3^{*} \\
(9.9)\end{array}$ & $\begin{array}{c}-0.33^{\star * *} \\
(0.06)\end{array}$ & $--^{\star \star *}$ & $\begin{array}{c}-29.7^{\star \star *} \\
(6.1)\end{array}$ \\
\hline PPRi Zone & $\begin{array}{c}3.7 \\
(4.2)\end{array}$ & + & $\begin{array}{c}4.4 \\
(4.5)\end{array}$ & $\begin{array}{l}-, 0.05 \\
(0.03)\end{array}$ & $--^{* *}$ & $\begin{array}{l}-3,6 \\
(4.0)\end{array}$ \\
\hline Zone Robien B1 x PPRi Zone & $\begin{array}{l}-9.4^{*} \\
(5.5)\end{array}$ & $-{ }^{* \star *}$ & $\begin{array}{c}-10.1^{*} \\
(5.9)\end{array}$ & $\begin{array}{c}0 \\
(0.05)\end{array}$ & + & $\begin{array}{l}-1.9 \\
(6.6)\end{array}$ \\
\hline Zone Robien C x PPRi Zone & $\begin{array}{l}-5.6 \\
(0)\end{array}$ & - & $\begin{array}{l}-6.6 \\
(0)\end{array}$ & $\begin{array}{c}0.11^{* *} \\
(0)\end{array}$ & $t^{\star * \star}$ & $\begin{array}{c}10.7^{*} \\
(0)\end{array}$ \\
\hline After $1^{\text {st }}$ June $x$ PPRi Zone (IAL,obligatoire) & $\begin{array}{l}-1.5 \\
(4.8)\end{array}$ & - & $\begin{array}{l}-4.7 \\
(5.6)\end{array}$ & $\begin{array}{l}0.06^{*} \\
(0.03)\end{array}$ & $+^{\circ}$ & $\begin{array}{l}2.1 \\
(4.7)\end{array}$ \\
\hline Zone Robien B1 x After $1^{\text {st }}$ June x PPRi Zone (IAL,obligatoire) & $\begin{array}{c}1.4 \\
(5.3)\end{array}$ & + & $\begin{array}{l}3.4 \\
(6.7)\end{array}$ & $\begin{array}{c}-0.08^{\circ} \\
(0.06)\end{array}$ & $-{ }^{\circ}+x+3+3$ & $\begin{array}{l}-2.9 \\
(7.8)\end{array}$ \\
\hline Zone Robien C x After 1st June x PPRi Zone (IAL,obligatoire) & $\begin{array}{l}8.7 \\
(8)\end{array}$ & + & $\begin{array}{c}4.2 \\
(10.7)\end{array}$ & $\begin{array}{c}-0.09^{*} \\
(0.05)\end{array}$ & $-{ }^{*}$ & $\begin{array}{l}-3.7 \\
(7.3)\end{array}$ \\
\hline Lambda & 0 & 0.2 & 0 & 0 & 0.42 & 0 \\
\hline R2 & 0.58 & 0.59 & 0.57 & 0.51 & 0.52 & 0.51 \\
\hline Number of observations & 8,408 & 8,408 & 3,989 & 8,935 & 8,935 & 4,098 \\
\hline
\end{tabular}

Note: Significant at the $1 \%{ }^{* *}, 5 \%{ }^{* *}, 10 \%$ * $15 \%$ level. Standard errors (in parenthesis) are computed by cluster (cf. Table 3 ).

Coverage: Municipalities in mainland France in which at least one real estate transaction was recorded in 2006 and which was covered by a PPR in 2006, and outside seismic zoning and outside the scope of an official "natural disaster classification" in 2006.

Sources: Perval and BIEN 2006 notarial databases, Cartorisque, ONRN ; Insee ; Corine Land Cover, IGN ; author's calculations. 
transaction prices. In municipalities in the more tense zone B1, the impact was negative but to a lesser degree and was less significant.

\section{Placebo test}

We now test the effect of the fictitious implementation of the IAL at various dates prior to the enforcement of the IAL ( $1^{\text {st }}$ February, $1^{\text {st }}$ March, $1^{\text {st }}$ April and $1^{\text {st }}$ May). The expected effect of applying this placebo is zero. If it were significant, it would indicate that the sellers of properties exposed to risks had anticipated the introduction of the IAL requirement. From a methodological viewpoint, a significant effect of a "placebo" measure would raise concerns over a significant difference between housing transactions outside and within the PPR zones and that the selected control group is not therefore appropriate.

The difference between apartment prices in regulated PPRi zones and in the rest of the municipality is not affected by the fictitious introduction of the IAL on $1^{\text {st }}$ February, $1^{\text {st }}$ March or $1^{\text {st }}$ April (Table 7-A). However, the effect of a fictitious introduction on $1^{\text {st }}$ May has a significant effect of $-5 \%$. This suggests that after $1^{\text {st }}$ May 2006, the price of apartments in regulated PPRi zones were perhaps already lower than those of apartments in the rest of the municipality, which could be the sign of some slight anticipation. Conversely, the enforcement of the IAL requirement on fictitious dates did not affect house prices, regardless of the date. This test means we do not have to reject the assumptions used in identification of the difference-in-differences model for houses.

Finally, we run placebo tests for the sensitivity specifications for which significant effects were obtained (real estate market tension for individual houses, storey and past damage events in the municipality for apartments). For houses, the effect of a placebo IAL requirement crossed with Robien zones is not significant. For apartments, the effect of a fictitious IAL requirement crossed with the housing unit's storey is significant for an introduction date of $1^{\text {st }}$ March; this suggests that the price of ground-floor apartments was perhaps already lower in regulated PPRi zones than in the rest of the municipality. This result raises concerns over a bias in the estimate of the effect of the introduction of the IAL requirement on ground-floor apartment prices in PPRi municipalities and prompts us to interpret the difference-in-differences model result with

\section{Tableau 7}

Impact of the IAL on the average transaction prices (excluding agency and notary fees) within and outside the PPRi zones, by placebo month, as a $\%$ of the price

\section{A - Main specification}

\begin{tabular}{|c|c|c|c|c|}
\hline & February & March & April & May \\
\hline \multicolumn{5}{|l|}{ Apartments } \\
\hline $\begin{array}{l}\text { PPRi Zone x After the } \\
1^{\text {st }} \text { of ... }\end{array}$ & $\begin{array}{c}0.1 \\
(3.4)\end{array}$ & $\begin{array}{l}-0.0 \\
(2.4)\end{array}$ & $\begin{array}{l}-1.3 \\
(2.6)\end{array}$ & $\begin{array}{l}-4.5^{*} \\
(2.5)\end{array}$ \\
\hline R2 & 0.58 & 0.58 & 0.58 & 0.58 \\
\hline Number of observations & 3,468 & 3,468 & 3,468 & 3,468 \\
\hline \multicolumn{5}{|l|}{ Houses } \\
\hline $\begin{array}{l}\text { PPRi Zone x After the } \\
1{ }^{\text {st }} \text { of ... }\end{array}$ & $\begin{array}{l}-4.2 \\
(4.4)\end{array}$ & $\begin{array}{l}-1.8 \\
(3.6)\end{array}$ & $\begin{array}{l}-2.7 \\
(3.8)\end{array}$ & $\begin{array}{c}1.0 \\
(4.7)\end{array}$ \\
\hline R2 & 0.5 & 0.5 & 0.57 & 0.57 \\
\hline Number of observations & 3,465 & 3,465 & 3,465 & 3,465 \\
\hline
\end{tabular}

\section{B - Sensitivity}

\begin{tabular}{|l|c|c|c|c|}
\hline & February & March & April & May \\
\hline Apartments & & & & \\
PPRi Zone x After the $1^{\text {st }}$ of ... & 0.5 & 2 & -1.5 & -3.9 \\
& $(3.7)$ & $(2.7)$ & $(3.5)$ & $(2.7)$ \\
Ground floor/One-storey x & -2.4 & $-17.6^{*}$ & 0.3 & -4.5 \\
PPRi Zone x After the 15t of ... & $(8.0)$ & $(9.8)$ & $(13.5)$ & $(14.1)$ \\
R2 & 0.58 & 0.58 & 0.58 & 0.58 \\
Number of observations & 3,468 & 3,468 & 3,468 & 3,468 \\
\hline Houses & & & & \\
PPRi Zone x After the 1 ${ }^{\text {st }}$ & -5.1 & -0.5 & -2.8 & -1.5 \\
of ... & $(4.9)$ & $(3.8)$ & $(3.7)$ & $(3.6)$ \\
At least one 'CatNat' in 2005 x & $11.6^{*}$ & 0.7 & 3.6 & -7.1 \\
PPRi Zone x After the 1 ${ }^{\text {st }}$ of ... & $(6.0)$ & $(4.8)$ & $(5.1)$ & $(5.1)$ \\
R2 & - & 0.58 & 0.58 & 0.58 \\
Number of observations & 3,468 & 3,468 & 3,468 & 3,468 \\
\hline
\end{tabular}

Note: Significant at the $1 \%{ }^{* * *}, 5 \%$ **, $10 \%$ * level. Standard errors (in parenthesis) are computed by cluster (cf. Table 3).

Coverage: Municipalities in mainland France in which at least one real estate transaction was recorded in 2006 and which was covered by a PPR in 2006, and outside seismic zoning and outside the scope of an official "natural disaster classification" in 2006.

Sources: Perval and BIEN 2006 notarial databases, Cartorisque, ONRN ; Insee ; Corine Land Cover, IGN ; author's calculations. 
caution. Likewise, a fictitious IAL requirement on $1^{\text {st }}$ February has a positive effect on the price of apartments located within municipalities affected by a natural disaster in 2005, compared to those located in an unaffected municipality (non-significant effect) and those located in municipalities affected at least once in the five years preceding the sale.

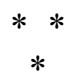

The aim of this paper was to test the assumption of complete and perfect information in the hedonic price model on the French property markets. The enforcement of the IAL requirement for properties located within the boundaries of a PPRi was used as a quasi-natural experiment of an information shock in the context of residential property transactions.

The results of the estimations suggest that the IAL had no significant impact on the average price (exclusive of fees) of properties sold in the 484 PPRi municipalities included in our estimation sample. One reason may be that the majority of buyers were already sufficiently informed about exposure to risks before the IAL came into force and thus the assumption of complete and perfect information is verified. However, it is also possible that buyers are poorly informed by the IAL (difficulties understanding the risk statement, technical information, etc.), and that this policy does not improve their risk perception, or that householders are informed at too late a stage in the transaction, meaning that the new information is not taken on-board when negotiating the price. In this case, the impact of preventive information on risk perception is underestimated because householders cannot exploit it during negotiations.

Nonetheless, from its year of introduction, for certain categories of properties and in certain municipalities, we can observe a depreciative effect of the IAL on the sales price of existing housing units. The introduction of the IAL led to an average fall of $9 \%$ of the price of ground-floor apartments in PPRi zones of municipalities subject to floods. The results also point to a negative impact on the price of houses on the least tense real estate markets (the so-called "recentred Robien zone C"). This policy could thus have modified some buyers' perception of natural risks, which somewhat undermines the assumption of complete and perfect information in real estate markets. The final results urge caution when interpreting the results of the hedonic price model for characteristics that cannot be observed directly or which are difficult to appreciate, such as exposure to natural risks.

The short estimation period after the IAL coming into force is the main limit of this study. Some potential buyers may well have decided not to buy after receiving the risk statement. The short-term effect of the IAL would thus be to lengthen the time it takes to sell a property in exposed, regulated zones. The price drop expected after a fall in demand for those properties would then be observed several months later, after adjustment of supply and demand. In the absence data for the years before and after 2006 , this possibility could not be tested.

It would therefore be useful to extend our study over several years, before and after the IAL coming into force, to obtain a more robust evaluation of the reform and be able to control better for seasonal effects on real estate markets. 
Ai, C. \& Norton, E. C. (2003). Interaction terms in logit and probit models. Economics Letters, 80(1), 123-129.

https://doi.org/10.1016/S0165-1765(03)00032-6

Bartik, T. (1988). Measuring the Benefits of Amenity Improvements in Hedonic Price Models. Land Economics, 64(2), 172-183.

https://doi.org/10.2307/3146822

Beron, K. J., Murdoch, J. C., Thayer, M. A. \&Vijberberg, W. P. M. (1997). An Analysis of Housing Market before and after 1989 Lima Prieta Earthquake. Land Economics, 73(1), 101-113. https://doi.org/10.2307/3147080

Bin, O. \& Landry, C. E. (2013). Changes in Implicit Flood Risk Premiums: Empirical Evidence From the Housing Market. Journal of Environmental Economics and Management, 65(3), 361-376. https://doi.org/10.1016/j.jeem.2012.12.002

Bin, O., \& Polasky, S., (2004). Effects of Flood Hazards on Property Values: Evidence before and after Hurricane Floyd. Land Economics, 80(4), 490-500. https://doi.org/10.2307/3655805

Box, G. E. P \& Cox, D. R. (1964). An Analysis of Transformations. Journal of the Royal Statistical Society. Series B (Methodological), 26(2), 211-252. https://www.jstor.org/stable/i349725

Cassel, E., \& Mendelsohn, R. (1985). The Choice of Functional Forms for Hedonic Price Equations: Comment. Journal of Urban Economics, 18(2), 135-142. https://doi.org/10.1016/0094-1190(85)90012-9

Caumont, V. (2014). Risque de submersion marine et marchés fonciers et immobiliers sur le littoral du Nord-Pas-de-Calais. Phase 2 : Analyse quantitative des marchés fonciers et immobiliers. Cerema, juin 2014. https://www.cerema.fr/fr/actualites/submersionmarine-marches-fonciers-immobiliers

Chaisemartin, C. de \& D'Hautlfoeuille, X. (2018). Fuzzy Difference-in-Difference. Review of Economic Studies, 85(2), 999-1028.

https://doi.org/10.1093/restud/rdx049

Cropper, M. L., Deck, L. B. \& McConnell, K. E. (1988). On the Choice of Functional Form for Hedonic Price Functions. The Review of Economics and Statistics, 70(4), 668-675.

https://doi.org/10.2307/1935831
Déronzier, P. \& Terra, S. (2006). Bénéfices économiques de la protection contre le risque d'inondation. Ministère de l'Écologie et du Développement Durable, D4E, Série Etudes N06-E05.

http://www.side.developpement-durable.gouv.fr/ EXPLOITATION/ACCRDD/doc/IFD/IFD REFDOC_TEMIS_0062929/benefices-economiquesde-la-protection-contre-le-risque-d-inondation

Grislain-Letrémy, C. \& Katossky, A. (2013). Les risques industriels et le prix des logements. Economie et Statistique, 460-461, 79-106. https://doi.org/10.3406/estat.2013.10200

Harrison, D. M., Smersh, G. T., Arthur L. Schwartz, J., (2001). Environmental Determinants of Housing Prices: The Impact of Flood Zone Status. Journal of Real Estate Research, 21(1-2), 3-20.

http://pages.jh.edu/jrer/papers/pdf/past/ vol21n0102/02.3_20.pdf

Letremy, C. (2009). Assurance des risques naturels en France : sous quelles conditions les assureurs peuvent-ils inciter à la prévention des risques naturels ? Commissariat Général au Développement Durable, Études et Documents $\mathrm{N}^{\circ} 1$.

http://www.side.developpement-durable.gouv.fr/ EXPLOITATION/DEFAULT/doc/IFD/IFD REFDOC 0503089/Assurance-des-risques-naturelsen-France-sous-quelles-conditions-les-assureurspeuvent-ils-inciter

Longuépée, J., \& Zuindeau, B. (2001). L’impact du coût des inondations sur les valeurs immobilières : une application de la méthode des prix hédoniques à la Basse Vallée de la Canche. Cahiers du GRATICE $\mathrm{N}^{\circ} 21,143-166$.

Klaiber, H. A. \& Smith, V. K. (2013). Quasi Experiments, Hedonic Models, and Estimating Tradeoffs for Local Amenities. Land Economics, 89(3), 413-431. https://doi.org/10.3368/le.89.3.413

Kuminoff, N. V. \& Pope, J. C. (2014). Do "Capitalization Effects" for Public Goods Reveal the Public Willingness to Pay. International Economic Review, 55(4), 1227-1250. https://doi.org/10.1111/iere.12088

MacDonald, D. N., White, H.L., Taube, P. M \& Huth, W. L. (1990). Flood Hazard Pricing and Insurance Premium Differentials: Evidence from the Housing Market. The Journal of Risk and Insurance, 57(4), 654-663.

https://doi.org/10.2307/252950 
Mauroux, A. (2015). Exposition aux risques, politiques de prévention et marchés immobiliers. Un état de la connaissance. Commissariat Général au Développement Durable, Études et Documents, $\mathrm{N}^{\circ} 134$.

http://temis.documentation.developpement-durable. gouv.fr/docs/Temis/0083/Temis-0083306/22286.pdf

Montz, B. E. \& Tobin, G. A. (1988). The Spatial and Temporal Variability of Residential Real Estate Values in Response to Flooding. Disasters, 12(4), 345-355.

https://doi.org/10.1111/j.1467-7717.1988.tb00687.x

Montz, B. E. \& Tobin, G. A. (1994).The Flood Hazard and Dynamics of the Urban Residential Land Market. Journal of the American Water Resources Association, 30(4), 673-685. https://doi.org/10.1111/j.1752-1688.1994.tb03322.x

Palmquist, R. B. (2005). Property value models. In: Maler, K.-G. \& Vincent, J. (Eds.), Handbook of Environmental Economics, vol. 2, 763-819. Amsterdam: North Holland.

Parmeter, C. F. \& Pope, J. C. (2013). QuasiExperiments and Hedonic Property Value Methods. In: List, J. A. \& Price, M. K. (Eds.), Handbook of Experimental Economics and the Environment, 3-66. Cheltenham, Northampton: Edward Elgar Publishing.

Pautard, E. (2014). Le sentiment d'exposition aux risques environnementaux. Commissariat Général au Développement Durable, Chiffres et Statistiques $\mathrm{N}^{\circ} 567$.

http://www.statistiques.developpement-durable. gouv.fr/fileadmin/documents/Produits_editoriaux/ Publications/Chiffres_et_statistiques/2014/chiffresstats567-eser-octobre2014.pdf

Pope, J. C. (2008a). Buyer information and the hedonic: The impact of a seller disclosure on the implicit price for airport noise. Journal of Urban Economics, 63(2), 498-516.

https://doi.org/10.1016/j.jue.2007.03.003
Pope, J. C. (2008b). Do Seller's Disclosures Affect Property Values? Buyer Information and the Hedonic Model. Land Economics, 84(4), 551-572.

https://doi.org/10.3368/le.84.4.551

Puhani, P. A. (2012). The treatment effect, the cross difference, and the interaction term in nonlinear "difference-in-differences" models. Economics Letters, 115(1), 85-87.

https://doi.org/10.1016/j.econlet.2011.11.025

Rosen, R. (1974). Hedonic Price Models and Implicit Markets: Product Differentiation in Pure Competition. Journal of Political Economics, 82(1), 34-55. https://doi.org/185.086.171.043

Sheppard, S. (1999). Hedonic analysis of housing markets. In: Chesire, P. C. \& Mills, E. S. (Eds.), Handbook of regional and urban economics, vol. 3 , 1595-1635. Amsterdam: North Holland.

Sigma, Re (2014). Catastrophes naturelles et techniques en 2013 : Les inondations et la grêle causent d'importants dommages ; Haiyan frappe les Philippines. Rapport Sigma $\mathrm{N}^{\circ}$ 1/2014.

Tallon, J.-M. \& Vergnaud, J.-C. (2007). Incertitude en économie de l'environnement. Choix privés et attitudes individuelles face à l'incertitude. Revue Française d'économie, 22(2), 3-56. https://doi.org/10.3406/rfeco.2007.1647

Travers, M., Bonnet, E., Chevé, M. \& Appéré, G. (2009). Risques industriels et zones naturelles estuariennes : une analyse hédoniste spatiale. Économie \& Prévision, 190-191, 136-158. https://doi.org/10.3406/ecop.2009.8001

Tversky, A. \& Kahneman, D. (1973). Availability: a heuristic for judging frequency and probability. Cognitive Psychology, 5(2), 207-232. https://doi.org/10.1016/0010-0285(73)90033-9

Vermont, B. (2015). Prix des logements : quels facteurs expliquent leur disparité au sein et entre les aires urbaines. Commissariat Général au Développement Durable, Études et documents $\mathrm{N}^{\circ} 120$. http://www.cohesion-territoires.gouv.fr/IMG/pdf/ ed120.pdf 
Natural and technological risk statement form in 2006

\section{Etat des risques naturels et technologiques}

en application des articles L 125 - 5 et R 125 - 26 du code de l'environnement

1. Cet état des risques est établi sur la base des informations mises à disposition par arrêté préfectoral $n^{\circ}$ du mis à jour le

\section{Situation du bien immobilier (bâti ou non bâti)}

2. Adresse commune code postal

3. Situation de l'immeuble au regard d'un ou plusieurs plans de prévention de risques naturels prévisibles [PPRn]

L'immeuble est situé dans le périmètre d'un PPRn prescrit

L'immeuble est situé dans le périmètre d'un PPRn appliqué par anticipation

L'immeuble est situé dans le périmètre d'un PPRn approuvé

oui

Les risques naturels pris en compte sont:

$\begin{array}{rrr}\text { Inondation } & \text { Crue torrentielle } \\ \text { Avalanche } & \square \\ \text { Séisme } & \text { Mouvement de terrain } \\ \text { Cyclone } & \text { Remontée de nappe } \\ \text { Sécheresse } & \\ \text { Feux de forêt } & \text { autre }\end{array}$

4. Situation de l'immeuble au regard d'un plan de prévention de risques technologiques [PPRt]
L'immeuble est situé dans le périmètre d'un PPRt approuvé
L'immeuble est situé dans le périmètre d'un PPRt prescrit *
"Les risques technologiques pris en compte sont :
Effet thermique $\square \quad$ Effet de surpression $\square \quad$ Effet toxique $\square$

5. Situation de l'immeuble au regard du zonage réglementaire pour la prise en compte de la sismicité

en application du décret 91-461 du 14 mai 1991 relatif à la prévention du risque sismique, modifié par le décret n²000-892 du 13 septembre 2000

L'immeuble est situé dans une commune de sismicité

$$
\text { zone la }
$$

zone lb

zone II

zone III

Zone 0

pièces jointes

6. Localisation

extraits de documents ou de dossiers de référence permettant la localisation de limmeuble au regard des risques pris en compte

vendeur/bailleur - acquéreur/locataire

7. Vendeur - Bailleur Nom prénom

rayer la mention inutile

8. Acquéreur - Locataire Nom prénom

rayer la mention inutile

9. Date

à

le

Le présent état des risques naturels et technologiques est fondé sur les informations mises à disposition par le préfet de département. En cas de non respect, l'acquéreur ou le locataire peut poursuivre la résolution du contrat ou demander au juge une diminution du prix. [V de I'article 125-5 du code de l'environnement] 


\title{
An evaluation of the methods used by European countries to compute their official house price indices
}

\author{
Robert J. Hill*, Michael Scholz*, Chihiro Shimizu**, \\ and Miriam Steurer*
}

\begin{abstract}
Since 2012, Eurostat requires the national statistical institutes (NSIs) in all European Union (EU) countries to compute official House Price Indices (HPIs) at a quarterly frequency. Eurostat recommends computing the HPI using a hedonic method. Most NSIs have followed this advice, although they differ in their choice of method. Some NSIs use stratified medians instead of hedonic methods. We evaluate the theoretical and empirical properties of both hedonic and stratified median methods. Of particular concern is the comparability of the HPIs across countries when computed using different methods. Our empirical comparisons use detailed micro-level data sets for Sydney and Tokyo, containing about 867,000 actual housing transactions. All the hedonic methods perform better than stratified medians. The hedonic methods generate quite similar results, except when applied to new dwellings in Tokyo. This finding shows that the choice of hedonic method can be important for smaller countries with less data. Also, the widely used hedonic repricing method becomes unreliable when the reference shadow prices are not updated frequently.
\end{abstract}

JEL Classification: C43, E31, R31

Keywords: housing market, price index, repricing, average characteristics, hedonic imputation, rolling time dummy

Reminder:

The opinions and analyses in this article

are those of the author(s)

and do not

necessarily reflect

their institution's

or Insee's views.

\footnotetext{
*Department of Economics, University of Graz, Austria (robert.hill@uni-graz.at, michael.scholz@uni-graz.at, miriam.steurer@uni-graz.at)

** Nihon University, Tokyo (shimizu.chihiro@nihon-u.ac.jp)
}

A preliminary draft was presented at $15^{\text {th }}$ Ottawa Group Meeting, 10-12 May 2017, Eltville am Rhein, Germany. We acknowledge financial support for this project from the Austrian Research Promotion Agency (FFG), grant \#10991131. Hill and Steurer were members of the Expert Team advising Eurostat on the treatment of Owner Occupied Housing $(\mathrm{OOH})$ in the Harmonized Index of Consumer Prices (HICP). The idea for this paper developed out of this project. The views expressed here are of the authors, and are not necessarily representative of those of Eurostat.

Received on 9 June 2017, accepted after revisions on 19 February 2018 
T he fundamental role played by housing in the broader economy has been demonstrated by the global financial crisis of 2007-2011, which began in the US housing market. It is essential therefore that governments, central banks and market participants are kept well informed of trends and fluctuations in house prices. In Europe, Eurostat - the statistical institute of the European Union (EU) - has required since 2012 (see Eurostat, 2017) that the national statistical institutes (NSIs) in all EU member countries compute official house price indices (HPIs). HPIs, however, can be highly sensitive to the method of construction, and this sensitivity can be a source of confusion amongst users (see Silver, 2015). In a European context it is also important that the HPIs of different countries are reasonably comparable, especially in the Eurozone where the HPIs are needed by the European Central Bank for its decisions on monetary policy, financial regulation, and the monitoring of financial stability.

The difficulty in measuring house price developments arises from every house being different both in terms of its physical characteristics and its location. HPIs need to take account of these quality differences. Otherwise, the price index will confound price changes and quality differences. The importance of these measurement problems has been recently recognized by the international community and the European Commission, Eurostat, the UN, ILO, OECD, World Bank and IMF together commissioned a Handbook on Residential Property Price Indices (RPPIs) that was completed in 2013 (see Eurostat, 2013).

Hedonic methods - which express house prices as a function of a vector of characteristics - are ideally suited for constructing quality-adjusted HPIs (see Diewert, 2010; Hill, 2013). Eurostat recommends that the HPI should be computed using a hedonic approach, but has not provided guidance to NSIs as to which hedonic method should be used. As a result, different countries have adopted different methods. In total six different methods are being used:

(i) Repricing: used by Austria, Belgium, Finland, Hungary, Italy, Latvia, Luxembourg, Norway, Slovenia;

(ii) Average characteristics: used by Romania, Spain;

(iii) Hedonic imputation: used by Germany, UK; (iv) Rolling time dummy (RTD): used by Croatia, Cyprus, France, Ireland, Portugal;

(v) Stratified median (or mix-adjusted median): used by Bulgaria, Czech Republic, Estonia, Iceland, Lithuania, Poland, Slovakia;

(vi) Sales Price Appraisal Ratio (SPAR): used by Denmark, the Netherlands, and Sweden.

The sources for the methods used by each country are listed in Online complement $\mathrm{C} 1$. The first four methods are hedonic. Method (v) by averaging medians across strata provides some partial quality adjustment, although not to the same extent as a hedonic method. Method (vi) combines actual prices with expert valuations (see Haan et al., 2008).

For each method, the taxonomy can be further refined, in that two countries using the same basic method in some cases differ slightly in the way it is formulated. For example, with regard to the RTD method, some countries use a two quarter rolling window while others use a four or five quarter window, while with the repricing method countries differ in the frequency with which the reference characteristics shadow prices are updated.

Our objective here is to evaluate the theoretical and empirical properties of the methods (i), (ii), (iii), (iv) and (v) used by NSIs in Europe to compute their HPIs. We do not consider method (vi) - the SPAR method - since for our data sets we do not have access to any expert valuations. Of particular concern is the comparability of the HPIs across countries when computed using different methods.

We show that the underlying structures of the repricing, average characteristics, and hedonic imputation methods share some common features. The RTD method is somewhat different in its approach.

Empirically we compare the hedonic methods and stratified medians using detailed micro-level data for Sydney and Tokyo. These data sets were chosen since together they contain about 867,000 actual housing transactions, and cover quite long time spans. The Sydney data covers 11 years, while the Tokyo data covers 30 years. When comparing hedonic methods, it is important to have a sufficiently long time series, since problems of drift or bias may only emerge over these kinds of time horizons. To understand how these hedonic methods perform in practice 
it is important that they are compared using real housing data sets, rather than just simulated data. Also, by evaluating EU methods using non-EU data we provide an independent check on method selection.

The empirical comparisons have two main objectives. The first is to establish how sensitive the HPI is to the choice of hedonic method. The second is to see whether any of the hedonic methods (computed on a quarterly basis) behave in anomalous ways, particularly over longer time horizons (e.g., 10+ years). This is potentially a concern especially for the widely used repricing method, which extrapolates to later periods using the estimated characteristic shadow prices of the base period.

The repricing method, when updated at least every five years, performs quite well on our datasets. The biggest surprise is that the Paasche and Laspeyres versions of the hedonic double imputation method exhibit substantial drift in the Sydney apartment dataset. Some drift is also observed in the Tokyo apartment dataset. Fortunately, no NSI in Europe is using either of these methods. The Törnqvist version of the hedonic double imputation method, used by Germany, is not affected by drift.

Eurostat recommends that each NSI compute separate hedonic indices for houses and apartments. We are able to do this for Sydney, but not for Tokyo, since almost all the transactions in the latter are for apartments. Furthermore, indices specifically for new housing are needed for the owner occupied housing price index (OOHI) which is being used on an experimental basis in the Harmonized Index of Consumer Prices (HICP) (see Eurostat, 2017). The age of dwellings is included as a characteristic in the Tokyo data set but not in the Sydney data set. Hence we are able to compute an HPI for new dwellings for Tokyo, but not for Sydney. Our findings for Tokyo in this regard have important implications for HPIs, OOHIs, and the HICP in Europe.

The remainder of the paper is structured as follows. The next section explains the theoretical properties of the hedonic methods used by NSIs in Europe to compute their HPIs. After that the hedonic methods are compared empirically using data for Sydney and Tokyo. Our main findings are then summarized in the conclusion.

\section{Some Alternative Methods for Constructing Hedonic House Price Indices (HPIs)}

All the methods considered here are formulated to be compatible with Eurostat guidelines. In other contexts, these methods could be structured in slightly different ways.

\section{Repricing method}

The repricing method is currently the most widely used hedonic method for computing the HPI in Europe. It is used by the NSIs of Austria, Belgium, Finland, Hungary, Italy, Latvia, Luxembourg, Norway, and Slovenia.

The repricing method begins by estimating a semilog hedonic model using only the data of year 1 . The hedonic model can be written as follows:

$\ln p_{(1, q), h}=\sum_{c=1}^{C} \beta_{1, c} z_{(1, q), h, c}+\varepsilon_{(1, q), h}$

where $z_{(l, q), h, c}$ is the level of characteristic $c$ in dwelling $h$ sold in year 1 , quarter $q$. Examples of characteristics include property type (e.g., house or apartment), number of bedrooms, and land area. Also, $\beta_{1, c}$ denotes the shadow price on characteristic $c$ in year 1 , and $\varepsilon$ is a random error term.

The objective in (1) is to estimate the characteristic shadow prices $\beta_{1, c}$. These shadow prices are computed using the whole year's data.

As it is typically applied in the HPI, the repricing method compares one quarter $(t, q-1)$ with the next quarter $(t, q)$ using the base year's shadow price vector $\hat{\beta}_{1}$.

The repricing price index formula consists of two components: a quality unadjusted price index (QUPI) and a quality adjustment factor (QAF). The QUPI is the ratio of the geometric mean prices in both periods $(t, q-1)$ and $(t, q)$, computed as follows:

$\operatorname{QUPI} I_{(t, q),(t, q-1)}=\frac{\tilde{p}_{(t, q)}}{\tilde{p}_{(t, q-1)}}$

where $\tilde{p}_{(t, q-1)}$ and $\tilde{p}_{(t, q)}$ denote, respectively, the geometric mean price of dwellings sold in year-quarter $(t, q-1)$ and year-quarter $(t, q)$. 
$\tilde{p}_{(t, q-1)}=\prod_{h}^{H_{(t, q-1)}}\left(p_{(t, q-1), h}\right)^{1 / H_{(t, q-1)}}$

$\tilde{p}_{(t, q)}=\prod_{h}^{H_{(t, q)}}\left(p_{(t, q), h}\right)^{1 / H_{(t, q)}}$

where $H_{(t, q-1)}$ and $H_{(t, q)}$ denote the number of properties sold in $(t, q-1)$ and $(t, q)$ respectively. Arithmetic means could be used instead. However, geometric means have the advantage of being more compatible with a semi-log regression model.

The next step is to compute a quality adjustment factor (QAF). This is done by using shadow prices of year 1 as a point of reference to compare quality of the average dwelling sold in periods $(t, q-1)$, and $(t, q)$. The formula of the quality adjustment factor is as follows:

$Q A F_{(t, q-1),(t, q)}=\frac{\exp \left(\sum_{c=1}^{C} \hat{\beta}_{1, c} \bar{z}_{(t, q), c}\right)}{\exp \left(\sum_{c=1}^{C} \hat{\beta}_{1, c} \bar{z}_{(t, q-1), c}\right)}$,

where

$$
\begin{aligned}
& \bar{z}_{(t, q-1), c}=\frac{1}{H_{(t, q-1)}} \sum_{h=1}^{H_{(t, q-1)}} z_{(t, q-1), h, c}, \\
& \bar{z}_{(t, q), c}=\frac{1}{H_{(t, q)}} \sum_{h=1}^{H_{(t, q)}} z_{(t, q), h, c},
\end{aligned}
$$

denote the average basket of the characteristic $c$ of periods $(t, q-1)$ and $(t, q)$, respectively, computed using the arithmetic mean formula. In the case of dummy variables, such as postcodes, the average measures the proportion of transactions that feature that postcode. For example, if 1 percent of the transactions occur in postcode 1 , then the average basket for postcode 1 equals 0.01 .

The repricing price index is now obtained by dividing the quality-unadjusted index (QUPI) in (2) by the quality adjustment factor (QAF) in (4) as follows:

$$
\begin{aligned}
\frac{P_{(t, q)}}{P_{(t, q-1)}} & =\frac{\operatorname{QUPI}_{(t, q),(t, q-1)}}{Q A F_{(t, q-1),(t, q)}}=\frac{\tilde{p}_{(t, q)}}{\tilde{p}_{(t, q-1)}} / \frac{\exp \left(\sum_{c=1}^{C} \hat{\beta}_{1, c} \bar{z}_{(t, q), c}\right)}{\exp \left(\sum_{c=1}^{C} \hat{\beta}_{1, c} \bar{z}_{(t, q-1), c}\right)} \\
& =\frac{\tilde{p}_{(t, q)}}{\tilde{p}_{(t, q-1)}} / \frac{Q_{1,(t, q)}^{L}}{Q_{1,(t, q-1)}^{L}}
\end{aligned}
$$

where $Q_{1,(t, q)}^{L}$ denotes a Laspeyres quantity index between year 1 and quarter $(t, q)$. It can be seen that the QAF can be rewritten as a ratio of Laspeyres indices as follows:

$$
\begin{aligned}
Q A F_{(t, q-1),(t, q)} & =\frac{\exp \left(\sum_{c=1}^{C} \hat{\beta}_{1, c} \bar{z}_{(t, q), c}\right)}{\exp \left(\sum_{c=1}^{C} \hat{\beta}_{1, c} \bar{z}_{1, c}\right)} \\
& / \frac{\exp \left(\sum_{c=1}^{C} \hat{\beta}_{1, c} \bar{z}_{(t, q-1), c}\right)}{\exp \left(\sum_{c=1}^{C} \hat{\beta}_{1, c} \bar{z}_{1, c}\right)}=\frac{Q_{1,(t, q)}^{L}}{Q_{1,(t, q-1)}^{L}} .
\end{aligned}
$$

More generally, relative to the first quarter in the data set $(1,1)$, the price index for period $(t, q)$ is calculated as follows:

$$
\begin{aligned}
\frac{P_{(t, q)}}{P_{(1,1)}} & =\frac{\tilde{p}_{(t, q)}}{\tilde{p}_{(1,1)}} / \frac{\exp \left(\sum_{c=1}^{C} \hat{\beta}_{1, c} \bar{z}_{(t, q), c}\right)}{\exp \left(\sum_{c=1}^{C} \hat{\beta}_{1, c} \bar{z}_{(1,1), c}\right)} \\
& =\frac{\tilde{p}_{(t, q)}}{\tilde{p}_{(1,1)}} / \frac{Q_{1,(t, q)}^{L}}{Q_{1,(1,1)}^{L}},
\end{aligned}
$$

where $\tilde{p}$ again denotes a geometric mean price as defined in (3). An interesting feature of the repricing method is that it only requires the hedonic model to be estimated once (in the base year). This is perhaps one reason why it has proved popular with NSIs.

The base year under the repricing method should be updated at regular time intervals. For example, Italy and Luxembourg update the base year every year. However, not all the NSIs using the repricing method update this frequently. Indeed this is the key problem with the repricing method. It provides a temptation to get lazy and not update the base year. In the empirical comparisons that follow based on Sydney and Tokyo data, we consider two versions of the repricing method. The first never updates the base year, while the second updates it every five years. Our empirical results show that failure to update the base year can lead to drift in the index.

\section{Average characteristics method}

The average characteristics method and the hedonic imputation method both begin by estimating the following semilog hedonic model separately for each period. For example, for periods $(t, q-1)$ and $(t, q)$, the regression model takes the following forms:

$$
\begin{aligned}
& \ln p_{(t, q-1), h}=\sum_{c=1}^{C} \beta_{(t, q-1), c} z_{(t, q-1), h, c}+\varepsilon_{(t, q-1), h} \\
& \ln p_{(t, q), h}=\sum_{c=1}^{C} \beta_{(t, q), c} z_{(t, q), h, c}+\varepsilon_{(t, q), h}
\end{aligned}
$$

where $h$ indexes the dwelling transactions in period $(t, q), p_{(t, q), h}$ the transaction price, and $z_{(t, q), h, c}$ is the level of characteristic $c$ in dwelling $h$. Unlike under the repricing method, the estimated shadow prices on the characteristics, 
$\beta_{(t, q), c}$, are specific to period $(t, q)$ and are updated every period.

The next step is to construct an average basket of characteristics. The hedonic method then measures the change in the imputed price of the average dwelling over time. The version used by European NSIs computes an average basket $\bar{z}_{t, c}$ based on a whole year's data calculated using the arithmetic mean formula. The price index between two adjacent quarters in the same year therefore is now calculated as follows:

$$
\begin{aligned}
\frac{P_{(t, q)}}{P_{(t, q-1)}} & =\frac{\exp \left(\sum_{c=1}^{C} \hat{\beta}_{(t, q), c} \bar{z}_{t-1, c}\right)}{\exp \left(\sum_{c=1}^{C} \hat{\beta}_{(t, q-1), c} \bar{z}_{t-1, c}\right)} \\
& =\frac{\exp \left(\sum_{c=1}^{C} \hat{\beta}_{(t, q), c} \bar{z}_{t-1, c}\right)}{\exp \left(\sum_{c=1}^{C} \hat{\beta}_{t-1, c} \bar{z}_{t-1, c}\right)} / \frac{\exp \left(\sum_{c=1}^{C} \hat{\beta}_{(t, q-1), c} \bar{z}_{t-1, c}\right)}{\exp \left(\sum_{c=1}^{C} \hat{\beta}_{t-1, c} \bar{z}_{t-1, c}\right)} \\
& =\frac{P_{t-1,(t, q)}^{L}}{P_{t-1,(t, q-1)}^{L}},
\end{aligned}
$$

where $P_{t-1,(t, q)}^{L}$ denotes a Laspeyres price index between periods $\mathrm{t}-1$ and $(t, q)$. From the first line of (9) we can see that the overall price index can be written as a Lowe index (i.e., it is a fixed basket index where the time period of the basket is not the same as that of the two time periods being compared). The second line of (9) shows that the overall price can also be expressed as the ratio of two Laspeyres price indices.

Once a year, the average basket of characteristics is updated. This can be done at the end of the year, once all the data for that year are available. The price index between the fourth quarter in one year and the first quarter in the next year therefore is calculated as follows:

$$
\begin{aligned}
\frac{P_{(t+1,1)}}{P_{(t+4)}} & =\frac{\exp \left(\sum_{c=1}^{C} \hat{\beta}_{(t+1,1), c} \bar{z}_{t, c}\right)}{\exp \left(\sum_{c=1}^{C} \hat{\beta}_{(t, 4), c} \bar{z}_{t, c}\right)} \\
& =\frac{\exp \left(\sum_{c=1}^{C} \hat{\beta}_{(t+1,1), c} \bar{z}_{t, c}\right)}{\exp \left(\sum_{c=1}^{C} \hat{\beta}_{t, c} \bar{z}_{t, c}\right)} / \frac{\exp \left(\sum_{c=1}^{C} \hat{\beta}_{(t, 4), c} \bar{z}_{t, c}\right)}{\exp \left(\sum_{c=1}^{C} \hat{\beta}_{t, c} \bar{z}_{t, c}\right)} \\
& =\frac{P_{t,(t+1,1)}^{L}}{P_{t,(t, 4)}^{L}}
\end{aligned}
$$

Again the overall price index can be expressed as the ratio of two Laspeyres price indices.

Relative to the first quarter in the data set $(1,1)$, the price index for period $(t+1,1)$ is calculated as follows:

$$
\begin{aligned}
\frac{P_{(t+1,1)}}{P_{(1,1)}}= & \frac{P_{0,(1,2)}^{L}}{P_{0,(1,1)}^{L}} \times \frac{P_{0,(1,3)}^{L}}{P_{0,(1,2)}^{L}} \times \frac{P_{0,(1,4)}^{L}}{P_{0,(1,3)}^{L}} \times \frac{P_{1,(2,1)}^{L}}{P_{1,(1,4)}^{L}} \ldots \\
& \times \frac{P_{t-1,(t, 4)}^{L}}{P_{t-1,(t, 3)}^{L}} \times \frac{P_{t,(t+1,1)}^{L}}{P_{t,(t, 4)}^{L}} .
\end{aligned}
$$

It turns out that the repricing method can be represented as a fixed base average characteristics method. Suppose, as with the average characteristics and hedonic imputation methods, the hedonic model is estimated for a single quarter. The imputed errors from the semilog hedonic model for quarter $s$ can then be written as follows:

$\hat{\boldsymbol{\varepsilon}}_{s h}=\ln p_{s h}-\sum_{c=1}^{C} \hat{\boldsymbol{\beta}}_{s, c} z_{s h c}$.

By construction under OLS, $\sum_{h=1}^{H_{1}} \hat{\varepsilon}_{s h}=0$. Hence

$\sum_{h=1}^{H_{s}}\left[\ln p_{s h}-\sum_{c=1}^{C} \hat{\beta}_{s, c} z_{s h c}\right]=0$

which in turn implies that the geometric mean price takes the following form:

$\tilde{p}_{s}=\exp \left(\sum_{c=1}^{c} \hat{\beta}_{s, c} \bar{z}_{s c}\right)$.

Substituting this expression into the repricing formula (with shadow prices estimated using only the first quarter not the first year) yields the following:

$$
\begin{aligned}
\frac{P_{(t, q)}}{P_{(1,1)}} & =\frac{\tilde{p}_{(t, q)}}{\tilde{p}_{(t, q-1)}} / \frac{\exp \left(\sum_{c=1}^{C} \hat{\beta}_{(1,1), c} \bar{z}_{(t, q), c}\right)}{\exp \left(\sum_{c=1}^{C} \hat{\beta}_{(1,1), c} \bar{z}_{(t, q-1), c}\right)} \\
& =\frac{\exp \left(\sum_{c=1}^{C} \hat{\beta}_{(t, q), c} \bar{z}_{(t, q), c}\right)}{\exp \left(\sum_{c=1}^{C} \hat{\beta}_{(t, q-1), c} \bar{z}_{(t, q-1), c}\right)} / \frac{\exp \left(\sum_{c=1}^{C} \hat{\beta}_{(1,1), c} \bar{z}_{(t, q), c}\right)}{\exp \left(\sum_{c=1}^{C} \hat{\beta}_{(1,1), c} \bar{z}_{(t, q-1), c}\right)} \\
& =\frac{\exp \left(\sum_{c=1}^{C} \hat{\beta}_{(t, q), c} \bar{z}_{(t, q), c}\right)}{\exp \left(\sum_{c=1}^{C} \hat{\beta}_{(1,1), c} \bar{z}_{(t, q), c}\right)} / \frac{\exp \left(\sum_{c=1}^{C} \hat{\beta}_{(t, q-1), c} \bar{z}_{(t, q-1), c}\right)}{\exp \left(\sum_{c=1}^{C} \hat{\beta}_{(1,1), c} \bar{z}_{(t, q-1), c}\right)} \\
& =\frac{P_{(1,1),(t, q)}^{P}}{P_{(1,1),(t, q-1)}^{P}},
\end{aligned}
$$

where $P_{(1,1),(t, q)}^{P}$ denotes a Paasche price index between periods $(1,1)$ and $(t, q)$. Hence the repricing method can also be interpreted as an average characteristics method that uses the Paasche price index formula.

As far as we are aware this is a new result in the literature. It is also somewhat counterintuitive that this version of the repricing method can be written as a ratio of Paasche price indices, since these price indices require the estimated characteristic shadow prices of the periods $(t, q-1)$ and $(t, q)$. By contrast, as can be seen from the first line of (11), in practice all that is needed are the characteristic shadow prices of period $(1,1)$.

\section{Hedonic imputation method}

Once a hedonic model has been estimated, it allows one to ask counterfactual questions 
such as what a particular dwelling actually sold in say period $t$ would have sold for instead in period $t+1$. Using this approach, the hedonic imputation method constructs price relatives measuring how the price has changed from period $t$ to $t+1$ for every dwelling sold in period $t$, and likewise for very dwelling sold in period $t+1$. These price relatives can then be averaged across dwellings to obtained the overall price index. Here we will present two slightly different variants of the hedonic imputation method. The first is used by the UK NSI and the second by the German NSI. Both versions use the same estimated hedonic model as the average characteristics method in (8) to impute prices for each dwelling. For example, let $\hat{p}_{(t, q), h}\left(z_{t-1, h}\right)$ denote an imputed price in period $(t, q)$ for dwelling $h$ which was actually sold one year earlier in period $(t-1, q)$. The UK version is a chained Lowe index where the reference basket is all the dwellings sold in the previous year. When comparing two quarters in the same year (here $t$ ), the formula is as follows:

$$
\frac{P_{(t, q)}}{P_{(t, q-1)}}=\prod_{h=1}^{H_{t-1}}\left[\frac{\hat{p}_{(t, q), h}\left(z_{t-1, h}\right)}{\hat{p}_{(t, q-1), h}\left(z_{t-1, h}\right)}\right]^{1 / H_{t-1}},
$$

where $H_{t-1}$ denotes the number of properties sold in year $t-1$. When the $4^{\text {th }}$ quarter is compared with the $1^{\text {st }}$ quarter of the next year the references basket is updated as follows:

$$
\frac{P_{(t+1,1)}}{P_{(t, 4)}}=\prod_{h=1}^{H_{t}}\left[\frac{\hat{p}_{(t+1,1), h}\left(z_{t, h}\right)}{\hat{p}_{(t, 4), h}\left(z_{t, h}\right)}\right]^{1 / H_{t}} .
$$

When the underlying hedonic model has a semilog functional form, the UK method is in fact identical to the average characteristics method described above. This duality between the average characteristics method and the hedonic imputation method is explored in more detail in Hill and Melser (2008). In the case of the UK method, the duality can be demonstrated as follows:

$$
\begin{aligned}
\frac{P_{(t, q)}}{P_{(t, q-1)}} & =\prod_{h=1}^{H_{t-1}}\left[\frac{\hat{p}_{(t, q), h}\left(z_{t-1, h}\right)}{\hat{p}_{(t, q-1), h}\left(z_{t-1, h}\right)}\right]^{1 / H_{t-1}} \\
& =\prod_{h=1}^{H_{t-1}}\left[\frac{\sum_{c=1}^{C} \exp \left(\hat{\beta}_{(t, q)} z_{t-1, h}\right)}{\sum_{c=1}^{C} \exp \left(\hat{\beta}_{(t, q-1)} z_{t-1, h}\right)}\right]^{1 / H_{t-1}} \\
& =\frac{\frac{1}{H_{t-1}} \sum_{c=1}^{C} \sum_{h=1}^{H_{t-1}} \exp \left(\hat{\beta}_{(t, q)} z_{t-1, h}\right)}{\frac{1}{H_{t-1}} \sum_{c=1}^{C} \sum_{h=1}^{H_{t-1}} \exp \left(\hat{\beta}_{(t, q-1)} z_{t-1, h}\right)} \\
& =\frac{\exp \sum_{c=1}^{C} \hat{\beta}_{(t, q), c} \bar{z}_{t-1, c}}{\exp \sum_{c=1}^{C} \hat{\beta}_{(t, q-1), c} \bar{z}_{t-1, c}}=\frac{P_{t-1,(t, q)}^{L}}{P_{t-1,(t, q-1)}^{L}} .
\end{aligned}
$$

In an analogous way it can be shown that:

$$
\begin{aligned}
\frac{P_{(t+1,1)}}{P_{(t, 4)}} & =\prod_{h=1}^{H_{t}}\left[\frac{\hat{p}_{(t+1,1), h}\left(z_{t, h}\right)}{\hat{p}_{(t, 4), h}\left(z_{t, h}\right)}\right]^{1 / H_{t}} \\
& =\frac{\exp \sum_{c=1}^{C} \hat{\beta}_{(t+1,1), c} \bar{z}_{t, c}}{\exp \sum_{c=1}^{C} \hat{\beta}_{(t, 4), c} \bar{z}_{t, c}}=\frac{P_{t,(t+1,1)}^{L}}{P_{t,(t, 4)}^{L}} .
\end{aligned}
$$

The German version by contrast uses a Törnqvist-type formula (i.e., the geometric mean of geometric-Laspeyres and geometric-Paasche-type formulas) defined as follows ${ }^{1}$ :

Geometric Laspeyres (GL):

$\frac{P_{(t, q)}}{P_{(t, q-1)}}=\left[\prod_{h=1}^{H_{(t, q-1)}} \frac{\hat{p}_{(t, q), h}\left(z_{(t, q-1), h}\right)}{\hat{p}_{(t, q-1), h}\left(z_{(t, q-1), h}\right)}\right]^{1 / H_{(t, q-1)}}$

Geometric Paasche (GP):

$\frac{P_{(t, q)}}{P_{(t, q-1)}}=\left[\prod_{h=1}^{H_{(t, q)}} \frac{\hat{p}_{(t, q), h}\left(z_{(t, q), h}\right)}{\hat{p}_{(t, q-1), h}\left(z_{(t, q), h}\right)}\right]^{1 / H_{(t, q)}}$

Törnqvist:

$\frac{P_{(t, q)}}{P_{(t, q-1)}}=\left\{\begin{array}{l}{\left[\prod_{h=1}^{H_{(t, q-1)}} \frac{\hat{p}_{(t, q), h}\left(z_{(t, q-1), h}\right)}{\hat{p}_{(t, q-1), h}\left(z_{(t, q-1), h}\right)}\right]^{1 / H_{(t, q-1)}}} \\ {\left[\begin{array}{l}\left.\prod_{h=1}^{H_{(t, q)}} \frac{\hat{p}_{(t, q), h}\left(z_{(t, q), h}\right)}{\hat{p}_{(t, q-1), h}\left(z_{(t, q), h}\right)}\right]^{1 / H_{(t, q)}}\end{array}\right.}\end{array}\right\}$

Here it makes no difference whether we are comparing two quarters in the same year or the last quarter in one year with the first quarter in the next.

When the underlying hedonic model is semilog, the geometric-Laspeyres (GL), geometric-Paasche (GP), and Törnqvist hedonic imputation indices can be represented as average characteristic methods as follows:

$$
\begin{aligned}
\mathrm{GL}: & {\left[\prod_{h=1}^{H_{(t, q-1)}} \frac{\hat{p}_{(t, q), h}\left(z_{(t, q-1), h}\right)}{\hat{p}_{(t, q-1), h}\left(z_{(t, q-1), h}\right)}\right]^{1 / H_{(t, q-1)}} } \\
& =\frac{\exp \left(\sum_{c=1}^{C} \hat{\beta}_{(t, q), c} \bar{z}_{(t, q-1), c}\right)}{\exp \left(\sum_{c=1}^{C} \hat{\beta}_{(t, q-1), c} \bar{z}_{(t, q-1), c}\right)}=P_{(t, q-1),(t, q)}^{L}
\end{aligned}
$$




$$
\text { GP: } \begin{aligned}
\frac{P_{(t, q)}}{P_{(t, q-1)}} & =\left[\prod_{h=1}^{H_{(t, q)}} \frac{\hat{p}_{(t, q), h}\left(z_{(t, q), h}\right)}{\hat{p}_{(t, q-1), h}\left(z_{(t, q), h}\right)}\right]^{1 / H_{(t, q)}} \\
& =\frac{\exp \left(\sum_{c=1}^{C} \hat{\beta}_{(t, q), c} \bar{z}_{(t, q), c}\right)}{\exp \left(\sum_{c=1}^{C} \hat{\beta}_{(t, q-1), c} \bar{z}_{(t, q), c}\right)}=P_{(t, q-1),(t, q)}^{P}
\end{aligned}
$$

Törnqvist:

$$
\begin{aligned}
& \left\{\left[\prod_{h=1}^{H_{(t,-1)}} \frac{\hat{p}_{(t, q), h}\left(z_{(t, q-1), h}\right)}{\hat{p}_{(t, q-1), h}\left(z_{(t, q-1), h}\right)}\right]^{1 / H_{(t, q-1)}}\right. \\
& \left.\quad\left[\prod_{h=1}^{H_{(t, q)}} \frac{\hat{p}_{(t, q), h}\left(z_{(t, q), h}\right)}{\hat{p}_{(t, q-1), h}\left(z_{(t, q), h}\right)}\right]^{1 / H_{(t, q)}}\right\}^{1 / 2} \\
& \quad=\left\{\frac{\exp \left[\sum_{c=1}^{C} \hat{\beta}_{(t, q), c}\left(\bar{z}_{(t, q-1), c}-\bar{z}_{(t, q), c}\right)\right]}{\exp \left[\sum_{c=1}^{C} \hat{\beta}_{(t, q-1), c}\left(\bar{z}_{(t, q-1), c}-\bar{z}_{(t, q), c}\right)\right]}\right\} \\
& \quad=\left(P_{(t, q-1),(t, q)}^{L} \times P_{(t, q-1),(t, q)}^{P}\right)^{1 / 2}=P_{(t, q-1),(t, q)}^{F}
\end{aligned}
$$

where $P_{(t, q-1)(t, q)}^{F}$ denotes a Fisher price index comparison between periods $(t, q-1)$ and $(t, q)$.

Relative to the first quarter in the data set $(1,1)$, the price index for period $(t+1,1)$ is calculated as follows:

$$
\frac{P_{(t+1,1)}}{P_{(1,1)}}=P_{(1,1),(1,2)}^{F} \times P_{(1,2),(1,3)}^{F} \times \ldots \times P_{(t+1,1),(t, 4)}^{F} .
$$

In practice this means that the UK method is essentially equivalent to the average characteristic method used by Romania and Spain. While Germany's method can also be represented as an average characteristics method, it is the only country in the EU that uses the Törnqvist formula to construct its HPI.

\section{Rolling time dummy method}

The Rolling Time Dummy (RTD) method, as proposed by Shimizu et al. (2010) (see also O'Hanlon, 2011), is used by a number of NSIs in Europe. RTD is a variant on the widely used time-dummy hedonic method. The relationship between time-dummy and hedonic imputations methods is explored by Diewert et al. (2009) and Haan (2010). When discussing the RTD method we use a slightly different notation than we have used thus far in this paper. We refer simply to periods denoted by $s$ and $t$, without distinguishing which year and quarter they are in. The RTD method begins by estimating the following hedonic model over a time window of $k+1$ periods starting with period $s$ :

$$
\ln p_{u h}=\sum_{c=1}^{C} \beta_{(s, s+k), c} Z_{u h c}+\sum_{c=1}^{C} \delta_{i} D_{i h}+\varepsilon_{u h}
$$

where $h$ now indices the dwelling transactions in periods $s, \ldots, S+k$, and $D_{i h}$ is a dummy variable that equals 1 when $u=i$ is the period in which the dwelling sold, and zero otherwise. Now the characteristic shadow prices for each period in the window are assumed to be equal (i.e., $\beta_{s, c}=\beta_{s+1, c}=\cdots=\beta_{s+k, c}=\beta_{(s, s+k), c}$ ). The RTD method then moves the window forward one period, and re-estimates the model.

The RTD method derives the price index comparing period $t+k-1$ to period $t+k$ as follows:

$\frac{P_{t+k}}{P_{t+k-1}}=\frac{\exp \left(\hat{\delta}_{t+k}^{t}\right)}{\exp \left(\hat{\boldsymbol{\delta}}_{t+k-1}^{t}\right)}$

A superscript $t$ is included on the estimated $\delta$ coefficients to indicate that they obtained from the hedonic model with period $t$ as the base. The hedonic model with period $t$ as the base is only used to compute the change in dwelling prices from period $t+k-1$ to period $t+k$. The window is then rolled forward one period and the hedonic model is re-estimated. The change in dwelling prices from period $t+k$ to period $t+k+1$ is now computed as follows:

$\frac{P_{t+k+1}}{P_{t+k}}=\frac{\exp \left(\hat{\delta}_{t+k+1}^{t+1}\right)}{\exp \left(\hat{\delta}_{t+k}^{t+1}\right)}$

where now the base period in the hedonic model is period $t+1$. The price index over multiple periods is computed by chaining these bilateral comparisons together as follows:

$$
\frac{P_{t+k+1}}{P_{t}}=\frac{\exp \left(\hat{\delta}_{t+1}^{t-k}\right)}{\exp \left(\hat{\delta}_{t}^{t-k}\right)} \frac{\exp \left(\hat{\delta}_{t+2}^{t-k+1}\right)}{\exp \left(\hat{\delta}_{t+1}^{t-k+1}\right)} \cdots \frac{\exp \left(\hat{\delta}_{t+k+1}^{t+1}\right)}{\exp \left(\hat{\delta}_{t+k}^{t+1}\right)} .
$$

A trade-off exists when choosing the window length. A longer window length increases the sample size and robustness of the price index. On the other hand, a longer window acts to smooth the price signal, providing a less timely and market relevant indicator. The optimal window length will differ depending on the datset. When data points are scarce, RTD4Q and RTD5Q (i.e., 4 or 5 quarter windows) are recommended over RTD2Q (i.e., a 2 quarter window). NSIs in Europe using the RTD method have selected the following window lengths: France $=2$, Cyprus $=4$, Ireland $=5$, Portugal $=2$, Croatia $=4$.

An important feature of the RTD method is that once a price change $P_{t+k} / P_{t+k-1}$ has been computed it is never revised. Hence when data for a new period $t+k+1$ becomes available, the price indices $P_{t}, P_{t+1}, \ldots, P_{t+k}$ are already fixed. The sole objective when estimating the 
hedonic model inclusive of data from period $t^{t+k+1}$ is to compute $P_{t+k+1}$, irrespective of how many periods are included in the hedonic model. More generally, this property of never being revised is recommended by Eurostat (2017) and is shared by all the hedonic price indices considered here. To be clear, by nonrevisability we mean that simply adding a new period of data does not change the results for earlier periods. If new data become available for earlier periods, this is another matter. In this case, it may be desirable to revise the existing index.

\section{Stratification and stratified medians}

The RPPI Manual published by Eurostat (2013) recommends that the data should be divided into broad strata by region and building type, and then hedonic methods should be applied separately to each stratum. The results are then averaged across strata typically using the arithmetic mean formula. One issue that arises is whether the arithmetic mean formula should be weighted by the number of transactions or the housing stock in each stratum. Weighting by the housing stock in each stratum might be preferable for macroeconomics analysis, when such stock weights are available. Failing that, weighting by number of transactions is probably preferable to equal weighting.

Sometimes however insufficient data or resources are available to compute hedonic indices. In such situations stratified medians are often used as a simpler and less reliable alternative to hedonic methods. The first step in computing a stratified (or mixadjusted) median index is to split the data set into strata. As with hedonic methods, the first split should be between houses and apartments. Each stratum should be further subdivided based on location, for example by province, county, district or postcode. When information on the physical characteristics of dwelling are available, splits can also be done based say on size (for example floor area less than 80 square meters and greater than 80 square meters), or age (e.g., new and existing). In the empirical applications, after splitting houses and apartments, we focus on locational stratification based on postcodes and Residex regions for Sydney, and wards in Tokyo.

Once the strata have been constructed, the median price for each stratum is computed. These medians are then averaged separately for houses and apartments, typically using the arithmetic mean formula. Again the issue arises as to whether the average should be weighted by the number of transactions or the housing stock in each stratum.

With regard to computational complexity, a stratified median method lies somewhere in between a simple median method and a quality-adjusted hedonic method ${ }^{2}$. Averaging medians across strata reduces the noise in the index resulting from compositional changes in the median dwelling over time. While in principle more strata should imply better quality adjustment, this approach soon runs into the problem when the classification becomes finer that some of the strata may be empty in some periods (i.e., there are no transactions with that particular mix of characteristics). This imposes limits on how far stratified median methods can take the quality-adjustment process.

\section{Evaluations of the different methods for Sydney (2003-2014)}

\section{The Sydney data set}

We use a data set obtained from Australian Property Monitors that consists of prices and characteristics of houses and apartments sold in Sydney (Australia) for the years 2002-2014. Results are presented for the years 2003-2014. For some methods, data for 2002 are needed to compute the reference baskets used in 2003.

The functional form for our hedonic models is semilog. The explanatory characteristics for houses are as follows:

- the actual sale price;

- time of sale;

- property type (i.e., detached or semi);

- number of bedrooms;

- number of bathrooms;

- land area;

- postcode (there are 202 postcodes in the data set).

For apartments we have the same set of characteristics. However, we drop the land area characteristic for apartments in our hedonic

2. The median price per square meter could be viewed as a highly restrictive version of a hedonic method. 
analysis since it refers to the whole strata, and we do not have any information on the number of apartments in the building. For a robust analysis it was necessary to remove some outliers. This is because there is a concentration of data entry errors in the tails, caused for example by the inclusion of erroneous extra zeroes. These extreme observations can distort the results. The exclusion criteria we applied are shown in Table 1. Complete data on all our hedonic characteristics are available for 380,414 house transactions. For apartments the corresponding figure is 250,005 .

\section{Summary of methods to be considered}

The methods that will be compared (of which the first ten are hedonic) are listed below:

1. Repricing (no updating of base year);

2. Repricing (base year updated every five years);

3. Repricing (base year updated every year);

4. Average characteristics;

5. Double imputation Geometric-Laspeyres;

6. Double imputation Geometric-Paasche;

7. Double imputation Törnqvist;

8. RTD (2 quarters);

9. RTD (4 quarters);

10. RTD (5 quarters);

\section{Stratified median.}

In the case of Sydney, price indices will be computed separately for houses and apartments. An overall HPI for Sydney could then be computed using the standard method for aggregating strata briefly discussed above and recommended in chapter 5 of the RPPI Manual (see Eurostat, 2013). For Tokyo only data for apartments are available. The age of dwellings is available for Tokyo but not for Sydney. So, for Tokyo we compute price indices for all apartments and for new apartments.
It is particularly important to determine how well the methods used by NSIs perform on a data set for new dwellings, since a price index for new dwellings is a key input into the experimental owner-occupied housing price index $(\mathrm{OOHI})$ in Europe. The OOHI is in turn being considered for inclusion in the harmonized index of consumer prices (HICP).

\section{House and apartment price indices for Sydney}

The house price indices (HPIs) for Sydney generated by the various methods discussed above are shown in Table C3-1 (in Online complement C3). Five of the series are graphed in Figure I. As is clear from Table C3-1 and Figure I, the HPI is quite robust to the choice of method. Over the whole sample period, depending on the choice of hedonic method, house prices rose by between 73.7 and 78.1 percent. The three repricing methods - RP1 which uses shadow prices from 2003, RP2 which updates the shadow prices every five years, and RP3 which updates the shadow prices every year - generate the lowest increase in house prices ${ }^{3}$. Also shown in Table C3-1 are stratified median results computed in two different ways. MIX-PC stratifies houses by postcodes of which there are 202 . MIX-RX stratifies by Residex region of which there are $16^{4}$.

The MIX-PC stratification is hence much finer than its MIX-RX counterpart. It is not surprising therefore that the MIX-PC index is less erratic and closer to the hedonic indices.

\footnotetext{
3. Examples of the estimated characteristic shadow prices from the hedonic models are provided for Sydney in 2003 and for Tokyo in 2002 in Online complement $\mathrm{C} 2$. It can be seen that most of the shadow prices are significantly different from zero at the 5 percent significance level, and the adjusted $R$-squared for are about 0.85

4. The Residex regions (with their constituent postcodes listed in brack ets) are as follows: Inner Sydney (2000 to 2020), Eastern Suburbs (2021 to 2036), Inner West (2037 to 2059), Lower North Shore (2060 to 2069), Upper North Shore (2070 to 2087), Mosman-Cremorne (2088 to 2091), Manly-Warringah (2092 to 2109), North Western (2110 to 2126), Western Suburbs (2127 to 2145), Parramatta Hills (2146 to 2159), Fairfield-Liverpool (2160 to 2189), Canterbury-Bankstown (2190 to 2200), St George (2201 to 2223), Cronulla-Sutherland (2224 to 2249), Campbelltown (2552 to 2570), Penrith-Windsor (2740 to 2777).
}

Table 1

Criteria for removing outliers

\begin{tabular}{|l|c|c|c|c|}
\hline & Price (in dollars) & Bed & Bath & Area $\left(\mathrm{m}^{2}\right)$ \\
\hline Minimum Allowed & 100,000 & 1 & 1 & 100 \\
\hline Maximum Allowed & $4,000,000$ & 6 & 6 & 10,000 \\
\hline
\end{tabular}


The MIX-PC index rises by 82 percent while MIX-RX rises by 87 percent. The concern is not just that it rises faster than the hedonic indices, but also that it is more volatile, as can be seen from Figure I.

Volatility is an important issue. A higher level of volatility can indicate insufficient quality adjustment $^{5}$. Two measures of volatility are the root mean squared error (RMSE) and mean absolute deviation (MAD) stated in (26) and (27) for the case of year-on-year comparisons for the same quarter. Here we define both RSME and MAD in terms of deviations of $\log$ ratios.

$$
\begin{aligned}
& \text { RMSE }=\sqrt{\frac{1}{T-1} \sum_{t-1}^{T-1}\left[\ln \left(\frac{p_{(t+1, q)}}{p_{(t, q)}}\right)-\frac{1}{T-1} \ln \left(\frac{p_{(t, q)}}{p_{(1, q)}}\right)\right]^{2}} \\
& \mathrm{MAD}=\frac{1}{T-1} \sum_{t-1}^{T-1}\left|\ln \left(\frac{p_{(t+1, q)}}{p_{(t, q)}}\right)-\frac{1}{T-1} \ln \left(\frac{p_{(T, q)}}{p_{(1, q)}}\right)\right| \\
& \mathrm{MIN}=\operatorname{Min}_{1, \ldots, T-1}\left\{100\left[\left(\frac{p_{(t+1, q)}}{p_{(t, q)}}\right)-1\right]\right\} \\
& \operatorname{MAX}=\operatorname{Max}_{1, \ldots, T-1}\left\{100\left[\left(\frac{p_{(t+1, q)}}{p_{(t, q)}}\right)-1\right]\right\}
\end{aligned}
$$

RSME, MAD, MAX and MIN statistics for Sydney houses are given in Table 2. These statistics are computed both on a year-by-year and quarter-by-quarter basis. It can be seen in Table 2 that the stratified median indices are more volatile than the hedonic indices (especially in the quarter-on-quarter comparisons). This is to be expected since the stratified medians fail to fully adjust for changes in the quality of the median over time. For the same reason, the volatility of the MIX.PC stratified median is lower than that of MIX.RX. This is because the finer stratification of MIX.PC allows it to do a better job of quality adjusting the price index.

The results for apartments in Sydney shown in Figure II are also reasonably robust to the choice of method, when we restrict the comparison to the hedonic methods actually used by NSIs to compute the HPI. The measured cumulative rise in apartment prices for the hedonic methods ranges between 68.1 and 72.6 percent. The stratified median index MIX-RX, by contrast, rises by 80 percent.

5. However, one must be careful in this regard since in a volatile market a good price index should capture this volatility.

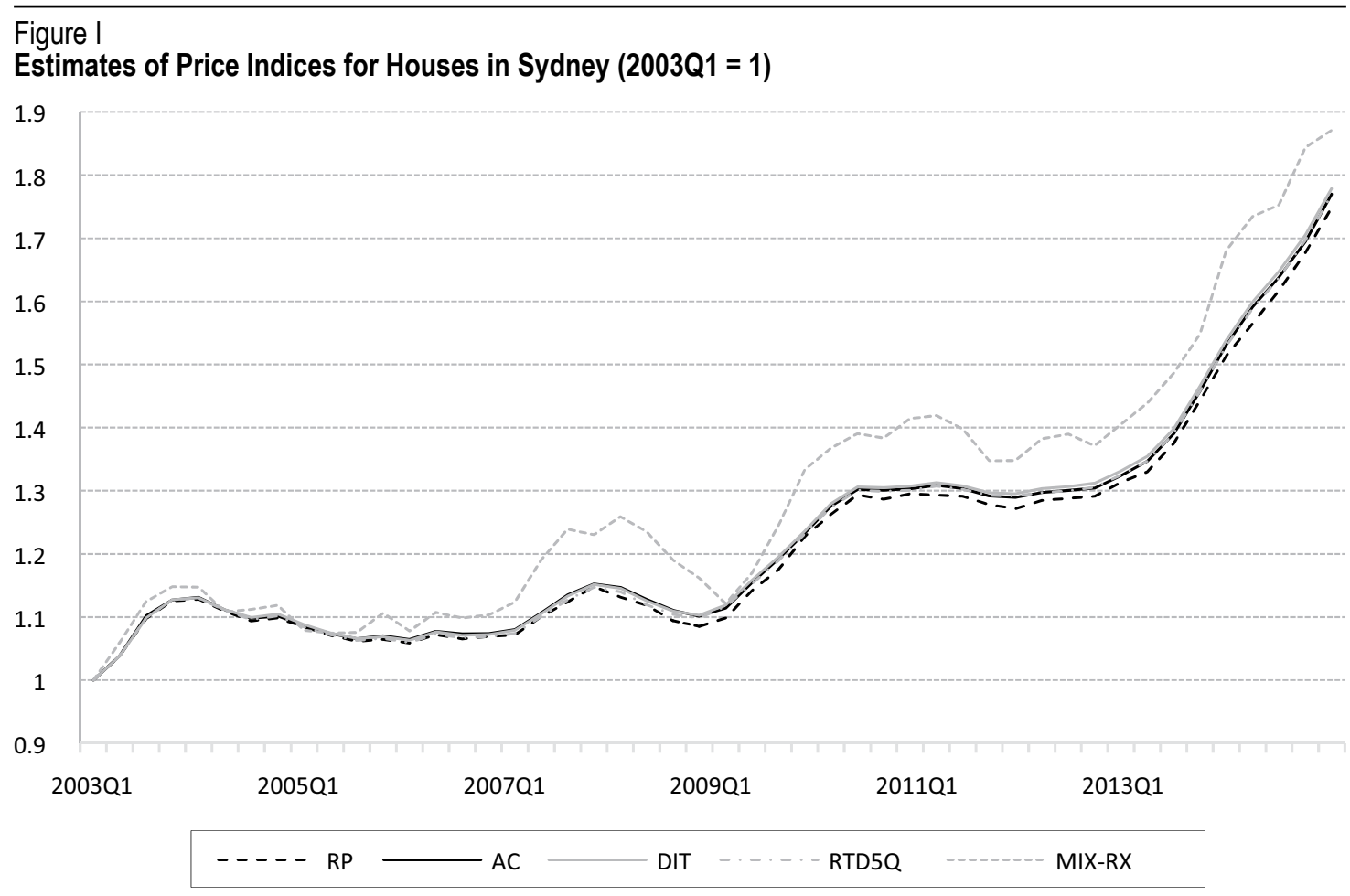

Note: Hedonic methods: RP = Repricing; $A C=$ Average characteristics; $D I T=$ Double imputation Törnqvist; RTD5Q = Rolling time dummy with five quarter window; Stratified median method: MIX-RX = Mix adjusted stratified by Residex region. Period: 2002-2014.

Coverage: Houses in Sydney, Australia.

Sources: Australian Property Monitors; authors' calculations. 
Table 2

Volatility of the House Price Indices in Sydney

\begin{tabular}{|c|c|c|c|c|c|c|c|c|c|c|c|c|}
\hline & RP1 & RP2 & RP3 & $A C$ & DIL & DIP & DIT & RTD2Q & RTD4Q & RTD5Q & MIX-PC & MIX-RX \\
\hline \multicolumn{13}{|c|}{ Year-on-Year (Q1) } \\
\hline RMSE & 0.068 & 0.065 & 0.066 & 0.068 & 0.067 & 0.066 & 0.067 & 0.067 & 0.066 & 0.066 & 0.086 & 0.096 \\
\hline MAD & 0.057 & 0.055 & 0.056 & 0.058 & 0.057 & 0.057 & 0.057 & 0.057 & 0.056 & 0.056 & 0.072 & 0.079 \\
\hline MIN & -3.90 & 3.90 & -3.93 & -3.96 & -3.69 & -3.79 & -3.74 & -3.76 & -3.95 & -4.03 & -6.31 & -10.95 \\
\hline MAX & 17.69 & 17.93 & 17.93 & 18.14 & 18.13 & 18.01 & 18.07 & 18.06 & 18.00 & 17.99 & 20.14 & 21.97 \\
\hline \multicolumn{13}{|c|}{ Year-on-Year (Q2) } \\
\hline RMSE & 0.057 & 0.056 & 0.056 & 0.056 & 0.056 & 0.055 & 0.056 & 0.056 & 0.056 & 0.056 & 0.068 & 0.069 \\
\hline MAD & 0.047 & 0.047 & 0.046 & 0.046 & 0.047 & 0.045 & 0.046 & 0.046 & 0.046 & 0.046 & 0.054 & 0.054 \\
\hline MIN & -3.47 & -3.47 & -3.56 & -3.36 & -3.36 & -3.25 & -3.30 & -3.31 & -3.40 & -3.46 & -4.28 & -5.29 \\
\hline MAX & 17.63 & 17.73 & 17.75 & 17.84 & 17.97 & 17.74 & 17.86 & 17.85 & 17.76 & 17.73 & 18.56 & 18.87 \\
\hline \multicolumn{13}{|c|}{ Year-on-Year (Q3) } \\
\hline RMSE & 0.058 & 0.057 & 0.057 & 0.057 & 0.057 & 0.057 & 0.057 & 0.057 & 0.057 & 0.057 & 0.066 & 0.071 \\
\hline MAD & 0.052 & 0.051 & 0.051 & 0.051 & 0.051 & 0.052 & 0.051 & 0.051 & 0.051 & 0.051 & 0.059 & 0.062 \\
\hline MIN & -2.93 & -2.93 & -3.10 & -2.95 & -2.95 & -3.07 & -3.01 & -2.99 & -3.04 & -3.04 & -3.79 & -3.95 \\
\hline MAX & 16.20 & 16.46 & 16.33 & 16.25 & 16.38 & 16.28 & 16.33 & 16.37 & 16.41 & 16.40 & 14.53 & 19.07 \\
\hline \multicolumn{13}{|c|}{ Year-on-Year (Q4) } \\
\hline RMSE & 0.069 & 0.067 & 0.066 & 0.067 & 0.067 & 0.066 & 0.066 & 0.066 & 0.067 & 0.067 & 0.071 & 0.077 \\
\hline MAD & 0.061 & 0.06 & 0.059 & 0.059 & 0.059 & 0.059 & 0.059 & 0.059 & 0.059 & 0.059 & 0.062 & 0.067 \\
\hline MIN & -5.46 & -5.02 & -4.21 & -4.45 & -4.43 & -4.03 & -4.23 & -4.21 & -4.17 & -4.24 & -5.64 & -5.58 \\
\hline MAX & 15.50 & 15.65 & 15.65 & 15.62 & 15.72 & 15.51 & 15.60 & 15.63 & 15.69 & 15.66 & 17.14 & 19.63 \\
\hline \multicolumn{13}{|c|}{ Quarter-on-Quarter } \\
\hline RMSE & 0.020 & 0.020 & 0.020 & 0.020 & 0.020 & 0.020 & 0.020 & 0.020 & 0.020 & 0.020 & 0.027 & 0.030 \\
\hline MAD & 0.018 & 0.017 & 0.017 & 0.017 & 0.017 & 0.017 & 0.017 & 0.017 & 0.017 & 0.017 & 0.021 & 0.025 \\
\hline MIN & -2.22 & -1.74 & -1.74 & -1.75 & -1.76 & -1.74 & -1.74 & -1.76 & -1.81 & -1.79 & -4.82 & -3.64 \\
\hline MAX & 5.69 & 5.69 & 5.76 & 6.08 & 5.78 & 5.86 & 5.82 & 5.79 & 5.75 & 5.73 & 7.53 & 8.54 \\
\hline
\end{tabular}

Note: The RSME, MAD, MIN and MAX statistics are defined in (26), (27), (28) and (29). The hedonic methods are as follows: RP1 = Repricing without updating; RP2 = Repricing where the base period is updated every five years; RP3 = Repricing where the base period is updated every year; $A C=$ Average characteristics; DIL = Double imputation Laspeyres; DIP = Double imputation Paasche; DIT = Double imputation Törnqvist RTD2Q = Rolling time dummy with a 2 quarter rolling window; RTD4Q and RTD5Q have 4 and 5 quarter rolling windows; the stratified median methods are as follows: MIX-PC = Mix adjusted stratified by postcode; MIX-RX = Mix adjusted stratified by Residex region. Period: $2002-2014$.

Coverage: Houses in Sydney, Australia.

Sources: Australian Property Monitors; authors' calculations.

The double imputation Paasche (DIP) and Laspeyres (DIL) indices - shown in Table C3-2 (see Online complement C3) but excluded from Figure II - exhibit clear evidence of drift. According to DIP, prices rise by only 65.3 percent while according to DIL prices rise by 78.1 percent. It is fortunate therefore that none of the NSIs are using either DIP or DIL. The German NSI uses the double imputation Törnqvist (DIT) method, which is the geometric mean of DIP and DIL. The results indicate that the drift in DIP and DIL is offsetting, and hence DIT seems to be unaffected by any drift problems.
Given the duality between average characteristic and hedonic imputation methods, we should also consider the implications of this finding for the former. The average characteristics method, which uses a Laspeyres type formula, is potentially also at risk of drift. However, the drift arises here when the average dwelling is updated each quarter based on the previous quarter's data. The average characteristics method used by NSIs only updates the average dwelling annually and computes it based on a whole year's data. This seems to be enough to prevent drift. 


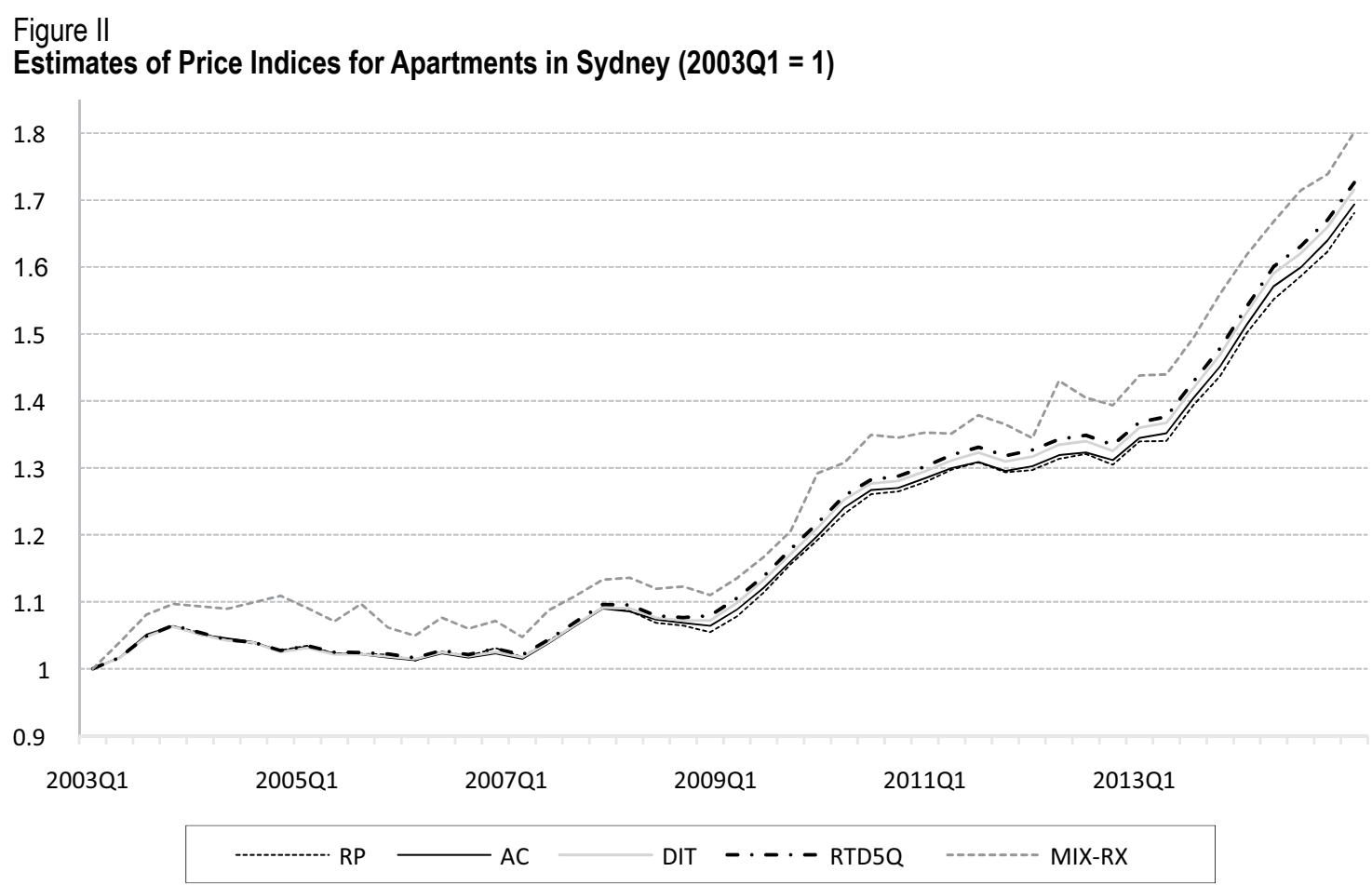

Note: Hedonic methods: RP = Repricing; $A C=$ Average characteristics; $D I T=$ Double imputation Törnqvist; RTD5Q = Rolling time dummy with five quarter window; Stratified median method: MIX-RX = Mix adjusted stratified by Residex region. Period: 2002-2014.

Coverage: Apartments in Sydney, Australia.

Sources: Australian Property Monitors; authors' calculations.

The results for the RSME, MAD, MAX and MIN statistics for Sydney apartments are given in Table 3. Again the stratified median indices are more volatile than the hedonic indices. Overall, the results in Tables C3-1 and $\mathrm{C} 3-2$ should be reassuring to Eurostat. They indicate that the HPIs of different countries should be broadly comparable even when computed using different hedonic methods. For those countries using stratified medians, it is important that the strata are sufficiently finely defined. Otherwise, like MIX-RX, the index will behave erratically.

\section{Evaluations of the different methods for Tokyo (1986-2016)}

\section{The Tokyo data set}

The Tokyo data set consists of 23 wards of the Tokyo metropolitan area (621 square kilometers), and the analysis period is approximately 30 years between January 1986 and June 2016. The data set covers previously-owned condominiums (apartments transactions) published in Residential Information Weekly (or Shukan Jyutaku Joho in Japanese) published by
RECRUIT, Co. This magazine provides information on the characteristics and asking prices of listed properties on a weekly basis. Moreover, Shukan Jutaku Joho provides time-series data on housing prices from the week they were first posted until the week they were removed as a result of successful transactions. We only use the price in the final week because this can be safely regarded as sufficiently close to the contract price.

The available housing characteristics are: floor area, age of building, travel time to nearest station, travel time to Tokyo central station, and the 23 wards (i.e., city codes). The hedonic model for Tokyo is estimated over 237,190 observations. A few observations were deleted since they were incomplete, or contained clear errors. The total number of deletions was less than 1 percent. The functional form for our hedonic models is again semilog. The explanatory variables used are:

- $\log$ of floor area;

- age (included as a quadratic);

- time to nearest station;

- time to Tokyo central station (included as a quadratic);

- ward dummy. 
Table 3

Volatility of the Apartment Price Indices in Sydney

\begin{tabular}{|c|c|c|c|c|c|c|c|c|c|c|c|c|}
\hline & RP1 & RP2 & RP3 & $A C$ & DIL & DIP & DIT & RTD2Q & RTD4Q & RTD5Q & MIX-PC & MIX-RX \\
\hline \multicolumn{13}{|c|}{ Year-on-Year (Q1) } \\
\hline RMSE & 0.055 & 0.053 & 0.053 & 0.054 & 0.054 & 0.053 & 0.054 & 0.054 & 0.053 & 0.053 & 0.054 & 0.059 \\
\hline MAD & 0.045 & 0.043 & 0.044 & 0.044 & 0.044 & 0.042 & 0.043 & 0.043 & 0.043 & 0.043 & 0.044 & 0.051 \\
\hline MIN & -2.17 & -2.17 & -1.75 & -2.00 & -2.26 & -1.51 & -1.89 & -1.90 & -1.88 & -1.86 & -3.52 & -3.77 \\
\hline MAX & 15.81 & 16.25 & 16.25 & 16.25 & 16.42 & 16.29 & 16.36 & 16.38 & 16.33 & 16.32 & 15.22 & 15.87 \\
\hline \multicolumn{13}{|c|}{ Year-on-Year (Q2) } \\
\hline RMSE & 0.045 & 0.044 & 0.044 & 0.045 & 0.045 & 0.044 & 0.045 & 0.045 & 0.044 & 0.044 & 0.049 & 0.050 \\
\hline MAD & 0.034 & 0.035 & 0.034 & 0.035 & 0.036 & 0.034 & 0.035 & 0.035 & 0.035 & 0.035 & 0.039 & 0.038 \\
\hline MIN & -1.90 & -1.90 & -1.78 & -2.20 & -2.24 & -1.75 & -1.99 & -2.01 & -1.85 & -1.80 & -3.24 & -1.74 \\
\hline $\operatorname{MAX}$ & 13.82 & 14.16 & 14.16 & 13.92 & 14.18 & 14.17 & 14.17 & 14.18 & 14.18 & 14.15 & 14.40 & 15.63 \\
\hline \multicolumn{13}{|c|}{ Year-on-Year (Q3) } \\
\hline RMSE & 0.047 & 0.048 & 0.047 & 0.048 & 0.049 & 0.047 & 0.048 & 0.048 & 0.048 & 0.048 & 0.051 & 0.048 \\
\hline MAD & 0.043 & 0.043 & 0.043 & 0.044 & 0.044 & 0.043 & 0.044 & 0.044 & 0.043 & 0.044 & 0.047 & 0.042 \\
\hline MIN & -1.50 & -1.50 & -1.47 & -1.77 & -1.84 & -1.55 & -1.69 & -1.70 & -1.49 & -1.45 & -2.39 & -3.36 \\
\hline $\operatorname{MAX}$ & 12.93 & 12.95 & 12.94 & 12.95 & 12.97 & 12.92 & 12.94 & 13.00 & 13.00 & 12.96 & 11.69 & 11.97 \\
\hline \multicolumn{13}{|c|}{ Year-on-Year (Q4) } \\
\hline RMSE & 0.055 & 0.053 & 0.053 & 0.055 & 0.055 & 0.053 & 0.054 & 0.054 & 0.054 & 0.054 & 0.059 & 0.059 \\
\hline MAD & 0.049 & 0.048 & 0.047 & 0.049 & 0.049 & 0.047 & 0.048 & 0.048 & 0.048 & 0.048 & 0.053 & 0.050 \\
\hline MIN & -3.44 & -3.40 & -3.02 & -3.56 & -4.10 & -3.05 & -3.58 & -3.48 & -3.49 & -3.52 & -3.92 & -4.27 \\
\hline MAX & 13.05 & 12.82 & 12.75 & 12.62 & 12.65 & 13.52 & 12.89 & 12.83 & 12.90 & 12.82 & 14.11 & 16.39 \\
\hline \multicolumn{13}{|c|}{ Quarter-on-Quarter } \\
\hline RMSE & 0.017 & 0.016 & 0.016 & 0.016 & 0.017 & 0.016 & 0.016 & 0.016 & 0.016 & 0.016 & 0.021 & 0.023 \\
\hline MAD & 0.015 & 0.014 & 0.014 & 0.014 & 0.014 & 0.014 & 0.014 & 0.014 & 0.014 & 0.014 & 0.018 & 0.019 \\
\hline MIN & -1.65 & -1.48 & -1.48 & -1.34 & -1.54 & -1.22 & -1.38 & -1.34 & -1.43 & -1.44 & -2.60 & -3.20 \\
\hline MAX & 4.49 & 4.17 & 4.17 & 4.28 & 4.34 & 4.15 & 4.25 & 4.24 & 4.22 & 4.21 & 5.91 & 7.17 \\
\hline
\end{tabular}

Note: The RSME, MAD, MIN and MAX statistics are defined in (26), (27), (28) and (29). The hedonic methods are as follows: RP1 = Repricing without updating; RP2 = Repricing where the base period is updated every five years; RP3 = Repricing where the base period is updated every year; $A C=$ Average characteristics; DIL = Double imputation Laspeyres; DIP = Double imputation Paasche; DIT = Double imputation Törnqvist; RTD2Q = Rolling time dummy with a 2 quarter rolling window; RTD4Q and RTD5Q have 4 and 5 quarter rolling windows; the stratified median methods are as follows: MIX-PC = Mix adjusted stratified by postcode; MIX-RX = Mix adjusted stratified by Residex region. Period: 2002-2014.

Coverage: Apartments in Sydney, Australia.

Sources: Australian Property Monitors; authors' calculations.

The hedonic method considered is essentially the same as for Sydney. The reason for including quadratics for age and time to Tokyo central station is that the impact of these variables on $\log$ (price) may be nonlinear and even possibly non monotonic. For example, there may be an optimal time to Tokyo central station (i.e., one may not want to live too near and not too far way either). This quadratic specification, however, can create problems with the repricing method, as is explained below.

\section{Price indices for all apartments in Tokyo}

The results for Tokyo for the years 1986 to 2016 for all apartments are shown in Table C3-3 (in Online complement C3) and Figure III. The general pattern that emerges is similar to that observed for Sydney, although there are some important differences.

Focusing first on the differences, two versions of the repricing method without rebasing - RP1(qd) and RP1 - are presented in Table C3-3. RP1 is much closer to the other methods than RP1(qd). RP1(qd) and RP1 differ in that the former uses the functional form discussed above that includes age and time to Tokyo central station as quadratics. RP1 includes these variables as linear functions. The problem with RP1(qd) is that while the quadratics by construction fit the data well in 
1987 - the first full year of the data set - this specification does not perform so well when it is applied to data in other years. The squared term in the quadratics can distort the results for later years. The implication is that there is a trade-off between model fit in the base period and overall performance of the HPI. When the repricing method is used, quadratic terms in the hedonic model should be avoided. It is better to stick with a simpler more linear model. This problem was not observed for the Sydney data set because these variables were not included in the hedonic model.

A second difference is that there is no clear evidence of drift in the DIL and DIP results in Table C3-3, as compared with what was observed for Sydney apartments. Over the whole sample period, the rise in apartment prices for all hedonic methods, excluding repricing without updating, ranges between 8.5 and 13.8 percent. The average masks a rollercoaster ride where prices first went way up and then way down before gradually returning to near their starting point.

Turning now to the similarities between the results for Sydney and Tokyo, the drift in the repricing results is again downward; although smaller for RP1 than RP1(qd). According to RP1, prices rose by about 7 percent, as opposed to a 6 percent fall when $\operatorname{RP} 1(\mathrm{qd})$ is used. It

\section{Table 4}

\section{Volatility of the Apartment Price Indices in Tokyo}

\begin{tabular}{|c|c|c|c|c|c|c|c|c|c|c|c|c|}
\hline & $\operatorname{RP} 1(q d)$ & RP1 & RP2 & RP3 & $A C$ & DIL & DIP & DIT & RTD2Q & RTD4Q & RTD5Q & MIX \\
\hline \multicolumn{13}{|c|}{ Year-on-Year (Q1) } \\
\hline RMSE & 0.106 & 0.102 & 0.096 & 0.091 & 0.092 & 0.092 & 0.091 & 0.091 & 0.092 & 0.092 & 0.092 & 0.103 \\
\hline MAD & 0.087 & 0.082 & 0.074 & 0.07 & 0.073 & 0.072 & 0.072 & 0.072 & 0.072 & 0.072 & 0.072 & 0.085 \\
\hline MIN & -17.12 & -16.58 & -15.33 & -15.55 & -15.47 & -15.61 & -15.48 & -15.54 & -15.55 & -15.52 & -15.52 & -15.46 \\
\hline MAX & 33.88 & 34.42 & 34.42 & 30.79 & 30.14 & 30.09 & 30.41 & 30.25 & 30.27 & 30.67 & 30.84 & 32.38 \\
\hline \multicolumn{13}{|c|}{ Year-on-Year (Q2) } \\
\hline RMSE & 0.104 & 0.100 & 0.095 & 0.093 & 0.093 & 0.093 & 0.092 & 0.093 & 0.093 & 0.093 & 0.093 & 0.098 \\
\hline MAD & 0.08 & 0.077 & 0.073 & 0.072 & 0.072 & 0.073 & 0.071 & 0.072 & 0.072 & 0.072 & 0.072 & 0.077 \\
\hline MIN & -20.31 & -19.45 & -17.93 & -18.07 & -18.34 & -18.36 & -18.20 & -18.28 & -18.28 & -18.28 & -18.28 & -15.88 \\
\hline MAX & 30.43 & 30.60 & 30.60 & 27.52 & 26.82 & 27.11 & 27.45 & 27.28 & 27.30 & 27.75 & 27.93 & 28.90 \\
\hline \multicolumn{13}{|c|}{ Year-on-Year (Q3) } \\
\hline RMSE & 0.100 & 0.098 & 0.095 & 0.094 & 0.092 & 0.093 & 0.093 & 0.093 & 0.093 & 0.093 & 0.093 & 0.106 \\
\hline MAD & 0.077 & 0.075 & 0.074 & 0.073 & 0.072 & 0.073 & 0.072 & 0.072 & 0.073 & 0.073 & 0.073 & 0.082 \\
\hline MIN & -20.93 & -20.32 & -19.12 & -19.20 & -19.35 & -19.43 & -19.39 & -19.41 & -19.41 & -19.38 & -19.35 & -19.07 \\
\hline MAX & 21.36 & 21.70 & 21.70 & 21.13 & 20.17 & 19.94 & 20.03 & 19.95 & 19.99 & 20.32 & 20.42 & 30.99 \\
\hline \multicolumn{13}{|c|}{ Year-on-Year (Q4) } \\
\hline RMSE & 0.109 & 0.106 & 0.101 & 0.098 & 0.100 & 0.099 & 0.100 & 0.100 & 0.100 & 0.101 & 0.101 & 0.116 \\
\hline MAD & 0.084 & 0.078 & 0.074 & 0.073 & 0.074 & 0.074 & 0.074 & 0.074 & 0.074 & 0.075 & 0.075 & 0.088 \\
\hline MIN & -19.25 & -18.38 & -16.98 & -17.14 & -17.12 & -17.14 & -17.38 & -17.26 & -17.27 & -17.30 & -17.29 & -17.92 \\
\hline MAX & 30.17 & 30.24 & 30.24 & 29.17 & 30.43 & 29.53 & 30.63 & 30.08 & 30.02 & 31.80 & 31.58 & 38.98 \\
\hline \multicolumn{13}{|c|}{ Quarter-on-Quarter } \\
\hline RMSE & 0.037 & 0.035 & 0.033 & 0.033 & 0.032 & 0.032 & 0.032 & 0.032 & 0.032 & 0.033 & 0.033 & 0.042 \\
\hline MAD & 0.027 & 0.025 & 0.023 & 0.022 & 0.022 & 0.022 & 0.022 & 0.022 & 0.022 & 0.022 & 0.022 & 0.033 \\
\hline MIN & -6.41 & -6.72 & -6.72 & -6.52 & -6.30 & -6.23 & -6.29 & -6.26 & -6.27 & -6.32 & -6.35 & -9.52 \\
\hline MAX & 18.14 & 18.05 & 18.05 & 22.35 & 17.50 & 17.90 & 16.89 & 17.39 & 17.35 & 18.49 & 18.95 & 17.47 \\
\hline
\end{tabular}

Note: The RSME, MAD, MIN and MAX statistics are defined in (26), (27), (28) and (29). The hedonic methods are as follows: RP1 (qd) = Repricing without updating where the impact of age and time to Tokyo central station are modelled using quadratics; RP1 = Repricing without updating; $\mathrm{RP} 2=$ Repricing where the base period is updated every five years; RP3 = Repricing where the base period is updated every year; $A C=$ Average characteristics; Double imputation Laspeyres = DIL; Double imputation Paasche = DIP; Double imputation Törnqvist = DIT; RTD2Q = Rolling time dummy with a 2 quarter rolling window; RTD4Q and RTD5Q have 4 and 5 quarter rolling windows; the stratified median method is: MIX = Mix adjusted stratified by ward. Period: 1986-2016.

Coverage: Apartments in Tokyo, Japan.

Sources: Residential Information Weekly (RECRUIT, Co); authors' calculations. 
is noticeable that, as with Sydney apartments, RP2 (repricing where the base period is updated every five years) generates very similar results to the average characteristics (AC) method. Given the duality that exists between the repricing and average characteristics methods this result is not so surprising. However, such similarity in the RP2 and AC results was not observed for houses in Sydney in Table C3-1.

The stratified median index differs quite significantly from the hedonic indices. It rises by 27.4 percent, as compared with the hedonic range of 8.5 and 13.8 percent. It is worth noting that the stratified median indices in all three Figures rise faster than their hedonic counterparts. One possible explanation for this finding is that the average quality of dwellings sold has increased over time. The results for the RSME, MAD, MAX and MIN statistics for Tokyo apartments are given in Table 4. Again the stratified median index MIX is more volatile than the hedonic indices.

\section{Price indices for new apartments in Tokyo}

Estimating a price index for new apartments is difficult for the Tokyo data set due to the small sample size. We define a new build as any apartment that is less than three years old. We would have preferred less than two years old, but this is not really feasible. The main problem here is to estimate shadow prices for the locational ward dummy variables. For some wards, no transactions on new dwellings are observed in some quarters. This is a problem particularly for the average characteristics and hedonic imputation methods that begin by estimating a separate hedonic model for each quarter as stated in (8). One way of dealing with missing wards is to restrict a comparison between adjacent quarters to the apartments sold in wards that are observed in both quarters. This means that two different hedonic models need to be estimated for each quarter $q$. The first includes the apartments sold in wards that are observed in both $q-1$ and $q$, while the second includes the apartments sold in wards observed in both $q$ and $q+1$. If the characteristics vectors $z$ being priced include any wards not included in the estimated hedonic model, then these wards are dropped and the weights on the remaining wards are adjusted so that they still sum to one.

This problem is not as severe for the repricing method since it estimates the hedonic model

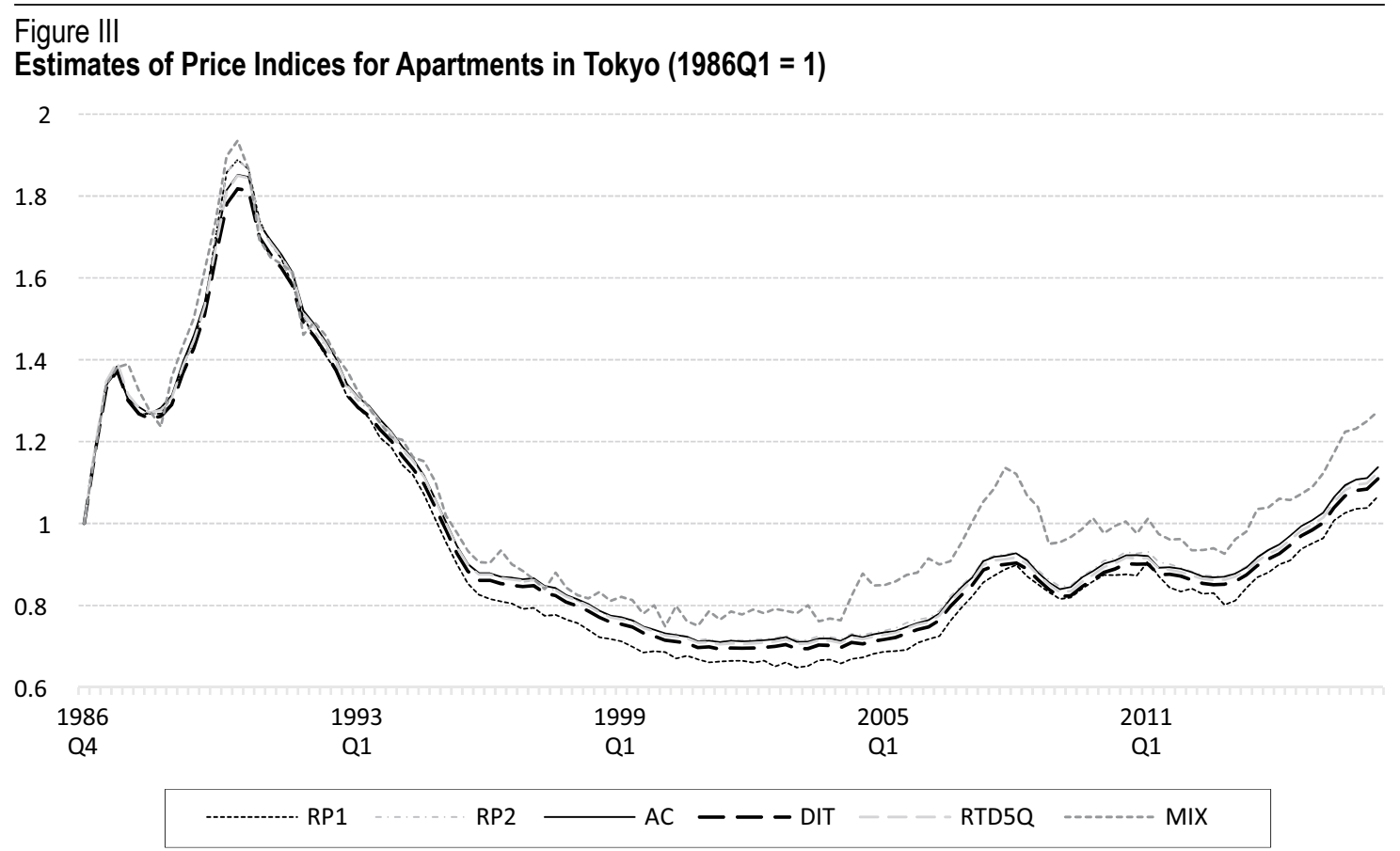

Note: Hedonic methods: RP1 = Repricing; RP2 = Repricing where the base period is updated every five years; $A C=$ Average characteristics DIT = Double imputation Törnqvist; RTD5Q = Rolling time dummy with five quarter window; Stratified median method: MIX = Mix adjusted stratified by ward. Period: 1986-2016.

Coverage: Apartments in Tokyo, Japan.

Sources: Residential Information Weekly (RECRUIT, Co); authors' calculations 
based on a whole year's data, as stated in (1). Again, though, if a ward is nor observed in the base year, then all apartments sold in that ward in future periods are excluded from the comparison. An alternative approach would be to substitute an adjacent ward for these apartments.

By contrast, the problem of missing wards does not arise for the RTD method. Any wards that are observed in any quarter can be included in the RTD hedonic model, as stated in (22). This example illustrates an important advantage of the RTD method, in that it performs well on smaller data sets.

The new apartment price indices are shown in Figure IV. It can be seen that the index is much more sensitive to the choice of method than in Figures I, II, and III.

The stratified median index is particularly badly affected by the small sample size. Faced with a small sample problem, we have greatest confidence in the RTD method with a relatively long window (e.g., RTD5Q). Using RTD5Q as our benchmark, the downward drift in the repricing index (RP1) is much more pronounced than in the previous figures. Updating the reference shadow prices every five years (RP2) solves this problem. Indeed RP2 approximates RTD5Q quite closely. The average characteristics and hedonic imputation methods in this case are somewhat erratic. This is presumably because there are not enough data points to justify estimating a separate hedonic model each quarter.

The results for new builds in Tokyo have important implications for the HPI in smaller EU countries. In cases where there are less data, as Figure IV clearly illustrates, the choice of method for constructing the HPI becomes much more important. The number of new built apartments in Tokyo each quarter may well be higher than the total number of house or apartment transactions in countries such as Slovenia, Malta and Cyprus.

Figure IV also illustrates one of the problems with the acquisitions method for including owner-occupied housing $(\mathrm{OOH})$ in the HICP. The acquisitions method as recommended by Eurostat requires, where possible, a price index specifically for new builds. It is much harder, however, to construct a reliable quality-adjusted HPI for new builds than it is to construct an index covering all housing transactions.

\section{Figure IV \\ Estimates of Price Indices for New Apartments in Tokyo $(1986 Q 1=1)$}

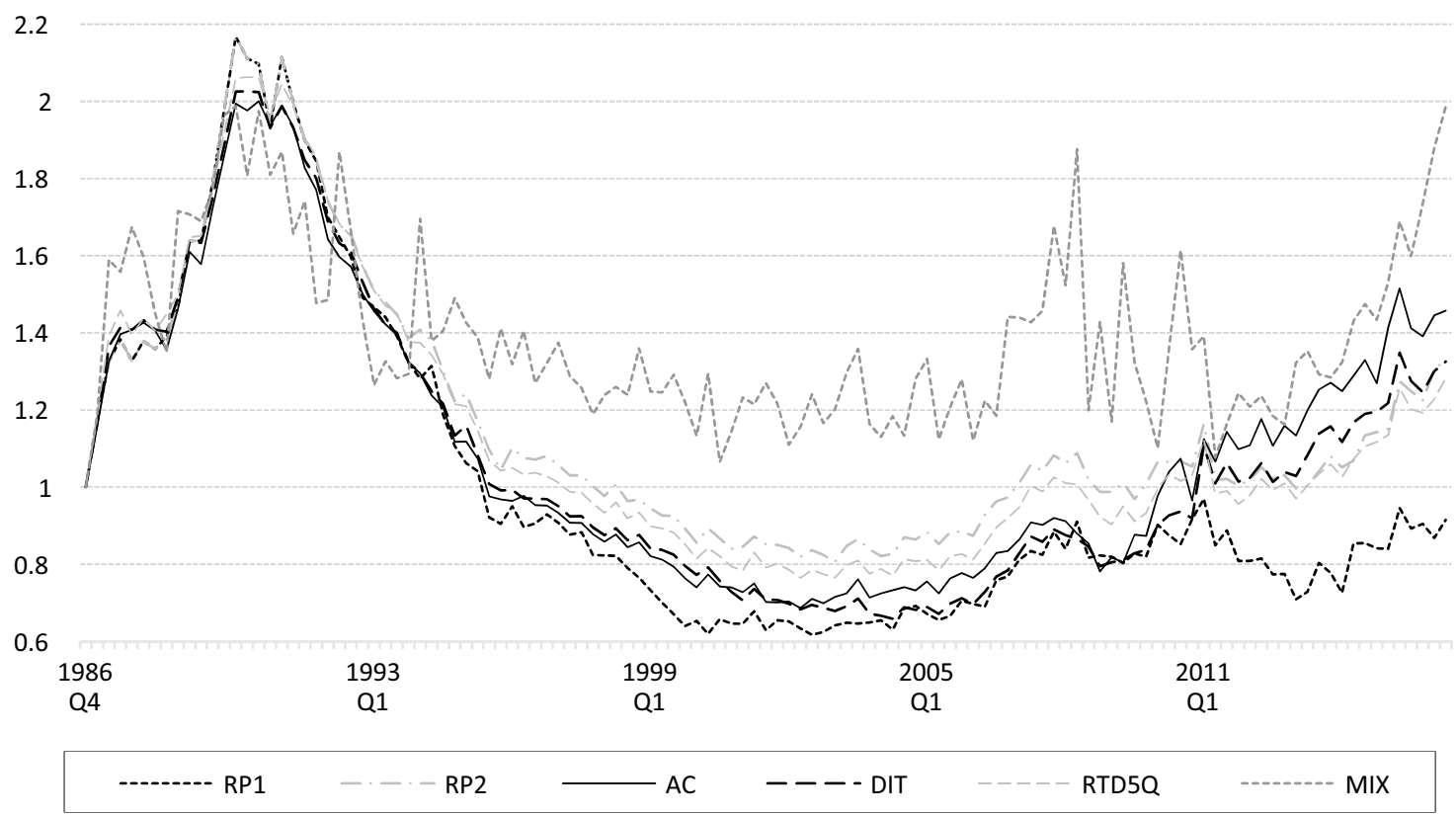

Note: Hedonic methods: RP1 = Repricing; RP2 = Repricing where the base period is updated every five years; $A C=$ Average characteristics DIT = Double imputation Törnqvist; RTD5Q = Rolling time dummy with five quarter window; Stratified median method: MIX = Mix adjusted stratified by ward. Period: 1986-2016.

Coverage: New Apartments in Tokyo, Japan

Sources: Residential Information Weekly (RECRUIT, Co); authors' calculations. 
While a price index for new builds may be needed in Europe for the HICP (when $\mathrm{OOH}$ is included using the acquisitions method), in the context of the HPI it does not make sense to compute separate HPIs for new builds and existing dwellings and then combine them. Rather, when available, age (or a dummy variable for new builds) should be included directly as a characteristic in a single hedonic model that encompasses both new and existing dwellings. Separate hedonic models, however, should be estimated for houses and apartments since the list of available characteristics for each may differ, and even when they do coincide, shadow prices that are representative for one may not be for the other. The methods outlined in chapter 5 of the RPPI Manual can then be used to construct an overall HPI that combines both houses and apartments (see Eurostat, 2013).

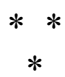

Our main findings are as follows:

- The price indices seem to be quite robust over the range of hedonic methods used by NSIs in Europe to compute their HPIs.

- In smaller data sets (e.g., new builds in Tokyo), the HPI becomes more sensitive to the choice of method. Hence smaller countries in the EU need to be more careful when choosing a method. We recommend RTD4Q or RTD5Q for smaller countries with less housing transactions.

- The double imputation Paasche and Lasepyres (DIP and DIL) indices for apartments in Sydney are subject to drift. Evidence of a small amount of drift is also apparent in the Tokyo data. The results for Sydney apartments indicate that DIP and DIL should not be used. Fortunately, no NSIs are using either of these methods.

- The repricing method seems to have a downward bias relative to the other hedonic indices when the reference shadow prices are updated only every five years or not at all. However, this bias is no longer in evidence when the reference shadow prices are updated every year.
- With the repricing method, a hedonic model that performs well in the base period may not provide a good fit in later periods. In particular, for Tokyo the quadratic terms for age and time to Tokyo central station cause problems. In this sense, there is a greater risk of problems with the repricing method. Hence we recommend keeping the functional form of the hedonic model quite simple (e.g., with no quadratic terms) when the repricing method is used.

- We recommend that NSIs using the repricing method update the reference shadow prices frequently, preferably every year and at least every five years.

- Where possible, the use of stratified median indices should be avoided. This is because they fail to properly adjust for changes in quality over time. The upward bias of stratified medians over the whole sample period in both datasets can be attributed to an upward trend in the quality of transacted dwellings over time. The higher RSME and MAD statistics can be attributed to the stratified-medians not properly adjusting for changes in the quality of transacted dwellings on a period-to-period basis.

- It is more difficult to construct a quality-adjusted price index for new builds. Again, RTD5Q is recommended for computing an HPI for new dwellings when there is a shortage of data points.

- For the HPI we recommend not splitting new and existing dwellings. It is better to combine them in the same hedonic model, with age as one of the explanatory characteristics.

- Houses and apartments should be estimated using separate hedonic models, and then combined using the standard Eurostat method for combining strata (see Eurostat, 2013, chapter X).

- Finally, it should be noted that computing an HPI for a large city is easier than for a whole country, particularly if that country is small. Hence our empirical comparisons may err on side of underestimating the sensitivity of a national HPI to the choice of method used for constructing it. 


\section{BIBLIOGRAPHY}

Diewert, W. E. (2011). Alternative Approaches to Measuring House Price Inflation. Vancouver School of Economics - Economics Working Paper 2010-10.

https://econ.sites.olt.ubc.ca/files/2013/06/pdf paper erwin-diewert-10-10-alternative-approaches.pdf.

Diewert, W. E., Heravi, S. \& Silver, M. (2009). Hedonic Imputation versus Time Dummy Hedonic Indexes. In W. E. Diewert, W. E., Greenlees, J. \& Hulten, C. (Eds.), Price Index Concepts and Measurement. Chicago: University of Chicago Press, 161-196.

http://www.nber.org/books/diew08-1

Eurostat (2013). Handbook on Residential Property Prices Indices (RPPIs). Luxembourg: European Union.

http:/ec.europa.eu/eurostat/documents/3859598/ 5925925/KS-RA-12-022-EN.PDF

Eurostat (2017). Detailed Technical Manual on Owner-Occupied Housing for Harmonised Index of Consumer Prices. Luxembourg: Eurostat. http://ec.europa.eu/eurostat/documents/7590317/0/ Technical-Manual-OOH-HPI-2017/

Haan, J. de, Wal, E. van der, \& Vries, P. de (2008). The Measurement of House Prices: A Review of the SPAR Method. Statistics Netherlands Working Paper.

https://www.cbs.nl/nr/rdonlyres/1392243b-5bf2-4c5 6-8a4b-6c0c1a1cc6ee/0/20080814sparmethodart.pdf

Haan J. de (2010). Hedonic Price Indexes: A Comparison of Imputation, Time Dummy and Re-Pricing Methods. Journal of Economics and
Statistics (Jahrbuecher fuer Nationaloekonomie und Statistik), 230(6), 772-791.

https://doi.org/10.1515/jbnst-2010-0611

Hill, R. J. (2013). Hedonic Price Indexes for Housing: A Survey, Evaluation and Taxonomy. Journal of Economic Surveys, 27(5), 879-914. https://doi.org/10.1111/j.1467-6419.2012.00731.x

Hill, R. J. \& Melser, D. (2008). Hedonic Imputation and the Price Index Problem: An Application to Housing. Economic Inquiry, 46(4), 593-609. https://doi.org/10.1111/j.1465-7295.2007.00110.x

O'Hanlon, N. (2011). Constructing a National House Price Index for Ireland. Journal of the Statistical and Social Inquiry Society of Ireland, 40, 167-196. http://www.tara.tcd.ie/bitstream/handle/2262/62349/ o\% $\%$ hanlon $\% 20$ pdf.pdf? sequence $=1 \&$ is Allowed $=y$

Shimizu, C, Takatsuji, H., Ono, H. \& Nishimura, K. G. (2010). Structural and Temporal Changes in the Housing Market and Hedonic Housing Price Indices. International Journal of Housing Markets and Analysis, 3(4), 351-368.

https://doi.org/10.1108/17538271011080655

Silver, M. (2015). The Degree and Impact of Differences in House Price Index Measurement. Journal of Economic and Social Measurement, 39(4), 305-328. https://doi.org/10.3233/JEM-150406

Silver, M. (2016). How to Better Measure Residential Property Price Indexes. IMF Working Paper WP/16/213.

https://www.imf.org/external/pubs/ft/wp/2016/ wp16213.pdf 
$\mathrm{N}^{\circ} 500-501-502-2018$

\author{
MÉLANGES / VARIA
}

\title{
CROISSANCE ET PRODUCTIVITÉ DANS LES COLLECTIVITÉS FRANCAISES DU PACIFIQUE / GROWTH AND PRODUCTIVITY IN THE FRENCH PACIFIC TERRITORIES
}

- Croissance économique et productivité en Polynésie française : une analyse sur longue période /

Economic growth and productivity in French Polynesia: A long-term analysis

- Productivité sectorielle du travail et compétitivité de l'économie de la Nouvelle-Calédonie / Sectoral labour productivity and economic competitiveness in New Caledonia

- Commentaire - La productivité sur longue période dans les collectivités françaises du Pacifique /

Comment - Long-term productivity in French Pacific territories

\section{MOBILITÉ SOCIALE À L'ÉCOLE, PERFORMANCES SCOLAIRES ET PARCOURS UNIVERSITAIRES / SOCIAL MOBILITY AT SCHOOL, SCHOOL PERFORMANCES AND EDUCATIONAL CAREER PATHS}

- Une comparaison internationale des systèmes scolaires basée sur la mobilité sociale / An international comparison of school systems based on social mobility

- $50 \%$ à la licence... mais comment ? Les jeunes de familles populaires à l'université en France / $50 \%$ to the bachelor's degree... but how? Young people from working class families at university in France

$N^{\circ}{ }^{\circ} 97-498-2017$

\section{RÉGIONS ET TERRITOIRES / REGIONS AND TERRITORIES}

-Introduction - Régions et territoires : quelles évolutions ? / Introduction - Regions and territories: Evolutions and changes

\section{RÉFORMES TERRITORIALES ET DISPARITÉS / TERRITORIAL REFORMS AND DISPARITIES}

\footnotetext{
- Disparités et discontinuités territoriales dans la France des nouvelles régions : une lecture multiscalaire et multidimensionnelle / Disparities and territorial discontinuities in France with its new regions: A multiscalar and multidimensional interpretation

- Le théorème de la décentralisation s'applique-t-il aux collectivités locales françaises ? Un test empirique sur les compétences intercommunales / Does the decentralisation theorem apply to the French local governments? An empirical test on intermunicipal competences

- Commentaire - La difficile équation des réformes territoriales : du big is beautiful à l'impossible simplification du mille-feuille institutionnel / Comment - The difficult equation of territorial reforms: from big is beautiful to the impossible simplification of the institutional layer-cake
}

\section{SÉGRÉGATION DANS LES MÉTROPOLES : ENTRE VILLE-CENTRE, BANLIEUE ET PÉRIURBAIN / SEGREGATION IN URBAN AREAS BETWEEN CITY-CENTERS, SUBURBS AND SUBURBAN AREAS}

- Niveau de vie et ségrégation dans douze métropoles françaises / Standards of living and segregation in twelve French urban areas

- Commentaire - Ségrégation par le revenu dans les villes : réflexions sur les écarts entre concept et mesure / Comment - Income segregation in cities: A reflection on the gap between concept and measurement

\section{EMPLOIS DANS LES TERRITOIRES, PROGRÈS TECHNOLOGIQUE ET MONDIALISATION / EMPLOYMENT AT TERRITORIAL LEVEL, TECHNOLOGICAL CHANGE AND GLOBALISATION}

- Progrès technique et automatisation des tâches routinières : une analyse à partir des marchés du travail locaux en France dans les années 1990-2011 / Technical change and automation of routine tasks: Evidence from local labour markets in France, 1999-2011 
- Mesurer et anticiper la vulnérabilité des territoires face aux risques de délocalisation : une analyse à partir de données sectorielles pour la France / Measurement and anticipation of territorial vulnerability to offshoring risks : An analysis on sectoral data for France

- Commentaire - L'impact de la mondialisation et de la technologie sur les marchés du travail locaux / Comment - The impact of globalisation and technology on local labour markets

\section{PARCOURS GÉOGRAPHIQUE / GEOGRAPHICAL TRAJECTORIES}

- Parcours géographiques d'individus nés en France : construction d'une typologie / Geographical pathways of individuals born in France: Construction of a typology 


\section{Economie et Statistique / Economics and Statistics}

\section{Objectifs généraux de la revue}

Economie et Statistique / Economics and Statistics publie des articles traitant de tous les phénomènes économiques et sociaux, au niveau micro ou macro, s'appuyant sur les données de la statistique publique ou d'autres origines. Une attention particulière est portée à la qualité de la démarche statistique et à la rigueur des concepts mobilisés dans l'analyse. Pour répondre aux objectifs de la revue, les principaux messages des articles et leurs limites éventuelles doivent être formulés dans des termes accessibles à un public qui n'est pas nécessairement spécialiste du sujet de l'article.

\section{Soumettre un article}

Les propositions d'articles, en français ou en anglais, doivent être adressées à la rédaction de la revue (redaction-ecostat@insee. fr), en Word et mises en forme suivant les consignes aux auteurs (accessibles sur https://www.insee.fr/fr/information/2410168). Il doit s'agir de travaux originaux, qui ne sont pas soumis en parallèle à une autre revue. Un article standard fait environ 11000 mots (y compris encadrés, tableaux, figures, annexes et bibliographie, non compris éventuels compléments en ligne). Aucune proposition initiale de plus de 12500 mots ne sera examinée.

La soumission doit comporter deux fichiers distincts :

- Un fichier d'une page indiquant : le titre de l'article ; le prénom et nom, les affiliations (maximum deux), l'adresse e-mail et postale de chaque auteur ; un résumé de 160 mots maximum (soit environ 1050 signes espaces compris) qui doit présenter très brièvement la problématique, indiquer la source et donner les principaux axes et conclusions de la recherche; les codes JEL et quelques mots-clés; d'éventuels remerciements.

- Un fichier anonymisé de l'article complet (texte, illustrations, bibliographie, éventuelles annexes) indiquant en première page uniquement le titre, le résumé, les codes JEL et les mots-clés.

Les propositions retenues sont évaluées par deux à trois rapporteurs (procédure en " double-aveugle "). Une fois acceptés, les articles peuvent faire l'objet d'un travail éditorial visant à améliorer leur lisibilité et leur présentation formelle.

\section{Publication}

Les articles sont publiés en français dans l'édition papier et simultanément en français et en anglais dans l'édition électronique. Celle-ci est disponible, en accès libre, sur le site de l'Insee, le jour même de la publication ; cette mise en ligne immédiate et gratuite donne aux articles une grande visibilité. La revue est par ailleurs accessible sur le portail francophone Persée, et référencée sur le site international Repec et dans la base EconLit.

\section{Main objectives of the journal}

Economie et Statistique / Economics and Statistics publishes articles covering any micro- or macro- economic or sociological topic, either using data from public statistics or other sources. Particular attention is paid to rigor in the statistical approach and clarity in the concepts and analyses. In order to meet the journal aims, the main conclusions of the articles, as well as possible limitations, should be written to be accessible to an audience not necessarily specialist of the topic.

\section{Submissions}

Manuscripts can be submitted either in French or in English; they should be sent to the editorial team (redaction-ecostat@insee. fr), in MS-Word and follow the guidelines for authors (available at https://www.insee.fr/en/information/2591257). The manuscript must be original work and not submitted at the same time to any other journal. The standard length of an article is of about 11,000 words (including boxes if needed, tables and figures, appendices, list of references, but not counting online complements if any). Manuscripts of more than 12,500 words will not be considered.

Submissions must include two separate files:

- A one-page file providing: the title of the article; the first name, name, affiliation-s (at most two), e-mail et postal addresses of each author; an abstract of maximum 160 words (about 1050 characters including spaces), briefly presenting the question(s), data and methodology, and the main conclusions; JEL codes and a few keywords; acknowledgements.

- An anonymised file of the article (including the main text, illustrations, bibliography and appendices if any), mentioning only the title, abstract, JEL codes and keywords on the front page.

Proposals that meet the journal objectives are reviewed by two to three referees ("double-blind" review). Once the article accepted, further editorial changes may be made in order to improve their presentation and readability.

\section{Publication}

The articles are published in French in the printed edition, and simultaneously in French and in English in the electronic edition. The online issue is available, in open access, on the Insee website the day of its publication; this immediate and free online availability gives the articles a high visibility. The journal is also available online on the French portal Persée, and indexed in Repec and EconLit. 


\section{Economie Statistique}

\section{Economics AND Statistics}

Au sommaire du prochain numéro :

Mélanges

Forthcoming:

Varia 